UniVERSiDAd NACIONAL DE LA Plata

FACULTAD DE HuMANIDADES Y CIENCIAS DE LA EDUCACIÓN SECRETARÍA DE POSGRADO

\title{
El liberalismo hispánico y la cultura política en el proceso revolucionario rioplatense (1801-1814)
}

\author{
Facundo Carlos Esteban Lafit
}

Tesis para optar por el grado de Doctor en Historia

Director Fabio Wasserman, Universidad de Buenos Aires

Codirector Osvaldo Barreneche, Universidad Nacional de La Plata

La Plata, abril de 2018 


\section{Índice}

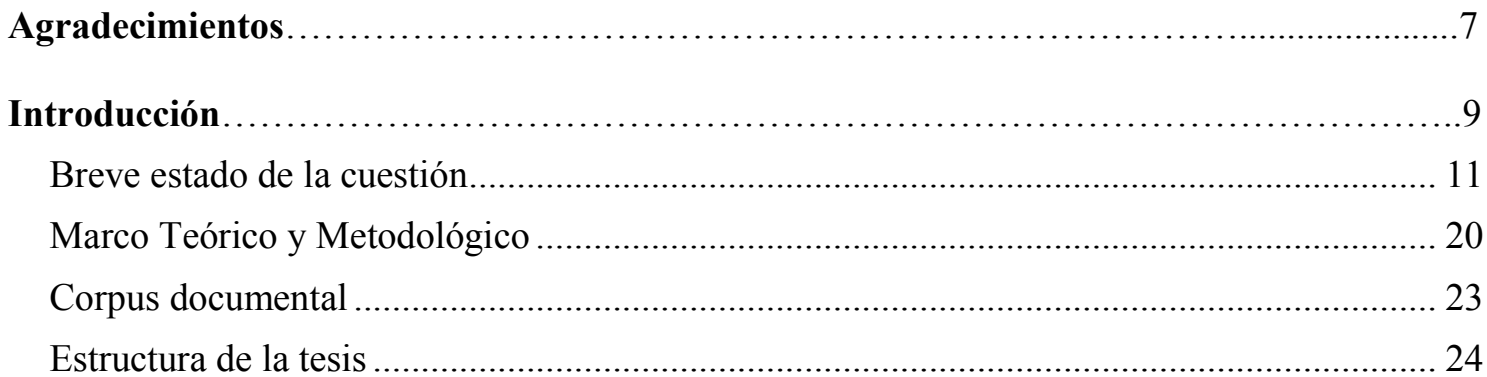

\section{Primera parte: LA MONARQUÍA ESPAÑOLA Y EL RÍO DE LA PLATA: ENTRE LAS REFORMAS Y LA CRISIS}

\section{Primera sección: EL REFORMISMO ILUSTRADO}

\section{Capítulo 1:}

La Ilustración en el mundo hispánico de fines del XVIII: Sociedades económicas y reforma universitaria

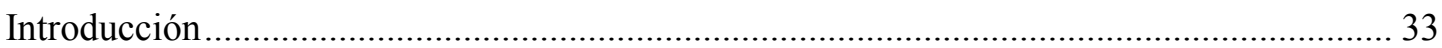

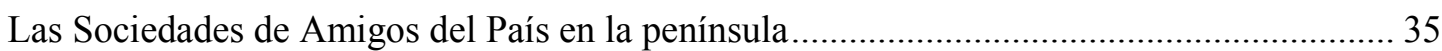

La reforma universitaria en la España de Carlos III: las cátedras de Economía Política y de Derecho Natural y de Gentes................................................................................................. 39

La Universidad de Salamanca y la Academia de Derecho .................................................... 41

La Universidad de San Francisco Xavier de Chuquisaca y la Academia Carolina. ................ 44

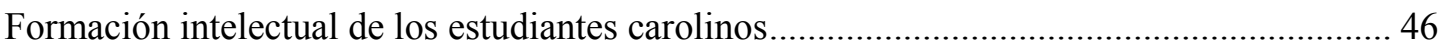

Los derechos indígenas y la reforma del imperio: Victorián de Villava y Mariano Moreno . 48

La conformación de una élite dirigente criolla .................................................................. 52

\section{Capítulo 2:}

Ilustración española y economía política en la prensa rioplatense tardo-colonial

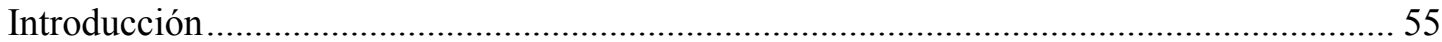

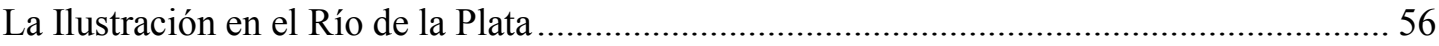

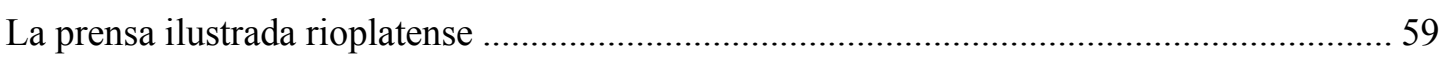

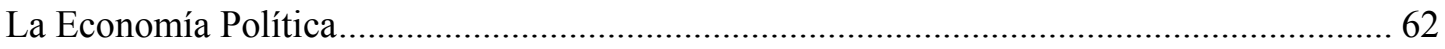

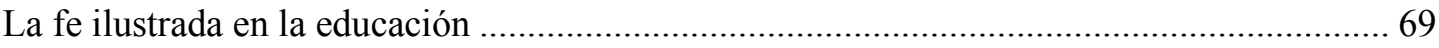

La historia y la geografía como saberes útiles ................................................................ 72

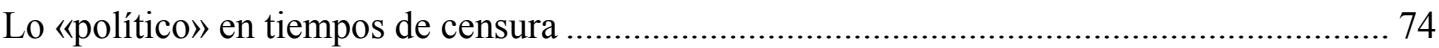

Crónica de una frustración ilustrada. Los proyectos de los "Amigos del País" en el Rio de la

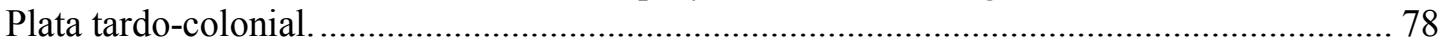

Algunas hipótesis de los porqués de su fracaso...................................... 84

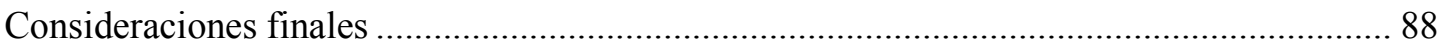




\section{Segunda Sección: LAS ALTERNATIVAS A LA CRISIS}

\section{Capítulo 3:}

\section{La revolución hispánica}

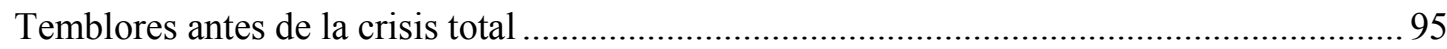

Las invasiones inglesas y el nuevo equilibrio en el Rio de la Plata ......................................... 96

La invasión napoleónica, las abdicaciones de Bayona y el comienzo de la crisis

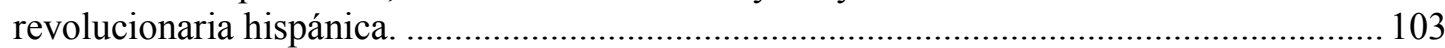

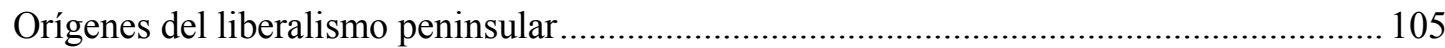

Impresión y reimpresión de proclamas, manifiestos y periódicos en Buenos Aires (1808-

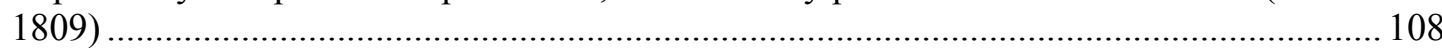

\section{Capítulo 4:}

\section{La alternativa carlotista}

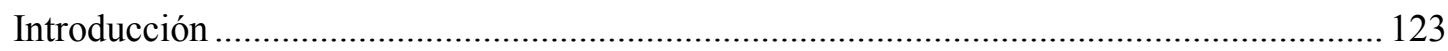

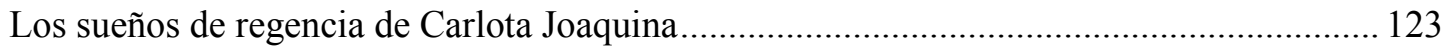

La Memoria de los criollos dirigida a Carlota .................................................................... 125

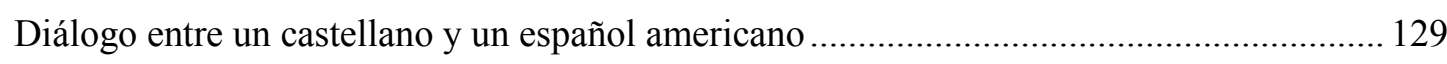

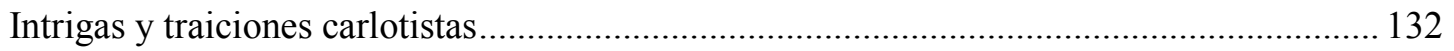

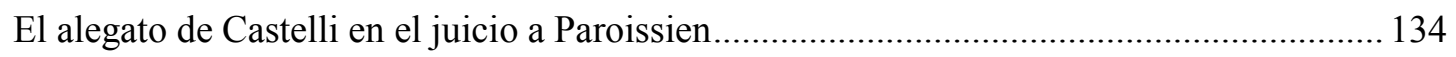

\section{Capítulo 5:}

\section{La alternativa juntista}

La rebelión lealista de Elío y la Junta de Montevideo ......................................................... 139

Un incómodo testigo del juntismo peninsular: Juan Martín de Pueyrredón ........................... 144

El frustrado intento juntista en Buenos Aires: La asonada del 1ero de enero de 1809......... 149

Diálogo entre Atahualpa y Fernando VII en los Campos Elíseos........................................ 155

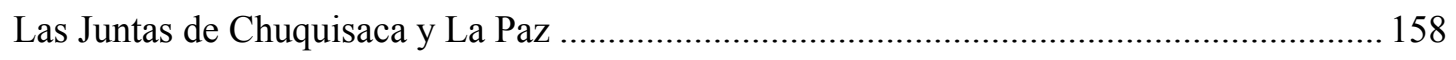

\section{Capítulo 6:}

La Real Orden del 22 de enero de 1809 y la elección de diputados a la Junta Central en el Rio de la Plata

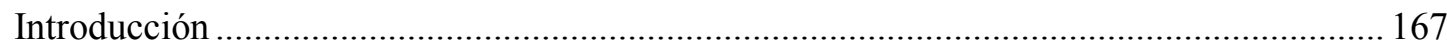

La participación rioplatense en los antecedentes directos al decreto de la Junta Central ..... 169

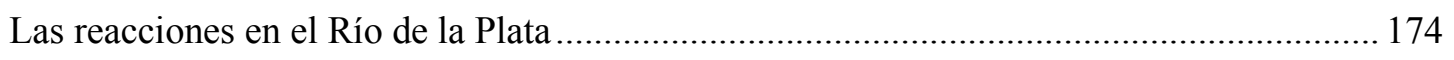

Implementación del decreto en el Río de la Plata ................................................................. 177

\section{Capítulo 7:}

El reformismo ilustrado español y napolitano en la Representación de los hacendados 


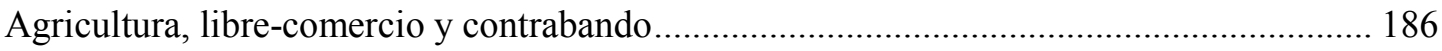

La economía política española en la Representación ........................................................ 189

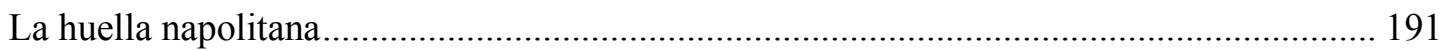

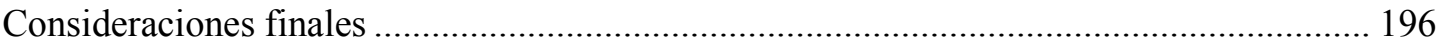

\section{Segunda Parte: LA REVOLUCIÓN}

\section{Capítulo 8}

\section{La revolución rioplatense}

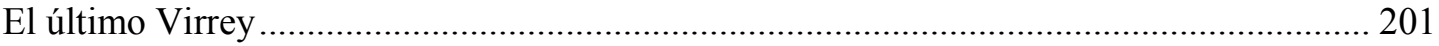

La situación en la península y la llegada de las noticias a América ...................................... 204

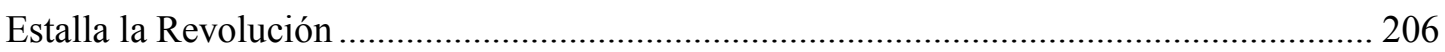

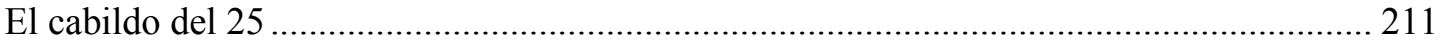

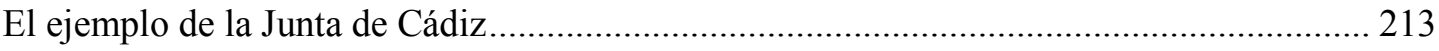

La herencia peninsular en el proceso electoral rioplatense................................................. 223

Las polémicas con las autoridades de Montevideo y con el embajador español en Brasil, el

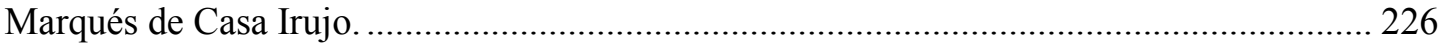

\section{Capítulo 9:}

\section{Ensayos liberales en la Gazeta de Moreno}

Pensamientos de un Patriota Español en la Gazeta de Buenos Aires. El lenguaje político del liberalismo peninsular (sin intermediarios) en la revolución rioplatense............................. 233

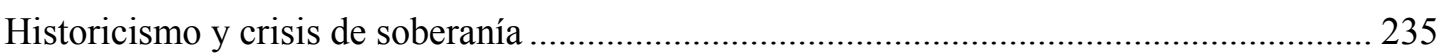

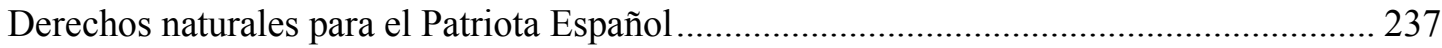

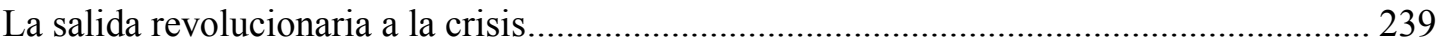

Moreno, las miras del Congreso y sus reflexiones sobre el proceso revolucionario peninsular.

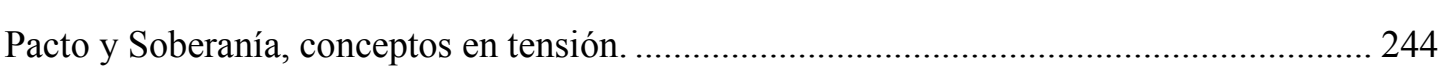

La revolución en la península como espejo imperfecto .......................................................... 248

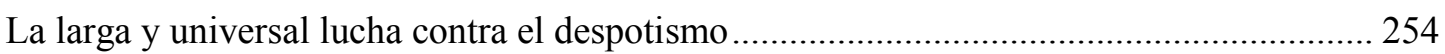

La Junta Grande, el desplazamiento del Secretario y el destierro de los morenistas............ 257

Los derechos de los pueblos indígenas. Castelli y la ceremonia de Tiahuanaco................... 261

\section{Capítulo 10:}

\section{El liberalismo peninsular ante la «cuestión americana»}

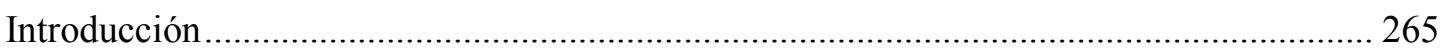

Manuel José Quintana, la pluma de la metrópoli en años de revolución............................... 265

Ganando enemigos en las dos orillas. Críticas de Álvaro Flórez Estrada al sistema monopólico comercial y a la insurgencia americana.

La posición oficial de la mayoría liberal peninsular en las Cortes. Agustín de Argüelles y su defensa de la política metropolitana 
Un amigo al otro lado del Atlántico. La voz disonante de José Blanco White y sus posturas

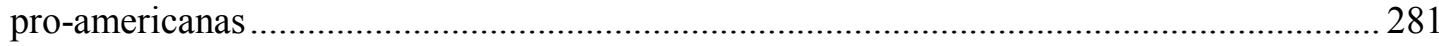

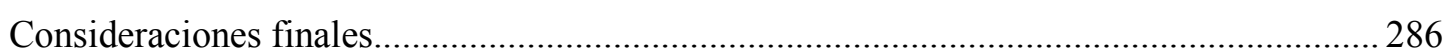

\section{Capítulo 11:}

Los escabrosos caminos para llegar a una Asamblea Constituyente en ambas orillas del Atlántico

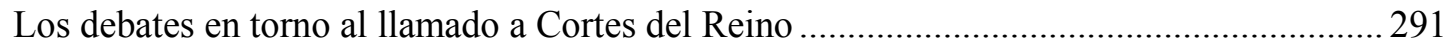

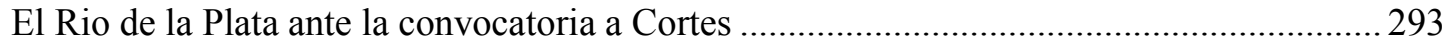

Los moderados en el poder: el Primer Triunvirato …........................................................... 296

El morenismo resurrecto: la Sociedad Patriótica ................................................................... 297

San Martin y la Logia de los Caballeros Racionales............................................................ 299

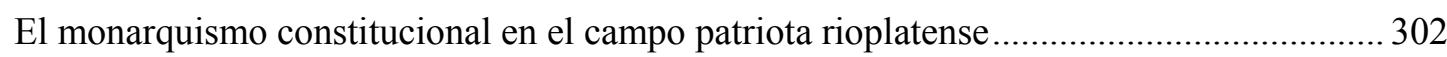

La frustrada Asamblea de abril y el golpe revolucionario de octubre ....................................304

Un congreso constituyente para los pueblos del Plata. El Decreto del Segundo Triunvirato del 24/10/12 y el Manifiesto de la Junta Central del 28/10/09 ................................................... 312

\section{Capítulo 12:}

\section{Las Cortes de Cádiz, la Constitución de 1812 y la Asamblea del año XIII}

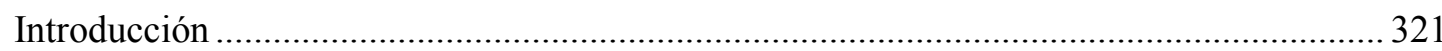

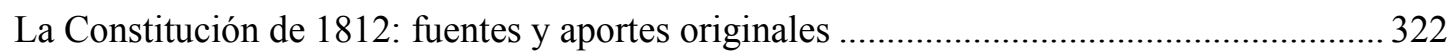

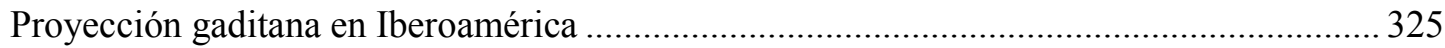

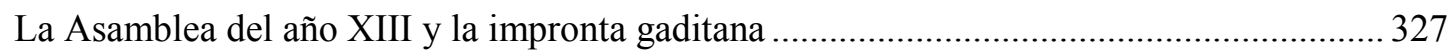

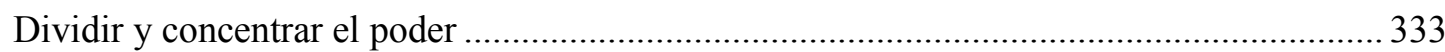

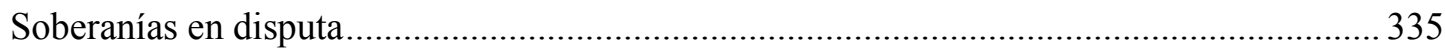

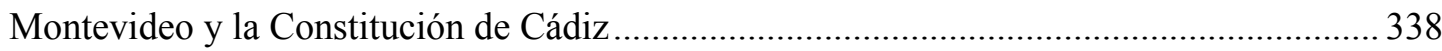

Clima tormentoso para la Revolución: la Asamblea naufraga en su impotencia ................... 340

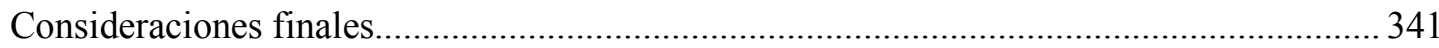

\section{Capítulo 13:}

La libertad de imprenta en el mundo hispánico. El caso peninsular y el rioplatense

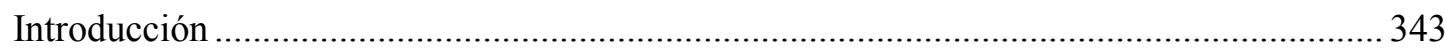

Los primeros escritos sobre la libertad de imprenta en el Río de la Plata. La recepción del

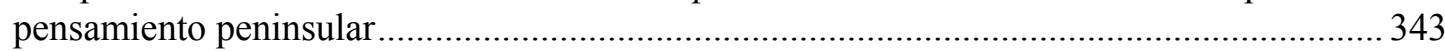

La libertad de imprenta en la península entre el levantamiento nacional y la reunión de

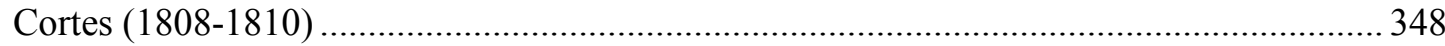

Tratamiento, promulgación y puesta en práctica por las Cortes de Cádiz ............................. 356

Circulación de la legislación sobre la libertad de imprenta en el mundo hispánico. El papel del Deán Gregorio Funes y de José Blanco White...................................................................... 363

La libertad de imprenta en la Gazeta de Montevideo .............................................................. 369 
Opinión pública vs opinión oficial. Los casos de El Censor de Pazos Silva y la Gazeta de Monteagudo

\section{Capítulo 14:}

La recepción de Blanco White en el Rio de la Plata

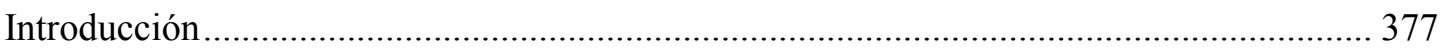

Las primeras reproducciones de Blanco White en el Río de la Plata .................................. 378

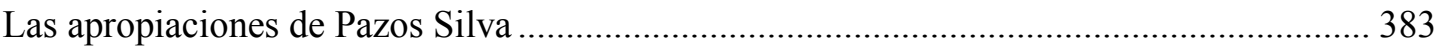

La polémica entre Pazos Silva y Monteagudo .................................................................. 388

Distanciamiento de la dirigencia porteña de la figura de Blanco White............................... 392

El Español, Servando Teresa de Mier y la Logia Lautaro ..................................................... 394

El Español en el giro conservador de la Logia ................................................................... 399

\section{Capítulo 15:}

\section{La Gazeta de Montevideo, entre Cádiz y Buenos Aires}

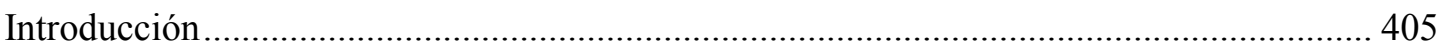

Fray Cirilo de Alameda y su cruzada de pluma y tinta ........................................................ 407

La prensa peninsular en las gacetas rioplatenses ................................................................ 410

Usos y sentidos de conceptos políticos en ambas márgenes del Plata y del Atlántico .......... 416

Las Cortes de Cádiz y la Constitución de 1812 en la Gazeta de Montevideo......................... 422

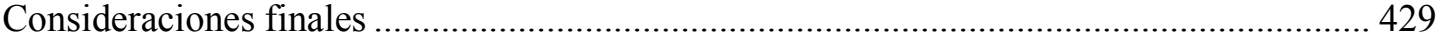

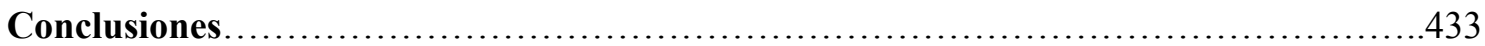

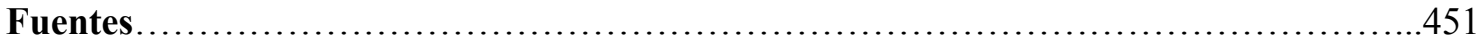

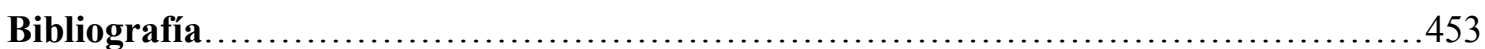




\section{Agradecimientos}

Toda historia tiene un comienzo, y la de esta tesis se remonta a los últimos años de mi carrera de grado, cuando cursando un interesante seminario con el profesor Luis Viguera sobre la Revolución Francesa, caí en la cuenta que la llamada "era de la revoluciones" constituía el período histórico que más me apasionaba y el campo de la historia de las ideas el que más llamaba mi atención. Por otra parte, siempre había sentido una particular inclinación hacia el pasado argentino y latinoamericano, seguramente por razones más vinculadas a lo político que a la mera curiosidad intelectual, aunque pensándolo mejor, constituyen dimensiones imposibles de disociar. Así que no me resultó difícil, en los años de los "bicentenarios", decidirme a revisitar el ya de por sí muy estudiado terreno de la cultura política durante la revolución rioplatense y comenzar el camino que hoy me trajo hasta aquí. Son varios y varias las que ayudaron a que dicho camino sea más llevadero, de distintas maneras y desde distintos lugares, pero hay algunas personas que no puedo dejar de mencionar.

Quiero agradecer en primer lugar a Fabio Wasserman por su esmerada, paciente y estimulante dirección. He tenido mucha suerte en poder contar con él como guía, no sólo por sus amplios conocimientos en el tema sino porque considero que su metodología de trabajo es la más adecuada a mis capacidades y necesidades. Siempre encontré en él una respuesta (o una repregunta) a mis inquietudes. A Osvaldo Barreneche, quien, además de haberme abierto las puertas de la cátedra de Historia Americana II, en la que actualmente me desempeño como docente, me orientó en mis balbuceantes primeras aproximaciones al tema y a la investigación en general. Estaré eternamente agradecido por su confianza y la excelente predisposición que tuvo durante todo este trayecto.

Quiero destacar a algunas profesoras que han sido muy valiosas en mi recorrido durante estos años. A María Inés Carzolio y Alejandra Mailhe les agradezco sus puntillosos y oportunos comentarios, correcciones y consejos, que hablan de una enorme generosidad y de un afecto hacia mí que nunca creí merecer, pero que es totalmente recíproco. A Noemí Goldman, que tuve la suerte de tenerla como docente en el Instituto Ravignani. Tanto sus escritos, como sus clases y conferencias, han sido completamente enriquecedoras e inspiradoras para mi investigación.

A los "peninsulares" Juan Gay Armenteros y Manuel Chust por haberme permitido llevar adelante mis estudios e investigaciones en la "Madre Patria". A la 
hermosa ciudad de Granada y a su gente, que me alojó en dos ocasiones en estos últimos años.

A mis compañeros de la cátedra, Andrés Stagnaro y Jorge Troisi, que supieron aconsejarme en muchas ocasiones y "esperarme" cuando hizo falta. A mis alumnos y alumnas de la materia, que muchas veces a partir de sus intervenciones me hicieron repensar algunos de los problemas de mi investigación.

A los colegas de la carrera de historia, a los del proyecto de incentivos y a los del CiSH y el IdIHCS en general, por sus comentarios, charlas y compañerismo. Muchas gracias sobre todo por la lucha compartida.

A mis padres, Mónica y Carlos, por las oportunidades que me dieron producto de su esfuerzo. Agradecido siempre por trasmitirme sus valores e ideales, que se pueden resumir esencialmente en pensar siempre en el otro, en ese otro colectivo y protagonista de nuestros sueños de justicia.

Gracias a Leticia, quien me dio el primer empujoncito para que me le anime a este desafío y me continuó acompañando y apoyando en el proceso. Estaré siempre en deuda por eso. A Juana, mi niña, por saber comprender que estos últimos meses papá tenía que trabajar más de lo normal y "la hora de jugar" era cada vez más cortita.

Finalmente gracias a la Facultad de Humanidades y Ciencias de la Educación de la UNLP y al Instituto Ravignani de la UBA por el apoyo que me dieron en todo sentido. A CONICET que gracias a su financiamiento me posibilitó enfocar mis tiempos y esfuerzos en esta investigación. Gracias en general al sistema universitario y científico argentino, hoy tan cuestionado y atacado. Mi reconocimiento a aquellos y aquellas que siguen apostando a su crecimiento a partir del esfuerzo cotidiano y no se resignan a verlo reducido nuevamente a una existencia testimonial. A los que con su trabajo y su lucha lo defienden tercamente día a día está dedicada esta tesis. 


\section{Introducción}

[...] creí oportuno recordar la conducta de los pueblos de España en igual situación a la nuestra. Sus pasos no serán la única guía de los nuestros, pues en lo que no fueron rectos, recurriremos a aquellos principios eternos de razón y justicia, origen puro y primitivo de todo derecho; sin embargo, en todo lo que obraron con acierto, creo una ventaja preferir su ejemplo a la sencilla proposición de un publicista, porque a la fuerza del convencimiento se agregará la confusión de nuestros contrarios, cuando se consideren empeñados en nuestro exterminio, sin otro delito que pretender lo mismo que los pueblos de España obraron legítimamente.

Mariano Moreno

"Sobre las miras del Congreso"

Gazeta de Buenos Aires [1810], p. 602

Durante mucho tiempo se discutió si la revolución rioplatense fue influida por la ilustración francesa o la neoescolástica española. La cita del secretario de la Junta Provisional Gubernativa que abre esta tesis, en cambio, al referirse explícitamente a los ejemplos de la revolución hispánica, nos da un indicio diferente que poco el foco en los lenguajes y experiencias políticas de la revolución española. La manifiesta vocación selectiva de aquello que era ventajoso adoptar de lo que no, y la preferencia de los ejemplos prácticos por sobre las elucubraciones teóricas, comprometen a su vez los tradicionales enfoques que se articulaban desde la idea de "copia" o "influencia". A partir entonces desde esta sencilla pista, esta investigación busca recorrer ese camino alternativo señalado por Mariano Moreno.

La revolución rioplatense formó parte de un proceso más amplio de ruptura con el antiguo régimen y el absolutismo. En el mundo hispánico, este movimiento tuvo su epicentro político e ideológico en la Península pero atravesó al conjunto del imperio. La dinámica política y militar del conflicto, y particularmente las contradicciones surgidas entre la dirigencia americana y el gobierno metropolitano en torno a los derechos de los habitantes del Nuevo Mundo, a raíz del llamado a Cortes del reino, terminaron 
condicionando el discurso y el plan de acción de los rioplatenses, ampliándose la brecha política e ideológica con el liberalismo peninsular.

Buscamos con la presente tesis realizar un aporte al estudio de la cultura política rioplatense en el tránsito entre el antiguo régimen y la república, presentando una lectura crítica de la relación entre el liberalismo hispánico y los grupos dirigentes del proceso revolucionario rioplatense, que contribuya a la profundización de una dimensión trabajada parcialmente, o realizada desde enfoques tradicionales que partían de la idea de "copia" o de "influencias". La tesis busca indagar en la recepción, apropiación, recorte y selección el pensamiento reformista ilustrado y, posteriormente, de la matriz liberal peninsular al calor de la crisis política imperial abierta con las abdicaciones de Bayona y la guerra contra la ocupación francesa. Esta elección no implica desconocer otras importantes fuentes de inspiración doctrinaria, o las significativas conexiones con otras experiencias políticas "modélicas" como la francesa, británica o norteamericana, en algunos aspectos hasta más determinantes, pero sí conlleva que éstas sean ubicadas en un segundo plano en el análisis, priorizando dar cuenta de las relaciones al interior del universo hispánico.

La tesis hace foco en la dinámica política de las elites de Buenos Aires, y en menor medida de Montevideo, sin pretender abarcar el conjunto del virreinato ni tampoco al mundo social extra-élite, aunque en muchos casos, tanto las provincias del interior, como los sectores subalternos, irrumpen necesariamente en el desarrollo narrativo y analítico. Temporalmente, nuestra investigación se centra entre los años 1801-1814, donde se puede observar no solo el contacto de la elite letrada rioplatense con el reformismo ilustrado hispánico, sino dar cuenta también del proceso de politización y radicalización que se irá operando en ella, hasta llegar al período revolucionario propiamente dicho (1808-1814), donde será verificable la articulación de la intelectualidad revolucionaria criolla en redes asociativas, desplegando una actividad política intensa, a través de la prensa, el catecismo político, la movilización, etc. La aparición de El Telégrafo Mercantil, y las transformaciones que este medio produce en el espacio rioplatense, son tomadas como punto de partida para la periodización. El corte en 1814 lo definimos a partir de la reimplantación del absolutismo en la península con la vuelta de Fernando VII y la creación del Directorio en el Río de la Plata, con una impronta más conservadora del gobierno de allí en adelante. Por otro lado, se indaga también en el recorrido previo de algunos de los referentes, para observar sus primeros acercamientos y formación en la denominada ilustración católica, así como también el 
contacto con las obras de los pensadores iluministas europeos que comienzan a circular en el nuevo mundo en el último cuarto del siglo XVIII.

\section{Breve estado de la cuestión}

Durante muchos años constituyó un lugar común en la historiografía argentina considerar al liberalismo como la ideología que orientó la actuación de la dirigencia en el Rio de la Plata revolucionario. Pero a la vez que se señalaba el carácter central que tuvieron esas ideas, desde una interpretación teleológica advertían que las mismas no lograron fructificar hasta pasada la primera mitad del siglo XIX, momento en que la Argentina habría logrado constituirse como un Estado-nación de cuño liberal. La revisión historiográfica que realizamos a continuación no es exhaustiva, existen aportes tradicionales que retomaremos a lo largo de la tesis pero que aquí no están reseñados. Señalaremos sí los más recientes que nos sirvieron para pensar el problema.

La historiografía liberal desde sus inicios a mediados del siglo XIX ha resaltado la influencia del liberalismo francés y británico en la élite de Mayo, soslayando el papel que jugó la ilustración española y el liberalismo peninsular. Esto se explica fundamentalmente por la búsqueda de las primeras plumas historiográficas argentinas de acentuar de esa forma la idea de ruptura con el pasado hispánico, sin dejar de tener en cuenta el profundo rechazo al carácter cultural español de varias de ellas. ${ }^{1}$

Por otra parte, el "revisionismo histórico" argentino de la primera mitad del siglo XX ha coincidido con esa caracterización, pero atribuyéndole un valor negativo a esta influencia, producto de su nacionalismo de derecha y/o reivindicación de la tradición católica. ${ }^{2}$ Una variante de ese revisionismo, por el contrario, ve como principal fuente ideológica a pensadores de origen jesuita como Francisco Suárez. ${ }^{3}$

Ricardo Levene se diferencia de algunas posiciones de la historiografía tradicional al afirmar que la revolución de 1810 está enraizada en su propio pasado, nutriéndose de fuentes ideológicas hispanas e indianas. ${ }^{4}$ Para el renombrado historiador sólo periféricamente tienen resonancia los hechos y las ideas del mundo exterior a España e

\footnotetext{
${ }^{1}$ Mitre, Bartolomé, Historia de Belgrano y de la Independencia Argentina, [1858], Buenos Aires, 1950; López, Vicente Fidel, Historia de la República Argentina, su origen, su revolución y su desarrollo político hasta 1852, [1883-1893], Buenos Aires, Imp. de G. Kraft, 1913.

${ }^{2}$ Irazusta, Julio, Tomás de Anchorena, o la emancipación americana a la luz de la circunstancia histórica, Buenos Aires, Huemul, 1962.

${ }^{3}$ Furlong, G., Nacimiento y desarrollo de la Filosofía en el Río de la Plata, Buenos Aires, Ed. G. Kraft, 1952.

${ }^{4}$ Levene, Ricardo, Las ideas políticas y sociales de Mariano Moreno, Buenos Aires, Emecé, 1948.
} 
Hispanoamérica, que, según él, constituía un orbe propio. Considera absurdo concebir la revolución hispanoamericana como un epifenómeno de la revolución francesa o de la norteamericana.

Autores como Julio V. González y Demetrio Ramos caracterizan a la Revolución de Mayo como un capítulo de la revolución hispanoamericana y a ésta de la revolución democrática europea. ${ }^{5}$ Presentan argumentos a favor de la importancia de la ilustración española en la formación de la intelectualidad criolla y el impacto de la producción política e ideológica del juntismo peninsular en el proceso revolucionario rioplatense. Lineamientos que luego serían continuados y profundizados, enfatizando el carácter revolucionario y democratizador del liberalismo peninsular, por un sector del revisionismo argentino denominado por uno de sus autores como "socialista" o "federal-provinciano". ${ }^{6}$ Entienden que el proceso revolucionario efectuado contra la "España negra" reaccionaria y feudal estaba conformado tanto por la España liberal como por la América insurgente, ya que "los hombres de Mayo se hicieron revolucionarios en las fraguas españolas”. Para estos autores entonces, la Revolución de Mayo no fue un levantamiento contra España, sino contra una de ellas junto a la otra. Para liberarse del yugo feudal o para sostenerlo, americanos y españoles combatieron en ambos campos.

Tulio Halperín Donghi analiza el lugar de la tradición política española en el proceso abierto con la crisis de la Monarquía, como un elemento importante en la construcción de una personalidad propia del liberalismo constitucionalista español, destacando el pensamiento de, entre otros, Jovellanos y Martínez Marina. ${ }^{7}$ Pero, a pesar de que para el renombrado historiador la dirigencia revolucionaria rioplatense utilizó dicho marco para replantear inicialmente la relación con la metrópoli y la legitimidad del nuevo gobierno -la retroversión de la soberanía al pueblo en ausencia del Rey-, la Revolución de Mayo significó una ruptura con la tradición política española, construyéndose al avanzar su propia justificación teórica e interpretación del pasado. El autor y la corriente influenciada por él pusieron el acento en las contradicciones locales y la crisis monárquica para explicar el fenómeno independentista.

\footnotetext{
${ }^{5}$ González, Julio V., Filiación histórica del gobierno representativo argentino, Buenos Aires, La vanguardia, 1937; Ramos, Demetrio, "Formación de las ideas políticas que operan en el movimiento de mayo de Buenos Aires en 1810", Revista de estudios políticos, Vol. 134, Madrid: Inst. de Studios Políticos, 1964, pp. 139-218.

${ }^{6}$ Ramos, Julio A., Revolución y Contrarrevolución en la Argentina, Buenos Aires, Editorial Distal, 1999; Galasso, Norberto, Mariano Moreno, el sabiecito del Sur, Buenos Aires, Colihue, 2004.

${ }^{7}$ Halperín Donghi, Tulio, Tradición política española e ideología revolucionaria de mayo, Buenos Aires, Eudeba, 1961.
} 
Entre los historiadores contemporáneos, José Carlos Chiaramonte se destaca por sus aportes específicos en el tema. En varios de sus trabajos indaga en la forma en que circularon las ideas de la Ilustración en el virreinato, e impugna las tesis que plantean a los americanos como meros repetidores de las doctrinas europeas, poniendo énfasis en las necesidades, conscientes por parte de los criollos, de la adaptación de este aparato conceptual al contexto americano. ${ }^{8}$ Los fundamentos iniciales de la ruptura responderían, a su entender, más que a la adopción de un aparato conceptual revolucionario de inspiración francesa, a la pervivencia del Derecho Natural y de Gentes, siendo central en ello la noción de "consentimiento", presente tanto en la neoescolástica como en el iusnaturalismo y el enciclopedismo francés. ${ }^{9}$

La reconsideración del liberalismo hispánico atendiendo a las particularidades de la estructura social, las prácticas, las instituciones y los actores tienen diversas fuentes de inspiración, destacándose por su gran influencia la obra de François-Xavier Guerra. ${ }^{10}$ En ella se enfatiza la unidad de la elite dirigente e intelectual iberoamericana en la adopción de las "ideas modernas". En este aspecto se resalta la difusión del liberalismo español en América, fundamentalmente a partir de 1808. Al calor de la crisis política abierta, un sector de los letrados criollos tomaría un rumbo más radicalizado que sus referentes peninsulares, acercándose por lo tanto al modelo revolucionario de corte francés. Guerra enmarca estas transformaciones conceptuales con las alteraciones ocurridas en el plano de las prácticas políticas como resultado de la emergencia de nuevos ámbitos de sociabilidad y sujetos políticos. Finalmente, y como conclusión central, sostiene la tesis que la ilustración de la élite dirigente, al menos de una parte, chocó con la sólida muralla de las tradiciones y el conservadurismo de la gran mayoría de la sociedad americana, provocando el derrotero infructuoso del liberalismo en el continente. Para el autor esta contradicción entre modernidad política y arcaísmo social generó, a su vez, una hibridez del lenguaje político latinoamericano.

Elías Palti discute la interpretación de Guerra y la llamada escuela revisionista, al afirmar que, al mantener la dicotomía entre modernidad y tradición, no terminan de romper con la visión teleológica de la historia que ellos mismos critican al cuestionar

\footnotetext{
${ }^{8}$ Chiaramonte, José Carlos, La ilustración en el Río de la Plata: Cultura eclesiástica y cultura laica durante el Virreinato, Buenos Aires, Puntosur, 1989.

${ }^{9}$ Chiaramonte, José Carlos. Fundamentos intelectuales y políticos de las independencias. Notas para una nueva historia intelectual de Iberoamérica. Buenos Aires: Teseo, 2010.

${ }^{10}$ Guerra, François-Xavier, Modernidad e independencias, Madrid, Mapfre, 1992.
} 
los "mitos nacionalistas" de la historiografía tradicional. ${ }^{11} \mathrm{El}$ autor propone hacer foco en la historización de los lenguajes políticos, es decir en el estudio de las condiciones de producción de los enunciados políticos e ideológicos y de los conceptos (soberanía, pacto, centralismo, nación, etc.) despojándolos del anclaje en "tipos ideales" y las visiones dicotómicas tan comunes a la Historia de las Ideas tradicional.

Roberto Breña plantea una crítica similar a la tesis de Guerra, argumentando la imposibilidad de encontrar "estados puros" tanto del liberalismo como del absolutismo a nivel iberoamericano, prefiriendo utilizar la díada "reformismo-tradicionalismo" para analizar el pensamiento español de ese período. ${ }^{12}$ El autor investiga en profundidad las relaciones entre los liberales peninsulares y americanos, llegando a la conclusión de la fuerte homogeneidad ideológica entre ambos producto de la importante difusión del liberalismo español gracias al surgimiento de la prensa. Por otro lado, resalta las contradicciones materiales e ideológicas que llevaron a ponerlos en veredas opuestas en el marco de las luchas emancipatorias americanas.

Una nueva reflexión sobre la cultura política en los últimos 20 años ha puesto más el acento sobre las fallas o aporías constitutivas de los propios modelos constitucionales modernos y sus usos selectivos por parte de los actores iberoamericanos, que sobre la falta de originalidad o inadecuación social de sus empleos en Hispanoamérica. En ese sentido, uno de los historiadores que más aportes han hecho en los últimos años a este campo es José Portillo Valdés. ${ }^{13}$ En sus trabajos establece la idea de una cultura constitucional hispánica, con elementos propios y singulares que la diferencian respecto a otros procesos de la revolución constitucional atlántica. Entre 1808 y 1824 ningún otro espacio se mostró tan proclive a la experimentación constitucional como el que componía la monarquía española. La originalidad tanto del texto gaditano, como de los americanos, se puede observar en relación al tratamiento de lo religioso, donde se establecen a diferencia de otros textos constitucionales la confesionalidad del estado y la intolerancia hacia otros cultos que no sean el católico. Los textos y la cultura constitucional hispánica en general estaban impregnados de una fuerte carga de catolicismo.

\footnotetext{
${ }^{11}$ Palti, Elías J., El tiempo de la política. El siglo XIX reconsiderado, Buenos Aires: Siglo XXI, 2007.

${ }^{12}$ Breña, Roberto, El primer liberalismo español y los procesos de emancipación de América, 1808-1824. Una revisión historiográfica del liberalismo hispánico, México, El Colegio de México, 2006.

${ }^{13}$ Portillo Valdés, José María, Revolución de Nación. Orígenes de la cultura constitucional en España, 1780-1812, Madrid, Centro de estudios Políticos y Constitucionales, 2000.
} 
Son importantes los recientes trabajos que desde el campo de la historia de los conceptos y de los lenguajes políticos, partiendo de una crítica hacia la tradicional historia de las ideas o del pensamiento político y sus definiciones apriorísticas del liberalismo, han estudiado la evolución, durante la primera mitad del s. XIX, de las nociones e identidad política "liberal/liberalismo", para el conjunto del mundo hispánico y en particular para el caso rioplatense. Javier Fernández Sebastián parte de entender al liberalismo no como una corriente de pensamiento inmemorial, sino de un concepto forjado por los liberales -y los antiliberales- en el trascurso de luchas políticas concretas. ${ }^{14}$ Destaca como rasgos distintivos de ese precoz liberalismo la amplia participación popular que propició, su carácter corporativo y escasamente individualista, o su confesionalismo católico. De estos trabajos se desprende que la identidad política de los liberales fue en muchos casos bastante débil y difusa durante el periodo estudiado, y en algunos de los espacios americanos ni siquiera es fácil señalar cuándo el liberalismo entró en acción como un grupo político organizado y claramente identificable. En ese sentido, Fabio Wasserman sugiere que no es factible identificar un lenguaje propiamente liberal en el Río de la Plata, integrándose más bien algunos de sus elementos en otros lenguajes, como el republicano o el iusnaturalista. ${ }^{15}$

Los estudios de Noemí Goldman, desde el campo de la historia de los discursos, se distancian de la visión tradicional que asimilaba los discursos y prácticas políticas de los dirigentes criollos más radicales al modelo jacobino de la Revolución Francesa, y haciendo eje en algunas nociones fundamentales del período, desplaza el interés desde las influencias doctrinales hacia los discursos y sus vocabularios políticos. ${ }^{16} \mathrm{El}$ análisis de la concepción de la revolución en Moreno, Castelli y Monteagudo revela no sólo la distante realidad política con respecto al proceso francés; también pone en evidencia una tensión permanente, tanto en los discursos como en las prácticas morenistas, entre actitud revolucionaria y moderada, interés político y convicción. El examen de los conceptos políticos llevó a concluir a la investigadora y su grupo de trabajo que los significados de términos como ciudadano, nación, opinión pública, pueblo o soberanía no eran unívocos, ni se ubicaban necesariamente en una línea de continuidad con los

\footnotetext{
${ }^{14}$ Fernández Sebastián, Javier (coord.), La aurora de la libertad. Los primeros liberalismos en el mundo hispánico, Madrid, Marcial Pons, 2012.

${ }^{15}$ Wasserman, Fabio, "Liberal/Liberalismo" en Goldman, N., Lenguaje y Revolución, Conceptos políticos clave en el Río de la Plata, 1780-1850, Buenos Aires, Prometeo, 2008.

${ }^{16}$ Goldman, Noemí, Historia y lenguaje. Los discursos de la Revolución de Mayo, Buenos Aires, Centro Editor de América Latina, 1992.
} 
significados que hoy se le atribuyen. ${ }^{17}$ En estos trabajos se destaca que si bien la polisemia es constitutiva del lenguaje político, la creciente inestabilidad semántica en la producción conceptual del período constituye en sí mismo una novedad, explicada por los grandes cambios acaecidos a ambos lados del Atlántico con la crisis de la monarquía española de 1808, la acefalía real y el inicio de los procesos revolucionarios. Esta reinserción en la crisis imperial hispanoamericana y peninsular, ha revelado la importancia de los circuitos de difusión de las ideas, sus dinámicas de apropiación y su resignificación en distintas coyunturas. La obra recoge estos aportes y los articula para delinear un cuadro de problemas sobre el proceso de desmembración del virreinato y la constitución de las comunidades políticas provinciales, realizando una reconstrucción semántica en la que el contenido es definido desde el contexto ideológico, lingüístico y político.

Esteban de Gori problematiza los imaginarios y lenguajes políticos que se inscribieron en los textos de Mariano Moreno para dar cuenta del complejo haz de vocabularios y culturas políticas que contribuyeron a la formación de un nuevo orden político en la ciudad cabecera del Virreinato del Río de la Plata, considerando el vínculo entre la producción del lenguaje y las estrategias políticas desarrolladas por los actores que pugnan por el poder. ${ }^{18}$ Pone el acento en las articulaciones que efectuaron los insurgentes entre los imaginarios republicanos y constitucionalistas con el legado monárquico, y la resignificación, apropiación y uso de la figura del rey y otros símbolos del mundo borbónico; de conceptos como república, pacto, patria, buen gobierno, bien común, etc. ; y de prácticas trasmigradas a través del tiempo. Entendiéndolas no como "resabios" o "residuos" de otros tiempos -como si existiesen prácticas o conceptos "puros- sino como parte de dinámicas, estrategias y caculos políticos orientados a la consolidación de un nuevo orden político.

En relación a los estudios de casos de recepción del pensamiento liberal español en el Río de la Plata, son de destacar los trabajos de Alejandra Pasino sobre los usos, apropiaciones y adaptaciones que tuvieron los escritos de José María Blanco White y Manuel Quintana en el contexto de los primeros años de la revolución, sirviendo para cuestionar la mirada generalista que algunos especialistas en la obra de estos liberales

\footnotetext{
${ }^{17}$ Goldman, N., Lenguaje y Revolución, Conceptos políticos clave en el Río de la Plata, 1780-1850, Buenos Aires, Prometeo, 2008.

${ }^{18}$ De Gori, Esteban, La República Patriota: Travesía de los imaginarios y de los lenguajes políticos en el pensamiento de Mariano Moreno, Buenos Aires, Eudeba, 2013.
} 
tienen cuando abordan el análisis de la incidencia de sus ideas en los territorios españoles en América. ${ }^{19}$

En los últimos 25 años han proliferado las investigaciones que abordan el surgimiento de nuevas formas de sociabilidad en el período. Esta perspectiva inaugurada para el mundo hispánico por Guerra, ha sido retomada para estudiar el proceso revolucionario rioplatense por diversos historiadores. ${ }^{20}$ En sus trabajos se analiza el surgimiento del movimiento asociativo -sociedades patrióticas literarias y políticas-, la construcción del espacio público y los modos de socialización o publicidad -la prensa-, y el rol de esta última en la conformación de la opinión pública. La convergencia con la experiencia europea en este plano constituye un aspecto central en el análisis. La influencia de Guerra también se percibe en el estudio de Gabriela Tío Vallejo sobre la vida política en Tucumán entre 1770 y 1830, otorgando un especial análisis a las prácticas electorales y las relaciones entre vecindad y ciudadanía. ${ }^{21}$ Para el estudio de la formación universitaria chuquisaqueña está la tesis de maestría del Clement Thibaud, realizada bajo la dirección de François-Xavier Guerra. ${ }^{22}$ El objetivo principal del trabajo consiste en esclarecer el modo de existencia de un grupo que pertenece a la elite criolla, penetrar sus formas de pensamiento, su sociabilidad, sus representaciones de sí mismos, en la víspera de las guerras de independencia.

Marcela Ternavasio hace hincapié en el carácter particular de fenómenos y procesos políticos usualmente considerados como expresiones típicas del liberalismo como el voto o la división de poderes. ${ }^{23}$ Su mirada intenta insertar estas problemáticas en el contexto atlántico, es decir, en permanente relación con los sucesos, los lenguajes y las experiencias del resto de las colonias y de la misma metrópoli en lucha contra

\footnotetext{
${ }^{19}$ Pasino, Alejandra, "El Español de José María Blanco-White en la prensa porteña durante los primeros años revolucionarios", en Herrero, F. (comp.), Revolución. Política e ideas en el Río de la Plata, Buenos Aires, Ediciones Cooperativas, 2004; Pasino, A., "Las impugnaciones a las Cortes de Cádiz en el Río de la Plata revolucionario a través de la recepción de El Español de José María Blanco White. (1810-1812), en Gullón Abao, A.; Gutiérrez Escudero, A., La Constitución gaditana de 1812 y sus repercusiones en América. Universidad de Cádiz, 2012.

${ }^{20}$ González Bernaldo de Quirós, Pilar, "La Revolución Francesa y la emergencia de nuevas prácticas de la política: la irrupción de la sociabilidad política en el Río de la Plata revolucionario (1810-1815)" Boletín del Instituto de Historia Argentina y Americana "Dr. E. Ravignani" Tercera Serie, núm. 3, Buenos Aires, 1991; Molina, Eugenia, El poder de la opinión pública. Trayectos y avatares de una nueva cultura politica en el Río de la Plata, 1800-1852, Santa Fe, Ediciones de la Universidad del Litoral, 2009.

${ }^{21}$ Tío Vallejo, Gabriela, Antiguo Régimen y liberalismo: Tucumán, 1770-1830, (Cuadernos de Humanitas, number 62), San Miguel de Tucumán, Argentina: Facultad de Filosofía y Letras, Universidad Nacional de Tucumán, 2001.

${ }^{22}$ Thibaud, Clement, La Academia Carolina y la independencia de América. Los abogados de Chuquisaca (1776 - 1809), Sucre, Editorial Charcas, 2010.

${ }^{23}$ Ternavasio, Marcela, Gobernar la revolución: poderes en disputa en el Río de la Plata, 1810-1816, Buenos Aires, Siglo XXI Editores Argentina, 2007.
} 
Napoleón. Así, es la definición de un marco de referencia epocal lo que le permite precisar las similitudes y especificidades de las circunstancias vividas por los grupos políticos porteños, desarrollando las posibilidades analítico-comparativas que abrió François-Xavier Guerra. En ese mismo registro, también interesan a este estudio sus trabajos sobre el desenvolvimiento de la alternativa carlotista o del constitucionalismo doceañista en el Río de la Plata. ${ }^{24}$

Si nos remitimos exclusivamente al campo del pensamiento económico, los aportes realizados por Rodolfo Pastore y Nancy Calvo reconocen una vinculación intelectual en el Rio de la Plata tardo-colonial considerablemente más compleja que la simple adscripción a los conceptos de las escuelas fisiocráticas o la librecambista, como desde la historiografía tradicional siempre se afirmó. ${ }^{25}$ Estos autores entienden que prevaleció una «amalgama de pensamientos diversos por encima del seguimiento exclusivo de algún enfoque económico en particular», y destacan la atención puesta por los rioplatenses en las obras y debates de los economistas peninsulares. Observan en ese sentido una adopción correctiva de las ideas generadas en los centros de conocimiento de acuerdo a la percepción de las condiciones culturales y socioeconómicas que operan en el plano local.

Contamos en ese sentido con los trabajos de Federica Morelli sobre la recepción de la llamada "Escuela Napolitana" en América, donde se identifican dos etapas en ese proceso, especialmente para el caso de Gaetano Filangieri. ${ }^{26}$ En una primera, que sitúa en el último cuarto del siglo XVIII y los primeros años del XIX, los americanos acogieron mayoritariamente los temas económicos, mientras que una segunda etapa, a partir de la deriva que la crisis monárquica va tomando en América con la formación de gobiernos autónomos, la recepción va a ser en clave de la crítica al antiguo orden legislativo.

\footnotetext{
${ }^{24}$ Ternavasio, Marcela, "El Río de la Plata divido. La experiencia gaditana en Buenos Aires y Montevideo (1810-1814)", en Breña, R., Cádiz a debate: actualidad, contexto y legado, El Colegio de México, México, 2014, pp. 277 - 302; Ternavasio, M., Candidata a la corona: la infanta Carlota Joaquina en el laberinto de las revoluciones hispanoamericanas. Buenos Aires: Siglo Veintiuno editores, 2015.

${ }^{25}$ Pastore, Rodolfo y Calvo, Nancy. «Cultura colonial, ideas económicas y formación superior 'ilustrada' en el Río de la Plata. El caso de Manuel Belgrano». Prohistoria núm. 4 (2000): 27-57; Pastore, R.; Calvo N., "Ilustración y economía en el primer periódico impreso del Virreinato del Río de la Plata: el Telégrafo Mercantil (1801-1802)”, Bulletin Hispanique, núm. 107-2, 2005, pp. 433-462.

${ }^{26}$ Morelli, Federica. «Tras las huellas perdidas de Filangieri: nuevas perspectivas sobre la cultura política constitucional en el Atlántico hispánico». Historia contemporánea núm. 33 (2006): 431-462; Morelli, Federica. «Filangieri y la "Otra América": historia de una recepción». Revista Facultad de Derecho y Ciencias Politicas vol. 37 núm. 107 (2007): 485-508.
} 
Silvana Carozzi, desde el campo de la filosofía, se propone un estudio del discurso de la obra de algunos de los principales publicistas rioplatenses entre $1810 \mathrm{y}$ 1815. ${ }^{27}$ Concretamente, se centra en el grupo morenista, los "jacobinos rioplatenses", y sobre todo los escritos en la prensa periódica de tres de sus protagonistas: el propio Mariano Moreno, Manuel Belgrano, y Bernardo de Monteagudo. La representación que del proceso revolucionario fueron elaborando esos autores, no necesariamente siempre a la luz de Rousseau -aunque le otorga un lugar muy destacado en su análisis- es el foco temático central. Una indagación en los usos que filósofos y textos provenientes de otros contextos tienen en las disputas intelectuales encaradas por los publicistas más radicales de los primeros años revolucionarios. En las polémicas y las discusiones con Vicente Pazos Silva, el deán Gregorio Funes o con autores españoles y americanos puede verse el valor pragmático del "gesto de selección", que posibilita una "identificación imaginaria" de los horizontes de los actores rioplatenses con aquellos de los filósofos retomados; de este modo, aunque los libros "no se constituyen en causa de las acciones rebeldes, son el yacimiento seleccionado por los actores, por diversos motivos, para justificar sus acciones". ${ }^{28}$ La propuesta de Carozzi se ubica a cierta distancia de los enfoques que parten de la pregunta por los orígenes intelectuales de la revolución, y se aboca a intentar rastrear, a partir del acontecimiento revolucionario, el mundo de las representaciones de ese grupo intelectual y el gesto por el cual ellos mismos deciden expresar su elección filosófica, puestos ya a explicar y propagandizar una revolución que, según la autora, sin haberla programado o previsto, están protagonizando concretamente.

El estudio de Patricio Clucellas, tanto por algunos hallazgos significativos producto de su trabajo en los archivos españoles- como por su emparentamiento con los objetivos de esta tesis, merece un lugar en este estado de la cuestión. ${ }^{29}$ El autor pretende demostrar el influjo decisivo y directo del pensamiento liberal hispano y sus raíces ilustradas en la revolución política del 25 de mayo de 1810. Destacando como ejemplos de esa impronta hispana las dos primeras normas constitucionales rioplatenses dictadas ambas en 1811: el reglamento de libertad de imprenta y el decreto de seguridad personal.

\footnotetext{
${ }^{27}$ Carozzi, Silvana, Las filosofias de la revolución: Mariano Moreno y los jacobinos rioplatenses en la prensa de Mayo: 1810-1815, Buenos Aires, Prometeo Libros, 2011.

${ }^{28}$ Ibid., pp. 38-39.

${ }^{29}$ Clucellas, Patricio, 1810 Revolución de dos mundos. La presencia de España en el Mayo rioplatense, Ed. Torre de Hércules, 2012.
} 
Autores como Klaus Gallo y Beatriz Dávilo han puesto el acento en la recepción y usos de otras corrientes liberales como el utilitarismo, que esta tesis no se plantea tratar pero que son muy importantes para conformar una visión panorámica completa de la circulación de ideas en la primea década del Rio de la Plata independiente. ${ }^{30}$ Resaltan que lo que muchos políticos y publicistas buscaban en estas doctrinas eran respuestas al problema que afectaba a las sociedades que estaban transitando o habían transitado procesos revolucionarios: la necesidad de crear un nuevo orden social y político, apelando a una perspectiva historiográfica que indaga sobre el uso en contexto de las ideas -descartando una visión genética de las mismas- en el ámbito de la opinión porteña.

\section{Marco Teórico y Metodológico}

El marco teórico de nuestra investigación se inspira en el modelo de las "Revoluciones Hispánicas" inaugurado por François Xavier Guerra, compartiendo la percepción global de un amplio escenario de profundas transformaciones interconectadas, donde las mutaciones en la cultura política en ambos hemisferios juegan un rol fundamental. Partimos entonces desde esta perspectiva, que ha sido enriquecida por las valiosas críticas realizadas, hace algunos años, por Roberto Breña y Elías Palti, ya referidas en los antecedentes.

El estudio de la cultura política se hará desde un enfoque que la entiende como "un marco dentro del cual se desarrollan las acciones, y por lo tanto, aquello que permite asignarles sentido. Se trataría de las reglas del juego político, pero tomando a éstas en un sentido amplio, no sólo las formales, explícitas o institucionales". ${ }^{31}$ Esto entendido obviamente de manera dinámica, ya que precisamente la política es en parte la ruptura de las reglas, sobre todo cuando hablamos de una revolución.

Asimismo, nuestro trabajo retoma algunos lineamientos metodológicos desarrollados por la historia cultural, fundamentalmente la necesidad de examinar las ideas, discursos y representaciones en su especificidad histórica. Consideramos por lo tanto sus aspectos materiales, las prácticas sociales y los sujetos que las producen y las

\footnotetext{
${ }^{30}$ Gallo, Klaus, "Jeremy Bentham y la "Feliz Experiencia". Presencia del utilitarismo en Buenos Aires 1821-1824”, Prismas, No. 6, 2002, págs. 79-96; Beatriz Dávilo, "De los derechos a la utilidad del discurso político en el Río de la Plata durante la década revolucionaria”, Prismas, N. 7, 2003, págs. 73-98.

${ }^{31}$ Wasserman, F., Comentarios al texto de Marcela Ternavasio "Política y cultura política ante la crisis del orden colonial", Bol. Inst. Hist. Argent. Am. Dr. Emilio Ravignani [online], 2011, n.33.
} 
consumen. La investigación se desenvuelve también a partir de los enfoques provenientes de la historia conceptual e historia intelectual, tomando como referencia los trabajos que vienen realizando Chiaramonte, Goldman, y Palti, por mencionar a los más representativos de dichos campos historiográficos. Buscamos descubrir los modos en que el contexto penetra en el plano simbólico, comprendiendo los discursos como hechos sociales, y no meras representaciones de realidades externas. Tratamos de tomar distancia de las perspectivas tradicionales que piensan el vínculo entre ideas y prácticas políticas en términos de 'influencias'. No se trata de ver cómo los actores se vuelven revolucionarios por abrevar en las modernas filosofías de los derechos, los libros no hacen revoluciones, pero tampoco caer en algunas de las interpretaciones actuales que ubican a la teoría sólo en el lugar instrumental de legitimación de hechos ya consumados, convirtiendo a los protagonistas en sólo pragmáticos otorgadores de sentido de los acontecimientos. Se trata, creemos, de reconstruir el proceso por el cual el pensamiento político de aquellos va dotándose de esos innovadores fundamentos a la par que se van constituyendo en revolucionarios. Discurso y acción se van condicionando mutuamente en función de los problemas que éstos se van planteando. No sería entonces ni puro pragmatismo ni pura ideología -no hay política sin distintas dosis de ambas-.

Esta investigación se propone llevar adelante una labor crítica, descartando justamente la noción de influencia -entendida como mera transmisión vertical de elementos estéticos, ideológicos o formales-, y apunta a pensar relaciones en una trama internacional dentro de la cual casi nunca transcurren en pie de igualdad. Por el contrario, implican desigualdades, asimetrías y diferencias. Tomando las palabras de Horacio Tarcus: "Para la historia de las ideas tradicional o para la crítica comparatista clásica, no había aquí un verdadero problema: las grandes doctrinas políticas como el liberalismo [...] eran por definición universales y su labor consistía en documentar su difusión desde ciertos centros de producción centrales hasta los últimos confines del planeta. Tomaba como punto de partida a los grandes pensadores o escritores representados por sus obras capitales, constituyendo así una suerte de modelo, y rastreaba de modo erudito su influencia, por ejemplo, en los cuerpos doctrinales periféricos, a los que se trataba como una copia. El juicio del historiador de las ideas apuntaba a apreciar el grado de fidelidad de una copia, por definición siempre imperfecta, respecto a un original erigido previamente en modelo. La historia de las ideas, como así también la crítica literaria, se centró durante décadas en la cuestión de la 
originalidad de la producción vernácula, preocupación que derivó luego en la pregunta por las condiciones de existencia de un genuino -esto es, endógeno y originalpensamiento argentino o, según los casos, latinoamericano". ${ }^{32}$

Con respecto al análisis de la circulación de los textos, compartimos el enfoque de Pierre Bourdieu, en el cual el sentido y la función de una obra extranjera están determinados tanto por el campo de recepción como el de origen. "En primer lugar, porque el sentido y la función del campo originario son, con frecuencia, completamente ignorados. Y también, porque la transferencia de un campo nacional a otro se hace a través de una serie de operaciones sociales". ${ }^{33}$ Desde luego que si las ideas circulan de un espacio social a otro sin sus contextos -con prescindencia de su campo de producción-, los receptores van a reinterpretarlas según las necesidades dictadas por su propio campo de producción. Esta es la causa, nos dice Bourdieu, de "formidables malentendidos" que no son circunstanciales: en la base de todo proceso de recepción habría un "malentendido estructural".

Lo que nos interesa son los procesos por los cuales se recepcionaron en el Río de la Plata las doctrinas, experiencias y el lenguaje del liberalismo peninsular, otorgando al momento de la recepción un carácter activo. Siguiendo nuevamente a Horacio Tarcus, que retoma aquí los planteos de Rosanvallón, "si se trata de reconstruir la manera como los individuos y los grupos han elaborado la comprensión de las situaciones y han procurado construir respuestas a lo que perciben más o menos confusamente como un problema", atendiendo sobre todo a las representaciones activas que orientan su acción, nuestro foco estuvo puesto en los usos que ciertos actores locales hicieron de las doctrinas del liberalismo "para pensar a los que identificaban como problemas y para intervenir sobre ellos, conforme su respectiva colocación, sus intereses y sus necesidades en un campo local de recepción". ${ }^{34}$ Como veremos a lo largo de la tesis esta recepción activa, la operación de selección y adaptación a las condiciones locales del pensamiento español, lejos de limitarse a casos puntuales sería la conducta constante de los letrados criollos. Preocupados por la falta de desarrollo agrícola del virreinato, los economistas rioplatenses adscribieron a los planteos a favor de la libre exportación de los frutos, pero no a un completo laissez-faire, impulsando una fuerte intervención de la

\footnotetext{
${ }^{32}$ Tarcus, Horacio, El socialismo romántico en el Río de la Plata (1837-1852). Buenos Aires, Fondo de Cultura Económica, 2016, pp. 54-55.

${ }^{3333}$ Bourdieu, P., "Las condiciones sociales de la circulación de las ideas" en Intelectuales, política y poder, Buenos aires, Eudeba, 1999.

${ }^{34}$ Tarcus, Horacio, óp. cit., p. 68.
} 
corona en pos de la modernización económica anhelada. O más adelante, ya en el contexto revolucionario, de los liberales españoles se apropiaran en gran medida de su labor político-jurídica pero descartando la arquitectura general donde estaba inscripta que era el modelo monárquico constitucional. En esta línea, resulta conveniente retomar la lógica interpretativa de H. G. Gadamer. Según su clásico trabajo sobre este tema, la relación entre texto y lector obedece a la lógica de pregunta y respuesta. ${ }^{35}$ El texto es, pues, la respuesta a una pregunta; dicho de otra manera, sólo percibo en un texto aquello que tiene algo que ver conmigo. Lo que me importa, lo que me interesa y está en línea con mis intereses, ideas y valores. Lo cierto, en ese marco de verdadera reflexión política, es que la respuesta que el texto da a mi pregunta nunca es plenamente suficiente, de manera que el propio texto plantea también preguntas, y es ahora al lector al que le toca encontrarlas.

Compartimos, en ese sentido, la hipótesis de trabajo de Silvana Carozzi, que parte de entender que el "gesto de selección" de autores y fuentes filosóficas de los rioplatenses, no era siempre azaroso o simple resultado de la disponibilidad material de los libros, sino que ciertas doctrinas se elegían ex profeso, a partir de lo que denomina ventajas teóricas. Que dependerían siempre de la posibilidad, dice la autora, de una cierta identificación imaginaria de horizontes de los publicistas locales con el filósofo en cuestión, inscripta a su vez en determinadas condiciones políticas o socioculturales y su representación. El resultado de esas "destilaciones conceptuales" acompañaría un verdadero campo de experimento político revolucionario y luego constitucional que, para Carozzi, excede cualquier concepción anclada en el esquema "modelodesviación" ${ }^{36}$ Como ejemplo la autora destaca la inscripción rousseauniana de ciertas ideas, intensamente declarada por parte de los morenistas, a partir de las ventajas teóricas que dicha doctrina ofrecía para validar un tipo de desobediencia como la revolucionaria. $^{37}$

\section{Corpus documental}

El corpus de esta tesis está compuesto por fuentes de muy variada naturaleza pero donde predominan la prensa periódica rioplatense -El Telégrafo Mercantil, Semanario de Agricultura, Correo de Comercio, La Gazeta de Buenos Ayres, La Gazeta de

\footnotetext{
${ }^{35}$ Gadamer, H. G., Verdad y método, Salamanca, Ed. Sígueme, 1977.

${ }^{36}$ Carozzi, S., óp. cit., pp. 37-38.

${ }^{37}$ Ibid., p. 28.
} 
Montevideo, El Censor, El Grito del Sud, Mártir o Libre, El Redactor de la Asamblea-; y en un segundo escalón la peninsular y londinense -Semanario Patriótico, El Español, El voto de la Nación española, El Duende Político, El Conciso, El Espectador sevillano, El Observador, por nombrar a los más utilizados-.

Asimismo, integran también el corpus actas de gobierno, proclamas, correspondencia, expedientes judiciales, memorias y crónicas rioplatenses. Muchas de estas fuentes directas han sido recopiladas en las colecciones Biblioteca de Mayo, Mayo Documental y La Revolución de Mayo a través de los impresos de la época. También proclamas, manifiestos, manuscritos y otros papeles de origen peninsular consultados en portales documentales como: el Portal de Archivos Españoles (PARES), la Biblioteca virtual Miguel de Cervantes, la Biblioteca Nacional Española, etc.

Completan el corpus documental ensayos filosóficos, políticos y económicos de los letrados de la época, tanto de origen americano como peninsular, recolectados de alguno de los portales mencionados como también de ediciones en formato de papel ej.: Escritos políticos de Mariano Moreno, Obras Completas de Jovellanos, etc.-

\section{Estructura de la tesis}

La tesis está organizada en dos partes y compuesta por quince capítulos, sin incluir esta introducción y las conclusiones. La primera parte abarca desde el surgimiento de la prensa periódica en el Rio de la Plata en 1801 -aunque el primer capítulo se retrotrae panorámicamente al "ilustrado y reformista" último cuarto del siglo XVIII hispanoamericano- hasta la antesala de la Revolución de Mayo. Esta primera parte está dividida a su vez en dos secciones, obrando como parteaguas la crisis monárquica tras las abdicaciones de Bayona y el levantamiento español de mayo de 1808. Algunos de los capítulos de esta primera parte están basados en gran medida en bibliografía secundaria, ya que han sido muchos y pormenorizados los trabajos que han estudiado la recepción del pensamiento ilustrado español en el Río de la Plata, permitiéndonos trazar un panorama político e intelectual a partir del cual podremos inscribir nuestros aportes. La segunda parte se inicia en los meses inmediatamente anteriores a la revolución rioplatense y finaliza en 1814, tomando como corte el retorno del absolutismo en la península con la vuelta de Fernando VII y la creación del Directorio en el Río de la Plata.

La primera sección de la primera parte aborda de manera general la Ilustración en el mundo hispánico de fines del XVIII y comienzos del XIX, y la formación y 
contactos de la elite letrada rioplatense con el pensamiento ilustrado español. El primer capítulo estudia el surgimiento y el papel de las llamadas sociedades económicas en la península y las características de la reforma universitaria de Carlos III, con la creación de la Academias de Derecho y la enseñanza de la economía política. Se presta especial atención a las Universidades de Salamanca y Chuquisaca por ser el medio académico donde se formaron intelectualmente varios de los futuros dirigentes del proceso revolucionario, tanto peninsular como rioplatense. En el segundo capítulo abordaremos de manera general el contexto rioplatense de principios de siglo XIX y el proceso de transformaciones que van permitiendo la aparición de una élite intelectual ilustrada y nuevos ámbitos de sociabilidad a nivel local. Se busca asimismo revelar las marcas ilustradas en la prensa entre los años 1801 y 1807, poniendo el acento en las formas de adaptación y los usos que los publicistas locales dieron a los textos y las ideas de los ilustrados españoles. Finalmente trataremos de explicar por qué fueron infructuosos los intentos por establecer una Sociedad económica en el Río de la Plata.

La segunda sección de la primera parte aborda fundamentalmente las distintas alternativas $\mathrm{u}$ horizontes de posibilidad barajados por la elite letrada rioplatenses ante la crisis abierta con las abdicaciones de Bayona y el proceso revolucionario juntista peninsular. La vertiginosa dinámica político-institucional comienza a tener mayor presencia a partir de aquí en la tesis, estructurándose esta sección con un criterio más acontecimental y cronológico que la anterior, pero sin dejar de poner el foco en las intervenciones discursivas y otras prácticas políticas de los distintos protagonistas, sean éstos aparatos gubernamentales, grupos o individuos, que buscaban interpretar e incidir en un proceso revolucionario plagado de incertidumbres. El tercer capítulo comienza abordando entonces los años inmediatamente anteriores a la crisis de la monarquía, subrayando el impacto capital que tuvieron las invasiones inglesas en la reestructuración del escenario político-social del virreinato. A continuación se desarrollan los inicios de la revolución hispánica a partir de la invasión napoleónica, las abdicaciones reales y el levantamiento juntista español. Se aprovecha también para ilustrar sucintamente los orígenes del liberalismo peninsular. El foco principal del capítulo está puesto en el análisis de la circulación, impresión y reimpresión de manifiestos y proclamas peninsulares y locales en el Rio de la Plata en los años 1808-1809. El cuarto capítulo se propone analizar cómo la estrategia de la regencia de la Infanta Carlota fue considerada como una alternativa viable por un grupo de criollos rioplatenses en el contexto de la crisis, representando un espacio donde los vínculos entre el pensamiento 
político hispánico de ambas orillas atlánticas se reconstituyeron y cobraron nuevos sentidos. El quinto capítulo estudia las diversas variantes en las que el movimiento juntista se manifestó en el virreinato, desde el autonomismo de Montevideo y el Alto Perú, pasando por el frustrado intento juntista del grupo acaudillado por Álzaga. En el sexto capítulo se indagan en las reacciones que generó en el Rio de la Plata el decreto la Junta Central del 22 de enero de 1809, que convocaba a los americanos a elegir diputados para el gobierno metropolitano. Destacamos algunos antecedentes directos de la disposición, en particular por el protagonismo que en ellos tuvieron justamente algunos rioplatenses. Asimismo, desarrollaremos el intento de implementación del decreto en las distintas jurisdicciones rioplatenses. El séptimo capítulo, y último de esta primera parte de la tesis, está abocado a echar luz sobre las marcas de la Ilustración española presentes en la Representación de los Hacendados de Mariano Moreno y el carácter de emergente transicional que de alguna manera asume entre los planteos reformistas criollos que venimos analizando y la etapa abiertamente revolucionaria que se estaría por inaugurar sólo unos cuantos meses después de su presentación.

La segunda parte de la tesis como dijimos corresponde a los primeros años del proceso revolucionario rioplatense, y sus capítulos - del 8 al 15- están organizados desde una lógica que no se corresponde tanto a una secuencia cronológica, aunque se busca que el desarrollo del contexto histórico político vaya acompañando, sino más bien se estructuran desde un enfoque que prioriza lo temático. El capítulo octavo comienza con un relato bastante acontecimental del Mayo revolucionario, deteniéndose concisamente a reponer algunos de los fundamentos doctrinarios detrás de la erección de la Junta porteña, algo que, de más está decir, ha sido profusamente trabajado por la historiografía nacional. La segunda parte del capítulo, en cambio, busca ofrecer una nueva mirada de algunos de los primeros documentos del gobierno revolucionario reproducidos a través de la Gazeta de Buenos Aires, poniendo el foco en la recepción y la comparación de los escritos y experiencias peninsulares en relación al Rio de la Plata. Son estudiados entonces el impacto de la proclama de la Junta de Cádiz en el movimiento juntista americano, y en especial en el rioplatense; la herencia peninsular en el primer proceso electoral autónomo rioplatense; y el uso dado por Moreno de la experiencia juntista valenciana en su polémica con las autoridades españolas. El noveno capítulo analiza dos de los principales ensayos filosóficos y políticos introducidos por Moreno en la Gazeta de Buenos Aires. El primero es titulado Pensamientos de un Patriota Español y constituye uno de los documentos cardinales del movimiento 
revolucionario en la península. La recepción de este documento así como otras reflexiones y usos que el secretario de la Junta Provisional Gubernativa da a la experiencia revolucionaria peninsular la desarrollamos la segunda parte del capítulo, donde analizamos la serie de artículos publicada en la Gazeta, y recopilada posteriormente en diversas ediciones bajo el título Sobre las miras del Congreso que acaba de convocarse y la constitución del Estado, que representa la reflexión de mayor sistematicidad y profundidad doctrinaria de nuestro revolucionario. En el décimo capítulo buscamos relevar las posiciones que con respecto a la llamada "cuestión americana" sostuvieron cuatro de los liberales peninsulares más representativos: Manuel José Quintana, Álvaro Flórez Estrada, José Blanco White y Agustín de Argüelles, fundamentalmente por las contradicciones que esta problemática hizo surgir en el seno del liberalismo hispánico. En el onceavo capítulo volvemos a retomar cierta contextualización del proceso, y realizamos un estudio comparativo sobre las formas, el itinerario y los vínculos que existieron alrededor de la convocatoria a las asambleas constituyentes en ambos espacios y los debates originados en torno a ellas. En el doceavo capítulo buscamos indagar la recepción que tuvieron tanto la Constitución de 1812 como la labor de las Cortes de Cádiz en el espacio rioplatense, en particular en la Asamblea General Constituyente del año XIII. El enfoque que utilizamos parte de entender a ambos procesos constituyentes enmarcados en una misma cultura constitucional hispánica, con un sustrato y lenguaje jurídico similar a ambos lados del Atlántico. El decimotercer capítulo estudia la trayectoria que la cuestión de la libertad de imprenta tuvo el mundo hispánico, entendiendo que constituye un problema clave no sólo para entender la etapa, sino también desde el cual podemos percibir los vínculos entre las elites dirigentes de ambos espacios. En el decimocuarto capítulo abordamos la recepción que los escritos de José María Blanco White, tanto sus artículos en el Semanario Patriótico como en El Español, tuvieron en el contexto de los primeros años de la revolución rioplatense, fundamentalmente los usos que los publicistas locales le dieron en relación al conflicto con la metrópoli y en las disputas facciosas de la elite porteña. Finalmente, en el decimoquinto y último capítulo de la tesis, analizamos el rol que jugó la lealista Gazeta de Montevideo en la disputas informativas y de opinión con los publicistas porteños, preguntándonos también qué uso se le dio a la prensa y a los decretos y proclamas peninsulares en el periódico montevideano, prestando atención no solo a las reproducciones efectivas, sino también a las dilaciones y las ausencias. 


\section{PRIMERA PARTE}

LA MONARQUÍA ESPAÑOLA Y EL RÍO DE LA PLATA: ENTRE LAS REFORMAS Y LA CRISIS 
PRIMERA SECCIÓN

EL REFORMISMO ILUSTRADO 


\section{Capítulo 1:}

\section{La Ilustración en el mundo hispánico de fines del XVIII: Sociedades económicas y reforma universitaria}

\section{Introducción}

No debemos representarnos a la Ilustración como una marea que barrió las ideas precedentes. En general, en toda Europa fue un fenómeno parcial, y en España con mayor razón por su relativo aislamiento y el peso de los patrones culturales tradicionales, respaldados por una Inquisición debilitada, pero aún activa. Los que intentaron despertar a la vieja gran nación no fueron sino unos cuantos, pero se terminaron imponiendo, por su saber y por su fe, al gobierno y a la opinión. Por necesidad y por urgencia, para sacar a España de su atraso, el movimiento que hasta ese momento se expresaba sólo en algunos núcleos desperdigados por la península, se fue convirtiendo en "política de Estado".

¿Quiénes fueron aquellos ilustrados? Fueron los ministros y consejeros de Carlos III y Carlos IV, como Campomanes, Floridablanca, Cabarrús y Aranda, los escritores como Cadalso y Meléndez Valdés, los sabios como Jovellanos y Cavanilles, los economistas como Campany, Asso y Olavide, entre otros. El primero de esos focos fue el asturiano, a partir de la actividad intelectual pionera del padre Benito Feijoo, y tiempo después del Instituto creado por Gaspar de Jovellanos en su Gijón natal. Junto a este último, la otra gran figura destacable del Principado fue Pedro Rodríguez de Campomanes, político, jurisconsulto y economista, a cargo del Ministerio de Hacienda en 1760 durante el reinado de Carlos III. ${ }^{38}$ El caldo de cultivo para el surgimiento de estos núcleos innovadores se encontraba en ciudades y comarcas dotadas de cierta infraestructura material e intelectual: imprenta, bibliotecas, centros de enseñanza superior, sector terciario desarrollado, burguesía culta, comunicación con el exterior, etc. Condiciones raras de encontrar en el interior de la península, salvo en casos como Madrid, Salamanca y Zaragoza. Más bien se hallaban en el litoral, en los puertos comerciales.

Aun cuando no ignoraban las doctrinas políticas o filosóficas más atrevidas que recorrían Europa, los reformistas españoles eligieron sugerencias más modestas y más

${ }^{38}$ Domínguez Ortiz, Antonio, Carlos III y la España de la Ilustración, Madrid, Alianza, 2005, p. 188. 
aplicables a su patria. ${ }^{39}$ Para ellos el fin supremo de la cultura era la eficacia y la utilidad pública la meta sagrada. La instrucción práctica ampliamente difundida debía ocupar el sitio de la "absurda" enseñanza teórica. Para el despotismo ilustrado, cuyo lema era "Todo por el pueblo, pero sin el pueblo", las luces debían irradiar desde lo alto, una transacción, al parecer, entre el pasado aristocrático y las nuevas libertades que se buscaban.

La simplista oposición entre el absolutismo y la ilustración con la que tradicionalmente se intentó explicar el período no refleja verdaderamente la compleja realidad de la época. En muchos campos existe un parentesco entre el imaginario del absolutismo y el de las élites modernas. Ambos "comparten una misma hostilidad hacia los cuerpos y sus privilegios, un concepto unitario de la soberanía, el ideal de una relación binaria y sin intermediarios entre el poder y los individuos". ${ }^{40}$ Existía un consenso total dentro de los ilustrados españoles en que debía ser el trono el dispensador y orientador de la cultura, porque sólo su autoridad y poder podían llevar a buen término una empresa de tal envergadura. El despotismo ilustrado fue característico de regiones que, como España, no contaban con las fuerzas sociales capaces de conducir esa modernización. Los ilustrados estaban convencidos y confiados en devolverle su grandeza a la monarquía española, y ese entusiasmo estalló en los periódicos, en las Sociedades económicas, e incluso en la poesía y las bellas letras. ${ }^{41}$

La prensa se constituyó en uno de los medios más importantes para la difusión de los nuevos valores y conocimientos, a la vez que instrumento de generación de una incipiente opinión pública. Los periódicos comenzaron a dar cabida, demostrando el interés de un sector de la población, a comunicaciones científicas, relativas sobre todo a la ciencia aplicada, pero en algunos casos también a la teoría pura. En el último cuarto del siglo XVIII son decenas las publicaciones que salen a la luz. Entre las más destacados podemos mencionar a El Censor de Luis Cañuelo, que aparece por primera vez 1781, y fue de los primeros en abogar por la economía del laissez-faire. ${ }^{42}$ Otro a

\footnotetext{
${ }^{39}$ Sarrailh, Jean, La España ilustrada de la segunda mitad del siglo XVIII, México, FCE, 1974, p. 117. Para una mirada panorámica sobre el movimiento de la Ilustración europea véase la clásica obra: Cassirer, Ernst, La filosofía de la Ilustración, Madrid, FCE, 1993.

${ }^{40}$ Guerra, François-Xavier, Modernidad e independencias, Madrid, Mapfre, 1992, p. 25.

${ }^{41}$ Sarrailh, Jean, óp. cit., pp. 181-182.

${ }^{42}$ El Censor se caracterizó también por la crítica social y por la publicación de poemas de Jovellanos y de Meléndez Valdés, cuestionadores de ciertas costumbres de la sociedad española. Algunos artículos demasiados críticos le valieron en 1784 la suspensión momentánea de la publicación a partir de la intervención disciplinadora del Consejo de Castilla. Pero al contar con el buen concepto del monarca logró continuar con su edición unos años más. Tan importante fue la controversia alrededor de periódico que en 1785 Carlos III promulgó una Real Orden retirándole la potestad al Consejo de censurar las obras
} 
subrayar es El Espíritu de los mejores diarios que se publican en Europa, que solía contener reseñas de libros y resúmenes de artículos impresos extranjeros. El Semanario erudito, fundado en 1787, estaba abocado a escritos sobre la historia de España. Pero no fueron los únicos, todas las principales ciudades españolas contaron con al menos un periódico de tendencia ilustrada. En Madrid podemos mencionar también al Semanario económico, el Correo general, el Correo literario de Europa; en Cartagena al Semanario literario y curioso; en Valladolid al Diario Pinciano, que resumía los trabajos de la Universidad y la Sociedad económica; en Barcelona al Diario curioso, histórico-erudito, comercial, civil y económico y al Diario de Barcelona, que siguió de cerca los adelantos en las ciencias naturales. Los suscriptores de estos diarios en general formaban parte de los sectores acomodados y cultos de la sociedad española. La mayoría eran miembros de la incipiente burguesía, principalmente hombres de carrera, negociantes y funcionarios de la burocracia real. Según el estudio de Richard Herr, se contarían entre varios miles las suscripciones y algunas decenas de miles de lectores, lo que lo lleva a conjeturar que aquellos que participaban activamente en esta fase de la Ilustración representaban apenas el $1 \%$ de la población. ${ }^{43}$

En este primer capítulo estudiaremos, por un lado, el surgimiento y el papel de las llamadas sociedades económicas en la península, y por otro, las características de la reforma universitaria de Carlos III, con la creación de la Academias de Derecho y la enseñanza de la economía política. Prestaremos especial atención a las Universidades de Salamanca y Chuquisaca por ser el medio académico donde se formaron intelectualmente varios de los futuros dirigentes del proceso revolucionario, tanto peninsular como rioplatense.

\section{Las Sociedades de Amigos del País en la península}

Las Sociedades de Amigos del País fueron en su origen una adaptación de sociedades extranjeras; y contaron con el decisivo impulso fundador y animador del Conde de Campomanes, quien en una circular del 18 de noviembre de 1774, invitaba a

de publicación periódica, que pasaron a ser controladas por los jueces de imprentas, ya no pudiendo ser embargadas sin aprobación directa del rey. Esta Real Orden ha sido considerada generalmente la primera ley de prensa de la historia de España. En 1787 El Censor interrumpió su publicación de manera definitiva. Al año siguiente, por algunas de las posiciones políticas vertidas en el periódico, y en un contexto signado por la agitación pre-revolucionaria que se vivía en la vecina Francia, Cañuelo fue llevado a un tribunal de la Inquisición, debiendo abjurar de levi. Herr, Richard, España y la revolución del siglo XVIII, Madrid, Aguilar, 1962, pp. 154-155.

${ }^{43}$ Herr, R., óp. cit., $164-165$ 
las autoridades de la península a fundar Sociedades, usando el ejemplo no solo de las de Berna o Dublín, sino de la Sociedad Bascongada, fundada 10 años antes. ${ }^{44}$ El marco general existente en los territorios forales favoreció el asentamiento de los focos ilustrados. Según Jesús Astigarraga "su situación geográfica y la posición interior de las aduanas constituían factores favorables a la penetración del pensamiento extranjero, mientras que el ascenso de algunos emigrantes a puestos de responsabilidad del Estado, un canal abierto para el posible apoyo desde éste a las iniciativas locales". ${ }^{45}$ De esta manera, la Ilustración vasca estuvo marcada por ritmos propios y gran autonomía con relación a la reforma impulsada desde la corona. El grupo de ilustrados más conocidos en el País Vasco eran los Caballeritos de Azcoitia y contaban con el Conde de Peñaflorida como principal orientador. Desde 1748 eran partícipes regulares de una tertulia en la villa de Azcoitia, un municipio de la provincia de Guipúzcoa, donde se hablaban de temas científicos, históricos y de economía aplicada. En 1765 fue institucionalizada como la Sociedad Bascongada de Amigos del País, que entre otras cosas se dedicó al estudio de la metalurgia. De los quince socios fundadores pasaron a más de un millar en poco tiempo y se hizo famosa en toda España. ${ }^{46}$ Entre las realizaciones más importantes de la Sociedad se encontraba la constitución del Seminario de Nobles de Vergara, donde se impartían un amplio elenco de materias científicas: matemáticas, geometría, física, química, agricultura, mineralogía, metalurgia, al lado de otras como comercio, economía política y lenguas modernas. ${ }^{47}$

Las Sociedades que florecen después fueron fundaciones del poder central, con la excepción de las andaluzas de Baeza, Jaén y Vera, que no precisaron de la demanda de Campomanes para lanzarse adelante. ${ }^{48} \mathrm{La}$ circular del procurador ilustrado fue acompañada por su Discurso sobre el fomento de la industria popular, contando ambos

\footnotetext{
44 “También se suele considerar un importante antecedente la publicación del Proyecto económico, de Bernardo Ward, escrito en 1762 pero impreso en 1779, donde se propone la creación de una Junta de mejoras de carácter nacional, pero con delegaciones provinciales, con objetivos bastante similares a los de las Económicas: estudiar las causas del estancamiento económico de España y proponer remedios, atrayendo a los elementos más activos de la sociedad, en particular a la nobleza y a los hacendados. Esta obra ejerció gran influencia en Campomanes y a través de él en las Sociedades de Amigos del País." Arias de Saavedra Alías, Inmaculada, "Las Sociedades Económicas de Amigos del País: Proyecto y realidad en la España de la Ilustración”, Obradoiro de Historia Moderna, núm. 21, 2012, p. 221.

${ }^{45}$ Astigarraga, Jesús, "Las Sociedades Económicas en Navarra en la segunda mitad del siglo XVIII", Instituto Gerónimo de Uztarriz, nro. 6/7, 1992, p. 27.

${ }^{46}$ Domínguez Ortiz, Antonio, óp. cit., pp. 189-190.

${ }^{47}$ Arias de Saavedra Alías, Inmaculada, óp. cit., p. 223.

${ }^{48}$ Gay Armenteros, Juan C.; Viñes Millet, Cristina, La ilustración andaluza, Sevilla, Editoriales Andaluzas Unidas, 1985, p. 42.
} 
con muy buen recibimiento. ${ }^{49}$ Poco tiempo después, en 1775 , el asturiano completaría su programa con el Discurso sobre la educación popular de los artesanos. En el primer discurso instaba a las Sociedades a estudiar las mejoras a introducir en cada provincia:

La agricultura, la cría de ganados, la pesca, las fábricas, el comercio, la navegación en su mayor aumento, en cuanto a las reflexiones científicas de propagar estos ramos, deben formar la ocupación y el estudio de las Sociedades Económicas, ya traduciendo las buenas obras publicadas fuera, con notas y reflexiones acomodadas a nuestro suelo, ya haciendo experimentos y cálculos políticos en estas materias, ya representando o instruyendo a los superiores a quienes pertenezca proveer de remedio. La lectura de las obras económicas es absolutamente precisa para formarse un cierto número de principios cardinales. ${ }^{50}$

Proponía que se inculque en los labradores y sus familias a dedicar sus ratos de ocio a trabajos accesorios y a humildes fabricaciones relacionadas con la agricultura. En su segundo Discurso, planteaba que las Sociedades debían estudiar la cuestión de los gremios y designar a un miembro "protector" de cada uno. Además, organizar exposiciones, concursos, distribuir premios, y abrir una "escuela patriótica de dibujo". 51

La Sociedad Matritense supo ser, después de la Bascongada, la segunda en importancia en España. Constituida bajo el estímulo de Campomanes en noviembre de 1775, se organizó en secciones de Agricultura, Artes y Comercio, y cumplió un papel muy cercano a la política gubernamental al emitir regularmente informes solicitados por las autoridades. Su primer Director fue Antonio de la Quadra, y se cuentan entre los colaboradores de la Sociedad destacadas personalidades como Cabarrús, Jovellanos, Sempere y Guarinos, entre otros. A subrayar es la participación de algunas mujeres de la élite madrileña a través de la Junta de Damas de Honor y de Mérito, que aunque no figuraron como socias plenas de la Económica, integraron este organismo paralelo, lo que les permitió realizar una destacada tarea, fundamentalmente en el ámbito educativo. En el resto de las Sociedades españolas las mujeres tuvieron vedada su participación, salvo en algunos pocos casos, que lo hicieron como socias honorarias.

\footnotetext{
${ }^{49}$ La tirada de 30.000 ejemplares fue excepcional para la época y se difundieron por corregimientos, municipios, chancillerías, audiencias, obispados, etc. Arias de Saavedra Alías, Inmaculada, óp. cit., p. 224.

${ }^{50}$ Rodríguez de Campomanes, Pedro, Discurso sobre el fomento de la industria popular, 1774, p. 42.

${ }^{51}$ Rodríguez de Campomanes, Pedro, Discurso sobre la educación popular de los artesanos y su fomento, 1775.
} 
La constitución de las Sociedades, aunque con algunas variaciones respondiendo a la comunidad local en la que se ubicaban, era en general similar en todos lados: unos pocos aristócratas ilustrados; prelados sacerdotes; burgueses, ricos o modestos; algunos enciclopedistas de las ciencias nuevas; y algunos de los llamados "filósofos". El manifiesto por excelencia de las Sociedades de Amigos del País era el Informe sobre la Ley agraria, publicado por la de Madrid a pedido del gobierno y obra de la pluma del ilustre Don Gaspar de Jovellanos. Para el asturiano, los medios principales, y complementarios entre sí, para que los adelantos de la economía política pudieran ser aplicados eran, por un lado, la difusión general de los conocimientos económicos, técnicos y científicos a través de la instrucción en las escuelas y de las Sociedades Económicas de Amigos del País; y por otro, la acción decidida del gobierno promoviendo la educación económica y técnica en Institutos, eliminando los estorbos políticos, morales y físicos, impulsando las reformas legislativas y financiando las inversiones públicas necesarias para el desarrollo económico y social. Lejos de un liberalismo económico ortodoxo, Jovellanos entendía decisiva, por lo menos para los países atrasados como lo era España, la "activa intervención de la mano visible e ilustrada del gobierno". 52

Fue en la educación popular el campo donde más importante acción desempeñaron las Económicas. Desarrollaron clases elementales, talleres de hilanzas, divulgación de técnicas agrícolas, y en las que picaban más alto, academias destinadas a la enseñanza de materias científicas y de esa nueva ciencia que empezaba a llamarse Economía Política. ${ }^{53}$ Las Sociedades actuaron como "centros importadores y difusores en España de la literatura económica europea, sobre todo a través de traducciones de autores tan importantes como Bielfeld, Necker, Turgot, Condillac, Justi, Filangieri, Genovesi o Melón". 54

Tanto los estudios clásicos como los más recientes sobre el tema, a pesar de destacar el dinamismo que tuvieron algunas de estas Sociedades y los logros conseguidos fundamentalmente en el campo educativo, remarcan el fuerte desfase entre la amplitud de los objetivos planteados en la circular de Campomanes y proclamados en sus estatutos, y los resultados concretos alcanzados antes de la decadencia general de estos cuerpos hacia mediados de la década de 1790.

\footnotetext{
${ }^{52}$ Llombart, Vicent, "Ni teoría sin aplicación, ni aplicación sin teoría: Economía política y realismo en Jovellanos", Revista asturiana de economía, núm. 45, 2012, p. 25.

${ }^{53}$ Domínguez Ortiz, Antonio, óp. cit., p. 176.

${ }^{54}$ Arias de Saavedra Alías, Inmaculada, óp. cit., p. 242.
} 


\section{La reforma universitaria en la España de Carlos III: las cátedras de Economía Política y de Derecho Natural y de Gentes}

Hacia el último tercio del siglo XVIII existían en España treinta universidades, todas de carácter eclesiástico. Poseían una amplia autonomía aunque desde fines del XVI se manifestó una mayor penetración del poder real a través del Consejo de Castilla. La titulación universitaria tenía tres grados: el de Bachiller que habilitaba para el ejercicio profesional; el de Licenciado, alcanzado con cursos complementarios y un alto costo de la ceremonia de investidura; y el Doctorado, aún más costoso y de un carácter más honorífico que intelectual. Persistía aún una fuerte huella medieval en los métodos pedagógicos. El Corpus Juris Civilis de Justiniano era la base de la enseñanza del Derecho; la Summa de Santo Tomás la de Teología y el Corpus de Galeno en las de Medicina. Ya que los libros eran muy caros y pocos alumnos podían acceder a ellos, la función del profesor era ofrecer resúmenes mediante el dictado y la explicación con la ayuda de manuales. La enseñanza de la Historia y la Geografía no formaba parte de los planes de estudio, por lo tanto el conocimiento de estos temas constituía más una búsqueda personal. La carencia más grave era en las llamadas ciencias de la Naturaleza. La Física, por ejemplo, era parte de la Filosofía Natural y estaba basaba en los conceptos aristotélicos. ${ }^{55}$

Éste era el panorama de atraso que caracterizaba el mundo académico español de mediados del XVIII, aún más acentuado si se lo comparaba con la realidad de otros países europeos. La ofensiva ilustrada para llevar adelante una reforma universitaria que corrigiera esta situación, hacia fines de 1760, provino inicialmente de la gestión de Campomanes como fiscal del Consejo de Castilla, y contó con el asesoramiento de reconocidos letrados de la época como Pablo de Olavide y Gregorio Mayan y Siscar. Tres fueron las principales iniciativas de la reforma universitaria: modificar el equilibrio de poderes fortaleciendo a los rectorados que comulgaban con las nuevas ideas; la modificación en los medios de selección docente, con atención a los méritos académicos y decisión del Consejo de Castilla; y el impulso a las universidades para que elaboren nuevos planes de estudios, nuevas formas de enseñanza, textos y asignaturas, y unificando a cuatro años los cursos para obtener el título de bachiller. El proceso encontró importantes resistencia por parte de los claustros universitarios, con resultados

\footnotetext{
${ }^{55}$ Domínguez Ortiz, Antonio, óp. cit., pp. 163-164.
} 
contradictorios, persistiendo al final del período las estructuras y enseñanzas tradicionales. Aun así, algunos núcleos ilustrados de varias universidades supieron aprovechar la brecha abierta por la política reformista borbónica y lograron instalar el debate intelectual de las nuevas ideas en el seno universitario. ${ }^{56}$

Con la reforma de 1771 se comenzaron a crear las llamadas "Academias de Derecho", espacios de formación práctica para los estudiantes de leyes en la exposición, defensa y disputa de temas. En Salamanca se introdujo en 1777 una perspectiva humanista con el estudio de la historia del derecho real español. El Derecho natural y de gentes se incorporó institucionalmente en unas pocas universidades -Granada y Valencia- y al poco tiempo, en 1794 , fue prohibido. ${ }^{57}$ Estas innovaciones no eran patrimonio exclusivo de España, sino que por el contrario formaban parte de un movimiento europeo general, que se estaba dando a la vez tanto en universidades católicas como protestantes. Los textos de Heineccius que se usaban en los cursos, como los de otros autores, contenían explícitamente la teoría del contrato. Aunque era usada para justificar la monarquía absoluta, negaban por inferencia el derecho divino de los reyes. Éstos habían sido elegidos por los vasallos y sus actos podían ser considerados injustos consultando una "ley fundamental" de la sociedad. El paso a la soberanía inalienable del pueblo no era muy grande pero representaba la diferencia entre Suárez, Grocio y Hobbes con Locke y Rousseau. ${ }^{58}$

En el marco de estas reformas, se instalaba por primera vez la enseñanza de la economía política, como una disciplina nueva y contrastante a la escolástica tradicional. Para fines del siglo XVIII, el concepto de economía poseía un significado más amplio y a la vez más complejo que el actual. La economía política cómo ciencia surgió de la necesidad ilustrada por estudiar la relación entre el hombre y la sociedad, el hombre y la naturaleza. De allí provenía su estrecho vínculo con la política y el derecho natural. Concebida como instrumentación práctica de la política, contaba con el amparo de los ministros ilustrados. Por ello, era común que las obras sobre estas materias fueran favorecidas con los permisos gubernamentales para circular, y hasta en algunos casos, con el patrocinio para su difusión. ${ }^{59}$

\footnotetext{
${ }^{56}$ Pastore, Rodolfo; Calvo, Nancy, "Cultura colonial, ideas económicas y formación superior 'ilustrada' en el Río de la Plata. El caso de Manuel Belgrano”, Prohistoria, núm. 4, 2000, p. 45.

${ }^{57}$ Pastore, R.; Calvo, N., óp. cit., p. 41-42

${ }^{58}$ Herr, Richard, óp. cit., p. 148.

${ }^{59}$ Fernández Armesto, María Verónica, "Lectores y lecturas económicas en Buenos Aires a fines de la época colonial", Información, cultura y sociedad, núm. 13, 2005, p. 34.
} 


\section{La Universidad de Salamanca y la Academia de Derecho}

Una de las primeras experiencias renovadoras se inició en 1787 en los cursos de la Universidad de Salamanca, en las actividades docentes de la Academia de Derecho Español y Práctica Forense a cargo del profesor Ramón de Salas y Cortés, parte de un grupo de profesores innovadores que estaban dando la batalla en los claustros universitarios. ${ }^{60}$ En su documento constitucional se planteaba que la Academia debía atender "a todo lo perteneciente a Policía, Industria, Agricultura y Comercio, en una palabra a todos los tratados de Economía política". Tanto en las obras que comenzaron a circular como en el ámbito de las cátedras de economía política, los nuevos principios conferían a la tierra un valor primordial y afirmaban que la riqueza no debía confundirse con la posesión de los metales precioso. ${ }^{61}$

El Rectorado que ejerció entre 1787 y 1789 Diego Muñoz Torrero, futuro referente de la diputación liberal en las Cortes de Cádiz, fue de los más progresistas en la incorporación de nuevos saberes, entre otras cosas con la ampliación de la biblioteca a partir de la incorporación de obras de Bayle, Condillac, Filangieri, Helvetius, Hume, Pufendorf, Rousseau o Smith. ${ }^{62}$ De la mano con ello se ampliaba la licencia del inquisidor para que todos los miembros pudieran leer los libros prohibidos. También se preocupó por la reforma de los métodos de enseñanza y por el cambio de planes de estudio, prácticas académicas y libros de textos.

Coincidiendo con el rectorado de Muñoz Torrero y la dirección de Salas de la Academia de Derecho, un joven y talentoso rioplatense recorría los recintos de la universidad con el espíritu abierto a incorporar los nuevos saberes que circulaban por el medio salamantino. En su autobiografía, Manuel Belgrano comentaba lo que había vivido en esos años:

Confieso que mi aplicación no la contraje tanto a la carrera que he ido a emprender, como al estudio de los idiomas vivos, de la economía política y el derecho público. En los primeros momentos en que tuve la suerte de encontrar hombres amantes del bien público que me manifestaron sus ideas útiles, se apoderó de mí el deseo de propender cuanto

\footnotetext{
${ }^{60}$ Para profundizar en el estudio de las reformas en la universidad salamantina ver Robledo, Ricardo, «Tradición e Ilustración en la Universidad de Salamanca: sobre los orígenes intelectuales de los primeros liberales», en Robledo, Ricardo et al. (eds.): Orígenes del liberalismo. Universidad, política, economía, Salamanca, Ed. Universidad de Salamanca, 2003, pp. 49-80.

${ }^{61}$ En Barcelona y en Madrid se esgrimieron como autoridad las doctrinas de Quesnay o de Adam Smith, de Mirabeau o de Turgot.

${ }^{62}$ Obtuvo el cargo de Rector con sólo veintiséis años, sin contar además con títulos nobiliarios ni fuertes vínculos con el poder.
} 
pudiese al provecho general y adquirir renombre con mis trabajos hacia tan importante objeto, dirigiéndolos particularmente en favor de la Patria. ${ }^{63}$

Como señala correctamente Rodolfo Pastore, claramente la atención del estudiante criollo estuvo menos puesta en la carrera que fue a aprender-derecho tradicional- que en la economía política y el derecho público, disciplinas que pudo encontrar en la Academia de Derecho. En los años que tuvo como moderante a Salas (1787-1792) funcionó en la práctica como una academia de enseñanza de la economía política, utilizando sobre todo las Lecciones de Comercio de Antonio Genovesi como material de estudio. ${ }^{64}$

Las noticias de la Revolución Francesa intensificaron la agitación y curiosidad filosófica entre los estudiantes de las Universidades españolas. Otro famoso párrafo de la autobiografía de Manuel Belgrano da cuenta de ello:

Como en la época de 1789 me hallaba en España y la revolución de la Francia hiciese también la variación de ideas, y particularmente en los hombres de letras con quienes trataba, se apoderaron de mí las ideas de libertad, igualdad y propiedad, y solo veía tiranos en los que se oponían a que el hombre, fuese donde fuese, no disfrutase de unos derechos que Dios y la Naturaleza le habían concedido, y hoy las mismas sociedades habían acordado, en su establecimiento directo, o indirectamente. ${ }^{65}$

Otro testimonio de esa efervescencia estudiantil, que los intentos de las autoridades no lograban evitar, nos lo ofrece el publicista sevillano José María Blanco White, del cual volveremos a hablar en repetidas ocasiones a lo largo de esta tesis por su rol central en la relación intelectual entre la península y América. En su periódico londinense El Español decía por marzo de 1811 en referencia al ambiente universitario de aquellos años marcados por el impacto de la Revolución Francesa: "En todas las universidades se formaban partidos de jóvenes que se instruían a su costa, y peligro, y muy a disgusto de los maestros. Entre estos había ya hombres llenos de buen gusto y de ciencia, y aunque en la cátedra seguían la rutina a que los obligaba el estado de opresión general. Fomentaban cuanto podían los estudios privados de sus discípulos". ${ }^{66}$ Entre los alumnos que pasaron por la aulas de la universidad durante el rectorado de Muñoz

\footnotetext{
${ }^{63}$ Belgrano, Manuel, "Autobiografía...", citado en Chiaramonte, J.C., Ciudades, provincias, Estados: Orígenes de la Nación Argentina (1800-1846), Buenos Aires, Ariel, 1997, p. 38.

${ }^{64}$ Pastore, R.; Calvo, N., óp. cit., pp. 53-55.

${ }^{65}$ Belgrano, Manuel, “Autobiografía...”, citado en Chiaramonte, óp. cit., p. 38.

${ }^{66}$ El Español, nro. XII, marzo 1811, p. 461.
} 
Torrero, coincidiendo con los estudios salamantinos de Belgrano, podemos encontrar a dos que a la postre se convertirían en importantísimos referentes del liberalismo español como eran Manuel Quintana y Juan Nicasio Gallego.

La circulación de manuscritos anónimos reproduciendo ideas consideradas subversivas e incendiarias por las autoridades se volvió algo común, así como la agudización de la censura y represión estatal como respuesta a ese fenómeno. Ramón de Salas recordaría décadas después, durante el trienio liberal, la circulación de manuscritos y obras prohibidas:

Ya el Espíritu de Montesquieu circulaba por las manos de muchos jóvenes de talento y de amor por las sanas ideas; el Contrato social de Juan Jacobo Rousseau se tradujo y se copió furtivamente, y corría en muchos manuscritos: los Tratados políticos del Abate Mabli [sic] eran bastante conocidos, y las obras del marqués de Beccaria y las de Filangieri que se publicaron traducidas al castellano fueron leídas con ansias y contribuyeron mucho a extender las luces a todas las ramas de la legislación, y a dar idea de la ciencia social. ${ }^{67}$

A partir de 1793 la política represiva se intensificó como respuesta a la ejecución de Luis XVI y la declaración de guerra a España hecha por la Convención. Entre los manuscritos, uno titulado "Oración apologética" tomó mayor relevancia porque circuló por todo el territorio español. La Inquisición sospechaba que provenía del profesor de Salamanca, Ramón de Salas. Después de una persecución que duró varios días, los inquisidores pudieron capturarlo y fue condenado a abjurar de levi ante doce testigos, siendo recluido y conminado a estudiar "doctrinas sanas" en un monasterio durante un año y a ser desterrado de Madrid y Salamanca por otros tres. ${ }^{68} \mathrm{Su}$ condena no respondía solo al hecho de haber sido supuestamente el autor del manuscrito, sino que en un clima general de reacción contrarrevolucionaria de parte de la corona borbónica, su innovador rol académico y pedagógico al frente de la Academia se constituyó la principal razón para ser acusado como "el corifeo de las perversas doctrinas que corrompen las universidades de España y perjudican la obediencia de los soberanos". ${ }^{69}$ A los sectores más tradicionalistas les preocupaba que se pudiera realizar una traducción de la nueva filosofía europea a los términos comprensibles de una nueva moral católica. En ese

\footnotetext{
${ }^{67}$ Salas, Ramón de, "Lecciones de derecho constitucional", citado en Clucellas, Patricio, 1810 Revolución de dos mundos. La presencia de España en el Mayo rioplatense, Buenos Aires, Ed. Torre de Hércules, 2012.p. 82.

${ }^{68}$ Ibid., pp. 274-275.

${ }^{69}$ Citado en Pastore, R.; Calvo, N., óp. cit., p. 50.
} 
sentido preocupaba mucho el dinamismo cultural de la Universidad de Salamanca bajo el rectorado de Diego Muñoz Torrero. ${ }^{70}$

\section{La Universidad de San Francisco Xavier de Chuquisaca y la Academia Carolina}

Adentrándonos ahora en el mundo universitario colonial, y particularmente en el de la Universidad de Chuquisaca, tenemos la suerte de contar con la valiosa tesis de maestría del Clement Thibaud, realizada bajo la dirección de François-Xavier Guerra. Según el autor el objetivo principal de su trabajo, al que recurriremos de aquí en adelante, es "esclarecer el modo de existencia de un grupo que pertenece a la elite criolla, penetrar sus formas de pensamiento, su sociabilidad, sus representaciones de sí mismos en la víspera de las guerras de independencia". ${ }^{71}$

Fundada por los jesuitas en 1621, la Universidad de San Francisco Xavier de Chuquisaca, se destacaba por su enseñanza teológica de gran calidad, y fue ganando aún mayor prestigio en el nuevo mundo gracias a su Facultad de Derecho establecida en 1706. ${ }^{72}$ Hasta 1791, que se creó la cátedra de Derecho de la Universidad de Córdoba, Chuquisaca reinaba solitaria en el Rio de la Plata en la formación de abogados. ${ }^{73} \mathrm{La}$ ciudad y la región donde ejercía su influencia estaba sub-poblada, pero a la vez era considerablemente rica y vivía una decadencia lenta producto del descenso de la producción de sus minas de plata. Era también un mundo desgarrado por las revueltas indígenas. Los años 1780-1782 estuvieron marcados por movimientos sociales y étnicos de gran amplitud que hicieron temblar los cimientos de la sociedad colonial. ${ }^{74} \mathrm{El}$ primero de ellos, el levantamiento de Túpac Amaru, llegó a movilizar la impresionante cifra de más de 100.000 insurgentes. Por su parte la rebelión de Túpac Katari combinó reivindicaciones tradicionales y objetivos políticos más audaces que su antecesora.

\footnotetext{
${ }^{70}$ Portillo Valdés, J.M., Revolución de Nación. Orígenes de la cultura constitucional en España, 17801812, Madrid, Centro de estudios Políticos y Constitucionales, 2000, p. 95

${ }^{71}$ Thibaud, C., La Academia Carolina y la independencia de América. Los abogados de Chuquisaca (1776 - 1809), Sucre, Editorial Charcas, 2010, p. 2

${ }^{72}$ El vínculo entre estas dos carreras estaba dado a partir de que casi todos los abogados egresados hicieron cursos de teología antes de consagrarse al derecho.

${ }^{73} \mathrm{La}$ instrucción en Córdoba se estableció con el viejo método de formación, a diferencia las novedosas prácticas de la Academia Carolina. Fue fundada la cátedra por un viejo alumno de Chuquisaca, Victorino Rodríguez, fusilado junto a Liniers en Cabeza de Tigre. La carrera de derecho de la Real Universidad de San Felipe de Santiago de Chile, fundada en 1758, recibió a varios rioplatenses como Manuel Dorrego, Antonio Álvarez Jonte y Miguel de Villegas, entre otros.

${ }^{74}$ Para profundizar en este tema ver los estudios de Walker, Charles, The Tupac Amaru Rebellion, Harvard University Press, 2014; Serulnikov, Sergio, Conflictos sociales e insurrección en el mundo colonial andino. El norte de Potosi en el siglo XVIII, Buenos Aires, Fondo de Cultura Económica, 2006; Stern, Steve J. (comp.) Resistencia, rebelión y conciencia campesina en Los Andes. Siglo XVIII al XX, Instituto de Estudios Peruanos, 1990.
} 
Centrada en el Alto, cerca de La Paz, los criollos fueron fundamentales para poder sofocar la rebelión. Como resultado, perduró en la "memoria blanca" europea y criolla el miedo constate a la agitación india. La administración colonial trasladó de allí en adelante esa desconfianza también hacia mestizos y criollos, a pesar de sus diferencias. $^{75}$

A partir de las reformas borbónica y la creación del Virreinato del Rio de la Plata, Charcas pasó a estar jurídicamente subordinada a una ciudad observada con cierta displicencia y considerada "advenediza". Aunque la Audiencia de Charchas siguió manteniendo jurisdicción sobre las provincias altoperuanas, la creación de la Audiencia de Buenos Aires la remplazó como la última instancia jurídica para toda la región rioplatense lo que implicó en concreto menos trabajo y dinero que antes, y eso explica en parte la emigración hacia Buenos Aires de numerosos abogados. ${ }^{76}$

Volviendo a la Universidad, la expulsión de los jesuitas en 1767 repercutió en todos los sentidos pero en primer lugar financieramente. A partir de allí comenzó la decadencia de la institución, que se manifestó entre otras cosas en que el remplazo de los profesores de la Compañía por otros, en su mayoría, de menor solvencia. Cambió también el contenido de la enseñanza; la obra de Suárez ahora pasaba a estar proscrita después de haber sido dominante y se retornó al estudio de textos clásicos como Instituta, Recopilación de Leyes de Indias y los Decretos de Gregorio IX. ${ }^{77}$ Pero el impulso reformador ilustrado de Carlos III, que recorría a todo el imperio y que como vimos había tenido su impacto en las universidades peninsulares a partir de los años setentas, como así mismo en las de Perú y Quito, llegó también a Chuquisaca de la mano de Ramón de Rivera, oidor de la Audiencia de Charcas. Con él, y con el acompañamiento del claustro de los "doctores", llegaron las innovaciones de esa nueva manera de enseñar a los abogados principiantes, menos centrada en la escolástica y la retórica, y más en la aplicación real y efectiva de la ley que expresaban las academias de prácticas jurídicas peninsulares. Bajo su patrocinio, el 3 de noviembre de 1776 una cédula real consagra la existencia de la Academia Carolina, que para su fundación toma como modelo la de La Coruña. La Academia no era estrictamente un curso superior de la Universidad, porque desde el punto de vista institucional dependía jurídicamente sólo de la Audiencia. Sin embargo, se fueron creando lazos desde un primer momento entre

\footnotetext{
${ }^{75}$ Thibaud, óp. cit., p. 7.

${ }^{76}$ Ibid., p. 109.

${ }^{77}$ Ibid., p. 13.
} 
ambas ya que algunos profesores enseñaban en las dos instituciones. En los hechos, finalmente se terminó convirtiendo en la clase superior de la Facultad de Derecho. ${ }^{78}$ Destinada a la práctica forense, se buscaba en ella un mayor conocimiento en el Derecho patrio (Derecho Real y de las leyes municipales) y la realización de ejercicios teóricos, bajo la forma de disertaciones públicas y prácticas que incluían la regular asistencia a los estrados de la Audiencia. ${ }^{79}$

El objetivo de la Academia era constituir una élite de juristas competentes y pragmáticos, pero capaces no solamente de ejercer su oficio en el foro sino también de ocupar puestos administrativos y políticos importantes en el seno de variadas instituciones. ${ }^{80}$ Esto implicó como corolario el nacimiento y la cohesión de una élite criolla. El carácter selectivo de sus miembros se manifestaba desde el procedimiento de ingreso, donde la candidatura para ser examinada debía probar la obtención de bachillerato de preferencia en Derecho Canónico o Civil en la Universidad, para después someterse a un difícil examen. Después de dos años de estudios, se debía atravesar un examen de egreso que habilitaba al postulante abogado a presentarse ante la Audiencia, a fin de ser afiliado al foro. En esta instancia además era necesario presentar un acta de bautismo, con el objetivo de aplicar el principio de pureza de sangre y de nacimiento de los futuros abogados. ${ }^{81}$ En síntesis, la carrera para poder ejercer efectivamente como abogado implicaba cuatro años de bachillerato en leyes, dos años en la academia y otros dos años más desempeñándose ad honorem para obtener finalmente las licencias generales.

\section{Formación intelectual de los estudiantes carolinos}

Clement Thibaud separa en tres niveles la formación intelectual de los futuros abogados. Habla de un sustrato escolástico, una etapa práctica jurídica y un estrato ilustrado. ${ }^{82}$ Como ya mencionamos anteriormente casi todos los abogados hicieron cursos de teología previamente a sus estudios en Derecho, y más de la mitad había alcanzado el título de Doctor. Por lo tanto poseían un amplio dominio de la filosofía en su versión aristotélica. Santo Tomas era el autor de referencia en los estudios de teología, pero leído a través de los ojos de Suarez, de Molina, y de Mariana. Aunque

\footnotetext{
${ }^{78}$ Ibid., pp. 21-22.

${ }^{79}$ Goldman, N., Mariano Moreno. De reformista a insurgente, Buenos Aires, Edhasa, 2016, p. 33.

${ }^{80} \mathrm{El}$ ejemplo de asesor letrado describe bastante bien la actividad media de estos funcionarios.

${ }^{81}$ Thibaud, C., óp. cit., pp. 19-21.

${ }^{82}$ Ibid., p. 59.
} 
prohibidos tras la expulsión, los autores de la alta escolástica jesuita siguieron siendo utilizados en los estudios. Fundamentos como el derecho de resistencia al poder tiránico, el contractualismo y la concepción de la soberanía en Suárez o el tiranicidio en Mariana, eran parte de las lecturas que los estudiantes tenían a su alcance durante los años de su formación. ${ }^{83}$ En las bibliotecas de Juan José Segovia y de Pedro Ulloa se podía ver claramente el predominio de las obras de estos jesuitas. El patronato y la protección intelectual que ejercían algunas de las autoridades civiles y eclesiásticas sobre los futuros abogados permitían el uso de dichas bibliotecas y la circulación de libros prohibidos, entre ellos los del iluminismo más radical. ${ }^{84}$ Uno de los casos más paradigmáticos, por la trascendencia histórica posterior que adquirió el protegido, fue la relación establecida entre el secretario del Arzobispado, el canónigo Matías Terrazas y el joven estudiante Mariano Moreno, llegado a Chuquisaca a comienzos de 1800 tras un largo y arduo viaje desde la capital virreinal para estudiar teología y leyes. Instalado en la lujosa y confortable casa de Terrazas, Moreno pudo acceder a una de las bibliotecas más ricas de la ciudad, como atestiguaba su hermano Manuel:

Favorecía su anhelo de instrucción una preciosa biblioteca, que Terrazas había acopiado con esmero, y tenía dispuesta con orden en un salón hermoso. Esta biblioteca contenía los mejores autores en religión, en ciencias, y literatura, y a más las obras de política y filosofía, que la inquisición prohibida con inexorable rigor pero el rango y dignidad del dueño lo ponían a cubierto de las pesquisas del tribunal: su carácter le aseguraba el privilegio de prescindir del índice del formidable expurgatorio, sin incurrir en anatemas, ni censuras; y su complacencia extendía secretamente el mismo privilegio a su protegido, porque estaba seguro de la solidez de su razón, y la firmeza de su fe. Allí se dedicó Moreno al estudio profundo de las escrituras sagradas, y de los padres, comparando los más doctos expositores. ${ }^{85}$

Con respecto a la formación más específica del derecho, según el estudio realizado por Thibaud, las referencias más frecuentes de la literatura en los manuales de práctica jurídica son a la Recopilación de Indias y la Recopilación de Castilla, seguidas por una serie de obras de jurisconsultos más o menos celebres, en su mayoría peninsulares. Esto se confirma constatando su presencia en las bibliotecas de Segovia y

\footnotetext{
${ }^{83}$ Para profundizar en estos fundamentos véase Halperín Donghi, T., Tradición política española $e$ ideología revolucionaria de mayo, Buenos Aires, Eudeba, 1961.

${ }^{84}$ Thibaud, C., óp. cit., pp. 60-67.

${ }^{85}$ Moreno, Manuel, Vida y memorias del Dr. Mariano Moreno, ed. La Cultura Popular, Buenos Aires, 1836, p. 35.
} 
Ulloa, donde las obras jurídico-técnicas representaban aproximadamente el $90 \%$ de su composición. ${ }^{86}$

Las obras de los pensadores iluministas tenían una gran recepción entre los estudiantes de la Academia, incluso por los examinadores, que no reprobaban los ataques a la escolástica. Eran material de consulta y de referencia las obras de los ilustrados españoles como Feijoo y Campomanes, o el napolitano Gaetano Filangieri. El clima reformista imperante permitía, aunque de forma limitada, la circulación de algunas gacetillas de origen francés y obras de autores prohibidos -Montesquieu, Volney, Raynal, Mably, Maquiavelo, Rousseau, los enciclopedistas, entre otros-, aunque existen pocos registros justamente por el carácter ilegal de la posesión de esos escritos. Aun así, es sabido que en el Río de la Plata el control era laxo y los libros llegaban escondidos en las cajas con adulteración de las listas de declaración ante la aduana. ${ }^{87}$ Manuel Moreno vuelve a darnos un testimonio valioso en este sentido:

Todos los mejores autores de Europa sobre política, moral, religión, historia, etcétera, que han pasado de cuando en cuando por entre las severas prohibiciones del despotismo inquisitorial hasta Buenos Aires, han ido regularmente a parar al Perú [Alto Perú], donde encuentran mejor recepción...siendo los que están encargados de estorbar la circulación de semejantes obras los mismos que las solicitan y colocan con preferencia en sus estantes. ${ }^{88}$

\section{Los derechos indígenas y la reforma del imperio: Victorián de Villava y Mariano Moreno}

Como dijimos anteriormente, uno de los ejercicios obligatorios por los que tenían que pasar los estudiantes de la Academia eran las disertaciones sobre distintos asuntos del derecho, y que se dividían en tres categorías: de entrada, de turno y de salida. Es conocida la disertación de turno de Mariano Moreno leída el 13 de agosto de 1802: "Disertación jurídica sobre el servicio personal de los indios en general, y sobre el particular de yanaconas y mitarios", que se centraba en la institución de la mita, y rechazaba la legitimidad del trabajo forzado y de cualquier otro impuesto personal sobre los indios. Como señalara Levene, la disertación fue "de valor más político que

\footnotetext{
${ }^{86}$ Thibaud, C., óp. cit., pp. 69.

${ }^{87}$ Goldman, N., óp. cit., pp. 33-34.

88 "Vida y Memorias del Dr. Dn. Mariano Moreno. Por su hermano Dn. Manuel Moreno", Biblioteca de Mayo, Colección de obras y documentos para la Historia Argentina, Buenos Aires, Senado de la Nación, 1963.Tomo II, “Autobiografías”, pp. 1166-1167.
} 
histórico" ${ }^{89}$ Y como refiere a su vez Goldman, "su lenguaje claro y categórico, alejado de barroquismos, nos revela una temprana pasión por la justicia y la libertad, y una toma de posición por los derechos de los habitantes originarios de América". ${ }^{90}$ La disertación académica estaba inscripta en la polémica que diez años antes había hecho confrontar al Fiscal de la Real Audiencia de Charcas, Victorián de Villava, y a Vicente Cañete, asesor letrado del Intendente de Potosí Francisco de Paula Sanz, en torno a la legitimidad de la mita para la minería de Potosí. El trasfondo de la polémica estaba dado, por un lado, por las grandes rebeliones indígenas ya señaladas, que habían tenido como uno de sus principales reivindicaciones la eliminación de este sistema de trabajo forzado. Y por otro, por los planes reformistas de la Corona que buscaban estimular la explotación minera con el fin de incrementar los ingresos fiscales de sus colonias. El alegato y los demás escritos generados en la polémica circularon en forma manuscrita entre los letrados y autoridades de Chuquisaca, Buenos Aires y Madrid, según refirió el propio Moreno. $^{91}$

Al igual que la disertación del futuro dirigente revolucionario, el alegato del fiscal constituía un firme rechazo al trabajo forzado de los indios, fundado en razones humanitarias cifradas en el pensamiento ilustrado de la época. El principio que guió tanto el alegato como la disertación se resume en el epígrafe de San Ambrosio que estaba incluido en ambos papeles y que rezaba: "Más debe mirarse por la vida de los mortales, que por el aumento de los Metales". ${ }^{92}$ El trabajo en las minas, para Villava, debía sostenerse desde una concepción de prestaciones libres de los ciudadanos a cambio de una remuneración, y no como una carga impuesta a los súbditos en reconocimiento del dominio real sobre los territorios conquistados. Cuatro eran los argumentos principales sobre los que se asentaba el alegato: 1ro: que el trabajo de las minas de Potosí no era público; 2do: que aun siendo público no daba derecho a forzar a los indios; 3ro: que el indio no era tan indolente como se pensaba; y 4to: que aun siendo indolente en sumo grado no debía obligárseles a este trabajo con coacción. ${ }^{93}$ En cambio,

\footnotetext{
${ }^{89}$ Levene, Ricardo, Ensayo histórico sobre la revolución de Mayo y Mariano Moreno: contribución al estudio de los aspectos político, jurídico y económico de la Revolución de 1810, Buenos Aires: El Ateneo, 1949, t. I, p. 86.

${ }^{90}$ Goldman, N., óp. cit., p. 41.

${ }^{91}$ Ibid., p. 31.

92 Citado en Goldman, N., óp. cit., p. 44.

${ }^{93}$ Levene, Ricardo, Vida y escritos de Victorián de Villava, Buenos Aires, Peuser, 1946, p. 31.
} 
la mayoría de los funcionarios coloniales como Francisco de Paula Sanz, entendían que los indios, doblegados en una guerra de conquista, debían ser tomados por siervos. ${ }^{94}$

Moreno por su parte ubicaba su disertación, como bien señala Goldman, en "esa encrucijada entre la reivindicación de la antigua tradición hispánica de protección de la libertad legítima y perfecta de los indios y la nueva reivindicación de los derechos indígenas fundada en el derecho natural y de gentes y la libertad dieciochesca". ${ }^{95} \mathrm{Y}$ como marca De Gori, estaba recuperando una tradición pactista que argumentaba que "tanto el derecho como el gobierno caían dentro del campo general de la moral, por lo cual el soberano se encontraba sometido a una crítica ética" ${ }^{96}$ El joven estudiante no solo seguía el pensamiento de Villava para construir su argumentación, sino que lo hacía también desde la indignación y el dolor que seguramente había experimentado al ser testigo él mismo de la inhumana explotación a la que eran sometido los indios en un viaje a Potosí realizado poco tiempo antes de su disertación. Sentimientos que, a pesar de la solemnidad que implicaba ese ejercicio académico, se dejaban traslucir en sus palabras:

[...] no fue menor la herida que recibieron con el tenaz empeño de aquellos que solicitaron despojarlos de su nativa libertad. Impelidos por bárbaros ejemplos de la antigüedad, o más bien seducidos por los ciegos impulsos de su propia pasión, no dudaron muchos sostener que los indios debían según toda justicia vivir sujetos bajo el grave y penoso yugo de una legítima esclavitud [...]Basta considerar el insufrible e inexplicable trabajo que padecen los que viven sujetos a este penoso servicio, para que cualquier imparcial quede plenamente convencido de la repugnancia que en sí encierra con el Derecho de Gentes, de la libertad y aun de la misma naturaleza. ${ }^{97}$

Victorián de Villava había nacido en 1747 en Zaragoza, en una familia de funcionarios de Aragón, después de estudiar teología y leyes fue nombrado profesor de Derecho en la Universidad de Huesca. Integraba una generación de letrados que floreció en torno a la creación de la Real Sociedad Aragonesa de Amigos del País, y además de su desempeño como catedrático se destacó como traductor de obras de la Ilustración

\footnotetext{
${ }^{94}$ De Gori, Esteban, "La Universidad de Charcas: Teoría y acción política", Revista Historia de la Educación Latinoamericana, vol. 14, 2010, Universidad Pedagógica y Tecnológica de Colombia, Colombia, p. 178.

${ }^{95}$ Goldman, N., óp. cit., p. 48.

${ }^{96}$ De Gori, Esteban, La República Patriota: Travesía de los imaginarios y de los lenguajes políticos en el pensamiento de Mariano Moreno, Buenos Aires, Eudeba, 2013, p. 165.

97 Moreno, Mariano, Escritos (prólogo y edición crítica de Ricardo Levene), Clásicos Argentinos, Estrada, Buenos Aires, 1956, tomo I, p. 5-34.
} 
napolitana. En la década de 1780 publicó por ejemplo una traducción/adaptación parcial de las Lecciones de Comercio de Antonio Genovessi y la Ciencia de la Legislación de Gaetano Filangieri. En 1791 se radicó en Chuquisaca, designado en el importante puesto de Fiscal de la Audiencia de Charcas, donde se desempeñó de manera destacada, sobretodo en la defensa de los indios, como pudimos ver.

Imbuido en las nuevas ideas del siglo y testigo directo del atraso en el que se encontraba la península, pero sobre todo América, Villava replantearía la relación de la metrópoli con sus colonias en el marco de pensar un proyecto integral de reforma de la monarquía. Titulado Apuntes para una reforma de España sin trastorno del Gobierno Monárquico, ni de la Religión, su obra más celebre, apuntaba justamente a concebir al imperio desde una lógica más centrada en lo comercial integrando los intereses colectivos de sus partes, alejándose de la reafirmación colonialistas que en muchos aspectos implicaban las reformas borbónicas. Como señala De Gori, Villava “comprendía que el comercio nutría de una nueva sociabilidad política a los órdenes estatales y sus dominios coloniales. Advertía que el espíritu de conquista, si pretendía garantizar la sujeción de las colonias, debía dar paso al espíritu de comercio, sólo el intercambio podía refinar las costumbres doblegando estados de guerra y saqueo". ${ }^{98}$ La propuesta reformista de la monarquía había abierto la posibilidad para que otros actores presenten o alienten otro tipo de reformas, que sin cuestionar a la monarquía si consideraba que la política centralizadora y uniformadora permitía el surgimiento de prácticas concebidas como despóticas. ${ }^{99}$

El aragonés apostaba a la conservación de las provincias americanas para la corona española pero su originalidad radicaba en la clara conciencia de que la situación en América ya no era la misma, y que sin un profundo cambio la dominación española no podría continuar. El fiscal, que participaba con asiduidad de las discusiones que se producían en el salón de la Academia, y que por un corto tiempo, en 1795, se desempeñó como director de la misma, lucidamente alertaba sobre los peligros de no cambiar el rumbo de la política imperial en relación a América: “...a la menor chispa que llegara, verían infinita la ocasión oportuna de sacudir un yugo que aborrecen, verían otros la proporción de erigirse independientes". ${ }^{100}$ Refractario además al absolutismo, defendía la idea de una monarquía moderada, limitada por un consejo semi-

\footnotetext{
${ }^{98}$ De Gori, Esteban, La República Patriota ..., p. 151.

99 Ibid., pp. 87-88.

${ }^{100}$ Citado en Levene, Ricardo, El mundo de las ideas y la revolución hispanoamericana de 1810 , Santiago de Chile: Editorial Jurídica de Chile, 1956, p. 104.
} 
representativo y por una nobleza no feudal que mediara entre el pueblo y el rey. Tampoco era partidario de profundos cambios revolucionarios, ni modelos republicanos, a los que veía con preocupación al estar convencido que acarrearían la inevitable división del pueblo en facciones y la guerra civil, y dada la conformación social y política de la América, para el fiscal, aquello no terminaría degenerando en otra cosa que el despotismo. Como propuesta concreta para la reformulación de la relación entre metrópoli y colonias planteaba la supresión de virreinatos e intendencias, la conformación de Audiencias con la mitad de sus integrantes de origen criollo, y el envío de diputados americanos al Consejo Superior de la Nación. ${ }^{101}$ El impulso reformador de la corona parecía inaugurar dos lecturas diferenciales de las transformaciones del orden estatal: "una de ellas apelaba a la reafirmación absoluta del rey para su reforma; la otra, recuperaba en su crítica al regalismo, las tradiciones pactistas y constitucionales hispanas". ${ }^{102}$ A diferencia de otros constitucionalistas peninsulares, el aragonés en sus Apuntes incorporaba a América, no como una colonia sino como territorio vinculado a la monarquía y a ese conjunto de pueblos que reunidos constituyen la nación. ${ }^{103}$

Mariano Moreno volvería a recurrir al pensamiento de Villava cuando ya radicado en Buenos Aires lleve adelante su famosa Representación de los hacendados, y se apoye también en los economistas napolitanos para sostener sus argumentos, seguramente a partir de las traducciones hechas por el aragonés. Ya como editor de la Gazeta de Buenos Aires no dudaría en reproducir parte de sus dictámenes para salirle al cruce a aquél asesor letrado del Intendente de Potosí, Vicente Cañete, que en 1810 se manifestaría contra la formación de la junta revolucionaria rioplatense y proponía como salida a la crisis monárquica un empoderamiento de los virreyes como los pilares desde donde reconstruir el poder español en América. ${ }^{104}$

\section{La conformación de una élite dirigente criolla}

La reorientación atlántica de Charcas hacia el Rio de la Plata se refleja claramente en la fuerte presencia rioplatense entre los estudiantes. El rasgo más importante es el origen criollo del 97,5\% de los abogados. Los rioplatenses en general eran hijos de españoles, de familias recién instaladas en América o producto de casamientos entre

\footnotetext{
${ }^{101}$ Thibaud, C., óp. cit., pp. 86-87.

${ }^{102}$ De Gori, Esteban, La República Patriota ..., p. 144.

${ }^{103}$ Ibid., p. 152.

${ }^{104}$ Gazeta extraordinaria (3/7/10): 114-117.
} 
españoles y criollas ricas. En su mayoría son hijos de funcionarios administrativos y militares, pero a partir de 1792-1796, se fue abriendo también a familias comerciales y a propietarios de tierras. Igualmente, no provenían del estamento dominante de la sociedad, que a partir de las reformas borbónicas estaba restringido a la pequeña y media nobleza española. ${ }^{105}$

Uno de los rasgos originales de la Academia, único en todo el continente, era que sus estudiantes no formaban parte de los gabinetes o bufetes de abogados de la ciudad. En consecuencia se formaba un grupo aparte, sólido, en el que se construían vínculos y amistades. El salón de la academia era el espacio privilegiado de sociabilidad para encontrarse y discutir, fundamentalmente sobre las nuevas ideas. Es que pesar de lo moderno de sus métodos de enseñanza, como aclara Thibaud, se mantenía la rutina y el conservadurismo en el contenido de sus programas teóricos. Entonces, si en la Academia se discutía sobre los filósofos y se hablaba de las Luces, era por fuera del marco del trabajo formal, se daba fundamentalmente en la vida social activa que tenían estos aspirantes a abogados, que tenía al salón de la Academia como punto de partida. ${ }^{106}$

El diálogo, debate y las lecturas entre alumnos y docentes se extendían hacia fuera de los claustros. Las tertulias platenses eran una prolongación de la Academia y del foro, y en palabras de Just Lleo, constituían un campo fértil donde se enraizaron las nuevas ideas. ${ }^{107}$ Estas reuniones eran frecuentes y congregaban no solo a estudiantes y profesores, sino también a abogados, clérigos y funcionarios. En una de ellas, que Manuel Moreno refiere como "tertulia americana", solían reunirse su hermano y dos de sus más cercanos amigos, Pedro José de Agrelo -futuro editor de la Gazeta rioplatensey el presbítero paceño José Antonio Medina. ${ }^{108}$ Según Manuel, en ella se "declamaba con ardor contra el estado de opresión en que se hallaba el país". ${ }^{109} \mathrm{Y}$ a pesar que aún no soplaban vientos revolucionarios ni independentistas, es indiscutible que tanto en los recintos universitarios como en estas tertulias, la crítica al sistema colonial y los planteos de reformas del reino fueron ganando en intensidad y adeptos. En ese sentido, otra de las formas privilegiadas de la actividad política en Chuquisaca consistió en la difusión de pasquines y manifiestos manuscritos, en algunos casos críticos al status quo,

\footnotetext{
${ }^{105}$ Thibaud, C., óp. cit., p. 41.

${ }^{106}$ Ibid., p. 21.

${ }^{107}$ Just Lleo, Comienzo de la independencia en el Alto perú: los sucesos de Chuquisaca, Madrid, 1969, citado en Thibaud, C., óp. cit., p. 106.

${ }^{108}$ El cura Medina sería pocos años después uno de los principales líderes del movimiento autonomista de La Paz.

${ }^{109}$ Citado en Goldman, N., óp. cit., p. 53.
} 
copiados rápidamente para ser distribuidos. La ausencia de imprenta en Charcas explicaba el enorme desarrollo de estos manuscritos. Es más, en la ciudad existían incluso oficinas especializadas en las que los amanuenses componían a pedido algún epigrama en rima sobre el tema que se les solicitaba. ${ }^{110} \mathrm{~A}$ través de estas prácticas, como las tertulias y los panfletos, iba surgiendo progresivamente una voz pública por fuera de la égida de la autoridad virreinal, en un campo donde las órdenes, cuerpos y estamentos no tenían el mismo peso. Estudiantes y futuros doctores creaban ámbitos de pronunciamiento y reflexión más allá del control de las autoridades. ${ }^{111}$

La formación de esta elite criolla, a la que tanto la Universidad y la Academia, como la sociabilidad chuquisaqueña aportaron, cobraría un nuevo sentido al momento de entrar en crisis el orden colonial finalizando la primera década del 1800, constituyéndose en un grupo dirigente con capacidad para tomar las riendas del poder. Muchos de los más de trecientos cincuenta abogados criollos que se formaron en la Academia se convertirían en dirigentes revolucionarios en el Rio de la Plata, el Alto Perú y Chile, como Mariano Moreno, Juan José Castelli, Juan José Paso, Bernardo de Monteagudo, el chileno Jaime Zudañez, así como muchos de los jueces que remplazarían a los oidores expulsados en junio de 1810 en Buenos Aires. Un tercio de los miembros de la Junta Provisional Gubernativa y casi la mitad de los diputados del Congreso de Tucumán que en 1816 declararon la independencia de las Provincias Unidas del Rio de la Plata había estudiado en esa institución. Pero como plantea Fabio Wasserman, “aún ese destino era inimaginable a fines del siglo XVIII, y por el contrario durante esos años el poder real parecía consolidarse cada vez más en el virreinato rioplatense y sus habitantes actuaban en función de las expectativas generadas por ese proceso". 112

\footnotetext{
${ }^{110}$ Thibaud, C., óp. cit., pp. 88-89.

${ }^{111}$ De Gori, E., La Republica Patriota ..., pp. 160-161.

${ }^{112}$ Wasserman, Fabio, Juan José Castelli. De súbdito de la corona a líder revolucionario, Buenos Aires, Edhasa, 2011, p. 31.
} 


\section{Capítulo 2:}

\section{Ilustración española y economía política en la prensa rioplatense tardo-colonial}

\section{Introducción}

En los últimos años la historiografía especializada considera que en el Río de la Plata, al igual que en el resto de la América española, existía un universo intelectual mucho más amplio y ecléctico que el que tradicionalmente se sostuvo en la antinomia ilustración francesa/neoescolástica española. Los trabajos de José Carlos Chiaramonte han echado luz en este sentido, destacando el papel desempeñado por la Ilustración española y el derecho natural y de gentes en la conformación de la cultura política rioplatense de la época. Por otro lado, si nos remitimos exclusivamente al campo del pensamiento económico, son valiosos los aportes realizados por Rodolfo Pastore y Nancy Calvo que reconocen una vinculación intelectual considerablemente más compleja que la simple adscripción a los conceptos de las escuelas fisiocráticas o la librecambista, como desde la historiografía tradicional siempre se afirmó. Estos autores entienden que prevaleció una «amalgama de pensamientos diversos por encima del seguimiento exclusivo de algún enfoque económico en particular», y destacan la atención puesta por los rioplatenses en las obras y debates de los economistas peninsulares. En el presente capítulo tomamos como punto de partida estas apreciaciones y, a partir de un estudio del conjunto de la prensa periódica de principios del siglo XIX, consideramos que las discusiones y planteos plasmados en los periódicos formaron parte del intenso proceso de circulación de saberes, discursos y prácticas culturales que atravesaron la Ilustración hispánica, y que no sólo remitieron a temáticas económicas, sino al conjunto de las preocupaciones que, tanto de un lado del Atlántico como del otro, desvelaban a aquellas elites letradas convencidas de las posibilidades de progreso material y espiritual de la Monarquía española.

En la primera parte del capítulo abordaremos de manera panorámica el contexto rioplatense de principios de siglo XIX y el proceso de transformaciones que van permitiendo la aparición de una élite intelectual ilustrada y nuevos ámbitos de sociabilidad a nivel local. La segunda parte está destinada a revelar las marcas ilustradas en la prensa entre los años 1801 y 1807, poniendo el acento en las formas de adaptación y los usos que los publicistas locales dieron a los textos y las ideas de los ilustrados 
españoles, como Campomanes, Foronda o Jovellanos, entre otros, en los dos primeros periódicos impresos rioplatenses: el Telégrafo Mercantil, Rural, Político, Económico e Historiográfico del Río de la Plata y el Semanario de Agricultura, Industria y Comercio. Finalmente trataremos de explicar por qué fueron infructuosos los intentos por establecer una Sociedad económica en el Río de la Plata.

\section{La llustración en el Río de la Plata}

Al igual que el resto de la América española, el Río de la Plata no permaneció ajeno al proceso de trasformaciones sociales y culturales que atravesaba al Viejo Mundo. El Iluminismo, aun en su versión moderada, impactó indefectiblemente en los territorios americanos y lo hizo a través del tamiz peninsular, y en muchos casos, como resultado directo de la política oficial de la corona, que, con una batería de medidas e instrucciones de tintes reformistas, buscaba reconfigurar el vínculo entre la metrópoli y sus colonias. Las reformas aplicadas desde fines del siglo XVIII trastocaron los equilibrios sociales, políticos y territoriales existentes en las áreas afectadas. Los grupos criollos más poderosos, acostumbrados a tener una fuerte incidencia y autonomía en el manejo de los asuntos de gobierno a nivel local, se sintieron muy afectados. En muchas regiones, los pueblos indígenas se resistieron a aplicar algunas de las medidas impuestas por los nuevos funcionarios, especialmente aquellas destinadas a ejercer sobre ellos mayor presión fiscal. El nuevo trato que los habitantes americanos recibieron por parte de la Corona fue percibido por muchos como humillante, al comprobar que perdían antiguos privilegios o que eran obligados a aumentar el pago de tributos a la metrópoli. ${ }^{113}$

Ahora bien, las resistencias a las reformas se manifestaron fundamentalmente en las zonas centrales del imperio. En el caso rioplatense, las nuevas medidas venían en muchos sentidos a favorecer una región hasta ese momento marginal. Con la creación del Virreinato del Río de la Plata en 1776, y la consiguiente instauración de la Audiencia en 1785 y la erección del Consulado con sede central en Buenos Aires en 1794, se establecieron las bases de una estructura organizativa enmarcada en la política reformista de la metrópoli para la región, y al mismo tiempo, convirtieron a esta ciudad en el centro económico y político de una extensa y floreciente jurisdicción, de tierras

\footnotetext{
${ }^{113}$ Ternavasio, Marcela, Historia de la Argentina, 1806-1852, Siglo XXI, Buenos Aires; 2009, p. 22.
} 
muy fértiles, transportes fluviales y marítimos accesibles, así como un puerto de ultramar que poco a poco iba tomando envergadura. Este es el contexto que fue propiciando y favoreciendo en la capital, a principios del siglo XIX, el surgimiento de una élite intelectual ilustrada preocupada por dar cabida a la discusión de ideas económicas y conocimientos «útiles» y a la difusión de las «novedades». De a poco fue irrumpiendo entonces una nueva práctica intelectual, que impulsó la creación de espacios y escritos donde las novedades científico-técnicas y las nuevas ideas económicas del Siglo de las Luces fueron adquiriendo matices locales.

En el marco de las reformas borbónicas, la expulsión de los jesuitas y los conflictos de frontera con Portugal, llegaron al Rio de la Plata funcionarios y oficiales enviados desde la metrópoli con el objetivo de poner en práctica las nuevas orientaciones de la corona. Era el caso del humanista e ilustrado aragonés Félix de Azara, quien en su calidad de militar e ingeniero fue destinado como Primer Comisario de la partida consignada a la definición de los límites fronterizos, tras las numerosas incursiones portuguesas en territorio español. Dificultada la tarea por la poca cooperación por parte de Portugal, Azara se dedicó durante los veinte años en los que reside en el Virreinato al estudio tanto de la geografía como de la fauna, flora, historia y costumbres de la región. Su aporte en este sentido fue sobresaliente, destacándose como uno de los principales introductores del saber y la preocupación ilustrada en la región. En este mismo sentido, la figura paradigmática de Juan Baltazar Maciel, reformista canónigo de Buenos Aires, educado por los jesuitas, refiere cómo al amparo del reformismo borbónico se difundieron en el Río del Plata líneas de pensamiento innovador. Pero la generalización de esta actitud crítica se correspondía no solo a las corrientes heterodoxas dentro de la Iglesia, sino también a la creciente laicización de la cultura rioplatense a fines del período colonial. Esto valía sobre todo para Buenos Aires, donde abundaban abogados y otros letrados laicos. Entendemos que, al igual que en España, se trataba de un contexto cultural muy dinámico que recogía y combinaba elementos del «reformismo escolástico, el regalismo estatal hispano, el reformismo institucional dentro de la Iglesia, la ciencia y la filosofía del siglo XVII, y la Ilustración». ${ }^{114}$.

En 1783 fue inaugurado el «Real Colegio Convictorio de San Carlos», por iniciativa del virrey Vértiz y bajo los planes elaborados por Maciel, quien sería su

\footnotetext{
${ }^{114}$ Chiaramonte, J.C., óp. cit., p. 108.
} 
primer rector. ${ }^{115}$ La creación del Colegio respondió a los cambios de orientación de los estudios que la Corona había dispuesto a ambos lados del Atlántico, luego del destierro de los jesuitas, quienes habían ocupado hasta entonces un lugar central en las instituciones educativas coloniales. ${ }^{116}$ Bajo un marcado eclecticismo, fueron incorporándose a la enseñanza los nuevos saberes, siendo el cuestionamiento, al menos parcial, del principio de autoridad, el elemento más significativo. A la vez que se afianzaba el regalismo, se promovía una moderada apertura a los progresos de la ciencia, renovándose también la enseñanza de la filosofía y la teología. ${ }^{117}$

Los viajes de estudios de los criollos a Europa también desempeñaron un papel importante de intermediación de los movimientos culturales. Los casos más sobresalientes a destacar por el papel pionero que desempeñaron, son el de Manuel José de Lavardén entre 1770-1778, el del Deán Funes entre 1775-1779, y el más conocido de Manuel Belgrano, entre 1786-1793, todos en la península. Este último, a quien podemos caracterizar como la figura señera de esta renovación cultural, promovió la instalación de academias -las de Náutica y Dibujo se fundaron ambas en 1799-, concursos y premios; y a través de las memorias anuales del Consulado, sus traducciones y escritos periodísticos, fue un pilar en la difusión del nuevo pensamiento económico en el Rio de la Plata. ${ }^{118}$. Al igual que mucho de los ilustrados hispanoamericanos, confiaba en el arbitraje del poder político sobre el despliegue de las fuerzas económicas para la transformación de la sociedad. ${ }^{119}$ Precedida por esta actividad, la nueva etapa que se abría a comienzos del XIX, estuvo marcada por la «aparición del periodismo como fenómeno estable, las iniciativas educacionales con fines utilitarios y elaboración de

\footnotetext{
${ }^{115}$ El célebre regente de los «Reales Estudios» se distinguía por su curiosidad intelectual, de la cual da elocuente prueba su «amplia y diversa biblioteca donde figuraban obras de teología, derecho canónico, jurisprudencia, filosofía, historia y letras de diversas corrientes intelectuales». Goldman, Noemí. «La ciudad letrada (1776-1820)». En Colección Historia de la Provincia de Buenos Aires coordinado por Fradkin, Raúl. Buenos Aires: Universidad Pedagógica Provincial, 2012, p. 303. Su domicilio era el hogar de una animada tertulia que reproducía la apertura intelectual que estaba ocurriendo en España en una escala mayor. Chiaramonte, J.C., La ilustración en el Río de la Plata: Cultura eclesiástica y cultura laica durante el Virreinato, Buenos Aires, Puntosur, 1989.

${ }^{116}$ Varios son los futuros protagonistas del proceso revolucionario rioplatense que pasaron por las aulas del San Carlos. Manuel Belgrano fue alumno de los cursos de filosofía de Luis Chorroarín entre 1783-85 y con esta acreditación ingresó a estudiar leyes a la Universidad de Salamanca. Juan Vieytes participó de los cursos de Vicente Juanzarás entre 1775-77 y en el trienio siguiente en los de Carlos García Posse; Manuel Lavardén, cercano a Maciel y afín con sus ideas, pronunció un discurso en los exámenes de filosofía en 1778; Juan José Castelli pasó por el colegio entre 1778-80 y Mariano Moreno entre 1793-95, antes de dirigirse ambos a sus estudios en Chuquisaca. Pastore, R. y Calvo, N., óp. cit., p. 35.

${ }^{117}$ Goldman, N., óp. cit., 2012, p. 303.

${ }^{118}$ Navarro Floria, Pedro. «llustración y radicalización ideológica en el Consulado de Buenos Aires (1755-1810)». Revista de Indias vol. XLIX núm. 186, 1989.

${ }^{119}$ Halperín Donghi, T., Revolución y guerra. Formación de una elite dirigente en la Argentina criolla, Buenos Aires, Siglo XXI, 1972.
} 
documentos políticos económicos y literarios de relevancia». ${ }^{120}$ Las fuentes utilizadas variaron desde un principio de las fisiócratas francesas y neomercantilistas españolas al posterior reconocimiento de las neomercantilistas de los economistas o "filósofos" del Reino de Nápoles --Antonio Genovesi, el abate Galiani, Gaetano Filangieri, entre ellos-que fueron, también, una fuente importante para la obra de los españoles de la segunda mitad de siglo. ${ }^{121}$

\section{La prensa ilustrada rioplatense}

Rezagado temporalmente en comparación con el resto de la prensa ilustrada hispanoamericana, y tomando como espejo la experiencia peninsular, el 1 de abril de 1801 vio la luz por primera vez el Telégrafo Mercantil, Rural, Político, Económico e Historiógrafo del Río de la Plata. ${ }^{122}$ Nacido fruto de la firme voluntad de Francisco Cabello y Mesa, un extremeño radicado no hacía mucho tiempo en la capital, que había hecho sus primeros pasos como periodista en España y que luego, en el Virreinato de Perú, editó una de las primeras publicaciones diarias de Hispanoamérica. ${ }^{123}$ Al igual que sus pares hispanoamericanos, el Telégrafo Mercantil se proponía la divulgación de «las novedades» como uno de sus objetivos primordiales, publicando tanto noticias y artículos de opinión estrictamente económicos, como un abanico más amplio de materias consideradas «útiles» para el mejoramiento de la sociedad. Constitutivo y a la vez orientador de la embrionaria opinión pública rioplatense, el periódico formó parte de un proyecto pedagógico de corte ilustrado que ambiciosamente Cabello y Mesa intentaba encarnar en el Río de la Plata, y que contaba con el paraguas protector del Estado borbónico, preocupado en la difusión de estas cuestiones en todos los territorios bajo su dominación. ${ }^{124}$ Existía también una búsqueda, por parte de éste y alguno de los

\footnotetext{
${ }^{120}$ Chiaramonte, J.C., óp. cit., 1997, p. 36.

${ }^{121}$ Ibid., p. 40.

122 En su corta vida se publicarán 110 de sus números, dos suplementos y trece ejemplares extraordinarios. Todos impresos en el único taller de la Ciudad-Puerto desde 1780, la Real Imprenta de los Niños Expósitos, relocalizada desde Córdoba a pedido del Virrey tras la expulsión de los jesuitas, con el fin de facilitar la impresión de papeles burocráticos, catones, catecismos y cartillas en todo el distrito del Virreinato.

${ }^{123}$ El 1ero de octubre de 1790 publica, bajo el seudónimo de Jayme Bausate Mesa, el primer número del Diario de Lima, curioso, erudito, económico y comercial. Pero la firme competencia del Mercurio peruano, aparecido el 2 de enero de 1791, con el respaldo de la Sociedad de Amantes del País limeña, hizo tambalear su economía, determinando finalmente el cierre de su empresa periodística. Martini, Mónica, Francisco Antonio Cabello y Mesa, un publicista ilustrado de dos mundos (1786-1824), Buenos Aires: Universidad del Salvador, 1998, pp. 23-24.

${ }^{124}$ En el prospecto del Telégrafo, el editor manifiesta los objetos o ejes temáticos a los que se atendrá el periódico. En primer lugar lo «Mercantil», donde incluye el comercio, la industria, el lujo y las artes. En
} 
colaboradores del periódico, de reivindicar a América frente a la intelectualidad europea, hartos ya de que siguiera circulando y alimentándose la imagen de continente bárbaro e incivilizado.

La divulgación de las novedades de la llamada «nueva ciencia experimental» tiene un espacio importante dentro de sus páginas, a partir de la reproducción de artículos y noticias, no sólo con el objetivo de saciar la curiosidad ilustrada, sino persiguiendo sobre todo las consecuencias «útiles» de su difusión. Esa intención la podemos emparentar con la prédica constante de Jovellanos a sus compatriotas a favor del estudio de "[...] aquellas ciencias que se llaman útiles por lo mucho que contribuyen a la felicidad de los Estados: [...] las matemáticas, la historia natural, la física, la química, la mineralogía y metalúrgica, la economía civil. Sin ellas nunca se podrá perfeccionar debidamente la agricultura, las artes y oficios ni el comercio". ${ }^{125}$

Como sucedía en el conjunto del mundo hispánico, al Telégrafo se le hacía muy difícil escapar a los controles establecidos por la censura gubernamental para definir qué era lo publicable y qué no. ${ }^{126}$ En la Recomendación del censor Benito de la MataLinares, regente de la real audiencia, dirigida al Virrey Marqués de Avilés el 31/10/1800, podemos apreciar los límites de esta Ilustración tutelada: “[...]guardar moderación, evitar toda sátira, no abusar de los conceptos, meditar bien en sus discursos para combinar la Religión, Política, Instrucción y principios, a efecto de que no sea fosfórica la utilidad de este proyecto, sujetándolo a una censura fina, y meditada, que deberá sufrir antes de imprimirse[... $]^{\prime 127}$.

La transgresión de algunos de estos principios por parte de Cabello y Mesa, entre otras cosas, empujó a la caída en desgracia del periódico. La clausura del Telégrafo ordenada por el virrey del Pino en octubre de 1802, se produjo tras la publicación del artículo titulado Política, Circunstancia en que se halla la provincia de Buenos-Aires e

\footnotetext{
segundo término lo «Rural», definiendo a la agricultura como «el nervio principal de los estados». Lo «Político-económico», en donde se desarrolla lo que el autor entiende por política. Habla de la difusión de las «gacetas de nuestras cortes y otras papeletas que merezcan propagación» en el Virreinato. Finalmente destaca lo «Historiográfico» advirtiendo el lugar preferencial que tendrá dentro del periódico, por su «valor educativo y artístico», como desarrollamos en la nota inmediatamente anterior (12-15).

${ }^{125}$ Jovellanos, G. Obras publicadas e inéditas, B.A.E. Madrid, 1859, t. L, p. 452 b.

${ }^{126}$ Seguimos a Cesar Díaz en que en teoría el sometimiento a todo impreso era inflexible, pero que "en la práctica se producían ciertas fisuras, posibilitadas por ocasionales complicidades entre los eventuales editores y censores, por las impericias o descuidos de estos últimos, o incluso, en la imposible circunstancia (a priori) de la ausencia de censura. Todas ellas, propiciadas, de algún modo, por la permisividad de las altas autoridades, quienes evidentemente confiaban más en la autocensura de los propios directores y/o los colaboradores de los periódicos que en el control ejercidos por sus propios funcionarios" Díaz, C., Comunicación y Revolución, 1759-1810. La Plata: EPC, 2012, pp. 188-189.

${ }^{127}$ Telégrafo, p. 6.
} 
Islas Malvinas y modo de repararse, considerada como demasiado corrosiva su crítica a la sociedad porteña. Pero tal artículo fue en realidad la gota que rebalsó el vaso, la agonía había comenzado varios meses antes, con intimaciones y quita de colaboraciones y suscripciones. ${ }^{128}$

Aunque se puede presentar al Semanario de Agricultura, Industria y Comercio como el continuador del Telégrafo Mercantil en muchos aspectos, a diferencia éste, que se planteaba abarcar una multiplicidad temática mayor, el primero era menos heterogéneo en su contenido, proponiéndose inicialmente el tratamiento casi exclusivo de las materias económicas, y en particular las relacionadas con la actividad agropecuaria. ${ }^{129}$ Con Juan Hipólito Vieytes a la cabeza de la empresa editorial, contó con la colaboración de varios de los letrados ilustrados de la capital virreinal, entre los que se destacaban Manuel Belgrano, Pedro de Cerviño, Gabriel de Hevia y Pando y Manuel de Lavardén. ${ }^{130}$

En su prospecto se propone ser «el Órgano por donde se trasmitan al pueblo las útiles ideas de los compatriotas ilustrados que quieran tomar parte en ésta empresa», y advierte que se abocará a cuestiones «de la agricultura en general, y los ramos que la son anexos», como así también de «todos los ramos de la industria que sean fácilmente acomodables a nuestra presente situación, del comercio interior y exterior de estas Provincias». ${ }^{131}$ Para el Semanario los párrocos rurales eran actores clave en la consecución de estos objetivos y por lo tanto se les reclamaba su colaboración en varios números. Se promueve desde el periódico que se conviertan en difusores en las campañas bonaerenses de los adelantos y novedades técnicas tendientes a la mejora de la agricultura y otros oficios en el Virreinato. El ser prácticamente los únicos letrados en ese medio, los convertía en el canal casi exclusivo para llegar a las poblaciones rurales,

\footnotetext{
${ }^{128}$ Dicho artículo, que en realidad se trataba de un plagio de un original de Juan de la Piedra de 1778, fue sólo uno entre varios que generaron controversias, no sólo con el gobierno virreinal sino en el seno de la emergente "esfera pública rioplatense". Para algunos estudiosos el tono satírico y el lenguaje soez del poema aparecido un mes antes firmado bajo el seudónimo de El poeta médico de las almorranas ya había condenado a muerte al periódico. Díaz, C., óp. cit. Más detalles sobre la clausura del Telégrafo en CailletBois, R., y González J. C., "Antecedentes para explicar el proceso de la clausura del Telégrafo Mercantil, el primer periódico impreso bonaerense". Revista de Historia de América núm.12, 1941.

${ }^{129}$ Llegó a manos de los porteños entre el 1ro de septiembre de 1802 y el 11 de febrero de 1807, con un período de interrupción durante las invasiones inglesas; y fueron publicados 218 números, dos suplementos y cuatro ejemplares extraordinarios.

${ }^{130}$ Vieytes era "el típico exponente del polígrafo finicolonial, transitó la economía política, la economía doméstica (en particular la aplicada al ámbito rural), la química, la historia y la geografía, la historia natural, la agricultura, el derecho y la filosofía política". Martínez Gramuglia, Pablo, "Autores y publicistas entre la colonia y la Revolución de Mayo". En Alabart, M.; Fernández, M.A.; Pérez, M. (ed.). Buenos Aires, una sociedad que se transforma. Buenos Aires: Prometeo, 2012.

${ }^{131}$ Semanario, pp. 5-7.
} 
en sintonía con la política regalista de los borbones. ${ }^{132}$ Foronda en su Cartas recomendaba el fomento del gusto por la lectura de «libros y diarios de agricultura» a las «gentes de conveniencias y a los señores Eclesiásticos». ${ }^{133}$ Como sugiere Martínez Gramuglia ambos periódicos, tanto el Telégrafo como el Semanario, definían su lector ideal como un sujeto débil, alejado del ideal ilustrado, que en cierto modo necesitaba de la conducción de un letrado para entrar en su "mayoría de edad": mujeres, niños, jóvenes, labradores, campesinos, analfabetos. ${ }^{134}$

\section{La Economía Política}

Al igual que con otro tipo de obras, las de economía política llegaban al Río de la Plata desde Europa por diferentes vías: a través de los libreros locales, por encargo a residentes en la Península, por viajes de estudios, o por los que realizaban los funcionarios de la administración virreinal y los eclesiásticos. ${ }^{135}$ La mayoría de los libros de economía con cierta trascendencia, contaron con una versión en español, adaptada en muchos casos a las necesidades del país y de la censura, de manera que ciertos libros originales prohibidos tenían su versión española «lícita». ${ }^{136}$ En principio,

\footnotetext{
${ }^{132}$ Martínez Gramuglia, Pablo. «El pensamiento agrario ilustrado en el Río de la Plata: un estudio del Semanario de Agricultura, Industria y Comercio (1802-1807)». Mundo agrario [online] vol.9 núm. 18, 2009, pp. 8-9.

${ }^{133}$ Foronda, «Carta VI», Cartas sobre policía, 161, tomado de Carzolio, María Inés. «Entre lo privado y lo público: las Cartas sobre la Policía de Valentín de Foronda». XII Jornadas Interescuelas-Departamentos de Historia. Bariloche, 2009, Inédito, p.15.

${ }^{134}$ Martínez Gramuglia, P., Nuevos textos, nuevos (y viejos) lectores: la representación del público en los periódicos desde 1801 hasta 1810. En Graciela Batticuore y Sandra Gayol (eds.). Lecturas de la cultura argentina 1810-1910-2010. Buenos Aires: Prometeo, 2012. Para profundizar sobre las características de los lectores y las lecturas del Semanario consultar Maggio Ramírez, M., "Un puro vegetar. Representaciones de la lectura en el Semanario de Agricultura, Industria y Comercio (1802-1807)". En Paulina Brunetti (et. al.). Ensayos sobre la prensa. Primer Concurso de Investigación en Periódicos Argentinos en Homenaje al Prof. Jorge B. Riviera. Buenos Aires: Ediciones Biblioteca Nacional, 2008.

${ }^{135}$ Las "librerías" se trataban en realidad de bibliotecas personales, con la particularidad de que se caracterizaban por un intenso préstamo de obras - también denominado "redes de lectores"- entre familiares, amigos y conocidos. Un ejemplo paradigmático es la biblioteca particular circulante que instrumentó Facundo de Prieto y Pulido para beneficio de sus allegados -cuya circulación asentó puntillosamente en su Quaderno de los libros que me an llevado prestados -, y que luego fuera donada al convento de la Merced, dando así lugar a un nuevo tipo de establecimiento: la biblioteca pública conventual. Según el registro del Quaderno, alrededor del $50 \%$ de las obras prestadas estaban escritas en lengua española. Para profundizar en el estudio de las bibliotecas y las prácticas de lectura de la época ver Parada, Alejandro. Cuando los lectores nos susurran: Libros, lecturas, bibliotecas, sociedad y prácticas editoriales en la Argentina. Buenos Aires: UBA, 2007; y Parada, A., De la biblioteca particular a la biblioteca pública: libros, lectores y pensamiento bibliotecario en los orígenes de la Biblioteca Pública de Buenos Aires, 1779-1812. Buenos Aires: Errejotapé, 2002.

${ }^{136}$ Podemos mencionar la traducción que Belgrano hizo de las Máximas de Quesnay fechada en Madrid en 1794, las Lecciones de comercio de Genovesi, traducidas y glosadas por Victorián de Villava en 1784, y la Ciencia de la legislación de Filangieri, por Jaime Rubio en 1787. Fernández Armesto, M. V., óp. cit., p. 39 .
} 
las obras de economía sorteaban más fácilmente las sospechas de peligrosidad, en gran medida porque ésta comenzaba a perfilarse como ciencia amparada en el prestigio de la Ilustración y encuadrada en una dimensión utilitaria. Según un estudio realizado a partir de los inventarios de las bibliotecas rioplatenses de la época, es destacable el predominio de obras de economía política de autores españoles como Pedro de Campomanes o Bernardo Ward, aunque sumamente lógico en el marco del proceso de circulación cultural en el mundo hispánico al que venimos haciendo referencia, como así también producto de su carácter «mediador» de las ideas en boga en los centros de conocimiento europeos. ${ }^{137}$ El historicismo tan característico en ellos y su atención a las condiciones particulares de la monarquía hispana, eran dos atributos muy atractivos para los rioplatenses. Notable es también la presencia de los economistas y juristas napolitanos en las bibliotecas, aspecto ya señalado por Chiaramonte en sus trabajos sobre la ilustración hispanoamericana y profundizado recientemente por las investigaciones de Federica Morelli. Sorprende sí, como menciona Fernández Armesto, la ausencia de obras de Jovellanos, pero a partir del análisis de los artículos tanto del Semanario como del Telégrafo que realizamos a continuación en este trabajo, podemos suponer que fue asidua lectura del grupo ilustrado rioplatense.

Desde las páginas del Semanario, Lavardén, bajo el seudónimo anagramático de Juan Anselmo Velarde, reconocía la ventaja de consultar las obras de los pensadores extranjeros en materia económica, pero a la vez advertía sobre las grandes diferencias que separaban al virreinato rioplatense de naciones como Francia o Inglaterra. Consideraba que: «Nos servirán los principios generales de la ciencia económica. El descenso a lo particular debe ser todo nuestro, porque no tenemos quien nos dé el ejemplo». ${ }^{138}$ En el artículo, Lavardén enumera entonces las particularidades de la región, que según él demandaban originalidad a la hora de la reflexión teórica.

En mayo de 1804 el Semanario publica una carta, probablemente del propio Vieytes, donde se aboga a favor de la exportación de los frutos de país. Una vez más se vuelve a hacer referencia a la nueva ciencia económica y las distintas teorías discutidas al otro lado del Atlántico. Propone tomar en cuenta el pensamiento de los sabios de Europa «no porque lo digan ellos, sino que se amalgaman admirablemente con la razón

\footnotetext{
${ }^{137}$ «Origen de los autores de obras económicas: Españoles 35: Campomanes 18, Ward 5, Arriquívar 3, Foronda 3, Uztáriz 2, Campillo 2, Sempere y Guarinos 2; Italianos 8: Filangieri 3, Genovesi 5; Franceses 7: Mirabeau 3, Quesnay 1, Montesquieu 1, Condillac 2; Escoceses 2: Smith 2. Ibíd., p. 49.

${ }^{138}$ Semanario núm. VII, 3/11/02, p. 50.
} 
y la experiencia». ${ }^{139}$ Finalmente va a transcribir un largo texto de Valentín de Foronda sobre el cultivo y comercio de los granos, en el que el vasco ponía en un lugar de privilegio a esta nueva disciplina:

Tampoco son favorables las providencias que han tomado los gobiernos con la saludable mira de ahuyentar la hambre, lo que no es extraño, porque la ciencia de la economía política es todavía más nueva que la física experimental, y así como se desatinaba antes del descubrimiento de esta llave de la naturaleza cuando se quería explicar las auroras boreales, el ascenso del agua en una bomba, los truenos, \&c. igualmente se han descarriado del verdadero camino los gobiernos que se han dejado conducir por una turba de politicastros que decidía descaradamente sobre materias que no se podían comprehender antes del nacimiento de la ciencia económico-política. ${ }^{140}$

La carta finaliza pidiendo que se continúen difundiendo entre los compatriotas las ideas de este «sabio Español»y de todos aquellos «sublimes políticos que tengan una conocida relación con nuestras circunstancias y situación». ${ }^{141}$ En 1806, Vieytes volvería a destacar la figura del vitoriano, entre otros economistas y pensadores europeos que invitaba a estudiar:

¡Cuánto desear que nuestros ciudadanos se empapasen en [los principios de la economía política] leyendo a este propósito a Ustáriz, Zabala, Campillo, Jovellanos, Foronda, \&c. entre los nacionales; y Galiani, el Marqués de Miraveau, al Hombre de Estado, y sobre todo al sublime economista Adam Smith, entre los Extranjeros. ${ }^{142}$

\section{Agricultura, comercio e industria}

La agricultura era considerada, tanto desde el Telégrafo como del Semanario, la actividad central a la que debían enfocarse los esfuerzos de las autoridades virreinales, como del conjunto de la sociedad rioplatense, en pos de potenciar al máximo el

\footnotetext{
${ }^{139}$ Semanario núm. LXXXVIII, 23/5/04, p. 299.

${ }^{140}$ Ídem.

${ }^{141}$ Ibid., p. 304.

${ }^{142}$ Semanario núm. CCXI, 24/10/06: 114. Entre 1788 y 1789 Foronda publicó veinte cartas sobre materias económicas y penales en el periódico Espíritu de los mejores diarios literarios que se publican en Europa. Según el inventario realizado al fallecer Juan Hipólito Vieytes, del cual conocemos sobre todo su predilección por el pensamiento de Adam Smith y otros exponentes de la ilustración escocesa, éste poseía doce tomos de esta publicación en su biblioteca personal. Torre Revello, José. El libro, la imprenta y el periodismo en América durante la dominación española. Buenos Aires: FFyL, Instituto de Investigaciones Históricas, 1940, pp. 72-89. Véase también Rojas, Ricardo Manuel. El pensamiento económico de Juan Hipólito Vieytes. Fundación San Antonio, 2010.
} 
desarrollo económico en la región. ${ }^{143}$ Cabello y Mesa, en el prospecto del periódico que editaba, la define como el «nervio principal de los estados», a la vez que afirma que el país «por su naturaleza debe ser agricultor y comerciante» ${ }^{144}$. Por su parte, también en el prospecto, pero en este caso del Semanario, Vieytes la pondera como «la base de las sociedades, la que alimenta a los Estados y la que hace a los hombres sencillos» ${ }^{145}$. En su primer número, dedicado íntegramente al tratamiento de la agricultura, el editor la ubica por encima del resto de las artes, incluidas la industria y el comercio. Y en lo que sería una constante a lo largo de este tipo de proclamas que priorizaban el desarrollo agrícola, hace referencia a la ventaja comparativa que implica la enorme riqueza del suelo local: "[...] las inagotables minas del Cerro del Potosí, los riquísimos criaderos de aquellas trazas enormes de plata maciza que ha dado Guntajaya, ni los poderosísimos planes de oro del Rio Tipuani; serán nunca comparables con el inagotable tesoro que pueden producir nuestros dilatados Campos". ${ }^{146}$

Otro argumento que se repite en varios escritos del Semanario, y que tiene una clara resonancia del pensamiento ilustrado español, fundamentalmente de la obra de Jovellanos, es concebir a la agricultura no sólo como una herramienta para el progreso material, sino también de regeneración moral, un arma contra los vicios de la ciudad: « [...] huirá de nuestros hogares la ociosidad, y la holgazanería que trae consigo aquellos vicios vergonzosos que degradan a la razón». ${ }^{147}$ Asimismo, para estos ilustrados la agricultura de pequeños propietarios o arrendatarios era preferible ya que producía un tipo de sociabilidad basado en la familia, y por ende, en el crecimiento demográfico, a diferencia de la ganadería que utilizaba poca mano de obra masculina.

La unión entre el hombre ilustrado de la ciudad y el labrador de la campaña era otro de los principios sostenidos recurrentemente en las páginas de la prensa rioplatense de principios de siglo. Se consideraba que sólo a través de este vínculo los adelantos en la técnica llegarían a conocimiento del que trabaja la tierra «cuando el hombre ilustrado se le acerque y le ponga a la vista las mejoras que ignoraba, entonces conocerá en la

\footnotetext{
${ }^{143}$ Cuando en el siglo XVIII la ganadería se valorizó enormemente por la exportación de cueros, la legislación acentuó su proteccionismo a ese sector en detrimento de la agricultura. Ésta era aún una industria exclusivamente de carácter suburbano, destinada más que nada a satisfacer las necesidades alimentarias locales Weinberg, F., Estudio preliminar. Vieytes, J. H. Antecedentes económicos de la Revolución de Mayo. Buenos Aires: Raigal. 1956.

${ }^{144}$ Telégrafo, p. 14.

${ }^{145}$ Semanario, p. 3

${ }^{146}$ Ibíd. p. 5.

${ }^{147}$ Ídem.
} 
práctica el Aldeano, el bien que reporta desprenderse de su bárbara costumbre [...]» ${ }^{148}$. Esa misma orientación la podemos encontrar con insistencia en el Informe sobre la Ley agraria de Jovellanos: «La agricultura no necesita discípulos doctrinados en los bancos de las aulas ni doctores que enseñen desde las cátedras», necesita, en cambio, «de hombres prácticos y pacientes que sepan estercolar, arar, sembrar [...], cosas que distan demasiado del espíritu de las escuelas y que no pueden ser enseñadas con el aparato científico». ${ }^{149}$

Es indiscutible la circulación del pensamiento fisiocrático entre los letrados del virreinato. Sin ir más lejos, el propio Manuel Belgrano fue uno de los principales difusores de la fisiocracia en el mundo hispánico, de lo cual dan cuenta entre otras cosas las traducciones al castellano de algunas obras de esta escuela de pensamiento. ${ }^{150}$ Tanto él como el propio Vieytes cumplieron con uno de los papeles distintivos del publicista de la época, ser traductor cultural, mediador entre dos códigos diferentes. ${ }^{151}$ Aun así, a partir del estudio del Telégrafo y del Semanario, podemos percibir una amplitud de lenguajes y enfoques sobre asuntos puntuales, que excedían a la doctrina fisiocrática. ${ }^{152}$ Prevaleciendo la agricultura en la consideración de la ilustración rioplatense como la principal actividad económica, no era entendida como la única generadora de riqueza, como tampoco sucedía con los reformistas metropolitanos. Pero al igual que en otros aspectos, esta cercanía con el pensamiento de la ilustración peninsular iba a estar matizada, como señalan Pastore y Calvo por «las diferencias que imponían las restricciones comerciales del sistema colonial y por las particulares condiciones del gran potencial de riqueza natural de la región». ${ }^{153}$

\footnotetext{
${ }^{148}$ Telégrafo núm. XVIII, 30/5/01, p. 173.

${ }^{149}$ Jovellanos, G., óp. cit., pp. 122b-123a. En el Telégrafo se hacen propias las palabras del Teatro Crítico de Feijoo, al que ponderan como un Ilustrísimo Sabio Español, donde se dice: «es preciso, é importantísimo, y aun absolutamente necesario mirar con especial atención por esta buena gente [por los labradores], tomando los medios mas oportunos, para promover sus conveniencias, y mirar sus gravámenes». Telégrafo núm. XVIII, 30/5/01, pp. 176-177.

${ }^{150}$ A las ya mencionadas Máximas generales del gobierno económico de un reyno agricultor de François Quesnay, se le suman la traducción de otros textos fisiocráticos en Buenos Aires en 1796, titulándolos Principios de la ciencia económico-politica.

${ }^{151}$ Martínez Gramuglia, P., óp. cit., 2012.

${ }^{152}$ «El tipo de explotación agraria que tenían en mente los fisiócratas, vinculada en gran medida a los farmers que operan a gran escala y con fuerte componente de trabajo asalariado, y compararla con esa intención de incentivar el desarrollo de los pequeños y medianos «labradores» que aparece en la mayoría de los escritos ilustrados rioplatenses. Nuevamente, esta será otra de las características comunes a los ilustrados españoles y, por tanto, de diferencia con los fisiócratas, su crítica a la gran propiedad pues llevaba a la separación de dominio y cultivo». Pastore, R.; Calvo N., "Ilustración y economía en el primer periódico impreso del Virreinato del Río de la Plata: el Telégrafo Mercantil (1801-1802)”, Bulletin Hispanique, núm. 107-2, 2005, p. 458.

${ }^{153}$ Ibid., p. 457.
} 
Íntimamente ligado a la actividad agropecuaria, el comercio en el Río de la Plata era concebido como el imprescindible complemento para el desarrollo económico y social de esas provincias. El editor del Telégrafo publicó en los primeros números un artículo bajo el título de Idea General del Comercio de las Provincias del Río de la Plata, donde se define al comercio como aquello que «principalmente influye en la prosperidad de los Reinos y Pueblos». ${ }^{154}$ En el artículo se destacan las bondades naturales de estas provincias y cómo éstas se potenciarían con un comercio fuerte. Aunque no se refieren directamente ni a la Corona ni a la metrópoli, se recrimina a quienes solo se dedicaban a buscar oro y plata en las «Provincias Argentinas». El autor se lamenta de la falta de decisión para encarar el desarrollo de otros ramos de la economía como eran la pesca, la salazón, las curtiembres, etc. Considera imprescindible vincular el puerto con las potencias europeas y potenciar de esa manera el comercio de la región, lo que según él, redundaría en beneficio de las arcas del estado. Esta leve insinuación de una política más flexible en lo comercial es parte de una crítica cada vez más frecuente en el debate local al mercantilismo, asociado a la realidad de postergación económica en el Río de la Plata.

En el Semanario también encontramos varios artículos que le otorgaban al comercio un lugar preponderante. En el número del 8 de octubre de 1802, en la nota bajo el encabezado de Comercio, su autor cita a Montesquieu para subrayar la relación existente entre el comercio y las suaves costumbres de las naciones que lo practican. Más adelante, el 10 noviembre del mismo año, aparece un nuevo artículo donde se explicita el planteo que promueve liberar las trabas a la exportación, dando curso al comercio de los productos de la tierra. Tanto Jovellanos en su Informe sobre la Ley Agraria, como Campomanes en sus Reflexiones sobre el Comercio Español a Indias (1762) abogaban por la liberación de las trabas al comercio de granos, pero es Valentín de Foronda quien quizás mejor representaba el espíritu librecambista del pensamiento ilustrado español. En este sentido, volvemos a hacer referencia a la carta del núm. 88, que sería del propio Vieytes, donde se consideraban las «indecibles ventajas que resultarían a la agricultura y comercio del Río de la Plata por una exportación continua y libre de los frutos del país», materia que formaba parte de las preocupaciones recurrentes del editor, y que encontraba en Foronda un vocero privilegiado para su causa: “[...] que no se prohíba la entrada ni la salida, que se deje subir o bajar el precio a

\footnotetext{
${ }^{154}$ Telégrafo, T. I, núm. III, 8/4/01, p. 17.
} 
proporción de las causas que producen la variación, que goce el comercio de trigo de una entera libertad, y salen fiadores de que se escapará de nuestro horizonte el espectro horrible de la hambre del mismo modo que se disipa la niebla al salir el Sol [...]". ${ }^{155}$

Por su parte, Jovellanos entendía que solo la libertad de comercio interior podía ayudar a corregir los desequilibrios productivos de las distintas provincias, aunque hacía una excepción al permitir la injerencia del estado en el mercado en momentos en los que era un imperativo político conseguir granos para mantener el orden público, pudiendo proceder temporalmente a tasas o requisas forzosas. ${ }^{156}$

Aunque es evidente que para el grupo ilustrado rioplatense la prioridad estaba puesta en el desarrollo agrícola, no fueron pocas las veces en que se manifestaron a favor del fomento de la industria y otros ramos de la economía. Una de las primeras voces en este sentido la encontramos en el Telégrafo, donde Ennio Tullio Grope -anagrama de Eugenio del Portillo, colaborador regular del periódico-- critica el artículo de Cabello y Mesa del Telégrafo del 27/5/01, titulado Rasgo político-moral sobre contrabandos, entendiendo que el contrabando no era un problema moral, sino de economía política. Afirma, amparándose en los reformistas ilustrados, que: “[...] siempre ha de subsistir el exceso considerable de Contrabando, mientras no se aumente la población, se mejoren con ellas las fábricas, las manufacturas, y toda especie de industria popular en la nación hasta el grado de poder surtir sus dominios y repulsar la concurrencia por las reglas de los SS Campomanes, Cabarrús y el Abate Genovesi." 157

El Semanario ya en su segundo número dedica un largo artículo al problema de la industria. Partiendo del lugar central de la agricultura, se aboga para que los brazos sobrantes deban canalizarse a la industria doméstica. Ancianos, mujeres y niños debieran ocupar sus esfuerzos en estas tareas, lo que no sólo redundaría en un progreso económico para el núcleo familiar, sino para la sociedad entera. Se avanzaría además, en el propósito de desterrar el vicio del ocio y en la mejora en las costumbres. Para reforzar su argumentación cita a un «dedicado y celoso patriota» español:

Labradores: Nación alguna puede prosperar sin el fomento de la industria: su extensión es inmensa, sus objetos innumerables, sus utilidades indecibles. Cuanto

\footnotetext{
${ }^{155}$ Semanario núm. LXXXVIII, 23/5/04, p. 303.

${ }^{156} \mathrm{El}$ comercio exterior debía regirse por los mismos principios; abogaba por una libre exportación salvo en lo referente a los granos, por lo menos, hasta que el desarrollo del sector convirtiera a España en país excedentario de los mismos, ya que como él mismo señalaba, la agricultura española estaba «en un estado progresivo de aumento», Jovellanos, G., óp. cit., p. 69.

${ }^{157}$ Telégrafo nro. 18, p. 444.
} 
producen los tres Reynos de la naturaleza, tanto es susceptible de industria, y cuanto abraza la industria tanto es útil a los hombres. Ella da ocupación y sustento a un sin número de familias: ella atrae la abundancia y las riquezas: ella aumenta la población y los consumos: ella destierra la pobreza y la mendicidad ; ella promueve la ciencia, y las artes; ella vivifica las Naciones, y sin ella jamás pueblo alguno pudo salir de pobre, bárbaro, e ignorante: sin ella casi de nada sirve la agricultura, porque ella es la que da valor a los frutos que cultiváis, y la que da ocupación y provecho a los débiles brazos de vuestra familia numerosa. ${ }^{158}$

Estas reflexiones formaban parte de una opinión de la época que juzgaba como uno de los problemas sociales más graves la «ociosidad» de la población, presente en los trabajos y discursos de muchos economistas españoles, particularmente en Campomanes.

La idea de recobrar la grandeza nacional de España era otra de las inquietudes presentes en los artículos y cartas que promovían el desarrollo industrial de la nación española. En carta al Semanario, Lavardén se lamenta de la decadencia a la que han llevado a la industria española la entrada indiscriminada de productos extranjeros, mientras el Imperio se adormecía con la plata y el oro americanos. ${ }^{159}$

Como hemos podido observar, los escritos en la prensa rioplatense de principios de siglo pusieron el foco en el desarrollo de la agricultura como la clave para el despegue económico y social de la región, fundamentalmente por las ventajas naturales que ésta poseía, pero eso no implicaba que no se depositaran expectativas en otras actividades como el comercio o la industria, a las que se las entendía como complementarias de la primera y con posibilidades de una dinamización recíproca.

\section{La fe ilustrada en la educación}

La cuestión de la educación, tanto técnica como moral, se convirtió en un tema recurrente del Telégrafo Mercantil. En sus primeros meses se publicaron una serie de

\footnotetext{
${ }^{158}$ Semanario nro. 2, p. 10. Hemos podido constatar que este extracto corresponde a un artículo titulado "Carta de un Guipuzcoano a dos paisanos suyos" aparecido en el Espiritu de los mejores diarios, núm. 185 del 15/6/89.

${ }^{159}$ A pesar de ello, señala que el historiador escocés William Robertson en su Historia de América publicada en 1777, trató de «alertar a las potencias europeas por haber observado que no hay Español que no guste, y tenga en su estante la Industria y educación popular de Campomanes. (Indirecto, pero digno elogio del raro sabio, que dando el primer impulso puso en arreglado movimiento nuestra industria.) Esto, según Robertson prueba que ya en España hay más ilustración, que la que conviene a los intereses de las demás Potencias» Semanario núm. XVII, 12/1/03, p. 133. Otro ejemplo que recorre similares argumentos es el artículo «Industria» del Semanario núm. XXXVI, p. 285.
} 
artículos que hacían referencia tanto a la educación doméstica como a la instrucción pública. Se reprodujo, por ejemplo, un artículo extraído de la Historia antigua de México de Francisco Xavier Clavijero donde un padre da recomendaciones sobre moral y conductas a su hijo. ${ }^{160}$ Más adelante será el turno de la educación pública, con un extenso artículo repartido en tres números consecutivos. En este fragmento se pueden percibir varias definiciones del tipo de educación a la que aspira el grupo ilustrado:

Cuando las escuelas y colegios se vean bien reglados, cuando la juventud reconozca superioridad y justos límites, cuando las leyes de estímulo puedan más que otras de temor, cuando un sabio plan económico y literario contraiga el entendimiento de los jóvenes, y menos distraídos en especulaciones fastidiosas y en morralla o bazofia literaria, sientan el buen gusto de sus adelantamientos; ¿por qué no deberemos esperar el remedio de las ciencias, el bienestar de nuestros patriotas, y si es posible, la gloria de la Religión y la felicidad del Estado? ${ }^{161}$

La fe en la educación, y en particular en la educación pública, fue siempre un componente clave del imaginario ilustrado, pero lo era aún más en la concepción de Don Gaspar de Jovellanos. Tanto es así, que en sus últimos años llegó a la conclusión de que la principal fuente de la riqueza no era propiamente la agricultura como hasta entonces había considerado, situándola junto a la industria, el comercio y la población como fuentes secundarias. Para el asturiano, el origen primario de la riqueza radicaba en la educación, y en particular en la instrucción técnica: «la perfección del arte de aplicar el trabajo» ${ }^{162}$. Esta cuestión la desarrollaría principalmente en la Memoria sobre la educación pública de 1802 y en las Bases para la formación de un plan general de instrucción pública de 1809, pero ya encontramos numerosos escritos a partir de 1796, donde la cuestión educativa se volvió el eje central de su pensamiento. En esos años, reflexionando en su diario sobre su querida Asturias afirmaba: «si no tiene buenas leyes las tendrá, porque éste debe ser un efecto infalible de la propagación de las luces. Cuando la opinión pública las dicte, la autoridad tendrá que establecerlas, quiera que no». ${ }^{163} \mathrm{Y}$ en la mencionada Memoria sobre la educación pública se preguntaba y

\footnotetext{
${ }^{160}$ Telégrafo nro. XIII, pp. 127-130.

${ }^{161}$ Telégrafo T. I, núm. XVI, 23/05/01, pp.123-124.

${ }^{162}$ Llombart, Vicent. «Ni teoría sin aplicación, ni aplicación sin teoría: Economía política y realismo en Jovellanos». Revista asturiana de economía núm. 45, 2012, p. 19.

${ }^{163}$ Jovellanos, G., óp. cit., p. 305.
} 
respondía: « ¿Es la instrucción pública el primer origen de la prosperidad social? Sin duda...»

El fomento a la instrucción técnica era también una temática usual de los periódicos. A los artículos que difundían los adelantos y mejoras en la técnica, que eran aún más cotidianos dentro del Semanario que en el Telégrafo, se sumaban reflexiones y discursos que apuntaban al establecimiento de academias y otras instituciones, que buscaban preparar a los habitantes del virreinato para las actividades productivas. ${ }^{164}$ Conocido es el Discurso de Manuel Belgrano en los Certámenes Públicos de la Academia de Náutica, que se reproduce dentro de las páginas del Telégrafo, donde resalta la importancia de la formación de individuos útiles a la sociedad y se anuncian los alumnos premiados por su esmero y logros. ${ }^{165}$

Por su parte, el Semanario también dedicó varias entregas a la cuestión educativa, y en particular a la instrucción técnica. Tempranamente, en sus números 4 y 5 , reproduce un artículo titulado Educación Moral, dirigido a los padres de familia de los sectores medios porteños, increpándolos por no promover en sus hijos el estudio y la preparación en oficios. Se explica que esto se debe al prejuicio existente en este grupo social con respecto al «deshonor» que implicaba el trabajo de artesano. ${ }^{166}$ Campomanes, en su Discurso sobre la educación popular de los artesanos, hablaba de estos prejuicios:

Ha sido grande error en política excitar cuestiones sobre la preferencia de las artes, y de los oficios: distinguiendo a unos con el dictado de liberales, y a otros con el de mecánicos. De ahí se pasó a hacer otra distinción de oficios bajos, y humildes; titulando a algunos de nobles. Estas denominaciones voluntarias y mal digeridas, han excitado repetidas emulaciones, y han sido parte, para que muchos abandonasen las artes, o apartasen a sus hijos de continuar en ellas, contra otra máxima general de hacer

\footnotetext{
${ }^{164}$ En un artículo sobre minería, Cabello y Mesa hace un exhorto a la creación de una Escuela de Mineralogía para la región. Telégrafo T. IV, núm. XV, 8/8/02, p. 540. La referencia a la Sociedad Bascongada de los Amigos del País como modelo a seguir que se realiza en dicho artículo no es casual. Éste posee varias expresiones utilizadas en el Proyecto de una escuela patriótica presentado a la Junta General de la Real Sociedad Bascongada de los Amigos del País por su Junta de Institución a 17 de septiembre de 1775.

${ }^{165}$ Telégrafo T. I, núm. XII, 21/3/02, pp. 177-185. La práctica de los premios fue una constante en las Academias y Sociedades del mundo hispánico, tal como lo propugnaba Campomanes, con el objetivo de estimular así el progreso y los adelantos entre los estudiantes y socios.

${ }^{166}$ Sobre la enseñanza de oficios mecánicos véase la tesis de maestría de Arata, N., La enseñanza de oficios mecánicos durante el Virreinato del Río de la Plata (1776-1810). Buenos Aires: Libros Libres, 2010. Internet.
} 
indirectamente hereditarios los oficios en las familias, para que los amen y

perfeccionen. $^{167}$

Siguiendo con el artículo del Semanario, se plantea que sólo los hijos de familias muy acomodadas o aquellos que hayan mostrado un talento superior pueden dedicarse a los «estudios liberales», algo que se considera directamente prohibitivo para el bajo pueblo, donde los jóvenes no deben correr su atención del aprendizaje de los oficios. ${ }^{168}$ Podemos observar aquí nuevamente la recepción de la obra del ministro ilustrado, en este caso de su Discurso sobre el fomento de la Industria Popular: «por fortuna es corto el número de los que deben dedicarse a las ciencias y ricos; en lugar que la industria Popular, de que trata este discurso, abraza la generalidad o mayor parte del pueblo». ${ }^{169}$

\section{La historia y la geografía como saberes útiles}

El rasgo historicista tan destacado en el pensamiento de los Ilustrados peninsulares como Jovellanos, Martínez Marina o Campomanes tuvo su correlato en el Río de la Plata fundamentalmente en el Telégrafo, que desde su mismo título anunciaba la vocación por la divulgación de trabajos historiográficos. Como antecedente en la región, que justamente no se caracterizaba por una tradición en este sentido a diferencia quizás de otras capitales americanas, podemos mencionar la obra del coronel de ingenieros Félix Azara. Inscripta en el marco de las reformas borbónicas, que al procurar un mayor control sobre las colonias dieron lugar a la actuación de funcionarios ilustrados que apuntaron a un mayor conocimiento sobre el territorio, la población y los recursos que administraban. Su obra Descripción e historia del Paraguay y del Río de la Plata marcó “el inicio de una nueva tradición que concebía a la historia como proveedora de conocimientos empíricos útiles para la sociedad". ${ }^{170} \mathrm{Y}$ para ello se imponía adoptar "nuevos criterios de verdad ligados a la experiencia y el uso de la razón en alianza con la filosofía y otros saberes prácticos como la economía y la geografía."

En el Telégrafo podemos encontrar varios artículos de temática histórica, destacándose aquel sobre la fundación de la ciudad de Buenos Aires, que generó una fuerte polémica involucrando a varios letrados rioplatenses. La controversia se inició

\footnotetext{
${ }^{167}$ Rodríguez de Campomanes, P., Discurso sobre la educación popular de los artesanos, 1775, pp. 417418.

${ }^{168}$ Semanario, núm. V, 20/10/02, pp. 38-35.

${ }^{169}$ Rodríguez de Campomanes, P., Discurso sobre el fomento de la Industria Popular, 1774, p. 4.

${ }^{170}$ Wasserman, Fabio. «La historia como concepto y como práctica: conocimiento histórico en el Río de la Plata (1780-1840)», História da historiografía núm. 4, 2010, p. 19.
} 
con el Examen crítico sobre la fecha de la fundación que realiza Eugenio del Portillo gobernador intendente de La Paz- discutiendo lo afirmado en los Almanackes y otros documentos de la época. ${ }^{171}$ Por otro lado, F. Juan Anselmo Velarde en carta al Semanario titulada Sobre las verdaderas causas de la decadencia del Estado económico de España, realiza un sucinto repaso por la historia de España, donde enarbola una fuerte defensa de la conquista y de la explotación del oro y la plata americanas por parte de la metrópoli. Enumera y describe en particular las principales razones por el estado actual del Imperio español: “el comercio exclusivo -inevitable por culpa de la piratería de las otras potencias-, la expulsión de los Moriscos, las rebeliones de nuestras Provincias, dos siglos de guerra fuera de España, la guerra de sucesión, y por ultimo una hostilidad [por parte de Inglaterra] periódica y sistemática". ${ }^{172}$

Cabello y Mesa, aficionado a los discursos históricos, se lamentaba por la escasez de documentos y establecía un juicio crítico sobre las crónicas, dando por seguro que "los Escritores de la conquista cada uno haya delirado a su modo, sin manifestarnos con fidelidad y claridad muchos acontecimientos, que han dado lugar a tantas dudas, y a que cada uno opine conforme a sus ideas". Alentaba a sus colaboradores a seguir dando curso a estos escritos históricos a fin de "disipar las imposturas de varios pedantes Escritores, que han tratado de desprestigiar a nuestra América, haciéndonos oriundo de las hez de la Nación, y de gente presidiaria, forajida, vagabunda, y de leva". ${ }^{173}$ Quien respondió a la convocatoria es nuevamente Eugenio del Portillo, aunque señalaba las dificultades de la empresa y proponía, en su lugar, abocarse a un "Proiecto Geográfico", puesto que la geografía es "uno de los ojos de la Historia". Este nuevo programa suponía la tarea de recolección de datos con el fin de lograr una descripción completa a través de la confección de informes, con sus respectivos mapas, de las ocho intendencias y de los gobiernos militares de Montevideo, Moxos y Chiquitos, estos dos últimos en el Alto Perú. Según lo analizado por Tatiana Navallo los informes leídos en conjunto, "al tiempo que fusionan los proyectos de Eugenio del Portillo y Antonio Cabello y Mesa -proyecto geográfico e historia general del virreinato-, presentan [...]

\footnotetext{
${ }^{171}$ Telégrafo, T. II, núm. XI, 5/9/01, pp. 392-395.

${ }^{172}$ Semanario, núm. XVII, 12/1/03, p. 133.

${ }^{173}$ Telégrafo Mercantil, T. III, núm. II, 10/1/02, p. 26. Si pensamos la constitución identitaria como algo inexorablemente relacional, estos escritos, al igual que otros que también nacían como respuesta al fastidio y la irritación que les provocaba la visión denigratoria de los letrados europeos hacia América, serán "la punta de lanza que tendrán los lectores coloniales para pensarse a sí mismos desde su diferencia ante la mirada que los vuelve exóticos" Maggio Ramírez, M., "Civilización imaginada. Lecturas sobre civilidad e identidad en el Buenos Aires colonial a través de su prensa periódica. La Biblioteca 8, 2009, pp. 254-262.
} 
relaciones en las que se proyectan salidas viables para el mejoramiento económico y cultural del virreinato, en el marco de la opinión pública". ${ }^{174}$

Imbuidas en un espíritu similar tenemos las cartas de Pedro de Cerviño al Semanario, donde recupera fragmentos de diarios de viajes de expedicionarios -pero también personales- que contienen algunas propuestas alternativas, dentro del reformismo modernizador, para expandir y fortalecer las fronteras internas y externas en la Patagonia y el Chaco, que al igual que los informes de Portillo se enmarcaban en una estrategia cognoscitiva imperial que buscaba al mismo tiempo que consolidar sus dominios territoriales, restituir su posición entre otros estados europeos y su centro en el circuito comercial del Atlántico. ${ }^{175}$

\section{Lo «político» en tiempos de censura}

Ya hemos advertido que cuestiones que tocaran tanto lo político como lo religioso eran posibles objetivos de la censura gubernamental, y que por lo tanto es poco lo que encontramos dentro de las páginas de la prensa de principios del siglo XIX sobre estos temas. Aun así, mientras los escritos no estuvieran impregnados de una crítica directa al statu quo podían llegar a ser publicados. Hemos podido identificar algunos que nos sirven para definir ciertos rasgos de la cultura política rioplatense de la época, que como hemos afirmado ya, se trataba de un período transicional donde varios conceptos políticos sufrieron una fuerte mutación de sentido, y donde se produjo una compleja mixtura de elementos provenientes de diferentes tradiciones, lenguajes políticos y corrientes de pensamiento, entrando en contacto las nuevas doctrinas iusnaturalistas propias del Siglo de las Luces, con los sustratos jurídicos y culturales hispanoamericanos, basados fundamentalmente en el derecho común y la neoescolástica.

Resulta aquí interesante hacer referencia al artículo de Cabello y Mesa: Rasgo político-moral sobre contrabandos, inspirado en un artículo del Espíritu de los mejores diarios europeos, pero aplicado a la realidad americana. El extremeño atacaba obviamente la actividad del contrabando, y lo hacía con argumentos que exaltaban el respeto tanto a la autoridad religiosa como estatal. Quien cometiera ese delito, dice, era

\footnotetext{
${ }^{174}$ Navallo, T., “Ideas ilustradas en el Río de la Plata: de los manuscritos al 'Proiecto Geográfico' del Telégrafo Mercantil (1801-1802)", TINKUY No 14, 2010, p. 192.

${ }^{175}$ Navallo, T., "Articulaciones históricas y culturales en zonas de frontera, difundidas en la prensa del Río de la Plata (XIX)”, Estudios Históricos 3, 2009.
} 
a la vez «mal cristiano, mal vasallo y mal ciudadano». Los fundamentos utilizados remiten a una clara concepción absolutista sobre el origen de la autoridad del soberano: «El Supremo e independiente Legislador del Universo, la fijó en el trono y la sostiene. Así los reyes reinan por Dios y a su nombre establecen las Leyes». Cita también la doctrina del Apóstol San Pablo: «El que resiste a la potestad resiste a la orden de Dios. No hay potestad que no emane de Dios. El súbdito ha de obedecer a su príncipe no solo por temor de la pena, sino también por los sentimientos de su conciencia». ${ }^{176}$ Conociendo la trayectoria de Cabello y Mesa, entendemos que dichas posturas no son precisamente una declaración de fe. Aún lejos de las posiciones de un liberalismo apenas embrionario en el mundo hispánico, si podemos caracterizar al pensamiento del periodista aventurero como de un regalismo moderado, más propio de los reformistas ilustrados peninsulares. Entonces, esta exaltada proclama absolutista se explica mejor, creemos, con la necesidad que tenía de congraciarse el autor con las autoridades virreinales, conociendo además el recurrente oportunismo que lo caracterizó a lo largo de su vida.

En el Semanario encontramos una carta de Lavardén interesante por su riqueza conceptual, orientada a discutir las visiones que se tenían desde el extranjero, fundamentalmente desde Inglaterra y Francia, sobre la situación económica que atravesaba España. Entiende que estos escritores, a los que considera filósofos de gabinete, en general «nos denigran para disimular la ignorancia en que están de nuestras cosas». Se dedica a rebatir entonces sus argumentos, y ante la acusación de que en España se enseñoreaba el despotismo monárquico, Lavardén hace gala de fundamentos anclados en el constitucionalismo histórico para contrarrestar aquellas posiciones:

Despotismo no hay en donde hay un código legal. Habrá arbitrariedad no despotismo. Reynal creería que sucedía en España lo que en Francia, en donde se gobernaban con ignominia de su decoro, por el derecho escrito de los Romanos, y por los fueros de las provincias que llamaban droitcontumier. Los Españoles han tenido la manía de los Atenienses, cuyo Legislador quiso arreglar hasta los concúbitos: hace mucho que España tiene Leyes fundamentales, que jura su Rey en su inauguración. Leyes fundamentales son las que hoy más a la moda se llaman constitucionales. Algunos creen que no tenemos constitución, porque cumpliéndose con exactitud no hemos tenido nunca motivo de hablar de ella. Por lo que hace a la administración de justicia y gobierno político

\footnotetext{
${ }^{176}$ También recurre Santo Tomás: «la observancia de las Leyes civiles es una obligación que trasciende el fuero de la conciencia, y que su infracción es un atentado indirecto contra la misma Ley eterna de Dios»». Telégrafo, t. I, núm. XVII, 27/5/01, pp. 161-163.
} 
son tantas que ya clamamos por su reducción. Una sola Ley no conocemos, que es la Ley marcial, y que yo no sé cómo han amalgamado los Ingleses con su decantada libertad. Supongo que la introducción de los Lores en la cámara de los comunes, y la prohibición de que estos tengan voto en la de los Pares, ya insinúa que aquel Pueblo está sabiamente alucinado. ${ }^{177}$

Hemos detectado que esta misma carta se reproduciría en el periódico madrileño El regañón general o tribunal catoniano: de literatura, educación y costumbres núm. 56-57 del 14/7/04 y 18/7/04. Demostrando que la circulación de escritos no sólo se daba en una sola dirección, si no que cada tanto un documento americano era publicado también en la península.

El constitucionalismo histórico tuvo su entrada en la palestra del debate público en el mundo hispánico a partir del discurso de ingreso que Jovellanos presentó ante la Real Academia de Historia en 1780, titulado Sobre la necesidad de unir el estudio de la legislación al de nuestra historia. Para el asturiano el conocimiento de la historia del derecho público nacional era fundamental para pensar en una Constitución para la Monarquía. Mientras que en España la literatura económica y social era riquísima, las obras dedicadas al derecho público podían contarse con los dedos de las manos. No existía una obra que recogiera los hechos y noticias relativos a la historia de su derecho. En momentos de la crisis monárquica abierta con las abdicaciones de Bayona, esta misma perspectiva sería utilizada por el liberalismo gaditano para legitimar una constitución que equilibre las prerrogativas de la soberanía real. ${ }^{178}$ Para los doceañistas se trataría de recobrar las libertades perdidas de un pasado idealizado y elevar unas nuevas Cortes basadas en la soberanía popular y la representación nacional, incluso cuando las Cortes planteadas por Jovellanos mantenían el tradicional carácter estamental. Pero no nos adelantemos, ya abordaremos esto más adelante. Los españoles ilustrados antes de 1789 no protestaron nunca contra la falta de convocatoria a Cortes de los Borbones. Nadie hablaba en España de despotismo o de absolutismo. Los hombres de la minoría ilustrada estaban convencidos de que vivían en una monarquía moderada. ${ }^{179}$ En todo caso, los escritos de Jovellanos jugaron un papel importante en el ámbito del naciente constitucionalismo americano, fundamentalmente en la obra del

\footnotetext{
${ }^{177}$ Semanario núm. XI, 1/12/02, p. 85.

${ }^{178}$ Jovellanos recordaba que la soberanía real estuvo históricamente, en los periodos visigóticos, asturiano y castellano, limitada por los Concilios primeramente y luego por las Cortes. La costumbre de reunirlas fue bastante olvidada por los Borbones, quienes solo convocaban a los diputados para el juramento de los nuevos monarcas.

${ }^{179}$ Sarrailh, J., óp. cit., pp. 578-582.
} 
novohispano Servando Teresa de Mier, pero como pudimos observar, también en la de letrados rioplatenses como Lavardén.

Por otro lado, quizás no en el orden estrictamente de «lo político», empezaron a aparecer en la prensa rioplatense artículos que sometían a la crítica a algunos aspectos de la sociedad colonial. En el Semanario núm. 64 --7/12/03-- se publica la carta de un supuesto preso, llamado Julián Topio, al editor, denunciando la penosa situación en las cárceles de la ciudad; seguida de una reflexión del editor donde se solidariza con la situación de los presos. En realidad, Julián Topio sería el anagrama --práctica habitual de la época-- de Juan Ipolito, por lo tanto el autor de la carta, como de la respuesta, no sería otro que el propio Vieytes. Manuel Fernández López en su trabajo Cartas de Foronda: su influencia en el pensamiento económico argentino, llama la atención de las similitudes entre la Carta dirigida al Editor desde la cárcel de esta ciudad y algunos fragmentos de las Cartas del vitoriano. Mientras en el Semanario se decía que la cárcel se ha establecido únicamente para «guardar con seguridad los delincuentes hasta el esclarecimiento de sus causas, que la desgracia debe ser siempre respetada, y que hasta la convicción el acusado no es sino un desgraciado» ${ }^{180}$; en la carta de Foronda leemos:

Tenga Vmd. Presente que las cárceles no tienen otro objeto que el resguardo de los que están indiciados de algún crimen: así se les debe encerrar en un lugar sano, bien aireado, y proveerles de todo lo que necesiten. De ningún modo se les deben...mortificarlos con otras vejaciones de esta naturaleza: es preciso recomendar a los carceleros que no traten duramente a los presos; pues la desgracia debe ser siempre respetada, y hasta la convicción, el acusado no es sino un infeliz. ${ }^{181}$

Otro artículo donde podemos percibir aquel rasgo humanista tan caro al espíritu de los ilustrados es la carta de Gabriel de Hevia y Pando titulada justamente Humanidad del Semanario núm. 65 del 14/12/03, donde se denuncian las insalubres condiciones a la que se ve sometido el trabajo de los indios en las minas del Potosí y los altos índices de la mortandad e infertilidad que esta situación estaría provocando entre los mitayos. Llama la atención el escrito por el elevado tono de crítica a una realidad social tan compleja que formaba parte del mismo corazón del sistema de explotación de la metrópoli sobre los recursos americanos, tanto humanos como materiales. Por eso no

\footnotetext{
${ }^{180}$ Semanario, núm. LXIV, 7/12/1803, p. 108.

${ }^{181}$ Foronda (1789), Carta I: 101-02, tomado de Fernández López, Manuel. «Cartas de Foronda: su influencia en el pensamiento económico argentino», en: XLI Reunión Anual de la Asociación Argentina de Economía Política. Salta, 2006.
} 
parece tan extraño que el «se concluirá...» con que cierra abruptamente el artículo, no se concrete al número siguiente ni en los que le continuarán. En realidad, lo que sucedió fue que la segunda parte de la carta fue finalmente impresa en el número 66 del Semanario, superando curiosamente el control del censor; pero hallándose ya listo para su distribución, llegó la orden del virrey censurando al crítico artículo. El número tuvo que rehacerse, existiendo dos tiradas del mismo: una permitida y la otra prohibida y con destino de hoguera, cosa que por lo menos para algunos ejemplares no sucedió porque circularon y fueron conservados en colecciones privadas. ${ }^{182}$ En ese sentido, se entiende que unos meses después, en marzo del año siguiente, se haya incluido un artículo del editor donde se plantea que lo denunciado sobre la situación en Potosí adolecía de actualidad, y donde se asegura que el Gobernador Paula Sanz se había preocupado por que las condiciones en los ingenios fueran lo más benignas posibles, llevando adelante importantes reformas durante su gobierno. ${ }^{183}$ A pesar de esta «aclaración», volvemos a insistir en lo destacable de la crítica social, y en definitiva política, que implicó el artículo, constituyendo uno de los primeros antecedentes de esta clase en la prensa rioplatense.

Varios años antes de la prohibición de la introducción de esclavos y el decreto de libertad de vientres por parte de la Asamblea del año XIII, que lo tuvo como uno de sus protagonistas, Vieytes ya abogaba desde el Semanario por estas mismas causas: «proscríbase para siempre este funesto tráfico que causa indispensablemente perjuicios tan enormes a millares de hombres, que al mismo tiempo sirven de oprobio a la sociedad, perpetúan la pobreza y la miseria de América». ${ }^{184}$ La posición del publicista criollo no sólo respondía a ese espíritu humanista ilustrado del que hablamos, era también un elemento importante en su concepción económica donde las artes y oficios debían ser patrimonio exclusivo de "hombres libres", desprovistos de cualquier tipo de sujeción.

\section{Crónica de una frustración ilustrada. Los proyectos de los "Amigos del País" en} el Rio de la Plata tardo-colonial

Una de las señas más representativas de ese proceso denominado Ilustración Hispanoamericana fueron sin dudas las Sociedades Económicas de Amigos del País.

\footnotetext{
${ }^{182}$ Díaz, C., óp. cit., p. 219.

${ }^{183}$ Ídem.

${ }^{184}$ Semanario núm. 186, 9/4/06, p. 258.
} 
Nacidas, como ya vimos, al calor de la política reformista de Carlos III y sus ministros ilustrados, fueron proyectadas como espacios de debate, elaboración de propuestas y asesoramiento en cuestiones económicas. Pensadas fundamentalmente además como centros claves en la difusión y aplicación práctica de los saberes útiles y los nuevos conocimientos económicos, las Sociedades se instituyeron también en espacios públicos definidos por una sociabilidad y forma de participación más horizontal que rompía con los criterios jerárquicos del Ancien Regime. Durante el último cuarto del siglo XVIII florecieron, bajo el estímulo de la corona, por sobre toda la geografía peninsular y, en menor medida, en las posesiones americanas. Hacia fines de la centuria las principales ciudades del nuevo continente, con la excepción de Buenos Aires, contaban con una Sociedad Económica de Amigos del País. Aquí radica el interrogante que guía éste apartado: ¿por qué siendo el Virreinato del Rio de la Plata uno de los territorios más favorecidos por las reformas borbónicas, y contar su capital con una incipiente pero dinámica "elite ilustrada", fueron finalmente infructuosos los intentos por establecer una Sociedad económica local? Intentaremos ensayar entonces algunas hipótesis de los porqués de su fracaso.

El impulso que había hecho surgir en la península numerosas Sociedades Económicas, no tuvo en el resto del imperio el mismo vigor ni resultados. En el continente americano la primera fundación es la de Mompox, en Nueva Granada en 1784, seguida por la de Santiago de Cuba y Veracruz en 1787, aunque esta última duró muy poco tiempo. En 1791 La Habana tuvo su Sociedad de Económica de Amantes del País y dos años después la tuvo Lima. ${ }^{185}$ De este primer período fundacional podemos mencionar también las de Guatemala, Puerto Rico, Quito, Sta. Fe de Bogotá y Caracas. ${ }^{186}$ Todas ellas contaron en el momento de su conformación con el beneplácito y la protección de las autoridades americanas, aunque no con el suficiente entusiasmo y la constancia en el tiempo como para lograr un desarrollo a la par de sus homólogas peninsulares.

A principios del nuevo siglo, de la mano del Telégrafo Mercantil, Francisco Cabello y Mesa encaraba la constitución en Buenos Aires de la primera "Sociedad Patriótico Literaria y Económica del Río de la Plata”, al estilo de las que ya existían en el Imperio hispánico. Pensada fundamentalmente como plafón desde donde el periódico

\footnotetext{
${ }^{185}$ Stoetzer, O. Carlos, Las raíces escolásticas de la emancipación de la América española, Madrid, Centro de Estudios Constitucionales, 1982, p. 160.

${ }^{186}$ Ruiz y González de Linares, Ernesto, Las Sociedades Económicas de Amigos del País, Burgos, Instituto Fernán González, 1972, p. 52.
} 
pudiera nutrirse e ir constituyéndose en un vocero de aquella. Permitiría garantizarse de artículos y textos para completar las entregas periódicas, teniendo en cuenta que el T.M. era un emprendimiento generado por iniciativa y esfuerzo personal del editor. Seguramente también entró en juego a la hora de decidir su conformación, lo acontecido en la experiencia limeña que, entre otras cosas, le dejó como aprendizaje que si quería que su aventura periodística tuviera visos de permanencia en el tiempo, debía contar no solo con el apoyo gubernamental sino con el anclaje y el sustento que la conformación de una Sociedad podía otorgarle. ${ }^{187}$ Ya en el segundo número del Telégrafo se plantea que dicha Sociedad tendría como principal propósito: "la ilustración de este País, en todas las Ciencias, y ramos de Literatura, extendiendo su atención, con particularidad, sobre adelantar el conocimiento de las cosas naturales y de las Artes útiles... como también sobre las producciones de su delicioso suelo". ${ }^{188}$ No sólo le eran reconocidas a las Academias y Sociedades el mérito de dinamizar económicamente su ámbito de influencia, sino que también desde el T.M. se destacan su impacto positivo en el mundo de las letras y el teatro. En carta de Eugenio del Portillo se dice que: “[...] el meritorio y digno lugar que ya en el día van ocupando los Señores Iriarte, Meléndez-Trigueros, Moratín, Ayala, Huerta, Jovellanos, Cortes, Clavijo, Cruz, Cadalso y otros gloriosos Apóstoles del primo, que a influjo y celo de las Academias y Sociedades Patrióticas, ha empezado a renovar el esplendor de las Musas Castellanas". 189

Cabello y Mesa se propone formar el estatuto de la que llama Real Sociedad Universal de la Argentina, sobre la base de las constituciones de las Sociedades de Vera -la $2^{\mathrm{a}}$ que se crea en Andalucía y la $4^{\mathrm{a}}$ en España-, Benavente y Medina de Rio Seco. Y establece los requisitos para poder acceder a la condición de socios:

Españoles nacidos en estos reinos, o en los de España, cristianos viejos limpios de toda mala raza, pues no se va a poder admitir en ellos ningún Extranjero, Negro, Mulato, Chino, Zambo, Quarteron, o Mestizo, ni aquel que haya sido reconciliado por el delito la Herejía, y Apostatía...; porque se ha de procurar que esta Sociedad Argentina se componga de hombres de honrados nacimientos, y buenos procederes $[\ldots]^{190}$

\footnotetext{
${ }^{187}$ El 1ero de octubre de 1790, Cabello y Mesa publica, bajo el seudónimo de Jayme Bausate Mesa, el primer número del Diario de Lima, curioso, erudito, económico y comercial. Pero la firme competencia del Mercurio peruano, aparecido el 2 de enero de 1791, con el respaldo de la Sociedad de Amantes del País limeña, hizo tambalear su economía, determinando finalmente el cierre de su empresa periodística.

${ }^{188}$ Telégrafo Mercantil, T. I, núm. II, 4/4/01, p. 40.

${ }^{189}$ Telégrafo Mercantil, T. II, núm. XVII, 26/9/01, p. 436.

${ }^{190}$ Telégrafo Mercantil, T. I, núm. II, 4/4/01, p. 41.
} 
Con motivo de estas disposiciones, el editor recibió cuestionamientos en varias cartas enviadas al periódico. En el Telégrafo núm. 26 (27/6/01), se publica una carta de Bertoldo Clark preguntando por qué su condición de extranjero le imposibilita el ingreso como socio de la Sociedad Argentina. En su respuesta, el editor hace una detallada referencia a las Leyes de Gentes y Leyes Naturales, y cómo derivan de allí las leyes específicas del reino sobre el acceso a los cargos o membresías. Finalmente, le ofrece ser corresponsal al no estar domiciliado en el país. En el Telégrafo núm. 36 (20/12/01), "La amante de su Patria" le escribe reclamándole que las mujeres puedan participar del periódico. Como ya pudimos ver al estudiar las Sociedades peninsulares era muy excepcional la participación de las mujeres en ellas. Aun así es una polémica de la que no escaparon las reflexiones de algunos ilustres pensadores españoles. Campomanes afirmó en su momento que "la mujer tiene el mismo uso de razón que el hombre. Sólo el descuido que padecen en su enseñanza la diferencia, sin culpa de ella". ${ }^{191}$ Jovellanos por su parte recomendaba que se la incluya con prudencia a las Sociedades de Amigos del País.

La lista de subscritores, potenciales socios, rebasó al círculo estrictamente ilustrado, conteniendo miembros de la alta burocracia colonial como a grandes comerciantes, que de esta manera comenzaban a apartarse del modelo de letrado colonial. Y como dice Pilar González Bernaldo, aunque la proyectada Sociedad "no rompe con el principio de sociedad de castas, sus objetivos exceden a esta asociación favoreciendo la instauración de nuevos espacios públicos en otros ámbitos de sociabilidad". 192

El extremeño envió invitaciones a los colaboradores del periódico y a figuras destacadas de la capital virreinal para integrarse como socios numerarios de su anhelada Sociedad. ${ }^{193}$ En el mes de agosto elevó a la Corte los nombres de quienes ocuparían los cargos de ésta: director, él mismo; vicedirector, Martin José de Altolaguirre; censores, Julián de Leiva y Juan José Castelli, censores sustitutos, Francisco Bruno de Rivarola y José Icazate; secretario, Manuel Belgrano; secretario sustituto, José Manuel de

\footnotetext{
${ }^{191}$ Tomado de Sarrailh, Jean, óp. cit. p. 519.

${ }^{192}$ González Bernaldo, Pilar, "La Revolución Francesa y la emergencia de nuevas prácticas de la política: La irrupción de la sociabilidad política en el Río de la Plata (1810-1815)", Boletín del Instituto de Historia Argentina y Americana "Dr. E. Ravignani”, III serie, núm. 3, 1991, p. 12.

${ }^{193}$ En carta de respuesta de Miguel de Azcuénaga a la invitación, éste le indicaba las que consideraba personas idóneas para invitar a la Sociedad: Luis Chorroarín, Carlos Montero, Domingo de Azcuénaga, Juan J. de Araujo, Julián de Leiva, entre otros. "Re. de M. de Azcuénaga a F. Cabello", tomado de Martini, Mónica, óp. cit., p. 204.
} 
Lavardén; contador Melchor de Albín; tesorero Antonio José de Escalada. ${ }^{194}$ La Sociedad poseería un sello que la identifique y contaría con una Sociedad subalterna en cada capital de intendencia.

Hacia fines de noviembre de 1801, Cabello y Mesa se dirigió a la Junta del Consulado porteño dedicándole el periódico y pidiéndole protección para la Sociedad patriótico-literaria y económica que quiere fundar. El síndico del Consulado, Ventura Marco del Pont, se mostró partidario de la formación de la Sociedad, y recomendó la creación de una biblioteca económica, y la adjudicación de premios, tal como lo había dispuesto Carlos III para la Sociedad matritense. En virtud de tal informe, la Junta de Gobierno del Consulado decidió apoyar económicamente el proyecto y comisionar a su secretario Manuel Belgrano, para que junto con Cabello y Mesa, dispusieran de los estatutos que debían reglar la Sociedad. ${ }^{195}$ Era conocida la simpatía de Belgrano por estas instituciones. Unos años antes, el exponente principal del grupo ilustrado rioplatense, destacaba la importancia del establecimiento de las Sociedades en la península para el desarrollo material y espiritual de la nación. En la Memoria Consular del 14/06/1798 afirmaba:

[...] sabemos todos cuanto (el gobierno español) ha distinguido a esa multitud de cuerpos patrióticos, a las sociedades económicas, digo, que en tan poco tiempo se han erigido en la Península, donde se ofrecen y distribuyen premios y honores en tanta cantidad, que sin exageración podemos asegurar que no hay nación en la Europa que la iguale. Regístrense las gacetas de nuestra Corte, examínense los capítulos que tratan de la materia y se hallarán ingentes cantidades, invertidas en distinguir y premiar a cuantos se dediquen al trabajo, ya comunicando sus ideas por medio de memorias, ya ejecutando obras de industria, nuevas máquinas o mejorando las antiguas, ya cultivando la tierra, haciendo nuevos plantíos, etc. Ello es que desde el establecimiento de las sociedades económicas, nuestra nación ha tomado otro vigor en la metrópoli $[\ldots]$

Pero pareciera que la propuesta no gozó del favor de las autoridades peninsulares. La nota agregada por el fiscal del Consejo de Indias a la presentación de los estatutos plantea dudas: "la Sociedad Patriótica [dice] podría ser... de utilidad. Pero estando este pensamiento en embrión, se puede dudar si en un país en que no hay mucha aplicación,

\footnotetext{
${ }^{194}$ Nota de los oficiales para reglar la Sociedad Argentina..., 22/8/01, en Expedientes relativos a la fundación, pp. CCXIII-CCXVI, tomado de Martini, Mónica, óp. cit., p. 208.

${ }^{195}$ Estatutos..., en expedientes relativos a la fundación, pp. CCVI-CCXIII, citado en Martini, Mónica, óp. cit., pp. 201-202.
} 
se llevará a debido efecto". ${ }^{196}$ La Real Orden del 12 de abril de 1802 a pesar de aprobar la suscripción realizada por el Consulado al periódico, determina suspender "los demás auxilios que propone relativos a la sociedad económica que ha proyectado el mismo Cabello y Mesa". 197

No hay constancias definitivas que prueben la verdadera existencia de la Sociedad de Cabello y Mesa. Estamos más cercanos a considerar que nunca llegó a conformarse realmente o que hubo de tener una existencia precaria. Es sumamente probable que no llegara a organizarse más que como una tertulia informal de quienes colaboraban en el T.M. Y como advierte Martini, conociendo al personaje, llama la atención que en ningún momento alardee de haber instalado dicha Sociedad. ${ }^{198}$

Más allá de que el Semanario de Vieytes y Belgrano no dependiera de la existencia de una Sociedad que lo nutra y sostenga, se propuso desde sus páginas la creación de este tipo de experiencias, con el objetivo de apuntalar el desarrollo económico y social de la región. Desde un comienzo el periódico contó con un apoyo oficial más decidido, fundamentalmente de parte del Consulado, sumado a que el núcleo letrado que lo impulsaba, contaba ya con el enraizamiento local del que Cabello y Mesa carecía. En el primer número ya tenemos mención a la importancia que significaron las Sociedades Económicas para el desarrollo agrícola de las naciones del viejo mundo:

No ha habido nación alguna que no haya creído como incontrastable esta verdad. La agricultura es el nervio de un Estado. De aquí es que todas a porfiase han empeñado en hacerla florecer, animando al Labrador con premios y recompensas para alentarle en el trabajo, y erigiendo Sociedades que analizasen las operaciones más comunes de la labranza: ha llegado a unirse de este modo, la teórica a la práctica; se ha conseguido separar algún tanto al Labrador de aquella practica errada que seguía como derivada de sus Padres, y se han hecho progresos indecibles. ${ }^{199}$

En el número 51 encontramos un llamamiento explícito a constituir una Sociedad en el Río de la Plata, y en sintonía con el eje temático preponderante del periódico, se plantea la necesidad del establecimiento de una Sociedad de Agricultura:

\footnotetext{
${ }^{196}$ Nota del fiscal al proyecto de Estatutos..., 5/2/02, AGI, Buenos Aires, p. 587, citado en Martini, Mónica, óp. cit., pp. 201-202

197 "Real orden del 12 de abril de 1802...", Documentos para la historia del general don Manuel Belgrano, Tomo I, Instituto Belgraniano Central, Buenos Aires, 1982, p. 441.

${ }^{198}$ Martini, Mónica, óp. cit., p. 203.

${ }^{199}$ Semanario, núm. I, 1/9/02, pp. 2-3.
} 
Una asociación de hombres amantes de la patria, inflamados del deseo de contribuir con sus conocimientos al bien de sus conterráneos, he aquí el único resorte digno de tocarse, y que dará un perene impulso a nuestra inerte máquina. Esta es la senda que han seguido los pueblos ilustrados de la Europa para tocar la cima de una felicidad independiente. Nosotros debemos imitarlos, y aprovecharnos de la protección que nos dispensa un Monarca justo, celoso hasta el extremo de la felicidad de sus vasallos, y declarado protector de los establecimientos útiles. ¿Qué nos falta pues para poner en ejecución una obra que nos es absolutamente necesaria? Ninguna otra cosa que determinarnos a arrancar de los brazos de la irresolución a aquellos ciudadanos útiles que pueden ser interesantes a la patria por sus luces, y reunirlos en un punto desde el cual se comuniquen al común del pueblo los conocimientos más precisos para obrar con discernimiento y elección en los diversos objetos a que la naturaleza los destina. ${ }^{200}$

Igualmente, aunque la agricultura sea su materia principal, el autor del artículo considera que las Sociedades también deben atender las necesidades de los artesanos y la industria. $\mathrm{Y}$ en este punto llama la atención para que no se terminen convirtiendo en un foro de divagues teóricos y discusiones en el aire. Sostiene que los socios no:

[...] vayan a leer discursos académicos a sus juntas, sino a conferenciar llanamente sobre los ramos de apicultura e industria que se pueden promover, y los medios de verificarlo: óigase al inteligente y práctico más bien que al elocuente; prevalezca en las juntas el dictamen de los labradores; artesanos y economistas sabios sobre el de los que quieren que todo ceda a sus títulos y dignidades; foméntense industrias acomodadas a las circunstancias del país, al genio de sus naturales, y a las primeras materias que abunden: imprimase poco y muy escogido y meditado: no se repitan las sesiones sin necesidad: haya en ellas fraternidad y cordialidad. ${ }^{201}$

La ofensiva por parte del grupo ilustrado que se nucleaba alrededor del Semanario existió, aunque al igual que en el caso del proyecto de Cabello y Mesa, no se han encontrado registros fiables que certifiquen que la Sociedad se haya establecido realmente.

\section{Algunas hipótesis de los porqués de su fracaso}

¿Cuáles son entonces las razones para que no se haya constituido finalmente una Sociedad económica en el Río de la Plata? Entendemos que no hay sólo una causa

\footnotetext{
${ }^{200}$ Semanario, núm. LI, 7/9/03, pp. 4-5. La propuesta consiste básicamente en comprar algunas hectáreas de terreno fértil para poder llevar adelante experimentos agrícolas.

${ }^{201}$ Semanario, núm. LII, 14/9/03, p. 10.
} 
posible sino que se debió a diversos factores. En primer lugar podemos analizarlo desde una perspectiva más global. Principios del siglo XIX no pareciera ser la época de esplendor de estas iniciativas. Los estudios realizados sobre las Sociedades peninsulares muestran que después del entusiasmo inicial pareciera que tendieron a disminuir su actividad y que varias de ellas, salvo quizás las de mayor envergadura como la de Madrid, Valencia, Zaragoza o la Bascongada, entraron en un letargo permanente. Prueba de ello podría ser la circular del Rey del 14 de julio de 1786 donde se pedía investigar "la causa de lo poco que prosperan los Cuerpos patrióticos". ${ }^{202}$ A esta situación se le sumaron los cambios producidos en el gobierno español en 1790, como respuesta al proceso revolucionario francés y los temores a sus réplicas en la península. Fueron desplazados Campomanes, Cabarrús y Jovellanos de los Ministerios. ${ }^{203}$ El 24 de febrero de 1791, Floridablanca, primer secretario del gobierno y famoso por su intento de levantar un cordón sanitario ante la Revolución Francesa, suspendió todos los periódicos no oficiales. En ese contexto reaccionario, se les ordenó a las Sociedades de Amigos del País que cesen con las discusiones sobre economía política y que disminuyan sus actividades. ${ }^{204}$

La Guerra de las Naranjas - mayo y junio de 1801-, que tuvo como contendientes principales a España y Portugal, pero que ya expresaba el conflicto de fondo entre Francia e Inglaterra por el dominio europeo, tuvo sus repercusiones, y no menores, en los territorios americanos. En agosto de ese año Portugal ocupó las misiones orientales inaugurando un nuevo ciclo de hostilidades entre ambos imperios en las fronteras rioplatenses. Esta situación, sumada a la latente amenaza marítima inglesa, entendemos que podría haber incidido para que, tanto las autoridades metropolitanas como locales, privilegiaran iniciativas tendientes a fortalecer la capacidad militar antes que embarcarse en proyectos como los de las Sociedades económicas.

En el plano local podemos suponer que los sectores dominantes de la capital virreinal no estaban del todo entusiasmados con la idea de la conformación de la Sociedad. Ni la burocracia ni los comerciantes monopolistas, de origen principalmente peninsular, consideramos que vieran muy conveniente su instalación. Los primeros, porque más allá que los proyectos separatistas aún no eran una amenaza real, si

\footnotetext{
${ }^{202}$ Citado en Sarrailh, Jean, óp. cit., p. 272.

${ }^{203}$ Cabarrús es denunciado a la inquisición por su Elogio a Carlos III y es encarcelado en junio de ese año. Jovellanos es conminado a salir inmediatamente para Asturias a escribir un informe sobre el Estado de las minas de carbón, lo que se parece más a un "destierro político" que a otra cosa. Al año siguiente, es destituido Campomanes de su cargo de Gobernador del Consejo de Castilla.

${ }^{204}$ Herr, Richard, óp. cit., pp. 215-217.
} 
desconfiaban de un cuerpo que pudiera ser caldo de cultivo para cuestionamientos cada vez más profundo al status quo colonial. ${ }^{205}$ Los comerciantes monopolistas, por su lado, estaban demasiado cómodos con el lugar de privilegio que poseían en el sistema mercantil colonial como para incentivar y apoyar espacios donde solían elaborarse proyectos que a la postre no les interesaban, como el desarrollo manufacturero de la región, o peor aún, propuestas que atentaban contra sus intereses como lo era la del libre-comercio. ${ }^{206}$ Belgrano advierte sobre esta cuestión en su autobiografía al afirmar que la intención de la metrópoli era que las juntas de los Consulados americanos cumplieran funciones análogas a las Sociedades, reemplazándolas:

Cuando supe que tales cuerpos en sus juntas, no tenían otro objeto que suplir a las sociedades económicas, tratando de agricultura, industria y comercio, se abrió un vasto campo a mi imaginación, como que ignoraba el manejo de la España respecto a sus colonias, y sólo había oído el rumor sordo a los americanos de quejas disgustos, que atribuía yo a no haber conseguido sus pretensiones, y nunca a las intenciones perversas de los metropolitanos, que por sistema conservaban desde el tiempo de la conquista...no puedo decir bastante mi sorpresa cuando conocí a los hombres nombrados por el Rey para la junta que había de tratar la agricultura, industria y comercio, y propender a la felicidad de las provincias que componían el virreinato de Buenos Aires; todos eran comerciantes españoles; exceptuando uno que otro, nada sabían más que su comercio monopolista, a saber: comprar por cuatro para vender por ocho, con toda seguridad. ${ }^{207}$

Desde el punto de vista de la Corona, para Eugenia Molina, pudo ser justamente el hecho de que el Consulado porteño cumpliera ya las funciones que la Sociedad se proponía lo que llevo a desinteresarlos de la conformación de la entidad, y que aun cuando anunciase la voluntad de colocarse bajo su protección, podía crear recelos y fricciones corporativas. $^{208}$

Otros elementos a considerar para el caso de la Sociedad pensada alrededor de la experiencia del T.M., son la situación y características personales de su principal

\footnotetext{
${ }^{205}$ A fines del XVIII, Aranda le escribe preocupado a Floridablanca: "Me he llenado la cabeza de que la América meridional se nos irá de las manos", Citado en Sarrailh, Jean, óp. cit., p. 587. Lo que predominaba igualmente era la opinión del conde de Fernán-Núñez, embajador de Carlos IV ante la Corte de Versalles, que el estado de atraso de las poblaciones eliminaba tal peligro por mucho tiempo. (Vida de Carlos III) Una razón más para no ofrecerles herramientas para el progreso como eran las Sociedades.

${ }^{206}$ Un ejemplo de esta desidia es el caso de la Sociedad Económica de Cádiz, que no pudo establecerse sino hasta 1813, casi 50 años después que la Sociedad Bascongada, producto de la mezquindad de la poderosa burguesía mercantil gaditana.

${ }^{207}$ Belgrano, Manuel, "Autobiografía...", en Mitre, Bartolomé, Historia de Belgrano y de la Independencia Argentina, Buenos Aires. 1945, p. 430.

${ }^{208}$ Molina, E., óp. cit., p. 130.
} 
impulsor, que atentaron seguramente contra las posibilidades de su conformación. Y es que Cabello y Mesa, por su condición de recién llegado a la capital virreinal, carecía de los vínculos sociales y políticos que le dieran una plataforma desde donde erigir ese emprendimiento. Se trataba de un elemento externo sin el grado de enraizamiento local como para encolumnar a la elite letrada porteña. A pesar de ello, se las ingenió para contar en un comienzo con el apoyo del Consulado y la colaboración de algunos de los hombres destacados de la ilustración de la ciudad para llevar adelante el T.M. Es también posible considerar que algunas características de su personalidad no ayudaron a dotar de la estabilidad necesaria al proyecto de la Sociedad. De condición aventurera, su vida estuvo marcada por indescifrables cambios de rumbo y reposicionamientos, que demuestran en general la búsqueda de reconocimiento y prosperidad material, por encima de la coherencia a enrolamientos políticos y doctrinarios. Por otro lado, en sus artículos se puede reconocer una inclinación recurrente a la polémica y al conflicto, no exentos de la sátira y la sorna como recursos. La opinión corriente entre los estudiosos es que la clausura del T.M. ordenada por el virrey del Pino, se debió a un artículo titulado Política, Circunstancia en que se halla la provincia de Buenos-Aires e Islas Malvinas y modo de repararse, considerado como demasiado corrosiva su crítica a la sociedad porteña. ${ }^{209}$

En síntesis, ni el contexto general marcado por un repliegue de las políticas reformistas en el Imperio español post revolución francesa, ni las condiciones locales, con un élite política y económica reacia a cualquier "experimento" que alterara el preciado status quo colonial, sumado a las características de algunos de sus principales impulsores, permitieron que las Sociedades Económicas tuvieran en el Rio de la Plata la oportunidad de ir más allá de los papeles y echar raíces de manera definitiva.

\footnotetext{
${ }^{209}$ El 9 de julio la Real Audiencia pidió cuentas de su labor a Benito de la Mata Linares, primer censor del periódico, debido a las sátiras y polémicas subidas de tono y mandó a que se intime al editor. A continuación, comenzó a sufrir la quita de colaboraciones, como podemos apreciar en carta al Secretario de Estado con fecha del 10 de julio, donde se queja que los administradores de la aduana de Buenos Aires y Montevideo se niegan a comunicarles las noticias de entrada y salida de las embarcaciones. Y si el art. Política hubo de herir el amor propio de los vecinos del Puerto, el Retrato político moral del gobierno secular y eclesiástico, antiguo y moderno de la Sierra del Perú publicado el 15/10 hizo lo propio con los del clero. Ese mismo día el comisario del tribunal de la Inquisición dirigió una nota al virrey acusando de libelo infamatorio al T.M y la Junta del Consulado decidió en sesión levantar su suscripción "viendo mucho tiempo ha que no hace más que separarse de la verdadera intención de este Cuerpo". Documentos para la historia del general don Manuel Belgrano, Tomo I, Instituto Belgraniano Central, Buenos Aires, 1982, p. 442.
} 


\section{Consideraciones finales}

Aun con cierto rezago y una moderación mucho más acentuada, el iluminismo hizo impacto de manera indudable en el mundo hispánico. Con fuerzas poderosas enfrente como una clase nobiliaria conservadora, la Iglesia y su temible Inquisición, la minoría ilustrada se las ingenió para ofrecerles pelea, con el objetivo de encarrilar a España y su Imperio en la «corriente civilizadora» que ya transitaban el resto de las potencias europeas. Despojada de un nacionalismo estrecho, a fin de cuenta poco productivo, consciente de que ya había pasado el tiempo de la hegemonía sobre Europa, que España no era ya sino «el esqueleto de un gigante», se sumergió en las nuevas ideas que atravesaron el viejo continente.

América no fue ajena a este proceso, con España ocupando el rol de mediadora de los debates y planteos de la Ilustración europea. La presencia de los ilustrados españoles en las bibliotecas de los letrados y en los periódicos rioplatenses era una clara prueba de ello. Como ya dijimos, la Ilustración española corría con ventaja entre los americanos por ofrecer una versión de las reformas más atenta a las condiciones particulares de la monarquía hispana. Los planteos tanto de Jovellanos como de Campomanes, Foronda y otros ilustrados, partían de la necesidad de sacar a España y el conjunto del Imperio del atraso en el que se encontraba y recuperar la grandeza perdida. Misma preocupación compartida por las élites letradas americanas. Depositaron su fe al igual que los peninsulares en la mejora que traería aparejado el fomento de la educación pública y la instrucción técnica en la población. En definitiva, el intento de modernización, conflictiva en muchos casos, del espacio público de opinión bajo la lupa de los funcionarios de la Corona, con una burguesía débil -en algunos casos, prácticamente inexistente- que cumpliera el papel de clase dirigente de la modernización capitalista, tanto en la península como en América, se buscó que fuera el Estado borbónico el que se pusiera a la cabeza del proceso de trasformaciones sociales y económicas, en pos de recuperar el tiempo y el terreno perdidos. En el Rio de la Plata era necesario atajar el deslizamiento que se venía produciendo de manera continua hacia la monoproducción ganadera. Como bien marcara Tulio Halperín Donghi, los economistas ilustrados iban convenciéndose que el juego automático de las fuerzas económicas no aseguraba la realización de sus ideales políticos ni éticos. ${ }^{210}$ Futuros dirigentes revolucionarios como Belgrano, inicialmente confiaron en que el gobierno virreinal iba a tomar las medidas

\footnotetext{
${ }^{210}$ Halperín Donghi, T., Tradición...., p. 155.
} 
modernizadoras reclamadas, cosa que sucedió a cuentagotas y que a fin de cuentas no generó más que desencanto entre los ilustrados rioplatenses. Entendemos que aquí radica una de las razones, entre otras, que explican que en el marco de la crisis monárquica varios de ellos buscaran replantear los términos de la relación con la metrópoli. En un mundo que ven desmoronarse frente a sus ojos, se ven compelidos a interrogarse sobre sus funciones y sobre qué contribución podrían hacer a la constitución de un orden nuevo. Igualmente, principios de siglo no era tiempo aún de críticas directas por parte del grupo de «intelectuales» a las autoridades virreinales, ni tampoco al sistema colonial. Muchos de ellos formaban parte del gobierno, y la mayoría consideraba además que era posible perfeccionar el sistema «desde adentro», sin la necesidad de grandes sobresaltos. En su doble calidad de escritores-funcionarios, cumplieron una labor de propaganda de este ideario en particular, en algunos casos muy a tono con el conjunto de reformas administrativas. Si decíamos que en la península era difícil encontrar cuestionamientos de orden político o religioso por la censura o directamente porque no formaban parte del repertorio de los reformistas, en la prensa rioplatense esto fue aún más marcado. Lo «político» casi no tuvo lugar en los periódicos de principios del XIX, notoriamente menos que en la metrópoli. Hubo que esperar a la Gazeta de Buenos Aires, surgida al calor de la Revolución para poder identificar temáticas propiamente políticas. Lo que no significa que estos letrados no estuvieran en contacto ya con los lenguajes políticos que conmocionaban Europa.

Con respecto a la recepción de los debates económicos, tradicionalmente se consideró que los ilustrados rioplatenses abrevaban casi exclusivamente en el pensamiento fisiocrático o en el liberalismo smitheano. Los trabajos de Chiaramonte fueron pioneros al señalar la fuerte presencia de la «Escuela napolitana» en los debates locales, rompiendo por primera vez con esa imagen tradicional. Más recientemente, Pastore y Calvo han acertado al plantear que los argumentos agraristas tanto del Telégrafo o el Semanario no deben ser adjudicables a una axiomática filiación fisiocrática, sino más bien hay que entenderlos como justificaciones conceptuales utilizadas para resaltar el papel del agro en desarrollo local, teniendo en cuenta las innegables ventajas comparativas de la región. Esto demuestra el proceso selectivo y de adaptación realizado sobre el pensamiento económico europeo, y particularmente español, por parte de la élite letrada rioplatense para aplicarlo a la realidad local. La recepción del pensamiento europeo en un medio local periférico como el Río de la Plata, experimentó entonces un proceso de modificación conceptual, y lejos de haber 
sido una un simple copia o imitación, se produjo una «adopción correctiva de las ideas generadas en los centros de conocimiento de acuerdo a la percepción de las condiciones culturales y socioeconómicas que operan en el plano local». ${ }^{211}$ A partir del análisis que hemos realizado de los periódicos podemos constatar que con los fisiocráticos se compartiría la importancia de la agricultura en la generación de riqueza, pero no su exclusividad. Con el liberalismo económico, los tibios pero cada vez más recurrentes planteos a favor de la libre exportación de los frutos, aunque sería Foronda antes que Smith al que citarían para reforzar estos argumentos. De los reformistas peninsulares la convicción de que era el Estado el principal actor que debía intervenir sobre la realidad social para provocar o permitir las transformaciones necesarias en el camino de racionalización económica y social anhelada del imperio, incluidas aquellas que empezaban a colisionar con el sistema colonial, indiscutido por los metropolitanos.

La novel prensa rioplatense se constituyó entonces como la plataforma donde la incipiente élite letrada porteña vehiculizó los debates y problematizaciones sobre la realidad socioeconómica del virreinato, y las posibilidades y opciones para transformarla. Y a la par, como sucedía en otros lugares de la América española, los periódicos cumplieron un papel destacado en el proceso difusor que había encarado la Corona. Con el contexto cultural hispánico de trasfondo, se produjo la incorporación de ciertos contenidos generales de la ilustración europea, y en particular la peninsular, a través de una receptividad que era a la vez un claro proceso de adaptación reflexiva.

\footnotetext{
${ }^{211}$ Pastore, Rodolfo. «El pensamiento económico rioplatense y sus vínculos con el debate económico en la España ilustrada», en Actas del Encuentro «El libro en el protopaís», 2002, p. 13. Disponibles en: http://www.bibnal.edu.ar/protopais/mat/h10.htm
} 
SEGUNDA SECCIÓN

LAS ALTERNATIVAS A LA CRISIS 


\section{Capítulo 3:}

\section{La revolución hispánica}

\section{Temblores antes de la crisis total}

El 23 de abril de abril de 1805 el Virrey Sobremonte le escribió una "reservadísima" carta al oidor Juan Bazo y Berry con el fin de que se ocupe inmediatamente de investigar sobre la propagación de ciertos papeles que anunciaban "trastornos y variaciones en nuestro gobierno", intimándolo a proceder con el mayor disimulo para, de ser cierto, dar con sus autores. ${ }^{212}$ El disimulo consistía en que la investigación no debía llevarse por los canales formales, sino que debía prescindir de autos y citaciones judiciales, confiando Sobremonte en la sagacidad del oidor para ocuparse eficientemente de dicho asunto. El 18 de julio éste le escribió al virrey informándolo de los avances de la investigación. La existencia de los rumores parecía ser veraz pero la posibilidad de conocer a los artífices de su divulgación según Bazo era extremadamente remota. Sostenía que eran los cafés el lugar elegido para propagar esas ideas sediciosas, informándole que intimó a sus propietarios a no permitir que se den ese tipo de conversaciones y a denunciarlas en caso de que sucediesen. Junto al informe, Bazo adjuntaba un papel secuestrado donde, según él, se manifestaban las "malignas ideas que se han procurado buscado imprimir en el público". ${ }^{213}$ A partir de la reconstrucción que pudo hacer del recorrido, la primera persona que lo tuvo en sus manos, habría sido el catalán José Presas. Éste manifestó que lo había encontrado en uno de las sillas del café del Colegio y se lo había pasado inmediatamente a otra persona. El oidor aprovechó una denuncia por una malversación de fondos contra Presas para arrestarlo y ver si de esa manera podían incautar otros papeles que lo comprometieran, siendo finalmente infructuoso el intento. Consideraba igualmente que

\footnotetext{
212 "Carta reservadísima del marqués de Sobremonte al oidor Juan Bazo y Berry", 23 de abril de 1805, Biblioteca de Mayo, T. XI, p.10073.

213 "Oficio del oidor Juan Bazo y Berry al marqués Sobremonte", 18 de julio de 1805, Biblioteca de Mayo, T. XI, p.10077. El supuesto papel adjuntado al oficio que figura en la colección Biblioteca de Mayo como "Discurso a Cortes por el presidente de la Nación de marzo de 1805" está repleto de una terminología que remite mucho más al contexto posterior a la crisis monárquica y no a una fecha tan anterior como 1805. El lenguaje por momentos parece propio del primer liberalismo español, dándole uso a conceptos como "derechos" y "soberanía" en un registro que por lo menos se empezaría a utilizar a partir de la eclosión juntista de 1808 . Tendemos a creer que se trata de una equivocación a la hora de la confección de la colección de mayo, aunque no nos aventuraremos a una conclusión tan taxativa ya que entendemos que merece una investigación más profunda. Biblioteca de Mayo, T. XI, p.10076-77.
} 
sus acciones, aun no habiendo logrado identificar a los autores últimos del líbelo, si habían generado la suficiente aprensión como para calmar el desorden y silenciar a aquellos que estaban esparciendo los rumores.

Las preocupaciones del virrey dan cuenta de cierto clima de tensión experimentado por las autoridades coloniales por esos años. A pesar de la relativa tranquilidad que se vivía en el Rio de la Plata, los temblores que habían sacudido al mundo europeo y americano en el último cuarto de siglo seguían repercutiendo en la memoria de los actores, tanto de los que procuraban preservar el statu quo como en aquellos que ambicionaban trastocarlo. La rebelión andina seguía resonando en el inconsciente tanto de criollos y españoles, constituyendo un temor latente explicado por la sencilla razón de que los motivos que originaron el levantamiento indígena no se habían solucionado. Más cerca en el tiempo, otra revolución social, en este caso exitosa, ponía la alarma en la amenaza que una gran parte de la población americana, los esclavos negros, siguieran el ejemplo haitiano y despertaran de su letargo. Revolución que echaba raíces en aquella que había cambiado la historia occidental para siempre, propagando no sólo la imagen de una experiencia que contó con amplia participación popular y radicalidad en sus formas, sino un conjunto de ideas, valores y nociones políticas que impactaron con fuerza sobretodo en una generación de letrados -y no sólo letrados-, que se sintieron atraídos por las banderas de libertad, igualdad y fraternidad. Los ecos fueron enormes, no sólo el derrumbe del Antiguo Régimen, sino la posibilidad de que ello ocurriera en uno de los Estados absolutistas más grandes y potentes de Europa, como era el francés. Por otro lado, la independencia de las trece colonias inglesas al norte del continente, que había inaugurado el proceso revolucionario mundial, afectaba con su ejemplo directamente los fundamentos del vínculo que existía entre la metrópoli y los territorios americanos. Fue todo un precedente anticolonial de referencia para los criollos iberoamericanos. Y aunque no creemos que fuera considerado por estos como un modelo a seguir, en especial porque los sistemas de colonización británico e hispano distaban mucho entre si y las distancias culturales eran grandes, no quiere decir que las futuras revoluciones hispanoamericanas no tomarían buena cuenta del precedente. Las autoridades del Río de la Plata tenían entonces suficientes razones -sin que se registrasen aún ni grandes conspiraciones, ni hambrunas que provocasen convulsiones sociales- para estar alertas a fin de anticiparse y cortar de raíz cualquier principio de cuestionamiento al orden político. Con más razón en un 
escenario de fuertes conflictos interimperiales como los que se vivían a principios de siglo.

El intento de redefinición imperial que implicaron las reformas borbónicas se produjo en un momento poco auspicioso para España. La situación internacional había ido tornándose cada vez más compleja, al calor de acontecimientos que trastocaron tanto el mundo europeo como el americano. La guerra desatada entre las colonias inglesas y Gran Bretaña, al declarar las primeras su independencia, alineó a Francia y España-tradicionalmente aliadas en contra de Inglaterra- con los Estados Unidos. Entre 1796 y 1802, las guerras se generalizaron en toda Europa y sus efectos se hicieron sentir inmediatamente en sus dominios en América. La flota inglesa bloqueó el puerto de Cádiz y otros puertos hispanoamericanos, lo que afectó de manera sustancial las relaciones comerciales entre la metrópoli española y sus posesiones americanas. ${ }^{214}$ En 1801 Carlos IV había reafirmado la alianza con Francia mediante el Segundo Tratado de San Ildefonso, en el que se conjuraban para terminar con el poderío naval británico. El precio fue la entrega de la Luisiana a Napoleón. A cambio, el monarca español obtendría el Reino de Etruria enclavado en la península Itálica. Las consecuencias de este Tratado se revelarían inmediatamente: se conminó a cerrar al tráfico marítimo británico a los puertos lusos, en especial Oporto y Lisboa. La negativa de la corona portuguesa va a provocar la denominada "guerra de las Naranjas" entre ambas monarquías peninsulares. ${ }^{215}$

Todo se agravó para España cuando en octubre de 1805 su armada fue prácticamente destruida en la batalla de Trafalgar, por lo que Inglaterra logró el pleno control de los mares, provocando que fuera virtualmente imposible el tráfico entre España y América. Sólo dos meses después, se produjo el triunfo de Napoleón en la batalla de Austerlitz, afianzando el dominio francés en Europa y profundizando por lo tanto el bloqueo al acceso inglés a los puertos continentales. En ese marco la posibilidad de que Inglaterra atacase las colonias españolas era altamente probable. Lo que no significaba que la opción de una ocupación y anexión a los dominios británicos fuesen la única alternativa. Son conocidos los intentos de Francisco de Miranda de contar con el patrocinio y la colaboración directa de Gran Bretaña para sus planes independentistas,

\footnotetext{
${ }^{214}$ Ternavasio, M., óp. cit., p. 24.

${ }^{215}$ Chust Calero, M. (ed.), Las independencias iberoamericanas en su laberinto. Controversias, cuestiones, interpretaciones, Valencia, Universitat de Valencia, 2010, p 21.
} 
planes que habían encontrado oídos receptivos en algunos sectores de la cancillería inglesa.

\section{Las invasiones inglesas y el nuevo equilibrio en el Rio de la Plata}

Como señala Fabio Wasserman, los años inmediatamente anteriores a las invasiones inglesas en el Rio de la Plata se caracterizan, lamentablemente, por una escasez muy marcada de documentos producidos por las autoridades españolas o por grupos civiles que dieran cuenta de las articulaciones y movimientos tendientes a producir cambios en el vínculo con la metrópoli. También atenta contra la posibilidad de trazar un derrotero del accionar de esos grupos la cambiante situación política tanto local como internacional que se vivía por esos años, que llevó a ensayar muy diversas tentativas, haciendo infructuoso distinguir una línea de acción precisa y coherente a lo largo del tiempo. ${ }^{216}$

Aun así, algunos autores se han animado a definir la existencia de por lo menos dos grupos que promovían planes autonomista o en algunos casos directamente la ruptura del vínculo con España. Por un lado aquél que propiciaba la protección francesa y que, según algunos historiadores, tenía como referentes a Juan Martín de Pueyrredón y Santiago de Liniers. Y por el otro, el llamado "Partido de la Independencia", formado alrededor del núcleo constituido por Castelli, Belgrano, Vieytes y los hermanos Saturnino y Nicolás Rodríguez Peña, más proclive al apoyo inglés y que evidenciaba sus propósitos con el envío en 1803 de Mariano Castilla como agente a Londres y en 1804 con la recepción que le brindaron al coronel James Burke en Buenos Aires. ${ }^{217}$ Luego de pasar varios meses en la ciudad, el oficial partió a Chile y luego al Alto Perú, donde sus movimientos generaron sospecha y fue detenido. Tras ser enviado a Buenos Aires, logró que el propio virrey permitiera su salida, dirigiéndose a Rio de Janeiro. Pero el tiempo que estuvo en Buenos Aires no había sido desaprovechado, logró trabar vínculos con distintos grupos y se hizo una idea del estado de opinión sobre el rol que esperaban que pueda cumplir Inglaterra en relación con el futuro de la región. A pesar

\footnotetext{
${ }^{216}$ Wasserman, F., Castelli..., p. 51.

${ }^{217}$ Se sabe que Saturnino Rodríguez Peña participó en las prácticas masónicas introducidas por los ingleses junto a Aniceto Padilla. Unos años después, ya en el marco de la crisis monárquica, la existencia de estas dos tendencias va a ser denunciada por la Real Audiencia de Buenos Aires en una carta al gobierno español donde se advierte sobre "la división de opiniones de los vasallos de estas provincias, fascinados unos de las máximas corruptoras de la revolución fatal de Francia; inclinados otros a una delirante y desatinada independencia influida por los ingleses". Documentación relativa a los antecedentes de la Independencia de la República Argentina, F.F. y L., Buenos Aires, 1912, p. 66.
} 
de la falta de documentación, se puede conjeturar que en sus reuniones con Castelli y los hermanos Peña les ofreció apoyo para lograr la independencia a cambio de ventajas comerciales. ${ }^{218} \mathrm{El}$ agente inglés se contaba entre los que consideraban que una invasión por la fuerza sería contraproducente porque provocaría el fuerte rechazo de la población local, como efectivamente sucedió unos meses después, lo que lo llevó a escribirle a sus superiores molesto porque sus recomendaciones no habían sido tomadas en cuenta.

Con respecto al grupo de criollos podemos decir que su coincidencia en una serie de actividades por estos años da cuenta de lazos preexistentes que fueron construyéndose, en primera instancia, a partir la participación en los mismos espacios de socialización estudiantil y universitaria, lo que nos da la pauta también de que recibieron una formación ideológica relativamente homogénea. Como señala Eugenia Molina también debemos considerar las relaciones literarias que surgieron durante las experiencias editoriales de comienzos de siglo, las cuales posibilitaron cierta intimidad junto a la que debemos contar los intentos por brindar una solución a la situación en la que había colocado a la región la situación imperial desde 1804. Finalmente, tampoco se puede dejar de tener en cuenta los vínculos familiares y amistosos, reforzados por los provenientes de otros ámbitos, los cuales constituyeron la base de díadas posteriores. ${ }^{219}$

Cuando el 25 de junio de 1806 se produjo sorpresivamente el desembarco de las tropas inglesas en la costa de Quilmes, la falta de previsión permitió que sólo dos días después éstas estuvieran entrando con facilidad a la ciudad de Buenos aires. Si bien la creación del Virreinato del Río de la Plata había tenido como principal objetivo reforzar militarmente la región austral del imperio, dada la constante presión portuguesa sobre Río Grande y Colonia de Sacramento, la Corona no se había ocupado de que tal refuerzo fuera significativo en términos del envío de tropas regulares y de la organización de milicias regladas locales. El virrey Sobremonte huyó al enterarse del desembarco decidiendo organizar la resistencia desde el interior del virreinato. El general William Beresford, a cargo de las fuerzas de ocupación, se erigió como una suerte de gobernador y ofreció garantías de mantenimiento de la esclavitud, respeto a la propiedad y al ejercicio de la religión católica, además de decretar la libertad de comercio y de prometer una rebaja de impuestos. A las autoridades civiles y eclesiásticas les prometió su continuidad en tanto sus miembros jurasen lealtad al rey

\footnotetext{
${ }^{218}$ Wasserman, F., Castelli..., p. 53

${ }^{219}$ Molina, E., "Sociabilidad y redes político-intelectuales: Algunos casos entre 1800 y 1852 ", CILHA, a. 12 n. 14, Mendoza, 2011, pp. 21-22
} 
Jorge III, cosa que hizo la mayoría al igual que los principales vecinos. El acto de juramento realizado en el fuerte causó desconcierto e irritación entre muchos pobladores. La fidelidad al rey español seguía siendo un valor demasiado capital para los vasallos que habitaban el rincón más austral del Imperio como para aceptar repentinamente un cambio de esa naturaleza. Manuel Belgrano, que había participado como oficial improvisado en las escaramuzas antes de la entrada inglesa a la ciudad, se contó entre aquellos a los que les causó una fuerte indignación el juramento. Cuando el Consulado en su conjunto, del cual como sabemos era el secretario, reconoció el nuevo estado de cosas, Belgrano pidió licencia y se marchó a la Banda Oriental. Castelli, que era su suplente, tampoco participó del juramento y presentó su renuncia. El propio Belgrano rememoraba esos días:

Aquí recuerdo lo que me pasó con mi corporación consular, que protestaba a cada momento de su fidelidad al rey de España; y de mi relación inferirá el lector la proposición tantas veces asentada, de que el comerciante no conoce más patria, ni más rey, ni más religión que su interés propio [...] Como el Consulado, aunque se titulaba de Buenos Aires, lo era de todo el virreinato, manifesté al prior y cónsules, que debía yo salir con el archivo y sellos adonde estuviese el virrey, para establecerlo donde él y el comercio del virreinato resolviese: al mismo tiempo les expuse que de ningún modo convenía a la fidelidad de nuestros juramentos que la corporación reconociese otro monarca: habiendo adherido a mi opinión, fuimos a ver y a hablar al general, a quien manifesté mi solicitud y defirió a la resolución; entretanto, los demás individuos del Consulado, que llegaron a extender estas gestiones se reunieron y no pararon hasta desbaratar mis justas ideas y prestar el juramento de reconocimiento a la dominación británica, sin otra consideración que la de sus intereses. Me liberté de cometer, según mi modo de pensar, este atentado, y procuré salir de Buenos Aires casi como fugado; porque el general se había propuesto que yo prestase el juramento, habiendo repetido que luego que sanase lo fuera a ejecutar; y pasé a la banda septentrional del Río de la Plata, a vivir en la capilla de Mercedes. Allí supe, pocos días antes de hacerse la recuperación de Buenos Aires, el proyecto, y pensando ir a tener parte en ella, llegó a nosotros la noticia de haberse logrado con el éxito que es sabido. ${ }^{220}$

El proyecto al que se refiere Belgrano no era otro que las iniciativas encabezadas por algunos criollos y españoles atentos a que la indignación en la población ante la ocupación iba creciendo. Entre ellas se destacaban el cuerpo de húsares organizado por

\footnotetext{
${ }^{220}$ Belgrano, M. «Autobiografía...». En Mitre, B. (1945). Historia de Belgrano y de la Independencia Argentina. Buenos Aires.
} 
Juan Martín de Pueyrredón; las milicias acaudilladas y financiadas por Martín de Álzaga, un próspero comerciante de origen vasco y alcalde del cabildo porteño; y la determinación del capitán de navío Santiago de Liniers, un francés al servicio de la corona española, bajo cuyo liderazgo se terminaron alineando las fuerzas regulares e irregulares. Desde Montevideo, con la colaboración del gobernador Pascual Ruiz Huidobro y en coordinación con las fuerzas de Álzaga, se organizó y ejecutó la reconquista. Las tropas inglesas fueron derrotadas y el 12 de agosto firmaron su rendición en forma incondicional.

El triunfo de las fuerzas milicianas no escondió la indignación hacia la máxima autoridad virreinal, que aún permanecía en Córdoba, acusada de haber abandonado a su suerte a la ciudad capital. Ante el desprestigio de Sobremonte y el clima enrarecido que se vivía se decidió la convocatoria a un cabildo abierto, donde fueron invitados más de 100 vecinos de la ciudad, de los cuales solo unos pocos eran americanos, para determinar el rumbo inmediato a seguir tras la reconquista de la ciudad. En las afueras del Cabildo se congregó una muchedumbre exigiendo la renuncia de Sobremonte. Ante lo inédito de la situación, invocando como argumento la aclamación general del pueblo, se optó por tomar una decisión salomónica: delegar el mando político y militar de la plaza de Buenos Aires en el héroe de la reconquista, Santiago de Liniers y el político en la Audiencia, pero por su calidad de representante directo del monarca, los cabildantes no avanzaron en su destitución formal. Aun así se trataba de un cambio decisivo en la dinámica política y la sociedad rioplatense, abriéndose de esa manera una lógica de intervención política donde los actores locales iban a ir tomando cada vez mayor peso. La primera invasión inglesa dejaba como legado varias novedades. Era ante todo, una crisis de autoridad sin precedentes: no sólo había quedado al desnudo la incapacidad de las fuerzas militares españolas para defender sus posesiones, sino también el dudoso comportamiento de las autoridades coloniales, duramente cuestionado por gran parte de los vecinos y habitantes de la ciudad.

La amenaza externa en el virreinato no había finalizado y la realidad era que la situación seguía siendo crítica. La escuadra inglesa al mando de Popham mantenía bloqueado el Rio de la Plata y recibía refuerzos, como consecuencia del entusiasmo que había generado en Londres la ocupación y el aval que finalmente había otorgado la 
corona británica a la iniciativa. ${ }^{221}$ En febrero de 1807, tras haber ocupado la campaña de la Banda Oriental, las tropas inglesas tomaron Montevideo. La gravedad de la situación volvió a poner en foco a la figura de Sobremonte y su incapacidad para enfrentar la amenaza. Un nuevo Cabildo abierto fue convocado y a partir de la solicitud de Martín de Álzaga, con la movilización de sus milicianos, finalmente se determinó la suspensión y arresto del Virrey. El gobierno recayó en el regente de la Audiencia y el mando militar continuó en manos de Liniers.

En este contexto volvió a entrar en escena Saturnino Rodríguez Peña, que valiéndose de su condición de ayudante de Liniers propició la fuga de Beresford. En los últimos meses había mantenido contacto a pesar de su condición de prisionero, alcanzando supuestamente un acuerdo donde el general habría de interceder a favor del viejo plan de apoyo inglés a la intención independentista del grupo, evitando así una nueva y quizás más perdurable ocupación. ${ }^{222}$ Pero una vez hallado Beresford en Montevideo, fueron infructuosos sus oficios para impedir el ataque, que se concretó finalmente el 28 de junio de 1807 con el desembarco en la Ensenada de Barragán de una gran cantidad de tropas bajo el mando del general John Whitelocke. Por su parte Rodríguez Peña terminó recalando en Rio de Janeiro donde, como veremos más adelante, continuaría alentando sus planes independentistas.

Mientras la invasión se preparaba llegó a Buenos Aires una Real Orden desde España donde se nombraba a Pascual Ruiz Huidobro como nuevo virrey del Rio de la Plata, pero al estar éste preso en Inglaterra tras la toma de Montevideo, Liniers asumió interinamente el cargo por ser el oficial de mayor rango, validando así su liderazgo de facto. Su estrategia consistió en esperar al ejercitó inglés en las afueras de la ciudad, pero fue derrotado el 1 de Julio y las tropas se dispersaron. Whitelocke cometió un grave error al intimar a la ciudad a rendirse en lugar de tomarla de inmediato, lo que permitió a Álzaga reorganizar las fuerzas locales y preparar la resistencia levantando barricadas y animando a los vecinos a participar desde sus casas para frenar el avance de las tropas inglesas. Prácticamente toda la población se levantó en armas y heroicamente ofreció un durísimo combate a las fuerzas invasoras que tras varios días de encarnizados enfrentamientos y tras haber sufrido numerosas bajas decidió

\footnotetext{
${ }^{221}$ La primera invasión que había llevado a la flota de Pophan y Beresford desde el Cabo de Buena Esperanza hasta el puerto de Buenos Aires en 1806- respondió a la propia iniciativa de los oficiales y no había contado con la autorización del gobierno británico .

${ }_{222}$ Entre los que fueron procesados por infidencia hacia los ingleses durante la ocupación se encontraba Francisco Cabello y Mesa, el polémico editor del Telégrafo mercantil.
} 
finalmente la capitulación. Fueron obligados también a evacuar la Banda Oriental, quedando Inglaterra sin ningún punto de apoyo en el Rio de La Plata. Tras el estrepitoso fracaso el Foreing Office comenzó a considerar nuevamente la alternativa de apoyar la independencia de las colonias para asegurarse sus mercados, y sobre esa posibilidad volvieron a orbitar algunos de los rioplatenses ya mencionados.

Pero lo más significativo es que el doble rechazo a las incursiones inglesas trastocó para siempre la realidad política rioplatense. La población había demostrado una fuerte lealtad hacia España y su monarquía, pero sus funcionarios coloniales no hacían otra cosa que desprestigiarse. En los meses que mediaron entre la primera y la segunda invasión inglesa, las precarias fuerzas voluntarias creadas por Liniers se hicieron más numerosas y organizadas. Sobre la base de un servicio y entrenamiento militar para todos los vecinos mayores de 16 años se crearon milicias que superaron los 8.000 miembros - la mayoría de origen criollo, en una ciudad que recién sobrepasaba los 40.000 habitantes - y que lograron suplantar la falta casi total de un ejército veterano capaz de defender los dominios de España. ${ }^{223}$ La emergencia de fuerzas locales en el curso de la resistencia y la expulsión del invasor había trastocado el equilibrio de fuerzas preexistente. Tal como ha destacado Tulio Halperín Donghi, el papel que asumieron las milicias fue crucial en el conflictivo escenario que dejaban por herencia las dos expediciones británicas. Erigidas en un nuevo factor de poder, esas milicias intervendrían en las querellas que se estaban desencadenando entre las autoridades coloniales. Los jefes de estas milicias, elegidos en aquellos años por la misma tropa, competían ahora con los grupos más encumbrados, funcionarios de alta jerarquía y grandes comerciantes, por prestigio y poder. Como señala Marcela Ternavasio, la popularidad de la que gozaban los protagonistas de la reconquista de la capital del Virreinato parecía no tener rivales. ${ }^{224}$

Asimismo, el triunfo militar contribuyó a la condensación de un fuerte sentimiento de orgullo local, cuya medida la da el acuerdo del Ayuntamiento de encargar una historia de aquellos sucesos. Justamente, el cabildo, dominado por su alcalde Álzaga, se había visto consolidado por su destacado papel en la defensa de la ciudad frente a la segunda invasión británica y por el consuetudinario rol que tenía de «representante» de la ciudad. De hecho, se trataba de la institución más antigua y

\footnotetext{
${ }^{223}$ Goldman, N., Ternavasio, M., "La vida política" en Jorge Gelman (dir.), Argentina: Crisis imperial e independencia, Taurus-Fundación Mapfre, Lima, 2010, p.50.

${ }^{224}$ Ternavasio, M., óp. cit., p. 37.
} 
arraigada de la capital virreinal, convertida al calor de los acontecimientos en el vehículo de las peticiones que culminaron con la destitución de Sobremonte. ${ }^{225}$ Tomando nuevamente las palabras de Ternavasio, esta medida inédita había abierto sin duda,

[...] una grieta vertical en el orden colonial rioplatense. No sólo porque hirió de muerte el prestigio de la máxima autoridad, sino porque privó al Virreinato, erigido hacía apenas treinta años, del primer eslabón sobre el cual se fundaba la relación de obediencia y mando en América, y en una coyuntura muy particular a nivel internacional. Tal acefalía creó a nivel local un marco de incertidumbre jurídica que dejó a la región en una situación de provisionalidad política y dio lugar a la emergencia de cierto margen de autonomía por parte de las autoridades coloniales respecto de la metrópoli. ${ }^{226}$

Siguiendo con esa perspectiva, para la historiadora las invasiones inglesas fueron el epílogo del plan reformista borbónico en el Rio de la Plata. Los orígenes marciales del virreinato quedaron en entredicho cuando todo el complejo administrativo y militar falló en ocasión de la primera expedición británica. La crisis institucional no cuestionaba aún la lealtad monárquica pero si el tipo de vínculo que las reformas habían querido crear. ${ }^{227}$ Manuel Moreno analizaría cuales eran las nuevas condiciones sobre las que se asentaban las relaciones con la metrópoli después de las invasiones inglesas:

La fidelidad de aquel pueblo, llevada en repetidos actos hasta cierto grado de fanatismo; sus costumbres, sus relaciones, hacían quimérico cualquier aspecto de mutación formal, y aun la reforma de abusos... Se había acabado la docilidad absoluta al régimen antiguo; mas todavía los límites de una separación completa estaban muy remotos... En una palabra: Buenos Aires, después de sus victorias, no podía continuar en ser el teatro del capricho de la metrópoli, pero debía ser siempre una parte del Imperio español. ${ }^{228}$

En esta precaria situación se encontraba el virreinato cuando se produjo el avance napoleónico sobre la península Ibérica y se abría la profunda crisis de la monarquía que cambiaría para siempre el mundo hispánico.

\footnotetext{
${ }^{225}$ Goldman, N.; Ternavasio, M.; óp. cit., p.50.

226 Ternavasio, M., óp. cit., p. 38.

227 Ídem.

${ }^{228}$ Moreno, Manuel, Vida y memorias del Dr. Mariano Moreno, ed. La Cultura Popular, Buenos Aires, p. 129.
} 


\section{La invasión napoleónica, las abdicaciones de Bayona y el comienzo de la crisis revolucionaria hispánica}

En 1807 el panorama político-militar en el continente europeo se traducía en la derrota de la mayoría de las dinastías absolutistas que habían sido sustituidas por la dinastía Bonaparte u obligadas a pertenecer a un sistema de alianzas con Francia. En ese marco, la mirada napoleónica volvió a fijarse hacia el único enemigo de los franceses en suelo europeo y aliado secular de los británicos: la monarquía portuguesa. Como señala Manuel Chust, para Carlos IV y Manuel Godoy había llegado el momento de devolver el golpe recibido en Trafalgar y en Buenos Aires con la ocupación de Portugal. Poco importaba que en anteriores pactos de familia se hubiera casado a la hija de los reyes españoles Carlota Joaquina con el rey de Portugal, Juan VI de Braganza. Éstas eran las circunstanciasen las que se va a establecer un tratado secreto entre Manuel Godoy, Carlos IV y Napoleón, firmado el 27 de octubre de 1807en Fontainebleau. ${ }^{229}$

El ejército francés atravesó rápidamente la península pero al llegar a Lisboa, su comandante, el mariscal Phillipe Junot pudo ver como la familia real portuguesa había dejado la ciudad embarcada rumbo a Rio de Janeiro junto con su corte y escoltada por la flota británica. El objetivo de la maniobra quedaba incompleto pero la lección sería aprendida para los sucesos de los próximos meses. El general Joaquín Murat, cuñado de Napoleón, se instaló en Madrid a principios de marzo de 1808 y con él ingresaron decenas de miles de soldados franceses que ocupan las principales ciudades y plazas españolas. La ocupación ya estaba en marcha. Alarmado, Manuel Godoy convenció a la pareja real de trasladarse hacia Nueva España, intuyendo que Napoleón había decidido ya trasmutar la alianza en un nuevo trofeo para sus ya colmadas vitrinas. En el camino hacia Cádiz, en Aranjuez, la traición fue otra, la del Príncipe de Asturias, Fernando, quien obligó a su padre a abdicar en él tras orquestar un motín popular en esa población contra Manuel Godoy, siendo proclamado rey el 19 de marzo de $1808 .{ }^{230}$

\footnotetext{
${ }^{229}$ Como refiere Chust "El tratado preveía el reparto de Portugal en tres zonas: el norte para el rey de Etruria, el centro para Napoleón — que incluía el puerto de Lisboa - y el sur para Manuel Godoy; la autorización de la entrada de tropas francesas en territorio español con el objetivo conjunto de invadir Portugal; el reconocimiento de Napoleón a Carlos IV como emperador de las Américas —quizá una de las claves del tratado- y el reparto de las colonias portuguesas, ni más ni menos que Brasil, tras el fin de la guerra contra Portugal. Ésta fue una de las claves de la invasión. Por supuesto que el objetivo central era ocupar los puertos lusos aliados de los británicos, pero sobre todo sustituir la familia real portuguesa por la bonapartista, establecer la nueva legitimidad monárquica, y por ella exigir la lealtad de los súbditos portugueses en Brasil. Una rica, productiva y gran colonia apetecible por la corona española y el Estado napoleónico". Chust, M., óp. cit., pp.23-24
}

${ }^{230}$ Ibid., p. 24 
El 20 de abril de 1808 Fernando VII llegaba a Bayona en busca del respaldo de Napoleón a su proclamación como rey, y diez días después lo haría su padre Carlos IV. El 2 de mayo, salía el resto de la familia real de la corte bajo las presiones de Joaquín Murat, mientras que los rumores de "secuestro" se iban expandiendo por la capital madrileña. Durante los primeros días del mes de mayo se produjo la secuencia de acontecimientos conocida como las "abdicaciones de Bayona". Fernando fue obligado a retornarle el trono a su padre, quien a su vez lo entregó a Napoleón y poco después éste coronaría a su hermano José Bonaparte como rey de "España y de las Indias" en un decreto fechado el 6 de junio. El dos de mayo madrileño quedó en la historia como el comienzo de la rebelión contra los planes bonapartistas y el inicio de la Guerra de Independencia española. La dura represión de Murat se hizo sentir sofocando la insurrección en la ciudad, quedando como fieles retratos de esas jornadas los cuadros de Goya. Pero la pólvora imperial no alcanzó para sofocar el estallido y la rebelión comenzó a recorrer toda la península. España se vio sumida en un sinfín de motines, revueltas, levantamientos y rebeliones que tenían a los franceses como objetivo. Se formaron juntas en las principales ciudades decididas a expulsar al francés y devolver al trono al rey cautivo, pero también se percibía en la revuelta popular la furia contenida después de tantos años de opresión absolutista. Son asesinados cuatro capitanes generales, varios gobernadores, corregidores y otras autoridades representativas del régimen absolutista. En el campo se asaltan casas de la nobleza, la cual huye a las ciudades, e incluso a la corte del rey francés en busca de protección. ${ }^{231}$ Analizando la revolución española Marx y Engels dirían al respecto: "Todas las guerras por la independencia dirigidas contra Francia llevan simultáneamente en sí la impronta de la regeneración mezclada con la de la reacción; pero en ninguna otra parte se presenta el fenómeno con la intensidad con que lo hace en España". 232

Las abdicaciones de Bayona y el levantamiento madrileño del 2 de abril, con sus repercusiones inmediatas en toda la península, desataron una profunda crisis de la monarquía española y con ella de todo el Antiguo Régimen. Fueron sus instituciones las que se resquebrajaron, altamente cuestionadas, y el nuevo poder que fue surgiendo sobre sus escombros lo hizo en parte a partir de una nueva legitimidad de carácter popular nacida de la sublevación que estalló en toda la península. ${ }^{233} \mathrm{Y}$ aunque las Juntas

\footnotetext{
${ }^{231}$ Ibid., pp. 25-26.

${ }^{232}$ Marx, Karl; Engels, Friedrich, Revolución en España, Barcelona, Ed. Ariel, pp. 90-91.

${ }^{233}$ Artola, Miguel, Los orígenes de la España contemporánea, IEP, Madrid, 1959, p. 103.
} 
surgidas al calor del levantamiento popular fueron rápidamente controladas por las élites locales, cancelando la posibilidad de una revolución más profunda, como sugirieron tanto el sevillano Blanco White como Marx unas décadas después, la realidad era que una amplia porción de la sociedad española presentaba importantes contradicciones con la estructura estamental del antiguo régimen. ${ }^{234}$ Como señalara Artola: "El campesino aspiraba a la propiedad libre de la tierra, el industrial a la libertad de trabajo, el comerciante a la del comercio, el funcionario a la racionalización de la administración, el jurista a la unificación legal y los representantes de las profesiones liberales a una concepción racional de la sociedad." ${ }^{235}$

Ese proceso de cambios profundos, lejos de limitarse al espacio peninsular, atravesó el conjunto del imperio español, estremeciéndolo de tal manera que significó el comienzo de su desintegración. Hablamos entonces de una revolución hispánica, como bien lo señalaba F. X. Guerra, donde la ruptura con el antiguo régimen y la emancipación americana formaron parte de un mismo proceso dialécticamente imbricado, donde la palabra, lo escrito, jugó un rol determinante. ${ }^{236}$ En ese contexto fue que pasaron a primer plano una serie de individuos que hasta ese momento actuaban clandestinamente, detectando la oportunidad de salir a la luz y batallar por sus ideas al calor del levantamiento nacional: los liberales españoles.

\section{Orígenes del liberalismo peninsular}

Como vimos en capítulos anteriores, hacia finales del siglo XVIII había comenzado a emerger una cultura política, aunque todavía subterránea en su manifestación, que apuntaba con claridad a una reforma profunda de la monarquía. La ilustración española iba incorporando y asimilando a su propio código cultural las innovaciones que el pensamiento político europeo estaba experimentando. Clandestinamente, simpatizando con las nuevas ideas que la revolución francesa había esparcido con la fuerza de una erupción, se fue configurando en la península un grupo de tendencia liberal que sin llegar todavía a ser un partido, iban compartiendo un similar cuerpo doctrinario e ideológico, objetivos comunes y una red de relaciones entre sus integrantes. Muy críticos del despotismo de Godoy, fueron las tertulias, los cafés y las reuniones clandestinas los lugares donde se afianzaron los lazos, convirtiéndose en

\footnotetext{
${ }^{234}$ Marx, K.; Engels, F., óp. cit., pp. 92-94.

${ }^{235}$ Artola, M., óp. cit., p. 53.

${ }^{236}$ Guerra, François-Xavier, Modernidad e independencias, Mapfre, Madrid, 1992, p. 12.
} 
verdaderos catalizadores políticos. ${ }^{237}$ En su mayoría los integrantes de estos grupos eran literatos, clérigos, juristas y funcionarios, quienes se articularon en las principales ciudades españolas como Madrid, Sevilla y Cádiz. ${ }^{238}$ En 1803 se fundó el Correo de Sevilla después de diez años que no se publicaba ningún periódico en la ciudad; vinculado a la Sociedad Económica sevillana, que tenía como socios a figuras que serían claves durante la crisis, como Alberto Lista y José María Blanco White. ${ }^{239}$ En Cádiz tuvieron mucha relevancia los cafés como espacios de sociabilidad política, entre los que se destacaban "La Estrella", "La Perla Gaditana" y "El Café de Cádiz". Una de las tertulias más famosa la constituyó la llamada "Fonda de San Sebastián", que funcionaba desde 1775 pero que a principio del XIX se había ido politizando en rechazo al gobierno de Godoy. Otra significativa era la tertulia de Salamanca que desde 1799 y bajo la égida del catedrático Ramón de Salas reunía a estudiantes simpatizantes de las nuevas ideas y era usina de panfletos y manifiestos que luego circulaban por toda la península. $^{240}$

Pero es alrededor de la figura de Manuel Quintana que se nucleó el sector más dinámico del incipiente liberalismo peninsular. Protagonista de primer orden de la revolución, Manuel José Quintana es considerado por algunos autores como el creador del periodismo político en España. Previamente a la crisis de 1808, aglutinó a su alrededor a un amplio espectro progresista, convirtiéndose en el orientador de su ala más radical. En las tertulias organizadas en su casa reunió a los hombres más importantes del liberalismo peninsular como Gallego, Tapia, Alcalá Galiano, Martínez de la Rosa, entre otros. Claro ejemplo del letrado comprometido con una causa política, desde sus artículos, el teatro y la poesía, batalló por las transformaciones revolucionarias en su patria a través de un nuevo lenguaje de intervención. ${ }^{241}$ Según María Esther Martínez Quinteiro “existen indicios suficientes como para asegurar que el pensamiento político liberal está ya configurado aquí antes de producirse la invasión napoleónica, y parcialmente expresado en las poesías del grupo quintaneano y, sobre todo del mismo Quintana". ${ }^{242}$ Aunque no compartimos completamente una afirmación

\footnotetext{
${ }^{237}$ Martínez Quinteiro, María Esther, Los grupos liberales antes de las Cortes de Cádiz, Narcea, Madrid, 1977, pp.15-17.

${ }^{238}$ Ibid., p. 64.

${ }^{239}$ Moreno Alonso, Manuel, La generación española de 1808, Madrid, Alianza Editorial, Alianza Universidad, 1989, p. 37.

${ }^{240}$ Martínez Quinteiro, M. E., óp. cit., pp. 19-20.

${ }^{241}$ Dérozier, Albert, Manuel José Quintana y el nacimiento del liberalismo en España, Ed. Turner, Madrid, 1978, p. 24.

${ }^{242}$ Martínez Quinteiro, M. E., óp. cit., p. 25.
} 
tan tajante, si podemos decir que algunos de los rasgos definitorios del primer liberalismo peninsular ya circulaban entre los integrantes del grupo. Pero como señala Javier Fernández Sebastián, el liberalismo en su etapa formativa, lejos ser una noción estable y definida fue una constelación variable de conceptos vagos y titubeantes. ${ }^{243}$

A partir del levantamiento de 1808, dicho grupo de entusiastas letrados-los "amigos de la libertad" como les gustaba llamarse a sí mismo-, pasaría a actuar decididamente de forma pública, convencido de aprovechar la coyuntura para llevar adelante su programa. ${ }^{244}$ Era imperioso ponerse a la cabeza de ese pueblo en armas. Los puntos fundamentales de ese programa fueron la soberanía nacional -que encontraba su base fáctica en el protagonismo del pueblo en la sublevación-, el estado de derecho, la igualdad jurídica y la representación popular. Para ello se lanzaron de lleno a construir una opinión pública favorable a estas aspiraciones, a través fundamentalmente de la prensa y los manifiestos. Como señalara Guerra:

[...] lo radicalmente nuevo es la creación de una escena pública cuando este nuevo sistema de referencias deja a los círculos privados en los que hasta entonces había estado recluido, para irrumpir en plena luz. Triunfa entonces una nueva legitimidad - la de la nación o la del pueblo soberanos-, una nueva política con actores de una clase nueva que, por primera vez pueden ser llamados políticos, en tanto que se constituyen precisamente para conquistar esa nueva legitimidad. ${ }^{245}$

Aquel primer liberalismo se distinguió sobre todo por su frontal rechazo al despotismo y la arbitrariedad, unido a una apasionada afirmación, como dice Fernández Sebastián, del valor de la libertad en política. ${ }^{246}$ Tempranamente los liberales se propusieron establecer una Constitución basada en la separación de poderes, que garantizase la igualdad ante la ley y ciertos derechos básicos como la seguridad, la

\footnotetext{
${ }^{243}$ Fernández Sebastián, Javier (coord.), La aurora de la libertad. Los primeros liberalismos en el mundo hispánico, Madrid, Marcial Pons, 2012, p. 14.

${ }^{244}$ En sus «Memorias», Quintana escribía en ese sentido «El partido, pues, que yo tomé desde luego irrevocablemente fue el de contribuir con todos los medios que estuviesen a mi alcance para libertar a mi patria de la tiranía de Bonaparte y de toda especie de tiranía. Así se lo dije a Antillón, manifestándole que era llegada la época de corregir los males políticos de España».

${ }^{245}$ Guerra, François-Xavier, óp. cit., p.13. En similar sentido, Richard Hocquellet aporta la siguiente reflexión sobre la proliferación de periódicos políticos en estos años: "Las ideas expuestas no son nuevas en sí, formaban parte de las discutidas durante las reuniones de las élites ilustradas, en tertulias o en las sociedades económicas de los amigos del país. En 1808, salen de estos círculos reducidos para tener un alcance más grande tal como lo permite la publicación.” Hocquellet, Richard, «La aparición de la opinión pública en España: una práctica fundamental para la construcción del primer liberalismo (1808-1810)», Historia Contemporánea. 2003 (II), nº 27, pp. 615-629.

${ }^{246}$ Fernández Sebastián, Javier, óp. cit., p. 263.
} 
libertad de expresión y la propiedad. Los más radicales solían apelar al pueblo y a la nación como fuente última de legitimidad política. ${ }^{247}$ En palabras de Roberto Breña:

[...]el primer liberalismo español constituyó una amalgama de doctrinas y normas políticas que, al socaire de la invasión napoleónica, fueron planteadas, debatidas, recuperadas $\mathrm{y} / \mathrm{o}$ repensadas por un reducido grupo de eclesiásticos, abogados $\mathrm{y}$ funcionarios que, decididos a terminar con el marasmo político-institucional que había caracterizado a la última etapa del reinado de Carlos IV, elaboraron e iniciaron la puesta en práctica (con las enormes limitaciones que la precaria situación del momento imponía) de una serie de disposiciones jurídicas que significaban una transformación radical de la política y de la sociedad españolas. ${ }^{248}$

Desde el enfoque de la Historia Conceptual, tomando nuevamente las definiciones de Fernández Sebastián, el liberalismo de esos primeros años se puede entender como "un macro concepto de perfiles difusos, progresivamente definido y esgrimido tanto por adversarios como por partidarios; un concepto polémico y disputado, construido y reconstruido por los agentes a través de su acción y de sus prácticas". ${ }^{249}$

Aunque originado en la península -los primeros liberales fueron españoles, al igual que las expresiones "partido liberal" y "liberalismo" se usaron primero en castellano-, en su mismo proceso formativo, sobre la base de una cultura católica, ilustrada y cosmopolita, irá adquiriendo una naturaleza atlántica. Muchos de los miembros de las elites políticas e intelectuales del mundo iberoamericano fueron grandes viajeros e incluso vivieron períodos prolongados en París, Londres, Madrid o Filadelfia. Los infortunios y las experiencias compartidas crearon entre ellos fuertes lazos de solidaridad, e incluso la conciencia de pertenecer a un movimiento común. Así se explica también el "liberalismo trasatlántico" de muchos de ellos. ${ }^{250}$

\section{Impresión y reimpresión de proclamas, manifiestos y periódicos en Buenos Aires (1808-1809)}

Cuando hablábamos de una fuerte imbricación entre el proceso en España y América, no sólo hacíamos referencia a la circulación de proclamas y manifiestos peninsulares en América, que llegaban regularmente en los barcos y, en muchos casos,

\footnotetext{
${ }^{247}$ Ibid., pp. 271-272.

${ }^{248}$ Breña, Roberto, «El primer liberalismo español y la emancipación de América: tradición y reforma», Revista de Estudios Políticos (Nueva Época) N 121. Julio-Septiembre 2003, pp. 257-289.

${ }^{249}$ Fernández Sebastián, Javier, óp. cit., p.14.

${ }^{250}$ Ibid., p. 15.
} 
rápidamente eran reimpresos en las pocas imprentas desperdigadas en las capitales virreinales, sino que lo publicado originalmente a ambos lados del Atlántico eran de una marcada semejanza entre sí tanto en su lenguaje como en sus temas y en los valores de referencia a los que remitían. La teoría política contenida en esos escritos, procedentes en su mayoría de España, y difundidos vigorosamente en América, explica la conformación de una conciencia pública y una movilización de voluntades en la línea de tensión que la hora marcaba. Como ya se ha dicho muchas veces, el conjunto del mundo hispánico reaccionó inicialmente ante la crisis dinástica y el enemigo exterior como una comunidad extraordinariamente homogénea. ${ }^{251}$ Como bien sugiere Guerra, una lectura incluso superficial de las fuentes de estos convulsionados años muestra el lugar central que ocupaban entonces los problemas generales. Sin lugar a dudas lo que preocupaba ante todo a los americanos era, por ejemplo, la lucha contra Napoleón, la constitución de la Junta Central en España, la reforma del sistema político, etc. ${ }^{252}$ Y como planteara a su vez Demetrio Ramos el contenido de estos escritos no se trataba de "enunciados de un gabinete de estudio, en frío y sin riesgos, como serían las conclusiones de unos juristas, por pura especulación intelectual. Parece más lógico comprender su redescubrimiento [y reelaboración, agregamos nosotros], sobre el peso de la formación jurídica antigua, a través de esta entrega doctrinaria, que les llega al mismo tiempo que la noticia de los sucesos". 253

En agosto de 1808 llegaron a Buenos Aires, llevadas por un enviado napoleónico, el Marqués de Sassena y, las novedades del cambio de dinastía. Pero previamente, a fines de julio, se habían recibido las noticias de la asunción al trono por Fernando VII. El virrey Santiago de Liniers, y el Cabildo, decidieron entonces organizar la acostumbrada ceremonia de juramento de lealtad al nuevo monarca, fijando la fecha del 30 de agosto. La posterior llegada del emisario francés añadió a esa decisión un nuevo sentido, el de reafirmar la adhesión al monarca legítimo y de repudiar lo ocurrido en Bayona, por lo que se decidió adelantar la fecha del juramento al día 21. Al igual que lo que sucedía en el resto de América, alejada físicamente de la guerra, las manifestaciones públicas fueron particularmente fastuosas. En ellas se reafirmaban de una manera solemne, sancionada por el carácter sagrado del juramento, el rechazo del poder arbitrario, la legitimidad del monarca y el compromiso de defenderlo. Pero también era

\footnotetext{
${ }^{251}$ Guerra, François-Xavier, óp. cit., p. 119.

${ }^{252}$ Ibid., p. 116.

${ }^{253}$ Ramos, D., "Formación de las ideas políticas que operan en el movimiento de mayo de Buenos Aires en 1810", Revista de estudios políticos, Vol. 134, Madrid: Inst. de Studios Políticos, 1964, p. 172.
} 
una manera de reformular el pacto que unía indisolublemente no sólo la nación al soberano, sino a cada uno de los vasallos entre sí. ${ }^{254}$

Las primeras proclamas y manifiestos que tanto la Junta de Sevilla -llegadas al Rio de la Plata por intermedio de su comisionado plenipotenciario José Manuel de Goyeneche- como otras juntas provinciales pusieron en circulación estuvieron destinadas a explicar las razones de su erección, a la condena total a los planes de Napoleón en la península, además de un llamamiento al pueblo español a rechazar la invasión por medio de las armas. ${ }^{255}$ La mayoría de estos escritos comenzaban con un raconto histórico de los últimos años, donde se contaba como el Emperador de Francia había logrado, a partir del engaño y la complicidad de Godoy, imponerse sobre la monarquía española, ocupando la península y obligando a los Borbones a abdicar por medio de la fuerza. Se decía también que el rechazo que estas ilegitimas acciones causó en el pueblo español, destacado en todas las proclamas como la principal reserva moral de la monarquía, originó no solo el levantamiento nacional sino que dio fundamento al desconocimiento de las autoridades extranjeras y generó las condiciones para la eclosión juntista bajo la tesis de la absorción de la soberanía por parte de la nación. Estos escritos, junto a algunos periódicos, dirigidos la mayoría de ellos "al pueblo español” o “a los españoles", no solo recorrieron la península sino que, como dijimos, cruzaron el Atlántico con destino a América, siendo en estos primeros meses la principal fuente de información que tuvieron los americanos en relación a lo sucedido en España. Esta primera etapa, que cubre todo el año 1808 a grosso modo, se caracterizó entonces por una propaganda incitante contra Napoleón, fervorosa de tópicos patrióticos y religiosos, pero donde ya se pueden empezar a rastrear algunos elementos que refieren a la mutación que se estaba produciendo en los lenguajes y pensamientos políticos hispánicos.

Una de las proclamas pioneras que seguramente se conoció en ambos hemisferios del imperio español relata la conformación de la Junta de Sevilla con fecha del 29 de Mayo de 1808. En ella, en pocas oraciones, se articulan varios de los tópicos que se repitieron en la mayoría de los escritos de aquellos meses, y que fueron definiendo el carácter doctrinario de la revolución en marcha: "El pueblo pues de Sevilla se juntó el

\footnotetext{
${ }^{254}$ Guerra, François-Xavier, óp. cit., p. 155

${ }^{255}$ Las autoridades de Buenos Aires dieron constancia ya a mediados de septiembre de que a la ciudadpuerto habían llegado no sólo las de la Junta de Servilla, sino las de todas las Juntas Provinciales. Manifiesto del superior gobierno y autoridades de Buenos Aires a los españoles, 9 de septiembre de 1808. p. 1
} 
27 de mayo, y por medio de todos los magistrados y autoridades reunidas y por las personas más respetables de todas las clases creó esta Junta Suprema de Gobierno, la revistió de todos sus poderes, y le mandó defendiese la religión, la patria, las leyes y el Rey". 256

Las expresiones de lealtad a Fernando del ayuntamiento de Buenos Aires son enfáticas y reiteradas, y transmitidas a las ciudades del virreinato para inducirlas a similar iniciativa. ${ }^{257}$ Entre los primeros manifiestos peninsulares que tenemos constancia que fueron reimpresos en la Real Imprenta de los Niños Expósitos y circularon en el territorio rioplatense por iniciativa del Cabildo de Buenos Aires, se cuenta otro que también anuncia la creación de la Junta Suprema de Sevilla, con fecha del 17 de Junio de $1808 .^{258}$ La necesidad de remediar los males que la Nación entera estaba sufriendo a causa de la usurpación napoleónica es la razón, decía el manifiesto, de que "se haya creado la Junta Suprema de Gobierno de Sevilla a instancia del pueblo y que en uso de sus facultades se haya declarado independiente, haya desobedecido al Consejo y Junta Superior, haya cerrado toda comunicación con Madrid, haya levantado ejércitos y hecho los a pelear contra los franceses". ${ }^{259}$ Ese "a instancia del pueblo" condensa de alguna manera la trascendente revolución de los fundamentos políticos del poder que comenzaba a experimentar la península a partir del levantamiento nacional y que irradiaba a América a través de estos escritos. La idea de la reasunción de la soberanía por parte del pueblo es planteada de manera aún más explícita, unida al concepto de pueblo mandatario, en la proclama de la Junta de Valencia, también reimpresa en Buenos Aires: «la Suprema Junta de este Reino, que reúne la soberanía por decisión del pueblo...». También lo podemos ver en el texto de la Junta de Murcia, donde aparece como instrumento representativo del pueblo el propio municipio: «quedando el Reino

\footnotetext{
${ }^{256}$ Proclama de la Suprema Junta de Gobierno de Sevilla a los españoles 29/5/08, p. 255.

${ }^{257}$ Chiaramonte, J.C., "Autonomía e Independencia en el Río de la Plata, 1808-1810”, Historia Mexicana, vol. LVIII, núm. 1, pp. 325-368, México, 2008, p. 333. Esto no impide que un rival del cabildo porteño, el gobernador de Montevideo, Francisco Javier de Elío, sugiriese dudas sobre la lealtad de los porteños debido a la amplitud del plazo decidido para la ceremonia. Un indicio de que estaba ya en el ambiente la sospecha de inclinaciones autonómicas que afloraron desde las invasiones inglesas. Se puede ver esto también en la contestación de Elio a la proclama peninsular que el cabildo porteño reimprimió e hizo circular por las ciudades del virreinato: «V. E. cree que para tomar su partido debía esperar el éxito de los sucesos de España; yo soy de muy distinto parecer...; a la misma España declararía la guerra, a toda Potencia, a toda Provincia, a todo individuo que no presente guerra, y guerra de muerte contra el inicuo monstruo...»". citado en Ramos, D., óp. cit., pp. 169-170.

${ }^{258}$ Manifiesto o Declaración de los principales hechos que han motivado la creación de esta junta Suprema de Sevilla, firmada en el Real Palacio del Alcázar a 17 de junio de 1808 por Francisco Saavedra, su presidente y todos sus componentes. El 26 de agosto fue distribuido este manifiesto por circular del Cabildo de Buenos Aires y enviado, por ejemplo, al Cabildo de Lima, con oficio del día 28.

${ }^{259}$ Mayo Documental, Buenos Aires: Imprenta de la Universidad, 1965, T. II, p. 14. El resaltado es nuestro, al igual que en el resto de la tesis, a menos que se indique lo contrario
} 
en orfandad y, por consiguiente, recaída la soberanía en el pueblo, representado por los cuerpos municipales...». ${ }^{260}$ Todos documentos que hacen referencia a la situación revolucionaria que se estaba viviendo, aunque no lo definieran con esas palabras. La legitimidad monárquica había sido sustituida, en los hechos, por la popular. Un bagaje doctrinario que, como sabemos, sería luego recuperado por los patriotas rioplatenses, y en especial por Juan José Castelli, en el Cabildo abierto del 22 de mayo de 1810.

Aunque en los primeros llamamientos toda la preocupación parecía volcarse en exclusiva sobre el drama propio, el temor a la pérdida de los dominios ultramarinos, sumado a la imperiosa necesidad de contar con su auxilio para solventar la guerra contra el francés, explica que ya en estas primeras proclamas se dedicasen algunos párrafos en ese sentido. En el mencionado Manifiesto del 17 de junio de la Junta de Sevilla podemos ver cómo se reafirma la lealtad americana a la vez que se anuncian los terribles males que se avecinarán si estas no se unen a la madre patria en su lucha contra Napoleón:

Las Américas tan leales a su Rey como la España europea, no puede dejar de unirse a ella en causa tan justa. Uno mismo será el esfuerzo de ambas por su Rey, por sus leyes, por su Patria y por su religión. Amenazan además a las Américas si no se nos reúnen, los mismos males que ha sufrido la Europa, la destrucción de la monarquía, el trastorno de su gobierno y de sus leyes, la licencia horrible de las costumbres $[\ldots]^{261}$

La colaboración que se esperaba del nuevo mundo es explicitada sin tapujos; caudales y donativos era los que la resistencia española precisaba con urgencia:

Burlaremos sus iras reunidas las Españas y las Américas españolas. Esta Junta Suprema cuidará de todo con un celo infatigable. Las Américas la sostendrán con cuanto abunda su fértil suelo tan privilegiado por la naturaleza, enviando inmediatamente los caudales reales, y cuantos puedan adquirirse por donativos patrióticos de los cuerpos, comunidades, prelados y particulares. ${ }^{262}$

Pero la Junta era consciente que no podía exigir así sin más, solo recurriendo a la "consabida lealtad americana", debía ofrecer a cambio algunas de las reformas y respuestas que desde el nuevo continente se venían reclamando: "El comercio volverá a florecer con la libertad de navegación y con los favores y gracias oportunas que le

\footnotetext{
${ }^{260}$ Tomadas ambas citas de Ramos, D., óp. cit., p. 172.

${ }^{261}$ Mayo Documental, T. II, p. 14.

${ }^{262}$ Ídem.
} 
dispensará esta Junta Suprema [...] Somos españoles todos. Seámoslo pues verdaderamente reunidos en la defensa de la Religión, del Rey y de la Patria". ${ }^{263}$ La evocación a la triada base del orden social de la monarquía española fue una constante en los escritos que, tanto en la península como en América, buscaban movilizar las energías de los españoles para encauzarlas en la guerra nacional contra el invasor. ${ }^{264}$ La independencia era asociada inseparablemente a la religión.

Como bien destaca Demetrio Ramos inmediatamente surgió la incertidumbre por la actitud que se tomaría en América, donde los gobernantes, todos, habían sido designados por Godoy. Era necesario llegar antes que los emisarios que pudiera enviar Napoleón, por lo tanto tempranamente encontramos proclamas y manifiestos que empiezan a dirigirse directamente a los americanos. Una de estos, firmado por los Sevillanos, cargado de un lenguaje tradicionalista y lleno de alusiones religiosas, los convoca a sumarse a la movilización anti napoleónica:

Americanos, noble progenie de ilustres españoles, fieles cual nosotros a su monarca, y ciegos adoradores de un mismo Dios [...] ¿no quisieras velar y unidos a la Patria vencer o morir defendiendo vuestra apreciable libertad, vuestra divina Religión y vuestro rey y señor Fernando VII, el amado? [...] La América y la España forman un solo cuerpo y sus sentimientos deben ser uniformes. ${ }^{265}$

El manifiesto de la Junta de Sevilla, como decíamos, fue reimpreso en Buenos Aires y enviado el 26 de agosto a varias ciudades y pueblos americanos junto a una circular del Cabildo, donde se enarbolaba la fidelidad de los habitantes de la ciudad hacia su

\footnotetext{
${ }^{263}$ Ibid., T. II, pp. 14-15.

${ }^{264}$ Misma expresión usada por ejemplo en la proclama de Córdoba por esos días: "Españoles; a las armas; sed fieles a Dios, al Rey y a la Patria". «Proclama de las autoridades de Córdoba» del 10 de junio de 1808. En Mayo Documental, t. I; p. 281. Formulada de otra manera pero utilizando similares nociones movilizadoras un manifiesto originado en Valencia y reimpreso en Buenos Aires que convocaba a los españoles al combate: "para vengar los ultrajes a nuestro amado Soberano, la ofensa de la Nación, la inmunidad de nuestros hogares, la majestad de las leyes, la santidad de los altares". «Manifestación política sobre las actuales circunstancias». Reimpreso en Buenos Aires en la Real Imprenta de Niños Expósitos. Mayo Doc., t. I, p. 107.

${ }^{265}$ Proclama reimpresa en Buenos Aires, incitando a los americanos a luchar contra el emperador Napoleón. (1808), En Mayo Doc., I, pp. 7-10. La respuesta de las autoridades de Buenos Aires a la Junta de Sevilla -firmada por el Virrey Liniers, el Obispo de Buenos Aires Benito Lué y Riega, el regente de la Real Audiencia Lucas Muñoz y Cubero y el alcalde de primer voto Martin de Álzaga-, buscaba despejar cualquier duda al respecto de la fidelidad de América: "alejad pues de vuestra idea, españoles (si os pudo ocurrir) la desconfianza que los americanos se separen de vosotros en la ocasión que os va a cubrir de gloria [...] en aquella provincia [Buenos Aires] era general el entusiasmo por la libertad de España, siendo el dictamen de sus naturales y habitantes no obedecer a otra autoridad que la legítima y en caso de faltar ésta, nombrarse independientes». Manifiesto del superior gobierno y autoridades de Buenos Aires a los españoles, 9 de septiembre de 1808.Fue publicado en Gazeta Ministerial de Sevilla, n. ${ }^{\circ}$ 60, del 23-121808 como "Mensaje del cuerpo superior y autoridades de Buenos Aires a la Junta de Sevilla".
} 
monarca caído en desgracia. La idea de una nación bihemisférica era repuesta contantemente en los papeles patrióticos. La circular proclamaba que las colonias se encontraban íntimamente unidas a la metrópoli por "los fuertes vínculos de la sangre y el interés nacional", y que Buenos Aires "sin antecedentes algunos uniformó en todas sus disposiciones con las de la Suprema Junta de Sevilla proclamando al señor FVII y jurando derramar hasta la última gota de sangre en su obsequio". ${ }^{266}$ Se insiste en que los rioplatenses no escatimarán esfuerzos en auxilio de España, decididos a enfrentar a Napoleón, "por la gloria de la nación y de la América del Sur". ${ }^{267}$

El mes de agosto fue muy prolífico también, a partir de la llegada al Rio de la Plata de los emisarios tanto de Napoleón como de la Junta de Sevilla, y la jura a Fernando VII, en la impresión de papeles no necesariamente oficiales o gubernamentales, pero seguramente promovidos por las autoridades. Tenemos por ejemplo la Proclama patriótica de un hijo de Buenos Aires, donde se asegura que no se debe temer una traición por parte del Virrey, que éste es fiel al Fernando VII y sus legítimos herederos, únicos que puede dominar estos territorios. Se exalta el patriotismo y la identidad española de los americanos y se convoca a guardar el suelo americano hasta la vuelta del soberano. ${ }^{268}$ Otro es el impreso anónimo firmado por "el americano" dirigido "a todos los habitantes de la américa meridional", del 26 de agosto de 1808, que en línea con las proclamas peninsulares realiza fuertes pronunciamientos en favor del "Rey, la religión y la patria" y se destaca la desinteresada predisposición de los porteños con sus donativos para auxiliar a la metrópoli y se insiste en su prosecución. ${ }^{269}$

Desde Galicia llegó el Manifiesto de Vicente Villares, también reimpreso por orden oficial en la Real Imprenta de los Niños Expósitos y circuló en el Río de la Plata en la segunda mitad de $1808 .{ }^{270}$ En él se describe el meteórico ascenso de Napoleón y su arrollador avance sobre Europa. ${ }^{271}$ Al igual que en otros escritos de la época, son

\footnotetext{
266 “Circular del excelentísimo cabildo de Buenos aires a los del reino y a los ilustrísimos prelados del Virreinato". Mayo Doc., t. II, p. 208.

${ }^{267}$ Ídem.

268 "Proclama patriótica compuesta por un hijo de Buenos Aires del memorable 21 de agosto de 1808, en que se juró a nuestro católico monarca el Sr. Fernando VII”, Mayo Doc., t. II, pp. 170-171.

${ }^{269}$ Mayo Doc., t. II, pp. 203-207.

270 «Manifiesto político y moral a mis compatriotas». Fue reimpreso en Buenos Aires en 1808 por la Real Imprenta de Niños Expósitos, Mayo Doc., t. I; pp. 12-23. Vicente Villares se desempeñó durante la guerra de independencia como publicista siendo responsable junto a Antonio Pacheco y Bermúdez de la redacción de la Gazeta Instructiva de la Junta Superior de Galicia (La Coruña, 13 de julio de 1811-17 de mayo de 1813). También en estos años fue Fiscal de la Audiencia de Galicia.

${ }^{271}$ Con respecto a la entrada del ejército imperial a la península llama la atención que dice que el pretexto fue tomar Gibraltar, en vez de atribuirlo a la necesidad de atravesar España para invadir a Portugal. "su tránsito por nuestras provincias ha sido el de una langosta desoladora”. Ibíd., p. 18
} 
fuertes y muchas las críticas contra el favorito Manuel Godoy, al que se responsabiliza de la funesta alianza con Francia. Pero el manifiesto es interesante para nuestro estudio, entre otras cosas, por el análisis que en él se hacen de las Cortes de Bayona convocadas por Napoleón. Las considera fundamentalmente una farsa destinada a darle una pátina de legitimidad a algo que a los ojos de toda Europa era una usurpación: "La constitución que se nos destinaba ya estaba hecha, y los diputados únicamente iban a recibirla y firmarla". ${ }^{272}$ Villares reivindica las instituciones y tradición política española, pero al igual que muchos otros letrados de su generación reconoce la necesidad de ciertos cambios y deposita en Fernando VII la esperanza que sea el artífice de aquellas transformaciones:

Nosotros estábamos contentos con esta respetable ancianidad [la de la monarquía]; y aunque apetecíamos la saludable reforma de algunos abusos introducidos en su constitución, contábamos para ello con la buena voluntad de nuestro joven monarca, cuyos primeros pasos en la carrera del reinar se habían distinguido por juiciosas providencias, y eran de feliz pronóstico para lo sucesivo [...] jamás han mendigado los españoles códigos extranjeros para sus gobierno. ${ }^{273}$

El gallego parecía responder a una proclama del 25 de mayo de 1808 de José I, el rey intruso, donde convocaba a las Cortes de Bayona:

"Vuestra monarquía es vieja, mi misión es rejuvenecerla. Mejoraré todas vuestras instituciones, y os haré gozar, si me secundáis, de los beneficios de una reforma, sin disgustos, sin desórdenes, sin convulsiones. Españoles, he hecho convocar una asamblea general de las diputaciones de las provincias y de las ciudades. Quiero asegurarme por mí mismo de vuestros deseos $\mathrm{y}$ de vuestras necesidades. [...], garantizándoos una constitución que concilie la santa y saludable autoridad del soberano con las libertades y los privilegios del pueblo. Españoles, acordaos de lo que han sido vuestros padres; ved a donde habéis llegado. La falta no es vuestra, sino a la mala administración que os ha

\footnotetext{
${ }^{272}$ Ibid., p. 19.

${ }^{273}$ Como parte de esa antigua constitución reivindica a las Partidas y destaca los aportes de pensadores como Campomanes, Lardizábal y Jovellanos. P. 20 El manifiesto concluye, como tantos otros, llamando a los españoles a obedecer a la Junta soberana del Reino y a empuñar las armas en una conflagración que define no como una habitual guerra de gabinetes, sino como una guerra santa. Es un llamamiento general pero que también particulariza dirigiéndose a los militares, magistrados, nobles y sacerdotes. Ibid., p. 23.
} 
regido. Tened confianza en las circunstancias actuales; pues quiero que vuestros últimos descendientes conserven mi recuerdo y digan: ¡Él es el regenerador de España!”. ${ }^{274}$

La idea de la "regeneración" se vuelve una constante. Esa noción comprendía desde medidas concretas, como la eliminación de los funcionarios vinculados al favorito, hasta aspiraciones más amplias como la justicia, la prosperidad, y, sobre todo, el fin del despotismo. En palabras de Guerra, el deseo de reforma social y político era, efectivamente, universal en 1808. ${ }^{275}$ Términos como "reforma", “abusos", "constitución" comenzaron su recorrido para volverse no sólo habituales sino centrales en el lenguaje político de la época. De aquí en adelante estas nociones, como veremos, fueron asociándose a otros conceptos y adoptando diversos sentidos de un lado del Atlántico y del otro, expresando de esa manera el distanciamiento que el proceso revolucionario va tomando en ambas orillas.

Similar tono y contenido tiene otro papel reimpreso en Buenos Aires conocido Manifestación política sobre las actuales circunstancias, en este caso originado en la ciudad de Valencia, donde se relatan los acontecimientos de los últimos años y se critica tanto a Napoleón como a Godoy y Carlos IV. En cambio, Fernando VII es exculpado de toda responsabilidad en la crisis y depositadas en el las expectativas de mejoras para la monarquía, en línea con la operación que buscaba construir una imagen del joven borbón como "el Deseado", que recorrió el mundo hispánico durante los primeros años de la crisis: «... la Nación miraba en Fernando VII un libertador suspirado, y un restaurador de sus leyes y sus glorias». ${ }^{276}$ Pero ¿cuál era esa Nación a la que estaban citando, quienes la componían? El vocablo nación aparece en una multitud de escritos en esta época, pero como dice Guerra,

[...] algunas veces, con un sentido moderno, como el conjunto de los españoles; en la mayoría de los casos, con una clara connotación de corona o reino, como una comunidad política antigua [...] La palabra nación ya no designa nunca en la España peninsular a las comunidades particulares en el seno de la Monarquía, sino sólo a «la

\footnotetext{
274 “Proclama a los españoles", 25 de mayo de 1808, citado en De Gori, E., La Republica Patriota..., pp. 170-171.

${ }^{275}$ Guerra, François-Xavier, óp. cit., p. 122.

276 «Manifestación política sobre las actuales circunstancias». Reimpreso en Buenos Aires en la Real Imprenta de Niños Expósitos. Mayo Doc., T.I, p. 104. En sentido similar estaba orientada la supuesta proclama de Fernando VII desde su cautiverio y reimpresa en la Real imprenta de los Niños Expósitos. Dirigida a los "fidelísimos españoles", el monarca cuenta como fue engañado por Napoleón, poniendo en todo momento como excusas su juventud "Mi poca edad y ninguna experiencia, y las circunstancias críticas del día disimulan y absuelven mi involuntario yerro del que me atormenta la triste memoria de su resultado hacia vosotros". "Proclama de Fernando VII", Mayo Doc., T.I, p. 11.
} 
nación española». Lo mismo ocurre en América, en donde todas les referencias remiten a una única nación, la nación española, aunque ésta sea vista como formada por europeos y americanos, como extendida a los dos hemisferios, o compuesta incluso por dos pueblos. $^{277}$

La concepción moderna de nación que la equiparaba a la noción de pueblo o aquella que hacía referencia a la reunión de las comunidades políticas que integraban la monarquía, empezaba entonces a circular en el mundo hispánico.

Junto con los manifiestos y proclamas, la Real Imprenta de la ciudad también se dedicó por órdenes de las autoridades a reimprimir algunos de los periódicos patriotas que comenzaban a llegar cruzando el océano. Tenemos por ejemplo reimpreso el primer número de la Gazeta Ministerial de Sevilla, del 1 de junio de 1808, publicada por orden de la Junta suprema. En ella se rebaten la información publicada en el Diario de Madrid, manejado por los franceses, y en diversos libelos, que hablaban de una abdicación consensuada por parte de la familia real. ${ }^{278}$ También es reimpreso el número correspondiente al 4 de junio donde se relata el levantamiento militar, las juras por Fernando VII en distintas ciudades de Andalucía y Extremadura, con un lenguaje anclado en aquellos fundamentos tradicionales de los que venimos hablando. La idea pactista de la retroversión se pone de relieve cuando se fundamenta la creación de la Junta de Sevilla, "fiel depositaria del poder soberano". ${ }^{279}$ Los invasores franceses, definidos como "demagogos de la república", son acusados de ser los peores conquistadores de la Historia, porque además de privar a las naciones de sus monarcas y su independencia, "las arranca de los brazos de aquellas costumbres, leyes y religión en la que han vivido, y que se han identificado en cierto modo con su existencia". ${ }^{280}$ No sólo la gaceta sevillana fue puesta en circulación en Buenos Aires, sino que también se hizo lo propio con el periódico de otra de las principales juntas peninsulares, como es la valenciana. Se destaca el llamamiento que se promueve en el Diario de Valencia del 6 de junio de 1808, donde se plantea que estando el reino sin cabeza "es necesario dársela

\footnotetext{
${ }^{277}$ Guerra, François-Xavier, óp. cit., p. 121.

${ }^{278}$ Fueron reimpresos en la Real Imprenta porteña varios números de la Gazeta extraordinaria de Madrid correspondientes al mes de abril de 1808. En ellas se encontraba un manifiesto del presidente del Consejo de Castilla del 8 de abril donde se informa que Napoleón está en Bayona deseoso de reunirse con la familia real para estrechar los lazos de amistad; que el monarca salía de la Corte con ese destino, y se le pedía al pueblo que mantuviera la tranquilidad. También un bando de Manuel Lapeña, gobernador de Sevilla, con fecha del 7 de mayo, contando los sucesos ocurridos en Madrid el 2 de mayo como obra de un pequeño grupo de alborotadores, pidiendo se mantenga el buen trato hacia las tropas francesas en todo el territorio.

279 "Reimpresión en Buenos Aires de la Gazeta Ministerial de Sevilla, del 4 de junio de 1808", p.3.

${ }^{280}$ Ibid., p. 4.
} 
por medio del Congreso general de la España Militar, que debe erigirse por muchos títulos en el principado de Asturias. Vendrán a él los diputados del Reino...". ${ }^{281}$ De a poco empezaba a circular la idea de la convocatoria a un Congreso general o unas Cortes del Reino, como herramienta para afrontar la crisis.

En ese sentido, la discusión sobre qué tipo de gobierno era necesario formar comenzó a generalizarse y fueron muchos los escritos que en forma de artículos o manifiestos salieron a tallar sobre el tema. La iniciativa política estaba asentada en la Junta de Sevilla, que en agosto de 1808 proponía la conformación de una Junta Central que concentrase la autoridad de las provinciales, pero eso no quería decir que no hubiera otros actores con propuestas alternativas o matices a la misma. Tenemos por ejemplo un papel reimpreso en Buenos Aires titulado Reflexiones de un verdadero español, publicado originalmente en la península el 19 de agosto, que discurre sobre la propuesta de la Junta de Sevilla. Su autor comparte la necesidad y urgencia de conformar una autoridad central, a la que denomina alternativamente como Consejo de Regencia o Junta Suprema de Regencia, pero entiende que esto es tarea exclusivamente de la nación y no de las juntas provinciales. ${ }^{282}$ La autoridad, dice, debe ser "la misma que las leyes fundamentales de España dan a sus legítimos Soberanos". ${ }^{283}$ Entiende entonces que, formada la Suprema Junta o Consejo de Regencia, las juntas provinciales deberían desaparecer. No puede ya, dice, "residir el poder del pueblo en las juntas provinciales, porque entonces se formaría, no un gobierno, sino un monstruo de muchas cabezas". Para el autor "el poder que la muchedumbre ha dado a las respectivas juntas en la crisis" debería concentrarse en una única autoridad, no sólo por una cuestión pragmática, sino porque, a su entender, mantener las juntas es hacer "una novedad en la constitución, antes de que llegue el tiempo que se altere o modifique, si es necesario". ${ }^{284}$ Como podemos ver, es temprana la mixtura de que se empieza a operar en el pensamiento político de los protagonistas del proceso, remitiendo a las "fundamentos históricos" del reino, aunque introduciendo paulatina pero sostenidamente la idea del pueblo como origen del poder soberano. Soberanía, que a entender de este letrado, no es divisible en tanto pueblos que componen la monarquía, como se reclamaba desde algunas de estas juntas provinciales, sino que por el contrario, estaba inexorablemente

\footnotetext{
281 "Reimpresión en Buenos Aires del Diario de Valencia del 6 de junio de 1808", p.1.

282،"Reflexiones de un verdadero español sobre el manifiesto de la Junta de Sevilla del 3 de agosto que trata acerca de la organización del poder supremos de la nación”, p. 1.

${ }^{283}$ Ibid., p. 9.

${ }^{284}$ Ídem.
} 
asociada a la unicidad que la nación española representaba. ${ }^{285} \mathrm{La}$ opción federalista, enarbolada por algunas provincias, generaba rechazos en gran parte de la dirigencia peninsular. Para Jovellanos, que reclamaba con urgencia un centro de autoridad, la descentralización implicaba la imposición de pasiones e intereses particulares. La precariedad de la legitimidad del poder y las diferencias políticas únicamente podrían resolverse con una salida constitucional a la crisis. ${ }^{286}$ La disyuntiva entre la soberanía del "pueblo" o de "los pueblos" ya encontraba su cauce en el debate peninsular, para ser central luego como veremos, cuando sean los americanos los que empiecen a reclamar sus derechos como pueblos soberanos.

Interesante por la presencia de algunos elementos innovadores es la proclama de un canónigo de Málaga que circuló en el Rio de la Plata en los últimos meses de 1808. Desde una concepción cifrada en el Derecho de Gentes se denuncia la injusticia llevada a cabo por Napoleón al enajenar la monarquía española imponiendo su propia dinastía. El canónigo denuncia que fue "usurpado por una Potencia extraña el primer derecho de la soberanía de todos los pueblos independientes cual es el de elegirse sus soberanos y arreglar las leyes constitucionales". ${ }^{287}$ Tenemos varios elementos aquí que dan cuenta del proceso revolucionario que se comenzaba a abrir paso en la península. Para el canónigo la agresión de Napoleón no había sido contra la familia borbónica, había sido fundamentalmente contra la nación española que era la depositaria del derecho soberano de poder elegir sus autoridades y formar su constitución. La lectura que iba emergiendo era que la crisis monárquica y la ocupación solo serían resueltas con la nación como sujeto protagonista. La idea de la soberanía nacional empezaba a ponerse en juego, todavía tímidamente, en los escritos de propaganda que inundaban a España y sus colonias. Por ejemplo, durante el mes de noviembre, circuló en la capital porteña un papel que entre otras cosas rezaba: «Nosotros concebimos que, destronada la Casa reinante, retrovertieron al Pueblo Español todos los derechos de la soberanía, y que usando de ellos como en el primer instante de su ser político, pudo crear nuevas autoridades, nuevas leyes, nuevas Constituciones..., hasta tanto que las armas

\footnotetext{
${ }^{285}$ El autor de las Reflexiones propone para conformar esa Junta o Consejo, entre otros, a Floridablanca, Saavedra y Jovellanos, porque entiende que no habría contradicciones con respecto a su legitimidad y capacidad para ocupar esa responsabilidad: "Son tan conformes a la voluntad general de la nación". p. 4. ${ }^{286}$ Portillo Valdés, J.M., óp. cit., p. 205.

${ }^{287}$ «Proclama del canónigo Francisco Xavier Asenjo [arcediano de Antequera] a todos los militares de la guarnición de Málaga», 3 de junio de 1808. Fue reimpresa en Buenos Aires, en la Imprenta de Niños Expósitos, en Mayo Doc., t. I, p. 274.
} 
restablezcan el carácter de la Monarquía». ${ }^{288}$ Otra vez una de las cuestiones que como venimos observando concentraron el interés del público lector de la época, la constitución, fuese la "antigua constitución" o la comenzada a imaginar por algunos y, con eso, como bien señala Chiaramonte, "la de los derechos de los súbditos de la monarquía a hacer valer el viejo, pero siempre vigente principio del consentimiento". ${ }^{289}$

A la par, y a veces de la mano con aquello, la prematura propuesta de convocatoria a Cortes del reino como respuesta a la crisis comenzaba a tallar en el debate e impactaba primera, que llegó al Plata en el bergantín «El Fiel Amigo», salida de Cádiz el 18 de mayo y que fondeó en Montevideo el 15 de julio. En ella, después de una acerba crítica a Napoleón, se hace un apasionado llamamiento a las armas que termina con un párrafo que hace referencia a aquello que venimos analizando: «Reynos y Provincias: Enviad vuestros Diputados a la Corte para organizar el Gobierno, de forma que se eviten los desastres que ya vemos venir....Castigad a los traidores actuales e imprimidles el sello del oprobio...». ${ }^{290}$ Este llamamiento tan prematuro seguramente sorprendió a los lectores rioplatenses, poniendo a disposición una carta nueva a la baraja de alternativas en juego, que, como veremos más adelante, no sería desaprovechada, por lo menos en el plano del discurso.

El manifiesto de la Junta Central del 26 de octubre de 1808, a poco más de un mes de su formación, constituye un jalón significativo en la mutación política que estaba viviendo la península. En él se afirma que España estaba viviendo efectivamente una revolución, despojando al concepto de la carga negativa con la que se lo había usado hasta el momento. Ya no era sólo la búsqueda de la restauración de las tradiciones sino una oportunidad para llevar adelante cambios tantas veces postergados. La Central solicita consejos y pareceres para que, examinadas las leyes antiguas, se programen las «alteraciones que deben sufrir, [...] reformas que hayan de hacerse en los Códigos civil, criminal y mercantil; proyectos para mejorar la educación pública, tan atrasada entre

\footnotetext{
${ }^{288}$ Citado Narancio E. M., «Las ideas políticas en el Río de la Plata a comienzos del siglo XIX. Contribución al estudio de su filiación y desarrollo iniciales», en Rev. de la Facult. de Hum. y Ciencias (Montevideo), núm. 14, 1955, p. 164.

289 “Cuando se difundió en España lo acaecido en Bayona, esta norma de la “antigua constitución”, la del consentimiento, en realidad proveniente de las doctrinas contractualistas propias del derecho natural, aflora inmediatamente: el príncipe no tiene derecho a enajenar su reino sin consentimiento de sus súbditos. Esta norma, cuyas raíces se remontan a la Edad Media, se la encuentra también, entre los siglos XVI y XVIII, en la Vindiciae contra Tyrannos, así como en Grocio, Pufendorf, Wolff, Vattel, Burlamaqui, entre otros". Chiaramonte, J. C., “Autonomía...”, p. 339.

290 «Relación manuscrita que circuló en Buenos Aires, perteneciente al archivo del doctor Mariano Morenos, que se inicia con los Sucesos memorables del reynado de Carlos IV desde el año de 1806 hasta el 19 de marzo de 1808”, Mayo Doc., t. I, pp.192-I94.
} 
nosotros; arreglos económicos para la mejor distribución de las rentas del Estado...». ${ }^{291}$ Ya no sólo la tarea de los patriotas españoles era sostener la resistencia contra el ejército invasor, el objetivo planteado por la Central y los elementos más radicales que desde la prensa operaban sobre la realidad era doble, por un lado «arrojar al enemigo más allá de los Pirineos y obligarle a que nos restituya la Persona Augusta de nuestro Rey»; y por otro, para acometer la edificación de ese Estado rejuvenecido, «sin cuya atención la Junta no llenaría más que la mitad de sus deberes». ${ }^{292}$

En esa línea innovadora estaba la declaración que se dedicó concretamente a los americanos en la Circular que la Junta Central dirige a los virreyes y capitanes generales, desde Sevilla, el 9 de enero de 1809, pocos días antes del famoso decreto del 22 de enero que convocara los americanos a elegir diputados para la Junta, que ya analizaremos en particular en un próximo capítulo. En la circular se retoma y profundiza aquel lenguaje reformista que buscaba diferenciarse del abyecto pasado reciente: “derribado el vil privado que causó tantas lágrimas y desastres en los dos hemisferios, de nada más se trata que de reformar abusos, mejorar las instituciones, quitar trabas, proponer fomentos y establecer las relaciones de la metrópoli y las colonias sobre las verdaderas bases de la justicia". ${ }^{293}$ Esa profundización reformista no sorprende si se tiene en cuenta que para estas fechas ya había fallecido el hasta ese momento presidente de la Junta, el Conde de Floridablanca, quien fue el principal dique conservador a las pretensiones transformadoras del ala más radical del proceso. ${ }^{294}$ Tanto los reformistas moderados con Jovellanos a la cabeza, como los revolucionarios acaudillados por Manuel Quintana, tuvieron a partir de allí un mayor margen de maniobra para imprimirle su sello a la conducción del proceso, preparando la convocatoria a las Cortes. Llama la atención que sólo un par de semanas antes del decreto del 22 de enero, se siguiera hablando todavía de "metrópoli y colonias", y quizás por ello, y no solo por el llamamiento a la elección de diputados, es que el decreto escrito por Quintana fue tan significativo en el desarrollo del proceso.

Aprovechando la crisis de prestigio de la Junta Central que resultó de una serie de fracasos militares, y la ausencia como dijimos de Floridablanca, la alianza de los

\footnotetext{
${ }^{291}$ Manifiesto de la Junta Central del 26 de octubre de 1808, citado por Ramos, D., óp. cit., p. 177. ${ }^{292}$ Ibid., p. 179

${ }^{293}$ Circular de la Junta Central a los virreyes y capitanes generales, 9 de enero de 1809, citado por Ramos, D., óp. cit., p. 180.

${ }^{294}$ La noticia de la muerte de Floridablanca, ocurrida el 30 de diciembre de 1808 en la ciudad de Sevilla, fue conocida por la población de Buenos Aires gracias a la reimpresión de la Gazeta extraordinaria de Sevilla del 4 de enero de 1809 en la Real Imprenta de los Niños Expósitos.
} 
constitucionalistas históricos y de los revolucionarios en la Junta Central condujo al decreto del 22 de mayo de 1809, conocido también como la "Consulta al país". En él se oficializaba una explicación política moderna de los males de la Monarquía: todo venía de la pérdida de las antiguas libertades. Como respuesta se anunciaba la convocatoria a Cortes para el año próximo y se pedía a "los Consejos, Juntas superiores de las provincias, Tribunales, Ayuntamientos, Cabildos, Obispos y Universidades, a los sabios y personas ilustradas", que elevaran propuestas en relación a medidas de gobierno necesarias para una mejor administración del gobierno y de la guerra, y las reformas necesarias para la mejora de la legislación e instituciones del reino. La convocatoria fue exitosa, por lo menos para el territorio peninsular, recibiendo la Junta Central numerosos informes y ensayos, muchos de ellos directamente con el formato de proyectos constitucionales. $^{295}$

Este vocabulario reformista, que fue ganando cada vez más lugar en las proclamas peninsulares, tuvo su correlato en el Río de la Plata enarbolado por un grupo de en su mayoría criollos que, detrás del carlotismo, también buscaban impulsar una serie de medidas que terminarían con lo que ellos consideraban como situaciones de "abusos" e "injusticias", de realidades enquistadas en el régimen colonial desde hacía mucho tiempo. ${ }^{296}$ Y sobre eso trataremos en el próximo capítulo.

\footnotetext{
295 Artola, M. óp. cit., p. 339.

296 “Memoria de Juan J. Castelli, Antonio L. Beruti, Hipólito Vieytes, Nicolás Rodríguez Peña y Manuel Belgrano a la Infanta Carlota Joaquina, en que reconociendo sus legítimos derechos piden protección para estos reinos". (20/9/08), Mayo Doc., p. 104.
} 


\section{Capítulo 4:}

\section{La alternativa carlotista}

\section{Introducción}

La opción de una Regencia por parte de la Infanta Carlota Joaquina de Borbón, hija mayor de Carlos IV y esposa del príncipe regente de Portugal, João VI, se fue constituyendo en una variante de cada vez mayor peso dentro del legitimismo, y fue en el Río de la Plata donde tuvo su epicentro de despliegue político. Incluso no logrando incitar numerosas adhesiones, con posibilidades de éxito que desde un comienzo se suponían inciertas, por no decir exiguas, el carlotismo, como bien sugiere Marcela Ternavasio, es relevante como tema de estudio sobre todo por "las tramas de relaciones de poder que dejo al desnudo, por los temores y fantasmas que desató en diversos frentes y por la reserva de experiencia que significó para quienes estuvieron directamente involucrados en ellas". 297

No nos toca a nosotros aquí hacer un desarrollo pormenorizado de su desenvolvimiento, existe ya una amplia bibliografía sobre el tema, con algunos aportes recientes muy valiosos. ${ }^{298}$ Nos enfocaremos en el presente capítulo en cambio en analizar cómo esta alternativa, que fue una más en el abanico que manejaron los distintos actores políticos rioplatenses, representó un espacio donde los vínculos entre el pensamiento político hispánico de ambas orillas atlánticas se reconstituyeron y cobraron nuevos sentidos. Tarea difícil para un período -entre 1808 y 1810- extremadamente convulso y dinámico en muchos aspectos, y en especial para una trama que abundó en conspiraciones, intrigas y dobles intenciones por parte de los protagonistas.

\section{Los sueños de regencia de Carlota Joaquina}

El traslado de la familia real portuguesa a Río de Janeiro a comienzos de 1808 y los contactos que la princesa pudo establecer desde allí con Buenos Aires, plantearon al Río de la Plata otras opciones para el depósito de la soberanía. Los fundamentos

\footnotetext{
${ }^{297}$ Ternavasio, Marcela, "Una princesa para América: la alternativa carlotista frente a la crisis monárquica de 1808", en Landavazo, Marco; Guzmán Pérez, Moisés (coord.), Guerra, política y cultura en las independencias hispanoamericanas, Editorial Porrúa, Morelia, 2013, p. 104

${ }^{298}$ A los clásicos estudios más enfocados desde las llamadas relaciones diplomáticas, se les suman desde una perspectiva renovada de la historia política los trabajos de Ternavasio, Marcela, Candidata a la corona: la infanta Carlota Joaquina en el laberinto de las revoluciones hispanoamericanas. Buenos Aires: Siglo Veintiuno editores, 2015, y Nogueira de Azevedo, Francisca, Carlota Joaquina na corte do Brasil, Río de Janeiro, Civilizacao Brasileira, 2002.
} 
jurídicos del reclamo a la regencia por parte de la infanta se basaron en la reivindicación del derecho a ejercerla dada la imposibilidad de su hermano Fernando y de toda la línea masculina de la familia real de ocupar el trono. En este reclamo -lanzado en un Manifiesto en agosto de 1808 - se destacan tres cuestiones. La primera es que Carlota no reconocía explícitamente a Fernando como rey sino que hablaba de los legítimos derechos del "Rey Católico, sin por lo tanto decir cuál, para no faltar a los deberes de hija y de hermana, ni de súbdito ni de aliada de V.M"; por otro lado, Carlota tampoco reconocía a las juntas de España; y finalmente, desde el punto de vista jurídico, el carlotismo se presentaba como la única opción legal y legítima, frente a la ilegitimidad de las abdicaciones de Bayona, para conservar y defender la "constitución fundamental del reino" basada en el derecho de sucesión declarado por las Leyes del Código Nacional, dejando en claro que el juntismo peninsular violentaba dicha constitución. ${ }^{299}$

Su propuesta encontró algunos interesados que se mostraron dispuestos a llevarla a la práctica. Pero como sugiere Fabio Wasserman, bajo el manto del carlotismo podían cobijarse diversas intenciones e intereses. Para los portugueses era un excelente medio para intervenir en la política rioplatense. Para los administradores coloniales, con sus mandatos cuestionados tras las abdicaciones de Bayona, podía ser un reaseguro de permanencia en el poder. Y finalmente, para quienes eran partidarios de una mayor autonomía o directamente de la independencia de las colonias, la opción carlotista podía facilitar la formación de un gobierno propio. ${ }^{300}$

Aunque existen constancias de que algunas autoridades coloniales tendieron líneas de manera reservada, la realidad es que a la hora de las manifestaciones públicas fue unánime el no reconocimiento de la infanta como regente. Aducían que no podían reconocer una regencia sin violar el juramento de fidelidad realizado a Fernando VII y a la autoridad que lo representaba en la Junta Central. ${ }^{301}$ A pesar de la distancia ideológica que podría existir entre un miembro de la Junta Central como Jovellanos y el gobernador de Montevideo Francisco de Elío, existía una solidaridad implícita entre el gobierno metropolitano y los agentes del régimen en las colonias. Para la Junta, aquellos implicaban la fórmula más inmediata de sostener el control de los dominios de ultramar, sin aventurarse a reformas demasiado arriesgadas; mientras que a las autoridades

\footnotetext{
${ }^{299}$ Goldman, Noemí; Ternavasio, Marcela, "Construir la república: semántica y dilemas de la soberanía popular en Argentina durante el siglo XIX”, Rev. Sociol. Polit., Curitiba, v. 20, n. 42, jun. 2012, p. 12. ${ }^{300}$ Wasserman, F., Castelli..., p. 65.

${ }^{301}$ El Virrey del Perú, Abascal se convirtió en el adalid del legitimismo fernandista y en uno de los más férreos opositores al carlotismo.
} 
coloniales mantenerse en esa posición les dejaba un gran poder y autonomía de gestión que no estaban dispuestos a renunciar. Es más, ante la eventualidad de la derrota definitiva de la metrópoli los virreyes seguramente especulaban en ser las cabezas sobre las cuales se reconstituyera en el continente americano la unidad imperial. Lógicamente esa autonomía y poder de los delegados del rey en América se vería limitada con Carlota coronada como regente. ${ }^{302} \mathrm{La}$ supuesta estrategia de los virreyes ya era denunciada en impresos anónimos que circularon por el espacio rioplatense de clara orientación carlotista, donde se calificaba como absurda la idea de crear "un sistema de gobierno colonial sin metrópoli y sin soberano efectivo...que expondría a las Américas a ser divididas en tantos reinos como virreyes, en tantos régulos como gobernadores". 303

También pesaban fuertemente en las autoridades coloniales los temores de que Carlota fuera el vehículo de la Corte bragantina para llevar adelante sus antiguas ambiciones expansionistas hacia territorios rioplatenses. ${ }^{304}$ No hacía ni dos años que habían experimentado una invasión británica, la poderosa aliada de Portugal, y esa desconfianza no habría de disiparse con el repentino viraje de las alianzas internacionales producido por la ocupación de la metrópoli por parte de las tropas napoleónicas. El cabildo de Buenos Aires fue lapidario en su rechazo, no sólo por haber jurado fidelidad a Fernando VII sino además porque decía tener "antecedentes seguros de las ideas que han abrigado el inglés y el portugués con respecto a estos dominios". 305

\section{La Memoria de los criollos dirigida a Carlota}

Ante la negativa de las autoridades coloniales, en el círculo de la Infanta se mostraron más activos en establecer contactos y sumar apoyos entre los grupos criollos civiles que estuvieran dispuestos a reconocerla, designando como agente para estas tareas en el Rio de la Plata al comerciante ítalo-portugués Felipe Contucci. Tras su paso por Buenos Aires se dirigió hacia Rio de Janeiro en una misión comercial, portando secretamente una memoria fechada el 20 de setiembre de 1808 y firmada por algunos criollos que se mostraban adictos al proyecto carlotista. ¿Quiénes eran? Varios de nuestros viejos conocidos. Entre los más destacados: Manuel Belgrano, Juan José

\footnotetext{
${ }^{302}$ Goldman, Noemí; Ternavasio, Marcela, “Construir...”, p. 12.

303 “Anónimo hallado en la calle por el capitán de la segunda compañía del batallón número 4, Juan Antonio de la Puebla", s/f, en Biblioteca de Mayo, p. 10141.

${ }^{304}$ La propia creación del virreinato, entre otros motivos, había respondido a poder ejercer un mejor control a la vocación expansionista portuguesa en la región.

305 "Representación del cabildo de Buenos Aires a los infantes doña Carlota Joaquina y don Pedro de Portugal”, Mayo Documental, t. III, p. 60.
} 
Castelli, Antonio Beruti, Juan Hipólito Vieytes, y los hermanos Saturnino y Nicolás Rodríguez Peña. Aunque minoritarios, no dejaban de tener peso en la sociedad a la que pertenecían, y lo cierto es que entre 1808 y 1809, ellos representaron prácticamente el único apoyo con el que contó la princesa en América.

El texto, discutido seguramente en el seno del grupo, por algunos giros estilísticos se lo ha adjudicado a Castelli, que aparece además como el primero de los firmantes. ${ }^{306}$ Comienza con un reconocimiento absoluto a la legitimidad de los títulos y por lo tanto de las pretensiones de la Infanta, rechazando de plano la respuesta negativa dada por el gobierno virreinal ante las gestiones iniciadas con el Manifiesto. Consideran que detrás de esta actitud se esconden inconfesados objetivos e intereses, en línea con una conducta abusiva de parte de las autoridades. ${ }^{307}$ Reconocen la lealtad y los esfuerzos demostrados por la Junta de Sevilla ante la acuciante situación en la que se encontraba la península, pero entienden que eso no alcanzaba para que esta se arrogue los derechos inmanentes de la corona. A los sumo consideran que para España sí era necesaria esa experiencia, cuando faltaba el soberano y no había constituida por él regencia del reino ni miembro de la dinastía presente a quien recurrir. Pero en América eran otras las condiciones, la ubicuidad de la Infanta Carlota exigía que sea ella quien deba responsabilizarse de la administración y gobierno de las posesiones americanas hasta que se restituyera la "Augusta Casa de Borbón" en el trono español. Mientras que la representación invocada por las juntas metropolitanas era de hecho, la de Carlota era de conocido derecho. Frente a la naturaleza inédita de la crisis monárquica, en realidad no era posible encontrar una respuesta jurídica única y legítima, una que respondiera más ajustadamente a la supuesta constitución fundamental del reino. Todo era materia de debate, donde los argumentos jurídicos se fueron politizando cada vez más. Lo que sí podemos resaltar es que esta variante del legitimismo se encontraba muy alejada de la idea de soberanía popular que enarbolarían varios de los integrantes del grupo durante los primeros años revolucionarios.

Profundizando aún más en la línea legalista, tampoco la Junta podría exigir obediencia a los dominios americanos, porque estos, desde la época de la conquista, fueron una anexión directa a la Corona de Castilla, y por lo tanto separada de ésta, no debía a otra parte del reino, en este caso la Junta de Sevilla, ni sumisión ni obediencia.

\footnotetext{
${ }^{306}$ Wasserman, F., Castelli..., p. 66.

307 "Memoria de Juan J. Castelli, Antonio L. Beruti, Hipólito Vieytes, Nicolás Rodríguez Peña y Manuel Belgrano a la Infanta Carlota Joaquina, en que reconociendo sus legítimos derechos piden protección para estos reinos". (20/9/08), Mayo Doc., pp. 101-102.
} 
Dejaban planteada de esa manera el estatus jurídico que entendían le correspondía a América dentro de la monarquía. José Carlos Chiaramonte ha indicado acertadamente que mientras en la península la discusión iba evolucionando desde la concepción de un Estado patrimonial hacia uno nacional, y tendía a considerar a las Indias como a otras provincias de España, formando con la Península "un sólo cuerpo unido de Nación”, el grupo criollo se aferraba a los privilegios que les concedía su calidad de parte de una monarquía patrimonial. Buscaban neutralizar de esa manera las pretensiones de los peninsulares y lograr el control de los asuntos locales que, sin perjuicio de su calidad de fieles súbditos de la monarquía, les correspondía en virtud del derecho de gentes. ${ }^{308}$

Los firmantes advierten que desde las invasiones inglesas "no se ha cesado de promover partidos para constituirse en gobierno republicano", y ponen la lupa en aquellos que aun teniendo ventajas considerables por sobre los americanos gracias al usufructo del monopolio, buscaban convencer a la población a la sombra de una declarada fidelidad a Fernando VII, escondiendo sus verdaderas intenciones de perpetuar sus beneficios bajo un control directo del gobierno local. ${ }^{309}$ Entienden que bajo el control de una "mano real inmediata", el abuso y el desprecio por las leyes de parte de estos grupos sociales y funcionarios coloniales no sería posible de ocultarse. Como bien afirma Fabio Wasserman, estas consideraciones podrían tener como propósito ganar el favor de Carlota al mostrarse devotos de la monarquía y adversarios de una república, pero es innegable la referencia al intento de los españoles europeos encabezados por Álzaga, de querer hacerse con el poder desplazando a Liniers. ${ }^{310}$ Es necesario aclarar que la noción de república era utilizaba en la época para referirse al gobierno del Cabildo, el cuál era manejado por este mismo grupo, que además contaba seguramente con una aceptación más benévola por parte de la metrópoli, por lo menos en comparación con el grupo criollo.

La memoria, a la vez que un reconocimiento de los derechos de Carlota, era también de alguna forma un pliego de condiciones que el grupo le manifestaba a la infanta para brindarle apoyo a su causa. Y creemos esto porque se afirma que con ella en la regencia

[...] cesaría la calidad de Colonia, sucedería la ilustración en el país, se haría la educación, civilización y perfección de costumbres, se daría energía a la industria y comercio, se extinguirían aquellas odiosas distinciones que los europeos habían

\footnotetext{
${ }^{308}$ Chiaramonte, J.C., “Autonomía...”, pp. 342-343.

309 "Memoria...", Mayo Doc., p. 104.

${ }^{310}$ Wasserman, F., Castelli..., p.66.
} 
introducido diestramente entre ellos y los americanos [...] se acabarían las injusticias, las opresiones, las usurpaciones las dilapidaciones de las rentas, y un mil de males que dependen del poder que a merced de las distancias del trono español se han podido apropiar sin temor de las leyes, sin amor a los monarcas, y sin aprecio de la felicidad general. $^{311}$

Era clara la intención de estos ilustrados de que la regencia de la Infanta fuera el instrumento desde el cual redefinir los vínculos entre la metrópoli y las colonias para alcanzar de esa manera un mayor grado de autonomía y autogobierno, y poder impulsar las reformas que venían anhelando, discutiendo y publicitando desde hacía ya varios años -como pudimos ver en el capítulo sobre la prensa ilustrada rioplatense-, pero que bajo el pesado régimen colonial veían postergarse indefinidamente, llegando al punto ya de desencantarse con la posibilidad que la monarquía las encarase algún día. Como plantea Ternavasio, los términos reforma y regeneración se volvieron cada vez más usuales en el idioma hablado en esos días, pero éstos indudablemente echaban raíces en el ilustrado siglo XVIII español. ${ }^{312}$ Se recuperaban a la vez algunos de los tópicos clásicos del "patriotismo criollo" y su incesante reclamo por el acceso a los cargos de los españoles americanos. ${ }^{313}$ También la memoria contenía vocablos que se repetían en los impresos y lenguajes que circulaban en el imperio transoceánico desde fines del siglo XVIII, pero actualizados con la crisis, como abusos, opresión, injusticia. Como vimos en el capítulo anterior, en la Circular que la Junta Central dirige a los virreyes y capitanes generales, desde Sevilla el 9 de enero de 1809, se puede leer por ejemplo: "se trata que de reformar abusos, mejorar las instituciones, quitar trabas, proponer fomentos y establecer las relaciones de la metrópoli y las colonias sobre las verdaderas bases de la justicia." ${ }^{314}$ Había allí un terreno compartido de lenguajes antidespóticos y de lucha contra gobiernos opresores incorporado por el grupo reformista para dar inicio a una crítica al sistema colonial que se iría volviendo cada vez más radical con el

\footnotetext{
311 "Memoria...", Mayo Doc., p. 104. Esta vocación reformista manifestada por el grupo causó no pocos reparos en el círculo íntimo de la princesa, preocupados de que los criollos consideraran que la autoridad que le investía "fuera fruto de su propia creación y no del derecho absoluto". Sydney Smith a Rodrigo de Souza Coutinho, Rio de Janeiro, 19 de noviembre de 1808, $A G N$, t. I, pp. 283-284, citado en Ternavasio, M., Candidata..., p. 151.

${ }^{312}$ Ternavasio, M., "Una princesa...”, p. 124.

${ }^{313}$ Véase Brading, David, Orbe indiano. De la monarquía católica a la república criolla, 1492-1867, F.C.E., 1993. Para los aspectos más jurídicos del criollismo ver Garriga, Carlos, "Patrias criollas, plazas militares. Sobre la América de Carlos IV", en Martiré, Eduardo (coord.), La América de Carlos IV. Cuadernos de Investigaciones y documentos. Buenos Aires, Instituto de Investigaciones de Historia del Derecho, 2006.

${ }^{314}$ Ramos, D., óp. cit., pp. 180-181.
} 
desarrollo del proceso. ${ }^{315}$ La asociación de la condición de colonia con la de esclavitud es quizás el ejemplo más ilustrativo en ese sentido. Refiriéndose a América llegan a decir que se trata de "un suelo que no ha conocido la libertad", 316

Los firmantes, además, reclaman a la Infanta que de aceptar la propuesta debería separar sus derechos de la corona portuguesa, para despejar cualquier suspicacia de los que se oponen a su regencia pero seguramente como reaseguro propio, recelosos ellos también de que la corona lusitana encuentre en esto una vía para concretar sus históricas pretensiones sobre el Rio de la Plata. Para terminar de hacernos la idea de lo extremadamente táctico de esta alianza, podemos tomar las apreciaciones de Contucci, uno de los agentes involucrados en esta trama, en carta al Conde de Linhares. Para el florentino el apoyo de los porteños no se debía "al amor a la antigua y venerable constitución española" sino de "un conjunto feliz de circunstancias que hacían coincidir los intereses de S.A.R. con los intereses y pasiones de los particulares". 317

\section{Diálogo entre un castellano y un español americano}

Entre los numerosos papeles anónimos de propaganda que circularon apoyando la regencia se destaca el "Diálogo entre un castellano y un español americano" fechado hacia fines de 1808. Atribuido a la pluma de Manuel Belgrano, fue enviado a la infanta a través de Felipe Contucci con el pedido expreso de reproducir cuatro mil ejemplares en la imprenta de la Corte para ser repartido en toda la América española, buscando hacer circular entre la población su caracterización del estado de cosas y fundamentalmente cual era el rumbo correcto a seguir por parte de los americanos ante la crisis que atravesaba la monarquía. ${ }^{318}$ Con un lenguaje accesible, seguía una modalidad pedagógica tradicional, recientemente revalorizada por el reformismo borbónico, que de alguna manera buscaba escenificar las discusiones ocurridas en plazas, cafés o tertulias. ${ }^{319}$

El Diálogo comienza con el castellano comentándole al americano lo afligida que se encuentra su alma producto de las recientes y funestas noticias llegadas desde la madre patria. El conocimiento en América del desastroso estado de la España con

\footnotetext{
${ }^{315}$ Ternavasio, M., Candidata ..., p. 146.

316 "Memoria...", p. 106.

${ }^{317}$ Citado en Ternavasio, M., Candidata ..., p. 163.

${ }^{318}$ Ibid., p. 163.

${ }^{319}$ Molina, E., El poder de la opinión pública. Trayectos y avatares de una nueva cultura politica en el Río de la Plata, 1800-1852, Santa Fe, Ediciones de la Universidad del Litoral, 2009, p. 46.
} 
Napoleón “desgarrándola por dentro" provoca, dice, el exaltamiento de los espíritus y, por lógica, la diversificación de las opiniones sobre el rumbo que debe tomar el nuevo continente ante la más que probable situación de que el águila imperial se apodere por completo de la metrópoli. Ante la consulta de su interlocutor, el castellano pasa a enumerarle las distintas opciones que son barajadas por la población. Algunos, dice, opinan que "debemos seguir la suerte de la metrópoli, aunque reconozca la Dinastía de Napoleón; otros que nos debemos constituir en República; otros que continúe el Gobierno en mano del actual Jefe hasta que vuelva Fernando VII; y otros que debemos que debemos reconocer a la Infanta de España D. Carlota Joaquina, por Regente de estos dominios". ${ }^{320}$ Preocupado por el tono acalorado de esos debates, teme la "anarquía y desolación" de estos países. Consultado por la razón de esta diversidad de opiniones, sostiene que se deben a la desunión, a la variedad de intereses y a la peligrosa ausencia de una autoridad que pueda fijarlas, más cuando se vislumbra una mano oculta que contribuye a la división para sacar un mejor provecho. Todavía en clave ilustrada, la diversidad de opinión era considerada negativamente, al igual que la existencia de intereses contrapuestos y del faccionalismo que se origina de aquellos. Falta todavía para que se empiece a considerar como un elemento positivo la contraposición de opiniones como punto de partida para la mejora del sistema.

Volviendo al Diálogo, el español americano toma de aquí en adelante el rol protagónico en la conversación, pasando a evaluar cada una de las opciones comentadas por su compañero. Seguir los pasos de la metrópoli a su entender debe ser descartado de plano porque no implica otra cosa que la traición misma, no sólo a los juramentos hechos a Fernando VII, sino también a la Santa Religión y a "nuestros bravos paisanos" que han dado su vida en suelo español. El castellano acota que "ojalá" escucharan esto los "del partido", haciendo quizás referencia a algún posible agrupamiento pro-francés en el virreinato.

Retomando el americano la palabra, considera aún más perjudicial la opinión de constituirse en Republica, y justifica sus razones en la ausencia de las bases principales en las que cimentarla, fundamentalmente genuinas riquezas y conocimientos, conduciendo a la división entre españoles y americanos, quedando a merced de la ambición de alguna potencia extranjera. Es interesante notar igualmente que no la descarta en términos teóricos, no manifiesta una oposición frontal a ese sistema de

\footnotetext{
320 "Diálogo entre un castellano y un español americano", Mayo Doc., t. 1, p.4.
} 
gobierno, sino que basa su rechazo desde la imposibilidad real de llevarlo a la práctica por falta de condiciones básicas. Similar idea que, como veremos más adelante, tenían algunos patriotas como San Martín y el propio Belgrano, lo que los inclinaba por el modelo de la monarquía constitucional como el más indicado para los pueblos americanos.

Con respecto a la opción que implica que el actual jefe siga gobernando hasta la vuelta de Fernando VII, el criollo la considera inviable por entender que las autoridades caducaron y que en este caso dejarían de representar a la nación, por no estar sostenidas ni por su constitución ni sus leyes. Faltaría poco, dice, para que los vasallos sintieran que sus derechos no están siendo protegidos y que la soberanía estaba siendo conculcada en sus manos. No podemos dejar de notar que términos como nación, constitución, derechos y soberanía están presentes en el documento, lo que hace referencia a las trasformaciones que se estaban produciendo en el lenguaje político del período, que como venimos observando, no se limitaban sólo al epicentro del proceso que era la península, sino que recorrían tempranamente toda la extensión imperial. La idea de autoridades incumpliendo sus deberes, desprotegiendo los derechos de sus vasallos, ya no solo hacía referencia al pactismo de la tradición hispánica. El problema de la representación y soberanía nacional comenzaba a tensionar al conjunto de lenguaje político, otorgándole otros sentidos a conceptos antes asociados a fundamentos tradicionales.

Finalmente, luego de descartar las primeras tres opciones, el americano afirma sin titubeos que la única que puede hacer felices a los pueblos americanos es reconocer a la Infanta Carlota Joaquina como regenta de estos dominios. Y ante la pregunta del cómo, responde que "haciendo revivir en estos dominios la España con su constitución, y leyes, esto es, siguiendo la Monarquía Española, bajo el gobierno representativo que la constituye, con arreglo a los fundamentos primordiales de Castilla". ${ }^{321}$ Según esto, era la Infanta Carlota la única integrante de la casa reinante en condiciones de hacerse cargo de representar esa soberanía. Considera poco fundamentados los temores, para tranquilidad del castellano, que plantean por un lado el peligro de pasar a ser un dominio portugués, ni aquel que aventura que Inglaterra intervendría en contra de estos planes. Cierra el americano, al escuchar con satisfacción que ha logrado convencer a su interlocutor, reafirmando que sólo ésta última alternativa conducirá a un gobierno

${ }^{321}$ Ibid., 6 
estable y ejemplar, evitando de esa manera la destrucción total del continente español americano.

La iniciativa de Belgrano en la estrategia carlotista no se limitó a este escrito de propaganda. Fueron varias las cartas que le envío a la misma Infanta, reclamándole su traslado a Buenos Aires, a la vez que le aconsejaba que lo hiciera "sin tropas ni séquito" para no generar recelos. En su arriesgado juego de ajedrez, le proponía que haga partícipe de sus planes al embajador español en Rio de Janeiro, el marqués de Casa de Irujo, desvirtuando de esa manera los puentes entre la metrópoli y los dominios americanos. $^{322}$ El levantamiento en Charcas de mayo de 1809 , que abordaremos en el capítulo siguiente, como rechazo a una supuesta conspiración carlotista de las autoridades, había estremecido al virreinato y Belgrano lo utilizaba también en sus comunicaciones con Carlota para acentuar la urgencia de que se decidiera a trasladarse a la capital.

\section{Intrigas y traiciones carlotistas}

Como parte de las acciones que buscaban erigir a Carlota como regente, sumadas a los escritos que acabamos de analizar, se destacaron varias intrigas paralelas que tuvieron a algunos de los miembros del "partido criollo" como protagonistas. Uno de ellas fue el plan ideado por Saturnino Rodríguez Peña, que permanecía exiliado en Rio de Janeiro tras haber facilitado la fuga del General Beresford. Demostrando un importante eclecticismo, sus miras independentistas bajo el patrocinio británico habían variado producto de las abdicaciones de Bayona y la llegada de Carlota a América, convirtiéndose en un fervoroso promotor de la regencia de ésta. De esa manera Peña pasaba a defender una independencia -según el vocablo por él utilizado- que implicaba mantenerse dentro de la monarquía y bajo la dinastía reinante, pero librándose del gobierno colonial al que consideraba corrupto y abusivo, y poniéndole un dique también a las ambiciones napoleónicas sobre el continente. ${ }^{323}$ A partir de la correspondencia que por esos meses seguía manteniendo con Francisco de Miranda, podemos saber además que en sus planes estaba contemplada la convocatoria a unas Cortes americanas, a través

\footnotetext{
322 “Carta de Manuel Belgrano a Carlota Joaquina”, 9 de agosto de 1809, citada en Ternavasio, M., "Una princesa...", p. 131.

${ }^{323}$ Esa independencia defendida por Peña es la que hoy los historiadores llamamos autonomía, y que como hemos visto en otros pasajes de la investigación, ha llevado muchas veces a confusiones, intencionadas o no, por parte de la historiografía nacionalista tradicional. Ternavasio, M., Candidata ..., p. 154.
} 
de las cuales poder acordar las condiciones de la regencia de la Infanta. ${ }^{324}$ Gracias a estas además era posible que América pudiera pasar de la condición de colonia a la de reinos de pleno derecho. A fines de enero de 1809, Belgrano hacía explicito el mismo objetivo en un manifiesto reclamando que en el caso de ser sometida la metrópoli "se celebren inmediatamente Cortes para que establecida la Regencia de la Sra. Infanta Da. Carlota Joaquina, haya un gobierno que sirva de ejemplo a la decadente Europa", asegurando que esta era la única opción de escapar a "la serpiente que quiere inducirnos a la democracia". ${ }^{325}$ Como bien señala Ternavasio era este el planteo más audaz de los criollos carlotinos para concretar su proyecto de americanización de la monarquía. ${ }^{326} \mathrm{El}$ llamado a Cortes como mecanismo para la reforma de la monarquía, a pesar de los diversos objetivos que perseguían, constituye uno de los puntos en común que podemos establecer entre los reformistas tanto de un margen del Atlántico como del otro, cuestión que desarrollaremos más adelante.

Peña, en contacto con la infanta gracias a la intermediación del almirante Sidney Smith, comandante de la flota inglesa, decidió enviar un nuevo agente al Río de la Plata para promocionar la regencia. El elegido era un medico ingles de ascendencia francesa llamado James Paroissien -luego castellanizado su nombre por el de Diego-, que había arribado a América durante la ocupación británica. ${ }^{327}$ La misión de Paroissien consistía, entre otros encargos, en hacer llegar varias cartas a diversos destinatarios en Buenos Aires, entre ellos Liniers, Álzaga, Sobremonte y obviamente el grupo de criollos reformistas. Pero el joven médico nunca pudo llegar a destino. Fue arrestado ni bien arribó a Montevideo, donde le fueron incautados los papeles y se le inició una causa judicial. Llamativamente la captura fue instigada por Carlota, que había introducido en el mismo barco un agente que debía delatarlo ante las autoridades y había enviado carta a Liniers donde lo acusaba de portar pliegos que contenían "principios revolucionarios y subversivos del presente orden monárquico". ${ }^{328}$ La maniobra fue orquestada por el secretario de la princesa, otro viejo conocido nuestro, el español José Presas. Parece que fue él el que le insinuó a Carlota que Peña y toda su red eran "republicanas" y que lo único que buscaban era usarla como un instrumento para alcanzar la independencia.

\footnotetext{
324 "Saturnino Rodríguez Peña a Francisco de Miranda", Rio de Janeiro, 4 de octubre de 1808, Mayo Documental, t. III, pp. 215-217.

325 "Manifiesto de 'Los hijos del Perú' a los de la gran Buenos Aires", fines de enero de 1809, Mayo Documental, t. VII, p. 292.

${ }^{326}$ Ternavasio, M., Candidata ..., pp. 154-155.

${ }^{327}$ Wasserman, F., Castelli..., p. 67.

328 "Carta de Carlota Joaquina a Santiago de Liniers", Rio de Janeiro 1 de noviembre de 1808, en Biblioteca de Mayo, t, XI, pp. 10095-10096.
} 
Aunque la idea original era dejarlo llegar a Buenos Aires para descubrir hasta donde llegaban los hilos de la conspiración, Elío al enterarse no pudo con su genio y quiso ser el también protagonista de esta historia de espionaje. Los porqués de la traición de Carlota aún siguen siendo motivo de especulación. El fiscal del crimen de la Audiencia de Buenos Aires, encargado de la investigación abierta con la detención de Paroissien, se planteaba dos hipótesis de trabajo para resolver la trama de la conspiración: o Carlota había engañado a los "revolucionarios" para que se pusiera en evidencia sus planes independentistas, o había promovido e instigado inicialmente al grupo, bajo tutela inglesa, pero al ver el "rumbo favorable" que tomaba la guerra en la península contra Napoleón había decidido echarse para atrás.

\section{El alegato de Castelli en el juicio a Paroissien}

El arresto de Paroissien desembocó como vimos en una causa judicial en la que estuvieron involucrados varios personajes destacados de la política local. Castelli, a pesar de ser nombrado en varias de las cartas incautadas, sólo es llamado como testigo en diciembre de 1808, donde declara que a pesar de tener vínculos personales con varios de los imputados en la causa, como los hermanos Rodríguez Peña, estos no son del tipo conspirativo y que en ningún momento alguno de ellos se pronunció en contra de Fernando VII o a favor de la independencia de España. La actuación de Castelli en la causa no terminaría aquí porque, en su calidad de abogado, asumió la defensa del desafortunado médico inglés. Y en dicha función es que presentó en marzo de 1810 un alegato forense de notable importancia para nuestro estudio, porque en él, además de un lúcido diagnóstico de la situación que atravesaba la monarquía española por esos meses, se anticipaban los argumentos que expondría en el Cabildo abierto unas pocas semanas más tarde.

En la argumentación desplegada en su defensa, Castelli advierte que las ideas contenidas en las cartas de Rodríguez Peña incautadas a Paroissien no eran las mismas que había sostenido en el pasado cuando tuvo que exiliarse en Río de Janeiro luego de facilitar la fuga de Beresford, con la esperanza de obtener el apoyo inglés para una lograr una independencia bajo su protectorado. Por lo tanto, si las cartas no contenían ninguna propuesta ilegal, Paroissien tampoco podría ser considerado un criminal.

Para Castelli, cuando Peña utilizaba la voz independencia en sus cartas no se estaba refiriendo a su antiguo objetivo de cortar los vínculos con la madre patria, por el 
contrario no había dudas que en realidad se refería a sustraer a América de una posible dominación francesa. Sus planes, por lo tanto, no solo no eran subversivos ni criminales, sino que constituían una actitud encomiable de un fiel defensor de la monarquía española, que se proponía constituir una autoridad legítima en manos de la infanta.

Esos papeles contienen no una independencia criminal, cuál sería la constitución democrática o aristocrática de la América española, de su gobierno legítimo, sino una constante adhesión a él, y una positiva oposición a depender en primer lugar de la nueva dinastía francesa, y segundo de toda dominación europea, en las suposiciones dadas; fijando, por conclusión, en el reconocimiento de la soberanía nacional la concentración del poder gubernativo trasladado a la América española. ${ }^{329}$

A su entender la voz independencia había variado de sentidos junto a las novedades políticas en España, convirtiéndose en "tan diversa, cuanto difieren las circunstancias, los motivos y los fines". Era necesario acoplarle un calificativo - "absoluta", "democrática", "aristocrática"- para ser identificada cabalmente por los protagonistas del periodo, porque a secas podía ser sinónimo como dijimos anteriormente de autonomía u autogestión.

Castelli aclaraba que la propuesta de la Regencia no se trataba de la exclusión ni de Fernando VII ni sus hermanos varones de su derecho al trono, y que duraría mientras estos estuvieran carentes de su libertad. Tampoco se trataba de la unión con la corona de Portugal. La regencia se establecería como poder central en América de un reino separado, que no trastocaría ni la forma ni la constitución de la monarquía, llevando adelante las reformas necesarias sin que esto implicase desquiciar el trono. Además deja en claro que la independencia política a la que se refería Peña era en la suposición de hallarse España ocupada por los franceses y no contar con un gobierno nacional representativo del soberano de España. En ningún momento atacaba la naturaleza monárquica del reino sino que por el contrario su propuesta la sostenía: "La conservación en el trono español de la familia de Borbón [...] es dogma político de la nación, sin que toda ella pueda variar la forma, y constitución del reino en nada, si no es por los mismo principios, y formas en que se constituyó como estado soberano, reconocido y garantizado por los estados libres, amigos y aliados, y de consiguiente

\footnotetext{
329 "Memorial de Diego Paroissien firmado por su defensor Juan José Castelli y su procurador Andrés José de Acosta, 14/3/1810", en Actuación de Saturnino Rodríguez Peña y Diego Paroissien, 1807-1810, Biblioteca de Mayo, t. XI, p. 10.344.
} 
sometido a la ley inviolable del instituto social". ${ }^{330}$ Detrás del alegato lo que se percibe es la continuidad de esa aspiración reformista que el grupo carlotista venía sosteniendo por lo menos desde principios de la crisis.

Castelli advierte que el acusado nada sabía al momento de trazar su plan de la instalación de la Junta Suprema Central, pero aun así -y aquí comienza a desplegar varios de los argumentos que servirán de sustento a su famosa exposición en el cabildo abierto del 22 de mayo-, plantea que la misma no posee la suficiente representación para arrogarse la soberanía sobre las provincias ultramarinas. La Junta Suprema Central tiene a su entender similar legitimidad que las otras juntas provinciales que pretendieron ejercerla en América, "sin títulos ni poder ni autoridad". Los pueblos de América “tenían el mismo motivo y ocasión de necesidad para exigir una representación de la soberanía embotada en la persona del Rey, como la tuvo Sevilla que ni es más ni es menos en los derechos de pueblos, y de parte integrante del Estado". ${ }^{331}$ Las autoridades coloniales por su parte tampoco podían representar la soberanía real, sólo obraban estas en mera ejecución subordinada y alterna. De esa manera Castelli no solo justificaba la iniciativa de Peña y Paroissien, sino que establecía un rechazo teórico a la potencial ambición de los Virreyes de erigirse en los nuevos pilares desde donde reconstruir el poder español en América una vez perdida la península.

Otro de los argumentos que se perfilan en el alegato y que luego serían utilizados por los miembros de la junta revolucionaria para legitimar su desconocimiento al gobierno metropolitano, es el que subrayaba que el vínculo de América no era con la España, sino con la Corona de Castilla, por lo tanto la propuesta de la regencia de la princesa borbona no constituía para nada un delito, al no privarle a la familia real del dominio de los territorios americanos.

Para justificar la discreción y el sigilo con el que Paroissien llevo adelante su misión, Castelli, carga contra aquellos "presuntuosos filósofos y publicistas, o imitadores ciegos de [...] las vagas ideas de libertad, e independencia popular". ${ }^{332}$ Explica que la actitud reservada responde a su vocación de asegurar la tranquilidad pública y evitar que "los pueblos entrasen en fermentación, cuando las ideas se difunden sin método y por conductos nada idóneos". ${ }^{333}$ Ya hablamos al comienzo del capítulo de los temores que recorrían a las élites coloniales después de los levantamientos indígenas

\footnotetext{
${ }^{330}$ Ibid., p. 10350.

${ }^{331}$ Ibid., p. 10351.

${ }^{332}$ Ibid., p. 10353.

${ }^{333}$ Ídem.
} 
andinos y la revolución esclava en Saint-Domingue. Castelli buscaba entonces desvincular del imaginario el accionar de su defendido de esos antecedentes, utilizando argumentos que parecieran provenir de un ideario seguramente mucho más conservador del que íntimamente adscribía.

Finalmente, para el abogado criollo era absurdo que fuera considerado un delito hablar de mejoras en las leyes, constituciones y reunión de cortes, en la medida que

\section{[...] los más acreditados españoles, las juntas supremas, y la Central no paran} de hablar y protestar cortes, y constitución, reformas en el gobierno, barreras al despotismo, derogación de leyes tiránicas, etc., anunciando la regeneración del estado, sobre su libertad, y restauración de la sagrada, y augusta persona del Rey, que fijan para el último periodo de la revolución. ${ }^{334}$

Es interesante este pasaje por varias razones. No sólo es calificado como una revolución al estado de la península, sino que también da cuenta de lo familiarizados que estaban los rioplatenses con los debates que la atravesaban, en relación a las distintas propuestas en danza para superar esa crisis inédita. El renovado lenguaje político del que hablábamos más atrás, marcado a fuego por las disputas hacia el interior de la Junta Central entre absolutistas, reformistas y liberales, era volcado intensamente también en las páginas de manifiestos, periódicos y otros papeles que cada tanto cruzaban el océano con dirección a América. La bandera de las reformas contenía las suficientes sugestiones como para brindar, dentro de ella, las ilusiones de su posibilidad. La cuestión radicaba en la confianza que pudiera merecer la metrópoli como garante de ese rumbo, y sobre todo en la participación que cada mundo tendría en la realización de esas mismas ilusiones y en el signo de tales aspiraciones. ${ }^{335}$ Por otro lado, también interesa el pasaje porque como se haría costumbre luego en las proclamas de la junta revolucionaria porteña, al igual que en la Gazeta morenista, el planteo de Castelli es a la vez una reivindicación del derecho que tienen los americanos a poder pensarse como partícipes en igualdad de condiciones en la discusión política de los destinos de la monarquía. Porqué en su caso sería delito pensar una solución a la crisis monárquica, porqué se les estaría negado proponer ciertas reformas al reino, mientras los peninsulares están embarcados en ello desde el mismo levantamiento nacional tras las abdicaciones de Bayona. Cuando Moreno tuviera que justificar la formación de la Junta

\footnotetext{
${ }^{334}$ Ibid., p. 10354.

${ }^{335}$ Ramos, D., óp. cit., p. 185.
} 
Provisional Gubernativa de las Provincias del Río de la Plata, recurriría a similares argumentos: porqué allá sí está permitido y aquí no. Esa noción legítima y compartida por ambos mundos de que sólo en la península se decidía los destinos de la monarquía hispánica, de la que habla Halperín Donghi en Revolución y Guerra, para principios del diez ya presentaba importantes fisuras. ${ }^{336}$

${ }^{336}$ Halperín Donghi, T., Revolución y Guerra..., p. 160. 


\section{Capítulo 5:}

\section{La alternativa juntista}

\section{La rebelión lealista de Elío y la Junta de Montevideo}

En agosto de 1808 Santiago de Liniers, como vimos, recibió junto al Cabildo y la Audiencia al emisario napoleónico, el Marqués de Sassenay, portando papeles en los que se daba cuenta de las abdicaciones, la elección del rey José Bonaparte y la convocatoria a un congreso en Bayona. Muchos de esos papeles estaban avalados con la firma de autoridades españolas, lo que generó bastante incertidumbre. El intento por parte de las autoridades de mantener en secreto estas gestiones y novedades fue en vano. El rumor de la presencia de Sassenay en Buenos Aires había trascendido, y despertó todo tipo de infidencias. Se especulaba sobre las apetencias de Napoleón respecto a las colonias españolas en América y esto abrió la puerta a los rumores sobre la posibilidad de que el Río de la Plata jurara obediencia a la nueva dinastía francesa. Con el objetivo de calmar las aguas, el 15 de agosto el Virrey lanzó una proclama a los habitantes de Buenos Aires en la que se informaba parcialmente la situación y se manifestaban las preocupaciones del gobierno virreinal. Se ratificaba la fidelidad del pueblo de Buenos Aires a su legítimo soberano pero lejos se estaba, por las expresiones utilizadas, de condenar a Napoleón. Si bien se presume que la proclama fue redactada por uno de los oidores y contó con el acuerdo de la Audiencia y del Cabildo, fue utilizada luego por los adversarios de Liniers para argumentar su postura indecisa respecto de Napoleón. ${ }^{337} \mathrm{Su}$ condición de francés de nacimiento lo colocaba en una situación complicada, más allá de que había dado sobradas muestras de su lealtad a la bandera española, para algunos un manto de desconfianza cubría su figura desde la invasión de Napoleón a la península. La llegada del enviado francés, su recibimiento y la supuestamente tibia proclama, no hizo otra cosa que dar argumentos a sus enemigos para atacarlo. Francisco Javier de Elío, gobernador interino de Montevideo, fue quién tomó la iniciativa y acusó de pro francés a Liniers. ${ }^{338}$ A través de un pliego firmado por el propio gobernador y cuatro miembros del Cabildo de Montevideo, y dirigido a la Audiencia y al Cabildo de Buenos

\footnotetext{
${ }^{337}$ Ternavasio, M., Historia de la Argentina, p. 54.

${ }^{338}$ Elío llegó a la región con el cargo de comandante general de la campaña cuando los ingleses dominaban la ciudad y fue designado gobernador interino por el mismo Liniers cuando estos se retiraron, ya que el titular del cargo, Pascual Ruiz Huidobro, había sido trasladado en calidad de prisionero a Inglaterra.
} 
Aires, le atribuyó una conducta "sospechosa" y lo acusó de "infidencia", solicitando que fuera removido del cargo.

Elío había manifestado siempre cierta insubordinación respecto de la autoridad virreinal, reavivando viejas rivalidades entre Montevideo y Buenos Aires. Pero ahora, ante tamaña declaración de hostilidad, Liniers reaccionó enviando al capitán de navío, Juan Ángel Michelena, para relevar del mando a Elío. Sin embargo, a pesar de contar con el apoyo de la Marina Real, a través del Comandante de la Marina en Montevideo Joaquín Ruiz Huidobro, nada pudo hacer cuando el rebelde gobernador se resistió a acatar la orden. La falta de respuesta de los comandantes de las tropas terrestres españolas de línea y milicias ante sus requerimientos, excusándose por diferentes razones, marcaban que el apoyo brindado por la marina no era esperable por parte de otras fuerzas. Durante la noche del 20 de septiembre se produjo una movilización de características tumultuarias oponiéndose al desplazamiento de Elío. ${ }^{339}$ El frustrado intento de poner orden por parte de Liniers terminó con la grotesca escena en la cual Michelena intentó hacer uso de las armas para obligar al insubordinado gobernador a aceptar su destitución, siendo vergonzosamente desarmado y golpeado por Elío. ${ }^{340}$

Un cabildo abierto reunido en Montevideo el 21 de septiembre respaldó al gobernador y resolvió "establecer una junta subalterna de la de Sevilla a imitación de las de España" para tutelar los derechos de Fernando VII al trono, nombrando a Elío como su presidente al día siguiente. En su breve pasaje por la plaza montevideana, el enviado de la Junta de Sevilla, el Brigadier José Manuel de Goyeneche, habría indicado al gobernador y miembros del Cabildo con quienes se reunió que "marchaba al momento à la Capital donde [...] trataría de formalizar la Junta à imitación de la Suprema de Sevilla, que para ello traía especial encargo, y después se formaría en esta [Montevideo] otra subalterna". ${ }^{341}$ De esta manera, como marca Ternavasio:

\footnotetext{
${ }^{339}$ Ferreira, Pablo, "La guerra de independencia española, los “empecinados” y el Montevideo leal, 18081814", Pasado Abierto No4. Mar del Plata. Julio-Diciembre 2016, p. 48.

${ }^{340}$ Olivero Orecchia, José M., "La junta de Montevideo en 1808, una situación interna con repercusiones internacionales: algunos aspectos de los intereses y acciones portuguesas, estudios históricos", CDHRP, Diciembre 2009, No 3 .

341 "Certificación del Cabildo de Montevideo de lo acontecido la noche del 19 de agosto de 1808 luego del arribo del brigadier José Manuel de Goyeneche a dicha ciudad”, citado en Frega, Ana Lucia, «La Junta de Montevideo de 1808» en Chust, Manuel ed., 1808. La eclosión juntera en el mundo hispánico, México, FCE, 2007, p. 247. A su arribo a Buenos Aires, Goyeneche se limitó a informar sobre el estado de la península y la alianza con Gran Bretaña, solicitando el envío de auxilios. Aparentemente nada presentó en torno a la formación de juntas en América. En nota dirigida al Conde de Floridablanca y la Suprema Junta de España e Indias en abril de 1809, Goyeneche desmintió el apoyo que pudo haber dado a la constitución de la Junta montevideana y acusó, por el contrario, al entonces alcalde de primer voto del Cabildo de Buenos Aires, Martín de Álzaga y Elío de haber conspirado contra el virrey. Ibíd., p. 248.
} 
[...] la Banda Oriental lograba lo que en el marco de la legalidad colonial no habría sido posible: la autonomía absoluta respecto de Buenos Aires. Una autonomía que, al recuperar el ejemplo juntista español y la declaración de fidelidad al rey Fernando VII, procuraba dotarse de una nueva legitimidad. En este punto, es importante subrayar que no existía en dicha junta un reclamo de derecho al autogobierno frente a las autoridades sustitutas del rey en la metrópoli -por el contrario, buscaba reforzar ese lazo, que en ese momento era con la Junta de Sevilla-, sino un reclamo de autonomía respecto -o en contra- de su antigua rival Buenos Aires. ${ }^{342}$

Fue ésta la primer Junta que en América invocó la conservación y defensa de los derechos de Fernando VII, pero como bien sabemos no sería la única. En sus nueve meses de funcionamiento gobernó en forma autónoma su jurisdicción y realizó gestiones ante las autoridades peninsulares, diversas ciudades del virreinato y representantes de gobiernos extranjeros.

Según Ana Frega, varios documentos emitidos por el Cabildo señalan su amplia representatividad. Y aunque la Real Audiencia bonaerense denunció el peligro de una "efervescencia popular tumultuaria", la realidad es que sus principales animadores fueron reconocidos miembros de la élite. ${ }^{343}$ Altos oficiales, funcionarios, importantes comerciantes y hacendados, letrados y sacerdotes aparecen repetidamente mencionados y sus firmas lucen al pie de las principales resoluciones. Como señala Wilson de Muro, la crisis monárquica y el conflicto con el Virrey le ofreció a la clase alta montevideana la oportunidad de obtener privilegios regionales en su puja mercantil con Buenos Aires, al tiempo que impulsó la revitalización política del Cabildo en una coyuntura signada por el vacío de poder y los debates sobre el problema de la soberanía y su retroversión al pueblo. ${ }^{344}$ Frega señala que:

\section{[...] junto al gobernador y los efectivos militares, importantes comerciantes} apoyaron la Junta e incluso fueron acusados ante las autoridades virreinales de ser los promotores de la rebeldía. Dedicados a la importación y exportación, se habían enriquecido con el comercio de esclavos, la extracción de cueros y carne salada y, más recientemente, con la adquisición de las mercaderías británicas luego de la capitulación en

\footnotetext{
${ }^{342}$ Ternavasio, M., Historia de la Argentina ..., p. 58.

${ }^{343}$ Frega, Ana, "Tradición y modernidad en la crisis de 1808. Una aproximación al estudio de la Junta de Montevideo". Sociedad y cultura en el Montevideo colonial. Eds. Luis Behares y Oribe Cures. Montevideo: Fac. de Humanidades y Ciencias de la Educación, Intendencia Municipal de Montevideo, 1997, pp. 283-294.

${ }^{344}$ De Muro, Wilson, "La participación política del clero rioplatense a fines del periodo colonial. El conflicto entre la Junta de Montevideo (1808-1809) y el párroco de la ciudad". Fronteras de la Historia, Vol. 21, N. ${ }^{\circ}$ 2, julio-diciembre de 2016, p. 137.
} 
julio de 1807 [...] No se oponían al comercio con Gran Bretaña, Portugal u otras potencias neutrales -lo practicaban de forma ilegal cuando España estaba en guerra con esas naciones-, sino a la pérdida de los privilegios de la intermediación y de las consignaciones. En ese sentido parecía vital conservar el control político de estos territorios, así como ventajoso lograr una jerarquía político-administrativa superior en la organización colonial, que les permitiera un mayor control de los recursos y autonomía en la toma de decisiones. $^{345}$

Pero aunque la justificación de las principales autoridades y la alta burguesía para la formación de la Junta respondiera a las supuestas maquinaciones del virrey con franceses, portugueses o independentistas, algunos letrados montevideanos se apropiaron del discurso "renovador" del proceso abierto con las abdicaciones y legitimaron el paso dado desde argumentos que hacían eje en la igualdad entre europeos y americanos para resolver el vacío de poder y dar una salida a la crisis que tuviera en cuenta la reasunción de la soberanía por parte de los pueblos. Es el caso del doctor Lucas Obes, que en correspondencia privada afirmaba que si el pueblo español había reasumido sus facultades y por ello podía introducir "novedades" en el gobierno, también podía hacerlo "la América como parte integrante de ese pueblo, nación, reino o como Ud. quiera llamarle". Para finalizar afirmando que "no solo estamos facultados para hacer lo que tenemos hecho sino también, para llevar nuestro voto a la Junta que reconozcamos por Suprema, que pensar de otro modo es establecer una distinción la más odiosa entre la Metrópolis y la América". 346

Al igual que sucediera en el resto del imperio, la formación de la junta provocó el inmediato rechazo por parte de las autoridades coloniales residentes en la capital, muy especialmente de la Audiencia. Los oidores calificaron a la junta montevideana como opuesta a las leyes, negándoles el derecho a legitimarse con el argumento de emular la situación en España, debido a la ausencia de un ejército invasor en América. Liniers y la

\footnotetext{
${ }^{345}$ Frega, Ana, "La Junta de Montevideo...”, p. 252.

346 "Carta de Lucas J. Obes al Dr. Vicente Anastasio de Echevarría fechada el 24 de octubre de 1808”. Citado en Frega, Ana, "La Junta de Montevideo...", pp. 254-255. Lucas J. Obes era oriundo de Buenos Aires, hijo de un alto funcionario español. Estudió en Buenos Aires y en el Colegio de Monserrat de Córdoba. Se recibió de abogado y terminó sus estudios en Madrid. Regresado en 1804 al Rio de la Plata instalándose en Montevideo, donde se desempeñó como asesor del gobierno. Cuando arribó el virrey Cisneros, que disolvió la Junta, pasó con él a Buenos Aires. Allí fue asesor del virrey y también estuvo en contacto con Mariano Moreno, tanto antes como después de la Revolución de Mayo. Volvió en diciembre de 1810 a Montevideo, donde el gobernador Gaspar de Vigodet lo hizo arrestar por partidario de la Junta de Buenos Aires. Cuando Elío asumió el mando en Montevideo, lo envió prisionero a España; tras un accidentado viaje en el que pasó por Río de Janeiro, Cuba y las islas Canarias, terminó por radicarse en Londres.
} 
Audiencia exigieron a Elío la disolución de la Junta, pero éste argumentó que era imposible debido a la "resistencia del pueblo".

Al virrey, como al resto de las autoridades coloniales le preocupaba que lo sucedido en la otra orilla del Plata sirviera de estímulo para la formación de otras juntas en la región, como podemos ver en este oficio que le envía a la Junta Suprema de Sevilla el 16 de octubre:

Esta inopinada insurrección combinada por un pérfido, que solo conspira a levantarse con el mando superior -creyendo sacar partida de las críticas circunstancias en que se halla la Península- me obligó a comunicar orden a este cabildo y a Elío, para que este continuase con el mando, y se disolviese la Junta, punto central de mis mayores cuidados para que este mal ejemplo no llegase a tener una influencia funesta en las Provincias Interiores. La Real Audiencia siguió los mismos principios por medio de una Real Provisión, pero esta, y mis órdenes fueron desobedecidas y la Junta subversiva continua sin reconocer ninguna autoridad. ${ }^{347}$

Pero a pesar de la evidente afrenta que la Junta significaba para su autoridad, Liniers decidió descartar la vía militar para la resolución del conflicto -en línea seguramente con el parecer del gobierno metropolitano-, eligiendo esperar al nuevo gobernador propietario designado en la península. Como señala Olivero Orecchia, Montevideo no se trataba de una ciudad fácilmente controlable por una autoridad externa si ésta no era aceptada. Era la principal plaza fortificada de la región, con una importante guarnición y control de la frontera terrestre en la Banda Oriental. Poseía además el Apostadero Naval, con la pequeña flota española del Atlántico Sur. ${ }^{348}$ También, como señala Frega, debió haber pesado a la hora de descartar el camino de la represión armada, el origen y posición social de los disidentes, así como su defensa de la legalidad monárquica. ${ }^{349}$ Muy diferente, como veremos, fue la actitud tomada poco después ante la Junta de La Paz. La mejor alternativa era entonces esperar que sea la metrópoli la que terminara resolviendo el conflicto, aun a sabiendas que los españoles tenían preocupaciones mucho más urgentes a las que atender.

\footnotetext{
347 "Oficio a la Junta Suprema de Sevilla del 16 de octubre de 1808", Documentos Relativos a la Junta Montevideana de Gobierno 1808, Montevideo, Junta Departamental de Montevideo, 1960, tomo 3, pp. 94-95. Citado en Olivero Orecchia, José M., óp. cit., pp. 6-7.

${ }^{348}$ Ibid, p. 4.

${ }^{349}$ Frega, Ana, “La Junta de Montevideo...", p. 257.
} 


\section{Un incómodo testigo del juntismo peninsular: Juan Martín de Pueyrredón}

Una muestra elocuente de los acelerados cambios ocurridos luego de la crisis monárquica y de los efectos que produjeron en los realineamientos de fuerzas internas es el proceso abierto a Juan Martín de Pueyrredón a fines de 1808, acusado de revolucionario y sedicioso. Veamos sucintamente las razones de tal procesamiento, que nos brindarán, a su vez, algunas claves interesantes para nuestro estudio.

Producto de su destacada actuación en la reconquista de Buenos Aires en 1806, al frente del escuadrón de Húsares, el cabildo abierto celebrado el 14 de agosto de ese año le había encomendado una misión a España, cuyo objetivo era dar cuenta al Rey de los méritos de la capital virreinal en su lucha contra los ingleses, con el objetivo de que le sean concedidas "las gracias, honras, exenciones y prerrogativas que fuesen de su real agrado". ${ }^{350}$ Aunque en cartas al cabildo confiesa que fue atendido con amabilidad por la pareja real, se queja del frío recibimiento brindado por el favorito Godoy y la poca voluntad de éste para atender sus pedidos, y lo responsabiliza de convencer al Rey para que ordene su vuelta a Buenos Aires. Denuncia también que un ministro le "manifestó descaradamente que el gobierno no debía acceder a las orgullosas ideas de Buenos Aires [...] y que nunca le permitiría a esa colonia, más que el adelantamiento en la ciencia abstracta de la teología y en la pastoría y la mineralogía". ${ }^{351}$ Desalentado y fastidiado con la actitud del Príncipe de la Paz y la corte de Madrid, escribe al cabildo dando a entender que el futuro le depara a la capital "glorias propias y empresas más grandes".

Los meses trascurrían en la capital española y el diputado porteño no hacía más que sumar frustraciones y resentimiento ante tanto destrato por parte del gobierno metropolitano. La llegada de la noticia del categórico triunfo del pueblo de Buenos Aires ante el nuevo intento inglés de someter la ciudad sería un alivio al espíritu del apesadumbrado emisario y un estímulo para renovar las gestiones ante la Corte. En noviembre de 1807 llegó a Madrid un nuevo enviado de Buenos Aires, Pedro de Altolaguirre, y junto a Pueyrredón se entrevistaron nuevamente con los reyes ahora con la novedad de la exitosa defensa ante la segunda invasión británica. Pero una vez más, a pesar de las felicitaciones protocolares, no obtuvieron respuestas positivas a los pedidos de la capital rioplatense.

\footnotetext{
${ }^{350}$ Acta del Cabildo del 24 de octubre de 1806. Citado en Raffo de la Reta, J. C., Historia de Juan Martín de Pueyrredón, Espasa - Calpe, Academia Nacional de la Historia, 1948, p. 48

${ }^{351}$ Citado en Raffo de la Reta, óp. cit., pp. 57-58.
} 
En diciembre de 1807 recibió del Cabildo un extraño encargo. Debía interceder ante los reyes para impedir que sea designado Liniers como virrey del Rio de la Plata. Martín de Álzaga, alcalde de primer voto y líder de la facción que dominaba el Cabildo, ya había lanzado su solapada guerra contra el héroe de la reconquista. Cercano a éste, Pueyrredón se encontraba en una incómoda situación, pero como enviado del Cabildo debía cumplir con la gestión, aunque lo terminó haciendo de manera estrictamente burocrática, trascribiendo punto por punto el oficio recibido. ${ }^{352}$

En dos documentos complementarios entre sí, Pueyrredón relata con detalle sus vivencias e impresiones sobre los hechos sucedidos en la península a partir de las abdicaciones de Bayona y el levantamiento juntista español. Esos papeles son "La fiel exposición que hace Don Juan Martín de Pueyrredón de su conducta pública” publicado en Rio Janeiro en 1809 y "La presentación al Cabildo" escrita seguramente también en 1809 en su viaje de vuelta a América pero publicada recién en 1815. En el primero de estos documentos, cuenta que en marzo de 1808, cuando estaba a punto de regresar a Buenos Aires, se produjo el Motín de Aranjuez, al que califica como un "feliz acontecimiento", debiendo postergar su viaje para "tributar a mi nuevo soberano los primeros homenajes del vasallaje", y muy especialmente después de que Su Majestad le mandara a decir que "esperase su vuelta pues quería que volviese yo contento y que contentase a mis paisanos". ${ }^{353}$ Pero esa entrevista no se habría de verificar porque poco tiempo después, Fernando VII era "conducido engañosamente a Bayona", por lo que el 1ero de Mayo el enviado porteño decidió salir precipitadamente de Madrid y dirigirse a Cádiz para poder embarcarse hacia Londres "con el objeto de tratar con aquella corte lo conveniente a la felicidad de mi amada patria", y de allí una vez concluidas esas gestiones proseguir hacia Buenos Aires. ${ }^{354}$ Pero en Cádiz las cosas comenzaron a complicarse para el enviado porteño. El gobernador de esa plaza, el Marques de Solana -acusado poco tiempo después por afrancesamiento y linchado durante el levantamiento popular-, le impidió embarcarse alegando órdenes de Madrid. Al parecer Murat exigía que se presentase en la Corte a la brevedad. Antes de acatar la orden, alcanzó a comisionar a José Moldes y Manuel Pinto para que se trasladen a Londres a solicitar asistencia militar para Buenos Aires, a cambio de ventajas comerciales. Regresó a

\footnotetext{
${ }^{352}$ Ya en agosto de 1808, en una situación política totalmente diferente con la invasión de Napoleón a la península y su ambición hacia los dominios americanos, ante una nueva comisión del Cabildo, Pueyrredón tendría esta vez mayor ímpetu pidiendo el alejamiento de Liniers del cargo.

${ }^{353}$ Museo Mitre. Documentos del Archivo de Pueyrredón. Buenos Aires: Imprenta de Coni Hermanos, 1912, Vol. II, p. 29.

${ }^{354}$ Raffo de la Reta, óp. cit., pp. $68-69$.
} 
Madrid en los primeros días de junio, pero poco después salió en fuga junto al salteño Francisco Gurruchaga - que iba disfrazado de cochero-, hacia Sevilla, donde después de doce días de una peligrosa travesía, se presentó a la Junta de esa ciudad, que luego de aprobar su conducta, le negó el permiso para regresar hasta tanto no recibieran noticias de oficio de haber reconocido el virreinato del Río de la Plata por gobierno de España e Indias a aquella Junta. ${ }^{355}$ Pidió entonces incorporarse al ejercito patriota español para luchar contra el invasor francés, pero la Junta le contestó una vez más negativamente, argumentando que "teniendo que arreglar muchos asuntos de América, era más conveniente que permaneciese cerca de aquella Junta Suprema". 356

En Sevilla pudo hacerse una idea bastante cabal de la situación en España y trasmitírsela mediante cartas al Cabildo porteño: “Cada junta era una soberana y cada una quería disputarse el poder y subordinación general. La de Sevilla se había abrogado facultades que le eran impropias. Una de ellas era el dominio y mando de estos vastos países, sin otro fundamento que su antojo y nombramiento. Yo examinaba estas debilidades y veía venir tristes consecuencias a todo el reino". ${ }^{357}$ En sus misivas Pueyrredón le aconsejaba al Cabildo de Buenos Aires, ante los desórdenes que presenciaba en la península, mantenerse prudentes y a la expectativa de los acontecimientos. Al repetirse sus inconvenientes con la Junta de Sevilla, que le confiscó unos pliegos enviados desde Buenos Aires, Pueyrredón decidió salir de España rumbo al virreinato, pero antes le escribió una nueva carta al Cabildo exhibiendo una clara percepción de los problemas derivados de la vacatio regis:

El reino dividido en tantos gobiernos cuantas son sus provincias: las locas pretensiones de cada una de ellas a la soberanía, el desorden que en todas se observa y las ruinas que les prepara el ejército francés...me impiden permanecer por más tiempo en el desempeño de una comisión que hoy veo sin objeto. En consecuencia me he retirado a la Junta de Sevilla por no haber en ella más facultades que en las demás para entender en los asuntos de mi cargo. ${ }^{358}$

Ese mismo día le escribía una carta a Justo José Núñez, escribano del Cabildo, en la que con más soltura se explayaba sobre el futuro de España:

\footnotetext{
${ }^{355}$ Museo Mitre, Documentos Pueyrredón, Vol. II, p. 33.

${ }^{356}$ Ídem.

${ }^{357}$ Citado en Raffo de la Reta, óp. cit., pp. 73-74.

${ }^{358}$ Citado en Ternavasio, M., Historia de la Argentina ..., p. 61.
} 
La ruina de este reino va a seguirse inmediatamente, y no crea usted otra cosa, aunque algunos escriban ocultando las divisiones en que están las provincias, y los males que las amenazan bajo la esperanza de una Junta central y suprema. Esta no tendrá efecto y cuando se verificase la reunión monstruosa que se prepara solo en las cabezas de los que aman el orden, solo serviría para aumentar el desorden. ${ }^{359}$

El fastidio que le había provocado el desprecio de Godoy lo trasladaba ahora a la Junta de Sevilla. Iba madurando en el enviado la clara conciencia de que para el gobierno metropolitano, sea este un ministro real o una junta surgida al calor del levantamiento nacional, los intereses de los americanos no eran nunca una prioridad, demostrando la fuerte mentalidad colonialista que primaba entre las elites peninsulares, más allá de sus liberales discursos. En su "fiel exposición" confesaba: "El imperio y desprecio con que esta junta y todo jefe y empleado mira a la América y sus cabildos, es en extremo irritante. Todos siguen el sistema del anterior gobierno, o para mejor decir, de dilatados siglos, en que sufren estos vastos países la más vergonzosa degradación colonial. Mi representación jamás tuvo la menor importancia porque: los esclavos políticos deben pedir la justicia misma como gracias y bondades". ${ }^{360}$ Desde España, pero en paralelo a muchos de sus compatriotas que a orillas del Plata se reunían clandestinamente, Pueyrredón iba asumiendo poco a poco que el único camino viable para la prosperidad de su patria natal era la ruptura con la metrópoli. En carta a sus Húsares daba cuenta del grado de maduración de estas ideas y la decisión de, ni bien llegado a Buenos Aires, ponerse en campaña para promover un movimiento autonomista: "Muy en breve volveréis a verme y oiréis de mis labios el lenguaje de la verdad y del desengaño [...] y formaréis el saludable sistema que mis sensibles observaciones hayan inspirado". 361

Las cartas enviadas por Pueyrredón no fueron bien recibidas por el Cabildo, le molestaba a la facción de Álzaga sus corrosivas críticas al gobierno peninsular y dudaban de su lealtad a la monarquía. Además, la designación de Liniers finalmente como virrey había sido entendida por Álzaga, o como obra propia del enviado o como resultado de que no había hecho lo suficiente para evitarlo. Los dichos de Pueyrredón contrastaban con los papeles públicos que les llegaban sobre el estado de España. Por lo tanto los capitulares se convencieron de que había que evitar su desembarco, confiscarle

\footnotetext{
${ }^{359}$ IbÍdem.

${ }^{360}$ Citado en Raffo de la Reta, óp. cit., p. 75

${ }^{361}$ Ibid., p. 81
} 
todos sus papeles apenas arribara al puerto de Montevideo "por el veneno que envuelven", y enviarlo inmediatamente en un buque "a disposición de la Junta Central ya establecida". ${ }^{362}$ En complicidad con Elío le prepararon a Pueyrredón la emboscada y al llegar a Montevideo el 4 de enero de1809, fue detenido e incomunicado. Allí lo embarcaron rumbo a España el 18 de febrero, pero una tormenta hizo arribar la nave a un puerto de Brasil, donde logró fugarse. Permaneció allí oculto un tiempo hasta que pudo embarcarse para Buenos Aires, a donde llegó el 15 de junio de 1809. Tras la frustrada asonada del 1 de enero, como veremos más adelante, Álzaga y su encono hacia él ya no significaba un problema del cual preocuparse. Inmediatamente se puso en contacto con el grupo de Belgrano y Castelli, acordando en líneas generales la necesidad de un cambio revolucionario para el Rio de la Plata. En su autobiografía Belgrano comentaba que en una de esas noches del invierno de 1809

[...] apareció en mi casa don Juan Martín de Pueyrredón y me significó que iba a celebrarse una junta de comandantes en la casa de éste, a las once de la noche, a la que yo precisamente debía concurrir; que era preciso no contar sólo con la fuerza, sino con los pueblos y que allí se arbitrarían los medios. Cuando oí hablar así y tratar de contar con los pueblos, mi corazón se ensanchó y risueñas ideas de un proyecto favorable vinieron a mi imaginación. ${ }^{363}$

Embarcados en ese rumbo le fueron asignadas las tareas de "catequización" de los jefes y oficiales de la guarnición. ${ }^{364}$ Sin embargo, en el mes de julio era relevado Liniers por el nuevo virrey Cisneros, y al no prestarle el debido juramento de obediencia, Pueyrredón fue arrestado. Después de unos días en prisión, en condiciones bastante laxas, logró fugarse una vez más y se trasladó nuevamente a Rio de Janeiro con el propósito de gestionar ante Carlota y la corte de Brasil apoyos al proyecto del grupo civil.

\footnotetext{
${ }^{362}$ En comunicación con Elío, Álzaga habla de Pueyrredón y del "horror que causa la lectura de sus cartas, escritas en un depravado idioma, con proposiciones tan escandalosas que prueban o una infame adhesión al Emperador de los franceses, o de ideas corrompidas por la independencia". Ibíd., P. 83.

${ }^{363}$ Belgrano, M. «Autobiografía...». En Mitre, B. (1945). Historia de Belgrano y de la Independencia Argentina. Buenos Aires.

${ }^{364}$ Raffo de la Reta, óp. cit., p. 93.
} 


\section{El frustrado intento juntista en Buenos Aires: La asonada del 1ero de enero de 1809}

El virreinato de Santiago de Liniers se encontraba contantemente bajo la tensión que los realineamientos de fuerzas que se venían produciendo en Buenos Aires como consecuencia de la crisis legada por las invasiones inglesas, y luego por la propia crisis de la Monarquía. Cada vez más enfrentado con el cabildo capitalino dominado por Álzaga, el virrey interino era además era acusado, alternativamente, de connivencia con portugueses e ingleses con el objetivo de emanciparse del dominio español, o bien de promover la fidelidad al emperador de Francia. No habían alcanzado las muestras de lealtad hacia el rey Fernando VII que exhibió Liniers para disipar las sospechas que caían sobre él. ${ }^{365}$ Hacia finales de 1808 , la ciudad latía al ritmo de las disputas entre el Cabildo, el virrey y la Audiencia que pugnaban por el poder. Éstas llegaron a su máxima expresión cuando, el 1 de enero de 1809, debía realizarse el recambio anual de cabildantes. Martín de Álzaga se propuso desplazar a Liniers y crear una junta, similar a la de Montevideo, que ejerciera el gobierno del virreinato. ${ }^{366}$ La búsqueda de emular a la junta montevideana no era casual, desde su constitución Elío había venido estrechando vínculo con los capitulares bonaerenses, especialmente con Álzaga, próximos por el común desafecto que sentían hacia el virrey. En diciembre de 1808, Elío se había dirigido por nota reservada al Cabildo de Buenos Aires denunciando los "pérfidos" proyectos que con la complicidad o inoperancia de Liniers se estaban gestando, para "la ruina del País y hacerle presa de la Inglaterra, dela Princesa del Brasil, o de cualquiera potencia extranjera". 367

La destitución de Liniers era una jugada audaz, a pesar de los rumores que se hacían correr sobre su dudosa lealtad, seguía gozando de un gran apoyo popular, heredado de su heroico desempeño durante las Invasiones inglesas. Aun así, el llamado "partido republicano" -no por su ideología, como dijimos, sino por su estrecho vínculo con el Cabildo-, se lanzó tras ese objetivo, y el primer día de 1809, decenas de personas se movilizaron hacia la Plaza de la Victoria -rebautizada así en homenaje a los triunfos

\footnotetext{
${ }^{365}$ Goldman, N., Ternavasio, M., "La vida política...", p. 53.

${ }^{366}$ José Presas le había advertido a la Infanta Carlota Joaquina en una carta de principios de octubre que el Cabildo de Buenos Aires estaba preparando un movimiento para tomar el poder y establecer un "Gobierno Republicano", "Carta de José Presas dirigida a la infanta Carlota Joaquina" del 7 de octubre de 1808, Mayo Documental, t. III, pp. 256-257.

${ }^{367}$ AGN-Montevideo, Fondo Archivo General Administrativo, Libro 336, ff. 6v-7v (copia de la nota reservada dirigida por Elío al Cabildo de Buenos Aires, Montevideo, 14 de diciembre de 1808). Citado en Frega, Ana, "La Junta de Montevideo...,", p. 258.
} 
sobre los ingleses-, mientras recibían el apoyo de algunos cuerpos milicianos como el de Catalanes, Gallegos y Vizcaínos. ${ }^{368}$ Una delegación del Cabildo cruzó la plaza hacia el Fuerte de Buenos Aires -sede del gobierno- exigiendo la renuncia del virrey y convocando a un cabildo abierto bajo el lema “ $¡$ Viva el rey Fernando VII, la Patria y la Junta Suprema!". Inesperadamente Liniers reunido con los oidores aceptó dimitir, bajo la única condición de que no se conformara una junta. Fue entonces cuando recibió dos apoyos decisivos: el de la Audiencia, preocupada de no seguir avalando novedades de ramificaciones impredecibles, y fundamentalmente, el de las milicias criollas que ocuparon la plaza comandadas por Cornelio Saavedra. Además del cuerpo de Patricios, fue importante la movilización de los de arribeños, pardos y morenos, en cuyas filas servían hombres que pertenecían en su gran mayoría a la plebe, donde Linieres gozaba de una fuerte popularidad. La balanza se inclinó entonces en favor del virrey, que decidió dar marcha atrás con su renuncia e impuso su autoridad sobre los complotados. Álzaga y el resto de los cabecillas del levantamiento fueron procesados y se los desterró en Carmen de Patagones por promover un supuesto plan de independencia, de donde meses más tarde serían rescatados por fuerzas enviadas por Elío. El café de Pedro de Marco y el "de los catalanes” fueron allanados por ser el lugar de reunión usual de los españoles europeos. ${ }^{369}$ También se disolvieron las milicias peninsulares que habían apoyado la asonada, permaneciendo en pie solo la de Andaluces y Montañeses que se habían mantenido leales a Liniers. ${ }^{370}$ Finalmente, en un acto cargado de simbolismo, Liniers ordenó bajar el badajo de la campana del cabildo y llevarlo al Fuerte, sustrayéndole al Ayuntamiento el instrumento utilizado para convocar al pueblo, emblema de su poder durante los últimos años. ${ }^{371}$

A pesar de que algunos han querido ver en la asonada del lero de enero el enfrentamiento entre dos grupos muy definidos, el de criollos y el de españoles

\footnotetext{
${ }^{368}$ Entre los movilizados se encontraban algunos destacados letrados rioplatenses como Pedro de Cerviño -antiguo colaborador del Telégrafo mercantil y editor junto a Vieytes del Semanario, y futuro director de la Academia de Matemáticas y de la Escuela de Náutica durante el Segundo Triunvirato- y Luis Chorroarín -sacerdote y rector del Real Colegio de San Carlos de Buenos Aires-.

${ }^{369}$ A Pedro José de Marco se le inició un expediente y se le clausuró el café, alegando que era responsable de las conversaciones públicas que se desarrollaron en su negocio sobre temas "políticos y administrativos" relacionados a la asonada. "Comunicación reservada del virrey interino Santiago de Liniers al alcalde de segundo voto Manuel Obligado, comisionado para levantar una información sobre la conducta de Pedro José de Marcó...", 5 y 6 de enero de 1809, en Biblioteca de Mayo, t. XI, p. 10424.

${ }^{370}$ Wasserman, F., Castelli..., p. 72.

${ }^{371}$ Ternavasio, M., Historia de la Argentina ..., p. 59.
} 
europeos, la realidad es que estos estuvieron mezclados entre ambos bandos. ${ }^{372}$ Además ninguna de las dos facciones buscó identificarse a partir de esa condición. Entre los vencidos se encontraban muchos de origen peninsular con fuerte control del comercio colonial, y entre los vencedores se contaban también españoles europeos, pero en este caso ligados a la alta burocracia virreinal. ${ }^{373}$ Criollos también encontramos en los dos lados, pero es indiscutible que la participación del cuerpo de Patricios y el grupo de Castelli sosteniendo a Liniers le dieron a los vencedores un carácter más americano que a los sublevados. Aun así, entre los participantes del levantamiento se contaban algunos criollos como el comandante del tercer Batallón de Patricios José Domingo de Urien, el sacerdote Luis Chorroarín y el joven abogado Mariano Moreno, aunque, según su hermano Manuel, no terminó de comprometerse del todo con la acción porque compartía la idea de la Junta pero no la forma en que quería imponerse: "Los deseos de deponer al virrey y de establecer una junta a imitación de las de España eran seguidos por muchas personas respetables, pero querían además que esta fuese compuesta exclusivamente de europeos", aspecto que Moreno no compartía evidentemente. ${ }^{374}$ Además, le habría parecido también demasiado "intempestivo" el movimiento pues no se había buscado el apoyo de las milicias criollas, a las que terminaron ubicándolas en la vereda contraria. ${ }^{375}$ Algunos autores, como Enrique Williams Álzaga, sostienen que el grupo de Castelli habría entrado en negociaciones con Álzaga, pero que la confluencia no se terminó concretando por el poco espacio que éste les reservaba a los criollos. ${ }^{376} \mathrm{La}$ realidad es que no hay testimonios contemporáneos a los hechos que confirmen esas tratativas. En todo caso, Moreno si defendió el propósito juntista del Cabildo y acompañó a la diputación del mismo que se dirigió al fuerte. Por su condición de abogado del Cabildo, por su amistad con Álzaga y sus notables condiciones intelectuales, fue oportunamente considerado por el "partido republicano" para integrar esa junta, que no sería exclusivamente española pero en la que éstos tendrían una amplia

\footnotetext{
372 Tanto en las memorias de Ignacio Núñez como en las de Damaso de Uriburu se describe a la asonada como un conflicto entre criollos y españoles europeos; imagen que después fue reproducida por varios historiadores. Biblioteca de Mayo, tomo I, pp. 528 y 628-630.

${ }^{373}$ Halperín Donghi, T., Revolución y Guerra..., p. 153.

${ }^{374}$ Moreno, Manuel, óp. cit., p. 121.

${ }^{375}$ Existen algunas dudas sobre la participación de Vieytes en esa jornada. En la famosa Carta de Saavedra a Viamonte, el presidente de la Junta Grande recordando la actuación de algunos de los morenistas durante la asonada, sugiere que Vieytes estuvo involucrado en ella o que por lo menos fue uno de los "censores de nuestras operación en aquel día". Biblioteca de Mayo, t. II, p. 1090. Halperín Donghi parece tomar esto por cierto incluyéndolo entre los criollos que apoyaron el levantamiento de Álzaga. Halperín Donghi, T., Revolución y Guerra ..., p. 153.

${ }^{376}$ Williams Álzaga, Enrique, Dos revoluciones: $1^{\circ}$ de enero de 1809 - 25 de mayo de 1810, Buenos Aires, Emecé Editores, 1963, p. 171.
} 
mayoría. El letrado representó a Álzaga, Felipe de Santenach y José Miguel Ezquiaga en el proceso judicial que les iniciaron como cabecillas del alzamiento, buscando aminorar las penas clasificando la acción en el largo listado de "conmociones populares" que el imperio sufría de tanto en tanto en sus territorios. ${ }^{377}$

La ausencia de proclamas o manifiestos de los promotores del levantamiento han permitido que desde la historiografía se elucubraran muy diferentes interpretaciones sobre los motivos del movimiento. Desde que se trató de un intento juntista anti absolutista en sintonía con los peninsulares y precursor directo de la Revolución de Mayo; ${ }^{378}$ o por el contrario, que se trató en realidad de un acción preventiva de naturaleza contrarrevolucionaria de la aristocracia mercantil porteña para evitar que, por conducto del partido criollo o por la supuesta inclinación pro-francesa de Liniers, Buenos Aires se abstrajera de la dominación colonial, afectándose irremediablemente los intereses económicos de ese sector. ${ }^{379}$ Nos queda indagar en los oficios que el Cabildo emitió en los meses precedentes para tratar de ensayar alguna interpretación de los hechos de enero de 1809. En sus funciones como abogado asesor del Cabildo es muy probable que Moreno haya sido el autor de la Representación que el 13 de septiembre de 1808 el ayuntamiento enviara a la Junta de Sevilla, quejándose del trato que la metrópoli le estaba dando en los últimos años a América, que "ha tenido que sufrir jefes corrompidos y déspotas, ministros ignorantes y prostituidos, militares inexpertos y cobardes [...]De aquí el deplorable estado de languidez y decadencia en que se hayan estos dominios, cuando por mil motivos debieran ser una piedra preciosa de la corona". 380

Dos meses más tarde, el cabildo volvía a enviarle un oficio al gobierno metropolitano, en este caso a la recientemente constituida Junta Central, reclamándole mayor atención hacia las provincias americanas para asegurar los medios para su

\footnotetext{
377 Goldman, N., Mariano Moreno..., p. 102. Felipe de Santenach luego confluiría con el grupo de Belgrano y Castelli, siendo designado como director de la Escuela de Matemáticas instaurada en agosto de 1810 por la Junta Gubernativa.

${ }^{378}$ Tesis sostenida por Enrique Williams Álzaga en la obra que citamos recientemente. Este autor plantea que el movimiento de Álzaga tenía como objetivo construir una "España americana", controlada por la alta burguesía española. p. 27.

${ }^{379}$ En este punto se puede establecer un paralelo con el golpe preventivo de Gabriel de Yermo en septiembre de 1808 contra el virrey Iturrigaray. No justamente en las formas, porque los peninsulares novohispanos reaccionaron contra la junta que promovía el ayuntamiento en este caso dominado por los criollos y la negativa del virrey a reconocer a la Junta de Sevilla, pero si en sus objetivos. Ante la vacation regis, vieron peligrar la dominación española en el territorio americano y estuvieron dispuestos a encabezar un gobierno propio, destituyendo al virrey, para garantizar la fidelidad a la península. De esa manera garantizaban también la continuidad de sus privilegios comerciales.

380 "Representación del cabildo a la Junta de Sevilla, 13 de septiembre de 1808". Citado en Williams Álzaga, óp. cit., p. 129.
} 
“felicidad, seguridad y conservación". ${ }^{381}$ En ambas representaciones se dejaba traslucir el malestar del ayuntamiento hacia el gobierno virreinal. Se pueden tomar como un anticipo por los canales institucionales de la medida de acción directa que los capitulares tomarían ese primero de enero de 1809 contra Liniers. Pero en los ofícios también se habla del derecho delos pueblos, de la felicidad de la nación, de déspotas y mandones, y se aboga por una absoluta regeneración en el gobierno de América. Todos ellos conceptos que como venimos analizando formaban parte del lenguaje político que con gran fuerza había irrumpido en el imperio hispánico a partir de la crisis, y que luego serían articulados por Moreno en un discurso de naturaleza abiertamente revolucionaria en su doble rol como redactor de la Gazeta de Buenos Aires y como secretario de la Junta. Justamente, en uno de sus artículos más destacados en el periódico porteño, titulado "Manifiesto de la Junta ante la ejecución de los sublevados de Córdoba", Moreno justificaba el uso de la violencia contra aquellos magistrados que avasallan la voluntad popular poniendo como ejemplo la forma en que fueron erigidas las Juntas en la península. En ese hilo argumental, haciendo clara referencia a los hechos del 1ero de enero de 1809, recordaba que la población de Buenos Aires no quiso tomar parte "de las tentativas de algunos particulares, que formaron el proyecto de mudar de gobierno; pues aunque su consentimiento pudo legitimar aquella empresa, no se consideró por entonces oportuna y necesaria". ${ }^{382}$ Y sí consideraba que las condiciones estuvieron dadas cuando decaída la confianza en la Junta Central, los americanos fueron testigos del avance arrollador del ejército invasor sobre Andalucía y de la división y desorden del campo patriota. En ese contexto fue que los rioplatense, ante la "necesidad de proveer en la inminencia de los peligros que lo rodeaban, a la seguridad de nuestra suerte futura, creó por la plenitud de sus votos la corporación de esta Junta Provisional de gobierno, al modelo de las que habían formado todas las provincias de España". ${ }^{383}$ Según Moreno entonces, la diferencia entre los movimientos estuvo dada por dos aspectos relacionados dialécticamente: su desigual oportunismo y el apoyo otorgado por el pueblo a los impulsores. En un intento seguramente de justificar su propio accionar, para el dirigente revolucionario ambos se inscribían en el más amplio movimiento juntista que recorría el imperio hispánico desde inicios de la crisis.

\footnotetext{
381 "Representación del cabildo a la Junta Central, 15 de diciembre de 1808”. Citado en Williams Álzaga, óp. cit., pp. 129-130.

${ }_{382}^{38}$ Gazeta de Buenos Aires, nro. 19 (11/10/10): 483.

${ }^{383}$ Ídem.
} 
La participación de Moreno y de otros letrados reformistas en la asonada, le otorgaron un matiz particular ligado a la reivindicación de la igualdad de derechos entre americanos y europeos, en sintonía con lo que sostenía su par montevideano Lucas Obes en la otra orilla. Pero este elemento, que da cuenta de lo complejo que era la coyuntura para los mismos protagonista y la naturaleza intrincada y volátil de los agrupamientos, no debe corrernos de la perspectiva histórica de que, al igual que la Junta montevideana, se trató en esencia de una reacción de la élite colonial para mantener sus posiciones y posesiones en medio de la crisis reinante. Lo que no quiere decir que muchos de ellos no buscaran a la vez modificar algunos aspectos de la relación con la metrópoli, quizás mayores grados de autonomía. Ambos objetivos no eran necesariamente contradictorios.

El saldo más importante del frustrado intento juntista fue, sin lugar a dudas, el poder logrado por los cuerpos milicianos criollos. Como sabemos, después de las invasiones inglesas, las milicias se habían constituido en un factor de poder ineludible capaz de torcer con su apoyo la suerte de las fuerzas en pugna. Y a pesar que afirmábamos que no se puede identificar linealmente como de criollos y peninsulares a los bandos enfrentados en la asonada, si podemos decir que la resolución del conflicto alteró el equilibrio entre ambos. Disueltos temporalmente varios de los cuerpos oriundos de la metrópoli, el de Patricios comandado por Saavedra se convertiría desde esa jornada en un árbitro insoslayable de la política rioplatense, y su jefe, en el hombre más requerido de ahí en adelante ante cada decisión importante. Como contracara, los capitulares y comerciantes monopolistas quedaron debilitados después del fracasado intento de hacerse con el control del virreinato, no solo por la disolución de su fuerza militar y los destierros de sus principales jefes, sino porque producto de esa debilidad política se abrían las puertas para que fuera cuestionado el control del comercio que tenían en sus manos, como veremos más adelante. El Cabildo tampoco quedaría indemne después del duro golpe. Cuando en enero de 1810 debió elegir nuevamente a sus miembros, la renovación se dio bajo la pauta de la inclusión de igual número de españoles y de criollos. No pasaría mucho tiempo para que alguno de los participantes del levantamiento, como Moreno y Larrea, se fueran alejando políticamente de Álzaga, confluyendo en las jornadas de mayo de 1810 con algunos de los vencedores de enero de $1809 .^{384}$

\footnotetext{
${ }^{384}$ Enrique Williams Álzaga sostiene en cambio que la participación de Moreno y Larrea en los sucesos de mayo se da bajo el impulso del comerciante español. Planteo discutible teniendo en cuenta que Moreno
} 


\section{Diálogo entre Atahualpa y Fernando VII en los Campos Elíseos}

Seguimos situados a comienzos de 1809 pero ahora los acontecimientos nos trasladan al Alto Perú, y en particular a la ciudad de Chuquisaca, famosa como sabemos por haber sido la sede de la Audiencia de Charcas y de la prestigiosa Universidad San Francisco Xavier. En esos primeros meses circuló en los claustros y cafés de la ciudad un manuscrito llamado a ser uno de los documentos precursores de los dramáticos hechos que estarían por suceder en la región. Se trataba del "Diálogo entre Atahualpa y Fernando VII en los Campos Elíseos", atribuido al abogado tucumano Bernardo de Monteagudo. Al igual que el "Diálogo entre un castellano y un español americano" de Manuel Belgrano, escrito solo unos pocos meses antes, Monteagudo recurrió a esa modalidad pedagógica tradicional caracterizada por un lenguaje accesible, pero en este caso no trató de escenificar la conversación entre dos simples vasallos sino el hipotético encuentro entre los espíritus de dos importantes figuras históricas. ${ }^{385} \mathrm{El}$ diálogo entre Atahualpa -muerto en 1532- y Fernando VII ocurre en los Campos Elíseos, espacio necesario e indispensable porque resuelve cualquier tipo de anacronismo y, como señala Gustavo García, garantiza la neutralidad del "campo de juego". En efecto, en este lugar paradisíaco del inframundo pueden coexistir ambos monarcas en igualdad de condiciones puesto que es el sitio sagrado donde las "sombras" delas personas virtuosas gozan la eternidad de una existencia dichosa. ${ }^{386}$

En el encuentro entre ambos, al momento de presentarse, Atahualpa trata de hacerle entender a Fernando VII que su desgracia, producto de la pérdida de su cetro en manos del "ambicioso Napoleón", no era muy diferente a la que el mismo había sufrido tras la conquista española de América. En su desarrollo, el antiguo rey inca argumenta que la única base y fundamento de la soberanía es "la libre, espontánea y deliberada voluntad de los pueblos en la cesión de sus derechos", y que quién asciende al trono sin cumplir con dicha condición no puede sino reputarse de tirano y usurpador. ${ }^{387}$ Compara la invasión del francés de la península con la del español en el Nuevo Mundo, ambas

con su Representación de los hacendados se había ganado la enemistad de los monopolistas españoles que habían llegado a pedirle a Cisneros que lo aleje de Buenos Aires.

${ }^{385}$ Los "diálogos de los muertos" fueron un género literario muy importante hasta el siglo XVIII (Luciano de Samosata, Alfonso de Valdés, Francisco de Quevedo).

${ }^{386}$ García, Gustavo V., "Incaísmo y legitimación de la "Nación” americana en el diálogo entre Atahualpa y Fernando VII en los Campos Elíseos”, Kañiga, Vol. 41, Núm. 2, 2017, p. 56.

${ }_{387}$ Monteagudo, Bernardo, "Diálogo entre Atawallpa y Fernando VII en los Campos Elíseos [1809]." Castañón Barrientos (ed.). La Paz: Empresa Editora Universo, 1974, p. 57. 
dice, impulsadas solo por la codicia. Le describe a Fernando VII la crueldad de la conquista, el terror infringido y la sangre derramada con el único objetivo de saciar la sed de oro y de plata. El vínculo entre codicia y despotismo había sido establecido por Villava en sus Apuntes para hacer referencia a la constitución del vínculo imperial: “desde los principios de la conquista miraron los españoles este país con ojos de codicia; pero de codicia tan bárbara e ignorante que por coger el fruto cortaban el árbol: no conocieron que las verdaderas riquezas de cualquier País son los hombres, y no el oro y la plata". ${ }^{388}$ Monteagudo retoma la crítica humanista de Villava y otros letrados europeos y americanos para cuestionar la configuración de un orden político en América guiado por la codicia y el desprecio a los naturales. En ese sentido, Atahualpa relata con detalle las penurias del trabajo indio en la extracción de los metales, cuestiones que evidentemente Monteagudo conocía de primera mano por vivir muy cerca de las minas de Potosí. El Inca le pide entonces al rey borbón que confiese que su trono, en relación a las Américas, "estaba cimentado sobre la injusticia y era el propio asiento de la iniquidad". ${ }^{389}$ A lo que el otro responde que todos los imperios -asirios, romanos, persas, griegos, etc.- han tenido que actuar con crueldad para llevar adelante una conquista efectiva. Atahualpa reconoce eso, pero señala que ningún pueblo fue tan sanguinario y cruel como el español en América. El Diálogo parece abrevar en los "Comentarios reales de los Incas" de Garcilaso de la Vega y en la "leyenda negra" de España, popularizada por Bartolomé de Las Casas y difundida por los imperios europeos rivales.

Fernando VII señala que el Papa cedió el Nuevo Mundo a los españoles con el fin de que propaguen el Evangelio, cosa que al presente lograron con creces, dice, teniendo en estos territorios "una multitud de santos altares sobre las ruinas de la idolatría, convertido un nuevo mundo, y en una palabra, establecida la verdadera religión mediante los sudores y trabajos de los españoles, que por este solo motivo pueden llamarse a presencia del mundo entero, legítimos poseedores de la América" ${ }^{390}$ A lo que su interlocutor responde que aquello no justifica la conquista de su reino, que la propagación del cristianismo no necesita ir de a mano de la dominación.

El monarca español contraataca entonces con el argumento de que los trescientos años de posesión, unido a los juramentos de fidelidad y vasallaje de los americanos,

\footnotetext{
${ }^{388}$ Villava, Victorian de, "Apuntes para una reforma de España sin trastorno del Gobierno Monárquico, ni de la Religión", citado en De Gori, E., La Republica Patriota ..., p. 154.

${ }_{389}$ Monteagudo, Bernardo, "Diálogo...", pp. 58-60.

${ }^{390}$ Ibid., p. 61.
} 
eran prueba de la feliz sujeción en la que estos se encuentran. Atahualpa replica que el hombre nació libre por naturaleza, y sus derechos han sido siempre imprescriptibles, y aunque haya decidido renunciar al "derecho de disponer de sus acciones y sujetarse a los preceptos y estatutos de un monarca, no ha perdido de reclamar su primitivo estado y mucho menos cuando el despotismo, la violencia y la coacción lo han obligado a obedecer una autoridad que detesta". 391 También dice que en el mismo instante que un monarca deja de velar por el bien de sus vasallos, faltando a sus deberes, rompe también los vínculos de sujeción y dependencia de sus pueblos. Por lo tanto, para el rey Inca, ni el juramento del vasallaje que han prestado al español los americanos, ni la posesión de trescientos años, son títulos suficiente para deberlos dominar. El Atahualpa de Monteagudo maneja con destreza fundamentos políticos ligados tanto al contrato rousseauniano -como eran el principio de la voluntad general como base de la soberanía y la libertad natural inherente e imprescriptible de todos los hombres-; como a la tradición política hispánica de vertiente neoescolástica, al señalar el derecho de los pueblos a la rebelión ante la mala praxis y desidia del soberano. De alguna manera el monarca Inca imaginado por el abogado revolucionario pareciera haber transitado los claustros de Chuquisaca y estar empapado del clima intelectual que allí se vivía. Monteagudo pone en boca de Atahualpa también varios de los reclamos que el pensamiento criollista venía esgrimiendo en los últimos años. Denuncia la ignorancia y la miseria a la que ha sumido España a la América, mientras se llevaba las riquezas que brindan prosperidad a la metrópoli. Condena también que se haya privado a los americanos de los empleos e impedido el comercio y las manufacturas.

Llegado el caso, pregunta el Inca, de que la metrópoli sucumbiera definitivamente a dominación francesa, ¿deben los americanos aspirar a vivir independientes? A lo que Fernando termina reconociendo que, convencido de sus razones, el mismo los movería “a la libertad e independencia más bien que a vivir sujetos a una nación extranjera”. Atahualpa agrega entonces, al estilo de una proclama, una sentencia de fuerte carga simbólica: "Quebrantad las terribles cadenas de la esclavitud y empezad a disfrutar de los deliciosos encantos de la independencia".

La radicalidad del escrito es quizás su aspecto más destacable, siendo uno de los primeros en América en abogar abiertamente por la independencia americana. Igualmente es preciso ser prudente en relación a la acepción que la voz independencia

${ }^{391}$ Ibid., p.62. 
tenía en la época, como ya hemos hecho referencia anteriormente. Era usual que se usara como sinónimo de autonomía y no de ruptura total hacia la metrópoli. Cuando los protagonistas querían referirse a esto último solían acompañarlo del término "absoluta". Sin embargo, conociendo la trayectoria política de su autor, no sería descabellado pensar que Monteagudo, aun en fechas tan tempranas, ya militara audazmente y de manera clandestina, a través de panfletos como este, el proyecto emancipatorio.

Otro punto a destacar, que sería retomado luego en distintas proclamas y discursos de los líderes revolucionarios americanos, es la búsqueda de identificación de la causa americana con los trescientos años de sometimiento de los pueblos indígenas andinos. El llamado incaísmo, tanto en su vertiente histórica -las rebeliones de Túpac Amaru II y Túpac Katari, 1780-1781-, como en la simbólica -“Comentarios reales”, “Tragedia del fin de Atahualpa", el folklore andino, y los mitos del Taky Ongoy y de Inkarri-, construía y prolongaba un espacio cultural asociado por razones prácticas e ideológicas a lo "americano": el imperio incaico. ${ }^{392}$ El Dialogo recoge y continúa una rica, aunque velada, tradición incaísta entre los letrados de la Universidad de San Francisco Xavier y la Academia Carolina de Chuquisaca. Su aceptación en distintos sectores sometidos a la dominación colonial, fundamentalmente entre los grupos indígenas, era un elemento significativo para que desde estas elites letradas lo hayan incorporado a su repertorio discursivo autonomista. Como señala Gustavo García “este es el elemento indispensable para legitimar la autodeterminación de los pueblos "originarios" (en realidad mestizos que subsumen al estamento indígena) como sucesores de los incas opuesto sal “desgobierno y tiranía” de los españoles. Se plantea, entonces, una ruptura política e histórica que es, a la vez, un entronque que intenta continuar y prolongar una imaginaria conflictiva "historia patria", excluyendo a los "godos", "gachupines" o “chapetones"(extranjeros), pero sin incluir a los "indios" a los "pardos" o a los "morenos" ". 393 En la imaginaria conversación entre estos dos monarcas fantasmales, incaísmo e ilustración europea se combinan armónicamente, para publicitar una propuesta revolucionaria e independentista.

\section{Las Juntas de Chuquisaca y La Paz}

La abdicación de Carlos IV en favor de su hijo Fernando, el cautiverio de la familia real y su forzada renuncia al trono en Bayona, el ingreso de las tropas

\footnotetext{
${ }^{392}$ García, G., óp. cit., p. 51.

393 Ídem.
} 
napoleónicas en España, el levantamiento del pueblo en Madrid el 2 de mayo de 1808 y la formación de la Junta de Sevilla fueron conocidas en Charcas entre el 21 de agosto y el 18 de septiembre de 1808. Además de informar de los acontecimientos peninsulares, la correspondencia enviada por el virrey Santiago de Liniers desde Buenos Aires también notificaba que el delegado de la Junta de Sevilla, el arequipeño José Manuel Goyeneche, recorrería el virreinato del Río de la Plata para pedir su lealtad a la misma. Estas noticias fueron dirigidas a la Audiencia, al presidente de ésta, Ramón García de León y Pizarro, y al arzobispo, Benito de María y Francolí Moxó. ${ }^{394}$ La Audiencia confirmó la proclamación y jura del rey, pero no tomó ninguna determinación en relación al reconocimiento de la Junta de Sevilla, a diferencia de la posición de su presidente y del obispo que públicamente se posicionaron a favor de ello. Este conflicto se agudizó con la llegada de Goyeneche el 11 de noviembre a Chuquisaca y la entrega de las cartas de Carlota Joaquina en las que, en ausencia de su hermano Fernando, se ofrecía a gobernar los territorios españoles. En la respuesta de García Pizarro, que es de características claramente protocolares, como fueron la mayoría de las respuestas que recibió la Infanta Carlota Joaquina a su misiva, dejaba en claro que el vasallaje era hacia el rey Fernando VII, y por lo tanto, no podía ser transferido a otros que pudieran arrogarse la soberanía como pretendía hacerlo la Infanta. ${ }^{395}$ Pero para los oidores el hecho de que el Presidente haya contestado oficialmente a la carta de la Infanta significaba reconocerle cierta legitimidad, y eso alcanzó para ser acusado junto a Goyeneche y al Obispo de formar parte de una conspiración en favor del proyecto

\footnotetext{
${ }^{394}$ Irurozqui, Marta "Del Acta de los Doctores al Plan de Gobierno. Las Juntas en la Audiencia de Charcas (1808-1810)", Chust, M., La eclosión juntera ..., pp. 194-195.

${ }^{395}$ El presidente de la Audiencia, al igual que todas las autoridades coloniales como pudimos ver, había recibido una carta de Carlota manifestando sus derechos a encabezar una regencia ante la prisión de su hermano Fernando VII. La respuesta de García Pizarro había sido la siguiente: “... desde el momento que tuve la noticia de lo obrado en Bayona con nuestro Augusto Soberano el señor don Fernando Séptimo y con todas las personas de la Real Familia que fueron allí conducidos con un engaño tan inicuo, como cobarde, anticipé de acuerdo con esta fidelísima Ciudad Capital, la Jura y Proclamación solemne del Señor don Fernando Séptimo por REY de España y de las Indias, sellando con este acto, la obligación que nos impone nuestra insigne fidelidad y Patriotismo. Esto es lo mismo que han ejecutado todas las Ciudades y Villas de esta América: estos son los sentimientos de que estamos poseídos: ni el Terror, ni la Sorpresa, ni el aspecto de la muerte misma, son capases de inmutar, o hacer vacilar, ni por un instante, nuestra característica fortaleza dispuesta a llenar en todas ocasiones los deberes de vasallaje. Yo por mi parte seguro a V. A. R. que soy Español, soy noble, soy Jefe de una Provincia, soy General, y por todos estos multiplicados Títulos, me reconozco con otros tantos motivos de hacer toda clase de sacrificios en defensa de los derechos de nuestro Soberano el Señor Don Fernando Séptimo de toda la Familia Real y de la Patria enormemente atropellada, por el ambicioso Emperador de los Franceses. Esta es mi resolución: esta es la de la Provincia que gobierno: esta es la de toda la Nación Española, y esta es la que llenará de satisfacción el grande y Real animo de V.A...". "Carta del Presidente García Pizarro a la Infanta Carlota Joaquina de Borbón". 25 de diciembre de 1808, citada en Soux, María Luisa, "El tema de la soberanía en el discurso de los movimientos juntistas de La Plata y La Paz en 1809", Rev Cien Cult n.22-23, La Paz, 2009, pp. 12-13.
} 
carlotista. Los oidores no se encontraban solos en esa interpretación sino que eran acompañados por los miembros de la universidad y del foro local, importantísimo factor de poder de la región como pudimos ver en el primer capítulo. ${ }^{396}$ Existía un larvado conflicto que se venía arrastrando desde hacía un tiempo entre el Presidente y el claustro universitario por la intención del primero de intervenir en la elección del rector de la universidad, lo que era interpretado como un acto de avasallamiento de la autonomía universitaria. ${ }^{397} \mathrm{El}$ enfrentamiento entre estas esferas políticas no haría otra cosa que ir incrementándose con el correr de los meses, hasta desembocar el 25 de mayo de 1809 en la destitución del presidente por parte de los oidores y la erección de la Junta Gubernativa en el marco de una jornada donde no faltó la movilización popular. El nuevo organismo asumió todos los poderes en nombre del rey Fernando sobre las de las cuatro intendencias que componían la Audiencia - Chuquisaca, La Paz, Potosí y Santa Cruz-, declarándose sólo responsable ante él y no ante el virrey del Rio de la Plata. Inmediatamente envió emisarios a otras ciudades para que relataran lo sucedido y buscaran adhesiones, organizó milicias, levantó defensas en la ciudad y asumió el control de las cajas reales. En su primera manifestación, el 26 de mayo de 1809, declaraban que asumían el mando de Chuquisaca ante la conmoción que sufría la ciudad producto de las intrigas carlotistas. El Tribunal había "tomado providencia para sosegarla, como el Excelentísimo Señor Presidente hubiese llegado al extremo de obstaculizar a los habitantes, a petición de estos no pudo menos el Real Acuerdo de reasumir el mando, y dictar otras aquella noche y los días siguientes para tranquilizar, y devolver el sosiego, lo que consiguió dando cuenta a las Superioridades, y a la Suprema Junta Central..." ${ }^{398}$ La proclama reconoce la legitimidad de la Junta Central, pero señala al pueblo de la ciudad como el artífice de su instalación, al responder a su pedido, siendo ésta una de las primeras manifestaciones americanas donde se empieza a plantear la cuestión de la soberanía popular. ${ }^{399}$ Como señala María Luisa Soux, el

\footnotetext{
${ }^{396}$ El 12 de enero de 1809 fue presentado un documento del claustro universitario conocido bajo el nombre del Acta de los Doctores. Escrito por el abogado de pobres Jaime Zudánez y dictaminado por su hermano Manuel Zudánez, síndico procurador de la Universidad, en él se rechazaron las proposiciones lusitanas, negándose a la corte portuguesa todo derecho a enviar pliegos a las autoridades legítimas del reino español.

${ }^{397}$ La actuación del Presidente había sido impugnada por los jueces de la Audiencia, lo que llevó a que García Pizarro recurriera al Virrey Liniers para que intermediara, que finalmente convalidó el proyecto de reforma universitaria, reprobando los procedimientos de los oidores. De Gori, E., La Republica Patriota..., pp. 126-127.

${ }^{398}$ Citado en Soux, María Luisa, óp. cit., p. 14.

${ }^{399}$ Los oidores habían cambiado de opinión respecto a la Junta. En su momento, cuando el virrey Liniers y el Presidente de la Audiencia habían pedido el reconocimiento de la Junta de Sevilla a todas las
} 
origen de su mando no vendría ya desde arriba, de un nombramiento dado por el Soberano, sino de la petición de los mismos habitantes. ${ }^{400}$

Por la información que contamos hasta ahora pareciera ser más un conflicto entre miembros de la élite local y las autoridades, con algunas características similares a la experiencia montevideana en la reivindicación de autonomía en relación a la capital virreinal, que un movimiento de claros objetivos independentistas, como ha sido considerado con poca consistencia por algunos historiadores. Como señala De Gori "la vacatio regis redefinía y trastocaba el lugar y jurisdicción de las autoridades, sobre todo, de aquellas que representaban directamente al rey. Ello planteaba problemas de gobernabilidad ya que mientras los virreyes gobernaban en nombre de un rey ausente y por frágil reconocimiento otorgado por la Junta Central de Sevilla-, los jueces lo hacían legitimando sus decisiones en el corpus jurídico hispánico". ${ }^{401}$ Lo cierto es que la emergencia de un poder local con capacidad de echar por tierra a una de las principales autoridades coloniales se insertaba en el clima político que, con otros objetivos ya más explícitos, se observaría en la revuelta de la ciudad de La Paz, el 16 de julio del mismo año, y en la constitución allí de una junta de gobierno, la denominada "Junta Tuitiva del Rey y de los Derechos del Pueblo", presidida por el comandante de milicias Pedro Domingo Murillo. El carácter mestizo de Murillo y otros participantes del movimiento, así como la decisión de incorporar a la junta a representantes de la población indígena, fueron otros de los principales rasgos revolucionarios de este intento de gobierno local, que en el hecho mismo de expresarse en la formación de una Junta testimonia un eco de la insurgencia española. ${ }^{402}$ En este sentido se diferencia de la chuquicaseña en el hecho de que aquella no había terminado de romper la institucionalidad existente, ya que el proceso juntista estuvo siempre controlado por la Audiencia y dirigido a formar sobre este cuerpo una legitimidad representativa preexistente. En el caso paceño, además, la denominación de la Junta nos habla de las trasformaciones en el sentido que el concepto de soberanía iba adoptando al calor de los procesos, al sumarle al tutelaje de la soberanía real la de los "Derechos del Pueblo". Ya

autoridades coloniales porque "ejercía autoridad soberana en representación del monarca ausente, cautivo y suplantado en su trono"; la posición de los oidores y el fiscal, reunidos en el Real Consejo, había sido diferente: exigían que para tomar una medida como la solicitada por el virrey era indispensable que llegara una nota de alguna autoridad legítima que explicara la situación en España. Para los oidores, era la Junta Gubernativa de Madrid la que ejercía el mando supremo por delegación del Soberano legítimo y no la junta de Sevilla, que ellos consideraban tumultuaria. Ibid., p. 12.

${ }^{400}$ Ibid., p. 14.

${ }^{401}$ De Gori, E., La República Patriota ..., p. 131.

${ }^{402}$ Chiaramonte, J.C. "Autonomía e independencia...” p. 334. 
no se trata además de "los pueblos", sino "el Pueblo", con mayúscula, produciéndose la identificación del término con el de nación en un sentido más moderno. ${ }^{403}$

El Cabildo Gobernador elaboró un documento conocido como "Estatuto Constitucional" o "Plan de Gobierno", promulgado el 21 de julio, por el que se creaba precisamente la Junta Tuitiva. En el último punto, de diez que posee el Estatuto, se dictamina lo siguiente:

No intenta más este pueblo que establecer sobre bases sólidas y fundamentales, la seguridad, propiedad y libertad de las personas. Estos tres derechos que el hombre deposita en manos de la autoridad pública, deben ser representados por todo el decoro y dignidad que se debe; de la invulnerabilidad de éstos, se sigue inmediatamente la tranquilidad y buen orden de la sociedad, y mientras no se tomen las precauciones para sostenerlos, nacen las crisis políticas que desorganizan trastornan las instituciones sociales. $^{404}$

La referencia del documento oficial a los derechos individuales es uno de los aspectos más sobresalientes del juntismo altoperuano. No hay muchos ejemplos tan prematuros en todo el proceso abierto con la crisis monárquica que alcanzaran ese nivel de definiciones. El autor del Plan de Gobierno fue casi con seguridad el presbítero paceño José Antonio Medina, aquel amigo íntimo de Mariano Moreno con el que compartía la participación en las tertulias durante sus estudios en la Academia Carolina. El clima intelectual vivido en Chuquisaca, donde se formaron varios de los dirigentes que protagonizarían este movimiento, se dejaba traslucir en la radicalidad que iban asumiendo sus proclamas. Pero también eran producto de la huella que iban dejando los escritos revolucionarios, originados en gran parte en la península, que circulaban desde hacía varios meses por todo el mundo hispánico, generando una acelerada mutación del lenguaje político.

Uno de los pocos manifiestos emanados por la Junta nos da algunas pautas para conocer los motivos de su constitución:

Hasta aquí, hemos tolerado una especie de destierro en el seno mismo de nuestra patria; hemos visto con indiferencia por más de tres siglos inmolada nuestra primitiva libertad al despotismo y tiranía de un usurpador injusto, que degradándonos de la especie humana, nos ha reputado por salvajes y mirado como a esclavos[...] Ya es tiempo, pues, de sacudir yugo tan funesto a nuestra felicidad, como favorable al

\footnotetext{
${ }^{403}$ Soux, María Luisa, óp. cit., p. 15.

${ }^{404}$ Citado en Soux, María Luisa, óp. cit., p. 16.
} 
orgullo nacional del español; ya es tiempo de organizar un nuevo sistema de gobierno fundado en los intereses de nuestra patria, altamente deprimida por la bastarda política de Madrid; ya es tiempo, en fin, de levantar el estandarte de la libertad en estas desgraciadas colonias, adquiridas sin el menor título y conservadas con la mayor injusticia y tiranía. ${ }^{405}$

Vemos nuevamente como el lenguaje característico del juntismo hispánico aparece con fuerza en este documento, pero en este caso asociado a la denuncia del estado de "despotismo y tiranía" vivido en América durante los últimos "tres siglos" bajo el "yugo" de un "usurpador injusto" que había adquirido esos territorios sin "el menor título". 406 Sorprende la contundencia de las expresiones elegidas para describir la dominación española, de un grado inédito hasta ese momento en los manifiestos americanos. Y es destacable que, aunque no se haga referencia a un fin independentista, los objetivos autonomistas del movimiento quedan muy claros cuando se habla de “organizar un nuevo sistema de gobierno fundado en los intereses de nuestra patria”. Resuenan en la proclama los ecos de la Carta dirigida los españoles americanos del jesuita arequipeño Juan Pablo Viscardo y Guzmán (1747-1798), quién después de su expulsión se dedicaría a reflexionar sobre las formas de ejercicio del mando de la corona en América. En este manifiesto, escrito en 1792 y difundido por Francisco de Miranda en 1806, Viscardo escribiría "El nuevo mundo es nuestra Patria, su Historia es la nuestra..." En esa Historia -la de los españoles americanos- proponía “examinar nuestra situación presente, para determinarnos por ella a tomar partido necesario en la conservación de nuestros derechos propios y de nuestros sucesores"; llegando a la conclusión de que "nuestra Historia de tres siglos sea tan uniforme y tan notoria que se podría reducir a cuatro palabra: ingratitud, injusticia, servidumbre y desolación". ${ }^{407}$ La unidad de ambos pilares de la monarquía, el español y el americano, solo podía estar

\footnotetext{
405 "Proclama de la ciudad de La Plata", citado en Chiaramonte, J.C., "Autonomía e independencia...", p. 335. Existen discusiones sobre la autoría de esta proclama. Para unos habría sido redactada en los círculos universitarios y revolucionarios de Chuquisaca y enviada a la ciudad de La Paz, en cuya redacción habría intervenido Bernardo de Monteagudo, mientras otros consideran que fue elaborada por el cura Medina.

${ }^{406}$ Con una diferencia de casi medio año, algunos pasajes del manifiesto nos recuerdan a la polémica proclama que el Consejo de Regencia español enviaría a los americanos en febrero de 1810 con motivo de su instalación y que analizaremos con mayor profundidad más adelante: "Españoles Americanos, os veis elevados a la dignidad de hombres libres: no sois ya los mismos que antes encorvados bajo un yugo mucho más duro mientras más distantes estabais del centro del poder; miradlos con indiferencia, besados por la codicia, y destruidos por la ignorancia". Es probable entonces que su autor, Manuel Quintana, tuviera presente a la hora de su confección las duras condenas que la Junta Paceña emitía en su manifiesto.

${ }^{407}$ Viscardo y Guzmán, Juan Pablo, "Carta dirigida los españoles americanos”, citada en De Gori, Esteban, La República Patriota ..., p. 90.
} 
garantizada por el reconocimiento igualitario de derechos. El despotismo implicaba la ruptura de esa ley fundamental. Viscardo sería el vehículo por el cual muchos americanos se acercarían al universo de problemas planteados por los jesuitas franceses como Gabriel Mably (1709-1785) y Guillaume Raynal (1713-1796). En su calidad de letrado patriota recuperaría y articularía las reflexiones de estos pensadores jesuitas, para defender los intereses de su tierra natal, siendo fundamental en la construcción histórica de una identidad americana, "que no solo apelaba al territorio y a los antepasado, sino que, construida en su debate con la Corona, vincularía la patria a la asunción de un destino particular y concreto". ${ }^{408}$

Teniendo en cuenta la posible intervención de Monteagudo en la redacción, es probable que el contenido de esta proclama paceña represente las expectativas del sector más radicalizado del proceso y no sea extensible al conjunto de los grupos que impulsaron y se vieron comprometidos con el movimiento juntista. De todos los papeles oficiales es el que más puntos de contacto tiene con el incendiario "Diálogo entre Atahualpa y Fernando VII en los Campos Elíseos" del tucumano. Varias de las ideas, e incluso algunos de sus giros estilísticos, reaparecen en la Proclama. Y aunque los documentos de este tipo son escasos, mientras que la mayoría de los testimonios con que los miembros de la élite paceña justificarían los motivos del movimiento consistieron en presentar la formación de la junta también como una reacción contra el "carlotismo" del gobernador intendente y del obispo en aras de salvaguardar la soberanía de Fernando VIIII, la contundencia de las definiciones a las que nos referíamos y la participación de varios destacados personajes que luego continuarán su trayectoria revolucionaria en las guerras de independencia, nos llevan a identificar en el juntismo altoperuano, y sobre todo en la junta paceña, elementos precursores del movimiento juntista americano que se desataría en la primera mitad de 1810 al conocerse las noticias de la entrada de Napoleón a Andalucía y la disolución de la Junta Central. Esta interpretación, que da cuenta de la complejidad del proceso que vivió toda la región rioplatense entre 1808 y 1810 , y que ve en la emergencia de las juntas la cristalización y confluencia de tendencias muchas veces antagónicas, se distancia tanto de la interpretación tradicional de ver al juntismo altoperuano como el primer grito independentista americano, como de la interpretación historiográfica actualmente

\footnotetext{
${ }^{408}$ Ibid, p. 99.
} 
dominante de reducirlo solo a disputas y recelos entre esferas de poder locales en búsqueda de mayor autonomía.

El proyecto de gobierno autónomo tendría una corta vida, sólo tres meses después, en octubre de 1809, la rebelión de La Paz fue sangrientamente reprimida por fuerzas militares que, dispuestas conjuntamente por el virrey de Perú Abascal y el flamante Virrey del Rio de la Plata Baltazar de Cisneros, fueron comandadas por el mismo oficial sospechado en Chuquisaca de carlotismo, el arequipeño Goyeneche. Cisneros le había ordenado que "procediese contra los reos pronta y militarmente aplicándoles todo el rigor de la ley"; mientras que el general Vicente Nieto pedía "practicar el pronto, ejecutivo y veloz escarmiento". Éste decretó la prisión, el embargo y el destierro de los principales promotores de la Junta de Charcas, pero respetó sus vidas. No fue el caso de los sublevados de la Paz, a los que Goyeneche reprimió con extrema dureza. Diez de los cabecillas fueron ahorcados, otros fueron degollados y sus cabezas clavadas en picas colocadas en la vía pública y otros ochenta fueron puestos en prisión o desterrados a las Malvinas y a las Filipinas. Los ejecutados el 29 de enero de 1810 fueron: Basilio Catacora, Buenaventura Bueno, Melchor Jiménez, Mariano Graneros, Juan Antonio Figueroa, Apolinar Jaén, Gregorio García Lanza, Juan Bautista Sagárnaga y Pedro Domingo Murillo, quien antes de su ejecución en la horca se dice que gritó al público presente: “Compatriotas, yo muero, pero la tea que dejo encendida nadie la podrá apagar, ¡viva la libertad!”.

La crueldad de la represión quedaría marcada a fuego en la memoria de la población altoperuana, pero también en la de varios de los futuros revolucionarios rioplatenses. Muchas de las primeras proclamas de la Junta revolucionaria porteña, como de los artículos de Mariano Moreno en la Gazeta, comenzarían su relato recordando a los mártires paceños y señalando la violenta represión como un ejemplo del salvajismo con que respondían las autoridades coloniales a los reclamos de los americanos. ${ }^{409}$ La severidad contrastaba con el indulto otorgado por Cisneros a los participantes de la asonada del lero de enero que en su mayoría eran españoles peninsulares. Los americanos entendían que no se estaba midiendo con la misma vara a los nacidos en uno u otro lado del océano. ${ }^{410}$ Cuando a finales de 1810 , tras un breve proceso y cumpliendo con las órdenes que la Junta le había dado a Castelli en su misión

\footnotetext{
${ }^{409}$ Gazeta de Buenos Aires Nro. 23 (8/11/10): 591-593.

${ }^{410}$ Wasserman, F., Castelli..., p. 76.
} 
al Alto Perú, sean fusilados los españoles Nieto, Sanz y Córdova, algunos como Monteagudo vivirían la situación como una suerte de revancha personal. 


\section{Capítulo 6:}

\section{La Real Orden del 22 de enero de 1809 y la elección de diputados a la Junta Central en el Rio de la Plata}

\section{Introducción}

El decreto de la Junta Central del 22 de enero de 1809, recibido casi cuatro meses más tarde en el Rio de la Plata, constituye un acontecimiento clave en el proceso revolucionario que atravesaba al imperio hispánico tras la crisis monárquica. ${ }^{411}$ Además de declarar que las Indias no eran colonias sino "parte esencial e integrante de la monarquía española”, la Real orden convocaba a los americanos a elegir representantes para el gobierno que actuaría en ausencia de Fernando VII, incorporándolos a la nueva estructura institucional que ensayaba la nación española. El manifiesto, que algunos se lo atribuyen a la pluma del poeta y publicista liberal Manuel Quintana, mientras otros como Demetrio Ramos entienden que fue obra del Conde de Floridablanca, tenía como claro objetivo estrechar la relación con las provincias ultramarinas en esos turbulentos meses, procurando evitar que los americanos avanzaran en la creación de gobiernos propios. Existía también la urgente necesidad de apuntalar la colaboración, fundamentalmente económica, de esos territorios para sostener la guerra contra el invasor francés. La Junta Central consideraba las proclamas y manifiestos los medios más confiables para convencer a los americanos sobre el rumbo que se estaba tomando en la península. Se buscaba mediante ellos exaltar el sentimiento patriótico, el carácter de guerra nacional contra el invasor francés, demostrando la comunidad de intereses entre la metrópoli y América. La Real Orden decía:

El rey nuestro Sr. D. Fernando VII, y en su real nombre la Junta Suprema Central Gubernativa del reino. Considerando que los vastos y preciosos dominios que España posee en las Indias no son propiamente colonias o factorías como los de otras naciones, sino una parte esencial e integrante de la Monarquía española, y deseando estrechar de un modo indisoluble los sagrados vínculos que unen unos y otros dominios, como así mismo corresponder a la heroica lealtad y patriotismo de que acaban de dar tan decisiva prueba a la España en la coyuntura más crítica que se ha visto hasta ahora nación alguna, se ha servido S. M. declarar, teniendo presente la consulta del Consejo de Indias de 21 de

\footnotetext{
${ }^{411}$ Según Demetrio Ramos el decreto debió conocerse en Buenos Aires el 10 de marzo, pero en las memorias de Juan Manuel Beruti se habla del 16 de mayo como la fecha en la que arribaron los pliegos dirigidos al Virrey. Ramos, D., óp. cit., p. 180-181.
} 
noviembre último, que los reinos, provincias e islas que forman los referidos dominios deben tener representación nacional e inmediata a su real persona y constituir parte de la Junta Central Gubernativa del Reino por medio de sus correspondientes diputados. ${ }^{412}$

Como bien señalara François Xavier Guerra, tras la aparente generosidad, se escondía en el texto una profunda ignorancia con respecto a las representaciones existentes en América. Que sean utilizados los términos «colonias» y «factorías» chocaba con la concepción que de las Indias se representaba en las leyes y en el imaginario de los americanos. La participación en la representación nacional, además, aparecía no como un derecho, sino como una concesión, como una recompensa por las muestras de solidaridad y patriotismo dadas al momento de conocerse la invasión napoleónica y el cautiverio de Fernando VII. Pero la principal afrenta que motivó el descontento de los americanos, y que inauguró una polémica que atravesó no solo el conflicto con la insurgencia en los años venideros sino también con los territorios lealistas que participaron por medio de sus representantes en las Cortes de Cádiz, era la desigualdad que expresaba el número de diputados: mientras que para la Península correspondían treinta y seis, a América y Filipinas les otorgaban solo diez, cuando se calculaba en la época que ambas tenían aproximadamente el mismo número de habitantes. "Para que tenga efecto esta real resolución han de nombrar los virreinatos de Nueva España, el Perú, Nuevo Reino de Granada y Buenos Aires, y las capitanías generales independientes de la isla de Cuba, Puerto Rico, Guatemala, Chile, provincias de Venezuela y Filipinas, un individuo cada cual que represente su respectivo distrito" ${ }^{413}$ En palabras del historiador hispanista, la igualdad les era negada en el momento mismo en que se afirmaba. ${ }^{414}$

La Real Orden, complementada después por el decreto de la Junta Central del 6 de octubre 1809, implantaba en América la función representativa, pero con modalidades de fondo y forma que en España estaban a punto de extinguirse: representación por ciudades, elección correspondiente a los cabildos y el sistema de sorteo para el mecanismo electoral. ${ }^{415}$

\footnotetext{
${ }^{412}$ Real Orden de 22 de enero de 1809, AHN Madrid, Estado 54 D - 68. Tomado de Navarro García, Luis, "Convocatoria de vocales americanos para la junta central, 1809”, Naveg@mérica, 2013, n. 10, p. 2 ${ }^{413}$ Ibid., p. 3.

${ }^{414}$ Guerra, François-Xavier, óp. cit., p. 130

${ }^{415}$ González, Julio V., Filiación histórica del gobierno representativo argentino, Buenos Aires, La vanguardia, 1937, p. 121.
} 
Solo los vecinos afincados -una minoría- formaban parte de las elecciones a través de los cabildos. En parte era una reposición de las instituciones castellanas, en las cuales la burguesía de las ciudades mandaba sus procuradores a Cortes. Pero no solo era un resabio tradicionalista, también remitía al proceso revolucionario español, teniendo en cuenta que las Juntas Provinciales de la península cuyos diputados habían formado la Central se habían formado partiendo de los principales ayuntamientos españoles. Ahora se encargaría a los ayuntamientos indianos elegir a quienes habrían de representarles en la misma. Como afirma Chiaramonte, la apertura de algo hasta entonces inexistente como un proceso electoral, inició una nueva época en las prácticas políticas en el Nuevo Mundo. De hecho, constituyó el primer paso, en lo relativo a la elección del personal de gobierno, para sustituir a las autoridades peninsulares por el "pueblo". 416

\section{La participación rioplatense en los antecedentes directos al decreto de la Junta Central}

Antes de analizar las reacciones que el decreto generó en América, y en particular en el Rio de la Plata, destacaremos algunos antecedentes directos de la disposición, en particular por el protagonismo que en ellos tuvieron justamente algunos rioplatenses. Aunque no lo suficientemente remarcada por la historiografía, se conoce que el 30 de septiembre de 1808 fue presentada una memoria, por intermedio del conde del Montijo a la Junta Central, confeccionada por tres rioplatenses residentes entonces en Madrid, pedro León de Altolaguirre, Nicolás Herrera y Manuel Rodrigo, donde se proponían "varios medios y gracias para asegurar la fidelidad de las Américas". ${ }^{417}$ Tanto el bonaerense Altolaguirre como el montevideano Herrera habían sido enviados a España para solicitar mercedes y honores para las dos ciudades con motivo del exitoso rechazo a las invasiones inglesas. ${ }^{418}$ Pero tras la ocupación francesa y las abdicaciones reales

\footnotetext{
${ }^{416}$ Chiaramonte, José Carlos, “Autonomía e independencia “, pp. 327-329

${ }^{417}$ AHN, Estado 56 A, doc. 2.

${ }^{418}$ Ninguno de los dos eran los delegados ordinarios de las ciudades, esa función estaba encomendada en la Corte a Miguel Pérez de Balbás, agente de Montevideo, y, como ya vimos, a Juan Martín Pueyrredón, por Buenos Aires. Nicolás Herrera había nacido en Montevideo en 1775, estudió en la Universidad Mayor Real y Pontificia San Francisco Xavier de Chuquisaca y fue ordenado allí de sacerdote, pero pronto abandonó los hábitos. Completó sus estudios de derecho en España y regresó a Montevideo en 1801. Después del mayo rioplatense tendrá una actuación destacada como funcionario y publicista, tanto en la Gazeta de Buenos Aires como en la de Montevideo. León Altolaguirre nació en Buenos Aires en 1752 en el seno de una renombrada familia colonial. Fue oficial de las milicias en el Paraguay, en 1800 ingresó como caballero en la Orden de Carlos III y al año siguiente actuó como comandante general del Resguardo del Río de La Plata. Durante las Invasiones Inglesas participó en la Reconquista de Buenos Ayres. Cercano al Virrey Santiago de Liniers, con quien estaba emparentado pues éste había casado con su hermana Martina de Sarratea y Altolaguirre. Vuelto al Rio de la Plata tras su actuación en Bayona y
} 
terminaron siendo convocados ambos como diputados a las cortes napoleónicas de Bayona. Se sabe que el primero no llegó a participar pero si el segundo, que tuvo una destacada actuación. Justamente son las manifestaciones y disposiciones tomadas en Bayona, entre ellas las de incorporar al gobierno español a veintidós diputados de ultramar, el antecedente más importante por su cercanía temporal y por su relevancia política e institucional al decreto de la Junta Central del 22 de enero de $1809 .{ }^{419}$ El título $\mathrm{X}$ de la Constitución de Bayona, titulado "De los reinos y provincias españolas en América Asia", proclamaba la igualdad de derechos de los habitantes de ambos mundos, decretaba y la libertad de cultivos e industrias, y reconocía el derecho de libre comercio entre todos y con la metrópoli. Nicolás de Herrera, junto al comerciante José Ramón Milá de la Roca, tuvieron mucho que ver con ese artículo. ${ }^{420}$ Ante los primeros borradores de la Constitución habían propuesto lo siguiente: "Quede abolido el nombre de colonias. Las posesiones españolas en América y Asia se titularán provincias hispano-americanas o provincias de España en América". De esa manera establecían la plena equiparación entre todos los territorios de la Monarquía, aspecto que, como bien marca Luis García Navarro, no se había establecido entre las metrópolis y colonias en las dos Constituciones inmediatamente anteriores y que sirvieron de modelo a la de Bayona: la francesa de 1799 y la holandesa de $1806 .^{421}$

ante la Junta Central, fue ascendido en 1809 a la dirección de la Real Renta de Tabacos, pero ese mismo año cayó en desgracia por su adhesión a Liniers y fue expulsado de Buenos Aires, pasando a España. Intentó volver después de mayo de 1810, siendo apresado en las costas de Montevideo por Javier de Elío, quién lo devolvió la península en la corbeta Proserpina. Pasó más tarde al Perú desempeñándose hasta su muerte como Contador Mayor, Decano de la Contaduría de Lima. El tercer firmante, Manuel Rodrigo, desempeñó funciones como Capitán de los Reales Ejércitos, y fue posteriormente uno de los diputados suplentes por Buenos Aires para las Cortes de Cádiz, junto a Francisco López Lisperguer y Luis Velazco. Su actuación le ocasionó sendos procesamientos judiciales tanto en España, acusado de masonería; como por el gobierno de Buenos Aires que nunca los reconoció a los tres como sus legítimos representantes, ya que desconocía la soberanía del conjunto de las Cortes.

${ }^{419}$ Tales diputados deberían ser propietarios de bienes raíces y naturales de sus provincias. Elegidos para un mandato de ocho años por determinados ayuntamientos designados por las autoridades indianas. Corresponderían dos diputados a Nueva España, Perú, Nueva Granada, Buenos Aires y Filipinas, y uno a Cuba, Puerto Rico, Venezuela, Charcas, Quito, Chile, Cuzco, Guatemala, Yucatán, Guadalajara, Provincias Internas Occidentales y Provincias Internas Orientales. Navarro García, Luis, óp. cit., p. 7.

${ }^{420}$ José Ramón Milá de la Roca había sido enviado a España por Liniers en demanda de auxilios militares. Nacido en San Sebastián de Guipúzcoa en el año 1769, de padre era catalán y madre vasca de origen noble, fue educado en Cataluña y en 1790, y producto de su orientación afrancesada partió de la península hacia el Río de la Plata y se asentó en Montevideo. Mantuvo vinculación con actores políticos sociales franceses durante la república, manteniendo una regular correspondencia con los mismos, participando en diversas operaciones comerciales de estos en la América Hispana. Tuvo un rol bastante activo en la resistencia a las invasiones inglesas y fue partidario del mayo rioplatense. Josep Milá de la Roca, su único hijo, fue secretario de Manuel Belgrano en la campaña de Paraguay, y amigo personal de José de San Martín. Camarda, Maximiliano, "De comerciante exitoso a hacendado y revolucionario. La estrategia económica de fines del siglo XVIII en el complejo portuario rioplatense a partir de un actor: José Ramón Milá de la Roca", Naveg@mérica.2014, n. 12.

${ }^{421}$ Navarro García, Luis, óp. cit., p. 7. 
Por lo tanto, cuando Nicolás Herrera -ahora junto a Altolaguirre y Rodrigopresentó el informe a fines de septiembre a la Junta Central, lo hacía desde la experiencia previa de su participación en Bayona, que había establecido un piso en el reconocimiento a América difícil de desandar por parte de un gobierno que se decía representante de los habitantes de ambos hemisferios y necesitaba imperiosamente de su auxilio en la guerra nacional contra la ocupación francesa. En el informe los tres firmantes sostienen que, dadas las muestras de lealtad de los americanos a su madre patria, donde ninguna seducción de las potencias extranjera ni la indiferencia del gobierno habían logrado hacer mella en los sentimientos de patriotismo, era hora ya que la metrópoli tomara en consideración la condición de América y obrara en consecuencia fortaleciendo fraternalmente los lazos que las unían. El nuevo mundo, afirmaban, había sufrido con igual constancia y fidelidad que España las consecuencias del poder arbitrario. $^{422}$

En la memoria se relata el asombro y la confusión que generaron en el Rio de la Plata las noticias de los acontecimientos que se vivían en la Península, y se enumeran los distintos canales por las que llegaron: comunicaciones oficiales del Consejo de Indias, emisarios tanto de Napoleón como de las Juntas provinciales, periódicos franceses y españoles-, cartas particulares, etc. Consideran que las informaciones parciales, contradictorias y muchas veces falsas que reciben los americanos constituyen un mosaico extremadamente confuso. Al desconocer la urgencia y necesidad que originó a las Juntas provinciales inevitablemente se puede caer en el error de interpretar que se atribuyen incompatiblemente el carácter de supremas de España e Indias, cuando existe ya el Consejo con esa función. No es extraño que se pinten entonces un cuadro de anarquía, que empiece a aflorar el resentimiento, o que fascinados por la idea del poder ilimitado de Napoleón juzguen a España condenada a sucumbir bajo su suela. Estas ideas, dicen, “agitarán el espíritu público en medio de una incertidumbre peligrosa. Las opiniones nacen de la incertidumbre: de las opiniones de los partidos". ${ }^{423}$

Se preguntan cuál será el sistema que adoptarán probablemente los gobiernos de América ante semejante confusión e intrigas. Sin dudar de la lealtad demostrada por aquellas provincias, entienden que "son demasiados lisonjeros los atractivos de la soberanía. Las pasiones que dirigen a la independencia y la autoridad, casi siempre

422 "Informe", Mayo documental, t. III, p. 176.
423 Ídem. 
ciegan la razón y sofocan los sentimientos de las más heroicas virtudes." ${ }^{424}$ No es inverosímil entonces que algunas provincias ultramarinas tomen el rumbo equivocado. Por eso, dice el informe, para atajar esas funestas consecuencias, el gobierno debe extremar su empeño en manifestar su aprecio a las Américas y persuadirlas de que se ocupan de su felicidad. En ese sentido, junto a los avisos sobre los "gloriosos triunfos y establecimiento de una autoridad suprema nacional", recomienda que se pida a todos los ayuntamientos americanos sus planes de prosperidad publica y solicitudes para que puedan ser atendidos y provistas inmediatamente, revitalizando las esperanzas y desterrando cualquier idea de arbitrariedad. Los firmantes ponen el acento en la comunicación directa con los cabildos, que son a su entender los "inmediatos representantes de sus derechos [de los pueblos] por las leyes constitucionales del reyno". ${ }^{425}$ Este planteo puede responder a distintas cosas: por un lado a la situación conflictiva en la que se encontraba para esas fechas tanto el Cabildo de Buenos Aires como el de Montevideo con el Virrey Santiago de Liniers. Pocos días antes de la presentación del informe, el 21 de septiembre, se había conformado la Junta de Montevideo, sustrayéndose de la órbita de la autoridad del Virrey. Obviamente Nicolás Herrera esto no lo sabía por los tiempos con que demoraban las comunicaciones, pero la beligerancia del gobernador Francisco de Elío y el cabildo montevideano contra Liniers venía ya de larga data. Tampoco eran buenas, como sabemos, las relaciones entre los capitulares bonaerenses y el virrey, al punto que solo unos meses después, el 1ero de enero de 1809, se produjo un levantamiento con el fin de deponerlo y formar también una junta. Por otro lado, como dijimos anteriormente, la idea de los cabildos como los genuinos representantes de los derechos de los pueblos no solo tenía raíces en la tradición castellana, sino que el levantamiento nacional había revitalizado esa noción, articulándola ahora con una germinal concepción de soberanía popular que la eclosión juntista había puesto arriba de la mesa.

Volviendo al informe, los firmantes aconsejan no remover a las autoridades coloniales hasta que no se escuchase la opinión de las ciudades. Consideran además, que con el fin de galvanizar de confianza la comunicación entre la metrópoli y las provincias, debían en elegirse para esa función a los individuos más respetados y preparados de aquellos países. Estos "emisarios" no solo actuarían como correa de trasmisión de la voluntad del nuevo gobierno nacional, sino que también informarían a

\footnotetext{
${ }^{424}$ Ibid., p. 177.

${ }^{425}$ Ibid., p. 178.
} 
éste de las noticias y necesidades de las provincias. ${ }^{426}$ Este conjunto de arbitrios y señales, a su entender, redundaría en mayor tranquilidad pública en las provincias y, sobretodo, funcionaría como un anticuerpo ante las operaciones extranjeras que promuevan la ruptura con la metrópoli.

El 5 de octubre los tres rioplatenses elevaron un nuevo informe, más centrado en este caso a obtener un reconocimiento para Montevideo y Buenos Aires por la defensa ante las invasiones inglesas, pero donde se profundizaba en la idea de reformular las relaciones entre la metrópoli y los virreinatos mediante una corte compuesta por representes de ambos hemisferios. Proponían por lo tanto que cada uno de los virreinatos tenga dos diputados que representen sus derechos ante el soberano. ${ }^{427}$ Éstos debían ser elegidos por una junta con sede en la capital de cada virreinato y compuesta por un enviado de cada provincia. A su vez, los electores debían ser nombrados por el cabildo secular y eclesiástico de la capital de cada provincia. En el informe se dejaba constancia que el nombramiento de cada diputado para la corte debía recaer en personas naturales de aquellos virreinatos, de notorio arraigo, probidad e instrucción, sin que los virreyes ni los cabildos pudieran alterar la elección que se realizara por pluralidad de votos.

El 10 de octubre fueron leídas a la Junta ambas memorias, y se acordó que se pasase también a informe del Consejo de Indias, lo que se concretó el 27 del mismo mes. La minuta de la Central que acompaña el informe llevaba consigo una propuesta concreta que, a pesar de que tomar la iniciativa los americanos, limitaba el número a un diputado por cada virreinato. Parece claro que ya en este momento se concebía la presencia de los representantes ultramarinos más que nada como algo simbólico. Más allá de eso, tomando en cuenta las disposiciones establecidas por la Junta Central en los meses siguientes, y en especial los decretos del 22 de enero y del 6 de octubre, podemos suponer que el informe de los tres españoles americanos no cayó en saco roto y dejó cierta marca en la consideración de los juntistas sobre el problema americano. Herrera, en carta al juez diputado de Montevideo con fecha del 14 de enero de 1809, alardeaba que el futuro decreto sobre la representación de América era consecuencia directa del memorial presentado a la Junta: "podrá usted anunciarles en virtud de una memoria

\footnotetext{
${ }^{426}$ En una nota que acompañaba el informe el Conde de Montijo los proponía tanto a Herrera y Altolaguirre como dichos "emisarios" para el Rio de la Plata.

427 "Informe de León Altolaguirre, Manuel Rodrigo y Nicolás de Herrera a la Junta Central sobre la necesidad de enviar emisarios a América, la urgencia en recompensar a Buenos Aires y Montevideo y que se acuerde a cada virreinato la franquicia de estar representado por dos diputados", 5 de octubre de 1808, Mayo Documental, T. III. , p. 235.
} 
presentada por mí al gobierno, en unión de Don León Altolaguirre y Don Manuel Rodrigo, ha acordado esta suprema junta que todos los virreinatos y capitanías envíen cada una un diputado para tener la respectiva representación nacional en dicha Junta" ${ }^{428}$ Un año después matizaría un poco su afirmación: “Acaso se hallaba esa idea en las deliberaciones justas del gobierno, pero como quiera que sea nadie puede disputarme la gloria de haber sido el primer español americano que propuso y promovió con toda eficacia un asunto cuya importancia para las provincias de América es incalculable por la influencia que tendrá siempre sobre la felicidad de todos los pueblos". ${ }^{429}$ Es probable que el tono moderado de las reformas y la vocación de unidad que destilaba el escrito favorecieran su recepción. Lo cierto es que la conciencia de que eran necesarias ciertas reformas en las relaciones hacia el interior del imperio ya estaba presente entre la dirigencia peninsular hacía varios años, sobre todo si no se quería repetir el ejemplo de la independencia de las colonias norteamericanas. ${ }^{430}$ La cuestión pasaba por cuán profundas estaban dispuestos los peninsulares a que sean esas reformas.

\section{Las reacciones en el Río de la Plata}

François Xavier Guerra en Modernidad e Independencia sostuvo que las reacciones de los americanos ante la real orden del 22 de enero fueron ambivalentes.

\footnotetext{
${ }^{428}$ Archivo Artigas, volumen III, introducción. Tomado de Sánchez Gómez, Julio, "Un rey para El Plata: monárquicos y monarquía en el oriente del Río de la Plata", en Álvarez Cuartero, Izaskun, Sánchez Gómez, Julio (eds.) Visiones y revisiones de la independencia americana: Realismo/Pensamiento conservador: ¿una identificación equivocada?, Salamanca: Ediciones Universidad de Salamanca, 2014, p. 252.

${ }_{429}$ Ídem.

${ }^{430}$ Uno de los exponentes más conscientes de esta situación era el propio Conde de Floridablanca, presidente de la Junta Central hasta su muerte. Como bien señala Luis Navarro García "mucho antes de ser ministro de Estado, José Moñino, futuro conde de Floridablanca, había sido fiscal del Consejo de Castilla, y como tal actuó con igual título en el Consejo Extraordinario dispuesto por Carlos III en 1767 a raíz del 'motín de Esquilache' y del que se derivaría la expulsión de los jesuitas. Esta expulsión dio lugar a algunas inquietudes y desórdenes en América, especialmente en México, motivo por el que el fiscal Moñino, conjuntamente con su colega Campomanes, emitió el 5 de marzo de 1768 un dictamen en el que se proponía al rey una nueva política indiana, 'no pudiendo mirarse ya aquellos países como una pura colonia, sino como unas provincias poderosas y considerables del Imperio español', por lo que convenía prevenir un posible espíritu de independencia atrayendo a los criollos a España para sus estudios, o empleándolos en el ejército y la administración, o incluso estableciendo 'del distrito de cada uno de los tres virreinatos su respectivo diputado, y un cuarto de las islas Filipinas... el cual asistiese en la Corte por un sexenio', 'incorporándose estos cuatro diputados de los reinos de Indias con los de Castilla, Aragón y Cataluña para conferir y representar humildemente lo que conviniese a la utilidad pública de aquellos dominios... formando de este modo un cuerpo unido de nación. Esta diputación desterraría la idea de una aristocracia separada, y aquellas provincias se considerarían como una parte esencial de la nación' ". Ideas similares había defendido Francisco de Saavedra, quien rubrica el decreto del 22 de enero de 1809, cuando visitó México como "comisionado regio" con ocasión de la guerra de independencia de las Trece Colonias británicas, "conviene tratar la América como lo que es, esto es, no como a colonias y factorías, sino como provincias de España”. Tomado de Navarro García, Luis, óp. cit., pp. 14-15.
} 
Existió, decía, por una parte, la satisfacción de poder participar por vez primera en el poder soberano, pero por otra, una profunda insatisfacción ante la desigualdad del trato que se les daba. ${ }^{431}$ Partiendo de esta idea, trataremos de indagar de aquí en adelante cuáles fueron específicamente las reacciones en el Rio de la Plata al conocerse el decreto, así como su puesta en práctica en términos institucionales.

De la llegada del decreto a la ciudad tenemos la crónica directa a través de las memorias de Juan Manuel Beruti:

El 16 de mayo llegaron los pliegos al señor virrey de un bergantín que entró en Montevideo procedente de Cádiz, y en él vino una real orden de la Junta suprema del reino, donde en nombre de Fernando VII dice al Virrey: he servido declarar teniendo presente la consulta al Consejo de Indias del 21 de noviembre de 1808, que los reinos, provincias e islas que forman los dominios de Indias deben tener representación nacional inmediata a su real persona y formar parte de la Junta Central gubernativa del reino por medio de sus correspondientes diputados. ${ }^{432}$

En los pliegos también se detallaban el método y forma que se debían guardar para la elección del diputado, así como la dieta que debía otorgársele para sus gastos de viaje y mantenimiento. Lamentablemente el cronista, que solía verter algunas impresiones sobre los sucesos que relataba se abstuvo en este caso, pero el hecho que lo reseñe denota en sí que lo consideraba un acontecimiento de cierta trascendencia.

Conocidas son las referencias que hizo Mariano Moreno en su famosa Representación de los hacendados sobre la Real Orden. Enmarcándola como parte de los "planes benéficos" e "ideas generosas" que la nación española comenzaba a llevar adelante en el contexto de su resistencia contra el yugo opresor francés, considera que “uno de los rasgos más justos, más magnánimos, mas políticos, fue la declaración de que las Américas no eran una colonia o factoría como las de otras naciones, que ellas formaban una parte esencial e integrante de la monarquía española y en consecuencia de este nuevo ser, como también en justa correspondencia de la heroica lealtad y

\footnotetext{
${ }^{431}$ Guerra, F-X., óp. cit., p. 135.

${ }^{432}$ Beruti, Juan Manuel, Memorias curiosas, Ed. Emecé, Bs. As., 2001, p. 124. Beruti llevó desde los trece años y durante su larguísima vida -nació en 1777 y murió en 1856- un diario de los acontecimientos públicos de la ciudad. Era hijo de españoles de respetabilidad social y buena posición económica. Estudió en el Real Colegio de San Carlos y luego se dedicó a la función pública. También se desempeñó como escribiente en la oficina de control de Artillería y luego como sobrestante pagador tesorero de la misma armada. Desarrolló funciones en Contaduría de la Aduana e integró el Tribunal de Cuentas; finalmente, trabajó como contador de número en tiempos de Rosas. Forace, Virginia Paola, "La condición testimonial de un escritor en transición: Memorias curiosas de Juan Manuel Beruti”, Anclajes vol.19 no.1, Santa Rosa, jun. 2015.
} 
patriotismo que habían acreditado a la España en los críticos apuros que la rodeaban, se llamaron estos dominios a tener parte en la representación nacional, dándoseles voz y voto en el gobierno del reino". ${ }^{433}$ Orientado su escrito a echar abajo el sistema monopólico al que estaba sometido el comercio virreinal, Moreno ponía el acento en las señales de igualdad que provenían de la península, buscando de esa manera influir no solo en la opinión del virrey sino del conjunto de autoridades coloniales de la justicia de dicha causa:

Esta solemne proclamación, que formará la época más brillante para la América, no ha sido una vana ceremonia que burle la esperanza de los pueblos, reduciéndolos al estéril placer de dictados pomposos, pero compatibles con su infelicidad. La nación española, que nunca se presenta más grande que en los apurados males que ahora la han afligido, procedió con la honradez y veracidad que la caracterizan, cuando declaró una perfecta igualdad entre las provincias europeas y americanas; sostuvo los derechos más sagrados cuando destruyó los principios que pudieran conservar reliquias de depresión en pueblos tan recomendables; premio con la magnificencia de una nación grande la fidelidad y estrecha unión, que tan brillantemente habían acreditado; y obró con la prudencia y políticas propias de un reino ilustrado. ${ }^{434}$

Para que esa proclama expresase verdaderamente un sentido de justicia y equidad, según Moreno, debía acompañarse de reformas concretas, tales como el fin del monopolio, que pusieran fin a esas "reliquias de depresión" de los pueblos. Con el tono irónico que lo acompañó en toda su vida pública, el futuro secretario de la Junta, califica al decreto como de "extraña ocurrencia", entendiendo que "según las leyes fundamentales de las Indias, nunca debió desconocerse" la categoría de reinos a los territorios americanos. Y se pregunta:

[...] ¿por qué títulos se nos podía privar de unos beneficios que gozan indistintamente otros vasallos de la monarquía española, que no son más que nosotros? El vocal que sostenga en la Junta Central nuestra representación, no contará distintos privilegios de los que adornan al representante de Asturias, o cualquiera otra provincia europea de las que se mantienen libres del enemigo; esta identidad debe transmitirse precisamente a los representados, y de este principio derivamos un título de rigurosa justicia, para esperar de V. E. lo que no podría negarse al último pueblo de España. Lejos de nosotros aquellas mezquinas ideas que tanto tiempo sofocaron nuestra felicidad: manda

\footnotetext{
433 "Representación a nombre del apoderado de los hacendados" en Piñero, Norberto, Escritos políticos y económicos de Mariano Moreno, Talleres Rosso, Bs. As., 1937, p. 31.

${ }^{434}$ Ibid., p. 32
} 
V. E. un gran pueblo que en nada cede al que sirvió de teatro a las distinguidas cualidades que garantieron a la Suprema Junta la tranquilidad y buen orden de estas vastas regiones; obre, pues, la justicia en todo su vigor para que empiecen a brillar los bienes que la naturaleza misma nos franquea pródigamente. ${ }^{435}$

No alcanzaba entonces solo con participar del gobierno central, los representados debían tener los mismos e iguales derechos de un lado y otro del Atlántico.

Es interesante prestar atención a la mirada de un agente "externo", aunque no por eso desinteresado, para calibrar mejor las condiciones en las que era recibido el decreto y alguna de las consecuencias imaginables que podía generar. Felipe Contucci, en un oficio al Conde de Linhares, interpretaba que la decisión de la Junta Central con respecto a la proporción de la representación, no provocaría otra cosa que alentar al "partido de la independencia", teniendo en cuenta que ya conocen los americanos que poseen "iguales derechos a los que viven en la Madre Patria". Y a la vez, le manifestaba su preocupación por que el "sistema democrático" propuesto por la Central encontraría adeptos en aquellos "españoles republicanos" que están en "perpetuo recelo" hacia la Infanta. Entendemos que no está hablando aquí del mismo partido, sino pareciera referirse a los protagonistas de la asonada del 1 de enero de 1809, pero por lo que hemos dicho hasta ahora, no tenemos indicios para afirmar que fueran éstos partidarios de "cambios democráticos", sino que la alternativa juntista lo que les abría eran las puertas para hacerse del poder local y así sostener los privilegios políticos, económicos y sociales que su condición de españoles europeos y comerciantes monopolistas les daba. Estos malos presagios del florentino, aunque quizás no terminan de dar una muestra acabada de los distintos agrupamientos políticos y sus diversas estrategias, si permiten dimensionar el agitado clima que se vivía hacia mediados de 1809 en el virreinato, y la escabrosas condiciones que tenía tanto la política metropolitana como la carlotista para poder convertirse en hegemónica y hacerse del control de la situación.

\section{Implementación del decreto en el Río de la Plata}

En relación al proceso electoral propiamente dicho, son discutibles, por lo menos para el caso rioplatense, aquellas afirmaciones lanzadas por Guerra que sostenían que toda América se lanzaba "con ardor a la elección de sus diputados para la Junta Centra". Según él, “de la primavera de 1809 al invierno de 1810, del norte al sur, de Sonora a

\footnotetext{
${ }^{435}$ Idém.
} 
Chile y al Río de la Plata, toda América vive al ritmo de las elecciones". ${ }^{436}$ Y decimos que son discutibles no sólo porque en ninguna ciudad del virreinato rioplatense se puede verificar un proceso electoral de "alta intensidad", sino que por el contrario lo que se percibe es, en algunos casos, una ejecución lenta y casi desganada, de mero cumplimiento administrativo, y en otros, como en la propia capital virreinal, que ni siquiera se llegaron a implementar. El detallado estudio realizado por Julio V. Gonzáles sobre el proceso en las distintas jurisdicciones rioplatenses es elocuente en este sentido. Una vez recibida la Real Orden el virrey se comunicó directamente con los cabildos de las siete ciudades, salteando llamativamente a la figura de los gobernadores, mecanismo que se volvería a repetir cuando la Junta patriota se dirija a los pueblos del interior del virreinato el 27 de mayo de 1810. Cada ciudad debía elegir una terna formada por vecinos respetables de la cual uno de ellos saldría sorteado. Estos compondrían a su vez, en una nueva instancia, el grupo del cual se elegiría una nueva terna, en este caso a criterio del Virrey junto al "Real Acuerdo", de la cual finalmente saldría sorteado el diputado que iría a la Junta central en representación del Virreinato.

De la actividad electoral en Córdoba se han conservado más documentos que en el resto de las ciudades y pareciera ser además la que nos dejó mayores elementos para el análisis. La recepción de la Real Orden por parte de los regidores no da la impresión de haber provocado ningún interés extraordinario porque éstos solo se limitaron a dar fe y recién se volvieron a convocar quince días después. La elección de la terna electoral, que comenzó a mediados de julio de 1809, se caracterizó por un fuerte hermetismo casi de conclave. Julio González lo explica a partir de la división en la que se encontraba la elite cordobesa prácticamente en dos bandos, uno encabezado por el gobernador Juan Antonio Gutiérrez de la Concha y Mazón de Güemes -célebre por haber sido junto a Liniers cabecilla de la contrarrevolución sofocada en los fusilamientos de Cabeza de Tigre-; y otro por los hermanos Gregorio y Ambrosio Funes, y Miguel Gregorio de Zamalloa -futuro rector de la universidad cordobesa durante la revolución-. Este marco de rencillas domésticas, sumado a la desidia que parecía despertar la convocatoria, determinó que el proceso de conformación de la terna electoral consumiera todo el año

\footnotetext{
${ }^{436}$ Guerra, F-X., óp. cit., p. 137. Completando su descripción del proceso: "Las ciudades no electoras reclaman su participación como un privilegio. La nación se concibe como un conjunto de cuerpos jerarquizados: reinos, provincias, ciudades y pueblos. Los ayuntamientos votan en la mayoría de los casos por las personas de mayor dignidad, siguiendo casi la escala de precedencias. Los poderes dados a los diputados son imperativos y redactados como una procuración de derecho privado. En las instrucciones coexiste un deseo de reformas económicas y administrativas — muy en la línea de la Ilustración-, con peticiones de privilegios de todo tipo para la ciudad o la región $\mathrm{y}$, a veces, de vuelta al estado anterior a las reformas borbónicas".
} 
1809, quedando finalmente compuesta por Zamalloa y los hermanos Funes. El sorteo, realizado el 17 de enero de 1810, dictaminó que fuera el Deán Funes el ungido como diputado para la Junta Central, que obviamente nunca llegaría a ejercer esa función, entre otras razones, porque solo un par de semanas después ésta dejaría de existir, responsabilizada por los desastres militares de los últimos meses en la península. ${ }^{437}$

Otra de las jurisdicciones donde se llegó a efectuar la elección fue en La Rioja, siendo curiosamente los hermanos Funes también parte de la terna electoral. Según González se sospechaba que la elección había estado digitada desde Buenos Aires. Finalmente sería sorteado el tercero de los integrantes, Juan Nicolás Ortiz de Ocampo, Vicario de Famatina. ${ }^{438}$

La situación de tensión política permanente que vivía la ciudad de Buenos Aires, prácticamente desde las invasiones inglesas, y agudizada a partir de crisis del imperio tras las abdicaciones de Bayona, explica en parte que en la capital del virreinato ni siquiera se haya llegado a conformar la terna de la que debía ser sorteado el diputado para la Junta Central. Como venimos observando, demasiado enrarecido estaba el clima político en la ciudad-puerto entre los distintos agrupamientos que se iban articulando y desarticulándose, entre las distintas esferas gubernamentales -hablamos de la hostilidad existente entre el Virrey y el Cabildo-, sumado como si fuera poco al conflicto entablado con la vecina Montevideo, como para que un acto de esa importancia pudiera desarrollarse normalmente.

Ese enfrentamiento entre la corporación municipal y la autoridad virreinal cada vez menos velado, se evidencia en el acta capitular del 25 de mayo de 1809, a razón del decreto del 22 de enero de 1809:

Se tuvo a la vista la resolución de la Suprema Junta Central de la gubernativa de España e Indias impresa en esta ciudad, para que se nombren en esta parte de América como parte integrante y esencial de la Nación, Diputados Vocales de aquella, cuya resolución no se ha comunicado aún de oficio por el Gobierno. Y los SS, conociendo que por el método acordado del sorteo con el Real Acuerdo con el Sr Virrey, queda al arbitrio de éste la elección de diputados privando a los Pueblos de la acción que en ella deben tener, y que se ha dignado a insinuarse en la misma resolución de la Junta Central; de la que debe precisamente resultar que no se arriba a la reforma o regeneración que tanto se necesita para la felicidad de estas Provincias, abatidas y casi arruinadas por continuada

\footnotetext{
${ }^{437}$ González, Julio V., óp. cit., p. 148-181.

${ }^{438}$ Ibid., 187-189.
} 
prostitución de los gobiernos acordaron se represente a S. M. en la Suprema Junta manifestando este gravísimo reparo, y otros más que se tocan en el método adoptado, y aplicándole se digne reformarlo en términos que queden expeditas las acciones y derechos de los Pueblos en visto que tanto les interesa. ${ }^{439}$

La queja no era por razones de prolijidad legalista. Era secundario que el Virrey no le había hecho llegar por los canales formales la Real Orden al Cabildo porteño, como si lo había hecho con Córdoba y los otros cabildos del interior, respondía más bien a la disputa política en la que se encontraban hace ya varios meses.

Los capitulares, haciendo suyos varios de los términos que desde la misma Junta Central se irradiaban al conjunto del imperio como "reformas", "felicidad" y "derechos de los pueblos", quiso hacer valer su rol como representante genuino de los súbditos bonaerenses, poniéndole un coto a la injerencia del Virrey en la elección del diputado. Pero esto no sólo remitía al conflicto local, en toda América se observaba un similar proceso por el cual los Cabildos, no sólo deseosos de recuperar sus libertades de movimiento, sino como representantes ahora de un interés colectivo, desbordaban sus preocupaciones, cada vez más, hacia las esferas de gobierno y la "política grande", aquella que excedía a sus jurisdicciones. ${ }^{440}$

La amenaza insinuada de que no se iba a llevar adelante el proceso electoral si no se adoptaba esta conducta, terminó materializándose en una postergación ad-infinitum. Ni siquiera la llegada al Rio de la Plata de la Real Orden del 6 de octubre de 1809, que excluía explícitamente la participación del virrey como una especie de árbitro de la operación electoral, en enero de 1810-para ese momento ya era Cisneros-, hubo de provocar que los cabildantes procedieran a conformar la terna. Pocos días después la Junta Central española sería disuelta, desatando una nueva concatenación de acontecimientos que para el Rio de la Plata significaría la formación de una junta autónoma. Los representantes por Córdoba, La Rioja, Salta, San Juan, San Luis, Mendoza, Potosí, Cochabamba, Mizque, Corrientes, Asunción, Montevideo, Santa Fe y La Plata no llegarían entonces a cruzar el Atlántico para cumplir con las funciones por las que habían sido elegidos; la junta de la que iban a formar había naufragado en su propia inoperancia. $^{441}$

\footnotetext{
439 Ibid., p. 194.

${ }^{440}$ Ramos, D., óp. cit., p. 150.

${ }^{441}$ Ternavasio, M., Historia de la Argentina ..., p.60.
} 
La gran idea que recorre la ya varias veces citada obra de Julio V. González es la concepción del conjunto del movimiento revolucionario rioplatense como herencia directa de la revolución peninsular. Fue ésta la que provocó el período de iniciación democrática en el Río de la Plata inmediato a la Revolución de Mayo con el llamado a elecciones de diputados a la Junta Central. A pesar de que, como ya dejamos constancia, uno de los objetivos centrales de nuestra tesis es justamente dar cuenta del papel motorizador que desempeñó la península en el proceso rioplatense, podemos afirmar que la convocatoria a elecciones no pareciera haber despertado demasiado entusiasmo en esta parte de América. Nos parece entonces que la tesis de González peca de cierto hiperbolismo, probablemente explicado por el contexto en el que escribió su obra, que no era otro que el de la Guerra Civil española, siendo aquél un reconocido simpatizante de la causa republicana. Como bien sugiere Chiaramonte, la novedad electoral de 1809 no tuvo reiteración inmediata en Río de la Plata:

Las deliberaciones y resoluciones durante los sucesos previos al 25 de mayo de 1810 tuvieron lugar en el ámbito del Cabildo y ocasionalmente en su forma ampliada de cabildo abierto. Los cabildos abiertos, prácticamente inexistentes hasta las invasiones inglesas - la primera en junio de 1806 y la segunda en enero de 1807—, fueron frecuentes de 1806 en adelante, pero sin revestir carácter electoral. Se trataba de asambleas políticas ajenas a la modalidad representativa de la soberanía y equiparables a la democracia directa. $^{442}$

En cambio, y en esto sí coinciden tanto González como Chiaramonte, cuando a poco de instalada la Junta Provisional Gubernativa tuvo que disponer la forma de elección de los diputados del interior rioplatense que debían incorporarse a su seno, lo hizo con el mismo régimen electoral de 1809. Mediante una circular, del 18 de julio de 1810, la Junta comunicó a los cabildos del interior que para elegir esos diputados debían seguirse las disposiciones de la Real Orden del 6 de octubre de 1809. No sería ni la primera ni la última vez que los rioplatenses recurran a lo ensayado en la península para llevar adelante su propia revolución.

${ }^{442}$ Chiaramonte, José Carlos, “Autonomía e independencia ...”, p. 329. 


\section{Capítulo 7:}

\section{El reformismo ilustrado español y napolitano en la Representación de los hacendados}

\section{Introducción}

Mientras se desarrollaba (o no) el proceso eleccionario en el Virreinato del Río de la Plata, como pudimos ver en el capítulo anterior, la crisis que vivía la monarquía hispánica se manifestaba también en otros planos. El examen de la Representación de los hacendados nos permite acceder a su análisis desde otra perspectiva. De sobra está recordar el valor que le ha otorgado la historiografía a este escrito, llegando algunos a considerarlo como el antecedente más directo de la revolución rioplatense, e incluso quienes lo han presentado como su documento programático más representativo. También existen aquellos que, por el contrario, le niegan dicha importancia pero no se privan de dedicarle algunas páginas o hasta libros enteros al tema. ${ }^{443}$ Mucho es lo escrito y polemizado alrededor de la Representación, y no es el fin de este capítulo hacer entonces un análisis pormenorizado del documento sino, como en otros casos, atenernos a los objetivos específicos de nuestra investigación e indagar y echar luz sobre las marcas de la llamada ilustración española presentes en él y el carácter de emergente transicional que de alguna manera asume entre los planteos reformistas criollos que venimos analizando y la etapa abiertamente revolucionaria que se estaría por inaugurar sólo unos cuantos meses después de su presentación. ${ }^{444}$

El nombramiento de Baltasar Cisneros en remplazo de Santiago de Liniers como virrey del Río de la Plata, venía a resolver fundamentalmente las desavenencias entre éste último y el gobernador de Montevideo, Francisco de Elío, buscando así pacificar el virreinato. También constituía una apuesta de la metrópoli para socavar el creciente poder que habían ido ganando las milicias criollas tras los últimos acontecimientos, en particular la frustrada asonada del 1ero de enero de 1809. Para recomponer la autoridad virreinal, entre sus primeras medidas, Cisneros dispuso la creación de un comité de vigilancia - preocupado sobre todo de las intrigas carlotistas y los recientes acontecimientos en el Alto Perú- y restableció parte de los cuerpos españoles disueltos

\footnotetext{
${ }^{443}$ Molinari, Diego, La Representación de los hacendados de Mariano Moreno: su ninguna influencia en la vida económica del país y en los sucesos de mayo de 1810, Imp. y Casa Editora de Coni Hnos., 1914.

${ }^{444}$ Para un estudio más amplio y profundo sobre el documento remitimos al excelente análisis que Noemí Goldman realizó en su reciente biografía sobre Mariano Moreno. Goldman, N., Mariano Moreno, pp. 103-117.
} 
tras la asonada. Pero uno de los principales problemas con los cuales tuvo que lidiar el flamante virrey, fue el importante déficit fiscal de la colonia. Déficit agravado, por un lado, por las crecientes necesidades presupuestarias de la administración local, volcadas principalmente al sostenimiento de las milicias criollas; por la interrupción de una parte importante de la provisión de metales preciosos que los levantamientos juntistas del Alto Perú había ocasionado; y por último, por el crecimiento del contrabando, producto de las complicaciones que la guerra en Europa había ocasionado al comercio marítimo. Una de las soluciones que Cisneros tenía a mano para paliar las necesidades del erario, pero que sin lugar a dudas le generaría tensiones con sectores poderosos de la sociedad colonial, era la apertura al comercio directo con los ingleses. No sería además la primera vez que se recurría a una medida de este tipo, ya se había hecho ante situaciones de "urgente necesidad" desde 1797 y sobre todo a partir de la batalla de Trafalgar. El cambio de alianzas provocado por la invasión francesa a la península había incentivado la presión inglesa sobre los puertos americanos. En este contexto, y no exento de las presiones de los comerciantes ingleses para introducir sus mercancías, Cisneros lanzó una consulta al Cabildo y al Consulado sobre la conveniencia de abrir el comercio directo con Gran Bretaña. La primera reacción fue la férrea oposición de los comerciantes monopolistas españoles que no estaban dispuestos a ver peligrar sus negocios. En respuesta a ese rechazo, y en representación de los "Labradores y hacendados" de las dos orillas del Plata, intervino Mariano Moreno con su célebre Representación. Es probable que el alegato haya respondido también, como sugiere Noemí Goldman, a una consulta privada del virrey. ${ }^{445}$ Las destacadas condiciones personales de Moreno -su gran capacidad de trabajo, determinación e ilustración- lo habían llevado a convertirse en los últimos años, y simultáneamente, en relator de la Audiencia y abogado particular del Cabildo. ${ }^{446} \mathrm{Al}$ tanto de esas condiciones, Cisneros recurrió a él al poco tiempo de su llegada como asesor para algunos temas jurídicos. ${ }^{447}$ Para los comerciantes monopolistas españoles, que hasta ese momento habían sido clientes de su estudio, la Representación es un punto de inflexión en su relación, pasando a ser considerado como una persona peligrosa, pidiéndole al virrey que lo

\footnotetext{
${ }^{445}$ Ibid., p. 106.

446 Ibid., p. 94.

${ }^{447}$ Manuel Moreno, en la biografía sobre su hermano, dice que Cisneros ya había recibido en Cádiz informes muy positivos sobre el abogado y que fueron confirmados al llegar al Rio de la Plata. Moreno, Manuel, óp. cit., p. 102.
} 
alejara de Buenos Aires con la promesa de un cargo de oidor en España, que Moreno rechazara oportunamente.

Si hasta 1778 las élites porteñas centraban sus negocios en el comercio de larga distancia, desde que la Corona promulgó el 12 de octubre de ese año el Reglamento para el Comercio Libre de España a Indias, no harían más que consolidar esa especialización. Como señala Jorge Gelman, los ricos de Buenos Aires a fines de la colonia no eran grandes estancieros, como quiere cierta tradición historiográfica, sino comerciantes. Algunos pudieron ser propietarios de estancias o de chacras en las cercanías de la ciudad, pero éstas sólo significan un detalle menor de sus intereses, que estaban centrados en la importación de esclavos y de mercancías europeas denominadas genéricamente «efectos de Castilla», a cambio de lo cual exportaban por el Atlántico, sobre todo, plata. ${ }^{448}$ ¿Quiénes serían esos "hacendados y labradores" a los que Moreno estaría representando? Como bien viene señalando la historiografía reciente, la campaña estaba lejos de estar dominada por hacendados y peones, la gran mayoría de los pobladores eran labradores y pastores que, o bien trabajaban sus pequeñas tierras o eran arrendatarios de los hacendados en forma independiente y, en general, se dedicaban a la producción de trigo para el consumo local o de mulas para Potosí. Mientras que los grandes propietarios, que producían principalmente cuero para la exportación, beneficiados por la apertura de Buenos Aires y Montevideo al comercio atlántico con la metrópoli, se concentraban en algunas zonas litoraleñas como la Banda Oriental. Aún a finales de la colonia casi el 80 por ciento de las exportaciones estaba compuesta por plata. Por ende, "el negocio central de las élites de Buenos Aires seguía siendo introducir esclavos y «efectos de Castilla», y redistribuir «efectos de la tierra» como la yerba mate de Paraguay para conseguir con ello concentrar el máximo de plata en el puerto y así reiniciar todo el ciclo". ${ }^{449}$ La producción agropecuaria todavía era una actividad secundaria pero con grandes expectativas de crecimiento, y en nombre de esa promesa futura es que Moreno elevó la Representación. ${ }^{450}$

\footnotetext{
${ }^{448}$ Gelman, J. (dir.), Argentina: Crisis imperial e independencia, Lima, Taurus-Fundación Mapfre, 2010, p. 130 ${ }^{449}$ Idém.

${ }^{450}$ Goldman, N., Mariano Moreno..., p. 116.
} 


\section{Agricultura, libre-comercio y contrabando}

El documento se divide en tres partes: en la primera Moreno busca subrayar la necesidad y justicia de liberalización comercial, con la intención de demostrar que es el único camino para "conciliar la prosperidad del país con la del erario". La segunda parte es una réplica a los argumentos de Miguel de Agüero, apoderado del Consulado de Cádiz, quien presentó, por su parte, una representación en contra de la libertad de comercio. La tercera consiste en una propuesta que responde a las "condiciones y trabas" que el Consulado había presentado en relación a la consulta del virrey, y que el Cabildo parecía apoyar.

La argumentación a favor de la liberalización comercial tiene uno de sus pilares discursivos en el acento puesto a la importancia del desarrollo agrícola para la región, en sintonía con lo que se había sostenido desde las "memorias consulares" de Manuel Belgrano desde finales del siglo anterior, y, como hemos podido ver en el segundo capítulo, también en los primeros periódicos rioplatenses, fundamentalmente desde el Semanario de Vieytes. Moreno retoma esos planteos y sostiene que "el que sepa discernir los verdaderos principios que influyen en la prosperidad respectiva de cada provincia, no podrá desconocer que la riqueza de la nuestra depende principalmente de los frutos de sus fértiles campos...". ${ }^{451}$ Reponiendo algunas definiciones ya formuladas en la tesis, la agricultura era considerada, en línea con el nuevo pensamiento económico que recorría Europa y que en particular tenía una fuerte impronta en los exponentes del reformismo ilustrado español como Gaspar de Jovellanos y Valentín de Foronda, la actividad central a la que debían enfocarse los esfuerzos tanto de las autoridades virreinales como del conjunto de la sociedad rioplatense, en pos de potenciar al máximo el desarrollo económico en la región. Más aún cuando para estos letrados era indiscutible la ventaja comparativa que implicaba la enorme fertilidad del suelo local.

Otro de los fundamentos en lo que se articula su alegato es la delicada situación en la que se encontraba España tras la invasión napoleónica y su urgencia de contar con recursos con los que sostener la guerra. Ya hemos hecho referencia a los constantes llamamientos de socorro económico que portaban las proclamas metropolitanas que se dirigían a los americanos. Moreno se aprovecha de aquello para argumentar a favor de la liberalización comercial, amén de los ingresos al erario que se generarían, posibilitando incrementar de esa manera las remesas hacia la península. A la par, y

\footnotetext{
451 “Representación a nombre del apoderado de los hacendados” en Piñero, Norberto, óp. cit., p. 115.
} 
manteniendo el foco en el aspecto político-militar, advierte sobre la continua amenaza que representaba la expansión portuguesa en la región y de la debilidad en la que se encontraba España para proteger a sus colonias. "Hay que armarse", dice, "con un poder respetable para defenderse y para eso se necesita un erario fuerte". ${ }^{452}$

El abogado señala que la introducción de productos británicos en el país era una realidad innegable desde las invasiones inglesas en 1806. Pero que su importación, practicada "contra las leyes y reiteradas prohibiciones", o sea introducida por contrabando, había privado al Estado de cobrar los respectivos derechos y a las provincias del estímulo que habrían recibido con "las exportaciones de un libre retorno”. En ese sentido exclama “¡Con qué rapidez no se fomentaría nuestra agricultura, si abiertas las puertas a todos los frutos exportables, contase el labrador con la seguridad de una venta lucrativa!". ${ }^{453}$ Moreno entiende que la libertad de comercio para los puertos americanos nunca había sido proscripta como un verdadero mal, sino "que ha sido ordenada como un sacrificio que exigía la Metrópoli de sus colonias". Y en este punto es donde comienza a diferenciarse de los planteos de sus predecesores ilustrados al criticar con agudeza el derrotero que el sistema comercial imperial había ido tomando: "es bien sabida la historia de los sucesos que progresivamente fueron radicando este comercio exclusivo, que al fin degeneró en un verdadero monopolio de los comerciantes de Cádiz..." ${ }^{454}$ El nuevo contexto que la crisis monárquica había abierto, para Moreno, posibilitaba el replanteo de la relación comercial entre la península y sus colonias. En ese sentido considera que la Metrópoli "ha proclamado como feliz origen de una regeneración que obrará la prosperidad nacional", trastornando los "antiguos motivos del sistema prohibitivo". ${ }^{455}$ En ese marco, y volviendo a resaltar la conveniencia que resulta al país de un libre comercio, entiende como un deber de justicia disponer de las medidas tendientes a unir al bien general el remedio de las necesidades urgentísimas antes expuestas. El alegato adopta en estos pasajes un lenguaje cifrado en las nociones del derecho y la justicia, que sería tan característico en los escritos del futuro secretario de la Junta, pero sin llegar a cuestionar aún la integridad imperial: "Las colonias sujetas al comercio exclusivo de su Metrópoli, son el digno objeto de esta enérgica declamación: nosotros tenemos más fuertes derechos, que elevan a un alto grado la justicia con que reclamamos un bien que aun en el estado

\footnotetext{
${ }^{452}$ Ibid., p. 118.

${ }^{453}$ Ibid., p. 127.

${ }^{454}$ Ibid., p. 132.

${ }^{455}$ Ídem.
} 
colonial no puede privarse sin escándalo". El gobierno peninsular había declarado en la Real orden del 22 de enero la igualdad política entre España y América, y es de allí que se toma Moreno para reclamar un trato justo. No sólo por el derecho que les asiste a sus representados, no sólo por la ley de la necesidad, sino de la justicia que deriva del nuevo estatuto de América dentro de la monarquía: "Si, señor, la justicia: la justicia pide en el día que gocemos un Comercio igual al de los demás Pueblos que forman la Monarquía española que integramos". ${ }^{456}$

Siguiendo en esa línea discursiva, Moreno trascribe lo que dice es un ejemplo con que un español trató de convencer sobre lo injusto, mal calculado, y contrario a sus propios fines del sistema prohibitivo que viene analizando:

Supongamos que el lugar de Vallecas pertenece a un país extranjero; que abundan en él pan, carne, tocinos y otros artículos de primera necesidad, y que el soberano de aquel territorio convida a los habitantes de Madrid (que no pueden lograrlos de ninguna otra parte en muchas leguas a la redonda) a que se provean de aquel abundante mercado. Supongamos igualmente que en estas circunstancias los comerciantes de Cádiz o Sevilla, sorprendiendo la buena fe del gobierno con razones sofísticas, consigan que los habitantes de Madrid, aunque estén amenazados de hambre, y aunque tengan a su puerta abundancia de pan fresco, no puedan tomar ni un solo pan, ni una libra de carne del mercado inmediato bajo las penas más rigurosas, sino que sólo ellos tengan el privilegio de comprar este pan y provisiones de Vallecas, llevarlo a Cádiz y Sevilla, y desde allí introducirlo en Madrid y venderlo a sus habitantes. Pregunto ahora, ¿cómo llevarían esta disposición los vecinos de Madrid? ¿Cómo la miraría la Nación entera? ¿No la darían la justa denominación, por lo menos, de perjudicial y mal calculada? ¿No representarían los vecinos que la escasez, alto precio y mala calidad de provisiones originadas de aquel sistema, al paso que los empobrecía con gran perjuicio del Estado, impedía los progresos de la población? ¿Habría un ministerio que no abriese inmediatamente los ojos sobre la injusta e inhumana ambición de los comerciantes de Cádiz o Sevilla, que por la mezquina ganancia que les daba su intervención, querrían tener constantemente en la miseria un pueblo honrado y que tenía por lo menos tanto derecho como ellos a la protección del soberano? No, comerciantes de los puertos; semejantes abusos no pueden continuar: Carlos IV es el padre de su pueblo; sus ministros son ilustrados y celosos; en el instante que vean vuestro retrato, se acabó el imperio del monopolio. ${ }^{457}$

\footnotetext{
${ }^{456}$ Ibid., p. 132.

${ }^{457}$ Ibid., p. 138.
} 
No tenemos constancia de la verdadera autoría de este pasaje, quizás es un mero ardid de Moreno para reforzar su argumentación simulando una voz peninsular crítica al sistema monopólico. Llama la atención sí, que esté ubicado el relato durante el reinado de Carlos IV, esto es previo a la crisis y a la declaración de igualdad entre España y América por parte de la Junta Central, cuando de aquel se desprende una equiparación entre los dominios americanos y peninsulares.

\section{La economía política española en la Representación}

Moreno recurre a Jovellanos, como habían hecho sus compatriotas ilustrados en los periódicos fini-coloniales, y en particular a su más aclamada obra, la Informe sobre la ley agraria, seguramente como maniobra para dar una pátina de mayor solvencia y legitimidad a su alegato, pero también por la profunda admiración que el pensador ilustrado le despierta y de la que dejaría constancia en repetidas ocasiones en la Gazeta de Buenos Aires. ${ }^{458}$ Recordemos que el ilustre asturiano era uno de los integrantes de mayor peso e influencia de la Junta Central, a la cual el virrey y todas las autoridades coloniales debían obediencia. En Jovellanos se escuda entonces para reafirmar la idea de que el primer deber de un magistrado es fomentar por todos los medios posibles la pública felicidad: "Entonces, dice un sabio español, los pueblos, como los individuos, bendicen la mano que los hace felices, y es indudable que el amor de los vasallos es la base más sólida del trono. De esta reciprocidad de intereses debe resultar el esmero de parte de los que gobiernan en fomentar la prosperidad general". ${ }^{459} \mathrm{Y}$ obrar por el bien público, según Adam Smith -al que conoce por Jovellanos, y considera junto con él, el "apóstol de la economía política"-, no es otra cosa que remover los obstáculos que impiden dicha prosperidad: “éste es el eje principal sobre que el señor Jovellanos fundó el luminoso edificio de su discurso económico sobre la ley agraria, y los principios de estos grandes hombres nunca serán desmentidos; rómpase las cadenas de nuestro giro, y póngase franca la carrera, que entonces el interés que sabe más que el celo, producirá una circulación que haga florecer la agricultura, de que únicamente debe esperarse nuestra prosperidad". 460

\footnotetext{
${ }^{458}$ Ya antes había citado al Informe sobre la ley agraria en un alegato en abril de 1808 en representación de don José Antonio Escalada.

${ }^{459}$ Ibid., p. 134.

${ }^{460}$ Ibid., p. 105.
} 
Las objeciones contra la propuesta de liberalización planteadas por el apoderado del Consulado de Cádiz, Miguel de Agüero, son respondidas una a una por Moreno, aprovechando para apuntar también contra el gremio de comerciantes monopolistas que esa corporación representa. En todo el documento va a contraponer los intereses particulares de los comerciantes al interés general del comercio, de la sociedad y del Estado. No duda que la medida inevitablemente afecta los intereses de ese sector, pero entiende necesaria y justa su implementación, contraponiéndolos a los beneficios que conllevaría para la que considera la parte más productiva de la población que serían los labradores: "¿deberá aplicarse el sacrificio al miserable labrador que ha de hacer producir a la tierra nuestra subsistencia, o al comerciante poderoso que el Gobierno y ciudadanos miran como una sanguijuela del Estado?" 461 Aquí nuevamente vuelve a remitir a un manifiesto de reciente publicación en España para apoyarse en los planteos allí contenidos:

¿Por qué se inclina usted en favor del labrador? Porque recibiendo de la tierra el sustento y lo que tiene, la estima en mucho más; porque ocupado noche y día en servir a la tierra y no a los hombres, es menos flexible por lo común; porque acostumbrado a que la tierra le rinda en proporción a la constancia y orden con que la cultiva, se hace por precisión justo y severo y aborrece la arbitrariedad y el desorden. No así los comerciantes: estudiando sin cesar los medios de hacerse con dinero, y teniendo siempre a la vista sus intereses particulares, se habitúan a sufrirlo todo, y a presenciar tranquilamente la opresión y tiranía del mundo entero, como sus intereses se aumenten o no padezcan. ${ }^{462}$

El escrito peninsular al que Moreno remite había sido publicado entre agosto y septiembre de 1808 bajo el seudónimo de Dr. Mayo, y es atribuido por el liberal Isidoro de Antillón a Julián Negrete, catedrático del Real Semanario de Nobles de Madrid, cercano al círculo de Manuel Quintana y redactor entre otros de El Espectador sevillano. ${ }^{463}$ De un contenido propagandístico revolucionario, abogaba por la convocatoria a Cortes y la proclamación de una constitución donde se limitara el poder de los nobles y eclesiásticos, clases que a sus entender eran las menos productivas de la nación. El manifiesto rezaba: "todos los vecinos son iguales, sin que el ejercicio o profesión alguna los degrade, ni menos estorbe proponer, discurrir y votar. Todos tienen

\footnotetext{
${ }^{461}$ Ibid., p. 141.

${ }^{462}$ Ídem.

${ }^{463}$ Clucellas, Patricio, óp. cit., p. 229.
} 
el mismo derecho a los empleos y honores, y solamente las luces y costumbres ocasionan la desigualdad de las familias". 464

Continuando con su refutación al escrito de Agüero, en un provocador planteo dice desconocer cuales son los derechos y títulos con los que supuestamente puede intervenir el Consulado de Cádiz en "el arreglo de nuestra economía interior" y "en la combinación de arbitrios que remedien los urgentes apuros que afligen a V. E.". ${ }^{465}$ Para el futuro dirigente revolucionario, el puerto de Cádiz no tiene con Buenos Aires distintas relaciones que los demás puertos de la península, recordando que la resolución de Carlos III de 1778 “cortó de raíz la feudalidad mercantil, que una continuada serie de desgracias había afirmado; todos los puertos de España quedaron igualmente habilitados para el comercio de América, y no se descubrirá un principio por donde el Consulado de Cádiz pretenda una intervención que los demás comercios no reclaman..." 466

\section{La huella napolitana}

Para responder a las advertencias que Agüero hace sobre la progresiva falta de metálico en el mercado interno que la apertura comercial conllevaría, Moreno recurre a su antiguo y admirado maestro de Chuquisaca, Victorián de Villava. El aragonés, según Moreno, sostenía que, "por conocimientos apoyados en experiencias y doctrinas de sabios economistas", para la conservación del giro interior de un pueblo comerciante basta una cantidad muy inferior a la que vulgarmente se cree y que no hay riesgo de que por motivo alguno desaparezca. Ya hemos podido conocer en capítulos anteriores las precursoras propuestas reformistas que Villava sugería para la monarquía, y en especial para las relaciones entre la península y América, entre ellas las comerciales. También sus temores de que si no eran adoptadas, la posibilidad de una pérdida total de las colonias era tan real como cercana en el tiempo. Moreno, como vimos, había tenido acceso a esta obra, los Apuntes para una reforma de España, y seguramente también la oportunidad de ser testigo de alguna disertación del aragonés en los salones de la Academia Carolina o alguna intervención más informal en una tertulia chuquisaqueña. Recordemos la fuerte presencia del alegato del antiguo fiscal sobre la mita y el trabajo

\footnotetext{
464 "Política popular acomodada a las circunstancias del día", p. 38; citado en Clucellas, P., óp. cit., p. 231.

${ }_{465}^{23}$ Ibid., p. 145.

${ }^{466}$ Ídem.
} 
indígena en la disertación del estudiante porteño como parte de los ejercicios de la Academia.

Pero, ¿quiénes eran aquellos sabios economistas de los cuales, según Moreno, Villava extraía las doctrinas que nutrían su pensamiento? Ya hemos dicho que uno de los puntos más destacados en la trayectoria intelectual del aragonés había sido la traducción/adaptación parcial de las Lecciones de Comercio de Antonio Genovessi y la Ciencia de la Legislación de Gaetano Filangieri. Y es justamente en este último en el que Moreno en numerosas ocasiones descansa a lo largo del alegato para defender la propuesta de libre comercio. ${ }^{467}$ Filangieri es tomado, por ejemplo, para rebatir cuestionamientos concretos del Consulado de Cádiz, como la posibilidad de que la industria y artesanía local quedasen arruinadas por la apertura comercial. Moreno lo cita para explicar que el enriquecimiento de los hacendados redunda en la riqueza del estado y de todas las clases de la sociedad que de alguna u otra manera están vinculadas a ese sector económicamente. O para criticar a aquellos comerciantes que escudándose en el monopolio realizan pingües ganancias a través del contrabando.

La recepción en España de las obras de los juristas y economistas napolitanos llegó principalmente de la mano de los ilustrados aragoneses y valencianos. Esa recepción se dio en la metrópoli por una lado en una vertiente más económica, en la difusión de las Lezioni de Genovesi y los Dialogues de Galiani, y en una versión más jurídica, en la Scienza de Filangieri. Estas dos vertientes combinaban elementos doctrinales críticos al tradicional mercantilismo, que como sabemos fundaba la riqueza de un estado en la posesión de metales precios y el proteccionismo comercial. La escuela napolitana se nutría entonces de la fisiocracia -que privilegiaban el desarrollo agrícola y la liberalización de la economía, y del neo mercantilismo - que también revalorizaba la agricultura y propugnaba por el libre comercio interior de granos, aunque consideraba que era necesario mantener las trabas al comercio exterior. ${ }^{468}$

Como señalara el historiador Jesús Astigarraga, la obra de Filangieri, y en particular su Scienza, generó en España un enormemente atractivo para una generación 'tardía' de ilustrados españoles -Foronda, Arroyal, etc.- que, a lo largo de los años ochenta, había comenzado a demandar una radicalización de las reformas económicas y a plantear la necesidad de vincularlas con las políticas. La Scienza fracturó de inmediato en dos a la intelectualidad española de su época; siendo situada en el centro de una

\footnotetext{
${ }^{467}$ Goldman, N., Mariano Moreno..., p. 112.

${ }^{468}$ Ibid., pp. 111-112.
} 
encarnizada batalla entre los sectores reformadores y los conservadores. ${ }^{469}$ Mientras que los reformistas la convirtieron en una de las obras más defendidas de toda la Ilustración, los ataques a la Scienza se iniciaron en 1780 y procedieron de los núcleos absolutistas políticos y religiosos, y obviamente de la Inquisición, que terminó por prohibir su circulación y su lectura en marzo de 1790, abortando la primera traducción que había comenzado a publicar tres años antes el jurista valenciano J. Rubio.

Por otro lado, el conjunto de censuras, aclaraciones y modificaciones de todo tipo que los ilustrados españoles introdujeron en sus traducciones, como señala Astigarraga, constituyó "un reflejo de un proceso de transmisión de ideas económicas que, en cuanto dirigido hacia una realidad cultural más atrasada que la napolitana, exigió un depurado proceso de adaptación de las mismas a la nación receptora". ${ }^{470}$ Villava se destacó entre los traductores que mayor intervención imprimían a sus trabajos. De hecho, pocas traducciones españolas de tratados económicos foráneos poseyeron en el siglo XVIII español el grado de matización con el que Villava enriqueció su versión española de las Lezioni de Genovesi.

Con respecto a su recepción en América, Federica Morelli identifica dos etapas. En una primera, que sitúa en el último cuarto del siglo XVIII y los primeros años del XIX, los americanos acogieron mayoritariamente los temas económicos de la Scienza, y esto se debe dice la historiadora italiana, a dos razones fundamentales:

En primer lugar, porque los que contribuyeron a difundir la obra en el continente, como Villava, se habían interesado a su vez por estos mismos aspectos. En segundo lugar, porque, en esta perspectiva, la Scienza representaba el punto de llegada de un largo debate que se había iniciado en la primera mitad del siglo XVIII en España y que había favorecido la introducción de algunas reformas importantes; reformas que evidentemente para los americanos se habían revelado inadecuadas. Aun así, se trataba de críticas dirigidas a reformar la monarquía desde el interior y no a interrumpir definitivamente la relación con España. ${ }^{471}$

La Ciencia de la legislación se proponía en ese sentido dictar las normas de una política económica dirigida a impulsar el tráfico en las colonias y Europa, y eso era

\footnotetext{
469 Astigarraga, J., «Diálogo económico en la 'otra' Europa. Las traducciones españolas de los economistas de la Ilustración napolitana (A. Genovesi, F. Galiani y G. Filangieri)», Cromohs, 9 (2004): p. 16.

${ }^{470}$ Ídem.

${ }^{471}$ Morelli, Federica. «Tras las huellas perdidas de Filangieri: nuevas perspectivas sobre la cultura política constitucional en el Atlántico hispánico». Historia contemporánea núm. 33 (2006), p. 450.
} 
fundamentalmente lo tomado tanto por ilustrados españoles como americanos. Sería recién en esa segunda etapa que plantea Morelli, cuando, a partir de la deriva que la crisis monárquica va tomando en América con la formación de gobiernos autónomos, la recepción de Filangieri va a ser en clave de la crítica al antiguo orden legislativo. Es en ese contexto que comenzaron a aparecer una serie de duras condenas al sistema jurídico colonial y a invocarse reformas de inspiración racionalista. La recepción de Moreno, vía Villava, de la Scienza de Filangieri debe entenderse en ese momento bisagra, donde el abogado recurre a la concepción jurídica iusnaturalista del napolitano y a sus críticas concretas a la legislación comercial entre España y América. Toda la Representación como hemos podido ir observando está impregnada de esa marca donde los derechos y la justicia, no solo la necesidad, determinan la legitimidad de la medida consultada por el gobierno virreinal.

Filangieri es utilizado una vez más por Moreno para rebatir al apoderado del Consulado de Cádiz sobre el supuesto de que concedido a los ingleses el comercio con las Américas, en el trascurso de pocos años se romperían los vínculos que unen al virreinato con la Península española. El agorero pronóstico, al que califica de injuriosa invectiva, a pesar de que responsabiliza el peligro a la codicia de los extranjeros, lo que en realidad está insinuando, según Moreno, es la falta de fidelidad de los americanos. Descarta que los ingleses estén interesados en un plan de conquista, ya que su política "no gira las empresas militares sino sobre los intereses de su comercio". ${ }^{472}$ No es necesario remitir a las recientes invasiones de 1806 y 1807 para tachar de ingenuo a Moreno, no creemos en realidad que esté siendo fiel a sus pensamientos en este punto en particular, es bien conocida su temprana desconfianza a la ambiciosa política exterior británica, aspecto que lo había mantenido al margen de entablar relaciones fluidas con el grupo de criollos probritánico integrado por Castelli y los hermanos Rodríguez Peña, entre otros. ${ }^{473}$ Una vez más es el abogado que busca lograr llevar a buen puerto su

\footnotetext{
${ }^{472}$ Piñero, Norberto, óp. cit., p. 163.

${ }^{473}$ Goldman, N., Mariano Moreno..., p 92. Ya como secretario de la Junta, en relación a las negociaciones con Inglaterra por su reconocimiento, Moreno no se privaría de advertir sobre los riesgos que podía implicar el libre comercio para las colonias: "Los pueblos deben estar siempre atentos a la conservación de sus intereses y derechos; y no deben fiar sino de sí mismos. El extranjero no viene a nuestro país a trabajar en nuestro bien, sino a sacar cuantas ventajas pueda proporcionarse. Recibámoslo en buena hora, aprendamos las mejoras de su civilización, aceptemos las obras de su industria y franqueémosle los frutos, que la naturaleza nos reparte a manos llenas; pero miremos sus consejos con la mayor reserva y no incurramos en el error de aquellos pueblos inocentes que se dejaron envolver en cadenas, en medio del embelesamiento que les habían producido los chichis y abalorios. Aprendamos de nuestros padres, y que no se escriba de nosotros los que se ha escrito de los habitantes de la antigua España con respecto a los cartagineses que la dominaron: Libre, feliz España, e independiente, Se abrió
} 
encargo el que está hablando. Además, como para no dejar dudas respecto de ello, ubica la prueba de la vigencia de la fidelidad hacia España en la resistencia protagonizada por los rioplatense a la invasión británica. "Los ingleses mirarán siempre con respeto a los vencedores del cinco de julio y los españoles no se olvidarán que nuestros hospitales militares no quedaron cubiertos de mercaderes, sino de hombres del país que defendieron la tierra en que habían nacido, derramando su sangre por una dominación que aman y veneran". ${ }^{474}$ Pero a la par que declama esa profunda fidelidad, advierte que no puede ser ésta siempre incondicional, y es aquí donde vuelve a recurrir al "gran Filangieri" y a su análisis sobre la independencia de las colonias norteamericanas, para por un lado ahuyentar los temores infundidos por el Consulado de Cádiz, pero a la vez poner sobre la mesa que la única garantía de la conservación de las colonias por parte de España debía ser a partir de una reformulación de los vínculos, asentándolos sobre el mutuo beneficio y el respeto por los derechos de los americanos. Reproducimos el párrafo trascripto por Moreno de Filangieri:

No se me oponga que estas colonias, si llegaban a ser ricas y poderosas, desdeñarían de estar dependientes de su madre. La carga de la dependencia solamente se hace insoportable a los hombres, cuando va unida con el peso de la miseria y de la opresión. Las colonias romanas... se gloriaban de una dependencia que constituía su gloria y su seguridad. Lo mismo sucedería con las colonias modernas: felices bajo su metrópoli, no se atreverían a sacudir un yugo ligero y suave para buscar una independencia, que las privaría de la protección de su madre, sin quedar aseguradas de poder defenderse o de la ambición de un conquistador, o de las intrigas de un ciudadano poderoso o de los peligros de la anarquía. No ha sido el exceso de las riquezas y de la prosperidad el que ha hecho rebelar a las colonias anglicanas; ha sido el exceso de la opresión el que las ha llevado a volver contra su madre aquellas mismas armas, que tantas veces habían empeñado en su defensa. $^{475}$

Similares argumentos que sostenían algunos liberales peninsulares por esos mismos años, como por ejemplo Álvaro Flórez Estrada o José María Blanco White, pero que Moreno seguramente conociéndolos, decide no incorporarlos al alegato. Blanco White, una vez radicado en Londres, no descansaría desde las páginas de El Español de abogar

al cartaginés incautamente: Viéronse estos traidores, Fingirse amigos, para ser señores; Y el comercio afectando, Entrar vendiendo para salir mandando". Gazeta de Bueno Aires, nro. 16 (20/9/10): p. 414.

${ }^{474}$ Piñero, Norberto, óp. cit., p. 163.

${ }^{475}$ Ibid., p. 164. 
por el libre comercio y criticar al gobierno metropolitano, demasiado influenciado según el por el gremio de los comerciantes de Cádiz:

A la vista está el resultado: ahora tienen las cortes que estar llorando duelos a la Junta de Cádiz, y los que no han querido condescender con los deseos de quince millones de hombres, que podían, y querían sacrificarla cuanto tienen, se ven obligados, a adular a quince o veinte hombres que te creen soberanos de Cádiz, y que son enemigos natos de las cortes. La piedra de escándalo ha sido el comercio libre. Si se abre el comercio en las América, perecen los comerciantes de Cádiz. Si no se abre perece la España, porque se ponen en revolución las Américas. Si se abre el comercio se enriquecerán los ingleses. También se enriquecerán los americanos, y unos y otros son los que sostienen la causa de España. España no tiene medios de hacer el comercio, y querer que no lo hagan otros es ser verdaderamente el perro del hortelano. ${ }^{476}$

El publicista sevillano reproduciría en su periódico, en uno de los pocos casos donde escritos americanos son publicados en la prensa europea, la Representación con muy elogiosas consideraciones hacia su autor tomadas de la British Review, donde también se publicó el documento. ${ }^{477} \mathrm{El}$ autor de dicha nota, que Blanco White hace propia, se lamenta de la reciente muerte del rioplatense, al que destaca por su desinterés, su talento, sus principios liberales y por los patrióticos servicios prestados a su nación, consagrando su vida "al proyecto de elevarla a la libertad civil". ${ }^{478}$ Blanco White afirma que el documento puede entenderse como "uno de los anuncios que el gobierno español tuvo de las conmociones que amenazaban a América y como una prueba clara de que aquellos pueblos han sido forzados a la revolución, por la tenacidad del gobierno a no concederles a tiempo lo que la necesidad exigía...". 479

\section{Consideraciones finales}

Antes de finalizar con este capítulo, nos interesa plantear una disquisición sobre cuán fiel es el documento en relación al pensamiento económico de Mariano Moreno. Algunos autores, entre ellos Ricardo Levene, consideran que en la Representación

\footnotetext{
${ }^{476}$ Este fragmento pertenece a las "Reflexiones de Juan Sintierra", publicadas en El Español núm. XIII y reproducidas luego por la Gazeta extraordinaria de Buenos Aires núm. 6 (21/11/11): p. 24.

${ }^{477}$ La publicación de la Representación va acompañada a su vez por una reseña de la British Review a una obra de Félix Azara, Voyagedans la Amérique Meridionale, donde se cita un comentario del General Belgrano sobre la expedición al Paraguay. La reseña termina siendo una extensa historia de los últimos años del Virreinato del Río de la Plata. El Español XVIII, 30/9/11, pp. 482- 488.

${ }^{478}$ El Español XVIII, 30/9/11, p. 488

${ }^{479}$ El Español XVII, 30/8/11, p. 445.
} 
Moreno expone sin ambigüedades su liberalismo económico, además de afirmar que tras la revolución, desde el gobierno capitaneado en los primeros meses por él, la política económica estaría guiada por la máxima que rezaba que el comercio era "la única raíz de la población y riqueza de los estados". ${ }^{480}$ A nuestro entender, varios de los pasajes que podrían ser considerados como expresiones de la más pura ortodoxia librecambista, responden más a las obligaciones profesionales de Moreno en aras de velar por los objetivos del sector que representa. Como sabemos, la función del abogado no es, y no lo era tampoco en esa época, dar fiel testimonio de sus convicciones, sino llevar adelante, a partir de las herramientas discursivas y doctrinarias de las que su bagaje intelectual puede permitir, la mejor defensa de los intereses de sus clientes. Por otros escritos del autor y por algunas de las disposiciones de la Junta Provisional Gubernativa, consideramos que Moreno no se distanciaba mucho en su pensamiento económico de las posiciones que sus compatriotas ilustrados, como Belgrano y Vieytes, venían sosteniendo en la última década. Ninguno de éstos deseaban para el Río de la Plata un futuro exclusivamente ganadero, ni esperaban que la Corona les asignase únicamente el rol de productor de materias primas. ${ }^{481}$ No creemos, como planteara Tulio Halperín Donghi, que la Representación marque el viraje ideológico de los criollos hacia un liberalismo económico más definido. ${ }^{482}$ Como bien señala Chiaramonte, recién cuando en 1823 se inaugure la cátedra de Economía en la Universidad de Buenos Aires, la ortodoxia smitheana predominará en la prensa oficial de Buenos Aires, tanto en el período rivadaviano como en el primer gobierno de Rosas. ${ }^{483}$ Consideramos que, como afirmábamos en un capítulo anterior, a pesar de los cada vez más recurrentes planteos a favor de la libre exportación de los frutos, los economistas criollos seguían manteniendo, al igual que muchos de los reformistas peninsulares como Jovellanosvehículo para el acercamiento a Adam Smith en el caso de Moreno-, la convicción de que era el Estado el principal actor que debía intervenir sobre la realidad social para provocar o permitir las transformaciones necesarias en el camino de racionalización económica y social anhelada. El problema era, como marcara con claridad Halperín Donghi, y ahí sí compartimos plenamente, que para varios de ellos la Corona ya no parecía cumplir esa misión tutelar histórica. ${ }^{484}$

\footnotetext{
${ }^{480}$ Levene, R., Las ideas políticas y sociales de Mariano Moreno, Buenos Aires, Emecé, 1948, pp. 66-78.

${ }^{481}$ Halperín Donghi, T., Revolución y Guerra ..., p. 128.

482 Ibid., p. 129.

${ }^{483}$ Chiaramonte, J. C., La ilustración ..., pp. 91-92.

${ }^{484}$ Halperín Donghi, T., Revolución y Guerra ..., p. 129.
} 
SEGUNDA PARTE

LA REVOLUCIÓN 


\section{Capítulo 8 \\ La revolución rioplatense}

\section{El último Virrey}

El 11 de febrero de 1809 la Junta Central designó como virrey para el Río de la Plata a Baltasar Hidalgo de Cisneros en remplazo de Santiago de Liniers, demasiado desgastado por las rencillas locales, buscando normalizar de esa manera la relación con el virreinato, poniéndolo más estrechamente bajo su órbita. Cisneros era un importante oficial de la marina española y había tenido una destacada actuación en el movimiento juntista español y en la resistencia a la ocupación francesa. Llegó al Rio de la Plata recién a fines de junio desprovisto de las tropas que había pedido a la Junta Central, por lo que la primer prueba que debía superar era lograr la obediencia de las fuerzas locales. Se trataba del primer virrey cuyo nombramiento no emanaba directamente de la autoridad real, dato no menor en el contexto en el que le tocó asumir su cargo. En tal sentido se dirigió primero a Montevideo, donde consiguió que Elío disolviese la Junta local y se subordinase a su autoridad. ${ }^{485}$ Durante su estadía allí se puso en conocimiento de movimientos opositores a su designación en la capital virreinal por lo que decidió quedarse en la Banda Oriental hasta que tanto autoridades como la oficialidad de Buenos Aires hicieran explícita su subordinación. ${ }^{486}$

¿En qué consistía ese mar de fondo que preocupaba a Cisneros? La realidad era que varios de los actores políticos a los que les fuimos siguiendo el rastro en capítulos anteriores intensificaron sus actividades conspirativas al conocer la designación del nuevo virrey, alegando por lo bajo que su autoridad era ilegítima ya que no provenía ni del rey ni del pueblo. Belgrano, por ejemplo, buscó convencer a Liniers de que no entregara el mando y se pusiera a la cabeza de la resistencia. Descartada esa posibilidad, según el letrado criollo, por falta de espíritu del mandatario, reincidió en su estrategia carlotista, tratando de sumar a Saavedra a dicho proyecto, con cartas de la infanta dirigidas a su persona. ${ }^{487}$ Resultaron infructuosas también esas gestiones. El comandante de los patricios se mantenía firme en su apreciación de que aún no estaban dadas las

\footnotetext{
${ }^{485}$ Wasserman, F., Castelli..., p. 74.

${ }^{486} \mathrm{La}$ Junta Central fue la que aconsejó a Cisneros fijar su residencia en Montevideo hasta tanto se asegurara el ser obedecido en la capital y "fortificar el partido del gobernador de Montevideo cuyo patriotismo parece indudable". También se lo prevenía sobre la conducta del virrey interino, rodeado de franceses y "otros malvados", intentando "granjearse la estimación de la gente soez". Citado en Frega, Ana, "La Junta de Montevideo...", p. 259.

${ }^{487}$ Belgrano, M. óp. cit.
} 
condiciones para un movimiento de esas características. Unos años después, en su famosa carta a Viamonte tras el desplazamiento de los morenistas del gobierno, Saavedra recordaría la disposición e insistencia del grupo de Castelli y los hermanos Rodríguez Peña para lanzarse a la toma del poder, a partir del mismo momento que frustraron el intento de la facción de Álzaga; y como debió poner paños fríos hasta considerar que había llegado el momento adecuado. ${ }^{488}$

La fidelidad de Liniers y la prudencia de Saavedra le permitieron a Cisneros ir de a poco consolidando su autoridad, $\mathrm{y}$, tras enviar emisarios a reunirse con el virrey saliente y algunos oficiales, que le manifestaron su apoyo, se trasladó finalmente a Buenos Aires para asumir el gobierno del virreinato. Aun así, la febril actividad conspirativa no menguó en un primer momento, y eran comunes las reuniones secretas entre oficiales y civiles, con la incorporación de algunos elementos nuevos como Juan Martín de Pueyrredón, recién llegado de España, y el deán cordobés Gregorio Funes. Tomás Guido en su ensayo "25 de Mayo de 1810. Reseña Histórica”, escrito en 1855, recordaba:

Con habilidad y cautela se predisponía el ánimo de los ciudadanos a favor del derecho inconcuso de América para cuidar de su propia suerte, desde que la prisión del rey y la ocupación de la península por tropas francesas, había desquiciado la máquina gubernativa y dejando a los pueblos a merced de sus propios instintos. La España había dado el ejemplo erigiendo sus juntas y proclamando en la mayor parte de sus provincias una especie de soberanía independiente, hasta que se instaló la junta central, cuya legitimidad, sin embargo, fue disputada y contrariada por algunas de las secciones de la misma España. ${ }^{489}$

Cisneros era consciente de su fragilidad relativa, por lo que procuró ir resolviendo los conflictos sin producir con sus medidas un desequilibrio significativo entre las fuerzas locales. Suspendió los juicios a los alzados del 1er de enero y ordenó que se rehabilitaran con otro formato los cuerpos milicianos disueltos en esa ocasión. Como contrapartida, y seguramente producto de negociaciones entabladas con la oficialidad para lograr su reconocimiento, la estructura de las milicias criollas no fue trastocada, desconoció la orden dada por la Junta Central de nombrar a Elio como inspector de

\footnotetext{
488 “Carta de Saavedra a Viamonte del 27 de junio de 1811”, Biblioteca de Mayo, t. II, pp. 1096-97.

${ }^{489}$ Guido, Tomás “25 de Mayo de 1810. Reseña Histórica”, en Fradkin, Raúl; Gelman, Jorge, Doscientos años pensando la revolución de Mayo, Buenos Aires: Sudamericana, 2012, p. 119.
} 
armas por la resistencia que provocaba en las tropas porteñas, y de remitir a Liniers a España permitiéndole afincarse en Córdoba.

Los levantamientos altoperuanos y su violenta represión agitaron aún más los ánimos en el caldeado Buenos Aires. Algunos destacados integrantes del círculo de Castelli y Belgrano como Domingo French y Antonio Berutti plantearon que era el momento de pasar a la acción y lanzar la rebelión, según relata el memorialista Francisco Saguí. ${ }^{490}$ Pero la realidad era que la gobernabilidad de Cisneros, aunque debilitándose progresivamente, todavía era relativamente sólida y tanto la monarquía como la metrópoli seguían manteniendo cierta cuota de prestigio entre la mayoría de la población rioplatense. Como describía Tomás Guido en el ya citado ensayo:

[...] los hábitos del coloniaje, la influencia de los magistrados peninsulares, las poderosas relaciones mercantiles y políticas con España, el gran número de empleados españoles, una extensa población del mismo origen ciegamente orgullosa de su dominio tradicional, la veneración supersticiosa del monarca, la indiferencia o inercia inseparables en los naturales de una servidumbre secular y por último, dos cuerpos de línea del Fijo y de Dragones, levantaban una barrera al parecer insuperable, para un círculo pequeño de hombres, que, si bien animosos, apenas contaban con el apoyo de una parte de la fuerza armada. $^{491}$

Esa tenacidad que caracterizaba al círculo se traducía en la aparición cada vez más usual de libelos cuestionando la autoridad virreinal, por lo que Cisneros a fines de noviembre encomendó al fiscal Antonio Caspe la creación de un Juzgado de Vigilancia contra "propagandas y manejos subversivos", disponiendo además que se arrestase a algunos sospechosos. ${ }^{492}$ En una comunicación fechada el 27 de noviembre, el virrey informa al gobernador de Salta: "He tenido positiva noticia de que en esa ciudad hay ciertos número de abogados que vierten públicamente especies subversivas contra los supremos derechos de nuestro augusto soberano sobre estos dominios, produciéndose con la mayor libertad". ${ }^{493}$ En diciembre de 1809, Cisneros hizo publicar un bando donde disponía medidas para reprimir los atentados contra el orden público y los falsos rumores de los que "pretendían variar la forma de gobierno". ${ }^{494}$ Una carta de José

\footnotetext{
490 "Memoria Francisco Saguí", Biblioteca de Mayo, t I, p. 121.

${ }^{491}$ Citado en 66. Fradkin, Raúl; Gelman, Jorge, óp. cit., p. 119.

${ }^{492}$ Este organismo no era una novedad, en su preocupación por la seguridad interior del Estado y por el control de cuantos afrancesados estuvieran camuflados en la administración, el 19 de octubre de 1808 la Junta Central había creado tribunales de vigilancia y seguridad pública.

${ }^{493}$ Citado en Williams Álzaga, E., óp. cit., p. 209.

494 “Bando del 18/12/1809”, La Revolución de Mayo y sus impresos de la época, p. 247-250.
} 
Manuel Alonso a Ambrosio Funes de ese mismo diciembre da certeza a esas prevenciones del virrey: "Los libelos corren como un torrente impetuoso y la detracción no tiene término. El castigo está remoto y así todos hacen gala del San Benito". ${ }^{495}$ En enero de 1810, el virrey decidió la expulsión del agente carlotista Felipe Contucci, vigilado hacía un tiempo por algunos movimientos sospechosos. Las intrigas carlotistas no habían cesado del todo, Belgrano y el deán Funes, entre otros, aún depositaban algunas expectativas en esa estrategia, mientras la Infanta seguía dilatando su muchas veces prometido traslado a Buenos Aires. La alianza de España con Inglaterra y Portugal complicaba las cosas para los planes autonomistas de los revolucionarios y el manto de legitimidad que seguía ofreciendo Carlota era una alternativa que no podían aún descartar.

\section{La situación en la península y la llegada de las noticias a América}

El 19 de noviembre de 1809, en las cercanías del pueblo toledano de Ocaña, se produjo un acontecimiento de naturaleza militar que cambiaría la historia hispánica irremediablemente. Se enfrentaron el ejército francés al mando del Mariscal Soult contra el español del general Aréizaga, arrojando al campo de batalla cerca de 100.000 combatientes en proporciones similares. El resultado, como bien se sabe, fue la desastrosa derrota española que le abrió las puertas a los franceses para la invasión de Andalucía y motivó la huida en estampida de la Junta Central, primero hacia Sevilla y luego hacia Cádiz. La guerra además entraba en una nueva fase, la de la guerra de guerrillas y las ciudades sitiadas. Los efectos de la derrota de Ocaña también se hicieron sentir en América. El pesimismo remplazó ahora a la euforia desmedida y altisonante con que habían sido recibidas en su día las más que alentadoras buenas nuevas de Bailén. Los rumores se adueñaron de las calles, cafés y campos, y las noticias se iban magnificando a medida que se propagaban. Así, se divulgó que el temido Napoleón iba a invadir los territorios americanos si éstos no acataban su legitimidad. ${ }^{496}$ En el Rio de la Plata, las importantes novedades que llegaban desde la península decretaron un verano más agitado de lo normal, intensificándose los encuentros clandestinos y la discusión de los planes a seguir ante un panorama tan incierto. La fábrica de jabones de

\footnotetext{
495 “Carta de José Manuel Alonso a Ambrosio Funes del 10/12/09”. Citado Williams Álzaga, óp. cit., p. 111.

${ }^{496}$ Chust, M. (coord.), España. Crisis imperial e independencia. Tomo 1: 1808-1830, Fundación Mapfre/Taurus. Madrid, 2010, p. 29.
} 
Vieytes y la casa de los Rodríguez Peña fueron los lugares más utilizados para las reuniones conspirativas, que eran cada vez más concurridas e iban adquiriendo propósitos más definidos. ${ }^{497}$

Mientras tanto, en la península, durante los primeros meses de 1810 las Juntas rebrotan -Sevilla, Extremadura, Cádiz, etc.-, con igual autonomía que en la primera época. El 20 de enero se produce una nueva derrota de las armas española. La desprestigiada Junta Central tenía los días contados; acosada por propios y extraños en su huida hacia el sur terminó disolviéndose el 29 de enero en el marco de una crisis total, no sin antes designar, ante las exigencias británicas, un Consejo de Regencia de cinco miembros que se presentaba como la única opción de sostener una conducción centralizada a la golpeada resistencia española hasta que se constituyeran las Cortes. La transferencia sin mediación popular de la soberanía contradecía mucho de lo que había sostenido la misma Central y varias de las juntas provinciales en los últimos meses, cuando desde los sectores conservadores proponían su reemplazo por una Regencia.

A fines de marzo, previendo los efectos que tendría el arribo de estas funestas noticias, Cisneros le ordenó a Elío que retenga en Montevideo todo navío procedente de España para que la información no se difundiera entre la población antes de ser analizada por las autoridades. El 13 de mayo arribó un barco inglés a Montevideo trayendo la noticia del arrollador avance francés y la disolución de la Junta Central. A pesar de los intentos de las autoridades de bloquear cualquier filtración, pronto comenzaron a circular los rumores, reforzados por la llegada de otra nave a Buenos Aires. ${ }^{498}$ El 18, el virrey decidió hacerse cargo de la situación por medio de un bando informando parcialmente lo sucedido y llamando a mantener la calma, la unidad y la lealtad. ${ }^{499}$ Ya era demasiado tarde, la ciudad estaba convulsionada, y aquellos que habían mantenido una paciente espera, supieron que era el momento de actuar.

\footnotetext{
${ }^{497}$ Tomas Guido reconoce que "se inventaban excursiones al campo y partidas de caza para disfrazar el verdadero intento de este figurado pasatiempo. Los concurrentes a esos memorables paseos, apenas se encontraban reunidos, sea bajo de los árboles o al abrigo de una choza campestre, se ocupaban exclusivamente de combinar los medios de llevar a buen término la obra de sus sueños y de sus esperanzas.". "25 de Mayo de 1810. Reseña Histórica”, Citado en Fradkin, R.; Gelman, J., óp. cit., p. 119. A partir de marzo también se empezó a utilizar el Correo de Comercio de Belgrano como pantalla para las reuniones.

${ }^{498}$ En el "diario de un soldado", de autor completamente desconocido pero que a claras no pertenecía a la elite letrada, el 16 de mayo de 1810 da cuenta que "se ha recibido noticia de que la España se ha perdido y que los españoles quieren entregar al francés estos dominios". Citado en Fradkin, R.; Gelman, J., óp. cit. p.44.

${ }^{499}$ En la imprenta de los niños expósitos se reimprimió la proclama de la Junta de Gobierno de Cádiz anunciando la creación del Consejo de regencia en Cádiz el 5 de febrero de 1810. El bando iba acompañado de una nota que refiere a que el documento llegó en una fragata inglesa despachado de
} 


\section{Estalla la Revolución}

Según las crónicas, Castelli y Saavedra, que se encontraban ese 18 de mayo en sus quintas de San Isidro debieron ser buscados de apuro para ponerlos al tanto de las últimas novedades, centrales como eran para cualquier decisión que quisiera tomarse. Belgrano también había tenido que ser convocado porque, como él mismo cuenta en su autobiografía, se encontraba en el campo cuando fue mandando a llamar con las noticias de la entrada de los franceses a Andalucía y la disolución de la Junta Central. ${ }^{500}$ Las reuniones que se sucedieron de ahí en adelante contaron con la participación tanto del grupo de Belgrano y Castelli como de los oficiales de los cuerpos milicianos cuyo representante más notorio era Saavedra. Parecía que para el comandante de patricios ahora sí finalmente las condiciones estaban dadas para lanzar el golpe de mando definitivo. También a los conspiradores se le sumaron algunos allegados de Álzaga, como Domingo Matheu, Juan Larrea y Mariano Moreno, que habían participado del movimiento del 1ero de enero de 1809 . No era un dato menor esta confluencia, dotaba al movimiento de una representatividad más amplia, sin contar que se convertirían en valiosos elementos de la revolución en los meses siguientes.

El acuerdo alcanzado en estas febriles reuniones consistió en la necesidad de la convocatoria a un cabildo abierto, y para ello fueron repartidas las tareas que se centraron fundamentalmente en esta primera etapa en la persuasión sobre las distintas autoridades para que accedieran pacíficamente al pedido, sin descuidar el trabajo sobre la "tropa propia" a fin de tenerla dispuesta a la acción si era necesario. Finalmente, después de varias entrevistas y gestiones, bajo un clima de tensión en la ciudad que fue coronado por una movilización frente al cabildo, de la que participaron según algunas crónicas muchos jóvenes acaudillados por French y Berutti, varios de ellos armados con puñales y pistolas, el 21 de mayo el virrey cedió a la presión y aceptó la convocatoria al

Gibraltar, tras 52 días de navegación y arribado a Montevideo el 14 de mayo y que se ponía al conocimiento del público, “como se ejecutará sucesivamente con los demás papeles y gacetas que ha conducido, para que se entere sin equivocaciones ni especies abultadas por la ignorancia o la malicia de algunos individuos, del estado en que se halla nuestra península en las fechas a que se contrae". También se reprodujo la resolución del 6 de febrero de la Junta gaditana de permitir la salida de barcos del puerto después de un tiempo de mantenerlo cerrado.

${ }^{500}$ Belgrano, “Autobiografía...”. Citado en Fradkin, R.; Gelman, J., óp. cit.p.75. 
Cabildo abierto. ${ }^{501}$ Rápidamente fueron cursadas las invitaciones para participar de la asamblea convocada para la mañana del día siguiente.

El 22 de mayo, a pesar de las casi cuatrocientas cincuenta invitaciones que se habían despachado, terminaron concurrieron solo doscientos cincuenta vecinos. Era notable que, además, gran parte de los presentes fueran criollos y algunos de ellos no necesariamente podían acreditar la condición de "vecinos". ¿Qué había sucedido? Muchos de los ausentes, que pertenecían a las más encumbradas familias de la elite española, favorables en su mayoría al virrey, no se animaron a salir de sus casas por las amenazas que habían recibido durante la noche anterior o directamente se les impidió llegar por la estratégica ubicación de las milicias criollas en los alrededores del cabildo. Además, como la imprenta la manejaba Agustín Donado, miembro del círculo revolucionario, se imprimieron invitaciones a personas no tan "respetadas" y muchos del llamado "populacho" se infiltraron en el cabildo. ${ }^{502}$

Las intervenciones que se sucedieron durante el cabildo del 22 son sobradamente conocidas y han sido profusamente analizadas por la historiografía, por lo que no ahondaremos mucho en su descripción y tratamiento. El primero en tomar la palabra fue el obispo de Buenos Aires, Benito Lué y Riega, fiel exponente del pensamiento más fidelista y conservador entre las autoridades virreinales. Su exposición estuvo centrada en reafirmar el carácter de colonias de los dominios americanos, a contramano aun de las proclamas peninsulares, y sostener que mientras quedara alguna autoridad en pie en España, esta seguiría detentando la soberanía en todos los dominios coloniales ya que se trataba de una autoridad indivisible. ${ }^{503}$ Terminado su discurso, fue el turno de Castelli, quien había recibido la confianza de sus compañeros para ser el vocero gracias a sus reconocidas condiciones oratorias. En líneas generales su planteo consistió en que, a partir de las abdicaciones de Bayona, había caducado el gobierno soberano de España, lo que ahora tenía mayor fundamento al haberse disuelto la Junta Central. Esta además no tenía facultades para establecer una regencia porque los poderes de sus vocales eran indelegables, a lo que se le sumaba que tampoco habían tenido participación los diputados americanos. Y fue en ese momento de su discurso que el llamado "orador de

\footnotetext{
${ }^{501}$ Galasso, Norberto, La Revolución de Mayo: (El pueblo quiere saber de qué se trató), Buenos Aires: Colihue, 2005, p. 23. En una carta con fecha del 20 de mayo firmada por Buenaventura Arzac se deja traslucir el tenso clima que vivía la ciudad: “...la mina ya está al reventar y empieza la jarana que andábamos buscando. El día de hoy ha sido grande; y te aseguro que en mi vida no he pasado horas más hermosa, y más tiernas, al ver a nuestros paisanos unidos y llenos de entusiasmo, yendo y viniendo por los arrabales para tener pronta la gente. Citado en De Gori, E., La Republica Patriota ..., p. 206.

${ }^{502}$ Galasso, Norberto, La Revolución ..., p. 24.

${ }^{503}$ Wasserman, F., Castelli..., p. 86.
} 
la revolución" sostuvo que ante la vacancia del poder real, la soberanía retrovertía a los pueblos, y por lo tanto, Buenos Aires tenía la potestad de erigir un nuevo gobierno que lo resguarde de seguir el camino de España, a punto de ser completamente ocupada por Napoleón. Señalaba que lo mismo habían hecho las ciudades españoles desde hacía dos años, como se conocía gracias a las proclamas y otros documentos oficiales metropolitanos que circulaban en América. ${ }^{504}$

Sin rechazar el argumento de Castelli sobre la reasunción de la soberanía, el fiscal Genaro Villota tomó la palabra para advertir que debía considerarse la situación excepcional por la cual la Junta Central decidió nombrar un Consejo de Regencia, cuyos vicios de origen podrían subsanarse con el reconocimiento posterior por parte de los pueblos. Agregó además que Buenos Aires no tenía derecho a decidir por sí sola en nombre de todos los pueblos del virreinato, por lo que debía esperar a estos se pronunciasen para tomar una decisión tan radical. Otros autores sostiene que en realidad el planteo de Villota se refería a que siendo la soberanía una e indivisible, sólo un congreso general que reúna a todos los representantes de la nación española podían decidir a quién delegarla. En uno u otro sentido, el planteo del fiscal implicaba inevitablemente la dilatación de la resolución, garantizando la continuidad del virrey, como terminaría votando minutos más tarde. ${ }^{505}$

Descolocados varios de los promotores del cambio por este último argumento, fue Juan José Paso quien salió rápidamente a replicar, sosteniendo que se trataba de una situación excepcional por lo que la capital podía actuar en nombre del resto de los pueblos esperando que estos ratificaran posteriormente la decisión tomada. Argumento que paradójicamente reproducía la defensa que había hecho el fiscal de la constitución del Consejo de Regencia. Por su parte, Saavedra apoyó la destitución del virrey con el radical planteo de que era el pueblo el que confería la autoridad o mando, mientras que Martín Rodríguez alertó sobre la imposibilidad de conciliar la permanencia de la autoridad del virrey con la opinión pública. ${ }^{506} \mathrm{La}$ intervención de estos últimos fue ovacionada por gran parte de los presentes, que sabiéndose mayoría instaron a no dilatar más la reunión y proceder a presentar las mociones para que se voten. Después de algunos intercambios sobre cuál era la moción que mejor expresase la disyuntiva, se terminó adoptando la siguiente: "Si se ha de subrogar otra autoridad a la Superior que

\footnotetext{
${ }^{504}$ Ibid., p. 87.

${ }^{505}$ Ibid., p. 88.

${ }^{506}$ Goldman, N., Mariano Moreno..., p. 137.
} 
obtiene el Excmo. Sr. Virrey, dependiente de la soberana; que se ejerza ilegítimamente a nombre del Sr. D, Fernando VII, ¿y en quién?”. De esa manera quedaba abierto el juego a que durante la votación se pudieran presentar las propuestas sobre quien debía asumir el gobierno en caso de que se hiciera cesar el cargo al virrey. ${ }^{507}$

Como el voto debía ser pronunciado en voz alta, aquellos que proponían la permanencia del virrey eran abucheados mientras que quienes propiciaban su deposición eran aclamados por los asistentes y el público que colmaba las galerías. La votación concluyó pasada la medianoche, postergándose el recuento definitivo para el día siguiente. El resultado igualmente estaba cantado, la diferencia a favor de la destitución del virrey y formación de la junta había sido notoria. Los promotores de la continuidad de Cisneros obtuvieron menos de setenta votos. El cabildo, con el voto decisivo del síndico procurador, tendría la responsabilidad de elegir a los miembros de la Junta, que gobernaría el virreinato en tutela de los derechos soberanos de Fernando VII hasta que se reuniera una Junta General de los pueblos rioplatenses.

La doctrina central utilizada por los cabildantes que propusieron la constitución de una Junta local fue, como pudimos ver, la de la retroversión de la soberanía a los pueblos en ausencia del monarca. Mismo argumento que enarboló el juntismo peninsular a partir de las abdicaciones de Bayona. Como viene demostrando hace ya varios años Chiaramonte, el principio de consentimiento no sólo se encontraba en la antigua tradición hispánica de raíz neoescolástica, con las obras de los teólogos jesuitas como sus mayores exponentes, sino que formaba parte fundamental de las doctrinas pactistas de la teoría del derecho natural y de gentes que se venía divulgando con fuerza en Europa y América durante el siglo XVIII. La amplia circulación de ideas durante el reinado de los Borbones, en especial en el de Carlos III e, inicialmente, en el de Carlos IV, había revitalizado viejas doctrinas provenientes del derecho natural, nunca desaparecidas de la cultura europea moderna, pero sí combatidas por los monarcas absolutos y sus defensores. La amplia difusión de las obras de autores iusnaturalistas había impuesto la noción del derecho natural como fundamento de la vida pública y privada. ${ }^{508}$ Una de estas nociones, la del pacto de sujeción, con su corolario de la retroversión de la soberanía al pueblo, como decíamos, fue el principal argumento legitimador del proceso de erección de juntas de gobierno locales, tanto en España como en América. En Buenos Aires, como había sucedido antes en Caracas y otras ciudades

\footnotetext{
${ }^{507}$ Wasserman, F., Castelli..., pp. 88-89.

${ }^{508}$ Chiaramonte, J.C., “Autonomía e independencia...”, p. 344.
} 
que habían levantado sus propias Juntas, el principio de consentimiento fue utilizado también para desconocer a la nueva autoridad metropolitana. El Consejo de Regencia se había constituido sin el consentimiento de los pueblos americanos, por lo cual carecía de legitimidad. Y estos pueblos, en uso legítimo de la soberanía reasumida ante la vacancia del trono, decidían evitar los riesgos de anarquía que generaba la falta de una autoridad local legítima constituyendo una Junta de gobierno propia. ${ }^{509}$ Utilizaban en su fundación, por lo tanto, un lenguaje político que sintonizaba perfectamente con el que contemporáneamente se estaba usando en la península. Esto se percibe claramente en el informe que dieran los miembros de la Audiencia sobre la intervención de Juan José Castelli en el cabildo abierto del 22 de mayo. Decían que Castelli

[...] puso empeño en demostrar que desde que el Señor Infante Dn. Antonio había salido de Madrid había caducado el Gobierno Soberano de España: que ahora con mayor razón debía considerarse haber expirado con la disolución de la Junta Central, porque además de haber sido acusada de infidencia por el Pueblo de su villa, no tenía facultades para el establecimiento del Supremo Gobierno de Regencia; ya porque los poderes de sus vocales eran personalísimos para el Gobierno y no podían delegarse, y ya por falta de concurrencia de los Diputados de América en la elección y establecimiento de aquel Gobierno; deduciendo de aquí su ilegitimidad y la reversión de los derechos de la Soberanía al Pueblo de Buenos Ayres y su libre ejercicio en la instalación de un nuevo Gobierno. $^{510}$

Y también nociones similares servían de fundamentos a aquellos que, como el fiscal, defendían la constitución del Consejo de Regencia. En el pensamiento suareciano, un gobierno ilegítimo en origen podía obtener posteriormente el consentimiento tras ejercer el poder de manera justa y apacible.

Asimismo, como bien señala Noemí Goldman, la apelación al Pueblo y a la "opinión pública" como fundamento de legitimidad de la autoridad en los discursos de Saavedra y Martin Rodríguez, introducía un elemento novedoso que se alejaba de la legislación conocida y se vinculaba con el clima de agitación y movilización que se vivía por esos días por fuera de la sala del Cabildo, en la plaza y en el cuartel de los patricios. La participación efectiva en el espacio público, ya no solo de las milicias, sino de un nuevo actor político: la plebe urbana, se constituyó en uno de los factores que

\footnotetext{
${ }^{509}$ Ibid., pp. 360-361.

${ }^{510}$ Citado en Ibid., p. 361.
} 
incidieron decisivamente en el rumbo del proceso, y que de ahí en más ganaría en importancia, fundamentalmente dentro de las disputas facciosas de la elite política. ${ }^{511}$

\section{El cabildo del 25}

Retomando el relato de los acontecimientos, el 23 de mayo los partidarios del virrey, a instancias del síndico Leyva, hicieron un último intento por mantener a Cisneros en el poder integrándolo a la Junta. Se trataba, no obstante, de una inclusión sui generis: se lo hizo abdicar previamente de su cargo para designarlo como presidente de la Junta, aunque sin la calidad de virrey. El resto de la Junta estaría integrada por dos peninsulares: Juan Nepomuceno Solá y José Inchaurreguí, y por los criollos Castelli y Saavedra. Era una falsa equidad; Cisneros, como presidente, tendría voto y mantendría el mando de las fuerzas militares entre otras prerrogativas. Inevitablemente, ni bien se conoció este cambio de planes orquestado tras bambalinas, no cayó para nada bien en el círculo de los más decididos revolucionarios, que entendían que no se estaba reflejando cabalmente el triunfo obtenido en la votación del día anterior. Aun así, en un clima que iba ganando en agitación, la Junta se constituyó el 24 cuando sus miembros juraron respetar las leyes del reino y conservar íntegros los dominios de Fernando VII. La aprobación de los comandantes de milicias había sido decisiva para permitir este desenlace. Que fue extremadamente efímero, porque al correrse la voz la indignación fue aumentando y la ciudad de a poco volvía a ser un hervidero. Para los complotados era claro que la presencia de Castelli y Saavedra en la Junta no constituía ninguna garantía, y reunidos en casa de Rodríguez Peña resolvieron boicotearla para lo que se repartieron las tareas de agitación, enfocándose principalmente en los cuarteles, y lograr así el apoyo necesario para influir sobre un timorato Saavedra, quien aún dudaba sobre qué debía hacerse. ${ }^{512}$ Algunas crónicas señalan que en esa noche del 24, Mariano Moreno se destacaría por su ímpetu y capacidad de persuasión, estrechando vínculos

\footnotetext{
${ }^{511}$ Goldman, N., Mariano Moreno..., p. 137.

${ }^{512}$ Wasserman, F., Castelli..., p. 91. Según el relato de Guido: "El pueblo pareció satisfecho de esta elección y los españoles se felicitaban de haber salvado del peligro de un trastorno fundamental viendo triunfante la autoridad del virrey. Muy diferente sensación produjo tan inesperado desenlace en el club reunido a las ocho de la noche en casa del Sr. Peña. Allí se analizó el carácter de los elegidos; se descubrió el origen de la candidatura de Cisneros; se reconoció por unanimidad que dos de los miembros de carácter ascético y tímido, se plegaría sin violencia a la política del presidente y hasta llegó a dudarse de la firmeza del corones Saavedra, bajo la presión e influjo de un jefe superior. Contábase solamente con la persona del Dr. Castelli: pero ninguno de sus amigos descubiertos como conspiradores, se reputo seguro continuando en el mando el general Cisneros. Era pues necesario deshacer lo hecho, convocar nuevamente al pueblo, y obtener del Cabildo se prestase a considerar ante otra reunión popular la sanción de la víspera".
} 
con French y Berutti, que a la postre serían dos de sus más fervorosos y decididos seguidores. ${ }^{513}$

El cabildo se reunió esa mañana temprano, y a pesar de las presiones y las renuncias de Castelli y Saavedra, se mantenía firme en la decisión de sostener la controvertida propuesta de Junta. Con el correr de las horas, la gente comenzó a acercarse al Cabildo a manifestar su descontento, inclusive llegando a golpear las puertas de la casa consistorial exigiendo la destitución de Cisneros, por lo que los cabildantes le pidieron a Saavedra y el resto de los comandantes que impusieran orden en la ciudad, a lo que estos se negaron rotundamente. La suerte de la junta "continuista" estaba echada. Entre los convocados en la plaza, varios de ellos armados como Dupuy, Berutti y French, empezó a circular una representación en la que a nombre del pueblo se pedía que se erigiera una nueva junta con la lista de aquellos que debían integrarla. ${ }^{514}$ Según Guido, la lista había sido confeccionada al alba en casa de Rodríguez Peña, después de varias horas de acalorada discusión. La representación, que estaba encabezada por los comandantes de las milicias, estaba firmada por más de cuatrocientas personas y en nombre de otras seiscientas lo hicieron French y Berutti. Mientras que afuera del Cabildo la muchedumbre aguardaba impaciente, varios de los manifestantes habían logrado entrar a los corredores y, según un protagonista, "no pocas veces fue interrumpida la grave sesión por la vocería popular animada por tribunos ardientes". 515

Finalmente los cabildantes, conscientes que no contaban con la fuerza suficiente para seguir resistiendo, cedieron a la presión y aceptaron la creación del nuevo gobierno, que se denominaría Junta Provisional Gubernativa de las Provincias del Rio de la Plata. Como habían exigido los manifestantes estaba presidida por Cornelio Saavedra y sus seis vocales eran Manuel Belgrano, Juan José Castelli, los comerciantes de origen catalán Juan Larrea y Domingo Matheu, el cura parroquiano Manuel Alberti, y el comandante de milicias Miguel de Azcuénaga. Contaba también con dos secretarios: Mariano Moreno a cargo del departamento de Gobierno y Guerra, y Juan José Pasó a cargo de Hacienda. La Revolución, por la que muchos de ellos venían trabajando silenciosa pero incansablemente, finalmente se había cristalizado.

\footnotetext{
513 “Memorias de Francisco Saguí", Biblioteca de Mayo, t. 1, p. 121.

${ }^{514}$ Ídem.

${ }^{515}$ Guido, Tomás, “25 de Mayo de 1810. Reseña Histórica”, en Fradkin, Raúl; Gelman, Jorge, óp. cit., p. 119.
} 


\section{El ejemplo de la Junta de Cádiz}

En la Gazeta extraordinaria del 9 de junio se publicaba completo el famoso manifiesto del 14 de febrero del Consejo de Regencia donde se reconocía la igualdad entre españoles y americanos y se convocaba a la elección de diputados para Cortes. En un comentario a pie de página se afirmaba que esta proclama no tenía firma ni autorización alguna, y que por lo tanto la Junta no estaba en la obligación de tenerla en cuenta. ${ }^{516}$ A continuación se reproducen en el periódico el intercambio de oficios de la Junta con la Real Audiencia sobre si se debía reconocer o no a la Regencia, sosteniendo cada autoridad posiciones antagónicas. El tribunal señala que la instalación del Consejo de Regencia y el juramento de la nación eran de público conocimiento, que se debían reconocer ya que en peores circunstancias se habían tomado decisiones importantes, sin esperar tanta formalidad. En respuesta, la Junta sostiene que reconocerá a toda representación soberana establecida legítimamente, pero que tomando lo dicho en la proclama sobre la igualdad entre América y la Península, no se considera con menos derechos ni menos representación que las provincias de aquellos reinos, para concluir reiterando su lealtad a Fernando VII. Entiende que lo más prudente era seguir conduciéndose así como lo hiciera el anterior gobierno en relación a la Junta de Sevilla, auxiliando a los demás pueblos de la Nación. ${ }^{517}$

En el contexto de dicha polémica con los oidores, en el suplemento a esa misma gaceta se reproducen algunos párrafos de una proclama que la Junta Superior de Cádiz dirigió a los Pueblos de América. Se aclara que más adelante se publicará entera pero que por ahora se inserta "la parte más necesaria; para que nadie dude la justicia y legitimidad de la instalación de nuestra Junta". ${ }^{518}$ La selección de los párrafos realizada por su editor, Mariano Moreno, no es para nada antojadiza y el incumplimiento de publicarla entera en los números siguientes tampoco. Pero antes de analizar la reproducción del escrito, retomemos un poco el hilo de los acontecimientos en la península para contextualizar su origen, y determinar el porqué de su relevancia histórica en el proceso juntista americano.

La precipitada salida de Sevilla de la Junta Central, camino a Cádiz en enero de 1810, provocó una situación temporal de desgobierno en la península, de ausencia de un poder constituido. Por lo que, pese a que la Junta anunció oficialmente su reinstalación

\footnotetext{
${ }^{516}$ Gazeta extraordinaria (9/6/10): 26.

${ }^{517}$ Ibid., 36.

${ }^{518}$ Suplemento a la Gazeta extraordinaria (9/6/10): p. 37
} 
tras su llegada a la Isla de León el 27 de enero, en Cádiz se planteó la necesidad de la formación de una nueva Junta que tuviese facultades soberanas. La propuesta partió del síndico del Ayuntamiento Tomás de Istúriz quien, en la noche del día 27 de enero de 1810, afirmó que la Junta Central Suprema Gubernativa del Reino había dejado de existir - pese a que dicha Junta había enviado oficio a Cádiz comunicando su reinstalación-, por lo que instó a formar una nueva Junta Superior Gubernativa que reemplazara a la formada en junio de 1808, y que se encargara de organizar la defensa y gobierno de la ciudad que por otra parte era ya, junto con la Real Isla de León, prácticamente el único territorio peninsular no controlado por los franceses. ${ }^{519}$

La creación de la nueva Junta gaditana significó un grave cuestionamiento a la autoridad y credibilidad de la Central, y sin lugar a dudas influyó en su disolución y cesión del poder al Consejo de Regencia, el 29 de enero, tras haber convocado Cortes. La Junta gaditana no sólo no se disolvió tras la creación del nuevo gobierno central si no que en un primer momento se negó incluso a reconocerlo y le disputó la preeminencia soberana. Los argumentos esgrimidos, como veremos, nos son familiares. La Junta Central, que había asumido la soberanía en nombre de los españoles, por cesión de estos, al cesar en sus funciones no podía ceder la soberanía a una Regencia, decían los juntistas gaditanos, sino que la soberanía debía retornar a los españoles, quienes deberían proceder a escoger un nuevo ejecutivo, una nueva Junta Superior Gubernativa. Estando toda España ocupada por el ejército invasor era la gaditana la que debía asumir las facultades soberanas. De esa manera, la Junta de Cádiz se presentaba a sí misma como un poder surgido de la voluntad popular, como un gobierno representativo, frente a la Regencia que se arrogaba un poder que a su entender había sido cedido ilegalmente. ${ }^{520}$

Trascurriría prácticamente un mes para que finalmente la Junta aceptase reconocer la autoridad soberana dela Regencia, siendo necesaria la intervención del embajador de Gran Bretaña, el marqués de Wellesley, insistiendo en la necesidad de contar con un gobierno fuerte y centralizado. Pero fundamentalmente la razón estribó en que la Regencia aceptó el 28 de febrero ceder a la Junta el control de la Hacienda, lo que se confirmó por contrato el 31 de marzo, y se mantuvo hasta octubre de ese mismo año, ya

\footnotetext{
${ }^{519}$ Ramos Santana, Alberto, "El manifiesto de la Junta Cádiz a la América española”, Funes, Leonardo (coord.), Hispanismos del mundo, Buenos Aires, Ed. Miño y Dávila, 2015, pp. 44-45.

${ }^{520}$ Ibid., 45
} 
constituidas las Cortes. ${ }^{521}$ En la práctica, como señalara Artola, los regentes parecían limitados a las tareas de reorganización de la defensa militar contra el asedio francés que al gobierno integral del Reino. ${ }^{522}$

Los argumentos de la Junta quedaron claramente expresados en el manifiesto $L a$ Junta superior de Cádiz a la América Española, fechada el 28 de febrero de 1810, en el que daba cuenta a los "pueblos de América" de los acontecimientos ocurridos desde principios de 1810, y les solicitaba su adhesión a la causa de la "salvación de la patria", colaborando con la propia Junta y con la Regencia a la que, como dijimos, ya había reconocido. En primer lugar buscaba dejar en claro los porqués de su instalación:

En tal incertidumbre, disueltos al parecer los lazos políticos que unen los diferentes miembros de la república; cada provincia, cada ciudad, cada villa tenía que tomar partido por sí sola, y atender por sí sola a su policía, conservación y defensa. Cádiz desde este instante debió considerarse en una situación particular y distinta de todas las demás ciudades de España. Su población, su opulencia, las relaciones inmensas de su comercio, la singularidad y fuerza de su posición debieron persuadirla que en ella iban a constituirse las principales esperanzas del estado. Creyóse con razón el objeto de mayor atención para los patriotas españoles, el lazo más importante de unidad con la América, y el interés y la expectación de toda Europa. El rumbo que ella siguiese, los sentimientos que manifestase debían ser principios de conducta y sendero de confianza para otros pueblos.

Como podemos apreciar, Cádiz se presentaba a sí misma como la principal esperanza para la salvación de España, y confiaba en que sus fluidos vínculos comerciales con América le favorecerían cumplir el rol de guía para con esos pueblos ante horas tan críticas.

Los siguientes cuatro párrafos del manifiesto fueron justamente los que Moreno incluyó en el suplemento a la Gazeta, en los que se relata el modo en que fue erigida la Junta. Ante la noticia de la invasión francesa de Andalucía, dice, todo Cádiz se movilizó y predispuso a la defensa de la plaza y para ello fue necesaria una reorganización política:

Mas para que el gobierno de Cádiz tuviese toda la representación legal y toda la confianza de los ciudadanos, cuyos destinos más preciosos se le confían, se procedió a petición del pueblo y propuesta de su síndico, a formar una junta de gobierno, que

${ }^{521}$ Ibid., 45-46.

${ }^{522}$ Artola, M., óp. cit., p. 373. 
nombrada solemne y legalmente por la totalidad del vecindario, reuniese los votos, representase las voluntades, y cuidase de los intereses. Verificose así, y sin convulsión, sin agitación, sin tumulto, con el decoro y concierto que conviene a hombres libres y fuertes, han sido elegidos por todos los vecinos, escogidos de entre todos, y destinados al bien de todos los individuos que componen hoy la Junta superior de Cádiz: junta cuya formación deberá servir de modelo en adelante a los pueblos que quieran elegirse un gobierno representativo digno de su confianza.

La junta gaditana hacía explícita su vocación de servirle de ejemplo a América, entendiendo seguramente que la llegada de las noticias del avance francés y la disolución de la Central inevitablemente generarían convulsiones al otro lado del océano.

La Junta se proponía como modelo pero unos párrafos más adelante -que ya no serían publicados en la Gazeta porteña- auto-limitaba sus atribuciones y daba cuenta de la necesidad de una autoridad central para la monarquía: "Contenida en los límites de su instituto, sin pretender dar leyes a los otros pueblos, y desechando toda idea de supremacía, tan ajena de su carácter y de sus principios, como perjudicial a la causa pública; deseaba con ansia el instante en que la autoridad soberana apareciese con la debida fuerza y energía, y se mostrase el centro de las operaciones de todo el reino". Y, a sabiendas de que no era conveniente en relación a América, nada decía de los cuestionamientos y resistencias que tuvo en su momento hacia el Consejo de Regencia, que la habían llevado a disputarle la "autoridad soberana" durante su primer mes de vida. Ya no existía ninguna duda sobre la legitimidad de la cesión de soberanía que invistió a los regentes:

No tarda este instante en llegar: los individuos de la Junta Suprema, a pesar de las contradicciones y aun desaires que sufrieron en su viaje de parte de los pueblos agitados, pudieron reunirse en la isla de León. Allí vieron que el poder que habían ejercido hasta entonces, ya sin acción en sus manos, debía transferirse a otras, para que pudiese salvar la patria. Convencida de esta necesidad, instruida por la voz de todos los buenos españoles, y por la lección de los sucesos mismos, la Junta Suprema terminó sus funciones con el acto solemne que a ella sola correspondía, creando un Consejo de Regencia, a quien trasladó la autoridad soberana de que estaba revestida.

$\mathrm{Y}$ haciendo extensivo ese razonamiento, convocaba a los americanos a reconocer y prestar juramento al nuevo gobierno metropolitano: 
En el júbilo que le cabe por un suceso tan deseado y por unas elecciones tan acertadas, la junta no hace más que manifestar franca y sinceramente sus sentimientos. ¡Puedan ellos extenderse con la misma uniformidad por todas las provincias de España, por todos los ámbitos de la América! En ellos están cifrados el crédito y majestad del gobierno, la obediencia a sus mandatos, el efecto de sus providencias, la consistencia y salvación de la monarquía.

Finalmente, volvía a exhortar a seguir su ejemplo, confiando en sus relaciones mercantiles como un factor determinante para influir en la voluntad de los americanos:

Cádiz os habla, pueblos de América, y confía que sus voces serán oídas de esos países con la adhesión y fraternidad que se deben a los vínculos estrechos que la unen con vosotros. ¿En qué ciudad, en qué puerto, en qué ángulo por remoto y escondido que sea no tiene Cádiz ahí un corresponsal, un pariente o un amigo? Por todo el universo se extienden nuestras relaciones de comercio, de amistad o de sangre, y es fuerza que las voces de nuestra lealtad y patriotismo exciten el interés de todos los hombres buenos del universo. ¡Oh americanos! Los mismos derechos tenéis que defender, el mismo rey que libertar, las mismas injusticias que satisfacer.

Es interesante reponer aquí uno de los planteos de Esteban De Gori sobre el lugar de la "ciudad" en el contexto de la crisis hispánica. La resignificación de la "tradición pactista y la reactivación del corporativismo municipalista o territorialista que consideraba que la ciudad representaba, según el iusnaturalismo católico, el lugar de la civilización y, por ende, de la política”. ${ }^{523}$ Trastocada la estructura piramidal propia del Antiguo Régimen por el marasmo institucional que provocó la crisis, el pueblo/ciudad, se revaloriza como fuente de legitimidad para ejercer el mando. Autogobierno y administración de los derechos del rey retrovertidos en el pueblo quedaron entrelazados en las propuestas insurgentes. Cohabitaban imaginarios y vocablos en lo que se articulaban monarquía y república, entendida esta última como gobierno del pueblo, como la causa pública. ${ }^{524}$

El historiador uruguayo Felipe Ferreiro en su libro La Disgregación del Reyno de Indias plantea que la proclama gaditana tuvo un impacto decisivo en la formación de las juntas americanas entre abril y septiembre de 1810 . Veamos entonces su recorrido para poder calibrar esta hipótesis, prestando particular atención en su recepción en el Río de la Plata. A principios de marzo de 1810 partieron de Cádiz, con representación oficial

${ }^{523}$ De Gori, E., La República Patriota ..., p. 196.
${ }^{524}$ Ibid., p. 284. 
del Consejo de Regencia para los territorios de Venezuela, Nueva Granada y Perú, Carlos Montúfar, Antonio Villavicencio y José de Cos Iriberri, quienes, junto con las instrucciones de la Regencia, llevaban también la "Proclama de la Junta Superior de Cádiz a la América Española". 525 Tras varias semanas de travesía llegaron al puerto de La Guaira el 17 de abril, dos días antes de la formación de la Junta de Caracas. Es más que probable entonces que los promotores de la revolución caraqueña hayan accedido a la proclama en esos agitados días y les sirviera como justificativo para su propio proyecto juntista. Un pasaje de las instrucciones de la Junta para sus enviados en Londres puede interpretarse en línea con ello: "no había más partido saludable para los Americanos que imitar el ejemplo mismo de las Provincias de España, cada una de las cuáles formó una Junta compuesta de individuos de su confianza". ${ }^{526}$

A fines de abril, dos de los comisionados gaditanos, Montúfar y Villavicencio, continuaron su periplo con rumbo a Cartagena de Indias, adonde llegaron el 8 de mayo. La situación que se vivió en Caracas parecía volver a repetirse, la ciudad levantaba su propia Junta y el 22 de mayo en un oficio del Cabildo de la ciudad dirigido al comisionado regio, se confirmaba, en este caso de manera más explícita, la huella del ejemplo gaditano: "El Muy Ilustre Cabildo de esta Ciudad, a instancias y expreso pedimento del Síndico Procurador personero del Común, [...] convencen la necesidad indispensable de establecer en esta plaza una Junta de Gobierno por el modelo que propone la de Cádiz para precavernos contra los diferentes géneros de funestos peligros a que están expuestos todos los dominios de S. M."527

Siguiendo lo que parece ser un itinerario establecido -en el que no se incluía Buenos Aires-, el 17 de junio llegó a Santafé de Bogotá Carlos Montúfar. Recién el 20 de julio se instauraría la Junta de Gobierno local, tras destituir al virrey Amar. Pero desde fines de junio el ayuntamiento "en respetuosas y sumisas representaciones" se había dirigido al Virrey, pidiéndole la instauración de un gobierno juntista. Azevedo Gómez, uno de los principales protagonistas de la revolución bogotana, en carta fechada el 29 de junio, y dirigida al enviado gaditano Villavicencio, confesaba la necesidad de un cambio en "el sistema de Gobierno, modificándolo a las actuales circunstancias y arreglándolo a los principios que adoptó el pueblo libre de Cádiz”, para insistir en la

\footnotetext{
${ }^{525}$ Ramos Santana, Alberto, óp. cit., p. 48.

${ }^{526}$ Citado en Ferreiro, Felipe. La disgregación del Reyno de Indias. Montevideo: Barreiro y Ramos. 1981, p. 95 .

${ }^{27}$ Citado en Ferreiro, F., óp. cit., p. 97.
} 
urgencia del "establecimiento en esta capital de la Junta Superior de Gobierno, a imitación de la de Cádiz". 528

Entre los meses de julio y agosto, según pudo comprobar Ferreiro, circuló en Santiago de Chile un escrito con la forma de catecismo, sin fecha ni lugar de edición, en el que se representaba una conversación entre un padre y un feligrés sobre el significado de las juntas de gobierno. Ante la pregunta sobre el origen de las ideas que circulaban por esos días, este último contestaba:

F- En todos los papeles públicos que han remitido a las Américas desde el principio de la instalación del Consejo de Regencia - Junta de Cádiz, que son los últimos que nos han llegado.

P- Y qué nos dicen en ellos?

F- Que las Américas son partes integrantes de la Monarquía, que son pueblos libres, que gozan de los mismos privilegios y fueros que los de España, que depende de ellos mismos la suerte de los que les han de mandar, y que por la regla de Cádiz, elijan un gobierno digno de su confianza.

P- Habéis entendido esta doctrina?

F- Sí Padre, porque está muy clara.

P- Y cuál es el gobierno digno de nuestra confianza?

F- El mismo que de España.

P- Cuál es el gobierno de España?

F- La Junta. ${ }^{529}$

E1 21 de septiembre Montúfar le escribió a su compañero de viaje Villavicencio desde Santiago de Chile contándole que, tras trabajar "a fin de conseguir la unión, el orden y tranquilidad tan terriblemente turbados, mañana queda instalada una Junta Superior de Gobierno, formada en todo según la de Cádiz; en el correo venidero te remitiré el acta acordada por la voluntad general del pueblo", ${ }^{530}$ Efectivamente el 22 de septiembre se formaba la Junta chilena, plegándose al movimiento que en América se había iniciado en Caracas, pero que evidentemente era un eco del peninsular.

Veamos por último, aunque no lo haya sido cronológicamente, el caso rioplatense. Sabemos que parte del manifiesto fue publicado el 9 de junio en la Gazeta de Buenos Aires, y teniendo en cuenta el itinerario de los tres comisionados gaditanos, que no incluía esta ciudad, debemos concluir que necesariamente este debió llegar por otra vía.

\footnotetext{
${ }^{528}$ Ibid., p. 109.

${ }^{529}$ Ibid., pp. 112-114.

${ }^{530}$ Ibid., p. 116.
} 
Una posibilidad bastante cierta es que lo haya hecho junto a las noticias del avance francés sobre Andalucía, la disolución de la Central y la formación del Consejo de Regencia a mediados de mayo, cuando la ciudad se convulsionó y comenzó la cuenta regresiva que terminó dando nacimiento a la junta revolucionaria porteña. La delegación oficial gaditana que tomó rumbo hacia Venezuela y Nueva Granada portando la proclama embarcó en los primero días de marzo, por lo tanto podemos suponer que por esos mismas fechas algún navío que partió con dirección al Rio de la Plata la conducía también, y teniendo en cuenta que la travesía duraba poco más de dos meses, es más que probable que arribara a Buenos Aires a mediados de mayo. ${ }^{531}$ Junto con ella, quizás por medios no tan oficiales como cartas de particulares con vínculos en América, la información que contradecía parte de su relato: que la Junta gaditana durante todo el mes de febrero no quiso reconocer a la Regencia y le disputó la autoridad. Asimismo, como del puerto Cádiz en realidad no habían salido buques con rumbo a América hasta mediados el mes de febrero porque la Junta mantuvo cerrado el Puerto por cerca de un mes, en el trascurso de pocos días llegaron a Buenos Aires correspondencia y manifiestos en pro y en contra del reconocimiento del Consejo de Regencia. Lógicamente esto tuvo como resultado una gran confusión e incertidumbre en la población de Buenos Aires. ¿Qué noticia era falsa y/o tendenciosa: ésta o aquélla, la de que Cádiz había reconocido a la Regencia y exhortaba a los demás Pueblos a seguir su camino o la de que se negaba a la subordinación y estaba resuelta a mantenerse insumisa y reclamaba la adhesión de las otras ciudades para su causa? ${ }^{532}$

En su "Examen imparcial" Flórez Estrada discurre justamente sobre esta situación, resaltando el error de cálculo -o ingenuidad- de parte de las autoridades gaditanas con respecto a la forma en que América conoció lo que sucedía en la península:

Los hombres de Cádiz para evitar en aquella ocasión los desastres con que los amenazaban la anarquía, y la aproximación del enemigo, crearon una nueva Junta. Esta, o temerosa del pueblo excesivamente prevenido contra la Junta Central, o más bien por una política mal entendida, tardó una porción de días en reconocer la Regencia lo que contribuyó en gran manera a agravar los males de la Nación tanto en la Península como en América. Al ver que la Autoridad más inmediata al pueblo donde residía el nuevo Gobierno, no quería o retardaba reconocerlo, las Autoridades de las otras Provincias,

\footnotetext{
${ }^{531}$ Durante el mes de Abril y los primeros días de Mayo de 1810, según las "Marítimas" del Correo de Comercio, no arribaron a Buenos Aires buques con procedencia de España.

${ }^{532}$ Ibid., p. 100.
} 
siempre prontas a ejercer todo el poder posible imitaron su ejemplo, y no quisieron reconocer la Regencia hasta pasados muchos días. La Junta de Cádiz había cerrado el Puerto, a fin de que no pudiese salir embarcación alguna para la América hasta que los negocios de la Península presentasen un aspecto más favorable, más no cuidó cuando llegó el caso de abrirlo que sólo saliesen los barcos Correos sin más correspondencia que la de oficio para hacer ver que se hallaba establecido un Gobierno legal y reconocido. En el mismo día en que se despachó el primer Correo a la América se abrió el Puerto a todas las embarcaciones detenidas, sin prever que podrían llegar éstas antes, como sucedió, y causar el trastorno, por cuyo temor muy prudentemente se les había prohibido salir antes. ${ }^{533}$

Es muy posible entonces que los revolucionarios de Mayo conocieran lo sucedido en Cádiz, en sus diferentes y contradictorias versiones, y que también hayan podido acceder a la proclama de la junta gaditana. Flórez Estrada, quien coincidió durante 1811 en Londres con Manuel Moreno y Tomás Guido, comisionados por el gobierno de las Provincias Unidas para las gestiones con Gran Bretaña, y que seguramente tuvo la posibilidad de conversar con ellos, es quién nuevamente nos da indicios de lo que podría haber sucedido: "Habiéndose sabido en aquella ciudad [alude a Buenos Aires] por una embarcación procedente de Málaga antes que se recibiese de oficio la instalación de la Regencia, los sucesos de la Península y que aquella no había sido reconocida por la Junta de Cádiz, el Cabildo convocó al pueblo el 22 de Mayo". 534 Según Ferreiro, con procedencia de Málaga entró el 13 de Mayo en el Puerto de Montevideo el Bergantín Español "San Juan Bautista", salido de aquel puerto el 24 de Enero. Ese buque pudo y debió hacer escala en Cádiz y como dicho puerto se clausuró, según ya expresamos, hasta mitad de febrero, resulta que en caso de haberse producido efectivamente sería el que Flórez Estrada sindica como el conductor de las trascendentes noticias. ${ }^{535}$

Pero no hay ningún documento oficial, ni correspondencia, ni crónica de un memorialista que dé cuenta de la proclama, hasta su publicación en la Gazeta de Buenos Aires del 9 de junio. Ni tampoco Castelli invocó el ejemplo de la Junta de Cádiz para justificar la constitución de la junta local ni en las actas del 25 se la menciona. Nos animamos a decir que este hecho no carece para nada de lógica. Invocar el precedente de la junta gaditana, sabiendo cómo se sabía ya durante las jornadas de mayo, que ésta finalmente había reconocido a la Regencia era perjudicar la propia argumentación. Era

\footnotetext{
533 Álvaro Flórez Estrada, Examen Imparcial sobre las Disensiones de la América con España, p. 30.

534 Ibid., p. 34

535 Ferreiro, F., óp. cit., p. 107.
} 
demasiado inconveniente, significaba dejarle servido a los que abogaban por la continuidad del virrey un argumento sólido para contrarrestar la formación de la junta autónoma. También implicaría una contradicción difícil de sortear para aquellos que inconfesamente aspiraban a una pronta ruptura definitiva con la metrópoli. En ese sentido, llama la atención que en el Cabildo abierto tampoco haya sido utilizado el ejemplo de la Junta de Cádiz por el fiscal Villota o algún otro de aquellos que planteaban la continuidad del virrey y el reconocimiento a la Regencia. Existe igualmente una explicación para esto también. El 22 de mayo las intervenciones de este sector fueron de tajante oposición a la formación de la junta, reconociera o no al nuevo gobierno metropolitano. Tampoco era conveniente para ellos sacar a colación lo sucedido en Cádiz.

Recién tras la "intervención selectiva" realizada por Moreno al publicar parte de la proclama, ésta y "la regla de Cádiz" pudieron ser utilizadas por los revolucionarios a favor de su propia causa. Toda referencia positiva al Consejo de Regencia y a la necesidad de subordinársele había sido extirpada, quedando solo aquellos párrafos que enumeraban los fundamentos de la erección de la Junta de Cádiz. Y no sería la primera ni única vez que desde la Gazeta se prometería una futura publicación íntegra de un documento peninsular que luego nunca vería la luz.

En síntesis, tomando nota del derrotero de los acontecimientos en América, consideramos que el manifiesto de la Junta de Cádiz, tuvo influencia en ella pero no con la intención última que contenía, el llamado a reconocer al Consejo de Regencia, si no que fue la explicación de porqué se pudo formar la Junta gaditana lo que terminó prosperando. En el número correspondiente al 30 de enero de 1811 de El Español de Londres, José Blanco White reflexionaba en ese mismo sentido:

Al disolverse la Junta [se refiere a la Central] y empezar la Regencia pasada, todo el mundo vio que la España, estaba en inminente riesgo de perder las Américas. El gobierno español, no supo emplear otros medios que una Proclama de la Junta de Cádiz, -mediador muy raro, si se consideran los intereses opuestos de aquellos comerciantes, y de los cultivadores y propietarios americanos- y de órdenes secretas a los gobernadores -piedra principal del escándalos en aquellos países-, para entretener a los americanos con palabras. ${ }^{536}$

\footnotetext{
$\overline{{ }^{536} \text { El Español, } 30 \text { de enero de } 1811 .}$
} 
La identificación de las autoridades de Cádiz, tanto el Ayuntamiento como la Junta, con el "partido mercantil" o con los "comerciantes monopolistas", no es exclusiva de Blanco White. Como ya pudimos ver en el análisis de la Representación de los hacendados, Moreno identificaba en dicha plaza y su burguesía un fuerte núcleo de poder cuyos intereses eran contrarios al desarrollo económico del virreinato. Y ya desde el gobierno no perdería oportunidad de remarcar esa característica, como podemos ver en un manifiesto de la Junta Provisional del 22 de septiembre: "pero el espíritu mercantil de Cádiz fecundo en arbitrios para perpetuar en las Américas la triste condición de una factoría, hizo bajar de los buques a los respetables varones, que se habían ocultado, y resultó de aquel congreso el establecimiento del Consejo de Regencia, que se nos ofrece hoy día con los caracteres de la soberanía". ${ }^{537}$ Paradójicamente, los revolucionarios americanos terminarán tomando como modelo para la formación de sus propios gobiernos a aquel que expresaría como nadie la intransigencia metropolitana a las reivindicaciones americanas.

\section{La herencia peninsular en el proceso electoral rioplatense}

Una de las primeras tareas a las que se abocó el flamante gobierno rioplatense fue la convocatoria a las ciudades del interior del virreinato para que enviarán sus diputados a fin de constituir una junta los suficientemente representativa que sorteara lo antes posible los cuestionamientos que ya desde el mismo debate del 22 de mayo hacían mella sobre su legitimidad. Sobre todo teniendo en cuenta que uno de los principales argumentos, sino el que más, para impugnar la formación del Consejo de Regencia era que en ella no se había contado con la participación de los americanos. Para constituirse entonces en autoridad suprema era necesario ampliar su representación, integrar al resto de las ciudades del Virreinato y reducir el poder de las instituciones coloniales, especialmente el que detentaba el Ayuntamiento capitalino. Como quedó registrado en el acta del mismo día de su instalación, la Junta definió que debían circularse en lo inmediato las pautas por las que debía regirse la elección y el envío de los representantes del interior: en su artículo décimo se llamaba a que se

[...] despachen sin pérdida de tiempo órdenes circulares a los Jefes de lo interior y demás a quienes corresponda, encargándoles muy estrechamente, bajo de responsabilidad, hagan que los respectivos, Cabildos de cada uno convoquen por medio de esquelas la parte

\footnotetext{
${ }^{537}$ Gazeta extraordinaria (25/9/10): 426.
} 
principal y más sana del vecindario, para que, formado un Congreso de solos los que en aquella forma hubiesen sido llamados, elijan sus Representantes, y estos hayan de reunirse a la mayor brevedad en esta Capital para establecer la forma de gobierno que se considere más conveniente.

El artículo undécimo por su parte rezaba

[...] que elegido así el Representante de cada ciudad o villa, tanto los electores como los individuos capitulares, le otorguen poder en pública forma, que deberán manifestar cuando concurran a esta Capital, a fin de que se verifique su constancia; jurando en dicho poder no reconocer -otro soberano que al Sr. D. Fernando VII y sus legítimos sucesores según el orden establecido por las leyes, y estar subordinado al gobierno que legítimamente les represente. ${ }^{538}$

En la circular del 27 de mayo a los pueblos del virreinato se concreta la convocatoria subrayándose por un lado la premura con que debe ser cumplida la elección y envío de los representantes; y por otro, que a cada ciudad o villa de las Provincias le correspondía un solo diputado. ${ }^{539}$

Como ya hicimos referencia anteriormente, las pautas elegidas por el primer gobierno criollo para el proceso electoral fueron tomadas de las dictadas por la Junta Central y el Consejo de Regencia para elegir diputados americanos a la mencionada Junta y a las Cortes, respectivamente, entre comienzos de 1809 y comienzos de 1810. La tipología electoral compartida se definía en razón del reconocimiento del derecho de representación a las "provincias" americanas en los máximos órganos políticos, y la atribución a los cabildos de la ejecución y control del acto. Tanto es así que para salvar una omisión de anteriores instrucciones respecto de las calidades que debían reunir los candidatos a diputados a la Junta, en una circular remitida a los pueblos del interior el 18 de julio de 1810, el gobierno mandaba poner en práctica la Real Orden del 6 de octubre de 1809 de la Junta Central española. ${ }^{540}$ Esta había implantado en América la función representativa, pero con modalidades de fondo y forma que, como ya dijimos, en España estaban a punto de extinguirse.

\footnotetext{
538 "Acta del 25 de Mayo", disponible en Actas capitulares de mayo de 1810, http://www.biblioteca.org.ar/libros/92665.pdf

539 "La Junta Provisional Gubernativa de la capital del Río de la Plata A los habitantes de ella y de las provincias de su superior mando", 27 de mayo, disponible en Actas capitulares de mayo de 1810 http://www.biblioteca.org.ar/libros/92665.pdf

${ }^{540}$ Chiaramonte, J.C., "Vieja y nueva representación: Los procesos electorales en Buenos Aires, 18101820", Annino Antonio coord., Historia de las elecciones en Iberoamérica, siglo XIX, Fondo de Cultura Económica. México, DF, 1995, pp. 22-23.
} 
Dentro del proceso de resquebrajamiento de la estructura política hispano-colonial y disolución de sus tradicionales instituciones, fue el Cabildo la única que logró mantenerse en pie. No es casual, en las últimas décadas se había asistido a un proceso de fortalecimiento y revitalización de los ayuntamientos, así que al llegar la crisis estos se convirtieron, gracias a sus carácter de representante de las ciudades, en las vías por donde se canalizó en muchos casos la emergencias de los nuevos poderes que de a poco iban afirmándose sobre la base de la soberanía popular. ${ }^{541} \mathrm{Y}$ en torno a ellos se definió un espacio político, la ciudad, que en principio apareció rigiendo todo el sistema de representación. En los diferentes reglamentos y estatutos que se sucedieron a partir de Mayo, y que se mantendrían durante toda la década, la institución encargada de controlar los actos electorales sería el Cabildo, tal como lo fue, según dijimos, en las primeras elecciones convocadas por la Junta Central de España de 1809. En parte era una reposición de las instituciones castellanas, en las cuales la burguesía de las ciudades mandaba sus procuradores a Cortes. De manera que, como señalara Chiaramonte, el sistema de representación excluía en un principio a la campaña, reduciéndose sólo al ámbito urbano. Solo los vecinos afincados -una minoría- formaban parte de las elecciones a través de los cabildos. Como se puede ver en el acta capitular del 25 de mayo, esta concepción restrictiva se manifestaba al referirse a la "parte principal y más sana del vecindario". Fue recién el Estatuto de 1815 el que incorpora la representación de la campaña. ${ }^{542}$ Por otro lado, que la representación fuera por ciudades no suponía que todas las ciudades y villas del territorio tuvieran derecho a elegir diputados. Si bien en un primer momento todos los cabildos debían participar de las elecciones, una disposición de la Junta de Gobierno del 16 de julio de 1810 volvió a limitar el derecho electoral a las ciudades principales. ${ }^{543}$ En general se siguió, nuevamente, la pauta establecida por la Real Orden del 6 de octubre de 1809, que limitaba el proceso electoral a aquéllas que sean "cabeza de partido" o de subdelegación.

Siguiendo con lo planteado por Chiaramonte, los procedimientos electorales confirman la convivencia de prácticas tradicionales y otras provenientes de sistemas de representación más recientes. En el Río de la Plata revolucionario, las primeras elecciones fueron realizadas bajo la figura del cabildo abierto, que adquiría el carácter

\footnotetext{
${ }^{541}$ Sobre el proceso de fortalecimiento de los cabildos tras las reformas borbónicas ver Molina Martínez, Miguel, Los cabildos y la independencia hispanoamericana, Granada, 2002.

${ }^{542}$ Chiaramonte, J.C., "Vieja y nueva representación...", p. 24.

543 "Mandando que las Villas que no sean cabeza de partido suspendan el envío de Diputados", Buenos Aires, 16 de Julio de 1810, Registro Oficial de la República Argentina, tomo I, 1810 a 1831, Buenos Aires, 1879, pág. 56. Tomado de Chiaramonte, J. C., "Vieja y nueva representación...”, pp. 24-25.
} 
de asamblea electoral, y sólo posteriormente, pasaron a tener el formato de comicios. El reglamento de febrero de 1811 para la formación de Juntas provinciales y Juntas subordinadas fue el que deslindó por primera vez el proceso eleccionario de la figura del cabildo abierto en su artículo relativo a la elección indirecta de vocales de las Juntas. Por otro lado, las atribuciones de los diputados eran definidas a través de una figura también tradicional, la del mandato imperativo. Los poderes e instrucciones eran los instrumentos a través de los cuales los diputados se convertían en apoderados de quienes se los conferían. ${ }^{544}$

\section{Las polémicas con las autoridades de Montevideo y con el embajador español en Brasil, el Marqués de Casa Irujo}

Las respuestas a la circular de la Junta del 27 de mayo de las ciudades del interior no fueron todas de aprobación y acatamiento. El Cabildo de Montevideo contestó a la Junta que había decidido en cabildo abierto plegarse a la convocatoria hecha por la capital enviando un diputado, pero todo cambió cuando entró un bergantín salido de Cádiz el 29 de marzo con la noticia de la instalación del Consejo de Regencia, reconocido por todas las provincias españolas, por Inglaterra y Portugal. El barco también traía proclamas del Consejo y de la Junta superior de Cádiz dirigidas a los americanos, que "se leyeron al público con satisfacción". El cabildo decía que fue el Pueblo de la ciudad quien al escuchar las proclamas peninsulares pidió "a voces" que se reconociese al Consejo de Regencia y se suspendiese la designación de diputado para la junta de Buenos Aires. ${ }^{545}$ No es para nada menor que la contestación del Cabildo de Montevideo recurra a la manifestación del pueblo para explicar y justificar porqué fue modificada una decisión tomada en Cabildo abierto, no acatando de esa manera la convocatoria hecha por la que sería su autoridad más próxima, el gobierno de la capital del virreinato, pero a la vez subordinándose a la instancia máxima del reino, la flamante Regencia. Como podemos ver, la apelación a la voluntad popular no sería exclusiva del campo revolucionario.

La respuesta de la Junta de Buenos Aires apuntaba a demostrar la ilegitimidad del Consejo de Regencia, planteando que según "los principios del derecho público de las Naciones y las Leyes fundamentales de la nuestra, la Junta [Central] no tenía facultad de

\footnotetext{
${ }^{544}$ Ibid., p. 32.

${ }^{545}$ Gazeta de Buenos Aires, Nro. 2 (14/6/10): 52
} 
trasmitir el poder soberano que se le había confiado". ${ }^{546}$ Señala que el mismo Consejo de Regencia en su proclama planteaba que los pueblos americanos son libres y que deben tener "un influjo activo en la representación de la Soberanía", y que es hora, dice, de palpar esas ventajas. ${ }^{547}$ Era necesario, entonces, conformar un congreso con diputados de estas provincias, donde, si correspondiera, se podría reconocer a la Regencia, pero para eso Montevideo tendría que mandar al suyo. Para finalizar, el gobierno porteño convocaba a seguir el ejemplo de aquellas juntas provinciales que existieron antes de la conformación de la Junta Central, y que carecían de "una representación soberana del Rey, por quien peleaban, y no por esto eran menos fieles, menos leales, menos heroicas, ni menos dispuestas a prestar reconocimiento a un Supremo poder apenas se constituyó legítimamente". ${ }^{548}$ Nuevamente se invocaba el ejemplo del juntismo peninsular para darle legitimidad al camino autonomista elegido inicialmente por la junta porteña.

Unos meses después, a mediados de septiembre, Mariano Moreno saldría al cruce desde la Gazeta de los planteos que en una proclama impresa en Rio de Janeiro, el Marqués de Casa Irujo, embajador español en la Corte de Brasil, dirigía a los habitantes españoles de América. El secretario de la Junta entiende que la proclama tiene como objetivo, en caso de que no se restituya a Cisneros en el mando y la junta persista en su resolución, concitar a los pueblos de América para que "venguen ese acto de perfidia". No cree, dice, que "los demás pueblos reciban gustosos el funesto presente de la guerra civil y general desolación a que se les convida". ${ }^{549}$ Moreno, una vez más, vuelve a referenciar a la Junta rioplatense en el movimiento juntista español, con el objetivo de refutar los ataques del marqués:

[...] la innovación del Gobierno de Buenos Ayres era igual en todos sus resultados, a la que gloriosamente había a ejecutado las Provincias de España y que gozando estos pueblos los mismos privilegios que los de España, no podía reprobarse nuestra Junta, mientras se reconociesen las de aquellos, ni podíamos acceder a un paso retrogrado hacia el humillante estado colonial, de que se nos acaba de extraer a la faz del mundo entero. ${ }^{550}$

Ante lo que entiende como un velado llamado a la guerra civil por parte del Marqués, recuerda en que marco fueron erigidas las juntas españolas. Dice que si

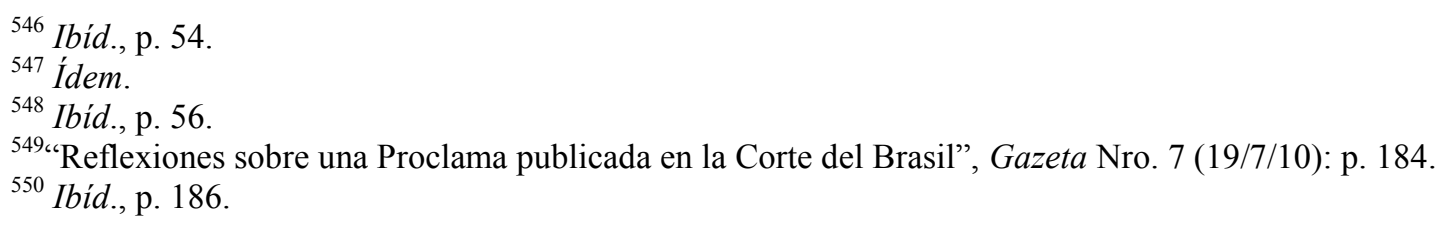


Fernando VII fuera finalmente rescatado de su cautiverio y retornara a España, debería recibir a las juntas que con lealtad y celo pelearon por su libertad, y "si la inmundicia del origen hacía notar los huesos de aquellos mandones inertes o traidores a quienes inmoló el furor popular para cimentar la estabilidad de sus respetables Juntas, no sufrirán estas seguramente la indignación de su Príncipe, antes bien condenaría eterno oprobio la memoria de esos hombres". ${ }^{551}$ No solo nos parece que es una desafiante respuesta al Marqués que busca demostrar la predisposición de la Junta de defender a sangre y fuego la revolución, sino que además, creemos que Moreno está aquí preparando a la opinión pública para el castigo a la ya lanzada insurrección cordobesa, que terminaría como todos sabemos con los fusilamientos del gobernador de la Concha y Santiago de Liniers, en Cabeza de Tigre.

Considera que la Junta de las provincias del Rio de la Plata, ante el hipotético regreso de Fernando VII al trono, podría presentarse ante éste elevando el voto de los americanos hasta su majestad. Y citando la proclama del 22 de enero de la Junta Central, le recordaría al Rey que el gobierno español reconoció "que los Pueblos de América eran parte integrante de la Nación, y que gozaban los mismos derechos, los mismos privilegios que los pueblos de España". Por lo tanto, los americanos "buscaron en la conducta de estos una regla para la suya; y encontraron que arrojados las Jefes que les había puesto vuestro padre, erigieron Juntas populares, que los rigiesen a vuestro nombre, y los dirigiesen en la defensa de vuestros derechos: Buenos Ayres hizo lo mismo, erigió su Junta bajo las mismas reglas que las de España, juró la conservación y guarda de vuestros augustos derechos". 552

Moreno acusa al Marqués de divulgar noticias falsas de victorias y proezas para las armas españolas, pretendiendo alimentar de esta manera quiméricas esperanzas. Afirma que el gobierno rioplatense está muy al tanto de la situación en la península por las gacetas que llegan desde Cádiz. Es muy sabido por ejemplo, dice, el implacable asedio y bombardeo conque el ejército de Napoleón somete a la ciudad diariamente. Pero incluso siendo ciertas las noticias del Marqués, y fundadas las esperanzas, se pregunta por qué la Junta de Buenos Aires debe disolverse, mientras en España las Juntas provinciales de los territorios no ocupados continúan instaladas: "La Junta de Valencia continúa en la plenitud de sus funciones ni reconoce al Consejo de Regencia, ni respetaba a la Junta Central mucho tiempo antes de su disolución: lo

\footnotetext{
${ }^{551}$ Ibid., p. 188.

${ }^{552}$ Ibid., p. 189.
} 
mismo sucede en las Juntas de las demás provincias libres de España y el Marqués elogia su fidelidad y no les dirige proclamas para que peleen unas contra otras". 553 Efectivamente como señala Moreno, la Junta de Valencia, formada casualmente también un 25 de mayo pero de 1808, había tenido una relación muy conflictiva con la Junta Central sobre todo desde mediados de 1809. La realidad es que, en un primer momento, la actuación de la Junta valenciana en la formación de la Central había sido decisiva. A mediados de julio de 1808 envió una circular a las diferentes Juntas supremas provinciales en la que expuso las apremiantes razones que había para establecer una autoridad superior, o la reunión de Cortes, con el objeto de coordinar aquellas facultades que sobrepasaban las ejercidas por las autoridades regionales o provinciales. Pero así como fue fundamental para su creación, también pesó mucho su influjo en los límites a las atribuciones que se le otorgaron a ésta. El nuevo cuerpo, fruto de un pacto federal, tendría competencias en el alto gobierno de la nación, la declaración de la paz y de la guerra, relaciones diplomáticas y la política colonial, las demás competencias las ejercerían las Juntas Supremas. En todo caso, según la Junta de Valencia, los vocales designados deberían dar cuenta de sus actuaciones en la Junta Central. ${ }^{554}$

Como señala Antonio Moliner Prada, el Reglamento sobre Juntas Provinciales del $1^{\circ}$ de enero de 1809 redujo sus competencias y facultades al introducir un plan uniforme en el gobierno y administración de las provincias. Las juntas perdían su protagonismo inicial y sus atribuciones, pasando a desempeñar un papel de meros organismos intermediarios entre el pueblo y las autoridades. Una prueba elocuente de este cambio es su nueva denominación: Juntas Superiores Provinciales de Observación y Defensa, pero también el establecimiento de una rígida jerarquía, y la tendencia a reducir sus miembros -nueve en las provinciales y cinco en las de partido-, absteniéndose de actos de jurisdicción y autoridad que no estuvieran enmarcados en dicho Reglamento. Con él triunfa definitivamente el criterio centralista, lógico en medio de una guerra, quedando las juntas provinciales como meros instrumentos de ejecución de las órdenes emanadas de la Central. ${ }^{555}$

\footnotetext{
${ }_{553}^{553}$ Gazeta Nro. 9 (2/8/10): 240.

${ }^{554}$ Moliner Prada, Antonio, "De las Juntas a la Regencia. La difícil articulación del poder en la España de 1808”, Historia Mexicana, vol. LVIII, núm. 1, julio-septiembre, 2008, p. 158.

${ }^{555}$ Moliner Prada, Antonio, "El movimiento juntero en la España de 1808", en Chust, M., La eclosión juntista...
} 
Cuando la Junta Central a mediados de 1809 lanzó el llamado a Cortes Generales del Reino, sería la Junta Valenciana la que cuestionó con fuerza la forma y la legitimidad de esa convocatoria en una exposición al resto de las juntas provinciales el 5 de agosto de 1809, disintiendo con el control que se atribuía el gobierno central en ese proceso. Planteaba que hasta que la nación no estuviera libre de enemigos no podía convocarse a Cortes porque no todas las provincias españolas podían elegir libremente a sus diputados. El hecho de cuestionar una decisión ya tomada y encima hacerlo dirigiéndose a las otras juntas provinciales sin pasar por la Central generó mucha irritación en Madrid y tensó la relación entre ambas. El 15 de septiembre en oposición a una medida de hacienda dictaminada por el Consejo Reunido ${ }^{556}$, la Junta de Valencia declaraba que "la confederación de las Provincias por medio de la Junta central, (...) es el monumento más glorioso de nuestra revolución", recordándole al Consejo que "El Pueblo se ha conquistado a sí mismo, nada debe a las autoridades antiguas, y tiene acción para pedir que se constituyan bajo la forma más conforme a su libertad y sus derechos". ${ }^{557}$ No es muy probable que a la Junta Central le agradase que se la denomine como una confederación, después de todos sus esfuerzos en pos de la centralización del poder. Como respuesta a lo que consideraba señales de clara rebeldía por parte de la Junta valenciana, la Central nombró al mariscal de campo Ramón de Castro Capitán general del reino de Valencia, con instrucciones para averiguar y eliminar la “insubordinación y desobediencia”. Automáticamente la Junta valenciana rechazó su nombramiento, ya en franca oposición al gobierno central.

En ese contexto de enfrentamiento, la Junta Central avanza desde su flanco más liberal con el "Manifiesto de la Nación" del 28 de octubre, redactado por Manuel Quintana, anunciando la inminente reunión de la asamblea. En uno de sus párrafos se hacía referencia a la conducta de la Junta valenciana sin mencionarla directamente: "Cuando la hidra del federalismo [...] osa otra vez levantar sus cabeza ponzoñosa y pretende arrebatarnos a la disolución de la anarquía; este es el tiempo de reunir en un punto la fuerza y la majestad nacional". ${ }^{558}$ Este manifiesto tendría una recepción bastante particular en el Rio de la Plata, cuestión que abordaremos más adelante cuando

\footnotetext{
${ }^{556}$ Consejo y Tribunal Supremo de España e Indias, constituido el 25 de junio de 1809 a partir de la fusión decretada por la Junta Central de los Consejos de Castilla, Indias, Hacienda y Órdenes, entre otros. Fue suprimido el 16 de septiembre de 1810 por la Regencia, que restableció a su antigua planta los consejos de Castilla, Indias, Órdenes Militares y Hacienda.

${ }_{557}$ Citado en Moliner Prada, Antonio, "De las Juntas a la Regencia...".

558 "Manifiesto de la Nación" del 28 de octubre de 1809, Junta Central.
} 
tratemos sobre la convocatoria a la Asamblea constituyente rioplatense. Pero por ahora no nos adelantemos.

Los conflictos entre la Central y la valenciana continuarían durante todo el año 1809. En diciembre es intervenida la Junta provincial y detenido y deportado a Ibiza el referente liberal valenciano José Canga Arguelles. En gran medida el desgaste provocado por este enfrentamiento, sumado a los desastres militares que se inauguran con la estrepitosa derrota de Ocaña, señalarían la suerte de la Central, en franca crisis al comenzar 1810. En cambio, la Junta valenciana tomaría nuevos bríos y protagonizaría una heroica resistencia hasta 1812 , cuando la ciudad tras un prolongado asedio cayera en manos francesas. Durante ese tiempo seguiría reivindicando su relativa autonomía frente al Consejo de Regencia, como lo había hecho con la Junta Central. Es por ello que Moreno a la hora de buscar un espejo en la península que legitime la postura autonomista pero todavía fidelista de la Junta porteña, recurra en varias ocasiones al ejemplo valenciano. 


\section{Capítulo 9:}

\section{Ensayos liberales en la Gazeta de Moreno}

\section{Pensamientos de un Patriota Español en la Gazeta de Buenos Aires. El lenguaje político del liberalismo peninsular (sin intermediarios) en la revolución rioplatense}

En sus célebres artículos conocidos como Sobre las miras del Congreso, Moreno exhortaba a no desaprovechar los pasos que en la península se habían dado en la conquista y el ejercicio efectivo de los "imprescriptibles derechos" que los pueblos poseían y que recién ahora estaban conociendo. Destacaba que en gran medida se debía a que en el contexto de la revolución que había desatado la invasión francesa "por todos los pueblos de España pulularon escritos llenos de ideas liberales" donde "se sostenían los derechos primitivos de los pueblos, que por siglos enteros habían sido olvidados y desconocidos." Moreno consideraba que había sido una verdadera ventaja para América "que la necesidad hubiese hecho adoptar en España aquellos principios; pues al paso que empezaron a familiarizarse entre nosotros, presentaron un contraste, capaz por sí solo de sacar a los americanos del letargo en que yacían tantos años". 559 Este prestar atención sobre los sucesos y escritos peninsulares que Moreno aconsejaba no era solo un acto declamativo, entre el 5 de julio y el 18 de octubre, habría de publicar en la Gazeta en varias entregas un ensayo anónimo editado en España a mediados de 1808, sin fecha ni pie de imprenta, titulado Pensamientos de un patriota español para evitar los males de una anarquía, o la división entre las provincias, que actualmente componen el territorio de toda la monarquía española, y establecer un gobierno conveniente a toda ella, observando lo que prescriben la justicia, la razón natural, y los derechos de la nación. En la presentación del ensayo, Moreno explica que lo reproduce para que así sus conciudadanos tengan la oportunidad de "estudiar con meditación la sublime doctrina de estos avisos, que se familiaricen con ellos y que los hagan materia de sus conversaciones". 560

Erróneamente, el secretario de la Junta adjudica el ensayo a Gaspar de Jovellanos por entender que la profundidad de los pensamientos allí contenidos y la similitud estilística con la célebre Ley Agraria no dejaban lugar a dudas. La historiografía en general ha incurrido en el mismo error, o en algunos casos, tomando en cuenta las

\footnotetext{
559 "Sobre el congreso", Gazeta extraordinaria (13/11/10): p. 600-601

${ }^{560}$ Gazeta Nro. 5 (5/7/10): 131.
} 
notables contradicciones conceptuales entre el éste y el pensamiento de Jovellanos, han aventurado que podría provenir de la pluma de Blanco White, dada su recurrente recepción en la prensa rioplatense. ${ }^{561}$ Pero como ha demostrado la investigación de Patricio Clucellas, en realidad se trata de un escrito elaborado por el turolense Antonio de la Peña y García, catedrático de geografía de la Sociedad Económica de Valladolid. ${ }^{562}$ La prueba, que debido a su contundencia despejó para siempre la confusión, es el opúsculo denominado Cuatro Verdades Útiles a la Nación, de Isidoro de Antillón, del $1^{\circ}$ de octubre de 1810 , donde recopilaba nueve resúmenes de impresos dados a la luz pública entre 1808 y 1809, por considerarlos útiles para "las extraordinarias circunstancias en que nos hallamos"; y entre ellos se encontraba el Pensamientos con la identificación de su autor. ${ }^{563}$

De la Peña había nacido en el pequeño pueblo de Ahedo de las Pueblas de la provincia de Burgos el 4 de septiembre de 1778 -curiosamente el mismo año que Antillón y que Mariano Moreno-, y en 1804 ya estaba a su cargo la enseñanza de Esfera y Geografía Universal dela Sociedad vallisoletana. Ante la llegada del invasor francés se vio forzado a redactar un periódico bisemanal y bilingüe del gobierno intruso para ser impreso en el taller, por lo que se ganó fama de afrancesado. Calificación discutible teniendo en cuenta que en agosto de 1811 se fuga de la ciudad para encaminarse a La Coruña con el propósito de embarcarse hacia Cádiz. Acción que no podría concretar debido al estigma de colaboracionista que seguiría acompañándolo, siendo procesado en 1812 por la Sala del Crimen de la Real Audiencia del Reino de Galicia y puesto en prisión para después de seis meses de cárcel, ser dejado en libertad restringida. Ese año

\footnotetext{
${ }^{561}$ Miguel Artola en su clásica obra Los orígenes de la España contemporánea ubica a este documento como uno de los más paradigmáticos del pensamiento peninsular revolucionario de la etapa inicial de la crisis, junto a la intervenciones de Álvaro Flórez Estrada y del grupo nucleado alrededor del Semanario Patriótico, pero no arriesga autoría limitándose a señalar el carácter roussoniano de este texto anónimo. Artola, M., Los orígenes..., p. 185.

${ }^{562}$ La hoja revolucionaria salió a la luz en la imprenta de la Viuda de Santander e Hijos de la mencionada ciudad -donde se editó también El voto de un español escrito por la misma pluma-. Taller por otra parte a cargo también del autor de Pensamientos. Como destaca Patricio Clucellas, el intendente colonial de Potosí Francisco de Paula Sanz tomó pronta nota de su publicación en el Río de la Plata y se percató del peligro que significaba su propagación para la causa realista. En carta al gobernador de Córdoba sobre las medidas a tomar para extinguir a la Junta de Buenos Aires, reprochó con dureza a los hombres de Mayo la publicación que hacían del ensayo: "La osadía de dar a la Prensa el criminalísimo papel que se titula El Patriota [español], y que atribuyen falsísima y calumniosamente a Jovellanos, es uno de los más graves delitos que se ha echado sobre sí la perversa Junta, que aclamando a Fernando VII da a luz un Libelo, el más denigrativo a su tan respetable dinastía”. Clucellas, Patricio, Un patriota español. El ignoto protagonista de la Revolución de Mayo. Buenos Aires, Ediciones de la Torre de Hércules, 2011, p. 6.

${ }_{563}$ BNE: VE/740, Palma de Mallorca, Imprenta de Domingo, 1810. Citado en Clucellas, P., Un patriota español..., p. 33.
} 
publicó, junto a un grupo de destacados de liberales -entre ellos Valentín de Foronda-, el diario El Ciudadano por la Constitución. ${ }^{564}$

\section{Historicismo y crisis de soberanía}

El ensayo comienza con un repaso sobre la historia de España remontándose desde el tiempo de los Reyes Católicos, al que considera el momento de mayor esplendor y gloria de la monarquía española. Entiende que desde allí en adelante todo comenzó a desmoronarse, a causa fundamentalmente del arribo de los Austrias al trono español. Sostiene que para ese momento la nación carecía de leyes y constitución suficiente para enfrentar al despotismo, pero, en evidente contradicción, afirma que "bajo la funesta casa de los Austrias se barrió con su antigua constitución” y se radicaron otras "muy contrarias a la razón y la ilustración" y al carácter nacional español. ${ }^{565}$ Lineamientos que podemos afiliar claramente con el historicismo constitucionalista español que, como ya pudimos ver, tuvo en Jovellanos su piedra fundacional -él también consideraba al reinado de los Reyes Católicos como el momento de mayor esplendor y equilibrio de la historia española-, y en Martínez Marina al pensador que lo desarrolló con mayor profundidad. A pesar de la contradicción marcada, se retoma aquella idea de una antigua constitución pisoteada por el despotismo primero de los Austrias y después de los Borbones, y con ella la grandeza del imperio español.

Se lamenta que "nuestros abuelos" no hayan aprovechado la oportunidad abierta con la Guerra de Sucesión para darse "una sabia y política constitución", y por el contrario terminar confiando en supeditar todo a las luces y la bondad del Monarca y sus ministros. Idea que veremos también en Moreno cuando justifique con sus propias palabras la necesidad de una constitución para las provincias del Plata. En su condena al régimen absolutista, De la Peña rescata a Carlos III, al que considera que fue "sin duda quien más trabajo por mejorar las instituciones y en ilustrar la nación", pero bajo el reinado de su hijo y su favorito Godoy se retrocedió todo lo que se había logrado avanzar, llevando el "despotismo hasta el último extremo". 566

\footnotetext{
${ }^{564}$ Ibid., pp. 43-55. En otra curiosa coincidencia, el periódico empleó como lema distintivo de sus números una versión abreviada de la frase de Tácito que encabezó durante casi dos años a la Gazeta de Buenos Aires.

${ }^{565}$ Gazeta Nro. 5 (5/7/10): 131-132.

${ }^{566}$ Ibíd., pp. 133-135.
} 
Después de relatar y analizar los acontecimientos trascurridos desde el levantamiento nacional hasta la victoria de Bailén y la posterior huida de José I de Madrid, Antonio de la Peña y García se propone abordar el problema de la soberanía, central a su entender para explicar el proceso y darle una salida a la crisis. En primer lugar considera que "aunque no esté disuelta la sociedad nacional, lo está el gobierno, es decir que sin el consentimiento expreso de toda la nación nadie puede ya revertirse del poder de la Soberanía, ni de ningún otro ramo de la autoridad pública". ${ }^{567}$ En sintonía con las corrientes iusnaturalistas que comenzaban a descollar en el pensamiento de los elementos más radicalizados del proceso, para el ensayista la soberanía no era otra cosa que "el ejercicio de la voluntad general", que ésta residía siempre en el pueblo, tanto como que es la fuente de donde dimana, y que, según los pactos y convenciones que los hombres se dieran, ésta pasaba a los reyes u otras autoridades importantes. Un fuerte contraste con el sector moderado de la revolución que tenía a Jovellanos como principal referente, que sostenía que las libertades debían fundamentarse en la historia, en las tradiciones y no en la voluntad general. ${ }^{568} \mathrm{El}$ pensamiento de Jovellanos, como el de otros moderados, desde su gestación ilustrada, tenía una idea de reforma que apuntaba a corregir la posición hegemónica de la nobleza hereditaria, fortaleciendo un poder monárquico con la capacidad de domesticarlo. En cambio, para el turolense la situación que atravesaba la nación española implicaba que debía reasumir toda la soberanía de hecho, "por ser ella sola la que conquista su libertad y sus derechos, rechazando al enemigo que se había apoderado de su Gobierno". ${ }^{569}$ Pero, ¿en qué consistía la nación para Antonio de la Peña y García? No era otra cosa que "la reunión e incorporación de muchas familias naturales es una sola política o moral, regida por unas mismas leyes con el fin de mantener y defender la seguridad de sus vidas, la libertad de sus personas, y todas sus demás propiedades". ${ }^{570}$ La preexistencia de la nación no era puesta nunca en cuestión, escapaba directamente al universo práctico de los problemas del primer liberalismo hispánico. Ni siquiera se preocupaba De la Peña en dejar planteado cuándo habría sido ese origen. El mismo levantamiento revolucionario había dado pruebas de la

\footnotetext{
${ }^{567}$ Gazeta Nro. 7 (19/7/10): 197.

${ }^{568}$ Marx definió a Jovellanos como un "reformista de toda la vida que por su excesiva consideración de los medios no había llegado nunca a ningún fin". Consideraba además que al momento de formar parte de la Junta Central el asturiano había envejecido demasiado y perdido muchas de sus energías. Marx, K., óp. cit., p. 99.

${ }^{569}$ Gazeta Nro. 7 (19/7/10): 198.

${ }^{570}$ Gazeta Nro. 8 (26/7/10): 230.
} 
entidad indudable de ella. ${ }^{571}$ Teniendo la nación la plena soberanía, imprescriptible e innegable, el geógrafo considera perjudicial -según enseñan, dice, los políticos, la razón y la experiencia-“que el pueblo o nación por sí misma llegue a ejercer de todo punto esta Soberanía", siendo necesario volver entonces a establecer pactos y leyes que garanticen sus derechos naturales. ${ }^{572} \mathrm{He}$ aquí uno de los núcleos problemáticos que atravesó el primer liberalismo hispánico, como plantea Elías Palti, en relación a la sede de la soberanía: la doble naturaleza del ciudadano moderno, la paradoja de que el mismo que será soberano, será a la vez súbdito. ${ }^{573}$

\section{Derechos naturales para el Patriota Español}

La protección de los derechos naturales, que el autor define como "la libertad, la igualdad, la propiedad y la seguridad", estaría dada por la imposición de una ley civil y la constitución de los tres poderes -legislativo, ejecutivo y judicial- que la pongan en práctica, galvanizando al gobierno para que no degenere hacia el despotismo ni la tiranía. Esa ley civil, para el ensayista, naturalmente debe ser "expresión de la voluntad y consentimiento de la nación, manifestada por ella misma o por medio de sus representantes, y publicada de modo que nadie pueda ignorar". ${ }^{574}$ Continuando con el método adoptado en el ensayo de ir definiendo didácticamente cada uno de los conceptos que va introduciendo, pasa en este caso a precisar que entiende por libertad civil, quizás la voz, dice, que más confusiones ha generado por asociársela a la licencia. Es entonces "la facultad de hacer con seguridad todo lo que al hombre le parezca más acomodado a sus deseos, mientras no perjudique a los derechos de otro hombre". Sus opuestos naturales son la esclavitud y la tiranía, porque justamente la libertad consiste en "obedecer a las leyes y en no obedecer a otro sino a ellas". ${ }^{575}$ Como también entenderán muchos diputados gaditanos, la trascendencia jurídica política de las reformas resultaba inseparable de su dimensión lingüística. La revolución debía tomarse además como un acto constituyente en la esfera de la lengua.

Con respecto a la igualdad va a establecer una diferenciación: por un lado existe la de hecho y por otro la de derecho. La primera consiste en que todos gocen sin

\footnotetext{
${ }^{571}$ Palti, E. J., El tiempo de la politica. El siglo XIX reconsiderado, Buenos Aires: Siglo XXI, 2007. pp. 99-100.

${ }^{572}$ Gazeta Nro. 7 (19/7/10): 198.

${ }^{573}$ Palti, E. J., óp. cit., p. 254.

${ }^{574}$ Gazeta Nro. 8 (26/7/10): 230-231.

${ }^{575}$ Ibid., p. 231.
} 
diferencia alguna de los mismos bienes. Esta igualdad, para el ensayista, "repugna" porque equipara permitiendo el mismo goce de comodidades entre el "industrioso" y "el holgazán, el pródigo o disipador”. Es casi lo mismo, dice, que la comunidad de bienes, tan opuesta a la naturaleza del hombre y a la propiedad de una sociedad civil. Al contrario, la igualdad de derecho consiste en que sean protegidas por la ley sin distinción ni diferencia alguna las facultades, medios y personas de todos los ciudadanos; que todos contribuyan a mantener las cargas de la sociedad sin más diferencia que en razón de sus haberes; que todos sean juzgados de una misma manera. Por lo tanto, la igualdad que pregona De la Peña no es otra cosa sino "el derecho de gozar de una misma condición y consideración a los ojos de la ley sin distinción alguna de personas". ${ }^{576}$ La propiedad es a su vez "la facultad de disponer y gozar a nuestro arbitrio de las adquiridas o poseídas por nosotros, excluyendo a los demás de este uso y aprovechamiento. La naturaleza nos da este derecho y la sociedad nos lo asegura y protege". ${ }^{577}$ Mientras que la seguridad es "la certeza y garantía que nos da la constitución o el pacto social de que no seremos inquietados ni en nuestras personas ni en nuestros bienes de modo alguno, ni por persona alguna". 578

Continuando con su discurso, se plantea diferenciar entre lo que significa una constitución política y un gobierno. Define a la constitución como aquella primera ley de una nación que no solo señala los derechos principales de todos los ciudadanos y sus primeras obligaciones, sino que además establece también sólidamente los límites de las facultades que se conceden a las autoridades, fijando así el modo con que deben ejercerse y obtener de esa manera una "recta distribución de todos los poderes por ser esta la más poderosa y eficaz garantía de la conservación de los derechos primitivos" ${ }^{579}$ En cambio, el gobierno son las autoridades revestidas del consentimiento tácito o expreso de la nación para componer el poder legislativo, el ejecutivo y el judicial; y su forma puede variar dependiendo de si el ejercicio de estos está concentrado en uno solo o repartido en varios. A la luz de la misma historia española considera peligrosa la primera opción por la propensión al despotismo de aquellos que contaran con la suma del poder público. En cambio, dice, otras naciones cultas de

\footnotetext{
${ }^{76}$ Ibid., p. 232.

577 Ibid., p. 233.

${ }^{578}$ Gazeta Nro. 9 (2/8/10): 247.

${ }^{579}$ Ibid., p. 247-248.
} 
Europa como Inglaterra los tres poderes están divididos y por lo tanto no hay riesgo de despotismo ni anarquía. ${ }^{580}$

\section{La salida revolucionaria a la crisis}

A partir de aquí, después de haber dedicado la primer parte de su ensayo a realizar una revisión de la historia española y de precisar el significado de algunos conceptos y voces centrales del lenguaje político que utiliza para interpretar la realidad, De la Peña comenzará a delinear cual, a su entender, es la fórmula para resolver el problema de la soberanía y encaminar la crisis hacia un proceso constituyente. Recurriendo una vez más a la propia tradición española, pero resignificándola como era costumbre de este primer liberalismo hispánico, encuentra en las figuras de los procuradores del común -o síndicos personeros en los pueblos- y el Procurador general de los Reynos, la legitimidad, responsabilidad y obligación de "mandar a deliberar para que la nación misma por medio de sus representantes pueda expresar su voluntad; o lo que tanto vale, pueda determinar quienes en la vacante del trono han de tener el poder legislativo, quienes el ejecutivo y quienes el judicial". 581

Conviene, dice, que la nación, y por consiguiente los pueblos que la componen, nombren sus representantes o apoderados para elegir y organizar en primer lugar "un gobierno autorizado con los poderes y consentimiento de toda la nación... y en segundo lugar para que estos representantes formen una constitución política que afiance nuestra libertad, fije las obligaciones y los derechos dela nación". ${ }^{582}$ Fiel exponente del primer liberalismo español, que como sugiere Elías Palti, comenzaba "apelando a la Historia para terminar encontrando en ella su opuesto: el poder constituyente, es decir, la facultad y la herramienta para cancelarla." ${ }^{, 583}$ En cambio, aquello constituye una nueva y marcada diferencia con el pensamiento de Jovellanos. En sus "instrucciones" a la Junta, el ilustre asturiano niega la necesidad de una nueva constitución política, y propone en cambio un "código legal" que reponga las viejas leyes reformadas. ${ }^{584}$

De la Peña considera que las Cortes de los últimos años no eran realmente una verdadera representación de la nación, entre otros "vicios" porque no existía una proporción ajustada entre los representantes y la población. Calculando que tanto la

\footnotetext{
${ }^{580}$ Ibid., p. 248-249.

${ }^{581}$ Ibid., p. 251.

${ }^{582}$ Gazeta Nro. 10 (9/8/10): 280.

${ }^{583}$ Palti, E. J., óp. cit., pp. 65-66.

${ }^{584}$ Artola, M., óp. cit., p. 307.
} 
península como sus posesiones, América y Filipinas, tenían similar número de habitantes -alrededor de 11 millones de personas-, correspondería proporcionalmente entonces un mismo número de representantes, evitando además toda queja o resentimiento. ${ }^{585}$ Antiguamente, dice, el derecho de concurrir a Cortes no solo era de pocas Ciudades, sino que también estaba vinculado a ciertos linajes, casas o familias, con exclusión de todos los demás ciudadanos. Si el primer derecho le parece injusto y solo sostenido por la "opresora feudalidad", al segundo lo califica como "bárbaro, antisocial y tiránico". ${ }^{586}$ Notable diferencia con la propuesta de unas cortes estamentales y bicamerales de cuño tradicional que defenderá Jovellanos en la polémica sobre la convocatoria. Un elemento más, y no menor, para dimensionar la distancia entre su pensamiento y el del ensayo, descartando de esa manera su autoría.

Para De la Peña, en cambio, era necesario romper con esa tradición, y sobre todo con la injusta y desigual representación dada a las distintas provincias: "En él día todos somos uno, todos somos españoles, todos somos iguales. Ya no hay más Galicia, ni más Asturias, ni más Vizcaya, [...] ni aun más América". ${ }^{587}$ Otro elemento aquí que será central en el liberalismo gaditano, esto es, la idea de la superioridad nacional por sobre el todo el territorio. La federalización de la soberanía para los diputados liberales era sinónimo de una posible desintegración de la monarquía. ${ }^{588}$ Consiente el ensayista de la premura y gravedad de la situación que atraviesa España, entiende que la primer convocatoria debería hacerse sólo en las ciudades de la península y tomando en cuenta la población de sus respectivas provincias, para luego sí avanzar hacia un sistema electoral que reglamente que "tanto la Península, como las Américas, deberán dividirse según su población en Comicios, Cámaras o Conventos electorales; arreglo que deberá ser una de las partes de nuestra constitución". 589

De la Peña se pronuncia a favor de una similar representación entre España y América, pero en línea con la postura que será hegemónica entre los diputados

\footnotetext{
585 "Dando un representante a cada treinta mil almas, corresponden a los veinte y dos millones, setecientos treinta y tres representantes" Número que le parece suficiente para evitar los vicios de que adolecían las antiguas cortes dado sus escasa cantidad de integrantes. Gazeta Nro. 10 (9/8/10): 281.

${ }^{586}$ Gazeta Nro. 14 (6/9/10): 363.

587 Ídem.

${ }^{588}$ Portillo Valdés, J.M., óp. cit., pp. 477-481.

${ }^{589}$ Llama la atención el poco restrictivo criterio para poder ser electo representante: "cualquier individuo que pase de 27 años, con tal que sea Español o natural y súbdito de la Monarquía española, aunque no sea vecino ni residente en aquella Ciudad que le nombre". Gazeta Nro. 10 (9/8/10): 282. Más adelante agrega que las votaciones organizadas por los procuradores "deben ser públicas y por propuestas individuales para evitar todo fraude, y para que solo se elija a los más beneméritos y dignos de la confianza pública". Gazeta Nro. 13 (30/8/10): 346.
} 
peninsulares en las Cortes, considera que es una cuestión que sólo tras la promulgación de la constitución debe resolverse, urgida España en atender problemas más acuciantes. Moreno hace oídos sordos de esto último, y en comentarios al pie de la última entrega del ensayo, retomará la cuestión del cálculo proporcional de los diputados por provincia, y suscribirá el planteo de que la mitad de ellos en la supuesta convocatoria a un Congreso deberían corresponder a América. El reclamo por la igualdad de representación como sabemos se constituiría en uno de los pilares argumentativos del gobierno rioplatense para no querer reconocer la legitimidad y autoridad de las Cortes gaditanas.

Volviendo al ensayo, los representantes elegidos de esta manera por la nación deberán contar con "poderes amplísimos para que uniéndose en nombre de la nación en la Corte $[\ldots]$ deliberen según su conciencia les dictare, que conviene al bien de la nación, a sus derechos y a su libertad, comenzando por formar la constitución política" ${ }^{590}$ La naturaleza del mandato de los diputados fue una de las cuestiones que mayor polémica despertaron tanto en la Península como en el Rio de la Plata. El liberalismo gaditano buscó al momento del congreso nacional, en línea con lo planteado por nuestro ensayista, dotar a los representantes de amplios poderes, subordinando a las provincias y "pueblos" al novedoso principio de la soberanía nacional. Y aunque partían de la convicción según la cual la representación debía ser expresión de ciudadanos libres, que de forma conjunta componían una nación, sujeto real de la soberanía, se escondía detrás ese temor del que hablábamos más atrás hacia el corporativismo territorial como germen de la disolución de la monarquía, no solo atribuible a los americanos sino también a los "antiguos reinos" peninsulares. El liberalismo español nacía con una fuerte pretensión centralizadora, más aún cuando su enemigo ideológico se solía escudar en el foralismo para defender sus privilegios feudales. ${ }^{591}$ Desde el Río de la Plata, esta voluntad centralista será utilizada también como argumento para desconocer a las Cortes, acusándola de no respetar y pisotear los derechos soberanos de los "pueblos". Pero como veremos más adelante en otro capítulo, cuando sea el turno de los revolucionarios rioplatenses en la formación de su propio congreso constituyente, se

\footnotetext{
${ }^{590}$ Ibid., pp. 346-347

${ }^{591}$ Algunos diputados conservadores, representantes de los viejos reinos peninsulares, buscaron en las Cortes poner nuevamente en discusión los antiguos fueros, debilitados durante la centralización borbónica y amenazados profundamente por la política centralista liberal. En su estrategia, llegaron al punto de apoyar los reclamos americanos identificándolos inteligentemente con los fueros provinciales. Chust Calero, M., La cuestión nacional americana en las Cortes de Cádiz, Valencia, UNED-UNAM, 1998, pp. 57-58.
} 
opondrán a los mandatos imperativos de los diputados por considerarlos disolventes y perjudiciales a la nación.

Otro de los elementos que De la Peña destaca en el ensayo, y que compartirá con gran parte del liberalismo hispánico, es la importancia de que lo debatido en las sesiones del Congreso no sea secreto y cerrado al público: "En efecto cuando las discusiones y deliberaciones de las cortes no son públicas, la libertad y los derechos de la nación están enteramente vendidos". ${ }^{592}$ En ese sentido, considera vital para poder amplificar la difusión de esos debates la cristalización de una amplia libertad de imprenta, aspecto que desarrollamos con mayor detenimiento en otro capítulo. A la par entiende también imprescindible para conocer los intereses nacionales, y formar su opinión publica que se permita formar clubes o sociedades, tanto de hombres como de mujeres, donde se discuta política sin ningún tipo de restricción. ${ }^{593}$

Hasta aquí el análisis de este ensayo, que no casualmente Moreno eligió entre tantos otros que circulaban por esos años en el mundo hispánico, por expresar uno de los mojones más radicales del pensamiento político español. En los apartados siguientes, cuando el secretario de la Junta se proponga sentar las bases doctrinarias para la convocatoria a un congreso constituyente, podremos seguir calibrando la selección, apropiación y el uso que de las ideas del liberal español se dieron en el Rio de la Plata.

\section{Moreno, las miras del Congreso y sus reflexiones sobre el proceso revolucionario peninsular}

La serie de artículos publicada por Mariano Moreno en la Gazeta durante los meses de noviembre y diciembre, y recopilada posteriormente en diversas ediciones bajo el título Sobre las miras del Congreso que acaba de convocarse y la constitución del Estado, representa la reflexión de mayor sistematicidad y profundidad doctrinaria de las elaboradas por el secretario de la Junta, y demás está decir que ha sido profusamente trabajada por la historiografía argentina. ${ }^{594}$ Es por ello que para no repetir un nuevo análisis pormenorizado de este documento solo señalaremos algunas aspectos que nos

\footnotetext{
592 Gazeta extraordinaria (17/9/10): 403.

593 Gazeta Nro. 17 (27/9/10): 445.

${ }^{594}$ Ver por ejemplo entre los trabajos más actuales: Goldman, N., Mariano Moreno. De reformista a insurgente. Buenos Aires. Edhasa, 2016. Carozzi, Silvana, Las filosofías de la revolución: Mariano Moreno y los jacobinos rioplatenses en la prensa de Mayo: 1810-1815. Buenos Aires: Prometeo Libros, 2011.
} 
parecen pertinentes en relación a los objetivos de nuestra investigación, teniendo en cuenta que, además, algunos de ellos ya los hemos abordados a lo largo de esta tesis.

Hacia noviembre, con un todavía breve pero intenso recorrido por parte de la Junta patriota, Moreno consideró que había llegado el momento de consolidar las conquistas revolucionarias. Y no concebía otra manera de hacerlo que no fuera que las provincias rioplatenses se dieran una constitución política propia. Los diputados del interior comenzaban a llegar a la capital y el secretario buscaba influir en ellos a través de los artículos de la Gazeta de Buenos Aires. En la misma línea de lo planteado por De la Peña en el ensayo Pensamientos de un Patriota Español, Moreno en sus artículos sostiene que el pueblo no debe contentarse con que sus jefes obren bien, debe aspirar a que nunca puedan obrar mal y que sus pasiones tengan un dique que su propia virtud. No puede esperarse que la prosperidad y felicidad general se derive de la bondad del gobierno, de las personas que lo ejercen, sino de una constitución firme. ${ }^{595}$

Desconoce que se pueda interpretar a las Leyes de Indias como el código político de los americanos, entre otras razones porque, dice, carecen de todo principio de razón, y están articuladas para sostener un sistema de comercio basado en el ruinoso monopolio y en la desigualdad práctica a la que es sometido el indio a pesar de las "protecciones" dispuestas. Condenando la antigua legislación colonial, Mariano Moreno exponía pues la crítica filangeriana, y más en general del tardío XVIII, al "constitucionalismo de antiguo régimen", atribuyendo al término constitución una concepción típicamente moderna. Como señala Morelli, Filangieri pensaba de hecho en realizar "un sistema completo y racionalizado de legislación" partiendo de pocos principios concatenados, y en particular de la teoría de los derechos del hombre, la verdadera estrella polar de todo el nuevo ordenamiento jurídico de clara matriz iusnaturalista. ${ }^{596}$

El espíritu igualitarista de Moreno, moldeado seguramente en sus años en el Alto Perú, salía a superficie al hablar del destrato al indio. También la conciencia anticolonialista que fue madurando durante su carrera profesional al ser testigo de la desigualdad concreta entre criollos y peninsulares en distintos planos de la sociedad virreinal: "No caigamos en el error de creer, que esos cuatro tomos contienen una constitución; sus reglas han sido tan buenas para conducir a los agentes de la metrópoli en la economía lucrativa de las factorías de América, como inútiles para regir un estado,

\footnotetext{
595 Gazeta Nro. 22 (1/11/10): 556

${ }^{596}$ Morelli, F., óp. cit., pp. 499-500.
} 
que como parte integrante de la monarquía, tiene respecto de sí mismo iguales derechos, que los primeros pueblos de España". ${ }^{597}$ Para legitimar este último supuesto, su razonamiento se desliza hacia una evidente contradicción, al remitir a las mismas Leyes de Indias-desconocidas párrafos atrás-, cuando "declararon que la América era una parte o accesión de la corona de Castilla, de la que jamás pudiera dividirse”. Por lo tanto, a causa de la rendición de Castilla al yugo de un usurpador se "dividió nuestras provincias de aquel reino; nuestros pueblos entraron felizmente al goce de unos derechos que desde la conquista habían estado sofocados". 598

\section{Pacto y Soberanía, conceptos en tensión}

Veamos cuál es la concepción de pacto y consentimiento que subyace en Moreno para analizar la relación entre la metrópoli y América, y la legitimidad de la ruptura. Como bien señala Noemí Goldman, Moreno fue adaptando los singulares principios del Contrato Social de Rousseau a la novedosa realidad creada en el Río de la Plata en 1810. ${ }^{599}$ Esbozó así una teoría de la soberanía para justificar el nuevo poder de los americanos:

Los vínculos, que unen el pueblo al Rey, son distintos de los que unen a los hombres entre sí mismos: un pueblo es pueblo, antes de darse a un Rey: y de aquí es, que aunque las relaciones sociales entre los pueblos y el Rey, quedasen disueltas o suspensas por el cautiverio de nuestro Monarca, los vínculos que unen a un hombre con otro en sociedad quedaron subsistentes, porque no dependen de los primeros; y los pueblos no debieron tratar de formarse pueblos, pues ya lo eran; sino de elegir una cabeza, que los rigiese, o regirse a sí mismos según las diversas formas, con que puede constituirse íntegramente el cuerpo moral. ${ }^{600}$

La ruptura entre el pueblo y el rey, no implicaba que su consecuencia fuera la disolución de la sociedad, una suerte de estado de naturaleza rousseaunniano. El punto de partida era el pueblo ya constituido que debía darse un poder político, y no el individuo. A la par de esta concepción repone una formulación más ligada a la doctrina de la retroversión de la soberanía, pero sin dejar de remarcar que el origen de ésta se encontraba en el pueblo y por lo tanto era suyo el poder constituyente: "La autoridad de

\footnotetext{
${ }^{597}$ Gazeta extraordinaria (6/11/10): 572-573.

${ }^{598}$ Gazeta Nro. 27 (6/12/10): 694.

${ }^{599}$ Goldman, N., Historia y lenguaje. Los discursos de la Revolución de Mayo, Buenos Aires, Centro Editor de América Latina, 1992, p. 332.

${ }^{600}$ Gazeta extraordinaria (13/11/10): 599.
} 
los pueblos en la presente causa se deriva de la reasunción del poder supremo, que por el cautiverio del Rey ha retrovertido al origen de que el monarca lo derivaba, y el ejercicio de éste es susceptible de las nueva formas, que libremente quieran dársele". ${ }^{601}$ Realiza por lo tanto un desplazamiento en el plano teórico del pacto de sujeción -con raíces en la tradición pactista hispana, que no sólo remitía al neoescolasticismo suareciano sino también tomaba elementos del iusnaturalismo de Grocio y Puffendorfpara reemplazarlo por un nuevo contrato de sociedad basado en la soberanía popular. ${ }^{602}$ Como señala Silvana Carozzi, por razones seguramente pragmáticas y de formación intelectual "el lenguaje de Moreno, en sus idas y venidas, circula en este momento muy amigable- y a veces indiferenciadamente-, por los campos conceptuales del pactismo antiguo y moderno". Caído el pactum subjetionis, sobrevive el societatis. ${ }^{603}$ Debemos entender esta operación discursiva también como resultado de su contexto de enunciación, los lenguajes políticos no son entidades auto-centradas y lógicamente integradas, sino que se fundan en premisas contingentes, históricas. Un discurso radicalmente incompatible con el imaginario tradicional puede nacer, y generalmente lo hace, de recomposiciones, de torsiones conceptuales, operadas desde sus propias categorías; tensionadas por un contexto que plantea nuevos problemas y terrenos al debate político. ${ }^{604}$

Develando gradualmente una concepción cada vez más radical de lo que entiende por soberanía, la va asociando indefectiblemente a la voluntad general del pueblo. Siendo la soberanía indivisible e inalienable "nunca ha podido ser propiedad de un hombre solo; y que mientras los gobernados no revistan el carácter de un grupo de esclavos, o de una majada de carneros, los gobernantes no pueden revestir otro que el de ejecutores y ministros de las leyes, que la voluntad general ha establecido". ${ }^{605} \mathrm{Y}$ siempre que los pueblos han logrado manifestar su voluntad general, como entiende que ha sucedido con el levantamiento juntista americano, han quedado en suspenso, dice, todos los poderes que antes los regían. Similar concepción de la soberanía que la del autor de "Pensamientos de un patriota español”, que también entendía que no era otra cosa que “el ejercicio de la voluntad general", que residía siempre en el pueblo, tanto como que es la fuente de donde dimana, y que, según los pactos y convenciones que los hombres

\footnotetext{
${ }^{601}$ Gazeta Nro. 27 (6/12/10): 693

${ }^{602}$ Goldman, N., Mariano Moreno..., pp. 214-215.

${ }^{603}$ Carozzi, Silvana, óp. cit., pp. 132-133.

${ }^{604}$ Palti, E., óp. cit., p. 105.

${ }^{605}$ Gazeta extraordinaria (13/11/10): 604-605.
} 
se dieran, ésta pasa a los reyes u otras autoridades importantes. ${ }^{606}$ Pero, como remarca Noemí Goldman, la soberanía nacional que el ensayista peninsular extendía a todo el ámbito de la monarquía española, Moreno la convierte en la soberanía popular de "estas provincias", donde deberá fundarse la constitución. ${ }^{607}$ Para ambos, como para el común del constitucionalismo hispánico de la época, el sujeto de la soberanía era colectivo, nunca el individuo. Y aunque los dos van a usar indistintamente el singular o el plural para señalar al pueblo o a los pueblos la competencia del ejercicio de la soberanía, en De la Peña es más marcada la tendencia a pensar la nación en clave de el pueblo, mientras que los revolucionarios americanos en general parten de la base de concebir a la monarquía como plural, constituida por los pueblos. ${ }^{608} \mathrm{Y}$ en este punto compartimos la perspectiva de Elías Palti que sostiene que ni la postura americana de una concepción plural de la monarquía era, en sí misma, tradicional, ni la idea moderna de una nación unificada era necesariamente colonialista, sino resultado de las circunstancias históricas y las formas en que se fue fijando el debate entre ambas orillas del atlántico. ${ }^{609}$

Para el revolucionario rioplatense las Américas no están unidas a los monarcas españoles por un verdadero "pacto social”, que según él únicamente puede sostener la "legitimidad y decoro de una dominación". Entiende si lógico que los pueblos de España se conserven dependientes del Rey cautivo, esperando su libertad y regreso, ya que ellos establecieron efectivamente la monarquía. Pero la América en ningún caso puede considerarse sujeta a aquella obligación; ella

[...]no ha concurrido a la celebración del pacto social de que derivan los monarcas españoles, los únicos títulos de la legitimidad de su imperio: la fuerza y la violencia son la única base de la conquista, que agregó estas regiones al trono español, conquista que en trescientos años no ha podido borrar de la memoria de los hombres las atrocidades y horrores con que fue ejecutada y que no habiéndose ratificado jamás por el consentimiento libre y unánime de estos pueblos, no ha añadido en su abono título alguno a el primitivo de la fuerza y violencia, que la produjeron. ${ }^{610}$

Y para Moreno, como para Rousseau, la fuerza, o sea la conquista, no induce derecho, ni puede nacer de ella una legítima obligación que nos impida resistirla. Como

\footnotetext{
${ }^{606}$ Gazeta Nro. 7 (19/7/10): 198.

${ }^{607}$ Goldman, N., Mariano Moreno..., p. 217.

${ }^{608}$ El liberalismo español entendía a la comunidad nacional como un conglomerado de pueblos que a su vez constituían cada uno de ellos un cuerpo colectivo de padres de familia. Portillo Valdés, J.M., óp. cit., pp. 238-239.

${ }^{609}$ Palti, E., óp. cit., p. 84.

${ }^{610}$ Gazeta Nro. 24 (15/11/10): 614.
} 
señala De Gori "el punto inicial del pacto reside en una voluntad libre y decisoria de la ciudad y no en una voluntad arbitraria que coacciona e intenta fundamentar el vínculo de la obediencia a través de la violencia y el peso de la costumbre". ${ }^{611}$ En ese sentido, es interesante reponer el planteo de Goldman sobre como en Moreno se fueron operando una serie de deslizamientos de sentido en ciertos enunciados, y de la aparición de otros como efecto de coyunturas determinadas: "Cada etapa de ese trayecto se define por el surgimiento de un nuevo enemigo: pueblo/autoridades coloniales, pueblo/españoles europeos, pueblo/rey, pueblo/criollos moderados". ${ }^{612}$ La figura del pacto entonces va trasmutando. Dentro de esta línea argumentativa, nos encontramos frente a un rechazo no sólo de un pacto colonial, sino paulatinamente de la monarquía como sistema de gobierno. $^{613}$

Se puede hacer aquí un contrapunto interesante con la idea de los pactos entre España y América sostenida por el liberal asturiano Álvaro Flórez Estrada. Para éste, los americanos con las muestras inmediatas que dieron de solidaridad y patriotismo al conocerse la invasión napoleónica sobre la península, habían establecido un nuevo pacto de unión con sus hermanos de ultramar, pacto que reemplazaba al anterior, aquél originado con la conquista. A este nuevo contrato, fundamentado además en el reconocimiento que hicieran las provincias al nuevo gobierno peninsular, se le suma un segundo que surge del compromiso manifestado de socorrer a la metrópoli en la guerra contra el invasor, principal enemigo de la libertad para el asturiano. La ruptura de dicho compromiso, con el levantamiento de algunas provincias justo en el momento de mayor gravedad en la situación de la península, lleva a considerarlo como un acto de la peor calaña, acusando prácticamente a los americanos de estar en confabulación con el enemigo francés:

En el hecho solo de haber las Américas reconocido voluntariamente al Gobierno de la Metrópoli, es indudable que renovaron el pacto que las unía con esta, o que lo formaron de nuevo, esto es convinieron en ser miembros de una misma familia política, o de componer una sola sociedad; primer contrato. Más las reiteradas promesas, que, para estimular a los Españoles a defender su libertad, y la de todos los hombres, hicieron

\footnotetext{
${ }^{611}$ De Gori, E., La República Patriota..., p. 54.

${ }^{612}$ Goldman, N., Historia y lenguaje..., pp. 36-37.

${ }^{613}$ Ibid., 44.
} 
entonces de auxiliarlos en cualquier evento, envuelven otra obligación todo diferente; segundo contrato. ${ }^{614}$

La principal diferencia entre la concepción de Moreno y la de Flórez Estrada estriba en que para el primero el vínculo original solo se había establecido -por instrumento de la fuerza- entre los americanos y la corona de Castilla, por lo tanto con los monarcas españoles; mientras que para el asturiano el pacto colonial era extensivo a la nación española, y que incluso roto este -que entrelíneas podemos adivinar que para él tampoco poseía gran legitimidad- había sido remplazado por un nuevo pacto y reafirmado por otro sucesivamente, que ligaba ahora sí estrechamente a españoles de ambos hemisferios. ${ }^{615}$ Moreno desconoce esos nuevos pactos. Siendo la Junta Central ilegítima en su origen, revistió al fin el carácter de soberanía por el posterior consentimiento que prestó América, aunque destaca que este fue hecho "sin libertad ni examen". La idea de falta de libertades y condicionamientos para que se produzca un verdadero y genuino consentimiento es clave en su argumentación. Nuevamente, como con el caso de la conquista, el vínculo era forzado, y por lo tanto ilegítimo. No existía entonces ese nuevo primer pacto del que hablaba Flórez Estrada, y por lo tanto tampoco un segundo. La caída de la Junta Central restituyó a los pueblos la plenitud de los poderes que, para el secretario, nadie sino ellos mismos podía ejercer. Era la primera vez que se ponía en cuestión la legitimidad de la Junta Central a ese nivel. Hasta ahora tanto en proclamas oficiales, en la correspondencia o en los artículos de su propia pluma, aunque se cuestionara algunos aspectos del origen de ésta, solo se desconocía de plano al Consejo de Regencia, y por traslación a la autoridad de los funcionarios virreinales que de él derivaban su poder.

\section{La revolución en la península como espejo imperfecto}

El artículo que corresponde a la Gazeta extraordinaria del 13 de noviembre contiene una serie de reflexiones en relación al proceso revolucionario español y su impacto en América, altamente significativas para nuestra hipótesis de trabajo. El despotismo, el gran mal que la revolución porteña había venido a combatir, según el revolucionario, también había campeado durante varios siglos en la península, sofocando los derechos de los españoles. No se diferencia aquí de lo manifestado por

\footnotetext{
${ }^{614}$ Álvaro Flórez Estrada, Examen Imparcial sobre las Disensiones de la América con España, p. 47.

${ }^{615}$ Como sugiere Elías Palti "la vacatio regis en América desnudaba así otra vacancia más fundamental, la vacatio legis". Palti, E., óp. cit., p. 128.
} 
De la Peña, Quintana y Flórez Estrada entre otros liberales peninsulares, que veían en el advenimiento de los Austrias el comienzo de una etapa caracterizada por la ausencia de derechos y libertades para los vasallos de la monarquía española, tanto de una orilla como de la otra. Para Moreno, en los orígenes de la revolución presente no obraron otros agentes que la inminencia del peligro y el odio a la dominación extranjera, pero que "apenas pasó la confusión de los primeros momentos, los hombres sabios salieron de la oscuridad, en que los tiranos los tenían sepultados; enseñaron a sus conciudadanos los derechos, que habían empezado a defender por instinto; y las Juntas Provinciales se afirmaron por la ratihabición de todos los pueblos de su respectiva dependencia" ${ }^{616} \mathrm{Y}$ a pesar de las graves dudas que le representa la legitimidad de la instalación de la Junta Central, entiende la necesidad y la urgencia de concentrar el poder de las Juntas Provinciales para así resistir unificadamente al poderoso enemigo.

Considera una ventaja para la América que la necesidad haya hecho adoptar en España aquellos principios liberales, "pues al paso que empezaron a familiarizarse entre nosotros, presentaron un contraste, capaz por sí solo de sacar a los americanos del letargo en que yacían tantos años". ${ }^{617} \mathrm{He}$ aquí, en palabras del factótum de la junta, la confirmación más nítida del impacto y la relevancia que tuvo el lenguaje político del naciente liberalismo peninsular entre los americanos. La llegada periódica de embarcaciones cargadas de noticias y escritos provenientes de la península a partir de mediados de 1808 encendió y fue alimentando un curso de transformaciones que ya no iría a detenerse.

Moreno no dejaba de destacar el fenómeno inédito que estaba viviendo la península, que ya hemos analizado en profundidad en relación a la proliferación de la prensa, los manifiestos políticos y la lucha en pos de la libertad de imprenta. Entusiasmado el secretario afirmaba "por todos los pueblos de España pulularon escritos llenos de ideas liberales, y en los que se sostenían los derechos primitivos de los pueblos, que por siglos enteros habían sido olvidados y desconocidos". ${ }^{618}$ Es recurrente la idea en Moreno de que la revolución viene a recuperar libertades, derechos y saberes perdidos u olvidados, tratando de nunca presentarlos como novedosos sino que habían estado negados por el despotismo reinante de los últimos tiempos. Ese es justamente un rasgo en común sobre todo con los reformistas ilustrados pero también

\footnotetext{
${ }^{616}$ Gazeta extraordinaria (13/11/10): 600

${ }^{617}$ Ibid., p. 601.

${ }^{618}$ Ídem.
} 
con los liberales peninsulares, formados en el pensamiento del constitucionalismo histórico, o con aquellos que buscaban introducir nuevos conceptos y prácticas pero bajo una pátina de tradicionalismo. ${ }^{619}$ El problema en Moreno es que, al descartar a las Leyes de Indias como un código político válido no tiene, a diferencia de los constitucionalistas peninsulares, desde donde recuperar la tradición para poder aggionarla a los nuevos tiempos. Para el secretario y el proceso rioplatense, la potencia creadora -en el sentido de la invención- del poder constituyente del congreso a convocarse, estaba en primer plano a la hora de pensar qué constitución y para qué nación. Es aquí donde Rousseau se presenta más útil para Moreno que por ejemplo un Jovellanos. Como señala Carozzi, el no existir ni constitución ni nación de preexistencia constatable, es el ginebrino el que ofrece más elementos para pensar esa realidad. ${ }^{620}$

¿Quiénes eran aquellos hombres sabios que Moreno destacaba como los que habían hecho conocer a sus compatriotas sus verdaderos derechos y ayudado a despertar a los pueblos tanto de España como de América del largo sueño embrutecedor a que el despotismo los había sometido? El dirigente revolucionario va a mencionar únicamente con nombre y apellido a lo largo de sus escritos en la Gazeta, como ya pudimos observar, a Jovellanos, por el que demuestra claramente una gran admiración. ${ }^{621}$ Pero en este pasaje del artículo en particular, donde se refiere a la circulación de los "principios liberales" va a hacer referencia, sin revelar su identidad, a "un abogado de Cádiz" y a "un sabio de Valencia". En primer lugar nos parecen que no son casuales las ciudades de origen de ambos personajes. Ya vimos en el capítulo anterior que las de Cádiz y la de Valencia fueron justamente las dos Juntas provinciales que mayores contradicciones tuvieron con el gobierno central, fuera éste la Junta Central o el Consejo de Regencia.

Sobre el primero dirá que dio a luz una "juiciosa manifestación de los derechos del hombre, y los habitantes de España quedaron absortos, al ver en letra de molde la doctrina nueva para ellos, de que los hombres tenían derechos". ${ }^{622}$ El historiador Patricio Clucellas en su obra 1810. Revolución de dos mundos llega a la conclusión de que se trata de José Manuel de Vadillo, abogado de los Reales Consejos y miembro de

\footnotetext{
619 "Yo me lisonjeo, que dentro de poco tiempo serán familiares a todos los paisanos ciertos conocimientos, que la tiranía había desterrado" Ibíd., p. 604.

${ }^{620}$ Carozzi, S., óp. cit., p. 133.

${ }^{621}$ En un pasaje del artículo recomienda a los americanos el consejo del que llama un español sabio y patriota refiriéndose a Gaspar de Jovellanos. Trascribe a continuación, y volviendo a equivocarse en la atribución de la autoría, un extracto de "Pensamientos de un patriota español" donde hace referencia al error cometido por "nuestros abuelos" al no fijar constitución. Gazeta extraordinaria (13/11/10): 607.

${ }^{622}$ Gazeta extraordinaria (13/11/10): 600.
} 
la orden de Carlos III, nacido en Cádiz en $1777 .{ }^{623}$ A partir de 1810 pasó a ser Secretario de la Junta Superior de Gobierno de la ciudad y entre otras ocupaciones también se desempeñó como redactor de periódicos liberales como El Observador, donde se destacó por artículos de contenido jurídico como el titulado Reflexiones acerca de la Constitución Política. ${ }^{624}$ Fue uno de los pocos particulares que respondió en 1809 a la Consulta al País de la Junta Central presentando tres textos que trataban sobre las reformas de las leyes y su relación con los derechos del hombre. Es probable que alguno de estos escritos haya llegado a manos del revolucionario rioplatense, despertando su admiración por lo avanzado de algunas de sus ideas. ${ }^{625}$

En su estrategia de emparentar las razones por las que se erigieron juntas en ambas orillas del Atlántico, Moreno se apoyará en un incógnito "sabio de Valencia “que, según él, había descrito con energía los principios de justicia que afirmaban la instalación de las Juntas. ${ }^{626}$ Clucellas también en este caso se anima a aventurar, según sus investigaciones, a quién se estaría refiriendo. ${ }^{627} \mathrm{Y}$ no sería otro que el liberal asturiano José Cangas Argüelles, uno de los vocales más destacados de la Junta de Valencia y redactor de sus proclamas y manifiestos. ${ }^{628}$ Clucellas considera además que el escrito al que se refiere Moreno es muy probable que sea el oficio de la Junta de Valencia dirigida a la Junta Central el 15 de septiembre de 1809 con motivo del ataque que esta última estaba sufriendo por parte del Consejo Reunido. En él además de cuestionarse la calidad y probidad de los miembros del Consejo, se defendía a la Central y se argumentaba en función de la legitimidad de las Juntas Provinciales y el proceso de movilización popular del que surgieron y por el que se mantenía a raya al enemigo francés: "El Pueblo se ha conquistado a sí mismo, nada debe a las autoridades antiguas, y tiene acción para pedir que se constituya bajo la forma más conforme a su libertad y a

\footnotetext{
${ }^{623}$ Clucellas, Patricio, 1810 Revolución ..., pp. 240-247.

${ }^{624}$ Allegado de Manuel Quintana, Agustín de Arguelles y el Conde de Toreno, fue elegido en 1813 diputado por Cádiz para a las Cortes ordinarias, volviendo luego a la vida pública en el trienio liberal. Ibíd., p. 241.

${ }^{625}$ Clucellas nos brinda una curiosidad que vale pena destacar. Desconociendo seguramente Vadillo la alusión que Moreno había hecho de él, devolverá aun así varias décadas después los elogios al calificar al Secretario porteño como "el más hábil de todos los revolucionarios, [...] el director verdadero de la Revolución”. Vadillo José María, La independencia de América, 1836, p. 382; citado en Clucellas, P., 1810 Revolución..., p. 247.

${ }^{626}$ Gazeta extraordinaria (13/11/10): 601

${ }^{627}$ Clucellas, Patricio, 1810 Revolución..., p. 234.

${ }^{628}$ Nacido en Oviedo en 1770, luego de desempeñarse como vocal de la Junta de Valencia fue diputado en las Cortes de Cádiz y ministro de Hacienda de la Regencia. Con la vuelta de Fernando VII fue confinado en Peñíscola (Castellón) para retornar nuevamente como Ministro de hacienda durante el trienio liberal.
} 
sus derechos". ${ }^{629}$ Cuando más adelante Moreno en un pasaje de su artículo plantee qué opciones tiene el congreso para formar un ejecutivo para las provincias americanas, volverá a retomar el modelo juntista peninsular y en particular su formulación centralizada: "si se prefiere el ejemplo que la España misma nos ha dado, no queriendo regentes, sino una asociación de hombres patriotas con la denominación de Junta Central, ella será el supremo jefe de estas provincias y ejercerá sobre ellas durante la ausencia del Rey los derechos de su persona con las extensiones y limitaciones que los pueblos le prefijen en su institución". ${ }^{630}$ Llama la atención aquí como dependiendo de la coyuntura y las necesidades políticas, Moreno pendula entre las críticas o los elogios a la Junta Central. Como vimos en el capítulo anterior, en sus reflexiones sobre la proclama del Marqués de Casa Irujo, Moreno había reivindicado a la Junta de Valencia y a sus planteos federalistas en relación al gobierno central. La utilizaba a fin de justificar el propio planteo autonomista de Buenos Aires con respecto a la Regencia. Ahora, abocado a la constitución de un gobierno centralizado para las provincias rioplatenses, más que la postura federalista de la valenciana lo que le servía era invocar las tendencias centrípetas que habían dado origen a la Junta Central.

Pero junto con el reconocimiento a los revolucionarios españoles del mérito de la gran obra que habían iniciado, el secretario de la Junta lanza su crítica más certera, aquella que además justificaba el camino independiente -aún sin decirlo abiertamenteque debían recorrer los territorios americanos. Les achaca que mientras "se trataba de las provincias de España, los pueblos podían todo, los hombres tenían derechos, y los jefes eran impunemente despedazados, si afectaban desconocerlos", pero que sólo "un tributo forzado a la decencia hizo decir que los pueblos de América eran iguales a los de España". ${ }^{631}$ Está hablando obviamente del manifiesto del Consejo de Regencia de España e Indias “a los americanos españoles” del 14 de febrero de 1810 redactado por Quintana, que como sabemos, además del pronunciamiento en relación a la igualdad de derechos entre peninsulares y americanos, contiene una fuerte crítica al pasado colonial y a la "vieja España". Sin embargo, dice Moreno, apenas los americanos quisieron pruebas reales de la igualdad que se les ofrecía, apenas quisieron ejecutar los mismos principios que los pueblos de España, "el cadalso y todo género de persecuciones se

\footnotetext{
${ }^{629}$ Oficio de la Junta de Valencia, citado en Clucellas, P., 1810 Revolución ..., p. 237.

${ }^{630}$ Gazeta extraordinaria (13/11/10): 606

${ }^{631}$ Gazeta extraordinaria (13/11/10): 601.
} 
empeñaron en sofocar la injusta pretensión de los rebeldes". ${ }^{632}$ Seguramente Moreno remite aquí a la cruenta represión llevada adelante contra la insurgencia altoperuana en 1809. Y recurriendo a la ironía que tanto caracterizaba a su pluma, aprovecha para recordar -sin nombrar a su autor- la poco feliz frase del bando del Virrey Abascal que declaraba reunidas las provincias del Plata a las del Perú, al afirmar que "valiera más dejarnos vegetar en nuestra antigua obscuridad y abatimiento, que despertarnos con el insoportable insulto de ofrecernos un don que nos es debido, y cuya reclamación ha de ser después castigada con los últimos suplicios." ${ }^{633}$

El mismo Manuel Quintana reconocería unos meses después, por medio de su Semanario Patriótico y con similares conceptos, lo flagrante de la contradicción en la que incurría el gobierno peninsular al oponerse a las juntas americanas:

¿Qué fundamento hay para negar a las provincias de América en un tiempo de desorganización y desorden un derecho que las de España tuvieron al principio de la revolución? Juntas supremas e independientes se erigieron en la península después del fatal 2 de mayo; juntas independientes y supremas se han establecido en las provincias de ultramar después de la invasión de la Andalucía y disolución de la Central. Como negar a un reyno, una provincia, a un hombre, la acción de mirar por su conservación y su felicidad, cuando las manos de quienes tenia confiado ese cuidado se hacen inhábiles a desempeñarle. ${ }^{634}$

Este artículo del liberal madrileño no pasaría desapercibido como veremos en otro capítulo, publicándose tanto en la prensa de Montevideo como en la de Buenos Aires.

En Moreno, como en Monteagudo más adelante, la causa de la libertad, aquella que definía a su enemigo en el despotismo, y que tenía a la conquista plena de los derechos del hombre como fin último, no se reducía únicamente al escenario americano ni a la cuestión colonial, sino que constituía una causa de orden universal, y en ese sentido el proceso peninsular podía ser valorado, y tomado, por qué no, como un espejo -imperfecto- desde donde reconocerse. Dice Moreno en un pasaje esclarecedor en esta línea de razonamiento:

[...] creí oportuno recordar la conducta de los pueblos de España en igual situación a la nuestra. Sus pasos no serán la única guía de los nuestros, pues en lo que no fueron rectos, recurriremos a aquellos principios eternos de razón y justicia, origen

\footnotetext{
${ }^{632}$ Ídem.

${ }^{633}$ Ibid., 602

${ }^{634}$ Semanario Patriótico $N^{\circ}$ XLVI, 21/2/11, p. 325.
} 
puro y primitivo de todo derecho; sin embargo, en todo lo que obraron con acierto, creo una ventaja preferir su ejemplo a la sencilla proposición de un publicista, porque a la fuerza del convencimiento se agregará la confusión de nuestros contrarios, cuando se consideren empeñados en nuestro exterminio, sin otro delito que pretender lo mismo que los pueblos de España obraron legítimamente. ${ }^{635}$

Es interesante la cita en varios aspectos. Por un lado es importante tener en cuenta que Moreno considera que el proceso ha madurado lo suficiente como para plantear la necesidad de una constitución propia, lo que no es otra cosa que el paso más firme en el sentido de la ruptura definitiva con la metrópoli. Pero eso no excluye que piense la causa de los americanos en algunos aspectos aún como parte de una misma lucha junto a los revolucionarios españoles, y que, debido al desfase temporal, reconoce la conveniencia de tomar al proceso peninsular como fuente de enseñanzas. Además, lo prefiere, dice, por encima de las reflexiones de cualquier publicista, no solo porque los saberes originados en la experiencia los entendía más enriquecedores que una simple elucubración teórica, sino además porque al tomarlos como ejemplo se subraya también la legitimidad de los propios reclamos y la flagrante contradicción por parte del gobierno peninsular de pretender negarlos.

\section{La larga y universal lucha contra el despotismo}

Moreno era consciente de que se le podía achacar a Buenos Aires que tampoco haya esperado, al igual que sucedió en España con sus Juntas provinciales, a que concurran los pueblos del antiguo virreinato para dar su consentimiento en la conformación del gobierno revolucionario, pero destaca que desde un primer momento la Junta se dio el carácter de transitoria a la espera de la celebración de un congreso. La legitimidad de las nuevas autoridades sólo podía fundarse en el asentimiento de los "pueblos", que en este caso no son otra cosa que las "provincias". En ese punto ubica al proceso del que es protagonista por encima de lo acontecido en la península: "Estaba reservado a la gran capital de Buenos Ayres dar una lección de justicia, que no alcanzó la península en sus momentos de sus mayores glorias". ${ }^{636}$ Esta idea se volvería a repetir en otra entrega de esta serie de artículos. El secretario considera que en la larga y universal lucha de la libertad contra la tiranía y el despotismo, España ya había agotado sus fuerzas, acechada por enemigos internos y externos, había sucumbido en sus propias

\footnotetext{
${ }^{635}$ Gazeta extraordinaria (13/11/10): 602

${ }^{636}$ Ibid., pp. 603-604.
} 
contradicciones; tocaba ahora el turno a la América, madura ya para terminar la obra que habían comenzado sus hermanos europeos: "lo que ha ejecutado antes la España misma, lo que se preparaba a realizar en los momentos de la agonía política que entorpeció sus medidas, y lo que deberemos hacer los pueblos de América, por el principio que tantas veces he repetido, de que nuestros derechos no son inferiores a los de ningún otro pueblo del mundo". 637

Y en una vuelta más en la deriva radical de su pensamiento, sostiene que si el mismo Fernando VII se opusiera al bien de los americanos, no merecería reinar sobre América. No podría, dice, oponerse a una constitución emanada del propio pueblo y que la Monarquía no supo dar. Lejos de agraviarse por la "sabia y prudente constitución de nuestro congreso", debería recibir con el mayor placer una obra que se proponía "sacar a los pueblos del letargo en que yacían enervados". ${ }^{638}$ Como señala De Gori, la reposición constante de las figuras de tirano y de déspota para cuestionar a los funcionarios imperiales -y de a poco y muy sutilmente también al rey-, tenían como objetivo en Moreno apuntar a debilitar las promesas, los tiempos y las expectativas internas que suscitaba la monarquía como régimen. ${ }^{639}$ Se pregunta, trazando un nuevo paralelo con el proceso en la península:

¿A qué fin se hallan convocadas en España unas Cortes que el Rey no puede presidir? ¿No se ha propuesto por único objeto de su convocación el arreglo del Reino, y la pronta formación de una constitución nueva, que tanto necesita? [...] El Rey a su regreso no podría resistir una constitución a que, aun estando al frente de las Cortes, debió siempre conformarse; los pueblos, origen único de los poderes de los reyes, pueden modificarlos, por la misma autoridad con que los establecieron al principio [...]. ${ }^{640}$

Es consiente que aún no están dadas las condiciones para plantear una salida política que implique despojarse de la figura monárquica, pero advierte que "si el amor a nuestro Rey cautivo no produjese en los pueblos una visible propensión a inclinar la balanza en favor suyo no faltarían principios sublimes en la política que autorizase al Congreso para una absoluta prescindencia de nuestro adorado Fernando". ${ }^{641}$ De esta manera va preparando el terreno para una ruptura futura que considera inevitable.

\footnotetext{
${ }^{637}$ Gazeta Nro. 24 (15/11/10): 617-618.

${ }^{638}$ Ibid., p. 616

${ }^{639}$ De Gori, Esteban, La República Patriota ..., pp. 70-71.

${ }^{640}$ Ibid., p. 617.

${ }^{641}$ Ibid., p. 614.
} 
El revolucionario finalmente se pregunta si toca al Congreso de las provincias del sur dictar una constitución o debe esperarse la reunión de toda la América. Confiesa que sería preferible lograr conformar una asamblea general que reúna la representación de todos los pueblos libres de la Monarquía, pero en principio lo considera inviable por distintas razones. Por un lado habla de la "perfidia de las autoridades de las capitales", y a eso le suma las grandes distancias y falta de comunicación entre las regiones. ${ }^{642} \mathrm{La}$ idea entonces de un gobierno federativo reconoce que es tentadora pero impracticable por el momento. Un congreso que reúna a los representantes de las provincias que comprendía el Virreinato si entiende que es factible y puede constituirse en el paso previo al objetivo de máxima aún irrealizable:

Yo deseara que las provincias, reduciéndose a los límites que hasta ahora han tenido, formasen separadamente la constitución conveniente a la felicidad de cada una; que llevasen siempre presente la justa máxima de auxiliarse y socorrerse mutuamente; y que reservando para otro tiempo todo sistema federativo, que en las presentes circunstancias es inverificable, y podría ser perjudicial, tratasen solamente de una alianza estrecha, que sostuviese la fraternidad que debe reinar siempre, y que únicamente puede salvarnos de las pasiones interiores, que son enemigo más terrible para un estado que intenta constituirse, que los ejércitos de las potencias extranjeras que se le opongan. ${ }^{643}$

Y aquí recuperamos la cuestión sobre cómo era entendida la nación, planteada unos párrafos más atrás en relación a la idea de pueblo y pueblos. Como señalara Antonio Annino, es Moreno un ejemplo de la emergencia temprana de un concepto de nación unificada, el virreinato como "una unidad indestructible", en contraposición a la idea de esta como mera agregación de pueblos. ${ }^{644} \mathrm{Se}$ apartaba de esta manera de la concepción dominante entre los diputados americanos en Cádiz, y se acercaba, aunque con otro resultado, a la nación entendida en términos del liberalismo peninsular.

\footnotetext{
${ }^{642}$ Gazeta Nro. 27 (6/12/10): 691-693.

${ }^{643}$ Ibíd., p. 697. Aquí las provincias aludidas, al referirse al conjunto de América, refieren a los virreinatos. Cuando la Junta discutió la propuesta de Juan José Castelli de atacar Perú para incorporarlo, fue justamente Moreno el que se opuso.

644 Annino, Antonio, "Soberanías en lucha", en Annino, A. et al, De los imperios a las naciones, Iberoamérica, Zaragoza, 1994, p. 249.
} 


\section{La Junta Grande, el desplazamiento del Secretario y el destierro de los morenistas}

Mientras Moreno redactaba estos célebres artículos, el clima político comenzaba a enrarecerse en el seno de la Junta. Al secretario le molestaban ciertas veleidades de su presidente Cornelio Saavedra. Su predisposición a las ostentaciones y honores propios de su cargo exasperaban a Moreno, llevándolo a acusarlo por lo bajo de actitudes despóticas. Saavedra por su parte no compartía el pulso vigoroso y radical del secretario, sobre todo en su manejo de la represión a los contrarrevolucionarios. Más allá de las diferencias de personalidad, allí radicaban realmente los motivos de las disputas. En las instrucciones reservadas que la Junta envió a Castelli para la ocupación del Alto Perú, bajo el influjo del secretario, se sostenía la misma orientación que para el sofocamiento de la insurrección en Córdoba. Como había sucedido con Liniers y de la Concha, los jefes realistas altoperuanos, Vicente Nieto, Francisco Paula de Sanz, el obispo de la Paz y José Manuel Goyeneche debían ser "arcabuceados" en cualquier lugar donde se encontraran. Orden que como sabemos fue cumplida por Castelli el 15 de diciembre en Chuquisaca, exceptuando a Goyeneche que logró retirarse a tiempo con su ejército. Asimismo Moreno señalaba en las instrucciones que “...en la primera victoria que logre dejará que los soldados hagan estragos en los vencidos para infundir terror a los enemigos". ${ }^{645}$ Saavedra le escribió al gobernador de Salta, Feliciano Chiclana, el 27 de octubre de 1810, evidenciando sus resquemores hacia la forma con que Moreno conducía la revolución en las provincias del interior: "Veo tu carta a Moreno y las que de oficio escribes a la junta. Ella me llena de complacencia al ver el acierto de tus providencias y el sistema de suavidad que has adoptado; él hará progresar nuestro sistema y de contrarios hará amigos: el hará conocer que no el terror sino la justicia y la razón son los agentes de nuestros conatos, y ojalá que todos siguieran este sistema" ${ }^{646}$ La "semilla de desunión" estaba plantada y la llegada de los diputados del interior a Buenos Aires tendría importantes consecuencias en el equilibrio interno de la Junta. $^{647}$

\footnotetext{
${ }^{645}$ Citado en Goldman, N., Mariano Moreno..., p. 162. En el Manifiesto de la Junta ante la ejecución de los sublevados de Córdoba Moreno escribía: "Hemos decretado el sacrifício de estas víctimas a la salud de tantos millares de inocentes. Solo el terror del suplicio puede servir de escarmiento a sus cómplices [...] El terror seguirá a los que se obstinaren en sostener el plan acordado con estos". Gazeta Nro. 19 (11/10/10): p. 494.

${ }^{646 ، " C a r t a ~ d e ~ C o r n e l i o ~ S a a v e d r a ~ a ~ F e l i c i a n o ~ A n t o n i o ~ C h i c l a n a " ; ~ e n ~ G a n d i ́ a, ~ E n r i q u e ~ d e, ~ L a s ~ i d e a s ~ p o l i ́ t i c a s ~}$ de Mariano Moreno. Autenticidad del plan que le es atribuido, Buenos Aires, Peuser, 1946, p.73.

${ }^{647}$ Expresión utilizada por Belgrano para referirse a las divisiones que entreveía entre los vocales de la Junta. Belgrano, M., “Autobiografía...”, p. 161.
} 
El hecho desencadenante del enfrentamiento final entre los dos dirigentes de la Junta fue el festejo que organizó el cuerpo de patricios por la victoria de Suipacha el 5 de diciembre de 1810. Según algunas de las versiones de lo ocurrido esa famosa noche, Moreno, quién no habría estado invitado a la celebración, logró entrar y presenció un brindis en honor a Saavedra donde se le habría entregado una corona de laureles acompañada de las siguientes palabras: "Viva el señor presidente don Cornelio Saavedra, emperador y rey de la América del Sur”. El secretario, furioso, redactó esa misma noche el famoso "decreto de supresión de honores", haciéndolo aprobar por toda la Junta al día siguiente. Allí se presentaban las reglas de virtud republicana que debían guiarla conductas y acciones de los funcionarios públicos, se hacía especial hincapié en la absoluta igualdad de todos los miembros de la Junta, tanto en lo relativo a sus atribuciones como en lo concerniente al protocolo que debía seguirse en sus celebraciones públicas, y se traspasaba el comando supremo militar, confiado a Saavedra por el Cabildo en el acta de erección de la Junta Provisional, a la Junta en pleno. Este último punto era especialmente importante porque privaba al presidente de la Junta de una de las atribuciones fundamentales heredadas del depuesto virrey: la comandancia general de las tropas, a las que trasladaba a la Junta en pleno. ${ }^{648}$

En la Gazeta Moreno escribiría: "La libertad de los pueblos no consiste en palabras, ni debe existir en los papeles solamente [...] si deseamos que los pueblos sean libres, observemos religiosamente el dogma de la igualdad". Para Moreno, la libertad estaba indisociablemente ligada a la igualdad, una y otra tenían sentido solo cuando iban unidas. Como marca De Gori, no era sólo un derecho que debía ser preservado sino el fundamento mismo para reasumir el destino de otro orden político". ${ }^{649}$ Más adelante continuaba: "en vano publicaría esta Junta principios liberales, que hagan apreciar a los pueblos el inestimable don de su libertad, si permitiese la continuación de aquellos prestigios, que por desgracia de la humanidad inventaron los tiranos". ${ }^{650}$ La utilización del sintagma "principios liberales" en ese contexto discusivo, como señala Wasserman, evidencia la incorporación de motivaciones políticas al concepto liberal, probablemente como un eco de las discusiones suscitadas en España que llegaban a América a través de

\footnotetext{
${ }^{648}$ Ternavasio, M., Historia argentina ..., p. 78.

${ }^{649}$ De Gori, Esteban, La República Patriota ..., p. 231.

${ }^{650}$ Gazeta extraordinaria, 8/12/1810, p. 710
} 
impresos, cartas y documentos oficiales. ${ }^{651} \mathrm{Sin}$ dar puntada sin hilo, Moreno aprovechaba para insistir con la necesidad de avanzar hacia un proceso constitucional: "una constitución justa y liberal da únicamente a las virtudes, el respeto que los tiraros exigen para los trapos y galones". ${ }^{652}$ Frente a los gérmenes del despotismo, contenidos en el egoísmo y el capricho, Moreno oponía el lenguaje republicano que vinculaba el ejercicio del poder a la virtud y el patriotismo. ${ }^{653}$

La disputa entre el ala moderada y la radical de la Junta alcanzó su punto culminante en la reunión convocada el 18 de diciembre para definir si los diputados de los pueblos, que ya habían arribado a la capital se incorporarían a la Junta, como quería Saavedra y el Deán Funes, o formarían parte de un congreso general, propuesta defendida por Moreno. La cuestión no respondía solo a una controversia jurídica, sino que implicaba que dependiendo cuál opción triunfaba, el equilibrio de poder se volcaría irremediablemente para uno de los bandos. La incorporación de los diputados del interior licuaría la influencia que el secretario había logrado sobre la Junta, más propensos éstos a un transitar más acompasado y refractarios del vértigo que Moreno buscaba imprimirle a la revolución. El tono más conservador de las elites políticas de las ciudades del interior se puede percibir claramente en las proclamas que los respectivos cabildos publicaron en apoyo a la formación de la junta patriota, cifradas en un lenguaje más tradicional, con una impronta religiosa mucho más marcada que el capitalino. ${ }^{654}$ Según Ignacio Núñez, Saavedra y Funes "se habían puesto de acuerdo que Moreno precipitaba la revolución, y ambos a la vez, aunque sin plan concertado, difundían esta idea, el presidente entre los jefes militares y el deán entre los diputados de las provincias". ${ }^{655}$ Existía de fondo la voluntad de postergar la convocatoria a ese congreso pretendido por Moreno, que, como tal, sería soberano y podría, por ejemplo, declarar la independencia y la constitución de una nueva comunidad política. Un sector importante de la revolución no consideraba que ése fuera el camino a seguir, por lo menos en el corto plazo.

En la reunión del 18 de diciembre, uno de los nueve diputados del interior, presumiblemente el Deán Funes, exigió en nombre de todos ellos que los representantes

\footnotetext{
${ }^{651}$ Wasserman, F., "Entre la moral y la política. Las transformaciones conceptuales de liberal en el Río de la Plata (1780-1850)", En Fernández Sebastián, J. (Coord.). La aurora de la libertad. Los primeros liberalismos en el mundo iberoamericano. Madrid: Marcial Pons, 2012, p. 51.

652 Gazeta extraordinaria, 8/12/1810, p. 711.

653 De Gori, Esteban, La República Patriota ..., p. 229.

${ }^{654}$ Ver por ejemplo las proclamas del cabildo de Salta y el de Tucumán en la Gazeta extraordinaria (23/7/10), pp. 210-217.

${ }^{655}$ Núñez, I., "Noticias históricas", Biblioteca de Mayo, p. 350.
} 
"por el derecho que les competía" se debían incorporar a la Junta y tomar una parte activa en el mando de estas provincias hasta la celebración del congreso que estaba convocado. Estos derechos se fundaban en primer lugar en la circular de la Junta del 27 de Mayo en que se invitaba justamente a los pueblos a "tomar parte activa" del rumbo de la revolución. Asimismo se esgrimía un argumento jurídico para fundamentar ese derecho: la capital no poseía títulos legítimos para elegir por si sola a los gobernadores del conjunto de los pueblos del virreinato. Como señala Noemí Goldman, Funes aquí estaba siguiendo el ejemplo español de la formación de la Junta Central a partir de la concurrencia de los diputados de las juntas provinciales. ${ }^{656} \mathrm{La}$ facción de Moreno insistía en que la función de los representantes era integrar un "congreso nacional”, y que hasta tanto se reuniese, era improcedente incorporarlos a un gobierno que tenía el carácter de provisorio. Pero la decisión ya estaba tomada y con ella la suerte de Moreno y del congreso constituyente. Al perder la votación, el secretario presentaría inmediatamente su renuncia indeclinable, aunque luego accedería a ser enviado a una misión diplomática a Londres, que como sabemos no podría cumplir, ya que moriría en alta mar en extrañas circunstancias.

Con el alejamiento de Moreno, y con Castelli y Belgrano fuera de la capital al frente de las expediciones militares, la facción radical quedaba muy debilitada, mientras que Saavedra y Funes comenzaban a bajarle los decibeles a la revolución. Como respuesta los seguidores de Moreno se agruparon en un club político, conocido como el Club de Marco, por el nombre del café donde se reunían. ${ }^{657}$ Desde esa posición acentuaron sus críticas al gobierno, lo que derivó en la detención de alrededor de ochenta jóvenes identificados con esa facción, y aunque luego fueron absueltos, la tensión entre ambos grupos parecía volverse insostenible.

El 5 de abril se produjo una movilización a la Plaza de la Victoria, cuyo componente popular y rural es destacado por todos los documentos -Núñez los llama en sus memorias "hombres de poncho y chiripá" que habrían generado horror en la "gente bien" de la ciudad-, donde se elevó un petitorio a las autoridades por conducto del Cabildo. ${ }^{658}$ En apoyo del presidente de la Junta y su grupo más cercano, las

\footnotetext{
${ }^{656}$ Goldman, N., Mariano Moreno..., pp. 230-231.

${ }^{657}$ Sobre el llamado Club de Marco ver Canter, Juan, Las sociedades secretas, politicas y literarias (1810-1815), Imprenta de la Universidad, Buenos Aires, 1942.

658 "Se apeló a los hombres de poncho y chiripá contra los hombres de capa y de casaca” Núñez, Ignacio, "Noticias históricas", Biblioteca de Mayo, tomo I, p. 452. Un análisis más extenso de estos hechos en Di Meglio, Gabriel, ¡Viva el bajo pueblo! La plebe urbana de Buenos Aires y la política, entre la Revolución de Mayo y el rosismo, Buenos Aires, Ed. Prometeo, 2006.
} 
peticiones exigían, entre otros puntos, tomar medidas drásticas contra los españoles, y la expulsión de los vocales vinculados al club morenista, su destierro de la ciudad de Buenos Aires, y la restitución a Saavedra de los poderes militares sustraídos con el decreto de supresión de honores. El gobierno, que había estado indudablemente detrás del movimiento conocido como "las jornadas del 5 y 6 de abril", anticipándose a un probable levantamiento de los morenista, cumplió con las peticiones. Son destituidos los vocales Azcuénaga, Larrea, Vieytes y Rodríguez Peña, y apartados de sus empleos Domingo French, Antonio Berutti, Agustín Donado, Gervasio Posadas y el Presbítero Ramón Vieytes; a todos ellos, en su carácter de "autores de la sedición", se les decreta la expatriación. En la Gazeta extraordinaria del 15 de abril se publica un manifiesto relatando los hechos donde se afirma que: “Toda revolución tiene en su seno hombres ambiciosos [...] Hace tiempo que hemos visto, con no poco sentimiento, irse introduciendo una furiosa democracia, desorganizada, sin consecuencia, sin forma, sin sistema, ni moralidad; cuyo espíritu era amenazar nuestra seguridad en el seno mismo de la patria" ${ }^{659}$ Gran parte de la dirigencia revolucionaria que había protagonizado la Revolución de Mayo es apartada violentamente del poder. ${ }^{660}$ En sus memorias Juan Manuel Beruti describía a las jornadas como una "contrarrevolución". 661

\section{Los derechos de los pueblos indígenas. Castelli y la ceremonia de Tiahuanaco}

Castelli, informado del golpe saavedrista, le escribió a Funes criticando lo sucedido y señalando que ponía en riego la libertad americana. A la par se cartea con Rodríguez Peña y Vieytes convocándolos a reunirse con él, y evaluando la posibilidad de hacerse fuertes en el norte. Contaban con el nada despreciable poder de un ejército que había logrado la ocupación del Alto Perú. En ese contexto, y acercándose el primer aniversario de la Revolución de Mayo, Castelli tomó la decisión de hacer un acto que sirviera de reafirmación del rumbo adoptado en las ruinas de Tiahuanaco, ubicadas a unas decenas de kilómetros de La Paz. Buscaba con ello dar un mensaje a propios y extraños, a aliados y enemigos. ${ }^{662}$ En su rol de representante había procurado forjar una relación estrecha con los indios, a quienes, según varios testimonios, trataba cordial y

\footnotetext{
${ }^{659}$ Gazeta extraordinaria (15/4/11): 277

${ }^{660}$ Galasso, N., Mariano Moreno. El sabiecito del sur, Buenos Aires, Ediciones Colihue, 1994, p. 128.

${ }^{661}$ Beruti, J. M., óp. cit., pp. 164-167.

${ }^{662}$ Wasserman, F., Castelli..., p. 187. Para profundizar en la conducta seguida por Castelli durante su misión en el Alto Perú, recomendamos leer esta excelente biografía.
} 
cariñosamente, buscando siempre ponerlos en un pie igualdad con los criollos. ${ }^{663} \mathrm{Su}$ actitud parecía ser auténtica y sentida, pero como señala Fabio Wasserman, no obedecía sólo a razones humanitarias e ideológicas, formaba parte también de su estrategia política y de las instrucciones que le habían impartido al nombrarlo representante.

La decisión de Castelli de abolir el pago del tributo indígena no remitía sólo a la voluntad reparadora de la Junta hacia los pueblos indígenas, estaba enmarcada en un contexto ideológico que incluía al mundo hispánico en su conjunto. Las Cortes de Cádiz a través de un decreto habían abolido el tributo el 13 de marzo de 1811 y luego harían lo mismo con la mita el 9 de noviembre de 1812. Erradicar tributos y mitas era, de alguna manera, despojar al indio de su "minoría de edad" y habilitarlo para asumir el estatus de ciudadano. Era, también, dentro de una tendencia reformista que tenía sus antecedentes como vimos en los escritos de Victorián de Villava, quebrar una de las bases del tradicional sistema colonial. En los debates sobre el tema, vinculados indefectiblemente a la cuestión de la representación americana en las Cortes, el diputado suplente por Buenos Aires, Francisco López Lisperguer, afirmaba que los indios no carecían de capacidad, sino de oportunidad y que, además, el sistema colonial los había tratado como a seres inferiores. En su discurso señalaba: "Esta rudeza [de los indios], además de no ser tanta como se pinta, es efecto de la opresión y tiranía de las autoridades; no es por falta de talentos ni aptitud, sino por la sinrazón con que los tratan...”. ${ }^{664}$ Es probable que al momento en que Castelli proclamara en las ruinas de Tiahuanaco la abolición del tributo, no se conocieran aún las noticias del decreto de las Cortes - no habían pasado ni siquiera tres meses entre uno y otro-, pero si era de público conocimiento su tratamiento en las sesiones desde hacía tiempo, impulsado fundamentalmente por las diputación americana. Seguramente, la proclama del representante de la Junta, además de ser expresión de una genuina voluntad de reparación histórica, en línea con su concepción de los derechos naturales, era también parte de una estrategia de anticiparse a la metrópoli para ganarse el apoyo de los pueblos indígenas a la causa insurgente.

La Junta porteña el 10 de enero había dispuesto la elección de un diputado que representara a los naturales en cada una de las intendencias de la Audiencia de Charcas

\footnotetext{
${ }^{663}$ Se dice que no dejaba agacharse a los indios cuando lo saludaban estrechándolos con en un fuerte abrazo. Tanto afecto logró entre el pueblo aymara que lo llegaron a considerar el nuevo Inca o por lo menos su pariente o aliado.

${ }^{664}$ Diario de las Discusiones y Actas de las Cortes, Tomo 3, Año 1811, Sesión del 25 de enero, pp. 8687. Citado en O'Phelan Godoy, Scarlett, "Los diputados peruanos en las Cortes de Cádiz y el debate sobre el tributo, la mita y la ciudadanía indígena", Revista de Historia Iberoamericana nro. 5 (1), 2012, pp. 97-98.
} 
y en las de Paraguay. ${ }^{665}$ Castelli decidió implementarla de inmediato y temiendo que la voluntad de las comunidades fuera defraudada, dispuso que solo los indios pudieran participar del acto electoral. El sistema electoral ideado por Castelli contemplaba tres grados y era similar al que la Junta Central había diseñado dos años antes para que los americanos eligieran a sus representantes a las Cortes. El bando informando la novedad es publicado en castellano, quechua, aymara y, según algunos autores, también en guaraní; debiendo bajar de las capitales a las cabezas de partido y de allí a los pueblos. Si bien era un grupo minoritario quienes sabían leer, como bien señala Wasserman, se trataba de un gesto de gran valor político en tanto reconocía a sus interlocutores como sujetos portadores de una cultura propia. ${ }^{666}$ En el acto, que según todos los testimonios fue imponente, estaban representados los diversos sectores que formaban la alianza interétnica liderada por Castelli. El discurso de cierre, a cargo del representante publicado también en castellano, quechua y aymara-, se centró en la idea de que la Revolución venía a terminar con la opresión sufrida por los naturales durante muchísimo tiempo y la instauración del gozo de los mismos derechos para todos los habitantes de las provincias americanas. Los derechos que Castelli proclamó recuperados por los indios, señala Goldman, fueron "sociales -derogación de todos los abusos perjudiciales a los naturales como cargas e imposiciones indebidas, otorgamiento de tierras y creación de escuelas- y políticos, al otorgarles el derecho de representación”. ${ }^{667}$ Estableció así, continúa Goldman,

[...] la libre elección de los caciques por parte de sus comunidades, y la eliminación de los privilegios de propiedad o de sangre de que gozaban sus jefes. Ordenó también la realización de elecciones libres en cada parroquia de indios, a fin de designar un diputado para el congreso general de las provincias a reunirse. Pero el reconocimiento por parte de Castelli de la calidad de ciudadanos a los indios, es decir, de individuos frente al Estado, no lo llevó sin embargo a decretar la supresión de la comunidad indígena: respetó su existencia corporativa, aunque ordenó la implantación de mecanismos de democratización interna. $^{668}$

\footnotetext{
${ }^{665}$ En la Gazeta nro. 33 del 24/1/11 se publica un oficio de la Junta Grande a Castelli con las instrucciones para la elección de los diputados indígenas. En la introducción se afirma que los indios son ciudadanos desde siempre por las Leyes de Indias, y que la Junta lo entiende así para el Congreso Nacional. pp. 57-58.

${ }^{666}$ Wasserman, F., Castelli..., p. 189.

${ }^{667}$ Goldman, Noemí, Historia y Lenguaje..., p.51.

${ }^{668}$ Ídem.
} 
La proclama del fin de la servidumbre indígena frente a las ruinas de Tiahuanaco, que concluyó con una fiesta popular con baile y música, fue sin lugar a dudas una de las expresiones más radicales del periodo revolucionario por sus connotaciones sociales. Esta política filo-indigenista propuesta por Castelli, que amenazaba el estatuto sólidamente arraigado de las castas altoperuanas, era una parte central de la concepción de la revolución de la facción morenistas. El mismo Moreno había dado muestras de ello durante su formación como abogado en Chuquisaca, y en varias oportunidades, como en los artículos de la Gazeta que analizamos en éste capítulo, había enlazado el nuevo lenguaje de los derechos del hombre con la denuncia de la opresión al indio y la necesidad de su liberación. 


\section{Capítulo 10: \\ El liberalismo peninsular ante la "cuestión americana»}

\section{Introducción}

Hacia mediados de 1810, la «cuestión americana» se estaba convirtiendo, a partir de los levantamientos de varias provincias del Nuevo Mundo y las reivindicaciones de la diputación americana en las Cortes extraordinarias de Cádiz, en un problema de primer orden para el liberalismo peninsular. Mucho fue lo escrito y pronunciado sobre el tema en estos tumultuosos años. Y no pocas fueron las contradicciones que esta problemática hizo surgir en su seno. La diputación peninsular de tendencia liberal en las Cortes mantuvo, en general, un posicionamiento homogéneo frente a la problemática americana, que entendemos no sólo respondió a principios doctrinarios sino también a situaciones de carácter coyuntural y a intereses de corte corporativo relacionados con el grupo social que esta corriente de alguna manera expresaba. Sin embargo, por fuera de los recintos de las Cortes, existían divergencias, en algunos casos significativas, sobre cómo fue abordado el problema entre distintos actores del llamado primer liberalismo español. En este capítulo buscaremos relevar, por lo tanto, las posiciones que con respecto a la América española sostuvieron cuatro de los liberales peninsulares más representativos: Manuel José Quintana, Álvaro Flórez Estrada, José Blanco White y Agustín de Argüelles.

\section{Manuel José Quintana, la pluma de la metrópoli en años de revolución}

Como ya hemos visto en otro capítulo, la Junta Central consideraba las proclamas y manifiestos los medios más confiables para convencer a los americanos sobre el rumbo que se estaba tomando en la península. ${ }^{669}$ Se buscaba mediante ellos exaltar el sentimiento patriótico, el carácter de guerra nacional contra el invasor francés, demostrando la comunidad de intereses entre la metrópoli y los territorios ultramarinos. Como secretario de la Junta Central, Manuel Quintana -del que ya hemos hecho bastante referencia en su rol de aglutinador y guía de los primeros círculos liberales- fue

\footnotetext{
669 "La voluntad de provocar el interés general responde en primer lugar al deseo de encontrar una legitimidad surgida de ese mismo interés general y crea un público para los asuntos políticos; es decir un destinatario colectivo para las manifestaciones del poder”. Hocquellet, Richard, «La publicidad de la Junta Central española (1808-1810)», en Guerra, François-Xavier; Lemperiere, Annick et al. Los espacios públicos en Iberoamérica, Ambigüedades y problemas. Siglos XVIII-XIX, FCE, México, 1998, p.140-167.
} 
prácticamente el autor de todos ellos. Desde sus cargos políticos, en la Junta Central como en el Consejo de Regencia, se enfrentó tanto a los elementos conservadores como al sector reformista expresado por los jovellanistas, aunque con estos últimos hubo de formular alianzas coyunturales. Los manifiestos y decretos emitidos por ambos órganos de gobierno provinieron en su mayoría de su combativa pluma. Aun así, fue consciente de que los hechos y no sólo las palabras, y en particular una convocatoria igualitaria a Cortes, era lo que esperaban muchos americanos, y entendía que accediendo a algunas de sus reivindicaciones era posible sumarlos a la lucha contra el absolutismo, manteniendo de esa manera integrada la monarquía. ${ }^{670} \mathrm{El}$ decreto del 22 de mayo de 1809 de la Junta Central fue un claro ejemplo de esta voluntad.

Una vez disuelta la Junta Central, Quintana conservó la confianza de los flamantes regentes y fue comisionado a la redacción de un manifiesto dirigido al Nuevo Mundo que informara la situación en la península, la invasión de Andalucía, la caída de la Junta Central y que a la vez otorgara legitimidad al Consejo de Regencia como nuevo y único gobierno de los territorios españoles, convocando también a enviar diputados a las Cortes extraordinarias. El manifiesto resultante, conocido como El Consejo de Regencia de España e Indias a los americanos españoles, al que ya hemos hecho referencia en esta tesis, y emitido el 14 de febrero de 1810 en la isla de León, dejó traslucir el pensamiento vivo de Quintana sobre el problema americano, más allá de haber sido un encargo del flamante gobierno peninsular. El claro pronunciamiento favor de la igualdad de derechos entre peninsulares y americanos, más la fuerte crítica al pasado colonial, a la «vieja España», escandalizó a no pocos en Cádiz, y fueron varios los que luego responsabilizaron a este escrito de incentivar las aspiraciones independentistas entre los americanos. Decía el documento:

Desde el principio de la revolución declaró la Patria esos dominios parte integrante y esencial de la Monarquía Española. Como tal le corresponden los mismos derechos y prerrogativas que a la metrópoli. Siguiendo este principio de eterna equidad y justicia fueron llamados esos naturales a tomar parte en el Gobierno representativo que ha cesado: por él la tienen en la Regencia actual; y por él la tendrán también en la representación de las Cortes nacionales, enviando a ella Diputados, según el decreto que va a continuación de este Manifiesto.[...]Desde este momento, Españoles Americanos, os veis elevados a la dignidad de hombres libres: no sois ya los mismos que antes encorvados bajo un yugo mucho más duro mientras más distantes estabais del centro del poder; miradlos con

\footnotetext{
${ }^{670}$ Dérozier, Albert, óp. cit., p. 506.
} 
indiferencia, besados por la codicia, y destruidos por la ignorancia. Tened presente que al pronunciar o al escribir el nombre del que ha de venir a representaros en el Congreso Nacional, vuestros destinos ya no dependen ni de los Ministros, ni de los Virreyes, ni de los Gobernadores; están en vuestras manos. ${ }^{671}$

Pero no debemos confundirnos y alistar a Quintana entre los letrados proindependentistas, como bien afirma Dérozier y como veremos más adelante a partir de otros escritos de su propia pluma. El madrileño consideraba a las Américas como subordinadas a España, al igual que la mayor parte de los liberales peninsulares, aunque aspiraba a que un futuro gobierno constitucional, surgido del proceso revolucionario, estableciera una relación diferente con estos territorios sin que se llegasen a cuestionar a fondo los pilares de esa dominación. ${ }^{672}$

Recibidas las noticias de las revoluciones de Caracas y Buenos Aires, la siguiente proclama de la Regencia dirigida a los americanos, emitida el 6 de septiembre de 1810, cambiaba notablemente su lenguaje. En ella Quintana comienza elogiando las muestras de fidelidad americana pero inmediatamente recrimina y condena a aquellos que, entiende, estaban abandonando la causa española:

Pero en medio de este gozo tan puro y tan macizo, ha sabido con sumo dolor y sobresalto, que en alguna ciudad y territorio de ese continente, como si no fuesen hijos de una misma madre, se ha experimentado conmociones de descontento y desobediencia, bajo el falso velo de seguridad y buen gobierno, promovidas por almas inquietas, ambiciosas, o alucinadas con doctrinas y máximas políticas de libertad, que han convertido a los que las predicaban en Europa en esclavos del tirano Napoleón.

La terminología utilizada es más conservadora, destacándose que en los primeros dos párrafos utiliza tres veces la palabra vasallos a la hora de dirigirse a los americanos. Llama a los españoles de ultramar a cortar de raíz dichos levantamientos y hace explicita la voluntad de la Regencia y de las autoridades virreinales de utilizarla fuerza si esto fuera necesario.

Espera la afligida y heroica España, que tiene vuelto los ojos y el corazón a esas felices regiones, y se promete el Supremo Gobierno que tiene el cuidado de todos, que un ejemplo tan abominable, será detestado de todos los habitantes del hemisferio Español,

\footnotetext{
${ }^{671}$ El Consejo de Regencia de España e Indias a los americanos españoles 14/2/10.
}

${ }^{672}$ Dérozier, Albert, óp. cit., p. 586-87. 
sofocado por sus propias manos si fuese necesario, y borrada para siempre hasta de su memoria. ${ }^{673}$

A la par de su rol como funcionario del gobierno, Quintana mantuvo una destacada actuación a través de la prensa. Comencemos ahora a analizar los artículos del Semanario Patriótico, que en su tercera etapa -noviembre de 1810 a marzo de 1812-, dedicó varias páginas a la problemática americana. Fue a través del periódico donde Quintana intervino de manera más personal en el proceso revolucionario, difundiendo el programa liberal y combatiendo las posiciones reaccionarias del partido lealista. Una de las primeras alusiones que podemos encontrar se refiere al debate sobre la representación americana -que ya constituía uno de los puntos más conflictivos de las nuevas Cortes- donde el poeta madrileño ponía en duda si el hecho de acceder a los reclamos de los diputados americanos podría aplacar las insurrecciones en las provincias americanas. ${ }^{674}$ En febrero de 1811 Quintana publica, dividido en tres números, un artículo donde reflexiona en profundidad sobre los sucesos acontecidos en América. En las dos primeras entregas, describe el derrotero de los acontecimientos, centrando su atención en los levantamientos de Caracas, Buenos Aires y Nueva España. Sobre este último vierte su primera condena categórica, justificando a su vez la represión llevada adelante por las autoridades virreinales: "Si estos actos no constituyen una verdadera declaración de guerra, y guerra la más terrible, no sabremos ya en adelante qué nombre dar a las cosas. Ha sido, pues, preciso contestar a ellos con guerra; y el nuevo Virrey no es menos conocido por los servicios que ha hecho a la patria con sus talentos militares que por la moderación, prudencia y cortesanía de su carácter."675

La última parte es quizás la más interesante por las reflexiones que allí están contenidas. El director del Semanario Patriótico reproduce con todo detalle cuáles eran, en voz de los americanos, las razones de su levantamiento, dando además crédito a las denuncias sobre los males e injusticias alegados en aquellas argumentaciones. Pero paso siguiente califica de ilegítimo en su esencia el levantamiento americano. Considera como oprobioso el cuadro de opresión y atraso que caracterizaba al sistema colonial, pero lo entiende como una realidad común a ambos hemisferios, descalificando

\footnotetext{
${ }^{673}$ Dicha proclama será publicada en El Español, periódico dirigido por Blanco White, editado en Londres y simpatizante de la causa americana, acompañada de comentarios de Simón Bolívar, donde se rebaten los argumentos de la Regencia y se perfilan los principales argumentos que esgrimirá el movimiento independentista americano en los años sucesivos. El Español $N^{\circ} X I I, 30 / 3 / 11$, p. 428.

${ }^{674}$ Semanario Patriótico $N^{\circ} X L I, 17 / 1 / 11$, p. 215.

${ }^{675}$ Semanario Patriótico $N^{\circ} X L V, 14 / 2 / 11$, p. 299.
} 
entonces aquel argumento como motivo de ruptura, menos aun cuando considera, desde su liberalismo militante, que una nueva era se había abierto con la revolución española y que ésta iba a dejar en el pasado toda especie de tiranía. ${ }^{676}$

El autor reafirma, en este mismo artículo, la idea de que los habitantes de ambos hemisferios eran una misma nación, con tantos atributos en común, que ni una derrota militar - por la batalla de Ocaña-, ni un gobierno poco hábil podrían disolver esas obligaciones mutuas. ${ }^{677}$ Más adelante, el autor plantea: "Insisten los disidentes de América en comparar su situación a la de las provincias de España cuando la invasión de Murat: Nosotros les negaremos siempre esta semejanza; y diremos que aguarden para hacerla a que los enemigos estén sobre ellas, interrumpan su comunicación recíproca, y las priven del vínculo universal que las reunía quitándoles el centro de autoridad a que pudieran acudir." ${ }^{678}$ Luego les aconseja que, si persisten en compararse con el juntismo peninsular, los imiten en su moderación y trasladen su soberanía al gobierno central. ${ }^{679}$

Como ya lo había manifestado en la proclama del 6 de septiembre de 1810 de la Regencia, Quintana vuelve a dudar de los reales motivos que impulsan a los insurgentes:

Pero aquellos que penetran más en lo interior de las intenciones políticas, y que no se pagan de las expresiones aparentes y formularias de juramentos, manifiestos y proclamas, dicen, que el blanco a que se dirigen las turbulencias de América, es a su entera separación de la metrópoli, a erigirse en tantas potencias independientes como provincias, y a conseguir de este modo la prosperidad y la gloria a que sujetas a España les es imposible elevarse. ${ }^{680}$

En los párrafos finales del artículo, el poeta madrileño descree de las posibilidades reales de los americanos de constituirse como naciones independientes, poco preparados sus habitantes para tal desafío y débiles sus países ante la segura ambición de las potencias extranjeras. Pronostica una inevitable guerra civil entre las provincias por la hegemonía, así como una sublevación de las castas ante el desorden generalizado. ${ }^{681}$

\footnotetext{
${ }^{676}$ Semanario Patriótico $N^{\circ}$ XLVI, 21/2/11, p. 325

${ }^{677}$ Ibid., p 326.

${ }^{678}$ Ibid., p. 327.

${ }^{679}$ Ibid., p. 328.

${ }^{680}$ Ibid., p. 328.

${ }^{681}$ «Entonces estos altivos independientes, que se arman con tal fiereza del rigor de los principios contra su Madre Patria, conocerán bien a su costa que la aplicación práctica de ellos tiene que sufrir a veces para bien general una prudente limitación: entonces se convencerán de que valía algo para su bien estar, y para su seguridad este prestigio de pertenecer a una grande y dilatada monarquía, en cuyo arbitrio siempre se
} 
Como cierre vuelve a cargar contra los independentistas y realiza la siguiente declaración de principios sobre las obligaciones de todo aquel que se considere un patriota español:

De cualquier modo que sea, nosotros, como ya hemos dicho no podemos elevarnos a esta altura indiferente de principios generales. Somos españoles: tenemos el interés más fuerte, el derecho más incontestable; o por mejor decir la obligación más estrecha de conservar la integridad de la monarquía; porque en esta integridad está cifrada su salvación. ${ }^{682}$

El Semanario Patriótico y la febril actividad política de Manuel Quintana fueron interrumpidos con la reacción de los persas, el regreso de Fernando VII y la persecución que éste desató contra la militancia liberal. ${ }^{683}$ Vendrán duros años de prisión hasta 1820 , cuando Quintana recupera su libertad y se integra una vez más activamente al resurgir político del liberalismo durante el llamado «Trienio liberal».

\section{Ganando enemigos en las dos orillas. Críticas de Álvaro Flórez Estrada al sistema monopólico comercial y a la insurgencia americana}

Pasemos a analizar las posiciones que con respecto a la «cuestión americana» sostuvo otro de los referentes del pensamiento liberal de la primera mitad del siglo XIX español: Álvaro Flórez Estrada. Este asturiano, destacado en el campo de la economía y el derecho, sobresalió entre sus pares por lo avanzado de sus ideas. Joaquín Varela Suanzes-Carpegna lo define como un liberal de izquierda, aquellos que en el período

suponían recursos inmensos y eficaces para contener en el deber a los que quisiesen invertir el orden y las leyes.» Ibid., p 329-330.

${ }^{682}$ Ibíd., p. 330.En números siguientes del Semanario Patriótico, se continuarían publicando noticias sobre el acontecer en América; condenándose el accionar insurgente, abogando por su castigo y festejando la represión llevada adelante por las fuerzas realistas. He aquí un ejemplo: "Las contestaciones que recibió de la nueva junta provisional, del ayuntamiento y de la audiencia de Buenos aires, convencieron al virrey y deben convencernos a todos de que fue falso el pretexto de que los facciosos se habían valido para excitar las turbulencias; falsa igualmente la moderación que hasta entonces habían afectado; y vanas las esperanzas de reducirlos con reconvenciones a la razón”. Semanario Patriótico $\mathrm{N}^{\circ}$ LXVI, 11/7/11, p. 384.

${ }^{683}$ El Manifiesto de los Persas es la denominación por la que se conoce un documento suscrito el 12 de abril de 1814, en Madrid, por 69 diputados de tendencia absolutista, encabezados por Bernardo Mozo de Rosales. El texto toma su nombre de una referencia, contenida en su primer punto, a la costumbre de los antiguos persas de tener cinco días de anarquía tras la muerte del rey. Los firmantes comparan esa anarquía con el periodo dominado por el liberalismo gaditano. Equiparan la "multitud de providencias de las Cortes de Cádiz" a la Revolución francesa, defienden la soberanía plena del Rey y piden la "celebración de unas Cortes especiales legítimamente congregadas, en libertad, y con arreglo en todo a las antiguas leyes", considerando que las de Cádiz no lo fueron. El documento sirvió de base al rey para el llamado Decreto de Valencia de 4 de mayo siguiente, que proclamó la restauración absolutista, aboliendo la Constitución y toda la legislación de las Cortes de Cádiz. 
tratado eran conocidos popularmente como liberales "exaltados" o "radicales" ${ }^{684}$ La revolución iniciada en 1808 lo encontró ocupando la plaza de Procurador General del Principado de Asturias por la recientemente formada Junta General. Desde un primer momento consideró un sinsentido la lucha contra el invasor francés si no iba acompañada de una profunda transformación política de la monarquía.

En esa línea, su acción política, sus escritos, tuvieron como denominador común un liberalismo radical en ocasiones más emparentado con el jacobinismo que con aquél más moderado que primaba en la península. De sus obras se desprende un planteo económico-social con algunos aspectos colectivistas en particular en lo referente a la propiedad de la tierra. ${ }^{685}$ En su proyecto constitucional, que remitió a la Junta Central el 1 de noviembre de 1809, el asturiano dice entre otras cosas: «todos los males de la sociedad, no tienen, ni pueden tener otro origen que la desigualdad de fortunas y condiciones» ${ }^{686}$ También se aleja del historicismo predominante de sus colegas liberales al plantear un "Congreso Nacional Soberano" como órgano legislativo de la nación, en lugar de llamarlas "Cortes", otorgándole además una forma asamblearia y cuasi federal de gobierno. ${ }^{687}$

En 1812 en el Cádiz de las Cortes y dela resistencia al invasor edita El Tribuno del Pueblo Español donde expuso sus ideas entre noviembre de ese año y abril de 1814 , cuando al igual que muchos de sus pares se exilió en Londres perseguido por la reacción absolutista. Retornaría a su país en los meses previos al período conocido como «Trienio Liberal», siendo elegido una vez más diputado a las Cortes.

Para conocer su posición sobre el problema americano abordaremos su Examen Imparcial sobre las Disensiones de la América con España, impreso primero en Londres en 1811 para luego reeditarse al año siguiente en la ciudad gaditana. El objetivo de este texto, según su autor, era aportar a la reconciliación entre españoles peninsulares y americanos. Entendía que sólo un análisis del todo imparcial podía ayudar a encaminar el conflicto a buen puerto. El trabajo está dividido en tres partes. En la primera y segunda se presentan las injusticias y faltas cometidas por peninsulares y americanos, mientras que en la tercera se exponen los defectos del sistema fiscal

\footnotetext{
${ }^{684}$ Varela Suanzes-Carpegna, Joaquín, Álvaro Flórez Estrada (1766-1853). Política, economía y sociedad, Junta General del Principado de Asturias, Oviedo, 2004, p. 15.

${ }^{685}$ Ibid., p. 16.

${ }^{686}$ Flórez Estrada, Álvaro, Obras de Álvaro Flórez Estrada, B.A.E., Tomo CXIII, Atlas, Madrid, p. 319320.

${ }^{687}$ Varela Suanzes-Carpegna, Joaquín, óp. cit., p. 28-30.
} 
colonial, causante principal, para Flórez Estrada, del decadente estado de la monarquía y de su crisis actual.

Al igual que Quintana, el asturiano partía del convencimiento de que los males del autoritarismo y la oprobiosa falta de libertades constituyeron una realidad común para españoles de ambos lados del Atlántico. Dejando constancia, desde el inicio, de que buscar separarse en circunstancias tan críticas como la invasión francesa a la península, sólo contribuiría a los planes del enemigo. ${ }^{688}$ Flórez Estrada no ahorra críticas a la conducta de la Junta Central con respecto a la forma en que resolvió la representación del Nuevo Mundo en el flamante gobierno. Entiende que la designación de sólo un diputado por cada virreinato, a diferencia de los dos que establecieron para cada provincia peninsular, era una afrenta a los americanos, dándoles de esa manera justos motivos a su descontento. Explica esta decisión de la Junta, al igual que tantas otras que no comparte, por los resabios absolutistas que aún permanecen en ella, en particular por la fuerte influencia que ejercía el conde de Floridablanca sobre este cuerpo. «La conducta, que en esta parte ofrece la historia de la Junta Central, es inconcebible, y su impolítica no puede atribuirse a otra causa que al hábito que había connaturalizado a los Españoles con los abusos,...» ${ }^{689}$ Señala que si por el contrario, la Junta Central hubiera promovido la formación de juntas locales elegidas por sus naturales, no hubiera existido espacio para el surgimiento de «ningún partido de descontentos». ${ }^{690}$

El asturiano reconoce a la Junta Central el haber declarado los territorios americanos como partes integrantes de la monarquía en igualdad de derechos con los reinos peninsulares de la monarquía, que a pesar de los innumerables ejemplos de injusticia que se pueden encontrar en cuanto a cómo fueron gobernadas las colonias, es una muestra más del mejor trato histórico que han tenido en comparación con la actuación de las otras potencias colonialistas. ${ }^{691}$ Aún más duro es a la hora de calificar la conducta del Consejo de Regencia. Si la Junta Central había pecado de incompetencia para prevenir los levantamientos americanos, demasiado anclada todavía en preceptos de un pasado que se trataba de transformar, la Regencia era responsable directa del rumbo que iban tomando los acontecimientos hacia una guerra civil y sanguinaria, con

\footnotetext{
${ }^{688}$ Flórez Estrada, Álvaro, Examen Imparcial sobre las Disensiones de la América con España, p. 8-9.

${ }^{689}$ Ibid., p. 14.

${ }^{690}$ «...un Gobierno elegido por los mismos Pueblos será siempre el menos defectuoso, el único legítimo, y el que mas confianza podrá inspirarles.», Ibíd., p. 17.

${ }^{691}$ Ibid., p. 18.
} 
la posibilidad cada vez más cierta de la independencia absoluta de las "Américas". ${ }^{692}$ Considera que el influjo de la Junta de Cádiz, compuesta en su mayoría por comerciantes monopolistas, es determinante a la hora de explicar esas posiciones de la Regencia. $^{693}$

Entrando ya en la segunda parte de la obra, Flórez Estrada pasa a centrarse en las razones y conductas de los insurgentes americanos. Como ya hemos dicho, para el autor tanto españoles como americanos habían sido víctimas de varios siglos de gobiernos despóticos, en particular bajo la privanza de Manuel Godoy. Pero esto no los facultaba a achacar estas mismas conductas al nuevo gobierno, que buscaba inaugurar una era donde la soberanía popular fuese la base de una regeneración de la nación española: "Pero alegar ahora los Americanos, para justificar su levantamiento, las injusticias de entonces, es reclamar agravios de quien no los cometió. Es barrenar el contrato, que tan solemnemente acababan de hacer, por faltas, que no habían cometido las Partes actualmente contratantes". ${ }^{694}$

Flórez Estrada impugna además la legitimidad de las juntas, tanto de la caraqueña como de la rioplatense, al entender que no contaron con el consenso necesario de la población al momento de su formación. ${ }^{695} \mathrm{El}$ hecho de que, al poco tiempo, hayan tenido que recurrir a la violencia para su sostenimiento, es una clara muestra para el autor de este defecto de origen.

Sobre la problemática de la representación, así como había criticado a la Junta Central por lo injusto de su resolución con respecto a la cantidad de diputados correspondiente a cada virreinato para el gobierno central, en lo que se refiere a la convocatoria a Cortes considera que no hay margen para el reclamo por parte de los americanos y por tanto, que la discusión sobre el derecho de indios y negros a tener representación no podía ser resuelta por ningún gobierno provisional. Por ende la

\footnotetext{
${ }^{692}$ «Si la Junta Central es culpable de no haber establecido en América Gobiernos populares elegidos por todos los habitantes con facultades superiores a los Capitanes generales y Audiencias, de cuyo despotismo provenían todas las quejas y vejaciones de aquellos Pueblos, la Regencia es criminal por haberse opuesto abiertamente a la existencia de aquellas corporaciones formadas ya por el Pueblo.», Ibíd., p. 36.

${ }^{693}$ Ibid., p. 38.

${ }^{694}$ Ibid., p. 48.

${ }^{695}$ El asturiano, como bien observa Pérez-Prendes, no ve un orden jurídico nuevo como base del levantamiento americano. Pérez-Prendes Muñoz-Arraco, José Manuel, «Álvaro Flórez Estrada y la emancipación de América», en Varela Suanzes-Carpegna, Joaquín (Coord.), Álvaro Flórez Estrada (1766-1853). Política, Economía, Sociedad, Junta General del Principado de Asturias, Oviedo, 2004, p. 294.
} 
cantidad asignada corresponde en justicia a la población de criollos y europeos en suelo americano. $^{696}$

Sin hacerlo de manera explícita, precaución que se explica por la condición de aliado en la guerra contra la Francia de Napoleón, el asturiano desliza una crítica a la actitud inglesa frente a la problemática americana:

El verdadero amigo del bien es el que solo se irrita contra el mal; es el que ataca la injusticia en donde quiera que la vea; pero, el que solo es severo para un partido, é indulgente para otro, ese obra por espíritu de parcialidad; ese aunque diga la verdad, la dice disfrazada, o solo la parte de ella, que le acomoda decir; ese aunque aparente amar vuestra libertad, ama solo nuestra separación, porque cree ver en ella su interés mal entendido. $^{697}$

Es posible que también se refiera a aquellos que como José Blanco White, a pesar de manifestar su deseo de reconciliación de ambas partes de la monarquía española, no ahorraban tinta para defender con vehemencia la postura de los insurgentes.

Al igual que Quintana, Álvaro Flórez Estrada descree de la posibilidad de los americanos de realizarse de manera independiente. Vislumbra en su futuro sangrientas guerras civiles, amenazas extranjeras, convirtiéndose en una utopía el que puedan alcanzar ese reino de libertad que tanto se proclaman en sus manifiestos revolucionarios:

Es decir la América no está en disposición de aspirar hoy a ser libre por sí. Es necesario que, si trata de serlo, lo sea incorporada a una Potencia Europea de las de primer orden. Su conservación política, su tranquilidad, y su interés así lo exigen. Sus mismas riquezas no servirán para libertarla de enemigos sino antes bien para excitarle muchos, y para inspirar tentaciones más fuertes a los que siempre las hallan en donde hay oro, y plata. ${ }^{698}$

Por el contrario, los convoca a recapacitar, a volver sobre sus pasos. Les asegura que manteniendo el lazo con la Madre Patria, los logros que allí estaban empezando a alcanzarse en materia de libertades y derechos, terminarían favoreciéndolos, ahorrándose de esa manera los traumas que implican su conquista. ${ }^{699}$

\footnotetext{
${ }^{696}$ Flórez Estrada, Álvaro, Examen Imparcial sobre las Disensiones de la América con España, p. 53.

${ }^{697}$ Ibid., p. 59.

${ }^{698}$ Ibid., p. 66.

${ }^{699}$ «La Nación iba a formar la Constitución; Representantes Americanos debían asistir al Congreso Soberano. La España no puede salvarse sin una Constitución muy libre, ó, lo que es lo mismo, muy justa.
} 
Para cerrar con el Examen Imparcial, observemos esta cita que a la vez que vuelve a recriminar a los americanos en su decisión rupturista, insiste en convocarlos a afrontar la búsqueda de la libertad de la mano de la Madre Patria:

¡En el momento en que ibais a ser Nación con nosotros; en el momento en que el Gobierno espontáneamente os había concedido ya derechos, que ninguna nación recobró jamás sin derramar mucha sangre; en el momento en que habíais ofrecido permanecer reunidos para llevar al cabo la empresa más gloriosa, que los hombres vieron; en el momento, en que todos íbamos a gozar por primera vez del privilegio de hombres libres, y a formar el Imperio más poderoso del Globo; en el momento en que para lograr todos estos grandes objetos nada más necesitábamos que trabajar de concierto; en ese mismo momento os separareis de nosotros, para que divididos, y sin fuerzas seamos todos presa de uno o de muchos tiranos! [...] Nosotros no os queremos esclavos; os queremos libres; os queremos iguales a nosotros; queremos que tengáis igual interés en ser libres y permanecer unidos, porque sabemos que los vínculos, que estrechan a los Pueblos, solo son fuertes y seguros, cuando el interés de formar una sola sociedad es igualmente recíproco a todos. No son tiranos los que os hablan, para que podáis desconfiar de sus promesas, son vuestros hermanos: son vuestros mismos compañeros de fortuna, cuyas desgracias no podéis desatender sin mancillar vuestra reputación. ${ }^{700}$

\section{La posición oficial de la mayoría liberal peninsular en las Cortes. Agustín de Argüelles y su defensa de la política metropolitana}

Agustín de Argüelles, otro de los destacados asturianos que protagonizó esta convulsionada etapa de la historia hispánica e hispanoamericana, fue ante todo un excepcional orador de las Cortes, referente del grupo liberal en las innumerables batallas emprendidas en la construcción de un régimen liberal para «las Españas». Apodado «el Divino» por sus dotes oratorias, estudió derecho en la Universidad de Oviedo, siendo en su juventud seguidor de Jovellanos y de su programa reformador ilustrado. Al igual que muchos de sus camaradas, su formación estaba marcada por el iusnaturalismo racionalista, aunque en su caso se detecta también el eco del positivismo

Había motivos muy fundados para esperar que la hiciese así, atendidos los principios, que ya se habían adoptado. Los Americanos, por la distancia del Enemigo, y por la imposibilidad en que este se halla de incomodarlos, iban a disfrutar desde luego el fruto de ella, y a verse libres de la opresión, que había impedido su prosperidad.», Ibíd., p. 67.

${ }^{700}$ Ibid., p. 60. 
de Bentham. ${ }^{701}$ Destacado en 1806 como diplomático por la Junta General del Principado de Asturias en Londres, Argüelles fue influido por el pensamiento liberal inglés, sobre todo a partir de entrar en contacto con Lord Holland -escritor, político e hispanista amigo de Jovellanos y de Quintana- y su círculo. La invasión francesa y la sublevación patriótica lo encontraron aún en Gran Bretaña, pero en 1809 retornó a su patria donde inmediatamente se alineó con aquellos que, a la vez que organizaban la resistencia al francés, buscaban acabar con el Antiguo Régimen y transformar radicalmente la sociedad española. ${ }^{702}$ En octubre de 1809 es nombrado secretario de la Junta de preparación de las Cortes Extraordinarias por la Junta Central, en la que, como hemos dicho, tuvo una destacada participación como diputado por Asturias, liderando en varias ocasiones al grupo liberal.

Analizar sus posiciones con respecto al problema americano implica por lo tanto indagar sobre el posicionamiento de todo su grupo y, de alguna manera, también en la del sector social que éste representa, la emergente burguesía comercial peninsular. Este abordaje lo realizaremos fundamentalmente a partir de algunas de sus siempre reveladoras intervenciones en las sesiones de las Cortes gaditanas, y del Examen Histórico de la Reforma Constitucional de España, escrito y publicado en Londres en 1835.

El Examen Histórico se centra en la experiencia política del asturiano en las Cortes Extraordinarias, aunque fue escrito atravesado por las vivencias del confinamiento y el destierro que sufrió el autor tras el retorno absolutista. Posee, por lo tanto, una distancia histórica nada despreciable, a diferencia de los textos de sus pares que hasta aquí venimos analizando. Veinte años después de aquellas acaloradas sesiones, Agustín de Argüelles seguía defendiendo sus posiciones políticas e incorporando reflexiones que en dicho contexto no hubiera podido manifestar a viva voz. De la obra se desprende claramente que sus posiciones en torno a la problemática americana están directamente ligadas a las discusiones que se mantuvieron en las Cortes, en su mayoría en sesiones secretas, con la representación americana. En numerosas ocasiones fue el asturiano quien salió al cruce de los planteos de los diputados de ultramar en nombre del partido liberal peninsular.

\footnotetext{
${ }^{701}$ Varela Suanzes-Carpegna, Joaquín, «La Constitución de Cádiz en su contexto español y europeo», ponencia presentada en el X Congreso Asociación de Constitucionalistas de España, UCA, 2012.

${ }^{702}$ Varela Suanzes-Carpegna, Joaquín, «La Constitución de Cádiz y el Liberalismo español del siglo XIX», $R C G \mathrm{n}^{\circ} 10$, Madrid, 1987, p. 29.
} 
Uno de los aspectos que Argüelles se esfuerza por dejar en evidencia es que las injusticias achacadas a España por los americanos como justificación del levantamiento, eran las mismas que se sufrían en la península. Eran por lo tanto facetas de la esencia del régimen absolutista que primaba en toda la monarquía y no la consecuencia de una política colonial injusta y deliberada. ${ }^{703}$ Para demostrar esto, el autor recurre al análisis histórico, método tan caro a los pensadores de su generación, afirmando que la misma conquista ya contenía los males que se habían comenzado a manifestar a partir de lo que él llama la «funesta revolución» del siglo XVI en todo el imperio español. Sin embargo considera que en América el cáncer del absolutismo fue menos dañino, siendo un ejemplo el que la Inquisición tuviera prohibida la persecución de los indios en el nuevo continente. ${ }^{704}$ Siguiendo con el análisis, Argüelles lleva adelante, como ningún otro de los liberales que hemos observado hasta ahora, una defensa del régimen colonial, que sin desconocer los errores, lo considera más benigno que el de otras potencias colonialistas. $^{705}$ Afirma que el monopolio comercial era entonces la práctica común de toda política colonial conocida, y que la prohibición que caía sobre alguno de los ramos de la agricultura en el Nuevo Mundo respondía a la búsqueda de un desarrollo más armónico de todo el Imperio. ${ }^{706}$ Argüelles define por lo tanto como injustas las acusaciones americanas y lo expone de esta manera en el siguiente pasaje:

Indicado el sistema con que España administraba sus colonias antes de la invasión de la península en 1808 resulta que las provincias de América y las de la metrópoli estaban administradas por los mismos principios. Que los males que experimentaban unas y otras procedían de un régimen común y que jamás se adoptó providencia o reforma para remediarlos, que no se extendiese al mismo tiempo a todas ellas, si se considera que su aplicación pues podía ser útil, o necesaria. Cabe que en esto se cometiesen errores; y no es posible dejar de reconocerlo; más no por eso es menos infundado y calumnioso el cargo de opresión deliberada hecho contra la metrópoli a fin de justificar la conducta de América durante la reforma constitucional. ${ }^{707}$

El gran orador liberal considera que a pesar de las muestras de patriotismo y fidelidad que llegaron desde América al momento de la invasión napoleónica, las

\footnotetext{
${ }^{703}$ «Mientras de una parte se acusa a España de haber oprimido deliberadamente a la América y se omite, o se aparenta desconocer lo que al mismo tiempo padecía la metrópoli;... », Argüelles, Agustín de, Examen Histórico de la Reforma Constitucional de España, Junta General del Principado de Asturias, Oviedo, 1999, p. 228.

${ }^{704}$ Ibid., p. 230.

${ }^{705}$ Ibid., p. 231.

${ }^{706}$ Ibid., pp. 232-233.

${ }^{707}$ Ibid., p. 237.
} 
circunstancias en las que se encontraba cada pueblo a ambos lados del Atlántico condicionaron el rumbo que tomaría cada proceso. La falta de peligro real de una ocupación extranjera fomentó en América las especulaciones oportunistas que terminarían desembocando en los movimientos insurgentes. ${ }^{708}$

Ante el temor de lo que la disolución del gobierno supremo de la metrópoli pudiera generar en América, Argüelles afirma que la Junta Central recurrió rápidamente a ofrecer una generosa participación en el congreso que se estaba convocando. Pero es llamativo que, unas líneas atrás, aclarara que la metrópoli no poseía la fuerza militar suficiente para sofocar la disidencia en las colonias, una clara muestra de la mentalidad colonialista del grupo liberal y los comerciantes gaditanos. ${ }^{709}$

Adentrémonos ahora en las reflexiones que Argüelles nos brinda sobre el problema americano en el seno de las Cortes. Fueron varias las batallas ideológicas que mantuvo con sus pares americanos, muchas veces enrolados en una misma trinchera pero también otras tantas enfrentados. Les reprocha no haber participado en el congreso como representantes de una nación, sino haberlo hecho desde un espíritu particularista. De ellos dice:

Pero en las Cortes extraordinarias había además cierto número de diputados, cuyas miras iban más allá de los límites prescritos por la sagrada obligación, y solemne promesa de sostener la unión e integridad de la monarquía en ambos mundos. En realidad los diputados de América formaban un partido separado no sólo en cuestiones y negocios que tocaban directamente a aquellas provincias, sino también en los asuntos generales, siempre que podían influir en el objeto peculiar a que aspiraban con respecto a su patria nativa. ${ }^{710}$

Los acusa de estar obstinados en proponer medios que, a su juicio y al de la metrópoli, no sólo «aceleraban la separación de todo aquel continente, sino que forzosamente la habían de hacer más violenta y dolorosa.» ${ }^{711}$ Considera que, con el

\footnotetext{
${ }^{708}$ Ibid., p. 240.

${ }^{709}$ «El único medio de evitar que la distancia y el estado de la península indujesen, a los espíritus ardientes y atrevidos en las colonias, a suscitar quejas, a promover reclamaciones peligrosas, era prevenirlas oportunamente, ofreciendo con generosidad lo que se había de pedir con resolución, y tal vez con amenazas. En la metrópoli se había considerado urgente el reunir al gran consejo de la nación, para fortalecer la unión y concordia de los ánimos, y dar al espíritu público el impulso y dirección que convenía a tan arrojada empresa.

Llamar a Córtes generales de todos los reinos y provincias, y no convocar a la América, hubiera provocado el descontento, y acarreado al fin una revolución en toda ella.», Ibid., p. 241.

${ }^{710}$ Ibid., t. II, p. 22.

${ }^{711}$ Ibíd., p. 30. Más adelante también afirma: «Verdad es que no se proponían explícitamente la independencia de América; pero se amenazaba con ella a cada paso, si no se concedía lo que se pedía en su nombre.» p. 39.
} 
decreto del 15 de octubre de 1810, las Cortes habían enmendándolos errores cometidos por las administraciones anteriores, que redimían a la metrópoli de los males que había provocado a las colonias y que respondían generosamente a los reclamos americanos. Pero la diputación americana, y sobre todo las provincias rebeldes, no lo consideraban así. Entendían que la igualdad de representación debía consumarse inmediatamente y no esperar a posteriori de aprobada la Constitución. ${ }^{712}$ Para Argüelles, los diputados americanos parecían decididos a «destruir el equilibrio e influencia de la metrópoli con una aplicación estricta y poco meditada del principio abstracto de igualdad a la representación de la América en las Cortes.» ${ }^{713} \mathrm{La}$ discusión pasaba por si debían considerarse a las castas -indios, mestizos y negros- a la hora de otorgar un número de representantes para el Nuevo Mundo, aspecto que de concretarse igualaría la proporción de ambas partes del Imperio español. La diputación peninsular, tanto liberales -aunque con algunas excepciones- ${ }^{714}$ como serviles, se oponían de plano a este reclamo, justificando su negativa en razón de que era necesario un riguroso estudio y una prolongada discusión que arrojara datos más precisos sobre la composición étnica y social de la población y demás información práctica para poder definir con fidelidad la representación. ${ }^{715}$ Los diputados peninsulares consideraban que esto no podía resolverse de la noche a la mañana; rechazaban además que este tema postergara las discusiones sobre la nueva Constitución para la nación española. ${ }^{716} \mathrm{El}$ verdadero temor para los metropolitanos residía en que si los americanos conseguían dicha representación podrían alcanzar así las reformas que venían reclamando, y que fundamentalmente, despojarían a la península del usufructo económico de los territorios de ultramar.

\footnotetext{
${ }^{712} \mathrm{Ni}$ bien comenzado el debate sobre cuándo debía efectivizarse la igualdad de representación entre ambas partes del imperio hispánico, Argüelles plantea: «habiendo declarado V.M. que las Américas eran partes integrantes de la monarquía, es preciso que gocen de absoluta igualdad de derechos. Esto es lo que va a formar una de las bases de la Constitución. Pero ahora la mayor dificultad estaría en la aplicación de estos principios a los casos particulares del momento.» Diario de Sesiones de la Cámara, Sesión 9 de febrero, Cádiz, 1812, t. III, pp. 316-317.

${ }^{713}$ Argüelles, Agustín de, óp. cit., t. II, p. 27.

${ }^{714}$ El diputado por Galicia y eminente liberal José Alonso y López, ante las profundas desavenencias que el tema de la representación estaba generando propuso como alternativa para zanjar las discusiones que las Cortes definieran por ley un número fijo y equivalente de diputados para ambas orillas del Atlántico. Argüelles no obstante sería quien como tantas veces responda en nombre de la Comisión de Constitución en la sesión del 20 de Septiembre, y como era de esperarse, sin dejar de valorar las buenas intenciones del diputado gallego, exponía que su propuesta «pugnaba con el sistema adoptado para la representación nacional. » DSC, óp. cit., p. 1887.

715 Rieu-Millán, Marie-Laure, Los diputados americanos en las Cortes de Cádiz: Igualdad o independencia, CSIC, Madrid, 1990, p. 275.

${ }^{716}$ Cuando la cuestión fue sometida a votación, desembocó en una frustración para los americanos. En una de las oportunidades la propuesta de mantener el criterio de representación resultó ganadora por 64 votos contra 56 , aunque más de veinte diputados peninsulares votaron a favor de los americanos.
} 
Argüelles sostenía que, más allá del número de la representación, era innegable la libertad para proponer y deliberar que tenían los representantes americanos, y eso a su entender era lo fundamental. Pero a la par esperaba de ellos muestras de sumisión y respeto filial hacia la Madre Patria, revelando una vez más un pensamiento que hacía foco en la subordinación como relación entre ambos mundos. ${ }^{717}$ Esa concepción queda claramente manifiesta en las discusiones en Cortes con respecto a la organización del Poder Ejecutivo, donde la mayoría liberal peninsular, incluido el asturiano, consideraban que los asuntos americanos debían dirigirse desde y por la Península. Como muestra podemos referenciar la oposición de éste a la posibilidad de descentralización del Ministerio de Guerra y Marina. ${ }^{718}$

Al igual que con el punto de la representación, sostiene que la discusión sobre el sistema comercial debió haberse trabajado de forma detenida, buscando de esa manera conciliar los intereses de ambos hemisferios. Entiende que la libertad de comercio exigida por los americanos implicaba un trastorno total del sistema económico y administrativo del imperio, la misma posición que sostenía el Consulado gaditano, institución representativa del gremio de comerciantes monopolistas peninsulares.

Para el autor de El Examen Histórico, la búsqueda de la conciliación con América fue lo que dominó en las Cortes extraordinarias. Argüelles se lamenta de que los americanos hayan vuelto deliberadamente la espalda a ese compromiso:

Tal fue el espíritu conciliador que animó invariablemente a las Cortes extraordinarias respecto a la América; y este congreso venerable fue tan escrupuloso en guardar fe, que, ni la oposición de personas y cuerpos poderosos, ni la misma ingratitud con que correspondieron las provincias disidentes, despreciando sus decretos, y ultrajando su autoridad, fueron parte para que faltase a sus promesas, ni a lo ofrecido anteriormente por los gobiernos que administraron el reino desde la insurrección en 1809 . $^{719}$

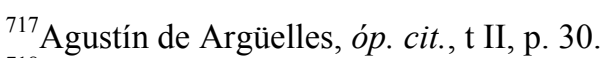

${ }^{718}$ «El sistema es uno mismo en Europa y en América. Ni el clima, ni la calidad, ni las producciones de los países influyen en la disciplina y la subordinación del soldado, ni en la parte científica de la guerra. Levantar tropas en Ultramar o enviarlas a la Península, fortificar plazas y puntos militares, y todo lo demás que exija la defensa de aquellas provincias, se ha de resolver en Europa...y con arreglo a los sucesos de Europa y las Naciones limítrofes a nuestras provincias fuera de la Península. » DSC, óp. cit., pp. 2235-2236.

${ }^{719}$ Argüelles, Agustín de, óp. cit., t. II, p. 45.
} 


\section{Un “amigo" al otro lado del Atlántico. La voz disonante de José Blanco White y sus posturas pro-americanas}

Otra de las grandes figuras del primer liberalismo español, al que ya hemos hecho varias referencias en esta tesis, es el controvertido periodista y escritor sevillano José María Blanco White. A pesar de haber emitido opiniones y sentado posicionamientos sobre un gran abanico de temas en estos convulsionados años, serían sus consideraciones sobre la «cuestión americana» las que causasen mayor polémica, diferenciándose claramente de la mayoría de sus pares liberales peninsulares.

En 1805 viajó a Madrid donde entró en contacto con el «círculo quintaneano» frecuentando la tertulia del poeta. Las relaciones que entabló en esa época lo llevan, una vez estallada la guerra de independencia, a formar parte del grupo de intelectuales que, de manera decidida, buscaban imprimirle al proceso un claro rumbo de transformaciones liberales. ${ }^{720}$ Ya de regreso en Sevilla, cuando el traslado del gobierno central, ocupó su primer lugar de relevancia política al quedar encargado, junto a Isidoro de Antillón, de la redacción del Semanario Patriótico en su segunda época. Ese período se caracteriza por la radicalización de las ideas contenidas en dicha publicación, lo que al cabo de un tiempo empezó a preocupar a la Junta Central, la cual a pesar de tener a Manuel Quintana como secretario, estaba dirigida mayoritariamente por un sector más moderado, que negocia constantemente con la reacción conservadora. Finalmente, y cuidando las formas, la Junta Central decidió arremeter contra el Semanario Patriótico censurando su contenido político, lo que llevó a Blanco White y a Antillón a resolver el cierre de su publicación, pero no sin antes acompañar su último número con una nota donde se daba a entender sutilmente la censura llevada adelante por el gobierno central. ${ }^{721}$ La enemistad con la Junta, más las diferencias que empezaron a surgir con algunos de sus pares liberales, llevaron a Blanco White a decidir trasladarse a Londres para desde allí ejercer su actividad periodística y propagandística sin trabas gubernamentales. Ya en la capital británica y bajo la protección de Lord Holland, publicó El Español, periódico de tirada mensual donde se abordaba el derrotero de la guerra de independencia española. Pero fue la «cuestión americana» la que iría ganando cada vez mayor lugar en el periódico y la que lo llevaría a distanciarse definitivamente

\footnotetext{
${ }^{720}$ Moreno Alonso, Manuel, Divina Libertad. La aventura liberal de Don José María Blanco White, 1808-1824., Ed. Alfar, Sevilla, 2002, p. 17.

${ }^{721}$ Semanario Patriótico $N^{\circ}$ XXXII, 31/8/09,Aviso al público, “Cedamos pues a las circunstancias: nuestros amigos sufrirán mejor que se interrumpa otra vez el Semanario que verlo mudado en otra cosa que lo que hasta ahora ha sido»
} 
de la mayoría de sus pares peninsulares. Apenas unos pocos números editados, llegaron a Europa las noticias de la revolución de Caracas de abril de 1810, a la que el andaluz saludó con entusiasmo, inaugurando una abierta posición a favor de la causa americana y sus reivindicaciones:

Parece que ha llegado la época de un grande acontecimiento político, que se ha estado esperando por largo tiempo: el estandarte de la independencia se ha empezado a levantar en América, y según podemos calcular, por lo que hemos visto acerca de la revolución de Caracas, no es un movimiento tumultuario, y pasajero el de aquellos pueblos; sino una determinación tomada con madurez, y conocimiento, y puesta en práctica bajo los mejores auspicios, la moderación y la beneficencia. ${ }^{722}$

En este número, además de reproducir la proclama caraqueña, el autor reflexiona sobre el sistema colonial vigente en América, donde critica fundamentalmente el monopolio comercial al que el Nuevo Mundo es sometido, a la vez que propone una alternativa confederada para la monarquía, con gobiernos residentes en las provincias americanas. ${ }^{723}$ La reivindicación del comercio libre es otro de los puntales argumentativos del autor, entendiéndolo como fundamental para la prosperidad americana así como para evitar el rompimiento de los lazos con la metrópoli. Sobre este tema escribe: «...si no quieren que se excite universalmente en los americanos el espíritu de independencia y aun de odio respecto de la metrópolis, quiten las trabas a su comercio.... $^{724}$

En el número V de El Español -30 de agosto de 1810- plantea entre otras cosas que los gobiernos metropolitanos no deben avanzar en temas ajenos a la guerra contra el francés, principalmente aquellos relacionados con América, hasta que ésta esté debidamente representada. ${ }^{725}$

\footnotetext{
${ }^{722}$ «La proclama de Venezuela respira amor a los españoles: éste es inextinguible en los americanos. Las Américas libres del yugo en que se las ha querido y quieren tener tan imprudentemente todavía, serán infinitamente más poderosas para mandar socorros a España...» El Español $N^{\circ} I I I, 1 / 7 / 10$, p. 315-316

${ }^{723}$ Ibid., p. 282.

${ }^{724}$ Ibid., p. 319.

${ }^{725}$ «Quantos reconocen a Fernando $7^{\circ}$ por soberano en las quatro partes del mundo, deben ser llamados por igual al congreso augusto que se convoca en su nombre. La parcialidad ácia unos ú otros en el número de representantes que se les señale destruiria toda la union y espíritu de patria que se apetece. Las provincias ultramarinas deben enviar los que les correspondan segun su poblacion, comparada con la de España. Entre tanto que esta reunion pudiera verificarse, las córtes de la península solo deberian tomar una medida respecto de la América: una sola, y generosa: Renunciar a toda pretension de superioridad sobre aquellos payses, y convidarles a que (los que no lo hayan hecho) nombren sus gobiernos interiores y économicos, y enseguida embien sus diputados al congreso de ambos mundos.» El Español $N^{\circ} V$, p. 376
} 
Para contrarrestar a quienes en la península denuncian la intención separatista que poseen los levantamientos en América, Blanco White explica lo que a su entender es el verdadero espíritu de éstos:

Independencia, reunida a la obediencia de los legítimos monarcas de España no puede jamás expresar separación de aquellos dominios. Independencia, entendida de este modo, es una medida de gobierno interior que todos los pueblos de España han tomado según les han dictado las circunstancias, y que no puede convertirse en delito porque la tomen los americanos. ${ }^{726}$

Nuevamente podemos percibir la complejidad del sentido que la voz independencia poseía en la época, y la necesidad recurrente de los protagonistas de tener que precisar su significado. Es interesante el punto de contacto que entre esta cita y el alegato de Castelli en el juicio a Paroissien, donde el abogado también debió aclarar que el uso del vocablo independencia por parte de Rodríguez Peña no podía ser considerado un delito, porque no implicaba la ruptura con la monarquía, y que estaba siendo utilizado en similar sentido al de los pueblos españoles.

También en este mismo número, les pide a los americanos que como gesto para alcanzar la conciliación -por la que desde El Español tanto se abogaba-, no continuasen manifestando dudas sobre la legitimidad del gobierno metropolitano, y que en el corto plazo socorrieran económicamente a la península en su guerra contra el ejército napoleónico. $^{727}$

Ya a esta altura eran muy fuertes las críticas que desde Cádiz lo tenían como blanco. Por ello, en la edición de septiembre del mismo año, el redactor se defiende. Niega haber promovido en ningún momento la ruptura de América con España, ${ }^{728}$ y ante la acusación de encontrase al servicio del gobierno británico, Blanco White dice: "Que habiendo entendido que algunos me creen escritor de este gobierno, protesto que nada me creo ligado a seguir sus opiniones y que, no obstante que las respeto, como debo, he escrito varias veces creyendo no ir conforme a ellas, y que he precedido así

\footnotetext{
${ }^{726}$ Ibid., p. 374.

${ }^{727}$ Ibid., p. 399-400.

${ }^{728} «$... jamás ha sido mi intención aconsejar a aquellos pueblos que se separen de la corona de España. Es menester ser ciego para no ver lo contrario en cuanto he dicho. Pero protesto que aborrezco la opresión, con que se quiere confundir la unión, de los Americanos, y que clamaré contra ella cuanto alcancen mis fuerzas, porque concibo que la falta de liberalidad con que se les ha tratado, y con que se insiste en tratarlos, es lo que más puede romper sus lazos con España.» El Español $N^{\circ} V I, 30 / 9 / 10$, p. 490.
} 
seguro de la liberalidad con que oye las de todo hombre, cuando habla según prescriben las leyes."729

En contestación a la carta enviada por un lector, el sevillano desarrolla lo que él considera son las legítimas razones del levantamiento americano:

La regencia no tiene más poder que el que ha recibido del pueblo español; o en otros términos, la regencia no representa a Fernando $7^{\circ}$ sino en lo que el pueblo español ha podido conferirle: el pueblo español no es soberano de América; luego la regencia no lo es tampoco, a no ser que aquellos países la quieran reconocer como a la junta central. Este raciocinio tiene tanta fuerza sobre mi entendimiento, que como todo el que se halla poseído de lo que le parece demostración, no puedo oír llamar rebeldes a los americanos, sin que se aumente más y más mi ardor por defenderlos. ${ }^{730}$

Hasta este momento Blanco White ha apoyado abiertamente a la insurgencia americana, admirado de la moderación con la que están llevando adelante su causa. Pero el fusilamiento de Liniers ordenado por la Junta de Buenos Aires, y la radicalización que empezaba a tomar el conflicto en los territorios sublevados, despertaron en el sevillano los primeros cuestionamientos. El olor a pólvora que fueron adquiriendo los acontecimientos preocupaban gravemente al editor, que no dudaría en exigir a la península gestos de grandeza para procurar evitar los terribles males que para ambas partes conllevaría una guerra civil. ${ }^{731}$ En mayo de 1811 , Blanco White volvía a la carga contra el gobierno metropolitano responsabilizándolo de la agudización del enfrentamiento entre la península y las provincias rebeldes. Y aun a sabiendas de que sus planteos no eran tomados en cuenta en Cádiz, propone:

Las condiciones de la medida que debe adoptarse son estas: 1a. Que haga cesar sin dilación la guerra civil que está devastando la América y deteniendo los socorros que necesita la España; 2a. Que inspire confianza a los Americanos para proceder a una composición en que ellos tienen poco interés y la España mucho, o todo. 3a. Que España esté dispuesta a ceder de lo que llama sus derechos, todo lo que no oponga directamente a la unidad de la Monarquía Española. ${ }^{732}$

La declaración de independencia venezolana significó un punto de inflexión en la consideración que el sevillano tiene del proceso americano. Se había deshecho en

\footnotetext{
${ }^{729}$ Ibid., p.490

${ }^{730}$ El Español $N^{\circ}$ VII, 30/10/10, p. 59-60.

${ }^{731}$ El Español $\mathrm{N}^{\circ} \mathrm{IX}, 30 / 12 / 10$, p. 252.

${ }^{732}$ El Español $N^{\circ} X I V, 30 / 10 / 10, p .144-145$.
} 
elogios para con la moderación de la Junta de Caracas y en general del conjunto de la insurgencia americana; por ende esta decisión le provocó un gran desaliento, confirmando desgraciadamente sus peores temores. Desde su periódico, la califica de caprichosa, imprudente y sobre todo innecesaria, desprovista de toda ventaja y portadora sí de muchos males. ${ }^{733}$ Considera que esta declaración terminaría desuniendo a los pueblos americanos, como ya sugería la correspondencia entre Santa Fe de Bogotá y Caracas. Prestemos atención al siguiente párrafo:

Todo indica que los actuales procedimientos de Caracas son efectos de una facción que repentinamente se ha hecho poderosa. La agitación que respiran sus declaraciones; la precipitación con que han dado este paso que ni aun tiempo habían tenido de redactar el Manifiesto; todo prueba que no estaba preparado, y que se ha hecho a manera de revolución, en que se va siempre a aprovechar un momento. ¿Quién ha puesto a esta facción en mando? Cortavarria, con su bloqueo: los Europeos de Coro con su invasión. Cuando los Jacobinos de Francia no tenían conspiraciones con que irritar al pueblo, las fingían: a los Jacobinos de América se les ha dado el trabajo hecho. ${ }^{734}$

Como vemos, el redactor de El Español ya no cree que el pueblo caraqueño siga siendo protagonista de la revolución, sino por el contrario una facción a la cual califica como un puñado de ambiciosos que, beneficiados por la intransigencia de la metrópoli, pudieron hacerse con el poder y materializar así sus planes independentistas.

$\mathrm{Su}$ estadía en Gran Bretaña ha trasformado al otrora radical militante liberal. La moderación y el sesgo aristocrático, tan característicos del liberalismo inglés, han hecho mella en Blanco White, como podemos observar en sus reclamos de contención a cualquier alteración del orden social americano. ${ }^{735}$

El disgusto que le provocaba el rumbo que van tomando los territorios rebeldes se refleja en el escaso espacio que empezaba a tener el problema americano en El Español. Sin embargo, en mayo de 1812, Blanco White vuelve a la carga con el tema a través de las llamadas "Conversaciones americanas sobre España y sus Indias", texto donde se representa el diálogo entre un grupo de personajes en un pequeño pueblo del Nuevo

\footnotetext{
733 «Caracas ha legitimado ahora esta guerra según las leyes del derecho de gentes, y su gobierno no puede quexarse de que lo llamen rebelde entre tanto que no gane el título de Soberano, con las armas.»El Español $N^{\circ} X I X, 30 / 10 / 11, \mathrm{p} 46$.

${ }^{734}$ Ibid., p. 53-54.

${ }^{735}$ En la biografía quizásmás completa dedicada a Blanco White, André Pons subraya la profunda mutación política sufrida por el sevillano a partir de su llegada a tierras de la vieja Albión. Aquel "jacobino" militante liberal va a dejar paso, según el autor, a un conservador al estilo de Montesquieu o de Jovellanos, «o incluso un contrarrevolucionario en la línea de Burke.» Pons, André, Blanco White y España, Instituto Feijoo de Estudios del Siglo XVIII de la Universidad de Oviedo, Oviedo, 2002, p. 409.
} 
Mundo, que debate sobre la realidad europea y americana. Aprovecha el sevillano para poner en voz de cada uno los principales tópicos del conflicto, y fundamentalmente a través del personaje del «viejo cura», su visión personal. Ante la intensidad del pensamiento del sobrino, encarnación de los líderes insurgentes, el párroco aboga por la moderación y el reformismo para resolver las graves enfermedades del nuevo continente: "Los males de nuestra América claman al cielo por remedio; pero si ha de ser pronto y efectivo el Cielo nos lo ha de conceder sin revolución completa. El mejor lazo que nos puede unir mientras aprenden estos pueblos a ser libres, es la España." ${ }^{736}$

El periodista exiliado estaba convencido de que tanto las Cortes como la Regencia se hallaban bajo el influjo del gremio de comerciantes ligados al tráfico con América, que constituían el sector más reacio a cualquier concesión hacia los reclamos americanos, en particular aquellos relacionados con la liberalización del comercio. Sin vuelta atrás era ya la relación que tenía a mediados de 1812 con el partido de gobierno metropolitano; El Español fue prohibido no sólo en Cádiz, sino también en la otra orilla, en la aún leal Nueva España. ${ }^{737}$ Blanco White no les perdonaba además a sus pares liberales, haber imposibilitado que Inglaterra actuase como mediadora, una de las pocas alternativas que consideraba aún viables como solución del conflicto. ${ }^{738}$

Pero al igual que Manuel Quintana, referente de aquellos liberales peninsulares con los que discute, está convencido de que la América española no se encuentra preparada para afrontar un camino de total independencia. Descree que esas sociedades estén lo suficientemente maduras para desplegarse exitosamente en el concierto de las naciones. Necesitan, por lo menos hasta que alcancen esa madurez, de la tutela de un poder externo, que garantice la unión y evite los errores de una clase dirigente criolla tan inexperta.

\section{Consideraciones finales}

Hasta aquí las posiciones analizadas en particular de cada uno de estos referentes del liberalismo peninsular. Una de las primeras cuestiones que entendemos se desprenden del análisis de sus discursos es que la «cuestión americana» tuvo un notable

\footnotetext{
${ }^{736}$ El Español $N^{\circ} X X V, 30 / 5 / 12$, p. 27.

${ }^{737}$ Pons resalta que El Español era «el único en mantener ideas que ponían en cuestión intereses muy poderosos, el único en tener una considerable audiencia en el Nuevo Mundo y el único que gozaba de un prestigio excepcional entre los diputados americanos...» Pons, André, Blanco White y América, Instituto Feijoo de Estudios del Siglo XVIII de la Universidad de Oviedo, Oviedo, 2006, p. 265.

${ }^{738}$ El Español $N^{\circ}$ XXVIII, 30/8/12, p. 277.
} 
peso en los debates que la elite dirigente peninsular tenía en aquellos años bisagra de la historia española.

Los autores trabajados, a pesar de compartir ciertas premisas, no siempre construyeron un mismo diagnóstico de la situación ni llegaron a las mismas conclusiones. Con respecto a la caracterización que hacían del sistema colonial, podemos afirmar que tanto Manuel Quintana como Álvaro Flórez Estrada coincidían en denunciar las injusticias vividas en el Nuevo Mundo, pero no las desvinculaban de la situación similar que, bajo el absolutismo, se sufría en la península. Por su parte Agustín de Argüelles también ponía énfasis en este razonamiento, pero su mirada sobre la situación de las colonias era mucho más benigna. Reducía las injusticias de la política colonial denunciadas por los americanos a meros errores de la administración y vicios de las autoridades virreinales. Por el contrario, José Blanco White desplegó, desde El Español, un juicio muy crítico de los trescientos años de colonialismo, en consonancia con lo denunciado por los insurgentes americanos. Al igual que Flórez Estrada, centraba su crítica en el sistema monopólico comercial, siendo para ambos la piedra angular del problema. Los dos se manifestaron abiertamente por su eliminación, entendiéndolo como un paso fundamental para la resolución del conflicto. Argüelles, en cambio, consideraba que no era conveniente introducir ninguna modificación radical en este punto, en razón de los trastornos que esto pudiera ocasionar a la economía hispánica. Podemos conjeturar que esta posición, que es la mayoritaria dentro del cuerpo de diputados de tendencia liberal en las Cortes, respondía a los intereses del gremio mercantil gaditano, como hemos dicho con fuerte presencia y capacidad de presión en los distintos gobiernos sucedidos en la metrópoli. Tratando de no caer en una reducción economicista, que la mayor parte de los diputados liberales provinieran de familias relacionadas al comercio ultramarino no significa un aspecto menor para entender los porqués de la intransigencia de este sector a la hora de ceder ante las exigencias americanas. Tanto Blanco White como Flórez Estrada, en la misma línea de Moreno en la Representación de los hacendados, adjudicaban a estos intereses económicos el trasfondo de la política metropolitana que para ellos no tenía otro resultado que precipitar la separación del mundo hispánico. Ambos cargarían en numerosas ocasiones contra la Junta Central y la Regencia por sus resoluciones con respecto a América, críticas que el sevillano trasladaría también a las Cortes extraordinarias.

Pasemos ahora a comparar la percepción que estos liberales tenían sobre la insurgencia americana. Tanto el madrileño como los asturianos consideraban que, detrás 
de las "lealistas" proclamas de los revolucionarios, se escondía una decidida intención separatista. Actitud que no podían perdonar, más aún cuando la metrópoli se encontraba ante la penosa situación de la ocupación extranjera. Blanco White, en cambio, no se cansaba de insistir en que los levantamientos americanos respondían a los mismos factores que habían llevado a las provincias peninsulares a la formación de sus juntas y que lejos estaban de plantearse una ruptura definitiva con la metrópoli. Quintana, como así también Flórez Estrada, le reprocharon a las provincias disidentes el hecho de levantarse esgrimiendo banderas de libertad cuando, a su entender, la revolución española que se estaba llevando adelante, y de la que ellos eran grandes protagonistas, terminaría beneficiando también a esos territorios, ahorrándoles los traumas y peligros del camino autónomo que estaban eligiendo.

En lo que van a coincidir los cuatro letrados es en considerar a los americanos como poco maduros política y socialmente para una vida independiente. Quintana y Flórez Estrada, como hemos visto, pronosticaban en el corto plazo, para el continente americano, graves tensiones sociales que desembocarían inevitablemente en guerras civiles, además del peligro de ser víctima de la codicia de las potencias extranjeras debido a las cuantiosas riquezas de esos territorios. Blanco White, a pesar de apoyar las reivindicaciones americanas, no dejó nunca de aconsejar mantenerse bajo la tutela española. Eso sí, bajo otro tipo de relación hacia el interior de la monarquía. Estos pensamientos demuestran la subestimación que en general mantenía el liberalismo peninsular sobre los habitantes del Nuevo Mundo, en particular hacia sus pares americanos, la intelectualidad criolla. No confiaban para nada en la capacidad de las élites americanas de convertirse en artífices de regímenes estables y perdurables.

En el periódico El Observador de septiembre de 1810 se decía tener certezas de los objetivos independentistas de las juntas americanas. Para el autor del artículo la fundamentación neoescolástica del "pacto traslati" de las juntas americanas era sólo una artimaña táctica. ${ }^{739}$ En general, existió un pésimo diagnóstico por parte del liberalismo peninsular sobre los sucesos en América. Las insurrecciones que se fueron encadenando no eran en principio para ellos otra cosa que meras conspiraciones de pequeños sectores de la élite, descontentos y ávidos de poder personal. ${ }^{740}$ Pero es necesario hacer una

\footnotetext{
${ }^{739}$ El Observador núm. 10, 7/9/10, pp. 159-160.

${ }^{740}$ Roberto Blanco Valdés, en su análisis del papel de las Cortes ante el «problema americano», sugiere la idea de una «teoría de la conspiración», esgrimida por parte de los diputados peninsulares como línea argumentativa para caracterizar los sucesos de ultramar, que resultaba claramente bloqueadora para un análisis de lo que acontecía realmente. Blanco Valdés, Roberto, «El "problema americano" en las
} 
doble lectura de estas afirmaciones, ya que pueden haber sido hechas sólo con el objetivo de desprestigiar a la insurgencia americana, mientras posiblemente se conocía con mayor fidelidad el alcance real de estos movimientos.

A excepción de Blanco White que, como hemos visto, manifestó en numerosas ocasiones su afinidad con la opción confederal para la monarquía española, la mayoría de los liberales peninsulares eran fuertemente reacios a esa idea. Como bien dice Manuel Chust, éstos identificaban el federalismo con el republicanismo, con toda la «carga francesa» que poseía ese sistema. Pero el liberalismo español nace también con una fuerte pretensión centralizadora, más aún cuando su enemigo ideológico se escudaba en el foralismo para defender sus privilegios feudales. ${ }^{741}$

La discusión sobre la representación y la calidad de ésta no era meramente una cuestión abstracta. Más allá de que podamos afirmar que gran parte del liberalismo peninsular tenía un claro convencimiento ideológico -según el cual la representación debía ser expresión de ciudadanos libres, que de forma conjunta componían una nación, sujeto real de la soberanía-, el corporativismo territorial que atribuían a los americanos tenía una explicación bien concreta en las relaciones históricas hacia el interior de la monarquía. Las prácticas colonialistas que se manifestaban en todos los campos administrativo, económico, social, etc.- volvían una quimera la concepción jacobina de representación nacional que poseían los liberales peninsulares. Si no se eliminaban aquellas prácticas, era imposible pensar en la igualdad política, jurídica y económica necesaria para poder materializar una verdadera representación nacional para el conjunto del mundo hispánico.

Para concluir con este capítulo, consideramos que el problema americano significó el aspecto de mayor contradicción teórica e ideológica para el naciente liberalismo peninsular. El radicalismo con que éste buscaba transformar la sociedad española no era transferible a América, salvo en el plano de lo simbólico. Los innovadores peninsulares no estaban dispuestos a extender los cambios que en materia de libertades se estaban alcanzando a las posesiones ultramarinas, a riesgo de perder los privilegios históricos gracias a los cuales había hecho usufructo de ellas la metrópoli

primeras Cortes liberales españolas, 1810-1814», Cuadernos Constitucionales México-Centroamérica16, Instituto de Investigaciones Jurídicas, México, 1995, p. 76.

${ }^{741}$ Algunos diputados conservadores, representantes de los viejos reinos peninsulares, buscaron en las Cortes poner nuevamente en discusión los antiguos fueros, debilitados durante la centralización borbónica y amenazados profundamente por la política centralista liberal. En su estrategia, llegaron al punto de apoyar los reclamos americanos identificándolos inteligentemente con los fueros provinciales. Chust Calero, Manuel, La cuestión nacional americana..., p. 57-58. 
imperial. Fuertes intereses económicos del grupo social del cual muchos de ellos provenían o al cual estaban ligados por redes familiares o profesionales estaban en juego, sin descartar el marco de mentalidad colonialista -que por ilustrada y filantrópica no lo era menos-, en el que estaba sumergida aún aquella generación.

No debemos partir desde conceptualizaciones cerradas a la hora de caracterizar a los hombres y las ideas de este período de la historia hispánica. La naturaleza «transicional» del mismo explica las ambigüedades ideológicas y doctrinarias de sus protagonistas, anclados aún en preceptos del pasado que se estaba dejando atrás. El liberalismo carecía, como es de esperar, de una entidad sólida, coherente y homogénea. En síntesis, estas ambigüedades teóricas resultantes de un liberalismo aún en gestación, interactuando con los condicionantes ejercidos por los intereses económicos de las elites comprometidos en el proceso, son el marco desde donde creemos poder explicar las contradicciones en las que cayó sistemáticamente el primer liberalismo peninsular en relación a la «cuestión americana», y seguramente una de las razones de su fracaso en lograr preservar la integridad de la monarquía hispánica. 


\section{Capítulo 11:}

\section{Los escabrosos caminos para llegar a una Asamblea Constituyente en ambas orillas del Atlántico}

\section{Los debates en torno al llamado a Cortes del Reino}

Aunque en 1808 en la Península era casi unánime la demanda de una convocatoria a las Cortes, la realidad indica que éstas no eran entendidas de la misma manera por los distintos sectores que pugnaban en el marco de la crisis monárquica. Los absolutistas pensaban en aquella institución estructurada por los Austrias, a la que los Borbones habían mantenido en el olvido, unas Cortes estamentales y limitadas únicamente a elegir una nueva regencia. En cambio los liberales propugnaban obtener unas nuevas Cortes racionalmente organizadas y con la misión fundamental de promulgar una constitución y llevar adelante un proceso de transformaciones profundas que sepultaran el Antiguo Régimen. Gaspar Melchor de Jovellanos, principal referente del sector moderado y hombre fuerte de la Junta Central, a pesar de ver en la coyuntura la posibilidad que se plasmaran las reformas ilustradas por las que venía batallando toda su vida, en numerosas circunstancias se posicionó en la vereda de enfrente del liberalismo, defendiendo el carácter estamental y tradicional de las cortes e impugnando la necesidad de una nueva constitución para la monarquía.

Mediante el Real Decreto del 22 de mayo de 1809, la Junta Central presidida por el Marqués de Astorga, ordenó la celebración de Cortes Extraordinarias y Constituyentes para el 1 de marzo de 1810. En junio de 1809 se conformó la Comisión de Cortes, mediante un decreto complementario, formada por 5 vocales de la Junta y presidida por Jovellanos, para que preparara el procedimiento para convocar la asamblea. Como primera medida se convocó a la llamada "Consulta al país", donde se pidieron informes y proyectos de reforma a distintas instituciones y personalidades del reino, en relación a la futura labor de las Cortes. Consistía en un cuestionario con cuatro preguntas claves, pero finalmente muchas de las respuestas terminarían siendo proyectos constitucionales. La llegada de informes a partir de julio superó ampliamente la capacidad de procesarlos de la Junta Central. ${ }^{742}$

El 27 de junio de 1809, la comisión propuso, y la Junta Central aceptó, que las Cortes se formasen por los tres brazos: eclesiástico, nobiliario y popular, es decir de

$\overline{{ }^{742} \mathrm{Al} \text { respecto Artola, Miguel. óp. cit. }}$ 
forma estamental y tradicional. La comisión también decidió que las ciudades que tradicionalmente tenían voto en Cortes y las Juntas de Defensa tuvieran un diputado para cada ente. Más tarde, la comisión debatió cual sería el modo de deliberación en las sesiones, y si las Cortes serían bicamerales o se regirían por el sistema francés de parlamento único. Jovellanos, como presidente de la comisión recibió con reservas la propuesta de John Allen, uno de sus consejeros ingleses en Sevilla, para que propusiese la convocatoria de Cortes en dos cámaras al estilo inglés, una para el común y otra para la nobleza, pero al final decidió proponerlo como forma de reunión en nombre de la Comisión de Cortes.

La Junta Valenciana, como ya vimos, se opuso a la convocatoria, cuestionando su legitimidad en una exposición al resto de las juntas provinciales el 5 de agosto de 1809 . Su principal disidencia era el control que se atribuía la Junta Central en dicho proceso. Planteaba, además, que hasta que la nación no estuviera libre de enemigos no podía convocarse a Cortes porque no todas las provincias españolas podían elegir libremente a sus diputados. Como respuesta a aquello, y en un contexto de fuerte enfrentamiento con la Junta valenciana, la Central avanzó con el "Manifiesto de la Nación" del 28 de octubre, redactado por Manuel Quintana, criticando los planteos federalistas y anunciando la inminente reunión de la asamblea.

Un mes antes, se había creado la Junta de Legislación el 27 de septiembre de 1809 para ayudar a concretar la convocatoria. La influencia del liberal asturiano Agustín Argüelles en ella derivó en que la Junta iniciara un viraje hacia el unicameralismo y la necesidad de redacción de un proyecto de Constitución. Arguelles consiguió la aprobación de una propuesta de la Junta, el 10 de diciembre de 1809, para que las Cortes se compusieran de 300 diputados -220 de la metrópoli y 80 de ultramar- sin distinción de clases o estamentos.

En el contexto de los graves trastornos militares y políticos sucedidos a fines de 1809 y principios del año siguiente, desaparecía la Junta de Legislación sin poder cumplir con su principal tarea, la redacción de un proyecto constitucional, lo que provocaría a la postre que sean las mismas Cortes las creadoras del código, y por lo tanto, que éste estuviera más influenciado por las tendencias revolucionarias. El 1 de enero de 1810 la Junta Central dictó una circular convocando a las ciudades con voto a Cortes y a las juntas a elegir los diputados que habían de representarlas. ${ }^{743}$

\footnotetext{
743 “Instrucción que deberá observarse para la elección de Diputados de Cortes", 1 de enero de 1810, disponible en www.congreso.es/docu/PHist/docs/01cad/ACD_P-01-000124-0015.pdf
} 
Llamativamente no fueron puestas en circulación las que correspondían a los obispos y grandes del reino. Jovellanos siguió insistiendo con el formato estamental y bicameral, logrando finalmente su cometido. La última acción de la Junta Central antes de su disolución sería un extenso articulado, escrito por el asturiano, dirigido a la Regencia donde se pautaron los puntos de la convocatoria para las Cortes, el famoso y controvertido decreto del 29 de enero de 1810, estableciendo los atributos tradicionales.

El Consejo de Regencia, de impronta más conservadora que la Junta, se caracterizaría por una actitud puramente dilatoria en relación al llamado a Cortes. Recién en junio empezó a implementar las instrucciones realizadas por esta última. Misteriosamente, el decreto de la Junta Central del 29 de enero desapareció, mientras que los diputados que ya habían llegado a Cádiz presionaron para que directamente éste no sea tomado en cuenta. ${ }^{744}$ El Consejo de Estado, ante el clima adverso que se vivía en la ciudad con respecto a una representación de tipo tradicional, finalmente definió la composición única y no estamental, a sólo cuatro días de que sean inauguradas las sesiones.

\section{El Rio de la Plata ante la convocatoria a Cortes}

La primera reacción en el Rio de la Plata ante la convocatoria a Cortes consistió en el intento de desconocerla, no dándole trascendencia ni en los documentos oficiales ni en la prensa. Pero cuando ya era una realidad su pronta instalación, se pasó a la crítica directa con el objetivo de deslegitimarla como verdadera representación de la monarquía. En la Gazeta de Buenos Aires del 31 de diciembre de 1810 se da cuenta de la llegada por intermedio de un parlamentario proveniente de Montevideo de un oficio de aquel gobernador, junto a otros impresos, donde se informaba de la instalación en la Real Isla de León el 24 de setiembre del congreso de las Cortes generales de la monarquía, "siendo uno de los principales actos, con que principió aquella asamblea, la

\footnotetext{
${ }^{744}$ Sería luego acusado el secretario de la Junta Central, Manuel Quintana, por el ocultamiento del decreto. De hecho, cuando Fernando VII fuera restaurado en el poder, el poeta liberal sería juzgado y condenado Según el fiscal: "Su voluntad decidida hacia las novedades que tanto han perjudicado a la nación se descubre contra la fuerte presunción que resulta contra Quintana en la ocultación del decreto dado por la Junta central para la convocación de las Cortes por estamentos..." "Segunda respuesta fiscal en la causa de Quintana y del Semanario". Citado en Palti, Elías, óp. cit., pp.58-59. En sus memorias Quintana se defiende de esta manera: "Las Cortes, pues, fueron reunidas bajo una representación única y nacional, no por la supuesta ocultación del decreto, sino porque los votos de los dos Consejos, la opinión pública decididamente declarada en este sentido y la situación de las cosas así lo prescribían”, Quintana, Manuel. “Memoria sobre el proceso y prisión de Don Manuel José Quintana en 1814". Alicante: Biblioteca Virtual Miguel de Cervantes, 1999, p. 199.
} 
declaración de una absoluta igualdad entre los españoles de ambos mundos, reputándolos por una familia nacional". ${ }^{745}$

La Junta Gubernativa, acusando recibo del citado oficio e impresos, dice protestar a toda la nación "su firme adhesión a la causa del desgraciado Rey Fernando, y el vasallaje a su soberanía, conforme a los sagrados é invariables principios de su instalación, fundados en la misma absoluta igualdad de derechos en ambas Américas y España, que no han podido desconocer las Cortes generales". ${ }^{746} \mathrm{La}$ noticia, tan trascendental para el conjunto del mundo hispánico, no merece más comentarios en el periódico, ni son reproducidos tampoco los impresos enviados por Elío. Se buscaba minimizar de esa manera la noticia, a la vez que se reafirmaba que el vínculo de los pueblos americanos era con el Rey. Dejando en claro asimismo que si las Cortes reconocieron la igualdad de ambos hemisferios, era por obligación y no porque así lo sintieran.

El triunfo de Suipacha el 7 de noviembre por parte de las fuerzas patriotas comandadas por Castelli y el inicio de la ocupación del Alto Perú generaron un clima de confianza y afirmación en la Junta. No obstante, el desplazamiento de Moreno y la consolidación del ala moderada de la revolución, sumado a las preocupaciones por el conflicto con Montevideo y Paraguay, implicaron que tampoco existía la determinación para una ruptura abierta con la metrópoli, como si ya parecía perfilarse la revolución en Caracas.

En una Gazeta de marzo de 1811 se cuestiona que la Regencia se haya arrogado la designación de los suplentes y se busca demostrar su ilegitimidad con una hipotética situación especular: “América puede ser igual de absurda y convocar cortes designado suplentes por Cádiz, Sevilla, etc. Si la regencia elije los suplentes, nosotros no reconocemos a la regencia por lo tanto tampoco a las cortes". ${ }^{747}$ Para el articulista las Cortes no albergaban la voluntad general de la nación porque no había existido "un contrato libre que una a sus partes sino que fue por medio de la conquista". ${ }^{748}$ Desautoriza tanto la figura del Rey como la de la Regencia para llamar a Cortes, entendiendo que solo los síndicos del común tenían los atributos para convocarla. Se retoman aquí los planteos del "Patriota Español" -reproducidos como vimos por Moreno

\footnotetext{
${ }^{745}$ Gazeta de Buenos Aires del 31 de diciembre de 1810, p. 761

${ }^{746}$ Ídem.

${ }^{747}$ Gazeta nro. 39 (7/3/11): 182.

${ }^{748}$ Ibid., p. 184.
} 
unos meses atrás en la misma Gazeta-, "cuyo luminoso escrito no han querido seguir sus paisanos, aunque tanto lo aplaudieron y elogiaron al principio de su revolución" ${ }^{749}$

Detrás de estas imposiciones e inflexibilidad hacia América, el articulista no veía otra cosa que el interés y la ambición de "algunos particulares y poderosos" que han prevalecido a los intereses del estado. Claramente se hacía referencia a los grupos comerciales gaditanos y su intransigencia a modificar el monopolio establecido sobre el nuevo mundo. Para el autor la desigual representación entre americanos y peninsulares respondía a imposibilitar que el régimen comercial fuera cuestionado, subrayando que cuando la diputación americana buscó tratar el tema su condición minoritaria impidió que progresara en los debates del recinto. Son reproducidos fragmentos de la obra Apuntes para una reforma de España de Victoria de Villava donde se alertaba que la opresión generaría que algún día España pierda América, no manteniendo ni siquiera buenas relaciones para comerciar con ella. ${ }^{750}$

Nuevamente se toma el ejemplo de Valencia para justificar la propia postura, dice que habiendo ésta enviado diputados a la Junta Central, incluso así no quiso subordinarse absolutamente, “¿y la América sin concurrir con ningún sufragio ha de estar recibiendo a un mismo tiempo los provistos de dos o más gobernaciones españolas, como ya ha llegado a suceder?” Para cerrar el artículo de manera categórica, aunque luego durante el Triunvirato se baje el tono y se vuelvan a tender algunos puentes: "Americanos: precipitad al mar, aunque sea a bayonetazos cualquiera virrey o sátrapa, que nos manden las juntas de España; no cuidéis de lo que ellas murmuren, que el mundo ilustrado juzgará de quien fuere la justicia". ${ }^{751}$

Pero desconocer a las Cortes por ilegítimas no resolvía el problema de qué tipo de organización se presentaría en cambio como alternativa para los provincias americanas. La idea de una convocatoria a un congreso constituyente en el Rio de la Plata, como vimos, tuvo sus primeras formulaciones en los escritos del secretario de la Junta patriota. ${ }^{752}$ Fueron sus seguidores quienes, ya en la oposición al Primer Triunvirato,

\footnotetext{
${ }^{749}$ Ibid., p.185.

${ }^{750}$ Ibid., p. 189.

${ }^{751}$ Ibid., p. 190.

${ }^{752}$ En la serie de artículos que publica en la Gazeta de Buenos Aires bajo el título "Sobre las miras del Congreso que acaba de convocarse y la Constitución del Estado", citada anteriormente, Moreno insiste recurrentemente en la necesidad del dictado de una constitución para las provincias del sur : "Nuestros representantes van a tratar sobre la suerte de unos pueblos que desean ser felices, pero que no podrán serlo, hasta que un código de leyes sabias establezca la honestidad de las costumbres, la seguridad de las personas, la conservación de sus derechos, los deberes del magistrado, las obligaciones del súbdito y los límites de la obediencia” Entiende que las Leyes de Indias no podían considerarse como dicho código, por carecer de principios de razón, reglar el comercio sobre base ruinosa del monopolio, entre otros aspectos.
} 
insistieron en la necesidad de una constitución para las provincias rioplatenses, imputándole al gobierno falta de voluntad para avanzar en ese camino. Pero antes de proseguir, contextualicemos un poco cuál era la situación política en las provincias del Rio de la Plata hacia mediados de 1811.

\section{Los moderados en el poder: el Primer Triunvirato}

A la avanzada portuguesa sobre la Banda Oriental, respondiendo al pedido de ayuda de Elío, se le sumó la desastrosa derrota del Ejército del Norte el 20 de junio en la batalla de Huaqui. Ante la grave posibilidad que un movimiento de pinza sofocase la revolución, la situación política en Buenos Aires se enrareció y la Junta Grande empezó a ser cuestionada por su inoperancia. El Cabildo porteño forzó entonces a la Junta a delegar el mando el 23 de septiembre en un ejecutivo que supuestamente implicaría una mayor operatividad: el Triunvirato. La Junta Grande, ahora Conservadora, adquiriría el carácter de un legislativo.

El nuevo gobierno estaba compuesto por Paso, Chiclana y Sarratea, pero la verdadera "alma mater" sería su secretario: Bernardino Rivadavia. Pocos meses después, era disuelta la Junta Conservadora y expulsados los diputados del interior. El Triunvirato continuó con la línea moderada de su antecesor, manteniendo la postura fidelista en relación a Fernando VII, y el 20 de octubre se pactó con Elio un polémico armisticio, lo que supuso el comienzo de una conflictiva relación de Buenos Aires con los patriotas orientales encabezados por Artigas. ${ }^{753}$

Con respecto a las Cortes con la llegada del Triunvirato se inauguró una etapa más conciliadora que se mantendría sin grandes modificaciones hasta la sanción de la Constitución de Cádiz. Se atenuaron las críticas en la prensa oficial, se estableció un discurso menos combativo y hasta se publicaron con mayor frecuencia fragmentos de las sesiones durante lapso. En la Gazeta del 5 de noviembre por ejemplo se publican las

El Secretario de la Junta considera que el americano es un teatro propicio como pocos para formar una constitución, caracterizando a las americanas como "poblaciones regulares y civilizadas" donde "la suavidad de nuestras costumbres anuncian la docilidad con que recibiremos la constitución que publiquen nuestros representantes; libres de enemigos exteriores, sofocada por la energía de la Junta la semilla de las disensiones interiores, nada hay que pueda perturbar la libertad y sosiego de los electores..." Gazeta de Buenos Aires, 1 y 6 de noviembre de 1810.

${ }^{753}$ En el tratado firmado se le daba a Elío el tratamiento de Virrey y se le reconocía su jurisdicción sobre la Banda Oriental y la costa este de Entre Ríos, estableciéndose la evacuación de la tropas porteñas sitiadoras de Montevideo. Además, en otra de las cláusulas las Provincias Unidas se reconocían como parte integrante de la nación española, que no tenía otro soberano que Fernando VII, y se obligaban a enviar comisionados ante las Cortes de Cádiz. Todo a cambio del retiro del ejército de ocupación portugués al mando de Souza. 
sesiones de las Cortes de enero de 1811, que se presentan como referidas a las Américas y se las introduce con la siguiente reflexión: "Su lectura instruirá al público del juicio que forman los miembros de aquella respetable asamblea, y si por el criterio con que se discuten por algunos, interesan a todos los indiferentes, debe ser asunto de meditación seria para los americanos, que pretenden aclarar sus derechos: estos testimonios irrefragables convencerán a los que mal intencionados, o ignorantes quieren deslumbrar a los incautos con ridículos sofismas". ${ }^{754}$ Asimismo, comienzan a publicarse también varios artículos de periódicos londinenses, donde se promueve la mediación inglesa en el conflicto entre España y América o directamente su protectorado, denotando un viraje hacía una política pro-británica en las relaciones exteriores de las provincias rioplatenses que, ya comenzada en las últimas semanas de la Junta Grande, con el Triunvirato se profundizó. ${ }^{755}$

\section{El morenismo resurrecto: la Sociedad Patriótica}

Hacia mediados de 1811 se comenzaron a reorganizar los desperdigados miembros del Club de Marco. La actividad de oposición a la Junta Grande no se había neutralizado del todo tras la asonada del 5 y 6 de abril, como demostró Fabián Herrero a partir de la difusión de pasquines infamatorios por parte de grupos de presión contra Saavedra y los principales referentes del ala moderada en las semanas inmediatamente posteriores al movimiento. ${ }^{756}$ Aquellos que habían regresado tras los destierros, como Vieytes, Peña, Berutti, Larrea y French, entre otros, constituyeron una nueva Sociedad Patriótica, y con el permiso del Triunvirato y tras la fachada de discusiones literarias, comenzaron a orientar una política que de a poco se fue convirtiendo en franca oposición al gobierno. Junto a ellos se fueron sumando otros actores como Julián Álvarez, Valentín Gómez, Francisco Planes y Manuel Moreno. Asimismo, contaban con el Regimiento Estrella como brazo armado del círculo revolucionario. Según un

\footnotetext{
${ }^{754}$ Gazeta nro. 1 (5/11/11): p. 3.

${ }^{755}$ Ver por ejemplo los artículos de los periódicos londinenses Correo Brasilienze, The Alfred o El Español publicados en las gacetas de agosto a noviembre de 1811.

${ }^{756}$ Herrero, Fabián, “Localistas' radicalizados. Pasquines infamatorios distribuidos luego de la asonada de los orilleros en abril de 1811”, en Bragoni, B. y Mata de López, S., Entre la colonia y la república. Insurgencias, rebeliones y cultura política en América del Sur, Buenos Aires, Prometeo Libros, 2009, pp. 245-268.
} 
comentario de Vicente Fidel López, la Sociedad se había convertido en “...un club político de oposición al gobierno bajo el influjo de los morenistas y Monteagudo". 757

Efectivamente, la llegada de Bernardo de Monteagudo a la capital había sido decisiva en ese rumbo. Su temperamento, sumado a la participación activa que había tenido en el movimiento altoperuano de 1809; su actuación junto a Castelli en la expedición auxiliadora, también en el Alto Perú; y su prédica periodística al frente de la Gazeta desde mediados de 1811, lo habían ido convirtiendo en el tribuno y "ego conductor" de la resucitada Sociedad Patriótica. ${ }^{758} \mathrm{Su}$ oratoria de amplios gestos y la fogosa contienda ideológica entablada con el editor de El Censor, Vicente Pazos Silva, atraía a la juventud y sumaba adeptos a la Sociedad. Monteagudo se erigía, tanto desde la tribuna de la Sociedad como desde las páginas de la Gazeta, en el continuador y defensor del ideario morenista, convertido ahora en mito de la revolución. Escribía el tucumano por esos días: "La gratitud se resiente del olvido a que se ha condenado la memoria de Moreno, como si su muerte pudiera borrar el aprecio que merecen los defensores de la LIBERTAD... todo ambicioso era rival suyo, y el que aspiraba a la gloria debía ser émulo de Moreno". ${ }^{759}$ En Monteagudo, como antes en Moreno, además existía la conciencia de estar protagonizando una revolución de escala global, mucho más trascendente que sólo un conflicto jurídico entre la metrópoli y sus colonias: "La suerte de la América pende de nosotros mismos, y la influencia que reciba directa o indirectamente de la Europa será siempre más favorable que contraria a sus intereses, considerado el estado actual de la revolución del globo; y los progresos que anuncian los extraordinarios tiempos en que vivimos". 760

Formalmente la Sociedad Patriótica inauguró sus sesiones en la Casa del Consulado el 13 de enero de 1812. El acto cobró gran resonancia y repercusión. En la “Oración inaugural", escuchada por integrantes del gobierno, mandatarios de la iglesia, jefes y oficiales, Monteagudo proclamaba vehementemente que: “...la soberanía reside sólo en el pueblo y la autoridad en las leyes: ella debe sostener que la voluntad general es la única fuente de donde emana la sanción de ésta y el poder de los magistrados: debe

\footnotetext{
${ }^{757}$ López, Vicente Fidel, Historia de la república argentina. Su origen, su revolución, su desarrollo político hasta 1852, Buenos Aires, La facultad, 1926, tomo IV, p. 169.

${ }^{758}$ Sobre la reconfiguración del sector más radical de la dirigencia porteña se puede consultar Molina, Eugenia. "Las modernas prácticas asociativas como ámbitos de definición de lazos y objetivos políticos durante el proceso revolucionario (1810-1820)". Revista Universum, n. 16, 2001, pp. 407-437.

${ }^{759}$ Gazeta nro. 23 (7/2/12): 120.

${ }^{760}$ Gazeta nro. 21 (24/1/12): p.105
} 
demostrar que la majestad del pueblo es imprescriptible, inalienable y esencial por su naturaleza..."761

Poco tiempo después, el 9 de marzo llegaban al puerto de Buenos Aires, después de cincuenta días de navegación a bordo de la fragata "George Canning", un grupo de oficiales americanos que retornaban después de haber prestado servicios en la península durante varios años. Allí venían José de San Martin, Carlos de Alvear, José Zapiola, Francisco Chilabert, Antonio Arellano y Francisco Vera. Inmediatamente, los recién llegados ofrecieron sus servicios al Triunvirato, encargándoseles distintas faenas militares. Pero más importante para nuestro estudio que por ejemplo la formación del regimiento de Granaderos, fue la instalación en la capital de una Logia -“de los Caballeros Racionales" inicialmente y luego llamada "Lautaro"-, extensión de otra formada en Europa, que tenía como presidente a Alvear y de vicepresidente a San Martin. No va a pasar mucho tiempo para que éstos traben relaciones con los miembros de la Sociedad Patriótica, tomando conciencia de su afinidad ideológica y objetivos en común, los lazos entre ambos grupos se fueron estrechando. Pero recapitulemos un poco para conocer sucintamente los orígenes de la Logia y el pensamiento político de uno de sus principales hombres, el futuro libertador americano.

\section{San Martin y la Logia de los Caballeros Racionales}

Las sociedades secretas - directa o indirectamente ligadas a la francmasonería- se convirtieron a partir del siglo XVIII en uno de los vehículos principales para la expansión del pensamiento anti-absolutista. En un medio hostil, se apelaba al sigilo y al compromiso juramentado de sus miembros, para la subsistencia y desarrollo tanto de las sociedades como de sus ideas. ${ }^{762}$ Por lo tanto, su estudio implica enormes dificultades que le son intrínsecas a su constitución y modus operandi. Ante la falta de documentación directa de estas instituciones muchas veces son los testimonios orales o

\footnotetext{
761 “Oración inaugural. Pronunciada en la apertura de la Sociedad Patriótica la tarde del 13 de enero de 1812”MONTEAGUDO, Bernardo de. Escritos políticos. Buenos Aires: La Cultura Argentina, 1916.

${ }^{762}$ Para una mejor caracterización de las mismas, es preciso hacer la distinción entre logias simbólicas $-\mathrm{O}$ formales- y logias operativas. Las primeras otorgan mayor importancia a los objetivos y vínculos espirituales e ideológicos, desentendiéndose de acciones políticas concretas. Son asociaciones filosóficas que resaltan por sobretodo valores como la Razón y la hermandad, dando gran importancia a las jerarquías, liturgias, consagraciones, etc. Las logias operativas, en cambio, son aquellas que privilegian objetivos políticos, en muchos aspectos cercanos a los del liberalismo revolucionario. La estructura jerárquica de la logia le permite robustecer la disciplina, mientras que el carácter secreto justifica la acción clandestina.
} 
escritos de los logistas, infiltrados o incluso delatores los que proporcionan pistas para su reconstrucción histórica. ${ }^{763}$

Cádiz, en su carácter de ciudad cosmopolita, libre y comercial, era entre las españolas la que contaba con la mayor cantidad de estas sociedades. Según la literatura de filiación masónica allí fue donde San Martín, ya con veintidós años al servicio de España, habría sido iniciado en los misterios de la orden en la "Logia de la integridad" en 1808. Cuando a principios de 1811 retornó a Cádiz, luego de una campaña en Portugal, conociéndose ya las noticias de los levantamientos americanos, se integró a la Sociedad de Caballeros Racionales Nro. 3. ${ }^{764}$ Ante el desesperanzador futuro que anticipaba el arrollador avance del ejército francés, esta nueva Logia se planteó como terreno para su despliegue político el nuevo continente y se fue preparando en ese sentido.

San Martín pudo ser testigo directo en esa asediada ciudad de las contradicciones de un liberalismo español que, a la par que iba avanzando en determinadas transformaciones que compartía -como la libertad de prensa o el fin de varios privilegios nobiliarios-, no aceptaba modificar realmente la relación con América, aferrados a los beneficios que su política imperial les deparaba. De convicciones reformistas y moderadas, compartiendo igualmente muchas de las premisas de aquel primer liberalismo hispánico, San Martin decidió por esos meses sumarse a la lucha de los insurgentes americanos, no seguramente por un llamamiento de intangibles fuerzas telúricas o emotivas, como bien señala el historiador Norberto Galasso, sino por la profunda convicción de que en esas trincheras se estaban dando las batallas decisivas por la causa de la Libertad, que ya en España parecían perdidas. ${ }^{765}$ Algo similar a lo planteado por Moreno en la serie de artículos "Sobre las miras del congreso": en la larga lucha de la libertad contra el despotismo, España ya había agotado sus fuerzas, acechada por enemigos internos y externos, había sucumbido en sus propias contradicciones; tocaba ahora el turno a América. Sin dudas habían influido en San Martín los contactos establecidos por esos años con muchos americanos que se hallaban en la península, y que bajo esta ola de asociacionismo inspirada en el movimiento ilustrado y liberal,

\footnotetext{
${ }^{763}$ Pasquali, Patricia, San Martín: la fuerza de la misión y la soledad de la gloria, Buenos Aires, Emecé, 2004, p. 68.

${ }^{764}$ Las reuniones de la Logia eran en la casa del teniente de carabineros Carlos de Alvear. Allí San Martín trabó relación no sólo con éste sino con Zapiola, el chileno Juan Miguel Carrera y los sacerdotes liberales Servando Teresa Mier y Ramón Anchoris.

${ }^{765}$ Galasso, N., Seamos libres y lo demás no importa nada: vida de San Martín, Ediciones Colihue, 2000, p. 49 .
} 
fueron delineando un proyecto que enlazaba la causa anti-absolutista con la de la emancipación americana. ${ }^{766}$

Unos cuantos años después, convertido ya en el gran Jefe de la guerra emancipatoria americana, San Martín haría referencia a los Constitución gaditana y los puntos de contacto entre la revolución española y la americana: "La revolución en España es de la misma naturaleza que la nuestra, ambas tienen la libertad por objeto y la opresión por causa [...] Pero la América no puede contemplar la constitución española sino como un medio fraudulento de mantener en ella el sistema colonial [...] Ningún beneficio podemos esperar de un código formado a dos mil leguas de distancia, sin la intervención de nuestros representantes". 767

Cuando a mediados de 1811 en Cádiz era uniforme el clamor por la intervención militar en América, y el terreno se volvía demasiado hostil para los conjurados americanos, la Logia Nro. 3 preparó furtivamente la partida de varios oficiales con destino al Rio de la Plata. En ese contexto es que podemos enmarcar la conocida referencia que San Martín hiciera ya en sus últimos años de su vida: "En una reunión de americanos en Cádiz, sabedores de los primeros movimientos de Caracas, Buenos aires, etc., resolvimos regresar cada uno a nuestros países de nacimiento, a fin de prestarle nuestros servicios en la lucha que calculábamos se había de empeñar". ${ }^{768}$

Concretada exitosamente la salida de Cádiz, los oficiales logistas recalaron en Londres donde conformaron otra filial de los Caballeros Racionales, distinguida con el nro. 7, que tendría como misión servir de nexo con las sociedades establecidas en Filadelfia, Caracas y Cádiz, así como brindar refugio a los hermanos escapados de esta última ciudad. En aquella nueva Logia fue admitido inmediatamente Manuel Moreno, que como sabemos se encontraba allí como diplomático tras ser enviado junto a su hermano en aquel fatídico viaje donde Mariano perdería su vida en sospechosas circunstancias. En enero de 1812, y portando una carta del revolucionario porteño que elogiaba sus virtudes y recomendaba sus servicios -elemento que allanaría mucho las cosas a su llegada-, partieron los logistas americanos rumbo a Buenos Aires.

\footnotetext{
${ }^{766}$ Hacia1809 se reunían en casa de Manuel Rodríguez en Sevilla, el alférez de navío Matías de Irigoyen, su primo el capitán Hilarión de la Quintana, Manuel Sarratea y León de Altolaguirre. En la misma ciudad andaluza se estableció al año siguiente una logia formal que ante el avance francés a principios de 1810 debió disolverse para reconstituirse en Cádiz. Sería la misma, según algunos testimonios, a la que se incorporaría San Martín en 1811. Pasquali, P., óp. cit., p. 72.

767 "Proclama desde Pisco", 8/9/1820, citada en Galasso, N., Seamos Libres..., pp. 99-100.

768 "Carta enviada por el Libertador al Mariscal Castilla, desde Boulogne-Sur-Mer el 11 de setiembre de 1848 ".
} 


\section{El monarquismo constitucional en el campo patriota rioplatense}

¿Cuáles eran las ideas políticas que traía San Martín a bordo del Canning? Varias manifestaciones a lo largo de su vida, sobre todo en su correspondencia, nos hablan de un hombre de convicciones políticas fuertes, ya suficientemente maduradas durante esos años de formación profesional en España, siendo testigo cercano de los profundos y revolucionarios cambios que estaban atravesando a Europa. Es conocida, aunque haya sido soslayada por cierta historiografía liberal, su preferencia hacia el sistema monárquico como forma de gobierno más adecuada para los pueblos americanos. Una monarquía constitucional, limitada, al estilo de la que bregaban los liberales gaditanos en las discusiones de los cafés y recintos de las Cortes.

Lo que no implicaba necesariamente que la monarquía atemperada fuera el sistema que en términos ideales o teóricos San Martín considerara el mejor o más evolucionado, sino el que mejor se adaptaba a la realidad americana. En carta a Godoy Cruz en 1816 con motivo de la reunión del Congreso de Tucumán, le reconocía que "por principios e inclinación" era "un americano republicano" pero que entendía que eran demasiados los obstáculos en las Provincias Unidas para adoptar ese camino. ${ }^{769}$ San Martín apoyaba la propuesta de Belgrano de la monarquía constitucional con un Rey perteneciente a la dinastía incaica. Proyecto que sería recibido con simpatía por gran parte de los diputados de las provincias norteñas y alto peruanas. Y contaría además con el apoyo de Martín Miguel de Güemes, hombre fuerte del norte y pilar fundamental en la contención a los realistas. La intención detrás de este proyecto era la unificación de los territorios americanos que ya comenzaban a separarse, bajo un gobierno fuerte, que contara con la legitimidad de estar enraizado en las tradiciones originarias, con el apoyo de las masas indias y mestizas, fundamentales para inclinar la balanza en la lucha contra el realismo, todavía muy fuerte en Perú y el Alto Perú. Los diputados porteños, en cambio, reaccionarían de manera muy adversa ante la propuesta, denotando no solo su poca voluntad de proyectar la revolución más allá del Rio de la Plata sino un fuerte desprecio por las masas indígenas de la América profunda.

A pesar de sus convicciones liberales, San Martín se había manifestado numerosas veces por la necesidad de un gobierno fuerte, centralizador, que fuera capaz de unificar y cohesionar a las distintas provincias americanas. ${ }^{770}$ El Libertador percibía ya las

\footnotetext{
769 “Carta de San Martin a Godoy Cruz”, del 24/5/1816, citado en Galasso, N., Seamos Libres..., p. 185.

${ }^{770}$ En otra carta a Godoy Cruz también con motivo del Congreso de Tucumán decía: “... por la patria le suplico no nos metan una regencia de personas; en el momento que pase de una, todo se paraliza y nos
} 
tendencias disolventes que amenazaban la unidad por él anhelada. Lo obsesionaba, al igual que a otros jefes americanos, la potencial anarquía, tanto como la servidumbre consiguiente. Una monarquía, además, habría de ser vista con buenos ojos en Europa, donde, como decía Belgrano, "antes el espíritu general era republicanizarlo todo, en el día se trataba de monarquizarlo todo".

Retornando a 1812, sólo unos días antes de que se concretara la llegada de San Martín junto a los otros oficiales al Rio de la Plata y mientras se preparaba la ciudad para la Asamblea general, los periódicos porteños se convirtieron en la plataforma de una polémica entre Bernardo de Monteagudo y Vicente Pazos Silva en relación a si debía adoptarse una monarquía o una república como forma de gobierno para las Provincias Unidas. En El Censor del 25 de febrero Pazos Silva respondía a un comentario de Monteagudo en la Gazeta del 21donde criticaba al gobierno por seguir hablando en nombre de Fernando VII. El editor, escandalizado por esas críticas, plantea que no existía contradicción entre la libertad y la monarquía. Conjetura que en un hipotético congreso constituyente:

[...] los diputados después de largas discusiones, y meditaciones profundas nombran un rey sujeto a una constitución sabia y liberal, en la que los pueblos gocen de sus derechos, y escudados por las leyes no teman los ataques del poder que resida en él rey. En este caso ¿los ciudadanos del nuevo estado serían esclavos? Seguramente serían tan esclavos cómo son hoy los ingleses, y como fueron los aragoneses bajo una constitución que formaron, y que hizo su gloría y felicidad. ${ }^{771}$

Pazos Silva traía a colación el modelo inglés, aunque seguramente eran los debates y proyectos constitucionales elaborados en Cádiz y divulgados a través de la prensa, donde desde los reformistas moderados hasta los liberales más radicales coincidían en la fórmula de una monarquía constitucional, los que al editor de El Censor le resultaban más cercanos para pensar la política local. Como en otros casos, no era conveniente reconocer esas influencias. Más adelante retomaba nuevamente su ataque a Monteagudo, corporizando en él a quienes se atrevían a plantear sistemas de gobierno alternativos: "es la prudencia, la política, y el saber las que han de dirigir nuestras deliberaciones, y no los delirios, de las ridículas é insensatas ideas de los filósofos

lleva al diablo; al efecto, no hay más que variar de nombre a nuestro director y queda un regente: esto es lo seguro para que salgamos a puerto de salvación." "Cartas de San Martín a Godoy Cruz", del 22/7/1816, en Documentos del archivo de San Martín. Buenos Aires: Imprenta de Coni, 1910, p. 546.

${ }^{771}$ El Censor nro. 8 25/2/12: 31. 
que parecen que viven entre hombres de otra naturaleza, o en un mundo enteramente nuevo, cuando dictan leyes, y pintan repúblicas". ${ }^{772}$

Dejar atrás el absolutismo del antiguo régimen significaba por esos tiempos elegir entre tres grandes caminos: el republicanismo de inspiración francesa, el republicanismo federal norteamericano o la monarquía constitucional, que tenía como mayor exponente a Inglaterra pero que justamente por esos meses estaba a punto de cristalizarse en España. Como vimos, tanto para José de San Martín como Vicente Pazos Silva, y tantos otros como seguramente también Belgrano y Funes, era este último modelo el que representaba la mejor opción para pensar un gobierno para los pueblos americanos. Recordemos que la alternativa carlotista abrazada por muchos dirigentes criollos durante el bienio de 1808-1809 se inscribía, quizás a pesar de la misma Infanta, en ese modelo de monarquía constitucional, como pudimos ver en la Memoria que el grupo de Castelli le elevara a Carlota.

No nos parece aventurado afirmar que, por la trayectoria de San Martín, quien se formó personal y profesionalmente en el medio español y fue partícipe directo de los primeros años de la revolución peninsular, y por las recurrentes referencias de Vicente Pazos Silva a los liberales y la prensa española en su rol como editor de El Censor como veremos en profundidad en otro capítulo-, en ambos la experiencia del liberalismo hispánico, tan rica como contradictoria, los inclinaba hacia dicho modelo de organización política.

\section{La frustrada Asamblea de abril y el golpe revolucionario de octubre}

Ni bien arribados los oficiales en el Canning a la ciudad capital fueron testigos de los febriles preparativos electorales para la asamblea general que debía instalarse en abril. El gobierno quería que aquella solo se restringiera a renovar a uno de los miembros del Triunvirato, pero la Sociedad Patriótica, a través fundamentalmente de la Gazeta en manos de Monteagudo, venía ejerciendo presión para que esta estuviera revertida de más amplios poderes y representatividad para encarar un proceso constituyente. Y, a pesar de las enormes distancias que lo separaban con el editor de $E l$ Censor, como pudimos ver sólo unos párrafos atrás, desde ambos periódicos se criticaba por esos días la tendencia del Triunvirato a ejercer el poder de manera despótica y autoritaria. Monteagudo desde la Gazeta invocaba el principio de división de poderes al

\footnotetext{
${ }^{772}$ Ídem.
} 
criticar la fusión de los poderes legislativos y ejecutivos en manos del gobierno. Decía, por ejemplo, sobre el Triunvirato: "ha dictado, y dicta reglamentos como si fuera un soberano, usa el poder legislativo en toda su extensión, al mismo tiempo que ejerce el ejecutivo, circunstancia que basta para graduarle de tiránico". ${ }^{773}$ Por su parte, en El Censor, Pazos Silva ponía el eje en la representación política como límite para evitar la tiranía. Es preciso dar al pueblo, decía, "el ejercicio de reclamar sus derechos por medio de representantes y el uso verdadero de la libertad de imprenta". ${ }^{774}$ Estos encendidos cuestionamientos llevaron a Rivadavia a decidirse por cerrar ambos periódicos días antes de la reunión de la asamblea, como ya veremos con mayor detalle en otro capítulo. Y ya con nuevo editor y nuevo nombre - Gazeta Ministerial -, se cuestionaba desde el periódico a las Cortes gaditanas, utilizando argumentos que buscaban deslegitimar en general a las asambleas de tipo constituyente, combinando el gobierno en una misma táctica, los frentes interno y externo.

Además de los cuestionamientos a las atribuciones que tendría la Asamblea, había otros puntos del reglamento para darle forma dictado en febrero que generaban polémica. Por un lado se criticaba la sobrerrepresentación otorgada a la ciudad de Buenos Aires en detrimento de los pueblos del interior. Según un complicado régimen electoral debían elegirse cien diputados por Buenos Aires frente a uno por cada una de las provincias restantes. ${ }^{775}$ Por otro lado, los apoderados electos en las ciudades debían estar en la capital, "aunque solo sea de paso", cuestión que recordaba a la controvertida y muchas veces criticada representación supletoria aplicada para los americanos en la convocatoria a las Cortes de Cádiz. ${ }^{776}$ Monteagudo fustigaba al Triunvirato, denunciando justamente que su vocación centralista reproducía lo que con justicia se le achacaba a la metrópoli:

Por la misma razón yo pregunto ¿qué pueblo tiene derecho a dictar la constitución de otro? Si todos son libres. ¿Podrán sin una convención expresa y legal recibir su destino del que se presuma más fuerte? ¿Habrá alguno que pueda erigirse en tutor del que reclama su mayoridad, y acaba de quejarse ante el tribunal de la razón del injusto pupilaje a que la fuerza lo había reducido? Los pueblos no conocen sus derechos: la ignorancia los precipitaría en mil errores, ¿y yo tengo derecho a abusar de su ignorancia, y eludir su

\footnotetext{
773 Gazeta de Buenos Aires, 15 de marzo de 1812.

${ }^{774}$ El Censor, nro. 12, 24 de marzo de 1812.

${ }^{775}$ Finalmente y por el pedido insistente del Cabildo para atenuar la asimetría pero sin anularla, esa cláusula sería modificada y el número de diputados por Buenos Aires pasó a ser treinta y tres.

776 Ternavasio, M., Gobernar la revolución, p.111.
} 
LIBERTAD a pretexto de que no la conocen? [...] Jamás pierdan de vista los argumentos con que nosotros mismos impugnamos justamente la conducta del gobierno español con respecte a la América. Toda constitución que no lleve su sello de la voluntad general, es injusta y tiránica. ${ }^{777}$

En una carta publicada en la Gazeta se cuestiona que en el reglamento se excluyera a quienes no sabían leer ni escribir:

Todo asociado capaz de deliberar y obrar por sí mismo, que ni haya atacado con sus crímenes el cuerpo político es ciudadano, y deba tener sufragio en la asamblea general para la formación de la constitución del estado... No es menester ser republicano para adoptar estos principios, ni hay necesidad de tomarlos de la doctrina de oro del ciudadano de Ginebra. Basta que los gobiernos monárquicos sean moderados, para que aun en ellos no se desconozcan esas máximas. Así es que se ven proclamadas en todos los papeles públicos de España después de su revolución, y adoptadas y puestas en ejecución respecto de sus provincias para la formación de su nueva constitución. Todo individuo residente en la nación española con sola la exclusión de los extranjeros ha prestado su sufragio para la elección de los diputados que en el congreso representen la voluntad general. Eso mismo deberemos observar nosotros religiosamente, (si hemos de adoptar ideas liberales, y establecer nuestra sabia constitución sobre una base sólida, y permanente) para la celebración de nuestro congreso general. ${ }^{778}$

No sólo se presionaba al Triunvirato con la necesidad que la asamblea sea realmente un congreso constituyente, sino que abiertamente y sin tapujos, lo convocaba a seguir "religiosamente" el ejemplo dado por la península, que sin ser una república, sino una monarquía moderada, había avanzado, amén de sus "ideas liberales", en garantizar los derechos de ciudadanía a todos los españoles. El autor de la carta, que firmaba como "un amante de la patria", no dudaba que el destino de América debía ser

\footnotetext{
${ }^{777}$ Gazeta nro. 24 (14/2/12): 126. También criticaba la exclusión de los habitantes de la campaña en el reglamento electoral del Triunvirato: ¿En qué clase se considera a los labradores? ¿Son acaso extranjeros o enemigos de la patria, para que se les prive del derecho de sufragio? Jamás seremos libres, si nuestras instituciones no son justas [...] No hay una razón para que los habitantes de la campaña, no sean admitidos proporcionalmente a la próxima asamblea: sus costumbres menos corrompidas que las nuestras y su razón quizá más libre de la influencia del interés, aseguran un éxito feliz en sus deliberaciones. Si el gobierno no reforma en esta parte su reglamento de 19 de febrero, comete un atentado contra los inviolables derechos de la porción más recomendable de nuestra población”. Gazeta nro. 26 (28/2/12): 137. La crítica reproducía aquella concepción ilustrada del halo de virtuosismo y pureza que rodeaban al trabajo y costumbres rurales, tan presentes en los primeros periódicos rioplatenses finicoloniales.

${ }^{778}$ Gazeta nro. 29 (20/3/12): 149. En la respuesta Monteagudo señala que el problema radica en que el analfabeto no se ha ilustrado en sus derechos por los periódicos y demás papeles públicos, pero aclara que si ha desempeñado algún servicio notable puede suplementar esa condición. P.150
} 
romper definitivamente con España, pero a la vez no tenía pruritos, como tampoco Monteagudo, en postularla como modelo a imitar en muchos aspectos de su revolución.

Para el líder de la Sociedad Patriótica ya no hacía falta tampoco legitimar el camino propio, por lo tanto le era posible reconocer en ese otro los avances en materia de libertades. Para ilustrar este concepto veamos estas breves líneas del tucumano a comienzos de 1812 en referencia a la voluntad del editor de la Gazeta de Valencia en denunciar las prácticas despóticas: "es preciso confesar que en el día conocen muy bien los españoles de Cádiz la libertad de que han estado privados en el sistema antiguo. Véanse todos los periódicos que allí se publican". ${ }^{779} \mathrm{O}$ más adelante, cuando en un artículo que versa sobre una propuesta para que la biblioteca compre y reimprima libros, elogie los rápidos progresos de los últimos tiempos de España en ese rubro, proponiendo que "sin declinar entre el espíritu de rivalidad", el Rio de la Plata pueda "surtirse por medio de Inglaterra de las mejores ediciones de la península". 780

En un clima de gran efervescencia, donde la cuestión de la división de poderes, el dictado de una constitución y la declaración de la independencia formaban parte de la agenda de esos días, la asamblea abrió sus deliberaciones el 4 de abril e inmediatamente emergieron todas las tensiones y conflictos preanunciados. Al día siguiente de su apertura la asamblea nombró como vocal reemplazante de Juan José Paso -triunviro saliente- a Juan Martin de Pueyrredón, y al estar éste ausente de la ciudad, a José Miguel Díaz Vélez como vocal suplente, hasta tanto pudiese hacerse cargo de su función. Ante el veto del triunvirato a la designación de este último, alegando cuestiones reglamentarias, la asamblea protestó y se declaró por "pluralidad" como “autoridad suprema sobre toda otra auto constituida en las Provincias Unidas del Río de la Plata" ${ }^{781}$ Ante tamaño desafío al poder del gobierno la suerte que corrió la asamblea fue la misma de la Junta Conservadora. El triunvirato le hizo saber a aquella que quedaba disuelta, considerando su actitud "nula, ilegal y atentadora contra los derechos soberanos de los pueblos y contra la autoridad de este Gobierno". ${ }^{782}$ Con esta medida, junto al amordazamiento de la prensa y el patrullaje represivo en la ciudad, el gobierno

\footnotetext{
${ }^{779}$ Mártir o Libre núm. 5, 27/4/12: 38.

${ }^{780}$ El Grito del Sud 7 25/8/12: 56.

781 “Acta de la reunión de la asamblea del 5 de abril”, Emilio Ravignani, Asambleas Constituyentes, t. 6, 1era. parte , p. 689.

782 "Oficio del Triunvirato al presidente de la Asamblea en que le hace saber su disolución a raíz de atribuirse la autoridad suprema". Emilio Ravignani, Asambleas Constituyentes, t. 6, 1era. parte, pp. 698699.
} 
afianzaba su manejo discrecional y avasallador del poder. Su cara más autoritaria ocultaba, no obstante, una debilidad que pronto habría de evidenciarse.

El tinte liberal de los decretos de seguridad individual y libertad de imprenta no alcanzaron para que la oposición, encabezada por la Sociedad Patriótica, dejara de considerar su conducción como demasiado timorata. Más aún cuando desde Venezuela llegaban noticias de la declaración de la independencia. Tampoco alcanzaba que en al conocerse las noticias de la promulgación de la constitución gaditana, el triunvirato abandonara su tibia postura ante las Cortes y la rechazara a través de la Gazeta de Buenos Aires desconociendo legitimidad: "Nos hablan ahora de constitución: pero esa constitución establece al dogma de la soberana nacional, reconoce por única base de su representación a la población dé las provincias, y si ella no ha existido para la América ¿tendrá ésta obligación alguna de obedecerla? Si esta constitución es justa y liberal, solamente la libre sanción de los pueblos puede legitimarla: la fuerza y la opresión jamás han producido derecho" ${ }^{783}$ Sólo el descubrimiento de la llamada conspiración de Álzaga, duramente reprimida por el gobierno, le otorgó una temporal tregua, preocupadas ambas facciones por la posibilidad de que las disputas internas facilitaran el resurgimiento local del principal enemigo. ${ }^{784}$

En medio de este contexto se discutía la convocatoria a una nueva asamblea para renovar a los vocales del triunvirato y la reforma del reglamento para llevarla a cabo. El gobierno, consciente de las dificultades que el reglamento anterior había generado, admitía su modificación, en particular en relación a sus aspectos más irritantes, suprimiendo el sorteo, achicando la desigualdad representativa entre Buenos Aires y los pueblos del interior, y estableciendo que los diputados no debían estar en Buenos Aires como exigía la convocatoria precedente. ${ }^{785}$ Asimismo, dicha asamblea sería la encargada de dictar, en acuerdo con el gobierno, el sistema electoral para regir la elección de diputados a un Congreso Constituyente. En su intento por controlar la futura asamblea, Rivadavia y Pueyrredón impugnaron la elección de algunos diputados -entre ellos el electo por Mendoza, Bernardo de Monteagudo. A pesar de las quejas, el gobierno decidió la apertura de la asamblea para el 6 de octubre remplazando a los

\footnotetext{
${ }^{783}$ Gazeta Ministerial del Gobierno de Buenos Aires, 11 de septiembre de 1812.

${ }^{784}$ Álzaga y más de treinta complotados-entre ellos el suegro de Pueyrredón, Francisco de Telecheafueron procesados y fusilados, y sus cadáveres colgados de la horca y expuestos públicamente.

${ }_{785}^{78}$ Ternavasio, Marcela. Gobernar la revolución: poderes en disputa en el Río de la Plata, 1810-1816. Buenos Aires: Siglo XXI Editores Argentina, 2007, p. 123.
} 
diputados impugnados, lo que terminó agudizado aún más la situación desembocando en los conocidos acontecimientos del 8 de octubre.

Durante los meses previos se habían ido estrechando los lazos entre la Logia y los miembros de la Sociedad Patriótica, muchos de ellos organizados a su vez, según algunos testimonios, en una entidad masónica encabezada por Julián Álvarez. Esta última terminaría siendo subsumida por la Lautaro, lo que implicaba a su vez que la Sociedad Patriótica pasaba a estar conducida en la práctica por aquella. La Logia, a pesar de la mala relación que mantenían sus principales figuras con Rivadavia, había atraído también a uno de los secretarios del Triunvirato: Nicolás Herrera. Por intermedio de Alvear sus miembros se vincularon con algunas de las familias de mayor renombre de la sociedad. Además, varios de sus oficiales estaban al mando de importantes regimientos. Controlaba por completo la oposición oral y escrita a través de la Sociedad Patriótica, y la imprenta a cargo de Donado, de donde salían los periódicos de Monteagudo. En poco tiempo la Logia había dinamizado y cohesionando a la corriente revolucionaria del proceso, logrando penetrar en los principales resortes de poder. ${ }^{786}$ Grupos y facciones se fueron aglutinando a su alrededor. Disconformes con la política tibia y moderada, y a su entender claudicante del gobierno, estaban decididos a dar un golpe de mando para encarrilar nuevamente el rumbo hacia los objetivos libertarios e hispanoamericanos iniciales.

La maniobra del Triunvirato impugnando a Monteagudo y a otros diputados que le resultaban adversos, sumada al nombramiento de los suplentes y ausentes, había logrado dejar en minoría a la oposición en la asamblea. Pero todo fue en vano, porque el 5 de octubre le fue asestado un duro golpe a su ya de por si castigado prestigio al

\footnotetext{
${ }^{786}$ Un testimonio respecto a esto es el del general Gerónimo Espejo, que sirvió en el ejército bajo las órdenes de San Martín y participó de la campaña de los Andes. En referencia a la constitución de la Logia de Buenos Aires, afirma que la erección de una logia política, semejante a las que había visto en Inglaterra y en Cádiz, fue la primera actitud de San Martín al llegar al Río de la Plata: "estudió a fondo todos los elementos morales de que podía disponer, y acabó por creer que las instituciones masónicas estaban desvirtuadas en las logias de Buenos Aires. Formaban parte de ellas muchos hombres de importancia muy secundaria, que bajo ningún aspecto eran acreedores a la confianza que era preciso hacer en ellos para dirigir con acierto la revolución. San Martín se explicó con Alvear y Zapiola, y todos tres acabaron por convencerse que se necesitaba una reforma radical en el sistema de sociedades secretas, para que éstas produjesen el efecto que convenía. De allí, pasaron a tratar los medios de organizar una nueva logia compuesta de un número más reducido de miembros. Debía formarse ésta de los personajes más importantes que hasta aquel momento contaba la revolución en sus filas con tal que éstos fuesen hombres de energía y decisión y que se hallasen dispuestos a arrostrar cualquier peligro por el triunfo de la causa en que estaban empeñados. San Martín quería sólo hombres de corazón, dispuestos a todo, y prontos para obedecer sus mandatos o los de otros corifeos, y confiaba en que con su ayuda podía dar a la revolución un vigoroso impulso, y quizá conducirla en pocos años". Espejo, Gerónimo. "El Paso de los Andes. Crónica histórica de las operaciones del Ejército de los Andes para la restauración de Chile en 1817”, en Biblioteca de Mayo. Tomo XVI, Primera Parte, pp. 13810-13811.
} 
conocerse la noticia de la victoria del Ejército del Norte en la batalla de Tucumán, que había sido conseguida por Belgrano contrariando las disposiciones del gobierno. Los festejos, traducidos en manifestaciones populares alentadas por la oposición a favor de la independencia -que incluyeron el apedreamiento de las casas de Pueyrredón y su hermano-, fueron las señales decisivas para lanzar la revolución que la Logia venía planificando. $^{787}$

La movilización comenzó cerca de la medianoche del 7 de octubre. La Plaza de la Victoria fue escenario de una nueva concentración popular, alentada no sólo por los tribunos de la Sociedad Patriótica sino también por el círculo del ex vocal Juan José Paso, que contaba con inserción entre los quinteros, peones y trabajadores de la aduana. Tropas de diversos regimientos tomaron posición frente al Cabildo, mientras se disponían "cañones asestados en las bocacalles y dos obuses en el arco principal de la recova apuntando a las casas consistoriales". A la cabeza del regimiento de granaderos a caballo con sus sables envainados estaban San Martin y Alvear. Detrás de ellos, el coronel Ortiz de Ocampo con su regimiento de infantería y el comandante Pinto con la artillería. ${ }^{788}$ Los cabildantes y el presidente de la Asamblea fueron convocados, y ya reunidos en la mañana del 8 se presentó una representación redactada por Monteagudo donde se acusa al gobierno de faccioso y despótico, de haber realizado una viciosa manipulación electoral con el fin de concretar su plan de avenimiento con las Cortes de Cádiz, -y como se recurría cada vez que se buscaba desprestigiar a un gobierno y justificar un golpe de mando- todo sobre la base del reconocimiento de los derechos sucesorios de Carlota Joaquina. ${ }^{789}$ Disuelto el Triunvirato y la Asamblea, el Cabildo junto a los comandantes de tropas -Ortiz de Ocampo, San Martin y Alvear-, luego de sortear un tenso enfrentamiento por los cargos con la facción de Paso que ya se estaba trasladando virulentamente a la plaza, concretaron la formación de un nuevo gobierno, en nombre de la voluntad popular expresada en la movilización. El segundo Triunvirato

\footnotetext{
${ }^{787}$ Es llamativo que en las semanas previas al golpe de octubre en El Grito del Sud, periódico que hacía las veces de órgano oficial de la Sociedad Patriótica, no se manifestasen críticas al gobierno, siendo su contenido de corte más teórico e inofensivo. En el número del 6 de octubre por ejemplo, un día antes del inicio del levantamiento, fue publicado un artículo de Eugenio del Portillo bien propio de su pensamiento ilustrado, se discurre sobre las sesenta y tres sociedades económicas que existían en España. Como dato curioso, en ese mismo artículo, propone al pasar Argentina como nombre para las provincias unidas. El Grito del Sud, núm. 13 6/10/12: 99. O es una estrategia de la Logia para no revelar sus planes, o el clima represivo impuesto por el ejecutivo era exitoso, imponiéndole al periódico una marcada autocensura.

${ }^{788}$ Mitre, Bartolomé, Historia de Belgrano y la Independencia argentina, Buenos Aires, Suelo Argentino, 1950, p. 49.

${ }^{789}$ La publicación de un decreto de las Cortes, donde se definía la línea sucesoria de Fernando VII en el infante Carlos María y en segundo lugar en Carlota Joaquina, en la Gazeta Ministerial del 25 de septiembre, podría haber sido interpretada por la Logia en ese sentido.
} 
estaría formado entonces por Juan José Paso, Nicolás Rodríguez Peña y Antonio Álvarez Jonte, sometiéndose la decisión a la aprobación popular de la gente reunida en la plaza.

Al día siguiente, la Sociedad Patriótica sesionaba y su presidente Francisco José Planes dejaba planteada la necesidad de "una constitución fija, y permanente, y no provisoria". ${ }^{790}$ Pocos días después, en una emisión extraordinaria de la Gazeta Ministerial, se publicaba un artículo en el que se relatan los acontecimientos y razones del levantamiento, y se argumenta a favor de la pronta reunión de la Asamblea:

Una asamblea general con toda la plenitud y legalidad que permitan las circunstancias, y a la que concurran los representantes de los pueblos con la extensión de poderes que quieran darles; es sin duda el mejor arbitrio para augurar la salud de la patria. $\mathrm{Su}$ primer objeto debe ser poner límites a la obediencia del pueblo, estableciendo la garantía de sus derechos, y fijando el sistema que debe regir a las provincias unidas, cuya indefinición no puede absolutamente justificarse, ni por las dificultades de la empresa, ni por los peligros que nos rodean. ${ }^{791}$

Una de las primeras evidencias de la instauración del nuevo gobierno fue, como siempre, el cambio en la línea editorial de la Gazeta. La voluntad de la Logia de re enraizar la revolución rioplatense en el medio americano se percibe rápidamente con la reproducción de proclamas y artículos periodísticos de los procesos insurgentes de Caracas, Cartagena, Santiago de Chile, etc. ${ }^{792}$ La visión estratégica de San Martín, que siempre antepondría el horizonte americano a cualquier desvío localista de las elites criollas, se combinaba con similares idearios del morenismo original recuperado desde la perspectiva universalista de Monteagudo. ${ }^{793}$ La Logia además poseía estrechos vínculos con entidades análogas en la mayoría de las capitales americanas que explican también esa perspectiva continental, aspecto de significativo interés e importancia que excede a nuestro estudio pero que entendemos no ha sido lo suficientemente trabajado aún.

\footnotetext{
790 "Deliberaciones y documentos producidos en la Sociedad patriótica relativos a la reunión de una Asamblea, a la declaración de la independencia y a la sanción de una constitución". En Ravignani, Emilio. Asambleas Constituyentes Argentinas, tomo 6. Buenos Aires: Instituto de Investigaciones Históricas, Universidad de Buenos Aires, 1937-39, pp.738-739.

${ }^{791}$ Extraordinaria Ministerial, 22 de octubre de 1812.

${ }^{792}$ Ver por ejemplo la Gazeta del 6/11/12 o los Gritos del Sur del 1/12/12 y el 8/12/12.

${ }^{793}$ Era muy recurrente en los artículos de Moreno en la Gazeta el uso del sintagma "Nuestra América" para referirse al escenario de la revolución en la que la rioplatense estaba inscripta, aun cuando había descartado por impracticable en el corto plazo un congreso constituyente que reuniera a todos los pueblos americanos.
} 
En relación a la política exterior con el nuevo Triunvirato se produce un fuerte cambio con respecto a las expectativas depositadas en la mediación inglesa en el conflicto con España, que como vimos había determinado gran parte de los posicionamientos de la administración anterior. ${ }^{794}$ La Logia, a pesar de ser consciente de que era necesario cultivar los vínculos con una de las principales potencias del mundo, no solo por la amenaza que representaba tenerla de enemiga, sino también si quería ganar a la larga el reconocimiento en el "gran concierto de naciones"-, se distanciaba de la política rivadaviana a la que consideraba demasiado proclive a dejarse conducir por esas influencias.

Ese cambio en la política exterior tenía también un correlato en la política económica, para el nuevo gobierno ya no eran admisibles algunos beneficios otorgados a los comerciantes ingleses cuando era necesario robustecer las arcas del estado para sostener militarmente la revolución y lograr expandirla. En El Grito del Sud del 8 de diciembre se publica una nota donde se critícala introducción sin límite de mercaderías, en muchos casos acompañada de sobornos a funcionarios. Denuncia la existencia de comerciantes especuladores extranjeros que se creen dueños de nuestro comercio y que habían contado con demasiadas consideraciones por los gobiernos pasados. Como alternativa plantea poner trabas racionales a lo que ya se produce en el país para no terminar con la ruina de los productores nacionales en manos de estos "nuevos ciudadanos". Es necesario, concluye el autor del capítulo, subordinar algunas cuestiones del comercio a las necesidades de la guerra. ${ }^{795}$ Interesante artículo que reafirma uno de los planteos que realizáramos en el capítulo 7 en relación al supuesto liberalismo económico de la dirigencia rioplatense. Como podemos ver, el librecambismo no era un axioma indiscutible sino que dependía del proyecto político-económico encarnado en el poder. Y mientras que con el triunvirato rivadaviano su política probritánica tendió a fomentarlo, con la Logia el librecambismo admitía también algunos límites virándose a un intervencionismo estatal más atado a las necesidades que imponía la guerra.

\section{Un congreso constituyente para los pueblos del Plata. El Decreto del Segundo Triunvirato del 24/10/12 y el Manifiesto de la Junta Central del 28/10/09}

El 24 de octubre de 1812 la Logia empezaba a saldar el principal motivo que la había llevado a levantarse contra el gobierno anterior dictando un decreto que establecía

\footnotetext{
${ }^{794}$ Véanse por ejemplo las Gazeta $s$ del 13 de noviembre de 1812 y la del 1ro de enero de 1813.

${ }^{795}$ El Grito del Sud 22 8/12/12: 174-175
} 
las condiciones para la elección de los diputados para la Asamblea General Constituyente. Como dijimos, no sólo se perseguía con ella la formulación de una constitución sino también el decisivo paso hacia la independencia que para la facción revolucionaria era imprescindible dar. Lo curioso, como veremos a continuación, es que se utilizó una vez más el molde peninsular en la búsqueda de romper definitivamente los lazos con la metrópoli. A partir de la comparación de los documentos hemos detectado, en un aporte inédito de nuestra investigación, que el decreto del Segundo Triunvirato fue en gran parte una adaptación de aquel manifiesto de la Junta Central del 28 de octubre de 1809 que también establecía la convocatoria a las Cortes extraordinarias para dotar de una constitución a la monarquía española. Incluso en momentos donde el timón de la revolución rioplatense era tomado por los sectores más radicales y abiertamente favorables a una salida independentista al proceso, el ejemplo peninsular seguía siendo valioso como guía, y no se dudaba en "tomar prestada" su rica elaboración discursiva y doctrinaria.

Como ya señaláramos, el manifiesto de la Junta Central, escrito por Manuel Quintana había sido en parte una respuesta a los cuestionamientos de algunos sectores opositores, fundamentalmente de la rebelde Junta de Valencia, al proceso de convocatoria a Cortes. Se buscaba con este extenso escrito explicar las razones detrás del llamado a la reunión del reino y contrarrestar esas críticas dejando en claro que ésta no replicaría la estrechez y restricciones de las antiguas Cortes. Permítannos entonces la comparación de alguno de los párrafos entre ambos documentos para ver cómo fueron adaptadas por el gobierno porteño, tres años después de escritas, varias de las expresiones y conceptos vertidos por el referente liberal peninsular, prestando sobre todo atención a las modificaciones introducidas y a aquello dejado de lado, ya que entendemos revelan más que lo transcripto textualmente, permitiéndonos un análisis más enriquecedor. En negrita marcaremos aquellas expresiones que claramente responden a una apropiación y adaptación del texto peninsular.

En el Manifiesto de la Junta Central se decía:

Por una combinación de sucesos tan singular como feliz, la Providencia ha querido que en esta crisis terrible no pudieseis dar un paso hacia la independencia, sin darle también hacia la libertad. La tiranía inepta ya y decrépita para remachar vuestros grillos y agravar vuestras cadenas, dio lugar al despotismo francés que, con el terrible aparato de sus armas y de sus victorias, [...] presumieron ganar vuestra voluntad prometiéndoos reformas de administración y anunciándonos en una Constitución hecha a 
su antojo, el imperio de las leyes. ¡Contradicción bárbara y absurda, digna ciertamente de su insolencia! ¡Querer hacernos creer que se puede sentar el edificio moral de la libertad y fortuna de una Nación sobre cimientos amasados con usurpación, iniquidad y alevosía! Pero el pueblo español, en cuyo seno se habían conocido primero que en otro alguno de los modernos los verdaderos principios del equilibrio social [...]pudo contestar a estos imprudentes legisladores que para él no eran leyes los artificios de los intrigantes ni los mandatos de los tiranos. ${ }^{796}$

En el Decreto del Triunvirato porteño:

Sí pudo proclamarse el triunfo de la disolución de la primera asamblea general del 6 de abril último la patria debe sin duda datar un nuevo nacimiento desde el instante mismo en que se salvó de la terrible crisis que preparaba la del 6 de octubre. La asamblea mostróse como un centro de impulsión arbitraria en una circunferencia aparentemente popular. ;Absurdo ciertamente insoportable figurarse representación de los pueblos habiéndose sofocado la expresión del voto general; y como si pudiera sentarse el edificio moral de la libertad sobre el cimiento de elecciones viciosas, exclusiones violentas, y suplencias ilegales! Pero los ciudadanos virtuosos superiores al choque de pasiones que habían empezado a estallar en toda fuerza, contestaron oportunamente, que para los que tienen y conocen sus derechos, no eran respetos los abusos, leyes los artificios, ni mandatos los caprichos. Por un movimiento tan feliz como majestuoso no quisieron dar un paso hacia la libertad ultrajada, sin darlo igualmente hacia la independencia nacional. $^{797}$

La gran oportunidad percibida por los liberales españoles para terminar con el régimen absolutista que se había abierto con la invasión francesa y la crisis monárquica es condensada en el manifiesto mediante la expresión: "en esta crisis terrible no pudieseis dar un paso hacia la independencia, sin darle también hacia la libertad". Como ya afirmáramos anteriormente, para el ala revolucionaria del proceso peninsular, la guerra nacional debía ser al mismo tiempo una revolución política, sino de nada servía. Por su parte, en el decreto porteño, haciendo referencia a la revolución del 8 de octubre, se utiliza una expresión similar pero es intercambiado el orden de los factores: "no quisieron dar un paso hacia la libertad ultrajada, sin darlo igualmente hacia la independencia nacional". El movimiento de octubre había sido un paso hacia la

\footnotetext{
796 "Manifiesto fijando los días en que se han de convocar y celebrar las Cortes generales de la Monarquía española, de 28 de octubre de 1809", disponible en la Biblioteca virtual Miguel de Cervantes http://www.cervantesvirtual.com/

797 "Convocando a elecciones para diputados a la Asamblea general", Buenos Aires, 24 de octubre de 1812, Registro Nacional.
} 
conquista de mayores libertades políticas, reponiendo el espíritu de Mayo corrompido por el Primer Triunvirato, pero la tarea subsiguiente era avanzar hacia la independencia nacional, o sea, la ruptura completa con España. ${ }^{798}$

La Junta Central alertaba sobre los peligros de disolución que contraerían planteos federalistas como los de la Junta valenciana, que serían inevitablemente aprovechados por Napoleón para concretar el sojuzgamiento de España. Sólo la unión en el gran cuerpo nacional que representaban las cortes y la expresión de la voluntad del pueblo español a través de sus representantes podía salvar a la Nación en tan crítico momento:

\footnotetext{
${ }^{798}$ Más adelante encontramos otro párrafo utilizado donde se busca resaltar la falta de violencia y moderación con que fueron instalados por un lado la Junta Central y por otro el nuevo Triunvirato porteño:
}

"Efecto inmediato de estas primeras ventajas fue la recomposición del Estado, dividido a la sazón en tantas fracciones como provincias [...] Sin contradicción, sin violencia, se estableció una autoridad suprema y el pueblo que acababa de asombrar al mundo con el espectáculo de su exaltación sublime y de sus victorias, le llenó de admiración y de respeto con su moderación y cordura".

"El objeto inmediato fue la organización del Estado, que no tenía ley, jurisprudencia, forma, ni genio alguno cierto, y donde una serie de decretos contrarios habían servido hasta aquí de título y alimento a la arbitrariedad de los magistrados. Sin violencia pues se estableció la autoridad superior que preparase el camino; y el pueblo que había asombrado al mundo el 25 de mayo de 1810 le dio nuevas lecciones de moderación y justicia con el espectáculo de la nueva instalación".

Y a continuación aquellos párrafos, en los que en uno y otro caso, se define que la principal obligación del nuevo gobierno, una vez superadas las urgencias militares, había sido las convocatorias a los congresos constituyentes:

"La Junta Central se instaló, y su primer cuidado fue anunciaros que si la expulsión de los enemigos era su primera atención en tiempo, la felicidad interior y permanente del Estado era la principal en importancia. Porque, dejarle anegado en el piélago de abusos agolpados para su ruina por el poder arbitrario, sería a los ojos de vuestro actual Gobierno un delito tan enorme como poneros en manos de Bonaparte. Así es que luego que el torbellino de los sucesos militares se lo permitió, hizo resonar en vuestros oídos el nombre de vuestras Cortes, que para nosotros ha sido siempre el antemural de la libertad civil y el trono de la majestad nacional. Nombre pronunciado antes con misterio por los eruditos, con recelo por los políticos, con horror por los tiranos; pero que desde ahora debe significar en España la base indestructible de la Monarquía, la columna más segura de los derechos de Fernando VII y de su familia, un derecho para el pueblo, y para el Gobierno una obligación".

"Constituido el gobierno, si su primer cuidado en tiempo fue la expulsión de sus enemigos exteriores, atender a los ejércitos, y rendir justo homenaje a los ilustres defensores de la patria en Tucumán, la libertad interior, y la felicidad permanente del estado ha sido su empeño principal en importancia. Cualquier abandono de los pueblos en el piélago de abusos agolpados para su ruina por el poder arbitrario, sería a los ojos de los individuos encargados de la autoridad un delito tan enorme, como sujetar su suerte a disposición y capricho del conquistador más insolente. Así es, que luego que lo permitió el torbellino de las primeras atenciones a que nos empeñaban los sucesos militares, se anunció un manifiesto la asamblea general prevenida en el bando ereccional del 8 del corriente: anuncio visto con recelo por los políticos misteriosos, temido con horror por los tiranos, y deseado ansiosamente por los amantes del orden, unión y prosperidad de estas provincias". 
[...] cuando la hidra del federalismo, acallada tan felizmente en el año anterior con la creación del poder central, osa otra vez levantar sus cabezas ponzoñosas, y pretende arrebatarnos a la disolución de la anarquía; cuando la astucia de nuestros enemigos está acechando el momento en que rompan nuestras divisiones para arrojarse a destruir el Estado, y sentar su solio sobre la cima de oprobio que le proporcionen nuestros debates; este es el tiempo, este, de reunir en un punto la fuerza y la majestad nacional, y de que el pueblo español por medio de sus representantes, vote y decrete los recursos extraordinarios que una Nación poderosa tiene siempre en su seno para salvarse. Él solo puede encontrarlos y ponerlos en movimiento; él alentar la timidez de los unos, contener la ambición de los otros; él acabar con la vanidad importuna, con las pretensiones pueriles, con las pasiones insensatas, que van, si no se agitan, a despedazar el Estado; él, en fin, dará a la Europa un nuevo ejemplo de su religión, de su circunspección y de su sensatez en el uso justo y moderado que va a hacer de esa hermosa libertad en que se le constituye.

En cambio para el gobierno rioplatense no era el federalismo -por ahora- el obstáculo a sortear, sino el faccionalismo, siempre denunciado como el principal mal por quienes alternativamente detentaron el poder, amén de aquella vocación unanimista tan característica del liberalismo hispánico:

\section{[...] cuando la hidra de las facciones se ha acallado felizmente con la creación} de una autoridad para llenar las intenciones de los pueblos, ¿qué otro tiempo puede esperarse para reunir en un punto la majestad y fuerza nacional? Esta sin duda debe ser la memorable época en que el pueblo de las provincias unidas del Río de la Plata, abriendo con dignidad el sagrado libro de sus eternos derechos por medio de libres y legítimos representantes, vote y decrete la figura con que debe aparecer en el gran teatro de las naciones. Elevados los diputados a la altura de su noble ministerio, y elevada la patria a su brillante destino, saldrán entonces las grandes medidas, la energía y la fortuna, la constitución que se sancione alentará la timidez de unos, acabará con la vanidad importuna, atajará pretensiones atrevidas, destruirá pasiones insensatas, $\mathbf{y}$ dará en fin a los pueblos la carta de sus derechos, y al gobierno el de sus obligaciones.

En este caso, a diferencia del escrito peninsular, la constitución no es una herramienta imprescindible para "salvar" a la Nación, sino que se la plantea fundamentalmente como el medio para establecer los derechos del pueblo y las obligaciones del gobierno, y "aparecer" así, legítimamente, ante "el gran teatro de las naciones". Mientras que para la Junta Central la conformación de las Cortes sería "la columna más segura de los derechos de Fernando VII y de su familia”, el decreto 
rioplatense advertía que "el eterno cautiverio del Señor Fernando VII ha hecho desaparecer sus últimos derechos". ${ }^{799} \mathrm{La}$ decisión de avanzar hacia un proceso constitucional, buscaba a fin de cuentas sustituir al Rey y a la propia Monarquía por un corpus normativo que estabilizara y legitimara al nuevo poder soberano, aun cuando la independencia absoluta no contaba todavía con un consenso mayoritario en el Rio de la Plata. $^{800}$

En la península, ante aquellos que se oponían a las Cortes por considerarlas provistas de una representación insuficiente, por entenderlas como inoportunas y hasta arriesgadas, o directamente inútiles, puesto que afirmaban que las Juntas superiores creadas inmediatamente por el pueblo eran sus verdaderos representantes; la Junta Central replicaba en su manifiesto:

Más la Junta había dicho expresamente a la Nación, que su atención primera en este grande objeto, sería ocuparse del número, modo y clase con que, según las circunstancias del tiempo presente, debería verificarse la concurrencia de los Diputados a esta augusta Asamblea, y después de esta declaración es bien superfluo, por no decir malicioso, recelar que las Cortes venideras hayan de estar reducidas a las formas estrechas y exclusivas de nuestras Cortes antiguas.

Si la Central, desde su ala liberal -que bien expresaba Quintana-, buscaba aprovechar las críticas de los valencianos para dejar en claro que no se iba a reproducir el antiguo formato de las Cortes, o sea el carácter estamental y bicameral, cuestión a la que, como vimos, los liberales de la Junta también se oponían; en el caso rioplatense las diferenciación era planteada hacia "las Asambleas anteriores", las convocadas en abril y octubre por el Primer Triunvirato, que habían provocado la oposición de la Logia y su pronunciamiento mediante el movimiento del 8 de octubre:

La representación en ella debe ser tan completa, cual deba y pueda en un congreso de tan alto carácter, e importancia; pero no habiendo forma alguna establecida que regle legítimamente el modo de las elecciones de representantes, de suerte que pueda decirse con verdad, que sus resoluciones sean la expresión de la voluntad general; y así para destruir el recelo que sea reducida la Asamblea a las formas estrechas y exclusivas de Asambleas anteriores.

\footnotetext{
799 "Convocando a elecciones para diputados a la Asamblea general”, Buenos Aires, 24 de octubre de 1812, Registro Nacional, p. 185.

${ }^{800}$ Sobre este punto De Gori, Esteban. “Autogobierno y revolución. Lenguaje político de las élites dirigentes de Buenos Aires”. Revista Politeia, UCV, n 43, 2009.
} 
Para evitar entonces "la arbitraria limitación prescripta por tímidos tiranos", el Triunvirato establecía a continuación el reglamento para la elección de los diputados por parte de las provincias. Es interesante ver qué puntos de contacto y que diferencias presenta con la "Instrucción que deberá observarse para la elección de Diputados de Cortes", que en definitiva y a pesar de los idas y vueltas que existieron en la península sobre el carácter que debían tener las cortes, una vez que triunfó el planteo de los liberales de la unicameralidad, se terminó utilizó aquella Real Orden de la Junta Central 1 ero de enero de 1810. Dicha normativa detallaba con precisión el modo de elección en tres grados -parroquias, partidos y provincias- de los diputados, el mapa electoral en que se dividió el territorio y los diputados que le correspondían a cada unidad, la composición y funciones de la Junta encargada de hacer cumplir la instrucción y de presidir las elecciones a Diputados en las capitales de provincia, los requisitos para votar y para ser elegido, y la fórmula electoral a aplicar en cada elección. ${ }^{801}$

En ambos reglamentos la idea de ciudadanía está asociada a una concepción tradicional de vecindad. Los alcaldes de barrio eran centrales en ese sentido para acreditar la condición de vecino. También coinciden en la disposición de un mecanismo de elección indirecta y en la votación en voz alta de los electores. Pero mientras que el decreto peninsular establece que las de primera instancia debían realizarse en parroquias, el rioplatense señala que el sufragio debía ser en los cuarteles. Ambos plantean que en caso de existir comicios en una ciudad en más de una parroquia o cuartel, esta debía realizarse a la misma hora. Un dato llamativo presente en el reglamento español que no tiene correlato en el americano, es la exhortación de la Junta Central a realizar una misa patriótica como antesala a cada comicio, donde se predique a los parroquianos sobre la importancia del acto cívico en el marco de la lucha de la nación por su independencia.

La principal diferencia entre ambos reglamentos radicaba en que en el metropolitano la representación para la península era establecida a partir de un censo, correspondiendo una cuota básica de diputado por cada cincuenta mil habitantes, mientras que en el Rio de la Plata se disponía un número fijo para cada ciudad: "la capital tendrá cuatro diputados por su mayor población e importancia política; las demás

\footnotetext{
${ }^{801}$ Como señala Casals Bergés "esta modalidad de elección por circunscripciones que contemplaba la instrucción fue la base que inspiró, con algunos retoques, la posterior normativa electoral desarrollada en la Constitución de 1812 y que podemos considerar como la génesis del sistema electoral contemporáneo español". Casals Bergés, Quintí, "Proceso electoral y prosopografía de los diputados de las Cortes extraordinarias de Cádiz (1810-1813)”, Historia Constitucional, n. 13, 2012. p. 201.
} 
capitales de provincia nombrarán dos, y uno cada ciudad de su dependencia a excepción del Tucumán que podrá a discreción concurrir con dos diputados a la Asamblea”. Llama la atención que se seguía reproduciendo la lógica establecida por la Junta Central en relación a la elección de los diputados americanos para las cortes. Mientras que para las provincias peninsulares la cantidad de representantes estaba determinada por el censo, como señalamos recién, para América se establecían veintiséis representantes distribuidos en las principales capitales. Igualmente, para el caso peninsular, existían dos condiciones más que otorgaban representaciones en Cortes. Por un lado se establecía un representante para cada una de las Juntas Superiores de Defensa constituidas en la nación y que habían participado en la constitución de la Junta Central; y por otro se conservaba un parlamentario para cada una de las ciudades con derecho a voto en las últimas Cortes celebradas en 1789.

Para cerrar este capítulo nos parece importante señalar que en ambos escenarios, el peninsular y el rioplatense, existió una fuerte pugna entre los sectores moderados y radicales en torno a la convocatoria a una asamblea que sentara las bases políticas de las nuevas entidades que estaban emergiendo en el marco de la crisis. Tanto los liberales peninsulares como la facción revolucionaria porteña debieron enfrentar las resistencias que, los reformistas y conservadores para el caso metropolitano o el moderantismo del Primer Triunvirato, ofrecieron para la instalación de un congreso de carácter constituyente. En la península la disputa se dio hacia el interior mismo de la Junta Central y sus Juntas dependientes, resolviéndose recién a favor de los liberales cuando en el marco de una Cádiz convulsionada por la llegada de miles de patriotas refugiados por el avance francés, las ideas más revolucionarias tuvieron el contexto propicio imponerse. El liberalismo, como pudimos ver, tampoco funcionaba homogéneamente, y las contradicciones se expresaron por ejemplo en el conflicto entre el centralismo del grupo de Quintana con los liberales valencianos de Cangas Arguelles. En cambio, en el Rio de la Plata, la facción revolucionaria, vigorizada y cohesionada por la instalación de la Logia, debió derrocar al vacilante gobierno, tomando en sus manos la conducción del proceso, para poder concretar la convocatoria a una Asamblea General Constituyente. Y a pesar de uno de los objetivos últimos de aquella era la declaración de la independencia y la formulación de una constitución propia, los revolucionarios rioplatenses no dudaron a la hora de nutrirse de la rica experiencia peninsular para encarar ese trascendental paso. 


\section{Capítulo 12:}

\section{Las Cortes de Cádiz, la Constitución de 1812 y la Asamblea del año XIII}

\section{Introducción}

La Constitución Española de 1812 lograría trascender el acotado marco en el que fue promulgada, una ciudad sitiada por el ejército más poderoso de su época, e irradiar el espectro del constitucionalismo en las décadas siguientes. Al momento de ser sancionada el 19 de marzo de 1812, los pueblos americanos ya habían comenzado con el sinuoso recorrido que terminaría desembocando en su emancipación. A pesar de esto, fue jurada en varios territorios que mantenían aún sus vínculos con la metrópoli, entre ellos los dos virreinatos más importantes. Sabemos que su impacto en dichas regiones leales fue capital, pero conocemos poco de sus efectos en aquellas que, como el Rio de la Plata -con excepción de Montevideo que se encontraba en manos lealistas-, no la juraron ni adoptaron. Desde el campo de la historia del derecho se han realizado algunos estudios que han destacado las “deudas gaditanas" en las primeras legislaciones rioplatenses, pero aún no se ha profundizado en otros aspectos más allá de lo estrictamente jurídico. ${ }^{802}$

En este capítulo buscamos indagar la recepción que tuvieron tanto la Constitución de 1812 como la labor de las Cortes de Cádiz en el espacio rioplatense, en particular en la Asamblea General Constituyente del año XIII. El enfoque que utilizamos parte de entender a ambos procesos constituyentes enmarcados en una misma cultura constitucional hispánica, con un sustrato y lenguaje jurídico similar a ambos lados del Atlántico. Desde esta perspectiva, buscamos demostrar que existen suficientes indicios para afirmar que, a pesar de no haber sido jurada, la Constitución de Cádiz tuvo una significativa recepción en el marco de los proyectos constituyentes que se comenzaron a discutir en el espacio rioplatense, en particular en el primer intento serio de organizar a las Provincias Unidas, como fue la Asamblea del año XIII. Y que dicha recepción no sería solo de los artículos de la Constitución sino también de la labor legislativa de las Cortes, de las discusiones que trajo aparejadas en la prensa y los tratados políticos,

\footnotetext{
${ }^{802}$ Ver por ejemplo González, Ariosto. Las primeras fórmulas constitucionales en los países del Plata: 1810-1813. Montevideo: Ed. Claudio García y Cía., 1941; también Levaggi, Abelardo. "Constitución de 1812: presencia latinoamericana". en: Terradillos Basoco, Juan (coord.). La Constitución de 1812: reflexiones jurídicas en la víspera del bicentenario. Cádiz: Diputación de Cádiz, 2006.
} 
integrándose a otros lenguajes y modelos constitucionales disponibles que operaban en el espacio rioplatense. Vínculos muchas veces omitidos por encontrarse en guerra con la metrópoli, al igual que fue enmascarado el influjo del pensamiento francés en las Cortes doceañistas por similares razones.

\section{La Constitución de 1812: fuentes y aportes originales}

El 19 de marzo de 1812 la Constitución era proclamada por las Cortes extraordinarias en medio de un clima de algarabía popular. Surgía como respuesta a la profunda crisis en la que se encontraba la monarquía española a partir de las abdicaciones de Bayona y la invasión francesa, pero fundamentalmente como producto genuino del proceso revolucionario que tenía como eje a la península pero que atravesaba a todo el Imperio. El parlamentarismo español nacía con diputados no sólo peninsulares; pensada como marco jurídico por el conjunto de la monarquía a ambos márgenes del Atlántico, fueron participes en su elaboración representantes de los distintos territorios americanos, aunque designados generalmente de manera arbitraria. Existe cierto consenso historiográfico en considerar que a pesar del variopinto componente ideológico de las Cortes -podemos diferenciar al menos 4 grupos: absolutistas, reformistas moderados, liberales y la diputación americana, que más allá de su heterogeneidad doctrinaria funcionaban en muchos casos como grupo en torno a las reivindicaciones del Nuevo Mundo-, el texto constitucional resultante reflejó en gran medida el ideario de la tendencia liberal. ${ }^{803}$ Esta afirmación no niega el hecho de que la Constitución de 1812, a pesar del predominio liberal, fue fruto de una negociación con los sectores moderados y reaccionarios que poseían una nada despreciable representación en las Cortes extraordinarias. Aun así, significó ésta una clara ruptura con el Antiguo Régimen, fundamentalmente en dos de sus principios medulares: la soberanía nacional y la división de poderes.

Mucho se ha discutido sobre la originalidad y las deudas de la constitución gaditana en relación a otros modelos constitucionales. A grandes rasgos la paternidad liberal de este texto la dotó de significativos vínculos con las Constitución francesa, fundamentalmente de la de 1791 y en menor grado, a la de 1793. Pero aun teniendo en cuenta esta filiación -expresada en su concepción racional normativa, la comprensión de

\footnotetext{
${ }^{803}$ Véase Fernández Sarasola, Ignacio. "La Constitución española de 1812 y su proyección europea e iberoamericana". Revista Fundamentos, Oviedo: Junta General del Principado de Asturias, núm. 2, 2000.
} 
los derechos como naturales y su fundamentación en la soberanía nacional-, la Constitución de 1812 presentaba importantes rasgos originales, entre ellos una lógica argumentativa que se destaca como uno de sus elementos más distintivos. Hablamos del fuerte historicismo nacionalista del que está impregnado prácticamente todo el texto gaditano. Esta corriente alcanzó su cénit en las obras de los ilustrados Francisco Martínez Marina y Gaspar de Jovellanos. Algunos historiadores consideran que aquello en realidad escondía un uso instrumental de la historia por parte del liberalismo, con el objetivo de legitimar, en base a una supuesta tradición, los cambios que traía aparejada la Constitución de 1812 y ocultar de esta manera el parentesco de aquellos con la legislación francesa. ${ }^{804}$

Entre 1808 y 1824 ningún otro espacio se mostró tan proclive a la experimentación constitucional como el que constituía la monarquía española. ${ }^{805}$ Los signos de "modernidad" que poblaron este período son elocuentes: constituciones, declaraciones, publicaciones, procesos electorales, etc. Se puede rastrear algunos antecedentes de lo que podemos denominar como cultura constitucional hispánica hacia las décadas finales del siglo XVIII. Son varios los letrados que a esa altura empezaban a reflexionar en base a la necesidad de una constitución como reaseguro de respeto de los derechos individuales y como mecanismo de equilibrio de poderes. Textos de Victorián de Villava o Valentín de Foronda iban en ese camino, discusiones que no se limitaban sólo a la Península sino que también se daban en el Nuevo Mundo.

La originalidad del texto gaditano, también se puede observar en relación al tratamiento de lo religioso, donde se establece a diferencia de otros textos constitucionales la confesionalidad del estado y la intolerancia hacia otros cultos que no sean el católico. Los textos y la cultura constitucional hispánica en general están impregnados de una fuerte carga de catolicismo. Se ha querido ver en el artículo referente a la religión de la Constitución de 1812 una concesión liberal a los conservadores, pero en realidad éste tenía que ver con un aspecto muy esencial y consecuente con la cultura del primer constitucionalismo hispánico. ${ }^{806}$

Por otro lado, en referencia a la cuestión de los poderes, se creaban dos organismos que tenían como objetivo controlar la acción del monarca: la Diputación

\footnotetext{
${ }^{804}$ Véase por ejemplo Breña, Roberto. El primer liberalismo español y los procesos de emancipación de América, 1808-1824. Una revisión historiográfica del liberalismo hispánico. México: El Colegio de México, 2006.

${ }^{805}$ Portillo Valdés, José María. "La constitución en el atlántico hispano, 1808-1824". Revista Fundamentos, Oviedo: Junta General del Principado de Asturias, n. 6, pp. 123-178, 2010.

${ }^{806}$ Ídem.
} 
permanente y el Consejo de Estado, ambos originales del doceañismo. ${ }^{807}$ Este último, de composición parcialmente estamental, sirvió como remedo de la cámara alta exigida por el realismo, muy afín al parlamentarismo británico, pero que terminó derrotado imponiéndose el formato unicameral de los liberales. Otra característica sobresaliente es la ausencia de una declaración de derechos, distanciándose de esta manera del modelo francés. Y aunque servía para diferenciarse, la realidad es que, como sugiere, Portillo Valdés la ausencia responde a una concepción donde la Nación, el colectivo, tiene primacía en el diseño constitucional. ${ }^{808}$ Los derechos individuales aparecen a lo largo del articulado y en función siempre de limitaciones a los poderes ejecutivo y judicial. ${ }^{809}$

Finalmente, la obra de Cádiz no fue solo en una dimensión jurídico-política, como señala Palti, era también un acto constituyente en la esfera de la lengua. No se puede disociar de lo lingüístico, porque una constitución es indefectiblemente una intervención en el lenguaje. ${ }^{810}$ La Constitución de Cádiz se puede entender, en palabras de Fernández Sebastián, como "un catálogo de definiciones en donde se explica de manera breve, casi aforística, en que consiste la nación, el amor a la patria, la ciudadanía o las Cortes". ${ }^{811}$ Esta exigencia de "legislar sobre el lenguaje" era resultado de la consciencia de los actores del período que los viejos nombres ya no alcanzaban ya a designar las nuevas realidades. ${ }^{812} \mathrm{O}$ en otros casos, era necesario cargar de nuevos sentidos a vocablos ya existentes. Citando a Palti nuevamente, "había, en fin, que refundar, junto con la nación, el idioma que la debía representar" ${ }^{813}$ Una de las operaciones más comunes sobre el lenguaje llevada adelante por el partido liberal, tomando préstamos del historicismo nacionalista del cual hicimos referencia unos párrafos atrás, consistía en legitimar las novedades políticas apelando a viejos términos. El ejemplo paradigmático de ello eran las propias Cortes. ${ }^{814}$ Ante las críticas de los sectores conservadores que veían en la atribución de nuevos sentidos a la antigua terminología una actitud perversa y peligrosa,

\footnotetext{
${ }^{807}$ Con respecto a la Diputación permanente, había existido bajo los Habsburgo un organismo con esa misma denominación. Su función era la de monitorear que se cumplieran las disposiciones de la Hacienda pactadas con el rey después de la conclusión de la reunión de las Cortes, pero en general se caracterizaban por estar cooptada por la monarquía. Los liberales en su afán historicista, revistieron con el mismo nombre al nuevo cuerpo, pero a diferencia del anterior, buscaban realmente que ejerciera un control y limitación al rey.

${ }^{808}$ Portillo Valdés, J., Revolución de nación..., pp. 385-387.

${ }^{809}$ Fernández Sarasola, Ignacio, óp. cit., p. 23.

${ }^{810}$ Palti, E., óp. cit., p. 69.

${ }^{811}$ Fernández Sebastián, J., óp. cit., p. 6.

${ }^{812}$ Palti, E., óp. cit., p. 69.

${ }^{813}$ Ídem.

${ }^{814}$ Ibid., p. 71
} 
Arguelles se defendía afirmando que encontraban en la historia fundamentos reales para sus propuestas:

Sólo personas que ignoren la historia del pueblo español, de la nación misma de que son individuos, pueden llamar ideas modernas, innovaciones de los pretendidos filósofos de estos tiempos, teorías de los publicistas, máximas perniciosas de los libros franceses, y qué sé yo cuántas otras inepcias, que sólo sirven para insultar la razón [...] Yo procuraré tranquilizar a cualquiera que recele de esta cuestión con razones y autoridades sacadas, no de monitores franceses, no de escritores extranjeros, ni filósofos novadores, sino de las fuentes puras de la historia de España, de los venerables y santos monumentos de nuestra antigua libertad e independencia, depositados para eterna gloria del nombre español en los fueros de Vizcaya y de Navarra, en el de Sobrarbe, en la constitución de Aragón, en los usages de Cataluña, en la constitución de Valencia, en las leyes de Castilla, envidia delas naciones mismas que más se han aventajado en las libertades de sus pueblos. ${ }^{815}$

\section{Proyección gaditana en Iberoamérica}

La Constitución de 1812, promulgada en el marco de una Cádiz asediada por el ejército napoleónico, logró a la postre vencer las particularidades de su nacimiento, y transcender e irradiar al constitucionalismo europeo e iberoamericano en la siguiente década. No solo fue traducida a varios idiomas, sino que tuvo una importante recepción en aquellos países que no poseían una tradición constitucionalista como era el caso de Portugal y de Italia, donde ganó el apoyo y fue difundida por los grupos liberales y progresistas. A pesar de estar emparentada con las francesas, contaba con la ventaja de ser más moderada que estas y no traer consigo el estigma de haber desembocado en el llamado "periodo de terror".

El primer impacto de la "Pepa"-como se la conocía popularmente a la Constitución gaditana- en Hispanoamérica, fue precisamente el de encauzar a sus provincias a las experiencias constitucionales. La Constitución es jurada y puesta en práctica, no sin resistencia como se sabe, en aquellas regiones que aún permanecían leales, pero también circuló y dejó su huella en los territorios insurgentes. Entre 1810 y 1824 se consolidó una cultura constitucional en el Atlántico hispánico, con una fuerte raíz en el derecho de gentes, particularmente en relación al problema de la soberanía nacional. Los españoles peninsulares encontraron en la constitución una herramienta viable para la resistencia a la invasión francesa y al intento de mediatización que

\footnotetext{
${ }^{815}$ Arguelles, Agustín de, DSC, 6/6/1811.
} 
Napoleón ambicionaba para la monarquía católica. En América, el paso de las juntas a los congresos constituyentes también coincidió con el momento en que fue necesario afirmarse como un cuerpo independiente de la metrópoli. Aun así debe decirse que hasta el regreso de Fernando VII, la respuesta constitucional fue pensado por muchos para el conjunto del espacio hispánico. ${ }^{816}$ Existía cierta idea de que mediante una constitución se podía recomponer un cuerpo político provincial y, a partir de ahí, intentar otra del cuerpo general de la monarquía. ${ }^{817}$

La mixtura de elementos históricos hispánicos que el texto gaditano conllevaba, con la filosofía iusnaturalista, significó una sencilla asimilación por parte de las élites ilustradas americanas, aventajando de esa forma a otros modelos disponibles como el británico y el francés. En ese sentido, una de las claves que permitió esta aceptación de la Constitución en las regiones realistas como también potenciar su recepción en los territorios insurgentes, fue que su concepción de la ciudadanía estaba ligada a la tradicional categoría de vecino. Los ciudadanos eran el conjunto de individuos bautizados, reconocidos y reconocibles del cuerpo de la Iglesia, pertenecientes por lo tanto a la comunidad parroquial. Los alcaldes de barrio y los curas continuaban siendo capitales para acreditar la condición de vecindad. La nación española era entendida, de esta manera, como la reunión de vecinos padres de familia que se organizaban en pueblos o provincias. ${ }^{818}$

Las primeras fórmulas constitucionales y legislaciones americanas también apelaron al pasado, a la justificación histórica, para legitimarse. En sus reivindicaciones ante la metrópoli, recurrieron a las antiguas Leyes de Indias y a la concepción de la monarquía plural de los Austrias. La perspectiva historicista recorrió desde la apelación al pacto subjectionis hasta la justificación de la ruptura condenando la conquista y realzando algunos aspectos del pasado prehispánico.

En palabras de Marcela Ternavasio:

La necesidad de pasar de una etapa juntista a otra constituyente en Cádiz fue producto de la precariedad de las juntas y de la necesidad de legitimar en un nuevo sujeto de imputación soberana - la nación española- el poder asumido de manera provisional por aquellos cuerpos (...) Lo ocurrido en América fue similar, sumado al hecho nada sencillo

\footnotetext{
${ }^{816}$ Portillo Valdés, José María. "La constitución ..."

${ }^{817}$ En 1810 el Deán Funes explicaba que sólo mediante medida de tipo constitucional, de reformulación del pacto, podía imaginarse una reconstrucción de la cadena monárquica española. Gazeta extraordinaria, 7 de agosto de 1810 .

${ }^{818}$ Para profundizar sobre estos temas véase Tío Vallejo, Gabriela. "Rupturas precoces y legalidades provisorias. El fin del poder español en el Rio de la Plata". Revista Ayer, núm. 74, 2009, pp. 133-162.
} 
de que cada comunidad debía adoptar una posición frente a las Cortes peninsulares y decidir si se integraba en esa nueva soberanía transatlántica. ${ }^{819}$

El Río de la Plata, aun no habiendo vivido el "experimento de Cádiz", con excepción de Montevideo y algunas provincias altoperuanas, como otras regiones del imperio colonial español, inició igualmente de manera muy temprana un período constitucional marcado por la elaboración de reglamentos, estatutos y proyectos de constitución, que intentaron ordenar lo que a la postre fue un derrotero bastante sinuoso durante toda la primera mitad del siglo XIX. ${ }^{820}$

\section{La Asamblea del año XIII y la impronta gaditana}

El triunfo de las fuerzas de Rondeau sobre los sitiados de Montevideo en el Cerrito el 31 de diciembre fue una excelente forma de terminar el año para los revolucionarios, y más aún cuando significó un preanuncio de la buena fortuna militar que los iba a seguir acompañando a comienzos de 1813. El escarmiento que San Martin y sus Granaderos a caballo dieron a las tropas de desembarco de la escuadrilla realista en el convento de San Lorenzo fue seguido el 20 de febrero por la nueva derrota que Belgrano, al mando del Ejercito del Norte, infringió a las tropas de Pío Tristán en la Batalla de Salta. Ésta puso poco menos que en fuga a Goyeneche, que temeroso de la insurrección cochabambina, abandonó Potosí, para poco después renunciar al mando. Con esta triple victoria parecía quedar legitimado en el plano militar el pronunciamiento de octubre.

La Asamblea se inauguraba en el marco de un clima de gran expectativa. El 31 de enero se produjo el juramento de los diputados, invocando la soberanía nacional como había sucedido en Cádiz, que fue acompañado por desfiles de tropas, fiestas nocturnas y adornos en la Plaza de la Victoria y el Cabildo. Ese mismo día la Asamblea dictó un decreto cuyo primer artículo declaraba "que reside en ella la representación y el ejercicio de la soberanía de las Provincias Unidas del Rio de la Plata”, y al determinar que debían promulgarse sus decisiones suprimió la frase "a nombre de Fernando VII", lo cual iba prefigurando el decidido propósito de encaminar sus pasos hacia la declaración de la independencia.

\footnotetext{
${ }^{819}$ Ternavasio, M., Gobernar la revolución..., p. 57.

${ }^{820}$ Es necesario ser más precisos aquí. Aunque no se llegó a aplicar, Salta y Jujuy también la juraron durante la efímera ocupación realista tras la derrota de Belgrano.
} 
Este rumbo rupturista al que se orientaba el Río de la Plata, no implicaba que el texto constitucional ni la legislación gaditana no formaran parte del repertorio de fuentes que permitieran pensar posibles recorridos constitucionales. ${ }^{821}$ Haber puesto en tela de juicio la legitimidad de las Cortes cuestionando la desigualdad de representación, no impedía que se compartiera muchas de las ideas que habían inspirado sus leyes. Un ideario, que como hemos dicho, era producto de una cultura política y constitucional común en el mundo hispánico.. Con motivo de la llegada al Rio de la Plata las noticias de la promulgación de la Constitución española, Nicolás Herrera -miembro de la Logiaseñalaba en la Gazeta la evolución ideológica compartida entre la península y América durante esos años revolucionarios. Destacaba en los españoles que hubieran podido elegir al gobierno que mejor se les acomodaba, restringiendo las facultades de su Rey, y que con la Constitución, la soberanía dejaba de estar depositada en aquel, sino solamente en la Nación:

¡Cuántas verdades que hoy son comunes, habrían quizá costado la vida al que imprudente las hubiese publicado en los principios de la revolución española! Estas doctrinas que tan escandalosas eran al común de los pueblos, hoy las vemos erigidas en dogma político y publicadas como leyes fundamentales de su gobierno. Ya todos saben que el único origen de toda autoridad pública es la voluntad de los pueblos, bien estén situados en la antigua Europa como en la moderna América [...] He aquí como sensiblemente se han cambiado las ideas del pueblo español. Ya los americanos, y los europeos, reconocen una misma base a su sistema. ${ }^{822}$

Se pregunta por qué entonces continúa la "guerra civil", y se responde atribuyéndola a la permanencia de las actitudes y los vicios de las autoridades que no están dispuestos a llevar a la práctica la igualdad tantas veces proclamada. A pesar del recorrido común realizado por el conjunto del mundo hispánico en relación al pensamiento político, era en la distancia que existía entre la idea de igualdad entre españoles y americanos y la realidad concreta, donde estaría la causa de la prolongación de la guerra. La dirigencia porteña remarcaba al comenzar el año XIII que las Cortes, con la promulgación de la Constitución española, a pesar de sus avances en el terreno de libertades, consagraba la desigualdad entre América y España, clausurando cualquier posibilidad de negociación: "Las Cortes han declarado a la faz del mundo que no quieren conciliación con las

\footnotetext{
${ }^{821}$ La Junta había enviado varios comunicados a las Cortes no reconociendo la representatividad de los diputados suplentes por Buenos Aires elegidos en Cádiz: Francisco López Lisperguer, Luis Velazco y Manuel Rodríguez.

${ }^{822}$ Gazeta Ministerial nro. 24 18/9/12: 285.
} 
provincias de América que se hallan en revolución. Desechando la conciliación han declarado implícitamente que es su voluntad, que las armas decidan la cuestión presente, que si los americanos son vencidos se han de someter por derecho de conquista a las leyes que las Cortes le han dado". ${ }^{823}$

La recepción de determinados textos jurídicos y constitucionales la podemos rastrear con anterioridad a la labor de la Asamblea. Sin llegar a compartir la tesis de Julio V. González, que veía al conjunto del movimiento revolucionario rioplatense como herencia directa de la revolución peninsular, son destacables algunos puntos de contacto entre ambos procesos. ${ }^{824}$ Es importante tener en cuenta que desde fines de 1811 circuló en el espacio rioplatense el "Proyecto de Constitución Política de la Monarquía Española presentado a las Cortes Generales y extraordinarias por su Comisión de Constitución", impreso en Cádiz en forma de folleto. ${ }^{825}$ En la reglamentación sobre libertad de imprenta de abril de 1811 dictada por la Junta Grande por iniciativa del Deán Funes se percibe ya cierta ascendencia gaditana, cuestión que abordaremos en profundidad en un capítulo más adelante. Como así también en el reglamento de división de poderes de octubre del mismo año establecido por la Junta Conservadora, muy similar al reglamento provisional del poder ejecutivo sancionado por las Cortes en enero de 1811. El padre intelectual del reglamento, una vez más el clérigo Funes, demostraba nuevamente su conocimiento y apego por la ruta emprendida en la península, donde también se había pasado del juntismo a un reglamento de división de poderes. Como señala Ternavasio, "la noción de la división de poderes ingresaba en el Río de la Plata por la vía gaditana y que fue a través del gesto de rechazo a participar en aquellas lo que permitió a los americanos a interiorizarse en el significado concreto de dicho principio". 826

Lo llamativo es que al conocerse el decreto de las Cortes sobre división de poderes del 28 de octubre de 1810, la prensa porteña había criticado la intervención "abusiva" del legislativo en los asuntos de gobierno: "Las Cortes han ocupado el lugar de la soberanía nacional erigida para el ejercicio de la voluntad general, y ya sentada en

\footnotetext{
${ }^{823}$ Gazeta Ministerial, 1 de enero de 1813.

${ }^{824}$ Para el autor es la revolución española la que provoca un período de iniciación democrática en el Río de la Plata inmediato a la Revolución de Mayo con el llamado a elección de un diputado vocal a la Junta Central. A su vez, entenderá que prácticamente todas las declaraciones y leyes más importantes de la Asamblea del año XIII son una glosa de iguales actos consumados por las Cortes de Cádiz. Muchos de sus planteos se entienden por el contexto en el que escribió esta obra y su afinidad política con la causa republicana en plena Guerra Civil Española. González, Julio V., óp. cit.

${ }^{825}$ Levaggi, Abelardo. óp. cit., p. 77.

${ }^{826}$ Ternavasio, M., Gobernar la Revolución..., p. 68.
} 
el carro del gobierno, y usando del Poder ejecutivo (...) Si sus funciones son las de primer orden, no puede ejercer las del segundo, pues el poder ejecutivo con el legislativo no pueden juntarse, sin exponer el cuerpo político, a ser presa de la violencia contra la cual fue instituido". ${ }^{827}$ Ya con el Primer Triunvirato y como parte de su estrategia para justificar indirectamente la disolución de la Junta Conservadora, se volvía a cuestionar esa arrogación de funciones ejecutivas, cuando en una carta al editor de la Gazeta se comentaba que en una tertulia se había observado "la mala conducta de las Cortes con la Regencia; y quedamos convencidos de que el sistema de abrogarse aquellos diputados un poder sin límites, y reducir la Regencia a la esfera de un tribunal el más subalterno e impotente, podría contagiarnos desgraciadamente, sino tomábamos medidas de precaución, en los casos que tuviesen analogía con aquellos". 828

Pero es en el período hegemonizado por la Asamblea General Constituyente y fundamentalmente en los proyectos constitucionales que fueron encargados por este cuerpo donde podemos observar la sombra de la Carta Magna doceañista con mayor intensidad. El mismo Reglamento de Policía Interior, único documento normativo de la Asamblea a falta de un estatuto propio, fue copiado casi textualmente del sancionado por las Cortes extraordinarias. ${ }^{829}$

Desde El Grito del Sud se insistía recurrentemente en la necesidad de ilustrar al pueblo como condición sine qua non para avanzar en el camino constituyente, y en ese sentido, se planteaba la importancia de la divulgación y discusión de modelos constitucionales vinculados de alguna manera a la realidad rioplatense:

Es por lo tanto deseable, que a la mayor brevedad al pueblo se le den cuando menos nociones nada equívocas, y de una manera sencilla y la más inteligible, de los derechos que le son imprescriptible. Sería también muy bueno se publicasen impresas las constituciones de los Estados unidos de Norte América: las que ha formado la nación Venezolana, y las que han hecho célebres y felices a otras repúblicas, en lo antiguo y en lo moderno. Hasta ahora no se le ha presentado para que se ilustre, sino el pacto social de Juan Jacobo Rousseau. Esta obra por excelente y aun magistral que sea, contiene muchas ideas abstractas, que el pueblo es casi imposible que llegue a comprenderlas [...] no

\footnotetext{
${ }^{827}$ Gazeta de Buenos Aires, 7 de marzo de 1811.

${ }^{828}$ Gazeta nro. 8 (29/11/11): 29

829 "Reglamento de Policía Interior", reproducido en Silva, Carlos A. Poder Legislativo de la Nación Argentina. Buenos Aires: Cámara de Diputados de la Nación, tomo I, 1937, pp. 74-77.
} 
estamos ciertos si las bellas reglas que da el autor teóricamente, tienen la misma belleza en

la práctica... ${ }^{830}$

En noviembre de 1812 el nuevo triunvirato se dirigió a la Sociedad Patriótica a fin de pedirle que estudiara aspectos relacionados con la administración del Estado. ${ }^{831}$ Para ello fue designada una comisión encabezada por su presidente Monteagudo. ${ }^{832}$ A su vez, el ejecutivo nombró una comisión oficial con el objetivo de elaborar un proyecto de código político que sirviera de base para las deliberaciones de la Asamblea. ${ }^{833}$ Finalmente ambos terminarían redactando proyectos constitucionales. ${ }^{834}$ Se le sumarían a estos dos documentos, otro que se considera como el proyecto propio de la Asamblea, y un cuarto atribuido al diputado artiguista Felipe Santiago Cardoso, de impronta federalista y con varios puntos de contacto con el constitucionalismo norteamericano. ${ }^{835}$

${ }^{830}$ El Grito del Sud, 20 de octubre de 1812.

${ }^{831}$ En la Gazeta Ministerial nro. 32 del 13/11/12 se escribía sobre la necesidad de una buena legislación, llamando a los ilustrados a la mayor dedicación, a ser originales y no repetir costumbres del pasado. Se reproducen las palabras de un sabio editor español que habla sobre el desarrollo de las ciencias y las artes y la importancia de la novedad: "tantas ideas y afectos rutinarios, que sin tener más fuerza que la del hábito, acabarían de precipitarnos en el abismo, a cuyo borde nos han arrastrado". pp. 335-336. El artículo, del que no se señala su origen, hemos determinado que corresponde al titulado "Ideas sobre la rutina", publicado originalmente en del Diario de Madrid del 20 de mayo de 1808. Considerado el primer diario publicado en España, fue fundado el 1 de febrero de 1758. Desde el 10 de mayo hasta el 17 de junio de 1808, período al que corresponde la cita, quedó en manos directas del Gobierno bonapartista, controlados personalmente por Murat. Mostrando una orientación esencialmente informativa, muy oficialista, con alguna concesión a novedades literarias, casi siempre francesas. Pero el diario se convierte en periódico deficitario y con escasos lectores, no tiene utilidad aparente al régimen napoleónico, cesa el 17 de junio. El "sabio editor español" al que se hacía referencia puede corresponder a José Marchena (Utrera, 18 de noviembre de 1768 - Madrid, 31 de enero de 1821).Fue un político, escritor y publicista ilustrado y afrancesado. Pasó la mayor parte de su vida exiliado en Francia, a donde se marchó para escapar de la Inquisición y donde tuvo una participación muy activa en la vida política e intelectual de la República y del Imperio napoleónico, colaborando con personajes tan destacados como Brissot y Sieyès. Volvió a España en 1808 con José I Bonaparte, ocupando diversos cargos en su administración, y tuvo que abandonarla de nuevo tras la derrota del ejército francés en la Guerra de Independencia. Después de un segundo exilio en Francia volvió a España tras el pronunciamiento del general Riego, con la idea de participar en la vida política española, pero la muerte lo sorprendió a los pocos meses de su regreso.

${ }^{832}$ El resto de la comisión estaba compuesta por Juan Larrea, Francisco José Planes, Tomás Valle, Antonio Sáenz y el doctor Dongo, en calidad de secretario. El Grito del Sud, 10 de noviembre de 1812.

${ }^{833}$ La comisión estaba integrada en este caso por Valentín Gómez, Manuel José García, Pedro José Agrelo, Pedro Somellera, Nicolás Herrera, Hipólito Vieytes y Luis Chorroarín -luego remplazado por Gervasio Antonio de Posadas-. Gazeta Ministerial del gobierno de Buenos Aires, 13 de noviembre de 1812.

${ }^{834}$ González, Ariosto, óp. cit.

${ }^{835}$ Con una partición destacada desde la misma Revolución de Mayo, Cardoso se vinculó hacia el año 1811 con el sector morenista formando parte activa de la Sociedad Patriótica y el movimiento del 8 de octubre. Con el ascenso de esta fracción al poder, Cardoso se irá distanciando debido al cambio que este grupo experimenta hacia una posición cada vez más centralista con respecto al poder político. $\mathrm{Su}$ militancia a favor del proyecto federal de Artigas lo posicionará ya a comienzos de 1813 como un elemento disidente para el gobierno porteño, al punto que se ordena su detención por fuerzas de seguridad en julio de ese año. Entre los papeles que se le secuestran de su domicilio se encuentran las constituciones de Estados Unidos, la de Venezuela y la española de 1812. Herrero, Fabián. "Fragmentos para armar. Indicios sobre la presencia artiguista en Buenos Aires". Revista de Indias, vol. LXX, núm. 250, pp. 623$650,2010$. 
El proyecto redactado por la Comisión oficial es el que mayores vínculos presenta con la Constitución de 1812. Consta de 263 artículos clasificados en 22 capítulos. En el primero establece que las Provincias Unidas del Río de la Plata forman una república libre e independiente, que "la soberanía del Estado reside esencialmente en el pueblo" y que "el pueblo es la reunión de todos los hombres libres de la república". ${ }^{836}$ En materia religiosa al igual que la mayoría de las legislaciones sobre este tema en todo el mundo hispánico, el proyecto coincide con lo acordado por los diputados gaditanos al disponer que la religión del Estado es la católica (cap. III, art. 1), pero se distancia de aquélla al consignar que "ningún habitante de la república puede ser perseguido ni molestado en su persona y bienes por opiniones religiosas" (art. 3). Podemos afirmar, sin temor a equivocarnos, que fue mucho más marcada la impronta religiosa y clerical en el liberalismo peninsular en comparación con el rioplatense. No sólo con respecto a las disposiciones jurídicas, sino sobre todo en la construcción discursiva de uno y otro. En relación a las disposiciones del proyecto con respecto a la ciudadanía y el régimen electoral, se perciben varios puntos de contacto con la Constitución española al organizar al igual que lo establecido en la metrópoli un sistema electoral de tercer grado.

El proyecto elaborado por la Sociedad Patriótica se destaca, en cambio, por la riqueza de fuentes que maneja, y fundamentalmente, por ser el más original de los presentados a la consideración de la Asamblea Constituyente. ${ }^{837}$ Fiel exponente del pensamiento del grupo revolucionario, el texto proclama la independencia de las Provincias Unidas, y a diferencia del proyecto de la comisión oficial, dedica dos capítulos a la declaración de los derechos individuales, emparentándose con las declaraciones francesas y distanciándose de esa manera del modelo español, que como hemos dicho los incluye a lo largo de todo el articulado. ${ }^{838}$ En este mismo sentido, el proyecto sí hace referencia al derecho a la igualdad omitido por las Cortes, y deja

\footnotetext{
836 "Proyecto de Constitución para las provincias del Rio de la Plata, formado por una comisión especial nombrada en 1812”. En Ravignani, Emilio, óp. cit., tomo 6, pp. 607-616.

837 "Proyecto de Constitución para las Provincias Unidas del Rio de la Plata en la América del Sud". En Ravignani, Emilio, óp. cit., tomo 6, pp. 616-633.

${ }^{838}$ En El Grito del Sud del 29/12/12 se había publicado una memoria titulada "Introducción al tratado de los derechos del hombre constituido en sociedad y sus obligaciones" donde se hacía referencia a la "revolución política" en la que se encontraban y que, por lo tanto, no se trataba solo de declarar la independencia sino de "darnos un gobierno liberal". Realiza también un llamamiento a "los hombres ilustrados que hacen de profesión la jurisprudencia, a ilustrar al pueblo y a no esconderse, ni retirarse". pp. 197-198. La convocatoria pareciera responder a la poca concurrencia que estaban teniendo las reuniones de la Sociedad Patriótica, situación descripta en una carta de un socio publicada en ese mismo número del periódico.
} 
claramente establecido que "todo hombre gozará de estos derechos en la Provincias Unidas sea americano o extranjero, sea ciudadano o no". ${ }^{839}$ Determina también que "la religión católica es y será siempre la del Estado", y aunque establece la tolerancia religiosa, se acerca más al texto doceañista al enfatizar en la protección que el Estado le brindará a culto católico, imponiendo similar castigo al que atentara contra él como si lo hiciera contra la misma Constitución. Con respecto a la división y forma de los poderes, el proyecto de la Sociedad pareciera estar inspirado en los textos constitucionales norteamericanos y en la Declaración venezolana. Debe destacársela propuesta de ejecutivo de carácter unipersonal, planteo que tenía a Monteagudo como principal impulsor desde sus tiempos de redactor de la Gazeta y que finalmente terminará imponiéndose en el cuerpo constituyente.

\section{Dividir y concentrar el poder}

En relación a la labor orgánica de la Asamblea, a pesar de no haber dictado constitución alguna, estableció por medio de leyes una organización rudimentaria de los poderes públicos, determinando su funcionamiento y fijándole límites al Estado. El 27 de febrero de 1813 el congreso aprueba el "Estatuto dado al poder ejecutivo", en el que se reglamentan sus atribuciones. Se mantiene la estructura colegiada de tres miembros y se le adjudica la tarea de "ejecutar las leyes y decretos soberanos" y de "gobernar al Estado"; mientras que la Asamblea se reserva la atribución de nombrar, enjuiciar y remover a cualquiera de sus miembros. El Estatuto se presentó públicamente en El Redactor de la Asamblea, periódico a cargo de Cayetano Rodríguez que, como solía hacer con lo tratado en cada sesión, acompañó la crónica con unas consideraciones sobre la división de poderes. Comenzaba diciendo: "la misma libertad conduce al despotismo y se convierte en un germen de anarquía y desolación, cuando los tres poderes que dirigen el cuerpo social se confunden en el ejercicio de sus atribuciones". Y más adelante agrega "la Asamblea General faltaría por lo mismo a sus primeros deberes, si después de haber constituido el Supremo Poder Ejecutivo lo dejase fluctuar en la

\footnotetext{
${ }^{839}$ Estos planteos ya los podemos encontrar en un artículo atribuido a Monteagudo en la Gazeta de Buenos Aires del 15 y 28 de febrero de 1812: "Todos los que no tengan derecho a ser ciudadanos deben dividirse en dos clases: extranjeros y simples domiciliados. Aquellos son los que no han nacido en el territorio de las provincias unidas: estos los originarios de ellas que por su estado civil o accidental están excluidos del rango de ciudadanos. Unos y otros deben ser considerados como hombres: su derecho es igual a los oficios de humanidad, aunque no gocen de las distinciones que dispensa la patria a sus hijos predilectos."
} 
perplejidad de sus atributos, exponiendo a tocar los límites del abuso, o proceder en deliberaciones con una lentitud incierta". ${ }^{840}$ Como nos sugiere Marcela Ternavasio en su trabajo ya mencionado, a pesar de que la Asamblea se esmeraba en exhibir su supremacía sobre el ejecutivo, las funciones asignadas y la actividad concreta de este último no parecieron ser tan despreciables. El Triunvirato continuaba siendo un verdadero centro de poder que acaparaba en su órbita la mayoría de los asuntos de importancia. En este sentido el caso rioplatense se alejaba bastante del modelo gaditano de clara supremacía del legislativo. Es posible inferir que esta situación se debió a la afinidad política entre los protagonistas de ambos poderes en el Río de la Plata. La Sociedad Patriótica y la Logia habían logrado colonizar los principales cargos del estado revolucionario.

Ya en agosto de 1813, la deriva hacia la concentración del poder que va teniendo la Logia bajo la conducción de Alvear, se percibe por ejemplo en las páginas de la Gazeta cuando se mencionan las amplias atribuciones del poder ejecutivo en Estados Unidos, con el poder de sancionar leyes o vetarlas. ${ }^{841} \mathrm{El}$ artículo se cierra citando a Burke y su reflexión sobre que "el pequeño catecismo de los derechos del hombre se aprende pronto, y las pasiones sacan las consecuencias." ${ }^{842} \mathrm{El}$ conflicto con el artiguismo luego del rechazo a los diputados orientales, aunque no sea mencionado aún abiertamente, se empezaba a expresar en este tipo de reflexiones, que irían ganando cada vez más un tono elitista y conservador. Y es posible que las referencias al modelo estadounidense respondieran también a esa disputa.

Cuando el contexto se volvió más adverso a la revolución, con las derrotas de Belgrano en Vilcapugio y Ayohuma, la llegada de refuerzos a Montevideo, el conflicto ya del todo abierto con el artiguismo, y las preocupantes novedades sobre los éxitos conseguidos por la resistencia española a la ocupación francesa, la dirigencia rioplatense tendería a una mayor concentración del poder ejecutivo. ${ }^{843}$ La Asamblea General le otorgaría no solo facultades extraordinarias, sino que terminaría decidiendo el remplazo del Triunvirato por una autoridad unipersonal: el Directorio. ${ }^{844}$ La idea de un dictador plenipotenciario, como hemos dicho, ya venía siendo publicitada por Monteagudo desde

\footnotetext{
${ }^{840}$ El Redactor de la Asamblea, en Ravignani, Emilio. óp. cit., tomo I, pp. 16-17.

${ }^{841}$ Gazeta Ministerial nro. 66 4/8/13: 505

${ }^{842}$ Ídem.

${ }^{843}$ Ternavasio, Marcela, Gobernar la revolución....

844 "Reforma del Estatuto Provisorio del Supremo Gobierno". En Ravignani, Emilio. óp. cit., tomo I, p. 83.
} 
marzo de 1812 en su periódico Mártir o Libre. ${ }^{845}$ Pero como el mismo Alvear reconoció en sus "Narraciones", había sido extremadamente difícil convencer a los diputados debido a la animadversión a concentrar el poder en una sola persona que existía en la Asamblea. La elite dirigente recurrió a la constitución norteamericana de 1787 y su régimen presidencialista a fin de legitimar el nuevo rumbo tomado.

Junto a la creación del Director Supremo, la reforma del Estatuto dispuso la conformación del Consejo de Estado, de similares características al establecido por el proyecto de constitución de la comisión oficial, inspirado como hemos dicho en la Constitución española de 1812. Finalmente la Asamblea se fue convirtiendo en un agente legitimador del ejecutivo, perdiendo sus originales funciones de equilibrar y evitar sus potenciales excesos. Unos días después de la reforma se podía leer en la Gazeta Ministerial: "esta grande y necesaria medida, acaso habría sido mortal para el estado, si ella no fuese dictada por un poder legislativo preexistente, y si no tuviese el sello de un consentimiento que casi se confunde con la aclamación universal del Pueblo". 846

\section{Soberanías en disputa}

La cuestión de la soberanía fue otro de los puntos que generó mayor conflictividad en las precoces Provincias Unidas del Rio de la Plata. A pocas semanas de la instalación de la Asamblea, su presidente Carlos María de Alvear propuso una moción que definiera que "los diputados de las Provincias Unidas, lo son de la nación en general, sin perder por esto la denominación del pueblo al que deben su nombramiento, no pudiendo en ningún modo obrar en comisión”. En el comentario sobre la sesión, El Redactor de la Asamblea decía: “[...] es indudable que por este principio es puramente hipotética la contradicción del interés parcial de un pueblo con el común de la Nación, resulta sin embargo que en el concurso de ambos, este debe

\footnotetext{
845 “¿Qué expediente deberá tomar la asamblea para dar energía al sistema, prevenir su decadencia y acelerar su perfección? La necesidad es urgentísima, el conflicto extraordinario y la salud pública es la única ley que debe consultarse: el voto de los pueblos está ya expresado de un modo terminante y solemne: su existencia y libertad son el blanco de sus deseos: todo lo que sea conforme a estos objetos, está antes de ahora sancionado por su consentimiento: últimamente, ninguna reforma parcial y precaria podrá salvarnos, sino se rectifican las bases de nuestra organización política. Yo no encuentro sino dos arbitrios para conciliar estas miras: declarar la independencia y soberanía de las provincias unidas o nombrar un dictador que responda de nuestra libertad, obrando con la plenitud de poder que elijan las circunstancias y sin más restricción que la que convenga al principal interés." Mártir o Libre, 29 de septiembre de 1812 .

${ }^{846}$ Gazeta Ministerial del Gobierno de Buenos Aires, 2 de febrero de 1814.
} 
prevalecer, determinando en su favor la voluntad particular de cada diputado considerado distributivamente." ${ }^{, 847}$

De esta manera la Asamblea, al subordinar a los "pueblos" al novedoso principio de la soberanía nacional, seguía los pasos de la Asamblea Nacional francesa y de las Cortes de Cádiz. El artículo núm. 11 de ésta última establecía la superioridad nacional sobre los territorios. Muñoz Torrero, vocero de los liberales, había alertado en las Cortes que la federalización de la soberanía, no sólo en relación a América sino también en el marco de la península, pondría en serio riesgo la monarquía. En la concepción de los liberales peninsulares las Juntas provinciales debían ser sólo un mero conducto por donde el gobierno central comunicase a los pueblos sus órdenes, reservándose solo el gobierno económico.

Cayetano Rodríguez y sus pares parecían olvidar las fuertes críticas lanzadas desde la prensa al congreso peninsular, cuando denunciaban el espíritu autoritario y centralista de las Cortes. Al conocerse la sanción de la Constitución española la dirigencia porteña decía en noviembre de 1812: "No se ignora que nadie representa a una Nación, sino los diputados que cada pueblo haya nombrado libremente, y en número proporcional a su población; y que estos diputados no tienen más poder que el que le hayan dado sus representados". 848

Los mismos que habían esgrimido el principio de la fragmentación y retroversión de la soberanía a los "pueblos" para oponerse a las autoridades peninsulares y legitimar su planteo autonomista, hoy entendían perjudicial a los intereses de la nación el "mandato imperativo" de los diputados. La elección de la suplencia en Cádiz había sido criticada en su momento por la prensa porteña justamente desde la concepción contraria: “[...] los miembros que deben componerlas [a las Cortes] han de ser todos procuradores nombrados por los pueblos, y llevar consigo los poderes que les hubiesen otorgados, porque son las únicas credenciales con que son reconocidos, incorporados y admitidos a deliberar en los negocios que tratasen." 849

Como observamos nuevamente, más allá de ciertas convicciones doctrinarias que indudablemente poseían, la dirigencia revolucionaria re significaba y adecuaba su discurso a las necesidades políticas de la coyuntura, recurriendo a aquellos conceptos y sentidos que fueran útiles a la causa última. En momentos cuando se hacía urgente la

\footnotetext{
${ }^{847}$ El Redactor de la Asamblea, en Ravignani, Emilio. óp. cit., tomo I, pp. 20-21.

${ }^{848}$ Gazeta Ministerial del Gobierno de Buenos Aires, 18 de noviembre de 1812.

${ }^{849}$ Gazeta de Buenos Aires, 28 de febrero de 1811.
} 
consolidación del estado nacional, en situación de guerra abierta contra la antigua metrópoli, era fundamental la unidad bajo una sola cabeza, y para la dirigencia porteña esa era la antigua sede administrativa del virreinato. ${ }^{850}$ Este afán centralista, que se volvió dominante en la primera década bajo la concepción de una "soberanía única", va a encontrar igualmente fuertes resistencias expresadas en el marco de la Asamblea por el artiguismo y sus proposiciones de tipo confederal. ${ }^{851}$ El rechazo de la diputación oriental por parte de la facción dominante responde a este conflicto que, con el correr de los meses, se irá agudizando hasta implicar el enfrentamiento en el plano militar. Las "Instrucciones" traídas por los diputados de la Banda Oriental postulaban un sistema confederal para las Provincias Unidas, presentando algunos lineamientos similares al proyecto de constitución presentado por el diputado Felipe Santiago Cardoso. ${ }^{852}$

En general todos los congresos constituyentes hispanoamericanos enfrentaron el mismo problema de la soberanía en su dimensión político-territorial. En el caso rioplatense la Asamblea no pudo resolver el conflicto y éste se proyectará más allá de 1815. El choque entre la vocación autonomista de las provincias del interior y el centralismo de la dirigencia porteña, con el trasfondo de los proyectos económicos y sociales que cada uno de alguna manera implicaba, marcarán el ritmo político del naciente estado-nación en las siguientes décadas.

Pero no sólo la discusión estaba planteada en términos de soberanías contrapuestas. Para la facción dirigente, la idea de proyectos alternativos, o más aun, de elementos opositores dentro del recinto, era contraria al principio de voluntad general tan característico en el primer liberalismo hispánico. La misma idea de dictar una constitución tenía también como objetivo acabar con esa falta de unidad denunciada, como se puede observar en este artículo reproducido en El Grito del Sud:

¿Qué será cuando la falta de constitución, deja un campo franco para dilatarse en opiniones, y querer reducir a todos al propio dictamen, aunque este no sea sino un tejido

\footnotetext{
${ }^{850}$ Chiaramonte, José Carlos. "La cuestión de la soberanía en la génesis y constitución del estado argentino", Historia Constitucional (revista electrónica), n. 2, 2001.

${ }^{851}$ Goldman, Noemí. "Crisis del sistema institucional colonial y desconocimiento de las Cortes de Cádiz en el Río de la Plata". en Chust Calero, Manuel (coord.). La eclosión juntera. México: Fondo de Cultura Económica, 2007.

${ }^{852}$ Fabián Herrero considera, y compartimos esa apreciación, que existen igualmente significativas diferencias entre las "Instrucciones" y el "proyecto federal" de Cardoso. Las primeras se encuentran en línea a un modelo de tipo confederal, mientras que el proyecto constitucional plantea una organización con características de "estado federal", con mayores atribuciones al poder nacional. Como bien razona Herrero, "es probable que esta segunda constitución federalista haya sido pensada como una alternativa en una instancia de negociación con los sectores centralistas porteños, ya que responde a las condiciones políticas de la época". Herrero, Fabián, "Fragmentos...”, p. 645.
} 
de ilusiones, o raciocinios forjados acaloradamente? La resulta, si, la resulta no es entonces otra, que la división en partido, bien pronto de estos se forman las facciones; y véase ahí la puerta abierta no solo para las disensiones que todo lo trastornan, sino que faltando la unidad, base o resorte esencialísimo de todo género de cosas, estas o se destruyen o se disuelven. En la indefinición pues de nuestro sistema han consistido todos nuestros males $[\ldots]$ mientras no se forme una regular constitución, no progresaremos en nuestra causa sagrada. ${ }^{853}$

En el discurso inaugural de la Asamblea General Constituyente su presidente decía:

Cerca de tres años hemos corrido desde el principio de nuestra revolución a paso vacilante, y sobre sendas inciertas por falta de un plan que trazase distintamente las rutas de nuestra carrera y destino. Tal vez éste es el único principio que ha originado la variedad de opiniones, y la división de partidos que han debilitado considerablemente nuestra fuerza moral, que es de mayor necesidad concentrar. ${ }^{854}$

Para éstos, una constitución era la obra de la voluntad general que se lograba a partir del proceso discursivo en asambleas, dándose lugar al intercambio de luces donde se "descubre" aquello que es mejor para la nación. No podía existir entonces una oposición legítima, era ésta tan sólo una voluntad errada, un producto de meros intereses parciales. ${ }^{855}$

\section{Montevideo y la Constitución de Cádiz}

En la otra orilla del Rio de la Plata, la leal Montevideo fue una fiesta a propósito del juramento el 27 de septiembre de 1812 de la constitución aprobada en Cádiz. El Gobernador y Capitán general Gaspar de Vigodet confiaban en que dicha constitución sería una herramienta muy útil para contrarrestar los argumentos de la insurgencia porteña. Prácticamente desde el comienzo del movimiento juntista, el enfrentamiento entre ambas ciudades había generado un cruce de acusaciones y réplicas que en muchos casos eran canalizadas a través de la prensa. La Gazeta de Montevideo, nacida como reacción a la difusión de su par la Gazeta de Buenos Aires en la Banda Oriental, se

\footnotetext{
${ }^{853}$ El Grito del Sud, 20 de octubre de 1812.

${ }^{854}$ Sesiones de los días 30 y 31 de enero de 1813, Gazeta extraordinaria Ministerial de Buenos Aires, en Ravignani, E, óp. cit., tomo I, p. 5.

${ }^{855}$ Al respecto Fernández Sarasola, Ignacio. "Los partidos políticos en el pensamiento español (17831855)”. Revista Historia Constitucional, núm. 1, pp. 97-163, 2000.
} 
convirtió rápidamente en un órgano de propaganda de la Regencia y las Cortes para los territorios rioplatenses. ${ }^{856}$

El 4 de septiembre Vigodet rechaza la propuesta de Buenos Aires para dar una salida negociada al conflicto, y le envía seis ejemplares de la Constitución. "decídase V. E., a jurar la Constitución de la monarquía, y decide así por la libertad e independencia de la América del Sur". Por su parte Buenos Aires tomó la promulgación de la Carta magna como la cristalización definitiva de la nula voluntad de la metrópoli de buscar una salida negociada al conflicto y endurecerá como respuesta sus posiciones autonomistas: "Las Cortes han declarado a la faz del mundo que no quieren conciliación con las provincias de América que se hallan en revolución. Desechando la conciliación han declarado implícitamente que es su voluntad, que las armas decidan la cuestión presente, que si los americanos son vencidos se han de someter por derecho de conquista a las leyes que las Cortes le han dado". 857

Más allá de la voluntad de las autoridades de Montevideo, la puesta en práctica de la constitución gaditana no fue para nada sencilla. Tras la jura de la Constitución, debía llevarse adelante el cumplimiento de los decretos relativos a la elección de diputados para las Cortes ordinarias, la diputación provincial y los ayuntamientos. El cuerpo capitular de Montevideo expuso en una comunicación reservada al Capitán General las razones por los cuales entendía inconveniente su aplicación. Consideraba que por "la revolución en que se hallan estas provincias, y pueblos de la campaña" la Junta preparatoria de las elecciones de diputados de Cortes debía fijarse en Montevideo, aun cuando los reales decretos señalaran a la Buenos Aires como la capital del Río de la Plata. ${ }^{858}$

En relación a la creación de nuevos ayuntamientos y la renovación de los ya existentes, el Cabildo advirtió sobre los "muy funestos resultados" de una elección popular: "es factible que caigan estos primeros empleos de la república en personas sospechosas, y desafectas al sagrado sistema que sigue la generalidad de este fiel Vecindario". ${ }^{859}$ En diciembre de ese año, finalmente, se procedió a la votación de electores para el nombramiento del nuevo cabildo. Sin embargo, como señala Ana

\footnotetext{
${ }^{856}$ Con el fin de que la Gazeta circulara fuera de Montevideo, la salida del Semanario pasó de los jueves a los martes para coincidir con la salida de los correos. Sánchez Gómez, Julio. "Montevideo y la Constitución de Cádiz". en Chust Calero, Manuel (coord.). 1812, El poder de la palabra, América y la Constitución de 1812. Madrid: AC/E, 2012.

${ }^{857} G B A, 01 / 01 / 1813$.

${ }^{858}$ Citado en Frega, Ana, "Ecos del constitucionalismo gaditano en la banda oriental del Uruguay", Trocadero: Revista de historia moderna y contemporánea, $\mathrm{N}^{\mathrm{o}} 24,2012$, p. 15.

${ }^{859}$ Citado en Ídem.
} 
Frega, esas prevenciones habían trascendido y fueron utilizadas por la prensa bonaerense para acusar a las miembros del cabildo montevideano de querer "violar la constitución que acaban de jurar". ${ }^{860}$

El crítico contexto militar no solo por el enfrentamiento con Buenos Aires, sino con la campaña ganada por el artiguismo, tuvo como consecuencia que la elección de diputados para las Cortes ordinarias de 1813 no pudiera realizarse. En noviembre de 1813 el Capitán General de las Provincias del Río de la Plata informó, entre otras razones, que ello obedecía a que el gobierno estaba "circunscripto a los muros de esta Plaza, único punto libre en toda la comprensión de mi mando". ${ }^{861}$

\section{Clima tormentoso para la Revolución: la Asamblea naufraga en su impotencia}

Desde fines del año XIII el contexto se fue volviendo cada vez más adversa, al seguro retorno de Fernando VII y la restauración cabalgando por toda Europa, se le sumaron las derrotas y desorganización en el Ejército del Norte y la expansión cada vez más pronunciada del artiguismo, atemperando los iniciales bríos de la Asamblea General Constituyente. Los ambiciosos fines de declaración de independencia y dictado de una constitución serían reemplazados por los más moderados pero no menos acuciantes del corto plazo. La revolución debía sobrevivir. Este cambio también se puede observar en la forma en que se fue reestructurando la elite dirigente. El estrechamiento de la base del poder revolucionario con el paso de la Sociedad Patriótica, cuyos fines pasaban por el esclarecimiento ideológico, a la Logia Lautaro, cabal ejemplo de una maquinaria de dominación política, monopolizada ahora por el alvearismo, muestra a las claras dicha necesidad de preservación. ${ }^{862}$ El alejamiento de San Martín de la capital, abocado de lleno ya a la campaña americana, permitió la hegemonía de Alvear dentro de la elite dirigente, liderazgo que fomentó dicho estrechamiento y agudizó las contradicciones con el artiguismo. Las dos tendencias dentro de la Logia habían estado presentes casi desde su misma constitución, pero durante la Asamblea del año XIII se fueron profundizando. El rechazo a los diputados de Artigas es también un golpe al proyecto de San Martin, ya que varias de las instrucciones se hallaban de acuerdo con el plan amplio y originario de la Logia. ${ }^{863}$

\footnotetext{
${ }^{860}$ Gazeta Ministerial del Gobierno de Buenos-Ayres, 22-1-1813.

${ }^{861}$ Archivo General de Indias, Estado, 81, N. 83. Oficio fechado el 4-11-1813. Citado en Frega, Ana, "Ecos del constitucionalismo...", p. 15.

${ }^{862}$ Halperín Donghi, T., Revolución y Guerra...

${ }^{863}$ Canter, J. óp. cit., pp. 164-165.
} 
El recurso a la opinión pública como medio de control y acceso al poder fue paulatinamente abandonado, la política se restringía a un sector bien reducido, y lo que se perdía en cuanto a base social se intentaba ganar en eficacia. ${ }^{864}$ Estrechamiento que se tradujo también institucionalmente. Desde la creación del Directorio, el 21 de enero de 1814, la Asamblea no volvió a reunirse cuando fue convocada por éste, retornando a un largo letargo, sólo para constituirse de manera extraordinaria para designar a Alvear en reemplazo de Posadas como Director en enero de 1815.

\section{Consideraciones finales}

A pesar de no declarar la independencia ni terminar dictando constitución, sus objetivos principales; la labor de la Asamblea tuvo una significativa trascendencia para el proceso emancipatorio del sur del continente. Fue sin lugar a dudas el intento más serio de parte del sector más revolucionario del movimiento de concretar las transformaciones políticas y sociales para romper de manera definitiva con el antiguo régimen y, en palabras de sus propios protagonistas, poner al Rio de la Plata en "el camino de la libertad". La promulgación del decreto de libertad de vientres, la libertad de prensa, la extinción del tributo, la mita y la encomienda, la abolición de la inquisición y del uso de tormentos, la supresión de los títulos de nobleza y del mayorazgo, entre otras resoluciones del Congreso, son ejemplos de esta vocación de embarcar al espacio rioplatense en la marea de cambios que estaba recorriendo gran parte de Europa y América. Para los "morenistas" separarse de España o de su rey no alcanzaba, era necesario construir una república inspirada en principios liberales e igualitarios. $^{865}$

Rastros de aquella cultura constitucional hispánica continuarían presentes en el Estatuto Provisorio de 1815 y en su reemplazante, el Reglamento Provisorio de 1817. Algunos de los preceptos compartidos con el doceañismo serían: la religión católica como religión del estado, el régimen de ciudadanía, el sistema electoral, la división de poderes con supremacía legislativa, el unicameralismo y las secretarias del estado, entre otros. Con el reglamento de 1817 culminaría la impronta peninsular en la legislación

\footnotetext{
${ }^{864}$ González Bernaldo, Pilar. "La Revolución Francesa y la emergencia de nuevas prácticas de la política: La irrupción de la sociabilidad política en el Río de la Plata (1810-1815)". Boletín del Instituto de Historia Argentina y Americana "Dr. E. Ravignani", III serie, n. 3, pp. 7-27, 1991.

${ }^{865}$ Goldman, Noemí. Historia y lenguaje...
} 
rioplatense para, desde aquí ir cediendo terreno con respecto a otras fuentes, en particular la Constitución de Filadelfia.

La Constitución de Cádiz sirvió como fuente, como hemos visto, para las legislaciones y proyectos constitucionales que estuvieron en discusión en los primeros años de camino propio de las Provincias Unidas del Rio de la Plata. Como bien dice Ternavasio, ésta puso a su disposición una gramática jurídica que presentaba importantes ventajas para ser asimilada y adaptada por las élites americanas. ${ }^{866}$ Pero poco a poco comenzó a ser remplazada por otras fuentes que fueron ganando terreno a medida que la ruptura total con la "Madre Patria" iba confirmándose.

Existió un lenguaje y una práctica política común a ambos lados del Atlántico, aunque en ocasiones, producto de las dinámicas particulares de cada proceso, adquirieran significaciones y usos divergentes. Las condiciones coyunturales y las necesidades políticas en muchos casos terminaban determinando las posiciones que adoptaron los actores políticos aun cuando en algunos casos contradijeran algunas de sus proclamadas convicciones doctrinarias. En el marco de una misma cultura constitucional hispánica, que se consolidó entre 1808 y 1824, la labor legislativa de las Cortes y fundamentalmente la Constitución doceañista pusieron a disposición de los rioplatenses un nuevo lenguaje constitucional que representó, por un lado, la posibilidad de dotarse de útiles herramientas político-jurídicas para promover los cambios que ambicionaban, pero que a su vez generó fuertes tensiones y contradicciones, en pleno proceso de emancipación de las antiguas colonias americanas.

\footnotetext{
${ }^{866}$ Ternavasio, Marcela. "La experiencia gaditana en el Río de la Plata: batallas retóricas y aprendizaje político". en Chust Calero, Manuel (coord.). 1812, El poder de la palabra, América y la Constitución de 1812. Madrid: AC/E, 2012.
} 


\section{Capítulo 13:}

\section{La libertad de imprenta en el mundo hispánico. El caso peninsular y el rioplatense}

\section{Introducción}

La lucha por la libertad de imprenta, y los debates originados alrededor de ella, se constituyeron en cuestiones tan significativas durante los años revolucionarios, tanto en América como en España, que no puede entenderse el proceso sin darle la centralidad que éstas se merecen. La misma identidad liberal se fue construyendo alrededor del reclamo por este derecho. En el otoño de 1810, en efecto, los espectadores de las discusiones de las Cortes habían empezado a llamar liberales al grupo de diputados reformistas, jóvenes en su mayoría, que abogaban por dicha libertad. ${ }^{867} \mathrm{Y}$ en gran medida el llamado partido servil se fue definiendo también en su oposición en esos mismos debates.

En el Río de la Plata revolucionario, la cuestión de la libertad de la prensa motivó la intervención pública tanto de parte de los sectores más radicales como de los moderados, ambos conscientes de su necesidad. Y como buscaremos demostrar a lo largo de este capítulo, constituye un problema clave no sólo para entender el proceso, sino también desde el cual podemos percibir los vínculos entre las elites dirigentes de ambas orillas del Atlántico.

Los primeros escritos sobre la libertad de imprenta en el Río de la Plata. La recepción del pensamiento peninsular

Tempranamente, en junio de 1810, en el tercer número de la Gazeta de Buenos Aires, el secretario de la Junta abordó la cuestión de la libertad de imprenta. El artículo, como demostrara Daisy Ripodas Ardanáz en uno de sus más reconocidos trabajos, está inspirado en la Disertación presentada a una de las sociedades del Reino por Valentín de Foronda, y publicada en 1789 en el Espíritu de los mejores diarios. ${ }^{868}$ La filiación está verificada por el contraste de fragmentos de evidente similitud. Moreno como

\footnotetext{
${ }^{867}$ Fernández Sebastián, Javier (coord.), óp. cit., p. 271.

${ }^{868}$ Espíritu de los mejores diarios que se publican en Europa nro. 179, 4/5/1789, pp. 1-14. Ripodas Ardanáz, Daisy, Refracción de las ideas en Hispanoamérica colonial, ECA, 1983, p. 144.
} 
sabemos ya había recurrido a él un año antes en la Representación de los Hacendados, aunque en ese caso dando cuenta de la fuente. ${ }^{869}$

La concepción de Moreno sobre la libertad de imprenta, más allá de los vínculos con el texto de Foronda, es de un talante similar a la defendida en esos mismos y agitados meses por el reformismo peninsular. Aunque ponía el acento más en las libertades que en las restricciones, no dejaban de estar presente aquella limitación, que se repiten en general en las legislaciones hispanoamericanas, en referencia a la prohibición de abordar cuestiones inherentes a la religión católica: "Desengañémonos al fin que los pueblos yacerán en el embrutecimiento más vergonzoso, sino se da una absoluta franquicia y libertad para hablar en todo asunto que no se oponga en modo alguno a las verdades santas de nuestra augusta Religión, y a las determinaciones del Gobierno, siempre dignas de nuestro mayor respeto." ${ }^{870}$ Estamos claramente ante una versión moderada de la libertad de imprenta, incluso si la enmarcamos dentro de las concepciones que circulaban en el mundo hispánico. Mientras la restricción con respecto a lo religioso como decíamos era moneda corriente, la particularidad estaba dada por su manifiesta prevención a la crítica contra las medidas gubernamentales. En realidad, Moreno está reponiendo textualmente las mismas limitaciones que figuraban en el texto de Foronda, la cuestión es que éste fue escrito más de veinte años atrás, donde era aún impensable el cuestionamiento directo y público a la autoridad real, por más que el alavés haya sido uno de los referentes de la renovación del pensamiento político español. Pero en los últimos años, y fundamentalmente tras la crisis de la monarquía, gran parte del liberalismo hispánico, deudor en parte del terreno sembrado por Foronda, entendía justamente que uno de los roles fundamentales de la libertad de imprenta consistía, por el contrario, en ser el vehículo de la opinión pública para servir de contralor y censor de las autoridades. Moreno seguramente era consciente de ese desfasaje histórico, pero quizás cierto pragmatismo le aconsejaba no cuestionar a fondo dos de las fuentes de legitimidad con las que poder erigir el nuevo sistema. Según reconocería su hermano Manuel unos años después, esa "discreta tolerancia" de la imprenta respondía al contexto amenazante de una revolución recién en ciernes, con una

\footnotetext{
${ }^{869}$ Tampoco era aquella la primera vez que Foronda era utilizado en el Río de la Plata. Unos años antes, en 1799, sus famosas Cartas sirvieron de sustento para la redacción por parte de Chiclana de un dictamen opuesto a la formación de gremios en el Virreinato, como también ha demostrado Rispodas Ardarnáz en el mencionado trabajo. Y como hemos destacado aquí, fue usual la recepción del ilustrado vasco en las postrimerías del virreinato, tanto en la prensa como en documentos oficiales, teniendo una especial ascendencia en el pensamiento de Juan Hipólito Vieytes.

870“'Sobre la libertad de escribir". Gazeta Nro. 3 (21/6/10): p. 59
} 
población aún poco instruida en sus derechos y una infinidad de enemigos acechantes. ${ }^{871}$ Justificándolo de alguna manera, Manuel Moreno destacaría que en sus planes estaba el de "introducir gradualmente la libertad de imprenta". 872

Esta misma problemática también tuvo su espacio en el otro periódico porteño de los primeros meses revolucionarios, el Correo de Comercio de Manuel Belgrano, que no tenía para nada acostumbrado a sus lectores a artículos de corte político, sino que por el contrario estaba más emparentado con la línea ilustrada de los periódicos finicoloniales, como el Telégrafo y el Semanario. Bajo el epígrafe de "La libertad de la prensa es la principal base de la ilustración pública", en agosto de 1810 , se asocia ese derecho no solo con la instrucción de los ciudadanos por medio de la comunicación de la luces, sino con la posibilidad de un desarrollo cabal de las libertades civiles. ${ }^{873} \mathrm{El}$ artículo sin embargo no pertenece a la pluma del vocal de la Junta, aunque él en ningún momento busque dejarlo en claro. En realidad es una copia textual e íntegra de un artículo que bajo el mismo título fue publicado en el primer número del periódico sevillano El Voto de la Nación española del 13 de diciembre de $1809 .{ }^{874}$ Este hecho, hasta ahora no percibido por la historiografía, que siempre concedió su autoría a Belgrano, refuerza aún más la imagen de la destacada recepción que venimos subrayando de los papeles peninsulares en la prensa rioplatense. Al final del artículo, al pie de una nota que completa lo desarrollado en su cuerpo principal, Belgrano agrega entre paréntesis: Minerva peruana del 10 de mayo de 1810. La cita pareciera referir solo a la nota complementaria, pero podemos suponer dos alternativas: o que en realidad Belgrano tomó el artículo completo del periódico peruano sin haber tenido nunca en sus manos el ejemplar peninsular, o lo que también es probable, sabiendo de la versión original, prefirió referenciarlo en el peruano, con el objetivo de ocultar los vínculos doctrinarios con el gobierno metropolitano, teniendo en cuenta que El Voto de la Nación española había oficiado de órgano de difusión de la Comisión de Cortes de la

\footnotetext{
${ }^{871}$ Moreno, Manuel, óp. cit., 165-166.

${ }^{872}$ Citado en Rispodas Ardanáz, D., óp. cit., p 147.

${ }^{873}$ Correo de Comercio, nro. 24, 11/08/1810, pp. 175-179.

${ }^{874}$ Aparecido el 13 de diciembre de 1809, el periódico estaba apoyado por la Comisión de Cortes de la Junta Central, donde tenían clara mayoría reformistas y liberales, y eso se expresó en el tono mucho más directo e innovador del lenguaje utilizado. Su preocupación central tenía que ver con la convocatoria de las Cortes y reproducían los debates que suponían ocurrirían en las sesiones de la futura asamblea. Fue el primero de los periódicos de esta época en desear abiertamente el triunfo de las ideas liberales y las presentaban como pensamiento ya sancionado por el público. Hocquellet, R., «La aparición de la opinión pública en España: una práctica fundamental para la construcción del primer liberalismo (1808-1810)», Historia Contemporánea. 2003 (II), nº 27, pp. 627-628.
} 
Junta Central, blanco esta última de fuertes críticas tanto en la península como en América.

Donde existe la libertad de imprenta, dice el escrito, no puede haber tiranía, y como contrapartida, ningún tirano ha dejado de quitarla ni bien impone su dominio. Con ella se disipan los errores de la primera educación, o de los "perversos libros que en España por desgracia han circulado". No sabemos a qué se puede estar haciendo referencia, aunque podemos suponer que estaba hablando de literatura extranjera que cuestionaba aspectos del dogma católico. Cuestión que luego sería retomada por los diputados liberales en las Cortes para defender el proyecto de ley, argumentando que la libertad facilitaba la apropiación de nuevos conocimientos y por lo tanto conducía a la verdad, inclusive la religiosa. Más adelante afirma que gracias a la prensa libre "se uniforma el modo de pensar de la nación, y las inclinaciones de sus individuos, y así se establece una voluntad general que hace una fuerza equivalente a la de muchos ejércitos". ${ }^{875}$ Era ésta una concepción común a las élites políticas e intelectuales hispanoamericanas, como bien señala Nancy Calvo: "la opinión pública invocada como origen y fundamento del sistema representativo siguió siendo una noción difícil de precisar y sobre todo de emancipar del ideal ilustrado según el cual la razón -una e indivisible- era el único y verdadero sostén de la opinión aceptable", 876

El ejemplo que se toma en el artículo para demostrar los beneficios de establecer la libertad de imprenta no es otro que el de Inglaterra; a través de la libertad de imprenta se daban allí a conocer los hombres más talentosos y justos para el mando, y el soberano era compelido a cumplir con sus obligaciones. Ante los que recelan contra los abusos de esta libertad, se advierte que con solo penar fuertemente a aquellos que escribieran contra la religión o recurrieran a la sátira u obscenidades contra otros ciudadanos, alcanzaría para poder disfrutar de todos los beneficios que ésta conllevaría sin los peligros de sus excesos.

En la nota que cierra el artículo se afirma que no hubiera sido posible la opresión a la que Carlos IV y Godoy sometieron a la nación española si ésta hubiera contado con la libertad de imprenta, y que por lo tanto tampoco hubiera sido factible que Napoleón ocupara la península.

\footnotetext{
${ }^{875}$ Correo de Comercio, nro. 24, 11/08/1810, p. 176.

${ }^{876}$ Calvo, Nancy, "Lo sagrado y lo profano. Tolerancia religiosa y ciudadanía política en los orígenes de la república rioplatense”, Andes. Antropología e Historia, nro. 15, Salta, 2004, p. 157.
} 
Otro documento de origen peninsular que aborda la cuestión es el ya analizado en un capítulo anterior Pensamientos de un patriota español, publicado por Moreno en la Gazeta de Buenos Aires entre los meses de julio y octubre de 1810. En él se destaca la importancia de que se termine con el hermetismo de las antiguas Cortes y que de ahora en adelante las discusiones que se vayan a dar en el futuro Congreso a conformar sean completamente públicas, subrayando la confianza que generará en los representados y los beneficios para la ilustración de la opinión pública, sobre todo en momentos en que la nación se estaba embarcado en la trascendental tarea de darse una constitución política. Tarea inviable si no era de la mano de la libertad de imprenta: "tan necesario es al mismo intento el que los hombres de luces y de talentos, concurran para ilustrar, y formar la opinión pública, por medio de sus escritos; pero como estos no pueden existir sin gozar la prensa, o el arte de imprimir de una amplia libertad, conviene concedérsela desde este instante". ${ }^{877}$ Se posiciona de esa manera su autor, Antonio de la Peña y García, entre los que consideran que no había que esperar a tener una constitución, ni siquiera a la reunión en Cortes, para llevar a la práctica dicho derecho. En consonancia con la ambición ilustrada por excelencia, considera que sin esa libertad es "imposible formar, ilustrar, o fijar una opinión porque el oro de la verdad no puede depurarse de las viles escorias, con que la ofuscan la ignorancia, el interés y el error, sino por medio de la discusión y del choque de opiniones". ${ }^{878}$ La cuestión religiosa queda exenta, nuevamente, de los alcances de dicha facultad en la consideración de este exponente del liberalismo peninsular: "La libre comunicación de los pensamientos (no tocando esta libertad en materia de religión) es pues indispensable puesto que perfecciona las facultades del hombre, le ilustra, y le hace conocer sus derechos y obligaciones" 879

Como pudimos ver, los primeros escritos que versaron sobre la libertad de imprenta en suelo rioplatense tienen sus raíces en el liberalismo peninsular. En el caso de Foronda se trata además de una especie de puente entre la generación ilustrada de fines del XVIII y el proceso revolucionario abierto con las abdicaciones de Bayona. El pensador vasco siempre se contó entre los elementos ideológicamente más avanzados, al punto de que algunos autores lo definen como el exponente más claro del preliberalismo hispánico. En su concepción de la libertad de imprenta se encuentran tanto la marca ilustrada que pone el acento en el objetivo de educar al pueblo, como aquel

\footnotetext{
${ }^{877}$ Gazeta extraordinaria 17/9/10, p. 404.

${ }^{878}$ Ibid, p. 405.

${ }^{879}$ Ídem.
} 
precoz liberalismo que la entiende como dique al despotismo y contralor del gobierno. ${ }^{880}$ Por su parte, el escrito aparecido en el Correo de Comercio, que ya no es sólo una apropiación libre, sino como demostramos, copia total de su original, representa un claro ejemplo de esos documentos que, en el marco de una España inundada de publicaciones, buscaban consolidar ese proceso presionando para que cristalice definitivamente en una ley de la nación. Trasladémonos ahora entonces al contexto peninsular para conocer un poco más ese proceso.

\section{La libertad de imprenta en la península entre el levantamiento nacional y la reunión de Cortes (1808-1810)}

Para llegar a su tratamiento en las Cortes, la cuestión de la libertad de imprenta tuvo que recorrer un largo camino desde el inicio del levantamiento nacional tras las abdicaciones de Bayona. La realidad es que aun sin que existiera ningún decreto ni legislación al respecto, en la práctica España estaba viviendo desde esos primeros meses revolucionarios de 1808 una libertad de imprenta cuasi de facto. Como varios autores han destacado, fue inédita la proliferación de escritos de todo tipo que acompañó y en gran medida motorizó la sublevación del pueblo español ante la ocupación francesa. Un verdadero alud de proclamas, periódicos y panfletos inundó la península, señalando el nacimiento de un factor político que será constitutivo de aquí en adelante de la legitimidad de cualquier fórmula de resolución que se ensaye para salir de la crisis: la opinión pública. $^{881}$

\footnotetext{
${ }^{880}$ La relación entre falta de ilustración y despotismo va a ser una constante en el ideario liberal. Una buena síntesis de ello es esta reflexión publicada en el periódico señero de esta tendencia: «El fundamento principal de este poder (absoluto) tan repugnante a la naturaleza, tan contrario al interés general de la nación y al particular de los individuos, consiste en la ignorancia. La ignorancia embrutece a los pueblos y los hace tener por derecho la usurpación y por deber la servidumbre. Así es que nada temen tanto los tiranos como la ilustración y se contemplan tan feos que quieren siempre rodearse de tinieblas». SemanarioPatriótico, nro. 9, 27/10/1808.

${ }^{881}$ Tomemos las palabras de François-Xavier Guerra para ilustrar este proceso: "Las proclamas y manifiestos de las juntas son el primero y más extendido tipo de escritos de esta primera época, seguidos poco después por escritos análogos de personalidades, particulares y cuerpos y, al fin, por una multitud de obras que utilizan toda clase de géneros literarios para manifestar el patriotismo: sermones, cartas, poesías, canciones, sainetes, sátiras, catecismos políticos. Deseosas, además, de poseer un medio permanente de información y de propaganda, prácticamente todas las juntas fundan periódicos y gacetas, en las que aparecen sus documentos oficiales, informaciones sobre la guerra y diferentes discursos patrióticos. En América, aunque no se constituyan entonces nuevos poderes, se asiste a un fenómeno análogo: los periódicos existentes se convierten en soportes de toda clase de producciones patrióticas, tanto peninsulares como americanas". Guerra, François-Xavier, "Voces del pueblo. Redes de comunicación y orígenes de la opinión en el mundo hispánico, 1808-1814", Revista de Indias nro. 225, 2002, pp. 358-359.
} 
Manuel Quintana, que desde las sombras junto a su renombrado círculo de amistades durante el gobierno de Godoy, habían estado preparando las condiciones para la publicidad de las nuevas ideas y el surgimiento del periodismo político, se asombraba genuinamente en septiembre de 1808, desde el Semanario Patriótico, de la profundidad que había alcanzado el proceso:

Si alguno hubiera dicho a principios de octubre pasado que antes de cumplirse un año tendríamos la libertad de escribir sobre reformas de Gobierno, planes de Constitución, examen y reducción del poder, y que apenas se publicaría escrito en España que no se dirigiese a estos objetos importantes, hubiera sido tenido por un hombre falto de seso, a quien tal vez se privara de su libertad por la que profetizaba a los otros. ${ }^{882}$

Esa libertad de imprenta de hecho, alentada por los grupos más radicales entre el bando patriota, tuvo que imponerse igualmente al rechazo que generaba entre los sectores más conservadores que poseían una cuota de poder nada despreciable tanto en el Consejo de Castilla como en la Junta Central. Así lo recuerda Argüelles: «La imprenta adquirió de hecho la libertad que no había tenido nunca, y desde los primeros momentos empezó a ejercer el ascendiente que era inseparable de la exaltación a que habían llegado los ánimos, a pesar de los esfuerzos que hacían las autoridades en muchas partes para reprimirle». 883

$\mathrm{Y}$ fueron probablemente aquellos recelos de algunas de las autoridades y grupos más apegados a los fundamentos del Antiguo Régimen los que impidieron que la libertad de imprenta no fuera convertida en ley hasta su promulgación por las Cortes de Cádiz el 10 de noviembre de $1810{ }^{884}$ Hubo sí varios proyectos presentados por algunas de las figuras más destacadas del reformismo y del liberalismo peninsular, que sirvieron en algunos casos de sustento para la definitiva formulación de las Cortes. Hagamos entonces un pequeño recorrido por ese derrotero.

Como mencionábamos, fue el Consejo de Castilla, principal reducto donde se refugiaba el absolutismo, el resorte fundamental desde donde se buscó poner límites al desbordado cauce de impresiones y manuscritos que inundaba España. Bien vienen las memorias de Alcalá Galiano para ilustrar las trabas que el Consejo de Castilla intentó imponer tras la salida de las tropas francesas de Madrid: «Entretanto, casi quedó establecida, bien que por plazo breve, la libertad de imprenta. Bien es cierto que el

\footnotetext{
${ }^{882}$ Semanario Patriótico, 4, edición del 22 de septiembre de 1808

${ }^{883}$ Argüelles, Agustín de, óp. cit., tomo I, p. 108.

${ }^{884}$ Fernández Segado, Francisco, "La libertad de imprenta en el periodo inmediato anterior a su legalización por las Cortes de Cádiz (1808-1810)”, Pensamiento Constitucional N 17, 2012, p121.
} 
Consejo, nada amigo de ella, trató de ponerle impedimento; pero en algún tiempo no lo consiguió, aunque lo mandase. Había censores, pero o no ejercían la censura, o no se hacía caso de ella, ni se necesitaba». ${ }^{885}$ Mediante una circular el 10 de agosto ponía bajo su control las funciones del juez de Imprentas, y el 26 prohibía que se imprimiera papel alguno sin su licencia. Igualmente, es difícil de creer que estas disposiciones del Consejo tuvieran efecto en Madrid, y está comprobado su nulo resultado en las provincias, donde se multiplicaron los folletos de todo tipo.

Pero el Consejo no fue el único de los poderes que buscó contener el aluvión de impresos. La recientemente constituida Junta Central, que a diferencia de aquel contaba con mayor legitimidad e influjo en las provincias, aportó su cuota en ese sentido. Y no es de extrañar si tenemos presente que su presidente era el Conde de Floridablanca, aquel que en su momento, durante los primeros años del reinado de Carlos IV, había tratado de establecer un «cordón sanitario» para aislar a España de los coletazos de la Revolución Francesa y sus peligrosas ideas. Sus intenciones consistían en restablecer las disposiciones de aquel entonces y de esa manera suplir el vacío de autoridad existente, en particular las relacionadas con la censura. A tal efecto, propuso y presentó a la Junta un proyecto de decreto que contó con el beneplácito de la mayoría de sus miembros, imbuidos de los mismos temores que su presidente, siendo aprobado el 30 de septiembre. ${ }^{886}$ Nuevamente estas restricciones cayeron en saco roto, la publicación de escritos patrióticos sin demasiado control siguió siendo la norma. Igualmente habría que matizar un poco esta afirmación. A pesar de que gran parte de la bibliografía sostiene que existía una ilimitada libertad en los hechos para publicar, como afirman Fernández Segado o De la Parra, hay algunos indicios que marcarían que no fue del todo así. ${ }^{887}$ Como bien señala Patricio Clucellas, es sugestivo un escrito de Isidro de Antillón describiendo la situación para el año 1809 en relación a este problema:

Solamente después de la evacuación de Madrid por los franceses en julio de 1808 hubo cierto intervalo cortísimo de libertad de escribir, que produjo algunos papeles, donde con menos trabas y disfraces se empezaban a examinar los principios de nuestra constitución política [...] Más esto fue como un relámpago. No tardó la autoridad que

\footnotetext{
${ }^{885}$ Alcalá Galiano, Antonio. "Recuerdos de un anciano". En Obras escogidas de D. Antonio Alcalá Galiano, (Biblioteca de Autores Españoles, tomo 83). Madrid: Ediciones Atlas, 1955, pp. 1 y ss.; en concreto, p. 42.

${ }^{886}$ Fernández Segado, F., óp. cit., p. 131.

${ }^{887}$ La Parra López, Emilio, La libertad de prensa en las Cortes de Cádiz, Alicante: Biblioteca Virtual Miguel de Cervantes, 2005.
} 
gobernaba en sujetar la imprenta a sus antiguos reglamentos [...] a todos los embarazos y

dificultades que habían paralizado anteriormente la pluma de los letrados españoles. ${ }^{88}$

Estas categóricas afirmaciones no surgían de la nada, Antillón mismo había sufrido en carne propia las presiones de la Junta Central para tratar de condicionar su labor periodística. Junto a José María Blanco White, fueron los encargados de la redacción del Semanario Patriótico en su segunda época, la sevillana, caracterizada por la radicalización de las ideas contenidas en dicha publicación. Al cabo de un tiempo esto empezó a preocupar a la Junta Central, que a pesar de tener a Manuel Quintana amigo de ambos- como secretario, estaba encabezada como dijimos por dirigentes de posiciones mucho más conservadoras. Finalmente, la Junta decidió arremeter contra el Semanario Patriótico censurando su contenido político, lo que llevó a Blanco White y a Antillón a resolver el cierre de su publicación, pero no sin antes acompañar su último número con una nota en donde daban a entender sutilmente la censura llevada adelante por el gobierno central: «Cedamos pues a las circunstancias: nuestros amigos sufrirán mejor que se interrumpa otra vez el Semanario que verlo mudado en otra cosa que lo que hasta ahora ha sido». ${ }^{889}$ Según Dérozier, esta decisión impactará negativamente en la imagen pública de la Junta. ${ }^{890}$

La segunda mitad de 1809 marcó, con el paso de los meses, un cambio de actitud de la Central respecto a la libertad de imprenta. Y ese cambio no estuvo desvinculado obviamente de la presión, tanto por dentro como por fuera de la Junta, que se empezó a acentuar exigiendo la convocatoria a Cortes del reino por parte del grupo de Quintana, en alianza coyuntural con el sector moderado expresado en Jovellanos. ${ }^{891}$ El llamado a la "consulta al país" establecido por la misma Junta, por lógica, implicaba la

\footnotetext{
${ }^{888}$ Antillón, Isidro de, "Núm X. Plan de la junta de instrucción pública...", en Colección de Documentos..., pp. 212-213. Citado en Clucellas, Patricio, 1810 Revolución ..., pp. 155-156.

${ }^{889 ، “ A v i s o ~ a l ~ p u ́ b l i c o ” . ~ S e m a n a r i o ~ P a t r i o ́ t i c o ~} N^{\circ} X X X I I, 31 / 8 / 09$.

${ }^{890}$ Dérozier, A., óp. cit., pp. 568-570. Jovellanos intentando explicar mediante una carta a un contrariado Lord Holland el cierre del Semanario, sostuvo que se debía al "resentimiento injustificado de sus directores ante el aviso que bajaran el tono de sus críticas, y les reprochó que no contentos con suspender la continuación de su papel, la anunciaron al público en una nota escrita con demasiada ligereza. Jovellanos, Carta del 12 de septiembre de 1809. Citado en Clucellas, Patricio, 1810 Revolución..., p. 158. ${ }^{891}$ Martínez Quinteiro, M. E., óp. cit., pp. 215-216.
} 
multiplicación exponencial del número de publicaciones. ${ }^{892}$ Era necesario entonces replantearse su posición hacia la libertad de imprenta. ${ }^{893}$

Fue el aragonés Lorenzo Calvo de Rozas, referente junto con Quintana del sector más radical, quien, a mediados de septiembre de 1809, desencadenó el primer debate en profundidad sobre este tema en el marco de la Junta Central y sus órganos. En su proposición el vocal enumeró los beneficios que conllevaría esa libertad: la ilustración de la Patria acerca de cuanto puede conducir a la mejora de sus leyes e instituciones, la formación y fortalecimiento de la opinión pública y la utilidad coyuntural, pero no por eso menos importante, de impedir que se apague "el noble entusiasmo que encendió la venganza nacional”. Adelantándose a las seguras impugnaciones de los elementos conservadores de la Junta, considera que «los males que puede ocasionar no son comparables con los bienes que puede producir, y esta sola consideración debe bastar para no desecharla, mayormente cuando los abusos son posibles de prevenir mediante algunas restricciones». ${ }^{894}$

La Junta reclamó, bajo iniciativa seguramente del sector conservador, el pronunciamiento de Consejo reunido de España e Indias -creado por ésta con los ministros que habían logrado llegar hasta Sevilla de los Consejos de Castilla, Indias, Hacienda y Órdenes-, y como era de esperar por su reaccionaria composición, su respuesta fue de firme oposición a la proposición de Calvo de Rozas, decidiéndose por el mantenimiento del régimen de censura previa: "Sucede con la libertad de la imprenta lo que con la tolerancia en materias de religión. Solo la pretenden los que son de las creencias no permitidas o no dominantes, pero estos mismos si llegan a conseguir la dominación son los más opresores o intolerantes”. El dictamen concluía sosteniendo que autores como Voltaire, Rousseau, d'Alembert, entre otros son "los que han puesto los fundamentos de la Revolución francesa, y los que han viciado a la juventud española, haciendo el mayor estrago en nuestras piadosas costumbres y destruyendo la pureza de nuestro sano modo de pensar". ${ }^{895}$

\footnotetext{
${ }^{892}$ Según Richard Hocquellet no sólo aumentan notablemente la cantidad de periódicos y otros impresos, sino que también los autores de los artículos develan más frecuentemente, incluso para firmar textos con contenido radical. Se está pasando entonces de una fase de confidencialidad a la de publicidad del debate. Los individuos sienten un reconocimiento tácito de sus derechos de expresión y no es extraño que en estas fechas se repitan los textos que pidan la sanción de la libertad de la imprenta como condición necesaria para el desarrollo de un espacio público de reflexión política. Hocquellet, R., óp. cit., pp. 620-621.

${ }^{893}$ Fernández Segado, F., óp. cit., p. 136.

${ }^{894}$ Citado en Fernández Segado, F., óp. cit., p. 141.

${ }^{895}$ Ibid, 146.
} 
La propuesta de Calvo de Rozas también pasó a ser tratada por la Comisión de Cortes, en particular por una de sus Juntas, la de Instrucción Pública que presidía Jovellanos. Esto motivó la presentación, el 7 de diciembre de 1809, de una Memoria por parte de uno de los vocales de la Junta, José Isidro Morales, que fue aprobada y que constituiría el precedente hispano de mayor vínculo con la futura regulación de las Cortes un año más tarde. ${ }^{896}$ Los posibles abusos de esta libertad los adscribe a «la doctrina de nuestra santa religión, la moral pública, la seguridad del Estado, y la seguridad privada», y entiende que la regulación de esta libertad «no puede tocar decidirla definitivamente al Gobierno de ella [de la nación]; solo puede tomar una resolución provisional. Su decisión toca a la representación nacional; ella es la que debe pronunciar si le conviene o no reservarse esta libertad en toda su extensión». ${ }^{897}$ Dicha posición iba en línea con el pensamiento del presidente de aquella Junta, que era como decíamos Jovellanos. Para el ilustre asturiano no solo había que esperar la reunión de las Cortes, sino que era partidario de que la libertad de imprenta se estableciera recién con la aprobación de la Constitución y no precediendo a ésta. ${ }^{898}$ Para los jóvenes liberales esto era un sinsentido, como subrayaría Arguelles: «cualesquiera que fueran las reformas que se propusiesen hacer las Cortes, la libertad de la imprenta debía precederlas», entendiendo que sin la guía y censura de la opinión pública los representantes no podrían dar con las mejores leyes para la nación. ${ }^{899}$

Otro antecedente significativo del decreto de libertad de imprenta, en este caso en especial por las divergencias que tiene con los lineamientos generales del liberalismo peninsular sobre la materia, es la propuesta de Álvaro Flórez Estrada, incluida como apéndice de la presentación de su Memoria sobre una Constitución para la nación española, a la Junta Suprema Gubernativa en noviembre de 1809. Sus Reflexiones sobre la libertad de imprenta se destacan por lo innovadoras en relación a las prácticamente nulas restricciones a las que debería someterse dicha libertad, de la mano de una tolerancia religiosa inaudita hasta el momento en este tipo de proyectos regulatorios:

\footnotetext{
${ }^{896}$ Morales, José Isidoro. Memoria sobre la libertad política de la imprenta (leída en la Junta de Instrucción Pública por uno de sus vocales y aprobada por la misma Junta). Sevilla: Manuel Muñoz Álvarez, 1809, 32 pp. Edición facsímil publicada en Peña Díaz, Manuel. José Isidoro Morales y la libertad de imprenta (1808-1810). Huelva: Universidad de Huelva, 2008.

${ }^{897}$ Citado en Fernández Segado, F., óp. cit., p. 152.

${ }^{898}$ Cuando efectivamente ésta se convierta en decreto por las Cortes, en carta del 5 de diciembre de 1810 Jovellanos le dirá a Lord Holland que "la resolución le parece muy anticipada [...] Esta libertad será buena como parte de una constitución ya hecha [...] No tenemos que esperar las luces que nos faltan de la libertad de imprenta, y tenemos más bien mucho que temer si nos vienen de afuera". Jovellanos, "Cartas", citado en Clucellas, Patricio, 1810 Revolución, p. 159.

${ }^{899}$ Arguelles, Agustín de, óp. cit., pp. 220-221.
} 
"Los únicos reparos que contemplo se pueden hacer contra la libertad de la imprenta son la propagación de malas doctrinas y el temor de las calumnias». ${ }^{900}$ Despojada de otro tipo de condicionamientos, la libertad de imprenta cumpliría cabalmente su rol fundamental para el asturiano: constituirse en un instrumento de fiscalización, control y freno del poder, equiparable en alguna medida al que desempeña la existencia de una constitución. Que se mantuviera la prevención contra las calumnias respondía al fuerte temor entre las élites de que esta libertad sirviera para atentar contra el honor de las personas. Como sugiere Guerra, la “pública opinión” que de alguien se tenía remitía a la fama, valor esencial en las sociedades hispánicas, y más importante aún que el estatuto o la fortuna en la jerarquía social. ${ }^{901}$ Retomando algunos argumentos anteriormente utilizados en su defensa, considera que la libertad de imprenta es condición indispensable para superar el momento crítico actual, tanto porque es un medio para infundir patriotismo al pueblo que está en guerra, como porque «sin libertad de imprenta no pueden difundirse las luces, y sin ellas ni puede haber reforma útil y estable, ni los españoles podrán jamás ser libres ni felices».

El debate abierto en la Junta de Instrucción pública, en el que tuvo también un destacado papel Antillón, propició la elaboración de un proyecto de reglamento, cuyo primer artículo decía: «La imprenta se declara libre de toda previa licencia, revisión o aprobación de cualquiera autoridad, sin excepción, quedando el autor y el impresor responsables a la ley de cualquier abuso que hagan de ella». Con el fin de resguardar este derecho ciudadano, y conocer a la par las denuncias por los posibles excesos, se contemplaba la creación de un tribunal o comisión nacional de la libertad de imprenta. La Junta de Legislación se puso manos a la obra en dicha tarea, entendiendo indispensable «que la libertad de la imprenta, al paso que se establezca del modo más amplio, quede siempre sujeta a las justas limitaciones prescritas por las leyes de los gobiernos liberales, prohibiendo, bajo de graves penas, escribir contra la religión, buenas costumbres, fama y reputación de los particulares».

La Junta Central, tras todo este largo y complejo procedimiento, iba a recibir dos documentos absolutamente antitéticos: el dictamen contrario a esta libertad del Consejo y el pronunciamiento favorable a la misma de la Comisión de Cortes, plasmado en el proyecto de reglamento. La Central adoptó, sin embargo, la posición más retrógrada al alinearse con el Consejo negándose aprobar el dictamen favorable al proyecto de

\footnotetext{
${ }^{900}$ Flórez Estrada, Álvaro, óp. cit., pp. 345-350.

${ }^{901}$ Guerra, F-X, Modernidad..., p. 379.
} 
reglamento. ${ }^{902}$ Lo hacía en un contexto además donde la presión de los publicistas liberales para que la libertad de imprenta se convirtiera en ley era constante. Al ya mencionado artículo de El Voto de la Nación española del 13 de diciembre de 1809, que fue "tomado" luego por Manuel Belgrano en el Río de la Plata para su Correo del Comercio, podemos sumar el Espectador Sevillano, de Alberto Lista, que en enero de 1810 insistía con dicho reclamo, e introduce un escrito donde repone el ejemplo inglés, destacando los límites que la opinión pública ejercía sobre el gobierno de aquel país y la mejora que implicaba en sus instituciones y leyes. El periodista reconoce necesaria solo una censura post-facto, y para casos muy particulares:

¿Pero en que se funda, y que es lo que constituye especialmente esa libertad? ¿Deberá acaso considerarse como una licencia absoluta de imprimir todo cuanto a cada uno se le antoje, y de calumniar y perjudicar impunemente a otro por este medio? No por cierto, pues que las mismas leyes que protegen sabiamente la persona y propiedad del individuo, saben defender igualmente su honra y su opinión (...) La libertad de imprenta, según existe en Inglaterra consiste en que ni los tribunales ni los jueces de cualquier clase pueden conocer de lo que se imprime hasta después del hecho, ni proceder en ningún caso sin la fórmula del juzgado por jurados. ${ }^{903}$

En tiempos de una Junta Central moribunda, tras el desastre de Ocaña, la minoría liberal hizo un nuevo intento en su búsqueda de plasmar en ley dicha libertad, logrando el más que modesto resultado de que ésta se pronuncie encomendándole a la futura Regencia que proponga necesariamente a las Cortes "una ley fundamental, que proteja y asegure la libertad de la imprenta, y entretanto protegerá de hecho esta libertad, como uno de los medios más convenientes, no solo para difundir la ilustración general, sino también para conservar la libertad civil y política de los ciudadanos". ${ }^{904}$ Detrás de esta encomienda se percibe la estrategia de Jovellanos, que a pesar de haberse manifestado a favor de la libertad, seguía considerando, en línea con su moderantismo cada vez más pronunciado, que no estaban dadas aún las condiciones para reglamentarla y que era ésta una tarea indefectiblemente de los diputados en Cortes.

Con un perfil mucho más retrógrado que su antecesora, el Consejo de Regencia, al igual que hizo con la mayoría de los requerimientos de la Junta Central, omitió el pedido en relación a la libertad de imprenta, y, no sólo eso, retomó las antiguas

\footnotetext{
${ }^{902}$ Fernández Segado, F., óp. cit., p. 168.

${ }^{903}$ Espectador sevillano, nro. 99, 8/1/1810, p. 389.

${ }^{904}$ Art. 19, Proyecto de Reglamento y Juramento para la Suprema Regencia.
} 
iniciativas gubernamentales para intentar restringirla. Consideraba que la derrota militar de Ocaña y las perturbaciones sociales que habían provocado la caída de la Central respondían justamente a esa falta de control:

Las máximas democráticas y jacobinas que por desgracia han cundido en España y hecho peligrosos a muchos hombres de talento, que sin ellas podrían ser muy útiles y muy apreciables, son la causa de la falta de respeto y de subordinación que han producido los desastres y desórdenes que son bien públicos; y para cortar en su origen tan graves males quiere el rey N. S. Fernando VII y en su real nombre el Consejo de Regencia de los reinos de España e Indias que el Consejo cele sobre esto con la mayor vigilancia y de ningún modo permita la impresión de papeles en que se viertan tales especies. ${ }^{905}$

\section{Tratamiento, promulgación y puesta en práctica por las Cortes de Cádiz}

La promulgación de la libertad de imprenta por parte de las Cortes, no se debió a la voluntad de un grupo de diputados, o por lo menos no sólo a ello, fue fundamentalmente una exigencia de las condiciones históricas del momento. Como ya destacamos en varias oportunidades, cuando salió del parlamento el reconocimiento legal de la libertad de prensa ésta se practicaba de hecho al menos desde dos años antes en la península. Y como pudimos ver, durante ese mismo período se produjeron repetidas solicitudes en favor de su declaración legal, hasta el punto de formar parte del programa básico de los primeros grupos liberales, junto al reconocimiento de la soberanía nacional, la convocatoria de unas Cortes representativas y la elaboración de una Constitución. La libertad de imprenta era entendida como uno de los elementos esenciales de la libertad de la nación. Concebida dentro del ámbito de aquello que afectaba a la soberanía nacional, y asociada siempre a la voluntad general más que a un derecho individual, las restricciones y formas de censura que se mantuvieron respondieron y se explicaron desde esa concepción. ${ }^{906}$

El tratamiento que le dará el Congreso nacional a este tema es una buena muestra del radical cambio de perspectiva de las Cortes respecto de la Junta Central y del Consejo de Regencia. Frente a la pusilánime y timorata actuación de una y de otro en relación a esta libertad, una de las primeras decisiones de las Cortes sería la de proceder

\footnotetext{
905 Artola, Miguel, «El camino a la libertad de imprenta, 1808-1810», en Carmen Iglesias, Carlos Moya y Luis Rodríguez Zúñiga (comp.), Homenaje a José Antonio Maravall, Madrid: Centro de Investigaciones Sociológicas y otras instituciones, 1985, p. 217, nota 11.

${ }^{906}$ Portillo Valdés, J.M., Revolución de Nación..., pp. 427-433.
} 
a su regulación jurídica, que es tanto como decir a su reconocimiento. El por demás expeditivo trámite parlamentario de este asunto confirma tanto la importancia que le otorgó el grupo liberal, como también su capacidad de acción en el recinto. Ya en el tercer día de sesiones, el 27 de septiembre, se constituyó una comisión encargada de entender en el tema, compuesta por varios de los más distinguidos liberales: Argüelles, Oliveros, Muñoz Torrero, Gallego, Pérez de Castro, entre once miembros. ${ }^{907}$ El proyecto de decreto fue presentado el 8 de octubre por Argüelles, iniciándose el debate el día 14, a pesar de la oposición de los diputados más conservadores, quienes intentaron infructuosamente demorar su comienzo alegando la ausencia en Cádiz de muchos diputados electos y la escasa preparación del Congreso para entrar en consideraciones sobre el asunto. ${ }^{908}$ El 19 de octubre fue aprobado su primer artículo por 68 votos contra 32, continuando en los días sucesivos las intervenciones de los diputados y la votación del resto del articulado, hasta su publicación definitiva en forma de decreto el 10 de noviembre de $1810 .^{909}$ Tras su aprobación la cantidad de textos y de periódicos se disparó en Cádiz. Y según Hocquellet estos fueron de una naturaleza diferente. Ahora, el objetivo fundamental ya no era "formar la opinión pública sino dar a cada corriente de opinión una tribuna fuera de la asamblea". 910

En el marco del debate los liberales -el "partido libre" como se los denomina en la crónica desarrollada en el Semanario Patriótico-, basaron la defensa del decreto en cuatro grandes ejes: es ante todo un derecho inherente del ciudadano, constituye además un vehículo esencial para la ilustración del pueblo, es también una garantía para atajar el mal gobierno así como a los gobernantes que se aparten del interés general y, por último, resulta necesaria en las circunstancias del momento. ${ }^{911}$ Este conjunto de ideas fueron formuladas de manera precisa y sistemática por Diego Muñoz Torrero -junto con Argüelles, el otro gran referente de la bancada liberal-, en la sesión del 21 de octubre en uno de sus famosos discursos cargado de riqueza doctrinaria. La referencia a la opinión

\footnotetext{
${ }^{907}$ Argumentando los porqués de la necesidad de dicha ley, Arguelles dijo: "Cuantos conocimientos se han extendido por Europa han nacido de esta libertad, y las naciones se han llevado a proporción a sido más perfecta. Las otras, oscurecida por la ignorancia y encadenadas por el despotismo, se han sumergidas en la proporción contraria. España, siento decirlo, se halla entre las últimas". DSC 27/9/10

${ }^{908}$ Semanario Patriótico nro. 34, 29-11-10, pp. 39-41.

${ }^{909}$ El artículo primero definía que «Todos los cuerpos y personas particulares, de cualquiera condición y estado que sean, tienen libertad de escribir, imprimir y publicar sus ideas políticas sin necesidad de licencia, revisión o aprobación alguna anteriores a la publicación, bajo las restricciones y responsabilidades que se expresarán en el presente Decreto», que se complementa con lo establecido en el art. 6 que aclara que «Todos los escritos sobre materia de religión quedan sujetos a la previa censura de los Ordinarios eclesiásticos, según lo establecido en el Concilio de Trento».

${ }^{910}$ Hocquellet, R., óp. cit., p. 621-622.

${ }^{911}$ La Parra López, Emilio, óp. cit.
} 
pública y su estrecha relación con la prensa libre jugaron un papel destacado en su argumentación. El vínculo de ambas con una verdadera división poderes y control de éstos por parte de la nación, poniendo siempre como ejemplo paradigmático a Inglaterra, fue remarcado también por el liberal extremeño: «si el ejecutivo debía ser moderado por el legislativo, éste no podía tener otro freno que el de la pública censura». La mejor salvaguardia de este Congreso, dice el extremeño, era la opinión pública, «no sólo no se debía prohibir la libertad de hablar, sino que debía oírse a todos, pues que esta voz sería la que expresase el dictamen, los deseos y las advertencias del pueblo, que en los países afortunados de libertad, no se tramaban conspiraciones, y sí en los que domina la tiranía, que el justo no teme, y el malvado se halla en continuo sobresalto». Su conclusión es inequívoca: «La libertad sin la imprenta libre, aunque sea el sueño del hombre honrado, será siempre un sueño». ${ }^{912}$

Por su parte Argüelles intervino en varias ocasiones, marcando también los tiempos y la tónica del debate. Ante aquellos diputados que encontraban en la libertad de imprenta una de las razones de la desorganización militar y el avance francés hasta las mismas puerta de Cádiz, como en su momento lo había manifestado el mismo Consejo de Regencia, Argüelles sostenía que justamente su ausencia era la que le había dado «armas al tirano» francés, pues el desconocimiento de los hechos que estaban ocurriendo y las versiones parciales de los mismos sumían en la contradicción y en no pocas indecisiones a los patriotas.

Los adversarios de la aprobación del decreto basaron la mayor parte de sus intervenciones en resaltar los males que ésta traería, motivando un relajamiento en las costumbres, perturbaciones en el orden social y ofensas inauditas al dogma católico. Tanto Inglaterra como Francia eran ofrecidas como contra-modelos, una por hereje, la otra por la anarquía revolucionaria que había soportado. En el Semanario Patriótico son descriptas algunas de las consideraciones de los diputados conservadores: "Antisocial, antirreligiosa y antipolítica decían sus adversarios que era esta libertad. Con ella se destruía el respeto a la religión, a las autoridades civiles, a las costumbres y al decoro público. Relajados con los abusos a que necesariamente dieron lugar los lazos y la jerarquía social, el orden político se disuelve y los imperios se arruinan... Con ella los filósofos, los literatos se habían apoderado allí de la opinión pública introduciendo en ella el veneno de sus errores." Y más adelante: "Esta facultad indiscreta era la que había

\footnotetext{
${ }^{912}$ El Conciso, nro. 33, 26/10/1810.
} 
introducido las infinitas sectas que había en Inglaterra, había llenado de horrores la Isla; y algún día la privaría de esa misma constitución de que tanto se gloriaba, como había destruido las diferentes leyes políticas que se han dado los Franceses". ${ }^{913}$

El esfuerzo de los liberales se orientó a dar vuelta el argumento principal de los opositores: no sólo no contradice la verdad católica, sino que la protege. Es más, la libertad favorece la adquisición de conocimientos y esto -defendió Argüelles- conduce a la verdad, incluso la religiosa. Muñoz Torrero también fue claro en este sentido: «La educación pública es el verdadero preservativo contra la impiedad y la salvaguardia de las costumbres».

Pero entre las filas liberales también se levantaron voces en contra de algunos aspectos del decreto. Cuando tocó discutir el artículo 6, que establecía que «Todos los escritos sobre materia de religión quedan sujetos a la previa censura de los ordinarios eclesiásticos, según lo establecido en el Concilio de Trento», el diputado americano José Mejía Lequerica presentó objeciones. Para el quiteño era necesario que se aboliera toda especie de censura, porque de mantenerse en algunos temas no podría considerarse concedida a su entender la libertad de imprenta, en la misma línea con el espíritu que emanaba aquella propuesta de Álvaro Flórez Estrada presentada a la Junta Central. El americano recordó que ni Esdras, ni San Pablo ni San Agustín estorbaron jamás la libertad de escribir, y sería «una especie de irreligión» empeñarse en ser más religiosos que ellos. Estas consideraciones ocasionaron un importante revuelo entre los diputados. Llaneras las calificó de poco conformes a la religión y solicitó de las Cortes la inmediata recogida del papel de Mejía para hacer el uso conveniente, lo que motivó la intervención de Argüelles recordando la inviolabilidad de los diputados. ${ }^{914}$ Pero la gran mayoría de los liberales no estaban dispuestos a tensar la cuerda con respecto a este tema, algunos por genuina convicción, otros por voluntad conciliadora hacia los sectores moderados y conservadores del parlamento, entre ellos, está de más decirlo, los miembros del clero. ${ }^{915}$ Muñoz Torrero, ante el planteo de su par quiteño, defendió los

\footnotetext{
${ }^{913}$ Semanario Patriótico nro. 34, 29-11-10, p. 42.

${ }^{914}$ La Parra López, Emilio, óp. cit.

${ }^{915}$ Argüelles, en sus memorias sobre aquel proceso originalmente publicadas en Londres en 1835, se lamentaba de que los intereses del clero se hubiesen impuesto y reconocía que con tal limitación «se hacía un doloroso sacrificio de la libertad de imprenta», pero que se dio por bueno ya que se imponía el sentido práctico de los más progresistas y anticlericales para conseguir aprobar una norma que se consideraba esencial para sus objetivos principales. Una restricción que se enmarca en una de las características sobresalientes del constitucionalismo hispánico: la intolerancia religiosa. Como plantea Nancy Calvo, "las profundas conmociones que atraviesa la sociedad española y la incertidumbre con respecto al futuro seguramente no están ausentes de las preocupaciones de los legisladores de Cádiz que sostienen, ya por
} 
términos del artículo 6, «recordando lo que el Concilio de Trento tenía dispuesto acerca de los escritos en materia de religión; que la sujeción a las decisiones de la Iglesia era inseparable de la nación española [...] y, sobre todo, que en el artículo 1 estaba ya decidido por las cortes que la libertad de imprenta se entendiese en materias no religiosas, y de consiguiente, éstas debían estar sujetas a la previa censura». ${ }^{916}$

En las publicaciones de carácter no religioso sólo se exige conste el nombre del impresor (art. 8), pero no el del autor, aunque es obligación del primero saber de dónde proceden los manuscritos que publique. No existe ningún tipo de censura previa, pero se fija la existencia de una Junta de censura en cada provincia y otra Suprema a nivel nacional para atender las denuncias practicadas contra las publicaciones. ${ }^{917}$ Todo ello entraña el abandono del régimen preventivo en el ejercicio de este derecho y la opción en favor de un régimen represivo o de responsabilidad posterior. ${ }^{918}$

Un año y medio más tarde, las Cortes garantizarán la libertad de imprenta, dándole rango constitucional: su protección será una de las facultades de las Cortes (art. 131) y se reconocerá, en el capítulo dedicado a la instrucción pública -dato no menor que reflejaba la fuerte carga ilustrada que aún poseía este derecho para los liberales-, en idénticos términos a como había quedado redactado en el artículo 1 del decreto de libertad de imprenta (art. 371 de la Constitución).

Coincidimos con Francisco Segado en que, sin negar en modo alguno el carácter instrumental o funcional que presenta esta libertad, estamos fundamentalmente ante un derecho, del mismo orden que los de seguridad individual, igualdad jurídica, etc. ${ }^{919} \mathrm{La}$ restricción del ámbito de la libertad de imprenta a las ideas políticas, con exclusión de las religiosas, no debe por lo tanto explicarse en base a su naturaleza funcional. Tal limitación responde más a las características particulares de la cultura constitucional hispánica, impregnada ésta de una fuerte carga de catolicismo. Aun siendo para un sector del liberalismo una pragmática transacción en un determinado contexto histórico,

convencimiento ya por necesidad, el principio de la unanimidad religiosa". Calvo, Nancy, óp. cit., pp. $155-156$.

${ }^{916}$ Semanario Patriótico nro. 34, 29-11-10, p. 42.

${ }^{917}$ La Suprema estaba integrada por nueve miembros nombrados por las Cortes, tres de ellos eclesiásticos. Las provinciales, compuestas por cinco miembros nombrados a propuesta de la Junta Suprema, debiendo ser dos de ellos eclesiásticos. Los restantes miembros de cada uno de estos órganos debían ser seculares, según se precisaba de modo específico.

${ }_{918}$ Fernández Segado, F., óp. cit., p. 43.

${ }^{919}$ Fernández Segado, F., óp. cit., p. 44. 
no deja de ser en líneas generales un aspecto esencial y consecuente con la cultura del primer constitucionalismo hispánico. ${ }^{920}$

Pero debemos reconstruir el cuadro completo. Más allá de que las Cortes proclamaron una amplia licencia para escribir sobre cuestiones políticas, y por ende, excluía la posibilidad de ser castigado por cuestionar a las autoridades o las medidas que emanaban de ellas, en la práctica el Congreso persiguió en muchas oportunidades las opiniones que pusieran en causa su legitimidad, o la del Consejo de Regencia, como representantes de la nación española y su soberanía.

En 1812 la publicista absolutista Manuela María López de Ulloa fue procesada porque en uno de sus escritos "se califica de viles Españoles a los que usan de las voces, Independencia, Libertad, Nación, ciudadano, Igualdad y Derechos imprescriptibles, que tan sabiamente han sacado nuestras Cortes del olvido en que yacían [...]". ${ }^{921}$ López de Ulloa fue una de las mujeres que más intensamente participó en los debates periodísticos surgidos en torno a las sesiones de Cortes y a la promulgación de la Constitución de Cádiz. Pocos datos biográficos se tienen de esta manchega que llegó a Cádiz en su condición de patriota insumisa a José Bonaparte. Próxima al círculo conservador de Frasquita Larrea y amiga del diputado y antiguo capellán del rey Blas de Ostolaza, escribió entre 1812 y 1814 más de veinticinco encendidos artículos contrarios a la Constitución y al liberalismo en los periódicos absolutistas gaditanos El Procurador General de la Nación y del Rey y Diario Patriótico de Cádiz, desde los que mantenía encendidas polémicas con los articulistas del periódico liberal El Redactor General. Finalizada la guerra y tras el regreso a España de Fernando VII, se traslada a Madrid, ciudad en la que continuará publicando sus artículos en periódicos absolutistas.

También en Cádiz en enero de 1811 el periódico El Robespierre español es suspendido y su autor, Pedro Fernández Sardinó, encarcelado, no tanto por su título y su lenguaje exaltado, como por expresar en sus artículos duras críticas a la Regencia y a la inoperancia del general Carrafa en la batalla de Badajoz. La Junta provincial de Censura de Cádiz entendía que las opiniones vertidas en el nro. 7 de El Robespierre español eran “sediciosas y subversivas de las leyes". ${ }^{922}$ La mujer de Fernández Sardinó, María del

\footnotetext{
${ }_{920}$ Portillo Valdés, José María. “La constitución...“, pp. 123-178.

${ }^{921}$ Manuela María López de Ulloa, "Respuesta de la española autora del papel Afectuosos gemidos, publicado en 14 de octubre de 1813 y detenido por subversivo con arreglo a la primera censura de la junta provincial de Cádiz", Cádiz, Oficina de D. Nicolás Gómez de Requena, 1813. Citado en Guerra, François-Xavier, "voces de pueblo...", p.380.

${ }_{922}$ Fernández Sardinó se defiende y acusa al Ministro de Gracia y Justicia de no respetar la libertad de imprenta: "Todo ciudadano que no siendo un idiota o un loco, ataca astuta o descaradamente a la libertad
} 
Carmen Silva, decidió continuar publicando el periódico y en el primer número bajo su dirección lo manifiesta combativamente: "Y yo, sólo por contrarrestar la iniquidad francesa voy a publicar a mi nombre la continuación del Robespierre y verán esos perversos vándalos que si han conseguido su intento, derribando a mi patriota esposo, aún existe quien sepa perseguirlos hasta la muerte". Lográndolo con éxito durante los restantes años de la guerra. ${ }^{923}$

Otro caso ilustrativo es el de El Duende político o la Tertulia resucitada, un semanario que vio la luz por primera vez en los últimos días del mes de marzo de 1811 y del cual sólo se llegaron a editar 16 números. Consagrado a la opinión política, la mayoría de las veces sus artículos estaban dedicados a cuestiones abstractas, en un estilo bastante retórico y con una relación meramente conceptual con la coyuntura. Se destacó entre sus pares por su liberalismo radical, sus posiciones anticolonialistas y por las corrosivas críticas a las Cortes y sobre todo al Consejo de Regencia. ${ }^{924} \mathrm{Y}$ aunque había celebrado la promulgación del decreto de libertad de imprenta por parte de las Cortes, observando su puesta en práctica, denuncia que «sus mayores panegiristas y protectores le mueven ya una guerra espantosa y cruel y no con las armas lícitas, sino con las prohibidas y aleves... Quisieran que fuésemos libres en escribir, pero esclavos en pensar». Manifiesta que todo lo que «no les acomoda o no les adula, es peligroso y ataca indirectamente la libertad de la prensa. No conspira al bien de la patria. Encierra pensamientos perniciosos. Fomenta la anarquía y ofende, mina, y compromete la

de la imprenta, es un execrable traidor a la Patria, sea quien fuere". El Robespierre español nro. 10, p. 158. Estos hechos provocaron una intensa polémica en la prensa de Cádiz.

${ }^{923}$ María del Carmen de Silva, lisboeta de nacimiento, se implica directamente en la causa española cuando a

mediados de 1808 libera a las tropas españolas comandadas por Carrafa, que fueron apresadas por Junot en Lisboa. Huyendo conoce en Badajoz a su marido y llegan juntos a Cádiz en 1811. Acostumbraba a organizar una tertulia que, por la escasez de datos, suponemos de menor importancia. Con el retorno al absolutismo se exilia en Londres, volviendo a España durante el Trienio Liberal y finalmente otra vez a Londres, donde se pierde su pista en 1829. Sánchez Hita, Beatriz, "María del Carmen Silva, la Robespierre Española: una Heroína y Periodista en la Guerra de la Independencia”, Irene Castells Oliván, M. Gloria Espigado Tocino, María Cruz Romeo Mateo (coord.), Heroínas y patriotas: mujeres de 1808, Madrid: Ediciones Cátedra, 2009, p. 399.

${ }^{924}$ Crítico frontal de las élites del Antiguo Régimen, de los Grandes y los Cortesanos, que «temen la propagación de las luces, y el reinado de la justicia; y nada los aterraría más que la aurora feliz de la libertad e igualdad política en medio de nosotros; es consecuente, pues, al sistema de su vanidad y su fanatismo; que odien las buenas ideas y el restablecimiento de los derechos imprescriptibles del hombre, que debe ser el grande estímulo y la primera base para engrandecer al pueblo español». Citado en Hernández González, Manuel, "Entre Europa y América. El periodismo de Cabral de Noroña. Del Duende Político gaditano al Observador Español en Londres". Cuadernos de ilustración y romanticismo, $\mathrm{n}^{\mathrm{o}} 16(2010)$, p. 5. 
seguridad del estado». ${ }^{925}$ Estas posturas, sumadas a su férrea oposición a la Junta de Censura, le fueron ganando cada vez más enemigos entre los conservadores, entre ellos el fiscal del Consejo Real Antonio Cano Manuel, quien en plena cacería de la prensa liberal más radical hacia junio de 1811, presentó una denuncia contra el Duende Político en las Cortes, que llevó a su editor a tener que comparecer ante los diputados para defenderse de los cargos. Estas parecen entonces ser las razones de la desaparición prematura del periódico y de la decisión de Cabral de Noroña, ante la posibilidad del encarcelamiento, de poner mar de por medio y huir hacia los Estados Unidos donde continuará su carrera como publicista. ${ }^{926}$

Estos pocos ejemplos, los hay evidentemente más, alcanzan para ver con claridad que la tan mentada libertad de escribir no era absolutamente incondicional en los hechos. Las autoridades, siguiendo las formalidades legales en la mayoría de los casos, presionaban, obstaculizaban o directamente perseguían a quienes a través de su pluma cuestionaban las decisiones del gobierno, con la excusa de ser opiniones subversivas, de alterar la paz social o de atacar el honor de las personas. Y esto valía tanto para los que criticaban desde posiciones conservadoras como a aquellos liberales más radicales inconformes con la moderación del rumbo tomado por las autoridades. Este tipo de arbitrariedades, veremos más adelante, no se remitieron sólo al territorio peninsular sino que en América, en un contexto de características diferentes, fue también moneda corriente.

\section{Circulación de la legislación sobre la libertad de imprenta en el mundo hispánico. El papel del Deán Gregorio Funes y de José Blanco White}

En la América española, mientras las autoridades coloniales siguieron siendo dominantes, la censura previa predominó. El caso más evidente lo constituyó el virreinato de Nueva España. ${ }^{927}$ Mientras la prensa oficial de la ciudad de México siguió

\footnotetext{
${ }^{925}$ Con respecto a la Junta de Censura, dice que al depositar esa responsabilidad en tan pocas personas estaremos «bajo las vicisitudes de la sorpresa o del terror» y ser éstos nombrados los de la Junta Suprema por las Cortes y los provinciales por la primera estaban propiciando su conversión en «una inquisición política y tiránica a la devoción del gobierno». Ibid., p.10.

${ }^{926}$ Durán López, Fernando, "Diputados de papel: la información parlamentaria en la prensa de la etapa constituyente (septiembre de 1810-marzo de 1812)", en Guerra de pluma: Estudios sobre la prensa de Cádiz en el tiempo de las Cortes (1810-1814), coordinado por Marieta Cantos Casenave, Fernando Durán López, Alberto Romero Ferrer (Cádiz: Universidad de Cádiz, 2008), pp.126-129.

${ }^{927}$ El virrey Venegas la proclamó el 30 de septiembre de 1812 y la suspendió el 5 de diciembre, luego de condenar un artículo publicado por José Joaquín Fernández de Lizardi en su naciente Pensador del 3 de diciembre. Loaiza Cano, Gilberto. «La libertad de imprenta en la América española (ensayo de historia comparada sobre la opinión pública moderna)». Historia y memoria, n 13 (2016): p. 51.
} 
sometida, los periódicos de la insurgencia, a pesar de las limitaciones técnicas, pusieron en práctica la nueva libertad y se convirtieron en medios de comunicación alternativos en las regiones de influencia de los ejércitos de Hidalgo y Morelos. En Buenos Aires, Santiago de Chile, Caracas y Santafé de Bogotá, el movimiento juntista motivó automáticamente el surgimiento de periódicos de contenido político, todos ellos en un primer momento bajo el paraguas oficial, concentrados en el examen de la situación inédita del imperio y en los primeros ensayos sobre las formas de organización política en el porvenir. ${ }^{928}$

La libertad de imprenta se estableció en el Río de la Plata por medio de los decretos del 20 de abril y del 26 de octubre de 1811, junto al decreto sobre seguridad individual. El primero de ellos transcribe, como es bien sabido, la disposición sobre libertad de imprenta promulgada por las Cortes de Cádiz el 10 de noviembre de 1810, y crea una Junta Suprema de Censura. El responsable de dicha iniciativa fue el Deán Funes, que se desempeñaba además como director de la Gazeta de Buenos Aires. En la extraordinaria del 22/4/11 publica el decreto, a la par que lo acompaña con su Discurso sobre la libertad de la prensa. Desde una perspectiva iluminista pone el acento en los beneficios que, en términos de instrucción y difusión de conocimientos, conllevaría el establecimiento de esa libertad. Se pregunta si ofrecer ahora este reglamento es arrogarse una facultad que debiera corresponder al congreso nacional que se está por convocar para legislar sobre los derechos del hombre, si hacerlo anticipadamente es arriesgar demasiado y abrirle las puertas a las inconsecuencias de malas doctrinas y vacilantes opiniones. Se responde que basta con que la licencia sea de carácter momentáneo para salvar los derechos del congreso. Pareciera solo una inquietud formalista, pero como veremos más adelante, no era sólo eso: la libertad de prensa debía anteceder al Congreso por razones más de tipo doctrinario.

No es casual que ni bien empiece a describir la naturaleza de esta facultad, lo primero que establezca es la excepción de la regla: “Aunque a la prensa deban las letras un adelantamiento prodigioso, también es ella la que ha inundado al mundo en errores sobre materia de religión". ${ }^{929}$ Después de relatar lo que considera que eran los peores sofismas anticatólicos que habían circulado en distintos momentos históricos, afirma que si el espíritu de la impiedad logró avanzar aun en contra de la censura, no es difícil imaginar lo que sucedería sin traba alguna. Para el Deán, coherente con su posición

\footnotetext{
${ }^{928}$ Ibid., pp. 57-58

${ }^{929}$ Gazeta Extraordinaria de Buenos Aires, 22-4-1811, p. 312.
} 
como miembro destacado del clero, el dogma católico estaba exento de ser materia para la crítica o revisión: "Después que la religión cristiana ha fijado su trono en un estado, ninguna precaución está de sobra para que se conserve inalterable". 930

En este punto Funes discute con el autor de "cierto papel”, al que le señala la contradicción de por un lado sostener que es necesaria la restricción de la prensa en materias religiosas, pero luego cuestionar a los emperadores de antaño, censurando esas mismas acciones como sinónimos de despotismo y oscuridades. Para Funes por el contrario era completamente reivindicable y hasta motivo de agradecimiento la actitud de dichos soberanos, aun los paganos, "en obsequio de una causa de un orden superior, como es la religión y su doctrina". El referido autor, que nunca es nombrado, no es otro que el onubense José Isidoro Morales, y el papel citado la Memoria sobre la libertad política de la imprenta, presentada la Junta de Instrucción Pública en 1809 en Sevilla. La relación entre los reglamentos de la Junta Grande y el decreto de las Cortes de Cádiz era más que conocida por la historiografía, pero no así el vínculo del Discurso de Funes con el antecedente oficial más cercano del decreto, como era la Memoria de la Junta Central. Como con el artículo de El Voto de la Nación española plagiado por Belgrano, este nexo constituye un nuevo hallazgo. Y una vez más, el origen peninsular del escrito utilizado es escondido por el publicista porteño, para no despertar suspicacias gratuitamente, o reconocer méritos al enemigo declarado. Pesaban quizás más los ánimos de diferenciarse del gobierno peninsular para así justificar la conformación de un gobierno propio que la variante de poder pensarse como parte de una misma experiencia política de ruptura con el absolutismo.

Volviendo al análisis del Discurso, después de marcar insistentemente la restricción con respecto al dogma, considera que "en todo lo demás el ejercicio de la prensa debe ser libre. Las verdades que pertenecen a la política, y a las demás ciencias naturales, se hallan más a los alcances de la razón humana; no es exclusivamente una sola la forma de gobierno, que puede hacer dichosos a los hombres, como es única la religión". ${ }^{931}$ Y aquí es donde el escrito se contorsiona y pasa a vestirse de un lenguaje político más innovador. Tomando prestadas las palabras de un "sabio político", sostiene que "en el pueblo es en el que reside originariamente el poder soberano" y por lo tanto de él es también la facultad de mudar las leyes según lo exija la necesidad del estado. Por ende, para Funes, el tribunal de la opinión pública es el vehículo para que se haga

\footnotetext{
${ }^{930}$ Ibid., 314.

${ }^{931}$ Gazeta Extraordinaria de Buenos Aires, 22-4-1811, 318.
} 
notoria la voluntad general. Y ese tribunal "es la prensa, y la señal de que sus puertas están francas, es la libertad". A partir de ella "sabrán los comisionados del poder la voluntad de su comitente, que es la nación; sabrán cómo interpreta su contrato social, modifica sus cláusulas, o las anula, revoca sus dones, establece un nuevo orden de cosas, y en fin rectifica las ideas del gobierno, y lo dirige". ${ }^{932}$

Sin libertad de prensa, dice Funes, el gobierno caminaría a ciegas, ignorando cuál es la opinión pública, y de ahí al poder arbitrario hay solo un paso. E insiste con la relevancia de la coyuntura: "en que la América por una feliz revolución ha entrado en todos sus derechos, y se halla próxima a levantar el edificio de su constitución”. En este punto es clara la correspondencia con aquellos que en la península también entendían que no había que esperar a fijar una constitución para establecer la libertad de imprenta, más aún era condición sine qua non para que el congreso constituyente obrara como expresión genuina del pueblo soberano. ¿Pero quién era ese pueblo para Funes? Definitivamente no lo era la multitud analfabeta, sino los "hombres de ilustración" que conformaban a la opinión pública que guiará al gobierno. No era necesario crear fantasmas donde no los había: "por fortuna la prensa es un santuario, que el vulgo respeta desde lejos". ${ }^{933}$ Cierra finalmente su discurso presentando el reglamento, el cual advierte fue "sacado en la mayor parte de algunos papeles públicos de la Europa". ${ }^{934}$ Un nuevo eufemismo que disfrazaba la apropiación literal del decreto de las Cortes gaditanas.

La disposición del 26 de octubre 1811, por parte del Primer Triunvirato, avanzaba al proclamar que todo hombre podía publicar libremente sus ideas sin previa censura, al establecer que las disposiciones contrarias a esta libertad quedaban sin efecto, y al eliminar "las restricciones", "los castigos" y "las multas" que recaían sobre autores e impresores, aunque cabe señalar que se mantuvo la "previa censura del eclesiástico" en materia religiosa. E innovaba con la creación de una Junta Protectora de la Libertad de Imprenta en reemplazo de la Junta Suprema de Censura. Como bien plantea Noemí Goldman, la nueva denominación implicaba a la vez un cambio en la concepción que sustentaba la tarea de la Junta. La de Censura, al mismo tiempo que debía asegurar la libertad de imprenta, procuraba también contener su abuso, mientras que la Protectora tenía como principal función evitar los efectos de la arbitrariedad en la calificación y

\footnotetext{
932 Ídem.

${ }^{933}$ Ibid., 319.

${ }^{934}$ Ibid., 322.
} 
graduación de los delitos producidos por transigir los límites de esa libertad. ${ }^{935}$ Cambia también la forma de elección de los sujetos que debían integrarla. El Reglamento del 22 de abril de 1810 determinaba: "Para asegurar la libertad de imprenta, y contener al mismo tiempo su abuso, se nombrará una Junta Suprema de censura, que deberá residir cerca del gobierno, compuesta de cinco individuos, y a la propuesta de ellos otra semejante en cada capital de provincia, compuesta de tres". ${ }^{936}$ Mientras que el del 26 de octubre disponía:

Para evitar los efectos de la arbitrariedad en la calificación, y graduación de estos delitos se creará una Junta de nueve individuos con el título de Protectora de la libertad de imprenta. Para su formación presentará el Excmo. Cabildo una lista de cincuenta ciudadanos honrados, que no estén empleados en la administración del gobierno; se hará de ellos la elección a pluralidad de votos. Serán electores natos el prelado eclesiástico, alcalde de primer voto, síndico procurador, prior del Consulado, el fiscal de S.M. y dos vecinos de consideración, nombrados por el Ayuntamiento. El escribano del pueblo autoriza el acto, y los respectivos títulos, que se librarán a los electores sin pérdida de instantes. $^{937}$

La figura de un jurado popular repercutió inmediatamente en la prensa. Ante una carta de un lector a la Gazeta de Buenos Aires preguntando qué sería considerado como abuso de esa libertad, Pazos Silva responde aclarando que el reglamento no podía detallar todos los casos de abusos posibles y agrega: "la calificación o graduación de este uso o de este abuso de la libertad pende del juicio de los hombres, por esto es, que su decisión se reserva al concepto de un tribunal popular". 938

La novedad del jurado de ciudadanos trascendió más allá de las fronteras del Plata. En su cruzada contra las disposiciones de las Cortes de Cádiz, y en particular contra el decreto de libertad de imprenta de noviembre de 1810, José Blanco White reprodujo en El Español el reglamento del 26 de octubre de 1811 del Primer Triunvirato, acompañado de un extenso y elogioso comentario. ${ }^{939}$ Como demostró Alejandra Pasino, Blanco White utiliza lo legislado por los rioplatenses como herramienta en su crítica a lo resuelto en Cádiz, justamente en dos de sus aspectos medulares. Por un lado, considera que en el decreto gaditano el rol de la opinión pública

\footnotetext{
${ }^{935}$ Goldman, N., "Libertad de imprenta, opinión pública y debate constitucional en el Rio de la Plata (1810-1827)", Prismas. Revista de historia intelectual, n 4, 2000, p.10.

${ }_{936}$ Gazeta extraordinaria de Buenos Aires, 22/4/1811, pp. 322-324.

${ }^{937}$ Gazeta de Buenos Aires, 26/10/1811, pp. 684-686.

${ }^{938}$ Gazeta Buenos Aires, 12/11/1811, "Respuesta a la carta del número anterior", p. 11.

${ }^{939}$ El Español XXIV, 30/4/1812, pp. 430-443.
} 
como contrapeso fundamental de gobierno -tan declamado y defendido por los diputados liberales- se diluía al ser las propias Cortes las que designaban a los censores. ${ }^{940}$ El sevillano ya había manifestado anteriormente que la única alternativa para evitar esa situación era que esos "tribunales que han de conservar la libertad de imprenta, fuesen nombrados directamente por el pueblo, como lo son sus representantes". 941

Otra de las cuestiones a las que se opone es a la indefinición de lo que se consideraría abusos de imprenta, entendiendo como demasiado vaga la referencia a la "subversión de las leyes fundamentales de la monarquía" que contiene el decreto. ${ }^{942}$ Por el contrario, con respecto al reglamento del Primer Triunvirato, afirma que era la mejor producción sobre la libertad de imprenta que se había sancionado en la revolución de los dominios españoles de ambos hemisferios por su "liberalidad, tino, moderación y saber"; y que el gobierno que lo había elaborado gozaba de su "veneración y respeto". ${ }^{943}$ Como destaca Pasino, Blanco White elogia la ausencia de "pedantería filosófica" que caracteriza al decreto, la capacidad de sus autores para explicar en qué consistía el abuso de la libertad de imprenta y sus propuestas para evitarlo sin poner en riesgo la libertad de expresión a partir de la creación de una Junta Protectora, constituida por un jurado elegido popularmente. ${ }^{944}$

Su crítica no constituía una mera manifestación de principios, buscaba en última instancia persuadir a la diputación gaditana sobre la necesidad de reformar el decreto de 1810, tomando para ello el ejemplo de Buenos Aires. Y tampoco era un planteo aislado, sino que respondía a un contexto particular: estaba inserta en el marco de las propuestas tanto del diputado novohispano Miguel Ramos Arispe en febrero de 1812, como por la presentada por Miguel Guridi y Alcocer -también representante de Nueva España- en marzo de 1812 para corregir los defectos de la ley de $1810 .^{945}$

Los dos casos tomados aquí, el del rioplatense Funes y el sevillano Blanco White, son sintomáticos del proceso de circulación de ideas, escritos, legislaciones, etc., que venimos intentando remarcar. Y son además un claro ejemplo de que, como la misma palabra lo sugiere, esa circulación no era unidireccional, desde Europa hacia América,

\footnotetext{
${ }^{940}$ Pasino, A., "Buenos Aires - Cádiz - Londres: circulación y recepción de la legislación sobre libertad de imprenta. (1810-1812)”, PolHis, núm. 12, 2013, pp. 83-94.

${ }^{941}$ El Español IX, 30/12/1810, p. 223.

${ }^{942}$ Ibid., p. 221.

${ }^{943}$ El Español XXIV, 30/4/1812, p. 432.

${ }^{944}$ Pasino, A., óp. cit., p. 91.

${ }^{945}$ Ibid., p. 92.
} 
como por mucho tiempo sostuvo la historia de ideas tradicional. Existía un ida y vuelta constante que cruzaba el Atlántico, sin negar por eso las evidentes asimetrías establecidas por el lugar de centro y periferia que ambas orillas ocupaban, en el gran conjunto que constituía el mundo hispánico. ${ }^{946}$

\section{La libertad de imprenta en la Gazeta de Montevideo}

Al igual que en la metrópoli, pero con un grado de intensidad definitivamente menor, en el Montevideo lealista el debate discurría también entre la mayor o menor restricción que debía tener la libertad de imprenta. En la Gazeta de Montevideo del 6/11/10 se publica una carta titulada "Sobre la prensa", donde se elogia y festeja la decisión del gobierno local de dejar atrás las prácticas despóticas pasadas y abrir las puertas a una prensa libre en la ciudad. Su autor se plantea, en primer lugar, abordar la cuestión desde el significado de las voces, para no caer -dice- en un altercado escolástico: "la palabra es el privilegio el más eminente del orden moral, sin el cual no hay sociabilidad que el hombre no haya inventado; cuya sublime, prerrogativa le ha sido dada para elevarla a su creador, para unirse con sus hermanos, modificándola como todo el resto deja la naturaleza [...] y que no se le ha concedido para despedazar a sus semejantes, y romper los lazos de unidad que debe formar". ${ }^{947}$ Desde esas bases considera que aun siendo la imprenta el móvil más activo para la ilustración de la opinión pública a la que debía formar y dirigir, entiende que no hay "nada más contrario a los primeros elementos de la moralidad, y la sociabilidad que el escribir libremente, es decir, contra las buenas costumbres, las personas, y sobre todo acerca del dogma sagrado bajo de cualquier pretexto que fuese". ${ }^{948}$ Considera legítimo que sean criticados los actos de gobierno pero no así las personas, llegando incluso a plantear que ni siquiera deben ser calumniados aquellos que por un error de concepto viven separados de la soberanía del gobierno. Principio que no será respetado por el periódico, siendo los revolucionarios porteños atacados sistemáticamente con todo tipo de descalificaciones.

\footnotetext{
${ }^{946}$ La geografía de la imprenta en el mundo hispánico de esta época es reveladora de esta asimetría: "por lo menos hay diez imprentas en Madrid en 1808 y una, por lo menos, en cada capital de las provincias españolas; más de veintiséis en Cádiz durante las Cortes; pero ninguna en Chile antes de 1812, la primera en Caracas en 1808, una o dos en Buenos Aires, Bogotá y Lima en 1810, ninguna en las provincias. Sólo la Nueva España se asemeja a la Península: cinco en la ciudad de México, y una en Veracruz, Guadalajara y Puebla". Guerra, F-X, "Voces de pueblo...", p. 376.

${ }_{947}$ Gazeta de Montevideo del 6/11/10, p. 36.

${ }^{948}$ Ibid., p. 37.
} 
Es para destacar, por otro lado, la ausencia total de referencias en la carta a la situación en la metrópoli, quedando como algo propio de Montevideo y no como parte de un fenómeno que empezaba a vivir el conjunto del mundo hispánico. Como pudimos ver, a pesar de que para ese momento no se había aún dictado el decreto de libertad de imprenta por parte de las Cortes, ya constituía una realidad de facto desde mediados de 1808, inundado Cádiz de publicaciones de carácter político. Recién cuando el tema empiece a tratarse en Cortes la Gazeta de Montevideo se hará eco. En marzo de 1811 se reproduce un artículo de El Conciso del 12/10/1810 que relata la lectura, por parte del diputado Argüelles, del proyecto de ley sobre la libertad de imprenta, que comprendía los límites a ésta y la creación de un "consejo supremo protector para ponerla a cubierto del despotismo Ministerial y de la tiranía”. También aparecía relatada la intervención del diputado liberal Muñoz Torrero saliendo al cruce a los recelos manifestados por el Consejo de Regencia contra aquellos que criticaban la labor de las Cortes.

Un ejemplo práctico sobre cómo se entendía la libertad de imprenta, así como el peso de la opinión pública en la consideración de los editores, lo podemos observar en una gaceta de febrero de 1813, cuando un lector escribía a su director, Cirilo de Alameda, quejándose de que haya introducido en un número anterior un artículo que a su entender le hacía el juego a los sitiadores de la ciudad. El punto en cuestión es que se hacía referencia a la existencia de unos supuestos montevideanos "angustiados", que no estarían tan seguros de la causa lealista, retratando un cuadro de debilidad en el contexto del Montevideo asediado. Muy indignado, le exige que sea mucho más estricto a la hora de definir qué escritos incorporar y cuáles no al periódico. El editor en su respuesta, se justifica argumentando que en algunas ocasiones lo han acusado maliciosamente de "infractor de la Constitución y del soberano decreto de la libertad de imprenta", y que por ello decidió publicar ese papel, que pertenecía a un amigo, sin previamente leerlo. ${ }^{949} \mathrm{El}$ caso evidencia la a veces "incomoda" situación en la que se encontraban los editores ante los cambios jurídicos y culturales que se venían produciendo en relación al oficio periodístico. Sometidos a distintas presiones, agudizadas en un contexto de guerra revolucionaria, con sus decisiones editoriales debían responder a la expectativa ya no solo del gobierno, que en la mayoría de los casos sostenía económicamente estas empresas, sino también de la embrionaria opinión pública, que ellos mismos estaban aportando a constituir.

\footnotetext{
${ }^{949}$ Suplemento Gazeta de Montevideo 7 16/2/13: 100
} 
Opinión pública vs opinión oficial. Los casos de El Censor de Pazos Silva y la Gazeta de Monteagudo

En el primer número de El Censor, del 7 de enero de 1812, bajo el título de "Tolerancia", su director Vicente Pazos Silva realiza un recorrido histórico sobre el difícil camino que tuvo que atravesar el derecho a la libertad de expresión para terminar imponiéndose como uno de los pilares en la construcción de las naciones modernas. Su abrupta salida de la Gazeta de Buenos Aires por decisión del Primer Triunvirato pareciera aún resonar en la conciencia del publicista, por lo que la elección de este artículo para iniciar su nuevo periódico suponemos no es para nada casual. Y se ve confirmada cuando el texto que le sigue es una carta donde un lector se queja del destrato sufrido por los dos editores de la Gazeta, el mismo Pazos Silva y Monteagudo, reivindicando la posibilidad que en un mismo periódico se pudieran leer dos posiciones tan disímiles -una moderada y la otra radical-, pero ambas a su entender provenientes de dos "apóstoles de la libertad de la patria", que merecen respeto y consideración. ${ }^{950}$

De a poco se hacía notorio el clima de tensión que comenzaba a vivirse a inicios de 1812 en Buenos Aires, entre el morenismo resurrecto y el Triunvirato timoneado bajo cuerda por Rivadavia. La recientemente reorganizada Sociedad Patriótica-Literaria contó en un primer momento con el permiso oficial para funcionar libremente, pero era claro que debía mantenerse bajo determinados márgenes de acción. ${ }^{951}$ Como anunciaba un comunicado de la misma aparecido en El Censor, los discursos o memorias de miembros de esa asociación que se diesen a la prensa, debían ser objeto de censura previa y llevar "nota de aprobación de los censores"; si no era así, no podían presentarse como propios de la Sociedad. ${ }^{952}$ La práctica de la autocensura por parte de las asociaciones nos arroja un nuevo elemento como para representarnos el verdadero cuadro en el que se iba construyendo la opinión pública en el Río de la Plata revolucionario y los límites concretos a la libertad de prensa. Unos pocos meses después, otro anuncio de la misma asociación, ahora en Mártir o Libre, su propio periódico, rezaba: "todos los ciudadanos que quieran concurrir [a la Sociedad] con sus conocimientos podrán hacerlo, en inteligencia que la previa censura que se exigía antes de publicar las memorias, se ha derogado en favor de la libertad que concede la ley a

\footnotetext{
${ }^{950}$ La carta relata un incidente en el cual un militar quema públicamente en un café un ejemplar de la Gazeta del 31 de diciembre de 1811, el último bajo su dirección.

${ }^{951}$ Sobre el surgimiento y derrotero de la Sociedad Patriótica ver la clásica obra Canter, Juan, óp. cit.

${ }^{952}$ El Censor, nro. 4, 28 de enero de 1812, p. 16.
} 
todo el que no abusa de ella". ${ }^{953}$ El contexto ya era otro, la evolución del conflicto entre facciones había llegado a otro nivel. Como ya vimos, la Sociedad desde mediados de marzo había comenzado a criticar al Triunvirato por el procedimiento y el reglamento con el que convocó a la Asamblea, y sobre todo la decisión finalmente de disolverla. ${ }^{954}$

Pero no era solo con el morenismo con quien el Triunvirato debía lidiar. A pocas semanas de vida de El Censor, Pazos Silva sería acusado por el gobierno a través de un fiscal de la cámara de apelaciones de haber violado la libertad de imprenta al incluir en número del 3/3/12 expresiones que según entendían ofendían la pureza del gobierno y constituían una amenaza a la tranquilidad general de las provincias si circulaban sin la explicación del editor. En particular, la frase que había generado malestar era esta: "una general apatía e indolencia es la que se nota cada día, y el interés verdadero de estas provincias se confía tal vez a la perfidia”. El alto peruano se defendió a través de una presentación a la Junta Protectora, que también publicó en su periódico, afirmando que debía ser repelida tal acusación por infundada, y que si no era así, entendería que la libertad de imprenta sería solo una cuestión meramente nominal, "o más bien una trampa o anzuelo para prender al ingenuo o menos cauto amigo de la verdad, del orden y la justicia". 955

La idea de la libertad de imprenta como trampa ya había estado presente en el Río de la Plata por intermedio del morenismo, según afirma Ignacio Núñez en sus famosas memorias. Perseguidos y desterrados muchos de ellos tras las jornadas del 5 y 6 de abril de 1811, los resabios del grupo revolucionario veían con extrema desconfianza el decreto emanado por la Junta Grande solo un par de semanas después, e impulsado por el Deán Funes, uno de sus principales adversarios. Decía Núñez: “los hombres, poco o nada acostumbrados a servirse de semejante instrumento, y fijándose en que se les facilitaba para escribir cuando al mismo tiempo a nadie se permitía hablar, en vez de recibir el reglamento como un beneficio, lo miraban como una trampa peligrosa". ${ }^{956}$ En definitiva, la libertad de prensa terminaba siendo considerada por los gobiernos, en España como en América, tanto lealistas como insurgentes, como un arma factible de ser usufructuada por los enemigos o adversarios políticos, o por lo menos, como un peligro para la "homogeneidad de la opinión" a la que se aspiraba.

\footnotetext{
${ }_{953}$ Mártir o Libre, nro. 4, 20/4/1812, p. 32.

${ }^{954}$ Mártir o Libre, nro. 3, 13/4/1812, pp. 19-20.

${ }^{955}$ El Censor, nro. 12, 24/3/12, p. 45

${ }^{956}$ Núñez, Ignacio, óp. cit., pp. 181-182.
} 
Continuando Pazos Silva con su defensa, considera que las expresiones imputadas son de un sentido general indefinido y de hecho contingente, por lo que no pueden ser ofensivas hacia nadie en particular. Para determinar la infracción a la libertad de expresión el acusador debe especificar exactamente el delito, cosa que entiende que no es el caso. La Junta Protectora le dará la razón dictaminando el 20 de marzo que no existió crimen en las expresiones reclamadas por el agente de la Cámara. $\mathrm{Y}$ en un giro inesperado, su enfrentamiento con el Primer Triunvirato, al cual había defendido en varias ocasiones de los ataques de la facción morenista, lo llevó a compartir las mismas críticas que realizara Monteagudo desde la Gazeta de Buenos Aires por la demora en la convocatoria de la Asamblea constituyente repetidamente postergada. No solo hizo explícitas esas coincidencias refiriéndose a lo planteado en la Gazeta del 20/3 -último número bajo la dirección de Monteagudo-, sino que en su disertación contra las medidas tomadas por el gobierno repondría, sin citar su autoría porque entendemos que no hacía falta, una de las célebres frases del referente (y ya mito) inspirador de la tradición en la que se identifica la facción más radical de la revolución: "mudar de tiranos, sin destruir la tiranía".957

Molesto con los intentos de censura que viene sufriendo, y seguramente previendo el cierre definitivo de su periódico, desplegó duras consideraciones contra el Primer Triunvirato, al que acusó de no cumplir con lo que él mismo había decretado y reglamentado, en particular el uso verdadero de la libertad de imprenta: "Este antídoto del despotismo, es el único camino para llegar al conocimiento de la verdadera opinión pública, es el sólo freno de la arbitrariedad de los que gobiernan". ${ }^{958}$ Se exponía nuevamente aquí esa tensión intrínseca propia de aquellos años revolucionarios, entre la búsqueda de la discusión pública que el propio reglamento legitimaba y la tendencia del gobierno a imponer la univocidad, exigencia creada por las dificultades de la guerra exterior e interior que se enfrentaba, sumado al faccionalismo que se agudizaba en dicho contexto. ${ }^{959}$ Tensión que se arrastraba en realidad desde su misma concepción iluminista, que Pazos Silva reponía al sostener que "del choque de las opiniones resulta la verdad y la ilustración". ${ }^{960}$ Podían existir diversas opiniones pero una sola verdad. Se repite el mismo axioma que ya habíamos podido observar en el escrito del Correo de Comercio de Belgrano, originalmente publicado en El Voto de la Nación española; o en

\footnotetext{
${ }^{957}$ El Censor, p. 47.

${ }^{958}$ Ibid., p. 48.

${ }^{959}$ Molina, E., El poder de la opinión..., pp.50-51.

${ }^{960}$ El Censor, p. 48
} 
el "Pensamientos de un patriota español" reproducido por Moreno en la Gazeta de Buenos Aires.

Hacia el cierre de su artículo, Pazos Silva insiste en la defensa del derecho de imprenta como salvaguarda del despotismo: "corra libremente la pluma por el vasto campo de los sólidos principios liberales para establecer el imperio de la justicia y de las leyes y arruinar el de la arbitrariedad que aún osa ejercer su poderío". Sabe que tamañas manifestaciones en contra del gobierno no iban a salirle gratis, y viéndose venir las represalias deja el interrogante si era esta la última oportunidad en la que escribía, y proclama grandilocuentemente que "de todos modos nunca desmentiré mis principios, ni prostituiré mi pluma cualesquiera que sea la intención de mis enemigos". ${ }^{961}$ Efectivamente, el del 24 de marzo fue el último número de El Censor, producto de la supresión por parte del gobierno del sueldo del editor, al igual que sucedió con el de Monteagudo al frente de la Gazeta de Buenos Aires en esos mismos días. ${ }^{962}$ No pasó mucho tiempo para que el líder de la Sociedad Patriótica volviera a la palestra con un nuevo periódico, el Mártir o Libre, declarando su fe inquebrantable en la libertad de opiniones: "Persuadido de estas máximas me creo en la obligación de sostener un nuevo periódico, que sirva de asilo a la LIBERTAD, continuando en él las materias que seguía en la Gazeta: de este modo el que quiera publicar sus sentimientos tendrá un recurso para hacerlo, y yo estaré siempre alerta para apoyar o impugnar las opiniones Ministerial es, aunque cargue sobre mí la execración de los tiranos y el escándalo de los esclavos".963

En el primer número de la nueva Gazeta ahora denominada Ministerial, su flamante editor, Nicolás Herrera, explica los motivos de la clausura de ambos periódicos:

[...] es una de sus primeras obligaciones [del gobierno] evitar el extravío de la opinión, y sofocar el espíritu de partido que por efecto de una mala entendida rivalidad fomentaban los periódicos publicados en esta capital, con evidente riesgo de los intereses de la patria, ha determinado suprimir las gratificaciones que se habían asignado a los redactores, y dará luz una Gazeta Ministerial que instruyendo a los ciudadanos de la

\footnotetext{
${ }^{961}$ Ibid., p. 48.

${ }^{962}$ Mientras que la Gazeta dependía directamente del Primer Triunvirato, El Censor era sostenido económicamente por el Cabildo.

${ }_{963}^{9}$ Mártir o Libre, Buenos Aires, 29 de marzo de 1812, 1-2.
} 
verdadera situación política del estado en todas sus relaciones interiores y exteriores, sirva de centro al espíritu público. ${ }^{964}$

Resulta irónico que justo cuando empezaban a existir coincidencias entre Pazos Silva y Monteagudo, es cuando el gobierno decide clausurar ambos periódicos con el argumento de la rivalidad fomentada por los publicistas. Por otro lado, como marca Eugenia Molina, este caso es ilustrativo de cómo la dependencia económica hacia el gobierno conformaba un límite obvio para la autonomía de los juicios de los publicistas. 


\section{Capítulo 14:}

\section{La recepción de Blanco White en el Rio de la Plata}

\section{Introducción}

El talento y la voluntad de José María Blanco White, más la amplia información de la que disponía, hicieron de El Español un punto de referencia obligado para los patriotas americanos. Su difusión por todo el continente está plenamente documentada y, pese a estar prohibido en Cádiz, fue también ampliamente comentado y criticado allí, en el centro mismo de la revolución liberal española. Según André Pons, El Español supuso una contribución indiscutible a la emancipación de las colonias hispánicas, porque apareció en el momento preciso en que los americanos necesitaban justificación y un soporte a varios de sus argumentos desde el otro lado del Atlántico. Sin su concurso, como afirma este autor, no hubiera existido tanto apoyo a los movimientos insurgentes en Londres y no se habría dado una defensa tan cerrada por parte de los diputados americanos en las Cortes. Aportó también a que los revolucionarios criollos hayan adquirido con tanta rapidez una consciencia de la unidad del movimiento emancipador y de la comunidad de sus intereses. Como ya hemos podido ver en un capitulo anterior, Blanco White nunca aconsejó a los autonomistas de América que se separaran de la Corona de España, pero como bien señala Roberto Breña, insistió una y otra vez en que la unión entre peninsulares y americanos tenía que ser en términos de estricta y absoluta igualdad, no de opresión. ${ }^{966}$

Con respecto a la recepción, circulación y usos de los escritos del publicista sevillano en el Rio de la Plata tenemos, tal como hemos reseñado en los antecedentes, los valiosos trabajos de la historiadora argentina Alejandra Pasino. En ellos se busca dar cuenta del tipo de recepción que los escritos de Blanco White tuvieron en el contexto de los primeros años de la revolución rioplatense, sirviendo para cuestionar la mirada generalista que algunos especialistas en la obra del sevillano tienen cuando abordan el análisis de la incidencia de sus ideas en los territorios españoles en América. En este capítulo entonces recurriremos en varias ocasiones a sus observaciones, incorporando

\footnotetext{
966 Breña, Roberto, “José María Blanco White y la Independencia de América: ¿Una postura proamericana?", Alicante: Biblioteca Virtual Miguel de Cervantes, 2015, p. 5.
} 
algunas resultados y reflexiones producto de nuestro propio trabajo sobre el corpus documental, principalmente en lo que respecta a la prensa periódica rioplatense.

\section{Las primeras reproducciones de Blanco White en el Río de la Plata}

La primera aparición de un escrito de José María Blanco White en la Gazeta de Buenos Aires se dio a los pocos días de la salida de Mariano Moreno del gobierno, en diciembre de 1810, estando ya el periódico bajo la redacción del Deán Funes. Durante los meses donde Moreno se había hecho cargo de la Gazeta, desde el inicio mismo de la revolución, los artículos del sevillano habían brillado por su ausencia, por lo que suponemos que no eran de la consideración del secretario de la Junta. Un indicio de esto se puede ver en una memoria de su hermano Manuel enviada al gobierno porteño desde su estancia en la corte británica, donde señaló que no consideraba a Blanco el publicista que necesitaban debido a su insistencia en buscar la conciliación entre España y América ${ }^{967}$ Pero ya desplazado el principal referente de la facción revolucionaria, y casi como un preanuncio del viraje del rumbo que tomaba el nuevo gobierno, comenzaron a introducirse los escritos del periódico londinense en la prensa oficial.

El 31 de diciembre de 1810, se publicó, junto a una nota elogiosa hacia el sevillano, el artículo "Reflexiones políticas" de El Español, aclarándose que no se suscribiría a aquello que "no sea conforme al interés general de la nación". ${ }^{968} \mathrm{El}$ artículo, al que ya hicimos referencia en el capítulo sobre las posiciones del liberalismo peninsular ante la cuestión americana, destaca la revolución de Caracas por haber sido llevada adelante con "moderación y beneficencia", y aunque advierte que el estandarte de la independencia ya se ha empezado a levantar en América, entiende que no hay en ella principios exagerados de libertad o de igualdad, ni intereses de partido, como sí existieron en la Revolución Francesa. Se busca, dice, hacer lo que se ha hecho en España, levantando gobiernos interinos hasta que vuelva el monarca:

\footnotetext{
967 "Memoria y observaciones hechas por Don Manuel Moreno desde su llegada a la Corte de Londres en 1 de mayo de 1811". Archivo General de la Nación (Buenos Aires), Sala X, 1-1-2. Citado en Pasino, Alejandra (2011), "Independencia y República: La polémica José María Blanco White - Servando teresa de Mier y su recepción en el Río de la Plata revolucionario", en Francisco Ortega y Yobenj A. Chicangana Bayona (Eds.) 200 años de independencia. Las culturas políticas y sus legados, Universidad Nacional de Colombia., p. 16.

${ }^{968}$ Define a su autor como: "un alma franca e ilustrada, que se atreve a manifestarse como ella es; y que por amor a su nación prefiere a la frívola gloria del aplauso pasajero, el honor sólido de disgustarla, haciéndole escuchar unas verdades, que si mortifican su amor propio, dejan entera su utilidad". Gazeta extraordinaria $(31 / 12 / 10): 756$.
} 
Los americanos no pensarán jamás en separarse de la corona de España, si no los obligan a ello con providencias mal entendidas. Los americanos solo es probable que quieran no estar esperando gobierno y dirección, de un país separado por un mar inmenso, de un país casi ocupado por enemigos, y donde un gobierno en perpetuo peligro, y que apenas puede mirar por sí en medio de las circunstancias que lo rodean, nada puede hacer respecto a los dilatados países del Nuevo Mundo, más que pedir socorros y mandar empleados. $^{969}$

Los revolucionarios porteños para ese momento seguramente ya conocían la designación de Francisco de Elío por parte de la Regencia como nuevo Virrey para el Rio de la Plata, y lo sentían como una afrenta directa, una clara señal de hostilidad, debido a la enemistad que existía entre ellos y el todavía gobernador de Montevideo asumió el 12 de enero de 1811 su nuevo cargo-, prácticamente desde el comienzo de la crisis. No era para nada casual que en éste número de la Gazeta de Buenos Aires se haya incorporado la postura del publicista sevillano. Se buscaba preparar al lector para la nota que seguía a continuación, en la que se informa de la llegada por intermedio de un parlamentario proveniente de Montevideo de la instalación Cortes generales de la monarquía. ${ }^{970}$

Pocos días después se vuelve a introducir en la Gazeta un nuevo artículo de $E l$ Español, en este caso titulado "Integridad de la monarquía española", donde el sevillano cuestiona el carácter de las Cortes por considerar que no reflejaban en la proporción de la representación la igualdad ya proclamada entre peninsulares y americanos: "Cuantos reconocen a Fernando $7 .^{\circ}$ por soberano en las cuatro partes del mundo, deben ser llamados por igual al congreso augusto que se convoca en su nombre. La parcialidad hacia unos $u$ otros en el número de representantes que se les señale destruiría toda la unión y espíritu de patria que se apetece". ${ }^{971} \mathrm{Y}$ al igual que reclamaban los diputados americanos desde la inauguración de las sesiones de las Cortes, Blanco White también sostenía que las provincias ultramarinas debían enviar los representantes que correspondían según su población, y que mientras tanto, las Cortes solo deberían tomar una medida respecto de la América: "Renunciar a toda pretensión de superioridad sobre aquellos países, y convidarles a que (los que no lo hayan hecho) nombren sus gobiernos interiores y económicos, y enseguida envíen sus diputados al congreso de ambos

\footnotetext{
969 Ibid., p. 758.

${ }^{970}$ El tratamiento de la nota y su respuesta ya lo analizamos en el capítulo 11 .

${ }^{971}$ Gazeta nro. 31 (10/1/11): p. 31
} 
mundos". ${ }^{972}$ Los rioplatenses se valían entonces de las palabras del liberal sevillano, para justificar el porqué de su desconocimiento a las Cortes, por lo menos a esas Cortes, a la vez que abrían las puertas -en teoría- a que si se respetaba la proporción y se reconocían las juntas como gobiernos legítimos, nada impediría la reunión nacional en un mismo recinto.

Podemos inferir además que, como se hizo luego con otros artículos del mismo autor, el público lector al que estaban dirigidos fundamentalmente era al de los españoles europeos, con el propósito de ganar su adhesión a la causa juntista. Como prueba de ello tenemos una supuesta carta al editor de una lectora donde se elogian las posiciones del artículo de El Español que acabamos de analizar, calificándola como "la más juiciosa apología de nuestra causa". ${ }^{973}$ Sugiere además que se publique un artículo del número VI para que todos los españoles europeos pudieran leerlo. En el número siguiente volvemos a tener otra muestra en ese sentido.

En una nueva carta, esta vez firmada sugerentemente como "el Europeo convertido", se elogian los artículos de El Español insertos en el periódico, mientras se afirma que no cree que haya español europeo que no pueda convencerse de sus argumentos, ya que él mismo se convirtió tras su lectura. La supuesta carta también nos da información importante para conocer la circulación del periódico londinense en Buenos Aires. Éste llegaba regularmente pero pareciera ser que era costoso: "tenga la bondad de continuar insertando en su gaceta los capítulos más análogos del referido periódico para la instrucción general; pues no todos tienen medios para comprar los números, ni proporción para leerlos". ${ }^{974}$ De lo oneroso que resultaba adquirir los escritos de Blanco White tenemos también constancia a través de la reproducción de un artículo del insurgente Diario secreto de Lima, donde se dedican elogiosas palabras hacia el publicista español, al que se lo considera autor de los ensayos Pensamientos de un Patriota Español -erróneamente, como ya vimos- y Reflexiones sobre el estado de España. Tan valiosas eran estos escritos para el articulista que consideraba que "todo buen patriota debe hacer el esfuerzo de encargarlas a Londres, pagando su peso en oro". ${ }^{975}$ Aprovecha entonces para criticar al Consejo de Regencia por haber prohibido la continuación de aquellas obras y mandado a recoger los cuadernos que se habían publicado, acentuando la falta de luces y adelantos de España en comparación de otros

\footnotetext{
${ }^{972}$ Ídem.

${ }^{973}$ Gazeta nro. $32(17 / 1 / 11)$, p. 38

${ }^{974}$ Gazeta nro. $33(24 / 1 / 11):$ p. 60

${ }^{975}$ Gazeta nro. 55 (27/6/11): 539-540
} 
países europeos. Mientras, dice, "los ingleses generosos protectores de los sabios, y de la libertad de la prensa han llevado a Londres al autor, que goza de las mayores estimaciones". 976

Ya con la Gazeta bajo la dirección de Pedro José Agrelo, El Español continuó siendo un referente ineludible al momento de informar sobre los sucesos de la península, tanto como para reproducir sus posturas en relación al conflicto entre la metrópoli y América. ${ }^{977}$ En la Gazeta del 11 de julio de 1811 se inserta un artículo del periódico londinense donde el sevillano vuelve a cuestionar al gobierno peninsular y su política hacia América. Se critican las proclamas de la Junta de Cádiz y los decretos de las Cortes, a las que identifica con los intereses de los comerciantes de aquella plaza, que no tienen otro objetivo que entretener a los americanos sin dar respuestas concretas a sus reclamos: "Declaraciones de derechos indudables, es lo que contiene el decreto de las cortes: pero solo promesas de poner en práctica sus inmediatas consecuencias: palabras, solo palabras [...] Las Américas, entretanto, se arden de un extremo a otro". 978 El publicista insiste en que la única manera de resolver el conflicto que desgarra a la monarquía es reconociendo inmediatamente por legítimas a las Juntas que han formado los pueblos de América y que se manden órdenes a todas capitales que aún no lo hayan hecho, para que las formen:

[...] llámense Juntas superiores, como las dé la península: dénseles el poder que tienen esos virreyes, y gobernadores, origen único de todos los males: pídanse al momento diputados para las cortes, no por el arbitrario, y descabellado plan, que se mandó a las Américas, sino por el mismo con que le han elegido es España; que si no es mucho mejor, tendrá por lo menos la ventaja de ser igual - para unos y otros. Hágase esto inmediatamente, y acaso no será tarde para lograr una feliz unión, que pongan fin a los horrores que la amenazan, que empiezan, que están destrozando ya a entrambos pueblos. ${ }^{979}$

Por primera vez desde que son incorporados los artículos del publicista español, el editor local, a través de una nota al pie, va a marcar un contrapunto con aquel. Sin dejar destacar el respeto que los talentos del editor de El Español le merecen, no puede, dice, dejar pasar que en estas últimas apreciaciones se haya engañado, y mucho. Considera que, a pesar de que se comprobasen las reformas pedidas por el sevillano, y reclamadas

\footnotetext{
${ }_{976}$ Ídem.

${ }^{977}$ Pedro José Agrelo editó el periódico desde el 18 de marzo y el 5 de octubre de 1811.

978 Gazeta nro. 57 (11/7/11): 589

${ }^{979}$ Ibíd., $589-590$
} 
en varias oportunidades por los americanos, ya la desconfianza hacia los gobiernos peninsulares era tan grande y tan delicada la situación de éstos, que entiende que no están en condiciones de ejercer ninguna superioridad: "somos iguales, y habiendo reasumida el carácter de provincias libres por su misma declaración, sería muy degradante sujetar la suerte de una porción de millones que habitan estos territorios, de los caprichos del corto número de vecinos de Cádiz y la Isla de León. Es muy tarde para semejante proyecto". 980

Vemos como las puertas que en un principio se dejaban entreabiertas a una posibilidad de reconciliación, en este momento parecieran cerradas y la responsabilidad es adjudicada, al igual que solía hacerlo el sevillano, al "partido mercantil gaditano". Blanco White no se cansaba de deplorar la excesiva influencia que los comerciantes monopolistas ejercían sobre la Regencia y que, en su opinión, provocaba las imprudentes medidas que ésta ponía en práctica. Este influjo era tan grande desde su punto de vista que constituyó uno de los principales motivos de su escepticismo respecto a un posible acuerdo con los americanos, y ese mismo escepticismo era compartido cada vez más por éstos.

Volviendo al escrito del sevillano, la decisión de hacer la guerra en América empleando tropas de criollos, dice, era el colmo de la locura, producto únicamente del furor del partido mercantil de Cádiz, y ahí estaba el "infeliz Liniers como víctima de ese necio proyecto". ${ }^{981}$ En el número anterior de El Español, Blanco White había criticado duramente la ejecución del ex-virrey y héroe de la reconquista de Buenos Aires, y de los otros sublevados en Córdoba: "Los que han hecho perecer a estos jefes en pocas horas, (pues tales son las circunstancias con que el suceso se pinta) han perdido malamente las ventajas que a los ojos del mundo todo les daba su antigua moderación, protectora poderosa de su justicia. Su causa es buena a toda prueba; pero de este modo va mui mal defendida". ${ }^{982}$ Podemos suponer que sin hacer mención directa a esas críticas, la nota al pie de Agrelo expresando diferencias con el publicista era más una respuesta a dicho artículo que al que se reproducía en este mismo número. De alguna manera buscaba diferenciarse del sevillano y mostrar el malestar por sus críticas, pero sin tener que romper abiertamente porque continuaba siendo útil en la disputa argumental contra la metrópoli.

\footnotetext{
${ }^{980}$ Ibid., p. 590.

${ }^{981}$ Ibid., p. 592.

${ }^{982}$ El Español N ${ }^{\circ}$ IX, 30/12/10, p. 250.
} 


\section{Las apropiaciones de Pazos Silva}

Como ya ha demostrado Alejandra Pasino, durante su dirección de la Gazeta, o en su propio periódico El Censor, Vicente Pazos Silva recurrió en varias oportunidades a la apropiación de artículos de Blanco White -como también de Manuel Quintana- sin hacer referencia a su autoría. Como dice Pasino, se trata en realidad de "una apropiación de ideas, vale decir de un plagio directo de un texto al cual sólo se le han omitido las referencias a situaciones españolas, o se ha compaginado de distinta manera". ${ }^{983} \mathrm{Y}$ aunque esto no era excepcional para la época, sino más bien una práctica bastante habitual, si se puede marcar, según la historiadora, como una seña característica del accionar de Pazos Silva en relación no sólo a las costumbres sobre la correcta mención al origen de los textos en la prensa local, sino por la importancia que Mariano Moreno le otorgó a la identificación del autor. ${ }^{984}$

Pazos Silva, entonces, se apropió de dos extensos artículos del Semanario Patriótico, todos ellos publicados en la edición sevillana del periódico y escritos, como dijimos, por su editor político Blanco White. El primero, aparecido originalmente en Semanario Patriótico XVI del 11 de mayo de 1809, se titulaba "Del egoísmo político" y es reproducido con algunas modificaciones la Gazeta Extraordinaria de Buenos Aires del 19 de noviembre de 1811 y en la Gazeta de Buenos Aires del 24 de octubre de 1811. El artículo versa fundamentalmente sobre la falta de patriotismo en la sociedad, y la ambición de mando y la tendencia al despotismo de la clase dirigente. Las modificaciones apenas responden a adaptar el escrito al contexto de reproducción, remplazando por ejemplo "pueblo español" por "americanos"; o una parte que hace referencia a la guerra contra el francés en la península por una que pareciera hacer alusión a la derrota de las fuerzas patriotas en el Alto Perú; o agregando algún adjetivo como por ejemplo "corrompidas cortes" donde antes sólo decía "cortes". La más destacable de la labor del editor es la exclusión de la página final en la cual el sevillano describía las reformas que eran necesarias para España: planteaba que no alcanzaba sólo con echar a los franceses, había que dictar una constitución benéfica y leyes para limitar

\footnotetext{
${ }^{983}$ Pasino, A., "Circulación y apropiación de escritos políticos en la prensa porteña revolucionaria: la labor de Vicente Pazos Silva (Pazos Kanki) como editor de La Gazeta de Buenos Aires y El Censor (1811-1812)", I Congreso Internacional de Historia Intelectual de América Latina, Universidad de Antioquia, Medellín, 2012, p. 3.

${ }^{984}$ Ibid., p. 6.
} 
a los ambiciosos del mando. ${ }^{985}$ Como sugiere Pasino, es probable que Pazos Silva no haya readaptado esa página a la situación local porque ello requería una intervención mayor a las producidas en los párrafos anteriores, o quizás, podemos agregar nosotros, porque no compartía del todo las reformas propuestas por el publicista. ${ }^{986}$

El segundo artículo de Blanco White apropiado es el titulado originalmente "De los nombres libertad e igualdad" aparecido en los números XVIII y XXII del Semanario Patriótico del 25 de mayo y el 22 de junio de 1809. Pazos Silva utiliza el texto para confeccionar dos artículos: el primero de ellos, bajo el título "Política", reproduce las consideraciones sobre el concepto de Libertad, publicado en la Gazeta del 5 de noviembre de 1811; el segundo, "De la igualdad", fue publicado en la Gazeta del 10 de diciembre de 1811. El editor de la Gazeta decide no incorporar la introducción donde Blanco White busca dar un sentido diferente a las voces de libertad e igualdad a las imputadas seguramente por el ala conservadora del proceso español, que las asociaba con la licencia y la anarquía propias de la Revolución Francesa. ${ }^{987}$ En su lugar Pazos Silva redacta una nueva introducción donde señala que el objeto e interés de todo gobierno es mantener la armonía social y proteger a los individuos que componen la sociedad. A ello agrega que la reunión de voluntades nacía del convencimiento de la utilidad de obedecer, utilidad que define como la conservación de la tranquilidad pública y particular, y la seguridad de las propiedad, elementos que componen la libertad civil y política, como única garantía de una autoridad tutelar. Establece una estrecha relación entre la libertad y la opinión pública, a la que considera la garantía para poner límites a la ambición de los particulares.

Como había sucedido con el artículo anterior es excluida nuevamente la última parte del escrito en la que se explaya en las contradicciones entre la libertad y el despotismo. ${ }^{988}$ Como plantea Pasino no parece ser por motivos ideológicos el recorte, porque estaba en sintonía con muchos de los escritos del publicista altoperuano, sino que más bien demuestra que éste no realizó una selección del artículo del Semanario, sino que comenzó la apropiación y le puso punto final en función del espacio que

\footnotetext{
${ }^{985}$ Semanario Patriótico XVI del 11 de mayo de 1809, pp. 28-29.

${ }^{986}$ Pasino, A., "Circulación y apropiación...”, p. 14.

${ }^{987}$ Semanario Patriótico nro. 18, pp. 59-61.

${ }^{988}$ Ibíd., pp. 63-65.
} 
dispuso dedicarle en el periódico. ${ }^{989}$ Por otro lado, este mismo tema ya lo había desarrollado en la Gazeta del 10 de octubre de $1811 .^{990}$

En el segundo artículo titulado "De la igualdad" Pazos Silva se apropia, como dijimos, de la segunda parte del texto del Semanario Patriótico. En clara referencia, aunque no se explicite, a la Revolución Francesa, Blanco White exponía sobre la inutilidad de la lucha por la igualdad absoluta. Para el sevillano, en lo que constituye casi una prédica a aceptar la providencia, la guerra entre la "clase que nada tiene y la que lo tiene todo" solo traía desgracias: "contentaos con la parte de bienes que según vuestra clase seos deba". Y a pesar de que prácticamente todo el artículo va en línea con esta idea, cuando el sevillano señalaba lo injusto del orden social, Pazos Silva procede a extirparlo en su operación de apropiación, como hace por ejemplo con el siguiente párrafo: "La opulencia de las clases superiores del estado, y la facilidad con que se las ve satisfacer hasta sus caprichos, cuando el pueblo apenas alcanza una miserable subsistencia..." ${ }^{991}$ Igualmente el artículo original, como decíamos, aunque realizaba un diagnóstico claro de la desigualdad social, terminaba justificando la diferencia de riqueza, incluso la adquirida por nacimiento, y proponía como mucho morigerarla con el objetivo de mantener la paz social:

Para la tranquilidad y orden es necesario que haya una subordinación. Pero igual regla debe dirigir las dos limitaciones de libertad e igualdad. En tanto se puede privar a los hombres de estos naturales derechos, en cuanto sea necesario para el bien de todos. La sociedad que desnivele la suerte de sus individuos más allá de lo que exige la consecución de este objeto quebranta las obligaciones más sagradas, y se prepara su exterminio. ${ }^{992}$

En todo caso, dice, cuando las leyes son justas, ya que no pueden igualar a los ciudadanos en los bienes, los igualan en el derecho de conservarlos y adquirirlos. ${ }^{993}$

Si Pazos Silva intervino extrayendo algún párrafo del texto, no fue entonces para modificar sustancialmente una línea ya de por si conservadora en términos sociales, sino más bien para profundizarla. El texto original pareciera no tener como objetivo ilustrar sobre los nuevos derechos como otros artículos del sevillano, sino diferenciarse de algunas concepciones radicales de la igualdad. La incorporación por parte de Pazos Silva es probable que respondiera a los hechos sucedidos en Buenos Aires el 7 de

\footnotetext{
${ }^{989}$ Pasino, A., “Circulación y apropiación...”, p. 16.

${ }^{990}$ Gazeta nro. 70 (10/10/11), p. 790-791.

${ }^{991}$ Semanario Patriótico, 22-6-1809 p. 125.

${ }^{992}$ Gazeta nro. $11(10 / 12 / 11):$ p. 45

${ }^{993}$ Ibid., p. 46.
} 
diciembre conocidos por la historiografía como el motín de las trenzas, protagonizados por los milicianos del Regimiento de Patricios, sin la participación de la oficialidad. Justamente en el mismo número de la Gazeta se publica el bando oficial relatando y condenando lo sucedido. ${ }^{994}$

Las interpretaciones de los historiadores sobre sus causas han sido diversas. Algunos siguieron la explicación que enarboló en ese momento el gobierno y consideraron que se trató de una acción desestabilizadora por parte del saavedrismo desplazado del poder en septiembre de 1811, mientras otros pusieron más el acento en la acción espontánea del cuerpo de patricios. Lo que desató inicialmente el amotinamiento fue la amenaza de parte de los mandos del Regimiento, Belgrano el principal, de cortarles las trenzas a varios soldados como castigo por ausentarse del cuerpo la noche del 6 de diciembre. En el primer punto del petitorio redactado por los cabos y elevado al gobierno se vislumbra la clave de la protesta: "Que este cuerpo que se nos trate como a fieles ciudadanos libres y no como a tropa de línea". ${ }^{995}$ Los patricios actuaron al sentir que sus derechos como milicianos no eran respetados. En el conflicto, como bien refiere Gabriel Di Meglio, apareció fugazmente la diferencia social entre oficiales y tropas, y esto se expresó a partir de la cuestión de las vestimentas. Cuando el teniente Pérez replicó a un soldado que si cortarse el pelo era una afrenta "el también estaría afrentado pues se hallaba con el pelo cortado", otro soldado "en tono altanero", le gritó "que él tenía traje y levitas para disimularlo". ${ }^{996}$ Al fracasar la negociación el gobierno se decidió por la represión y tras el ataque de las tropas la sublevación fue rápidamente sofocada, con varios muertos entre los insurrectos. Constituyéndose en uno de los primeros antecedentes de una práctica que abarcó todo el período: la rápida y decidida reacción de las autoridades ante los motines liderados por plebeyos. ${ }^{997}$

No parecieran haber dudas entonces de las razones que motivaron la publicación del artículo de Blanco White sobre la "Igualdad" días después de los hechos en la Gazeta. Las elites políticas, sobre todo sus elementos más moderados, se proponían lograr, utilizando un lenguaje moderno y no sólo ya el religioso, que los sectores subalternos aceptaran la subordinación y la desigualdad social para no tener que repetir muy regularmente este tipo de derramamientos de sangre. Seguía marcado a fuego en la

\footnotetext{
${ }^{994}$ Ibíd., p. 47. También debían seguir pesando los sucesos del 5 y 6 de abril, que habían causado mucho impacto en la elite porteña, preocupados por la fuerte movilización de los sectores de la plebe.

${ }^{995}$ Tomado de Di Meglio, G., óp. cit., p. 120.

${ }^{996}$ Citado en ibid., p. 122.

${ }^{997}$ Ídem., p. 122.
} 
memoria de las élites criollas la irrupción de los sectores subalternos que habían hecho tambalear el edificio social como el levantamiento indígena andino, o la triunfante revolución negra haitiana.

También en la Gazeta de Buenos Aires pero en la edición correspondiente a lo viernes, a cargo de Bernardo de Monteagudo, se reflexiona alrededor del concepto de igualdad, partiendo desde premisas bastante alejadas a las sostenidas por Blanco White y reproducidas por Pazos Silva. El escrito, parte sus famosos artículos doctrinarios titulados observaciones didácticas, constituye una apología a la idea de igualdad ante la ley, pieza central del pensamiento liberal que estaba emergiendo por esos años: "Todos los hombres son iguales en presencia de la ley: el cetro y el arado, la púrpura y el humilde ropaje del mendigo no añaden ni quitan una línea a la tabla sagrada de los derechos del hombre. La razón universal, esa ley eterna de los pueblos, no admite otra aceptación de las personas que la que funda el mérito de cada una..."998

A diferencia de las definiciones que analizamos recién, el texto de Monteagudo no tiene como objetivo delimitar el principio de igualdad de sus versiones más radicales, ni justificar la diferencia de riquezas entre los ciudadanos, a la que califica como "muchas veces injuriosa". Por el contrario está pensado fundamentalmente como alegato contra aquellos que desde una situación de poder y/o privilegio avasallan los derechos de sus pares bajo pretensión de superioridad:

Tales son los desastres que causa el que arruina ese gran principio de la equidad social; desde entonces sólo el poderoso puede contar con sus derechos; sólo sus pretensiones se aprecian como justas: los empleos, las magistraturas, las distinciones, las riquezas, las comodidades, en una palabra, todo lo útil, viene a formar el patrimonio quizá de un imbécil, de un ignorante, de un perverso a quien el falso brillo de una cuna soberbia, o de una suerte altiva eleva el rango del mérito, mientras el indigente y obscuro ciudadano vive aislado en las sombras de la miseria, por más que su virtud le recomiende, por más que sus servicios empeñen la protección de la ley, por más que sus talentos atraigan sobre él la veneración pública. Tal es ordinariamente la suerte del hombre virtuoso bajo un gobierno tiránico que sólo mira la igualdad como un delirio de la democracia o como una opinión antisocial. ${ }^{999}$

El texto es en sí mismo una denuncia a las situaciones de discriminación sufridas por los criollos en relación a los españoles europeos bajo la dominación colonial,

\footnotetext{
${ }^{998}$ Gazeta nro. 25 (21/2/12): 131.

${ }^{999}$ Ídem.
} 
cuando los primeros estaban prácticamente excluidos de la administración: "la sola idea de nuestro origen", dice, "marchitaba el mérito de las más brillantes acciones". ${ }^{1000}$

Y aunque es mucho más radical su discurso en comparación con el artículo de Blanco White, como hemos podido ver, marca igualmente un límite a esas pretensiones igualitaristas cuando señala las incuestionables obligaciones que nacen de la relación entre el magistrado y el súbdito:

Pero no confundamos la igualdad con su abuso: todos los derechos del hombre tienen un término moral cuya mayor trasgresión es un paso a la injusticia y al desorden: los hombres son iguales, sí, pero esta igualdad no quita la superioridad que hay en los unos respecto a los otros en fuerza de sus mismas convenciones sociales: el magistrado y el súbdito son iguales en sus derechos, la ley los confunde bajo un solo aspecto, pero la convención los distingue, sujeta el uno al otro y prescribe la obediencia sin revocar la igualdad. ${ }^{1001}$

\section{La polémica entre Pazos Silva y Monteagudo}

Hacia fines de 1811 las diferencias y rivalidad entre los dos editores de la Gazeta, Monteagudo y Pazos Silva, ya era evidente y se comenzaba a plasmar en los artículos del periódico. La reproducción de escritos de Blanco White no escapó a este contexto sino que fue utilizada por parte de Pazos Silva para polemizar con su adversario. En la Gazeta extraordinaria del 21 de noviembre de 1811, el altoperuano introduce un fragmento de la tercera carta de "Juan Sintierra" publicada originalmente en El Español XIII, donde se explaya sobre la necesidad de reorganización del ejército español y las reprimendas a los generales responsables del retroceso militar frente a los franceses. Las razones de la publicación de este escrito por parte de Pazos Silva son evidenciadas a partir de una nota al pie donde el editor advierte que de nada sirve realizar una lectura estéril de las reflexiones allí contenidas, sino que es necesario que sean aplicadas, dice, a los casos prácticos que se tienen a nivel local, relacionándolo con la obligación de castigar a los mandos responsables de la desastrosa batalla de Huaqui en el Alto Perú: "Estas reflexiones nos deben mover a reformar la conducta que se ha observado en nuestra revolución; de nada serviría, injertar estos discursos, si únicamente causasen una lectura estéril: La conducta de los agentes de la expedición desgraciada del Perú nos ha

\footnotetext{
${ }^{1000}$ Ídem.

${ }^{1001}$ Ibid., p. 132.
} 
deshonrado à la faz del mundo, y nos ha puesto al borde del precipicio, preciso es, que con inflexibilidad se castigue, después de un juicio imparcial, a esos profanadores sacrílegos de nuestra santa causa". ${ }^{1002}$ No es difícil suponer que el uso del artículo de Blanco White tiene como objetivo apuntar a los responsables del ejército auxiliar, fundamentalmente a Juan José Castelli y a uno de sus colaboradores más cercanos durante la expedición: Bernardo de Monteagudo. Castelli debió asumir la responsabilidad por la derrota de Huaqui y soportar la campaña de agravios que se desató en su contra, sobre todo desde el bando lealista, pero como podemos ver, también desde el campo propio. Estos últimos aún más comprometedores porque terminaron marcando el tono del juicio que se le inició por su actuación como representante en la expedición. ${ }^{1003}$

En el número siguiente de la Gazeta se introduce una carta firmada por el "ciudadano libre" comentando sobre la lectura del periódico en una reunión y la reacción encolerizada de algunos tertulianos ante la nota al pie que acabamos de citar. Éstos alegaban que el editor, con su ataque a miembros del gobierno anterior, condicionaba a los jueces y que esas actitudes lo hacían merecedor de "una paliza". En la respuesta Pazos Silva se defiende argumentando que se refería a los que en el día de la batalla desertaron, pero la realidad es que en el escrito incluido de Blanco White no quedan dudas que se refería al castigo a los mandos por inoperancia. ${ }^{1004}$ A continuación se inserta una carta del propio Bernardo de Monteagudo al editor, quejándose por la expresión utilizada en la nota al pie a la carta de "Juan Sintierra" a la que venimos haciendo referencia, donde llama a los agentes de la expedición al Alto Perú "sacrílegos profanadores de nuestra santa causa". Monteagudo se defiende y alega el derecho de inocencia hasta no ser juzgado. ${ }^{1005}$ En la contestación, Pazos Silva, que en todo momento se burla socarronamente de él llamándole "el doctor", reconoce que entre los expedicionarios existían hombres honorables, pero también culpables y es la justicia a quién tocará decidir quiénes son. Plantea no detenerse en estas pequeñeces, y remitiendo nuevamente al El Español, en este caso en su número XVI que contiene una crónica de las sesiones de las cortes del 24 de mayo de 1811, vuelve a cargar de forma elíptica sobre el ala radical de la revolución rioplatense: "así se ve que se enredan con controversias metafísicas, queriendo formar repúblicas platónicas: es preciso mudar de

\footnotetext{
${ }^{1002}$ Gazeta extraordinaria nro. $6(21 / 11 / 11)$, p. 24.

${ }^{1003}$ Wasserman, Fabio, Castelli..., p. 224.

1004 Gazeta nro. 8 (29/11/11): 29-30.

1005 Ibíd., p. 30.
} 
sistema, abolir los antiguos formularios de que están llenos nuestros doctores, y plantar un plan liberal, sino estaremos en el circulo vicioso, imitando el gobierno de la península que no ha podido organizar un sistema militar; los que gobiernan mírense en este espejo, para que no salga en América otro Juan Sintierra , y que los burle”. ${ }^{1006}$

La polémica sobre la necesidad o no de la independencia de las provincias rioplatenses entre Monteagudo y Pazos Silva a comienzos de 1812 fue otro de los contrapuntos donde los escritos de Blanco White tallaron a nivel local. ${ }^{1007}$ El disparador del debate fue la declaración de la independencia de Venezuela, acontecimiento que generó un fuerte impacto no sólo en América sino también en la orilla europea. Ya desde su propio periódico, El Censor, Pazos Silva se sumergió en la discusión a partir de la introducción de un artículo de El Español núm. XIX, que justamente reflexionaba sobre el Acta de Independencia de Caracas. El original comienza con una larga condena a la declaración de independencia absoluta, no incorporada por el editor local, donde el sevillano la caracteriza como un grave error que no hace otra cosa más que brindar nuevos argumentos a la metrópoli para continuar con su inflexibilidad y que arroja a un pueblo aún no preparado "al medio del golfo borrascoso de la democracia". ${ }^{1008}$

En el siguiente pasaje -éste si incorporado por Pazos Silva al periódico-, Blanco White advierte que tomada en abstracto la independencia es un bien del que nadie puede dudar pero que en la práctica, estando unida indisociablemente a la cuestión del poder, solo puede alcanzarse dependiendo lo que las facultades de cada pueblo lo permitan. El sevillano, entonces, no cuestiona el derecho a serlo, si no la conveniencia del momento. Considera que América aún no está preparada para dar ese paso. ${ }^{1009}$ Califica a la declaración venezolana de caprichosa, imprudente y sobretodo innecesaria, "desprovista de toda ventaja y portadora sí de muchos males". ${ }^{1010}$ Entiende que la medida alejará a los que ven en ella un peligro para la religión por asociarla a la monarquía. La "gente sencilla" será víctima segura de aquellos que proclamen que la independencia va en contra de la religión. ${ }^{1011}$ Considera que terminará desuniendo a los pueblos americanos,

\footnotetext{
${ }^{1006}$ Ibid., p. 32.

${ }^{1007}$ Para profundizar en la polémica sobre la declaración de la independencia entre los publicistas ver: Goldman, Noemí, "Iluminismo e independencia: Monteagudo y Pasos Silva (Kanki) en la prensa revolucionaria de 1811-1812, en Eliseo Verón y Leonor Arfuch, El discurso político. Lenguajes y Acontecimientos, Buenos Aires, Hachette, 1987.

${ }^{1008}$ El Español N $\mathrm{N}^{\circ} \mathrm{XIX}, 30 / 10 / 11$, p. 44.

${ }^{1009}$ El Censor nro. 8 25/2/12: Suplemento.

${ }^{1010}$ El Español $\mathrm{N}^{\circ} \mathrm{XIX}, 30 / 10 / 11$, p46, «Caracas ha legitimado ahora esta guerra según las leyes del derecho de gentes, y su gobierno no puede quexarse de que lo llamen rebelde entre tanto que no gane el título de Soberano, con las armas.»

${ }^{1011}$ Ibid., p. 47.
} 
como ya sugería la correspondencia entre Santa Fe y Caracas. En ese sentido se pregunta: "Si misterios sirven para fundar repúblicas ¿tan malo es el misterio de Fernando?". ${ }^{1012}$ Justamente sobre esta cuestión es que se había vuelto más virulenta la discusión entre los publicistas porteños después de que Monteagudo criticara al gobierno en la Gazeta del 21 de febrero por seguir hablando en nombre de Fernando VII, definiéndola como una "máscara tan inútil como odiosa a los hombres libres". ${ }^{1013}$

En el número siguiente del El Censor, el editor continúa reproduciendo el artículo de Blanco White acompañándolo con una nota introductoria donde justifica su publicación y la de las noticias de Caracas por la enseñanza que pueden implicar para la revolución en el Río de la Plata, más cuando esta se ve amenazada por el filosofismo y "las cabezas calcinadas de jóvenes fogosos". ${ }^{1014}$ A continuación introduce otro fragmento de un artículo del mismo número de El Español donde su editor se manifiesta escandalizado por la Declaración de los derechos del pueblo venezolana, la que entiende es una imitación servil de la Declaración de los derechos del hombre francesa: “en la América donde las clases inferiores podrán con dificultad entender una palabra que otra de esta quinta esencia filosófica, es probable que obre de muy distinto modo...es muy probable que diciéndoles como se les dice que el deber de cada individuo es mantener la libertad e igualdad, lo tomen más a pecho que lo que quisieran los que recomiendan tal máxima". ${ }^{1015}$ Nuevamente no es casual la reproducción de un artículo de El Español, sino que responde al contexto de disputa que tiene el sector moderado con el ala más radical del proceso. En este mismo número es publicado un oficio del Triunvirato al Intendente de policía advirtiendo que en las reuniones de la recientemente fundada Sociedad Patriótico-Literaria, de la que como sabemos Monteagudo era su "ego conductor", se discutían "temas ajenos a su instituto y muy capaces de dividir la opinión en perjuicios de los intereses de la patria, y del estado", encargándolo a tomar las medidas correspondientes para que se le imponga silencio a aquel orador "que se extravíen en sus discursos". ${ }^{1016}$ Pareciera que El Censor, en

\footnotetext{
${ }^{1012}$ El Español $N^{\circ} X I X, 30 / 10 / 11$, p. 46.

1013 Gazeta nro. 25 (21/2/12): 132

${ }^{1014}$ El Censor nro. 9 3/3/12: 35. El mismo Blanco White confiaba en tener algún tipo de ascendencia sobre los americanos: "Si mis reflexiones no sirven ya para Venezuela si por ellas me condenarían allí al último suplicio; podrán tenar algún peso para con las gentes moderadas de la demás de América, y acaso contribuirían a que eviten los dos precipicios a que están expuestos: la esclavitud y la anarquía”. El Español $N^{\circ} X I X, 30 / 10 / 11$, p. 80

${ }^{1015}$ El Censor nro. 9 3/3/12: 36.

${ }^{1016}$ Ídem.
} 
algunos casos, hacía las veces de periódico paraoficial, incidiendo en la opinión pública para justificar las medidas gubernamentales contra los adversarios políticos.

Pocos días después Monteagudo hace un paréntesis a sus "observaciones didácticas" para responder a lo publicado por Pazos Silva. En relación al debate sobre la conveniencia o no de declarar la independencia vuelve a manifestarse a favor, inscribiendo su discurso en el campo de memoria morenista pero con la emergencia de un nuevo enunciado: la necesidad de plasmar ese derecho en un acto jurídico. ${ }^{1017} \mathrm{Y}$ en clara referencia a los artículos de Blanco White publicados en El Censor comenta irónicamente: "sigamos con la máscara de Fernando VII, dicen algunos: las circunstancias no permiten otra cosa; ¡oh circunstancias, cuando dejaréis de ser el pretexto de tantos males!". ${ }^{1018} \mathrm{Y}$ aunque reconoce que el actual gobierno ha dado algunos pasos positivos como la libertad de imprenta, el decreto de seguridad individual, la supresión de la Audiencia y la convocatoria de una asamblea constituyente, opina sin embargo que la concentración de los poderes legislativo y ejecutivo en sí "basta para graduarle de tiránico". ${ }^{1019} \mathrm{El}$ enfrentamiento entre las dos alas del proceso ya era abierto y no pasaría mucho tiempo para que Monteagudo fuera desplazado de la redacción de la Gazeta por el Triunvirato y la Sociedad Patriótica comenzara a conspirar para deponerlo.

\section{Distanciamiento de la dirigencia porteña de la figura de Blanco White}

La insistencia por parte de Blanco White en la unidad del imperio hispánico, sus críticas cada vez más recurrentes al rumbo que iba tomando la revolución en Caracas y Buenos Aires, sumado a su militancia abogando por una mediación británica para resolver el conflicto - cosa que en el Rio de la Plata nunca terminó de ser vista del todo con buenos ojos, ni siquiera por el sector más probritánico-, llevó finalmente hacia mediados del año XII a un distanciamiento hacia el publicista sevillano por parte de la dirigencia porteña. Una muestra de ese alejamiento, en el contexto de ser conocidas las noticias de que las Cortes de Londres y de Cádiz se habían puesto de acuerdo en mandar una delegación a América, lo constituye la reproducción en julio de 1812 de un artículo publicado originalmente en la Aurora de Filadelfia el 10/12/11 y que se considera fue obra de José Álvarez de Toledo, representante por Santo Domingo en las Cortes de

\footnotetext{
1017 Goldman, N., "Iluminismo e independencia...", p.135.

1018 Gazeta nro. 28 (13/3/12): 144.

${ }^{1019}$ Ibid.
} 
Cádiz, que había huido de la península y se había refugiado en la mencionada ciudad. ${ }^{1020}$

Toledo dice haber leído El Español XVI del 30 de julio de 1811-donde figura una respuesta dada por Blanco White a Juan Roscio, secretario de relaciones exteriores del gobierno de Caracas- y el Examen imparcial de Álvaro Flórez Estrada -el que ya analizamos en un capítulo anterior-, y declara estar "escandalizado de ver a estos dos hombres, dotados de bastantes luces y de firmeza de carácter, prostituirse a las miras interesadas y tortuosas de la política Ministerial ; y declarándose por sus campeones entre las rocas de la prepotente y orgullosa Albión, insultar a los derechos y a la alta dignidad de todos los pueblos del nuevo mundo". ${ }^{1021}$

En el artículo del diputado por Santo Domingo se van analizando y contestando las distintas proposiciones de los publicistas peninsulares. A la opinión de que los nuevos gobiernos de América han usurpado la autoridad, que no cuentan con una representación legitima, y que han llevado adelante reformas y proclamado constituciones sin contar con la participación del pueblo, el autor les responde que la reacción para combatir y derrocar a la tiranía, "no puede ser emprendida jamás por el consejo de la multitud: es indispensable que sea siempre resultado de los cálculos, y esfuerzos generosos de algunos individuos". ${ }^{1022}$

Ante la afirmación de los que llama "aclamadores asalariados", de que la América española no puede erigirse en estado independiente imitando a los anglo-americanos porque sus circunstancias son absolutamente diferentes, sobre todo por la gran diversidad de castas que componen la población americana, contesta que no conocen realmente las características de América del Sur. Es inconcebible, para el autor, que el gobierno de Cádiz sea el único garante de la paz entre las castas. Sostiene que si se suman a los pardos a una misma unidad con los blancos no hay grandes riegos con la población negra. ${ }^{1023}$ Como dice Pasino, llama la atención que la carta de Filadelfia haya sido reproducida en el periódico oficial, que trataba de bajarle el tono al conflicto con la

\footnotetext{
1020 "Sobre el origen de texto André Pons señala al estudiar las zonas de difusión de El Español, que en la ciudad de Filadelfia existía un centro de difusión de la actividad hispánica, lo cual comprueba a partir de un informe de Blanco al F. Office en la cual señalaba la existencia de un "club" de españoles en dicha ciudad que era frecuentado por Álvarez de Toledo, diputado americano en las Cortes por Santo Domingo, que había huido de Cádiz con la ayuda de los Caballeros Racionales. En sus Cartas, Mier cita el "Manifiesto del diputado de Santo Domingo"; también se encuentran referencias al mismo en el periódico de Monteagudo Mártir o Libre (Buenos Aires) 18 de mayo de 1812". Pasino, A., "Independencia y República...”, p. 13.

${ }_{1021}$ Gazeta Ministerial nro. 11 19/6/12: 222.

1022 Ibíd., p. 223.

${ }^{1023}$ Ibid., pp. 223-224.
} 
metrópoli, pero si tomamos en cuenta que su editor era ya Nicolás Herrera, que había sido ganado a la Logia Lautaro, sus motivaciones pueden sospecharse. ${ }^{1024}$

\section{El Español, Servando Teresa de Mier y la Logia Lautaro}

Ya con la Logia Lautaro en el poder, buscando profundizar nuevamente el rumbo de la revolución, desde el periódico El Grito del Sud, que hacía las veces de vocero de la Sociedad Patriótica, se insistía con el programa independentista y volvía a involucrarse a Blanco White en el debate local. En el artículo titulado Reflexiones sobre la necesidad de independencia se discute el planteo de "independencia moderada" bajo protección británica vertido en El Español XXIV, que constituye la respuesta del sevillano a la primera Carta del novohispano Servando Teresa de Mier, parte del famoso intercambio que involucró a ambos letrados. ${ }^{1025}$ Como bien sostiene Alejandra Pasino, la polémica, en líneas generales, discurría por dos caminos: "los aspectos doctrinales y fácticos que legitiman la declaración de independencia americana, y una serie de consideraciones sobre el gobierno republicano que remiten a la posibilidad de su funcionamiento en Hispanoamérica". 1026

El autor de las Reflexiones descree de las promesas de "igualdad de derechos y leyes" que España garantizaría alcanzado un acuerdo, como afirma Blanco White en su artículo, y considera que más que hacerle caso al publicista, el mejor consejo está en la misma historia de la conducta de la metrópoli hacia América. Está convencido de que cuando ésta se recupere de su crítica situación volverá a tratar a las provincias americanas como colonias, abandonando todas las promesas de mayor autonomía y libre comercio. No puede, dice tajantemente, "haber reconciliación donde el odio ha echado raíces tan profundas", expresando la postura inflexible que la facción radical tenía hacia fines del XII con respecto al conflicto. ${ }^{1027}$

El articulista retoma el argumento sobre la desigual proporción de representación en las Cortes, donde se le negaba de esa manera, dice, la ciudadanía a la mitad de la

\footnotetext{
${ }^{1024}$ Pasino, A., "Independencia y República...”, p. 14.

${ }^{1025}$ La polémica se desarrolló en una serie de cartas remitidas por Fray Servando Teresa de Mier al editor de $E l$ Español - pero publicadas en forma independiente- y en las respuestas de Blanco editadas en su periódico entre 1811 y 1812 en Londres y tiene como punto de partida la declaración de independencia de Caracas en julio de 1811. Mier estaba recién llegado desde Cádiz donde había colaborado con la diputación americana en las Cortes reunidas en 1810, siendo testigo del primer año de sus sesiones.

${ }^{1026}$ Pasino, A., "Independencia y República...", p. 5. Sobre la polémica ver también Rosetti, M., "La práctica de la libertad civil: La polémica de Servando Teresa de Mier y José Blanco White en la fragmentación de la monarquía española", Dieciocho-Hispanic Enlightenment, vol. 37 nro. 2, pp. 295320.

${ }^{1027}$ El Grito del Sud 20 24/11/12: 156.
} 
población americana. En ese sentido entiende como sumisa e inútil la participación de los diputados americanos en las Cortes, y para reforzar ese razonamiento lo cita a Mier: "Infelices diputados de América, en representaciones, y protestas inútiles han consumido todo el tiempo de su representación". ${ }^{1028}$

Cargando nuevamente contra Blanco White lo acusa de perderse en un laberinto de contradicciones y sofismas. Recuerda que antes éste se había manifestado a favor de la independencia, y que consideraba que los derechos asistían a los americanos en ese sentido, pero ahora parece que ya no están preparados, y eso, según el porteño, sostenido en base a débiles argumentos como la presencia de criollos en los ejércitos realistas o la división interna en partidos. ${ }^{1029}$ Justamente para ejemplificar esto último el sevillano había recurrido al Rio de la Plata:

Los papeles de Buenos Aires están llenos de alusiones a los desórdenes del partido que acaba de ser depuesto. Antes de éste entiendo que había reinado otro, que fue el que dio muerte al desgraciado Liniers. La disposición de los pueblos se ve a las claras en la interesante narración de la retirada del Coronel Pueyrredón desde Potosí, que inserté en éste mismo número. Yo no podré decir en quien está la culpa, pero lo cierto es que apenas sufrió el ejército de Buenos Aires una derrota, cuando los pueblos a quienes iba a dar libertad se vuelven contra sus restos como tigres,[...] lo cierto es que este estado de cosas es muy poco favorable para fundar de repente estados independientes y soberanías. ${ }^{1030}$

A esto el articulista porteño le recuerda que tampoco la península escapaba a la división en partidos y facciones, que al igual que en todo proceso revolucionario existían rivalidades, intrigas y conspiraciones, y eso no invalida el derecho de los españoles a liberarse del yugo napoleónico.

Pero las referencias a Blanco White y el uso de sus escritos en la Gazeta Ministerial, aunque cada vez más escasos, no fueron siempre con el fin de polemizar con sus posiciones. En las primeras semanas del año XIII, mientras la Asamblea Constituyente empezaba a sesionar y se daban señales de una inminente ruptura definitiva con la península, en el periódico porteño se vuelve a introducir algunos extractos de las cartas de la polémica entablada entre Servando Teresa de Mier y José María Blanco White, pero esta vez son los argumentos de este último los que se toman

\footnotetext{
${ }^{1028}$ El Grito del Sud nro.23, 15/12/12: 179-180.

${ }^{1029}$ El Grito del Sud nro. 23, 15/12/12: 181.

1030 “Contestación a un papel impreso en Londres...” El Español XXIV (Londres) julio 1812.
} 
como fuente de autoridad para justificar los pasos que se buscaban dar. ${ }^{1031}$ En el suplemento a la Gazeta Ministerial del 1/1/13, bajo la edición de Nicolás Herrera, se publica la respuesta del editor sevillano a la segunda Carta de un Americano al Españolen Londres. ${ }^{1032}$ Frustrado por el rechazo de la propuesta de mediación inglesa, considera que: "las cortes han declarado a la faz del mundo que no quieren conciliación con las provincias de América que se hallan en revolución". ${ }^{1033}$ Ve como principales responsables de esta actitud no al partido servil, sino aquellos que a su entender se envanecen con el título de liberales pero, dice, "si no se ha trastornado en Cádiz el lenguaje como las ideas, yo creo que solo podrían llamarse liberales por antífrasis, o como comúnmente se dice, por mal nombre. La conducta que han seguido respecto a las Américas es el colmo de la iliberalidad (sic)". ${ }^{1034}$ Esa "iliberalidad" de los gaditanos también sería remarcada muchas veces por Monteagudo, señalando las flagrantes contradicciones en las que caía el liberalismo peninsular en relación a América

El sevillano dice renunciar a seguir aconsejando a los americanos, según las actuales circunstancias sus advertencias contra la independencia absoluta -que había sido rebatida con mucha solidez por Mier- ya no tenían sentido. Sí le preocupa que el "jacobinismo" y el "francesismo" sigan extendiéndose entre las nuevas dirigencias americanas e insiste en evitar esas doctrinas. ${ }^{1035}$ Como podemos ver, a pesar de que en numerosas ocasiones desde las plumas de la Sociedad Patriótica, fundamentalmente la de Monteagudo, se había cargado contra los artículos de El Español, en este caso sus críticas al partido liberal gaditano y su resignación con respecto a una inevitable ruptura total de América con la metrópoli son utilizadas por los revolucionarios en el marco de la futura apertura de la Asamblea a fines de ese mismo mes. Los planes que albergaba la Logia Lautaro de declaración de independencia tenían su eco en el fatalismo de Blanco White.

En la Gazeta Ministerial del 5/2/13 -donde se relata la apertura de la Asamblea, los decretos de su instalación y las sesiones de los primeros días-, se introduce un

\footnotetext{
${ }^{1031}$ La presencia de los textos que componen la polémica en el Río de la Plata, como ha señalado Pasino, "se constata además de la difusión de El Español y la reproducción de sus artículos en la prensa local, en los anuncios sobre la venta de las Cartas de Mier que aparecen en diferentes periódicos y la referencia a la misma en una carta enviada por Manuel Belgrano al gobierno de Buenos Aires en la cual solicitaba copias de la Carta del Americano para su distribución en el Alto Perú"”. Pasino, A., "Independencia y República...", p. 12.

${ }_{1032}$ Extraída de El Español nro. 28 del 30/8/12.

1033 Gazeta Ministerial nro. 39 1/1/13: 371.

${ }^{1034}$ Ibid., p. 372.

${ }^{1035}$ Ibid., p. 374.
} 
artículo titulado Reflexiones donde se aborda uno de los ejes argumentativos de Blanco White con respecto a la inconveniencia de la separación de América de la madre patria. Como hemos visto en un capítulo anterior tanto para el sevillano como para otros liberales peninsulares la inmadurez política de las elites americanas y de su población en general eran el principal desafío para pensar un devenir autónomo exitoso, augurando en cambio divisiones internas y anarquía social. El autor del artículo pareciera hacerse eco de esos pensamientos y sostiene: "Es verdad que la inexperiencia ha producido algunos males, pero también lo es que la elocución del remedio ha cortado en tiempo sus efectos". ${ }^{1036}$ Reconocía los escollos que en teoría representaban esa rusticidad en las costumbres de los americanos, pero confiaba que una dirigencia competente, ilustrada y unificada podía llevar adelante un proceso gradual de educación política sobre el conjunto del pueblo: "Los hábitos, las costumbres, la opinión y la fuerza irresistible de las preocupaciones, luchan incesantemente contra los encargados de dirigir por nuevos resortes aquella máquina, y la obra más difícil que mueven sus registros es la uniformidad y consonancia de todos los puntos al centro sobre que gira la dirección". ${ }^{1037}$

La Logia Lautaro apostaba a encontrar en la Asamblea ese centro unificador prescindiendo de la figura monárquica, y eliminando de la ceremonia inaugural el juramento a Fernando VII daba los primeros pasos en ese sentido. Coincidían con Mier en que la ilustración de los criollos se iría fortaleciendo y llegaría al resto de la población como consecuencia del proceso revolucionario: "No hay mejor academia para el pueblo que una revolución", ${ }^{1038}$ decía el novohispano en sus cartas a El Español, “¿Quiere usted que los hombres se ilustren?, júntelos en el foro de un Congreso. ¿Quiere que se entiendan y progresen los sólidos conocimientos? Hágalos libres: sacudan el yugo bárbaro de los españoles, cuyas leyes expresas son que nada pueda imprimirse en Indias sin la aprobación de su Consejo de España". ${ }^{1039}$ En cambio, para el sevillano, como marca Pasino, los "hábitos y costumbres" eran los conductos de la obediencia, y en este sentido la figura del monarca ausente debía seguir funcionando como fórmula para mantener la obediencia a los nuevos gobiernos internos hasta tanto

\footnotetext{
${ }^{1036}$ Gazeta Ministerial nro. 44 5/2/13: 399.

${ }^{1037}$ Ibid., p. 400.

1038 "Carta de un Americano..." (Londres) Noviembre 1811.

1039 "Segunda Carta de un Americano..." (Londres) Julio 1812.
} 
los criollos pudieran conformarse en una clase dirigente reconocida por el resto de la población. ${ }^{1040}$

Después de varios meses sin ser utilizado, a mediados de año se vuelven a introducir extractos del periódico londinense en relación a la discusión sobre la abolición de la Inquisición. La primer parte del artículo, obra del editor local, festeja la decisión de las Cortes de proclamar esta nueva ley, aunque resalta las dificultades que ha tenido que vencer el partido "que se dice liberal", y los peligrosos debates que tuvieron que sostener para alcanzar la abolición del Tribunal del Santo Oficio, en una demostración muy clara, dice, del grado de "ceguera y estupidez a que reduce a los Pueblos un mal Gobierno". ${ }^{1041}$ La primer parte del artículo de El Español, que introducía al decreto, era muy elogiosa con la decisión de las Cortes de abolirla, fragmentos que el editor de la Gazeta no eligió copiar demostrando la poca voluntad de dar demasiados créditos al gobierno metropolitano. ${ }^{1042}$ Sí elige marcar el contraste y las diferencias que existieron entre la península y el Rio del Plata para alcanzar esa resolución: "Pero si excita justamente la admiración de todos esta incomprensible ceguedad y fanatismo de la Nación española, rodeada por todas partes de las luces, y de los conocimientos que caracterizan nuestra era, no es menos digno de admiración el fenómeno que las Provincias de esta parte de América presentan observando una conducta enteramente opuesta en esta misma materia". ${ }^{1043}$ Siendo hijos de españoles, dice,

[...] es ciertamente muy honroso, que la experiencia haya de demostrado en esta ocasión que aquellas plantas ponzoñosas son extrañas a este benigno y dulce clima. Allá los Legisladores han necesitado de aventurar su autoridad para abolir la Inquisición; aquí el decreto ha sido una consecuencia precisa de las ideas generales del pueblo, y en honor se ha dicho del Clero él ha sido el que más se distinguió contra esa abominable institución...acá la opinión uniforme de todas las clases, no solo ha dejado enteramente libre el camino a la Ley, sino que el Cuerpo Legislativo habría perdido su opinión con la sanción de cualquier otra; no digo, que perpetuase el horrendo Tribunal, pero que conservara si quiera algún rastro de su existencia. ${ }^{1044}$

\footnotetext{
${ }^{1040}$ Pasino, A., "Independencia y República...", p. 6.

1041 Gazeta Ministerial nro. 64 21/7/13: 495.

${ }^{1042}$ El Español nro. 34, febrero de 1813, p. 97

1043 Gazeta Ministerial nro. 64 21/7/13: 495-496.

${ }^{1044}$ Ibid., p. 496.
} 
A continuación es introducido otro largo extracto de El Español, y aquí el verdadero fin de la reproducción del escrito del sevillano, donde se critica que las Cortes hayan mantenido las penas más crueles contra los crímenes de herejía:

Pero esta obligación (preguntaré yo ahora); es política o religiosa ?-Nadie podría probar que Dios ha encargado a las potestades seculares, que persigan a los que yerran en la fe [...] Si la experiencia de las naciones más cultas y florecientes del mundo no basta a quitar los recelos que manifiestan muchos en España, de que la libertad de ejercer otra religión que la católica, pudiera causar disturbios y alteraciones; prohíban, enhorabuena, el ejercicio, prohíban la predicación de otras doctrinas. Pero imponer pena de muerte al que no pueda convencerse de la verdad del todo o parte del catecismo Romano; es un abuso del poder, y un insulto al santo nombre de la justicia. ${ }^{1045}$

\section{El Español en el giro conservador de la Logia}

El clima independentista que había rodeado al inicio de las sesiones de la Asamblea prontamente se fue disipando, dejando paso a una mayor cautela producto de los conflictos con la disidencia del litoral comandada por Gervasio Artigas y a los avances antinapoleónicos en Europa que hacían prever una pronta vuelta al trono de Fernando VII en un contexto ideológico dominado por la Restauración monárquica, que chocaba de frente con el ideario inicial de la Logia Lautaro. ${ }^{1046}$

Por su parte, en la medida en que se fue convenciendo que la conciliación es cada vez más difícil, y casi imposible, Blanco White iría perdiendo interés en la cuestión americana y, a partir de mediados de 1812, pasaron meses sin que El Español se ocupe de ella. En un artículo de abril de 1813, el propio Blanco lo explica así:

No porque de algún tiempo a esta parte rara vez se nombra a la América española en este periódico, dejo de acordarme con frecuencia de aquellos países verdaderamente desgraciados. Pero como las cosas se han puesto en términos en que nadie puede oír razones por fuertes y poderosas que sean, y nada me es más repugnante que el escribir por sólo declamar, creo que lo más útil es interrumpir pocas veces este silencio. ${ }^{1047}$

Justamente este artículo, donde se critica la estrategia militarista que tiene Cádiz en relación al conflicto con América, es insertado en la Gazeta Ministerial del 22/9/13. El autor reconoce que en el presente es más verosímil que nunca que los españoles

\footnotetext{
1045 Ibid., p. 497.

${ }^{1046}$ Halperín Donghi, Tulio, Revolución y Guerra...

${ }^{1047}$ El Español, nro. 36, p. 328. Este número contiene además un Extracto de una Carta de Buenos Aires, de 15 de Octubre de 1812, con noticias del triunfo de las fuerzas patriotas en Tucumán.
} 
logren expulsar a los franceses de la península, pero duda que puedan dirigir pueblos más allá del océano. Para el sevillano la conducta de todos los jefes de armas en América es horrenda y considera que las Cortes deben tener presente que "aun mandando todas las tropas posibles y los mejores generales no podrán reconquistar la América si estos se unen definitivamente contra ellos". ${ }^{1048}$ Igualmente plantea que los criollos no han mostrado hasta ahora que sean capaces de lograr la unión que incline a su favor la contienda. Y sospecha Blanco White que, en esta situación, pronto el General Vigodet, gobernador de Montevideo, seguirá el ejemplo de los demás jefes militares contra el "desunido pero valiente pueblo de Buenos Aires". Insiste en que a pesar de todo el continente americano puede aún pacificarse, pero no, dice, mandando déspotas militares: "Con declarar la igualdad, y hasta con concederla en cantidad de diputados, tampoco alcanza; deben tomarse en cuenta las diferencias que separan a ambos países. Pónganse cuerpos representativos al estilo las colonias inglesas, con mayoría de naturales, y no cabildos con el misma autoridad que uno peninsular". ${ }^{1049}$

La facción revolucionaria no solo va perdiendo sus bríos independentistas de comienzos del año sino que también algunas de las aspiraciones "democráticas" que el morenismo de los primeros años había sabido encarnar. El conflicto con la "democracia bárbara" que expresaba el artiguismo, sumado a sus reclamos federalistas, ponían en tensión el discurso revolucionario de los porteños, moldeándolo de tal manera que iba limando sus aristas más radicales. En el discurso original de los morenistas, lo liberal estaba asociado con la igualdad, hacia fines del XIII y sobre todo a partir de la asunción de Gervasio Posadas como director supremo, el impulso igualitario se va desdibujando. Algunos de ellos, como Monteagudo, terminan abjurando del mismo, por lo que el concepto liberal se orientó hacia una idea más vinculadas al orden institucional, en tres grandes líneas: defensa de las garantías, libertades o derechos individuales; la institucionalización del poder en un régimen republicano y representativo, y en relación a ambas, la necesidad de limitar el poder político para así lograr esas libertades. ${ }^{1050}$

Una muestra elocuente sobre este giro conservador es el artículo titulado "Reflexiones sobre la causa de la desigualdad de las fortunas, y sobre la importancia de las ideas religiosas para mantener el orden público", atribuido a Belgrano, publicado en septiembre en la Gazeta Ministerial. En un curioso análisis, el escrito da cuenta de que

\footnotetext{
${ }^{1048}$ Gazeta Ministerial nro. 71 22/9/13, p. 528.

1049 Ídem.

${ }^{1050}$ Wasserman, F., "Entre la moral...”, pp. 54-55.
} 
las personas se dividen éntrelos que tienen propiedades -la tierra- y los que solo poseen su trabajo. Esta situación determina según el autor una lucha continúa entre las dos partes, pero en definitiva, agrega, los últimos se someten invariablemente a las leyes impuestas por los primeros. Cuando la recompensa de su trabajo es justa, dice, ninguna insurrección viene a turbar el ejercicio de semejante autoridad. El imperio de la propiedad es lo que reduce a la mayor parte de los hombres a esa dependencia. Considera que no se puede atacar ni siquiera ligeramente el derecho de propiedad porque se pondría en cuestión el orden social, "para mantener esta situación la educación política no alcanza por los abstracta y de difícil incorporación, son imprescindibles las ideas religiosas para este fin [...] Ninguna ciencia humana valdrá jamás en nuestro destino por una sola idea moral...de todas las ideas morales la mayor y la más magnifica, es la que la religión coloca en el corazón del hombre". ${ }^{1051}$

Plantea que hay algunos jefes que quieren poner en discusión abandonar el culto público a los caprichos de la libertad. Sostiene que el "trastorno universal" de los principios políticos sin el soporte de las ideas religiosas condujo a tiempos de confusión y tumultos; pero señala que a diferencia de Europa, "la adhesión constante de los Pueblos Americanos a los principios religiosos, y el respeto que les consagran sus Legisladores (digan lo que quieran nuestros maldicientes enemigos,) es, y será el más firme apoyo de sus costumbres, y de su libertad". ${ }^{1052}$ Libertad que como vemos ya no se iba a alcanzar sólo persiguiendo el fin del despotismo y el cumplimiento de los derechos civiles, sino que ahora estaba mediada por la necesidad de garantizar el orden y respeto a la autoridad a través de un reforzamiento de los fundamentos tradicionales. Y son las reglas morales brindadas por el dogma católico las que podían establecer ese marco de convivencia. No podemos no imaginarnos que estos planteos respondían a la preocupación que en la elite dirigente porteña despertaban las montoneras artiguistas y su cuestionamiento a la pretensión de Buenos Aires de centralizar el poder.

El conflicto con las fuerzas litorales se iba agudizando con el paso de los días y la Gazeta Ministerial lo fue reflejando en sus páginas. En el número correspondiente al 6 de octubre se introduce el dictamen del Asesor general de gobierno por la causa criminal elevada contra el artiguista Felipe Cardoso por haber dirigido "anónimos incendiarios promoviendo una liga con el Alto Perú contra el gobierno". ${ }^{1053}$ A

\footnotetext{
1051 Gazeta Ministerial nro. 70 1/9/13: 523-524.

1052 Ibíd., p. 524.

1053 Gazeta Ministerial nro. 73 6/10/13: 535.
} 
continuación del dictamen figura un artículo donde se plantea que "cualquiera puede proponer distintos sistemas de organización, como el de federación, a la manera de escritores publicistas promoviendo discusiones pacíficas y literarias, pero se ataca al estado cuando se promueve la guerra civil de unas provincias con otras, y eso es un crimen de lesa Patria”, y puede ser castigado con la pena de muerte o la confinación. ${ }^{1054}$ El localismo de la elite porteña había estado presente, en cierta medida, desde el inicio mismo de la revolución, pero se había ido profundizando al calor de la lucha facciosa entre las tendencias en disputa. Parte del discurso opositor a la Junta Grande durante 1811 había hecho hincapié en la condición de "forasteros" de Saavedra y de varios de los diputados, que debían ser removidos y remplazados por "verdaderos patricios". 1055 Con Alvear ya en la conducción de la tendencia radical, San Martin en un segundo plano, y el artiguismo como un verdadero foco de poder, el localismo y el centralismo se habían agudizado.

Más adelante se vuelve a citar el mismo artículo de El Español que hacíamos referencia un poco más arriba, con el propósito de demostrar que aquellos que forman un partido disidente "son indiferentes o antipatriotas", y terminarán sufriendo ellos también la venganza de los "déspotas" si se produce la restauración. Sin lugar a las ambivalencias define que: "o es el templo de la gloria o el cadalso, no hay medio, solo la fraternidad puede ser nuestra eterna garantía". ${ }^{1056}$ La incorporación del texto de Blanco White remitía claramente a ese contexto de enfrentamiento con el artiguismo, y sus escritos fueron usados para desprestigiarlos y acusarlos de que, en caso de una derrota de las fuerzas patriotas frente al bando fidelista, su disidencia iba a ser señalada como la principal causa.

El Blanco White que se retoma es aquel que también había hecho su propio proceso de abandono gradual de ciertas ideas radicales, para ir abrazando un pensamiento moderado y en algunos aspectos directamente conservador. El sevillano, que durante los primeros años de la revolución española defendió el principio de soberanía popular con vehemencia, sufrió una profunda transformación políticoideológica desde su llegada a Inglaterra; una mutación que lo llevaría, en un tiempo

\footnotetext{
${ }^{1054}$ Ibid., p. 535. El gobierno resolvió finalmente confinarlo en la Provincia de La Rioja por el término de 6 años "atendiendo a que el dicho Cardozo ha sido un ciego instrumento de que se ha valido el verdadero autor de esta criminal correspondencia". Ibid., p. 537.

${ }^{1055}$ Herrero, Fabián, "'Localistas' radicalizados. Pasquines infamatorios distribuidos luego de la asonada de los orilleros en abril de 1811", en Bragoni, B. y Mata de López, S., Entre la colonia y la república. Insurgencias, rebeliones y cultura política en América del Sur, Buenos Aires, Prometeo Libros, 2009, pp. 245-268.

${ }^{1056}$ Ibid., p. 538.
} 
relativamente corto, a posiciones muy diferentes a las defendidas anteriormente. En un artículo escrito en enero de 1813, llega a decir que la soberanía popular es "el más pernicioso de los dogmas liberales", pero su desconfianza hacia este principio era ya manifiesta desde, por lo menos, fines de 1810. En su carta al diplomático caraqueño Juan Roscio, de enero de 1811, Blanco escribe: "No quisiera que imitasen a las Cortes en las declaraciones de la soberanía de los representantes del pueblo, porque además de que la soberanía no consiste en declararla, este principio abstracto puede llevarlos a consecuencias prácticas peligrosas". ${ }^{1057}$ Dos años después, Blanco White insiste: "es un delirio decirle al pueblo que es soberano y dueño de sí mismo: porque el pueblo no puede sacar bien alguno de este, ni otros principios abstractos, que jamás son aplicables en la práctica: y porque en la inteligencia, se oponen a la subordinación, que es la esencia de toda sociedad humana". ${ }^{1058}$ Con el fin de legitimar el rumbo moderado que iba tomando el gobierno, que en unos meses se cristalizaría en el Directorio, los herederos del morenismo paradójicamente recurrían a los escritos de Blanco White, tal como lo había hecho Pazos Silva para polemizar con aquellos unos años atrás.

1057 Citado en Breña, Roberto, “José María Blanco White...”, p. 7.
1058 "Variaciones políticas dEl Español”, El Español, Parte I (1813), p. 15. 


\title{
Capítulo 15:
}

\section{La Gazeta de Montevideo, entre Cádiz y Buenos Aires}

\author{
Introducción
}

Poco tiempo había trascurrido desde la negativa de Montevideo a subordinarse a la recién constituida Junta revolucionaria de Buenos Aires, cuando las autoridades decidieron movilizarse rápidamente para procurarse de una imprenta y poder así "combatir la publicidad juntista con sus mismas armas". En esos acuciantes días José María Salazar, Comandante del Apostadero de Montevideo, escribía a Gabriel de Ciscar, Ministro de Marina español, enumerando algunas de las necesidades de la Plaza: "Entre las cosas necesarias [...] es una de las primeras una imprenta, porque en la de Buenos Aires solo se reimprime, y publican aquellos papeles de España y extranjeros, que creen convenirles, lo que es de un grandísimo perjuicio a la buena causa; además sin ella, carecemos de los medios de manifestar, y extender nuestro modo de pensar al interior". 1059

Pero no fue la península la que respondió a los ruegos montevideanos, la solución al problema llegó desde mucho más cerca, sin necesidad de atravesar el inmenso Atlántico. Fue la princesa Carlota, atenta siempre a las posibilidades de extender su influencia en los territorios americanos y ganar voluntades para la causa de la familia real española, pero sobre todo para la personal, quien le permitió a la ciudad portuaria contar con una imprenta propia. ${ }^{1060}$

Nicolás Herrera, asesor consultor del Cabildo, fue designado para que, sin dilaciones, pusiese la prensa en ejercicio con el fin de publicar un periódico semanal a un precio moderado que permitiera su lectura "a todas las clases del pueblo". Herrera

\footnotetext{
1059 "Carta de José María Salazar a Gabriel de Ciscar”, citada en Cremonte, Néstor. La Gazeta de BuenosAyres de 1810. Luces y sombras de la ilustración revolucionaria. Editorial de la Universidad de La Plata, La Plata, 2010. p. 122.

${ }^{1060}$ José Presas, secretario particular de la Princesa, fue el encargado de poner en ejecución el proyecto. Se entrevistó con el Conde de Linares, Ministro de Negocios Extranjeros de la corte de Rio Janeiro, quien accedió a que de la Imprenta Real se embarcaran sigilosamente para la ciudad-puerto una prensa y seis cajas de tipos. La imprenta llegó a la ciudad a fines de Setiembre de 1810 con la siguiente carta dirigida al Cabildo: "Mereciendo mi especial consideración y cuidado todo cuanto puede contribuir a la defensa de los dominios del Rey mi hermano, no puedo menos que atender la justa solicitud del Marqués de CasaIrujo relativa a la gran necesidad que teníais de una imprenta, para evitar los males que seguramente causarla en esas provincias la pérfida impostura con que esa cábula de facciosos pretende alucinar a los pueblos". Tomado de Estrada, Dardo, Historia y bibliografía de la imprenta en Montevideo 1810-1865, Montevideo: Librería Cervantes, 1912, pp. 8-9.
} 
solo alcanzó a publicar el Prospecto y los dos primeros números de la Gazeta de Montevideo, cuando a mediados de octubre fue sustituido por el doctor Mateo de la Portilla y Cuadra, continuándola hasta el 8 de Agosto de 1811, en cuya fecha la tomó definitivamente Fray Cirilo de la Alameda y Brea, quien estuvo a su frente hasta el 21 de Junio de 1814 en que apareció el último número.

La Gazeta de Montevideo significó una expresión más, en un contexto y circunstancia particular, de la irrupción sin precedentes del periodismo político en el mundo hispánico. Enlazada desde su mismo nacimiento a su homóloga bonaerense, ambas gacetas operaban prácticamente sobre una misma comunidad de lectores, disputándose el sentido que el público rioplatense le daba a los turbulentos tiempos que se estaban viviendo. Una de las principales funciones que cumplió la gaceta montevideana, desde el primero al último número, fue la de informar sobre la situación militar en la península y en las colonias. Información para nada inocua, la insurgencia americana desde el comienzo del conflicto había tratado de instalar la idea de que España estaba perdida militarmente para así justificar la legitimidad y necesidad del levantamiento. Las noticias publicadas en Montevideo, en cambio, hablaban de una intensa actividad bélica, cada triunfo era magnificado, minimizadas las pérdidas, pintándose siempre un horizonte esperanzador para las fuerzas patriotas españolas. Similar disputa informativa se daba sobre la suerte de las armas a lo largo y ancho del continente americano entre lealistas y revolucionarios.

Pero no fueron las noticias sobre la guerra las únicas que expresaron el enfrentamiento periodístico entre Montevideo y Buenos Aires, ambos periódicos se constituyeron en vehículos desde donde construir la legitimidad de cada causa y entablar el combate también en el terreno de las ideas. ${ }^{1061}$ Operaciones que no estuvieron ajenas al proceso de proyección y circulación tanto de la prensa como de otros escritos y proclamas que irradiaron desde la península.

Un primer relevamiento nos sugiere la difusión de un discurso de carácter más conservador de la prensa montevideana con respecto a la porteña y peninsular, definidas éstas por la irrupción de nuevos fundamentos políticos asociados al iusnaturalismo moderno y al incipiente liberalismo político. En ese sentido, la Gazeta de Montevideo

\footnotetext{
${ }^{1061}$ Algunos escritos de la Gazeta de Montevideo admitían la existencia de opiniones disidentes alineadas con las de la prensa bonaerense. Como por ejemplo el soneto publicado en febrero de 1813 que en uno de sus extractos dice: "Papeles incendiarios, mandan de Buenos Aires los facciosos, y aquí veo que varios, los leen como dogmas religiosos" Suplemento a la Gazeta de Montevideo, 23-2-1813: 131. Citado en González Demuro, Wilson, La prensa de Montevideo, 1814-1825 Imprentas, periódicos y debates públicos en tiempos de revolución. Tesis de Maestría, Inédito. pp. 79-80.
} 
demostraba estar alineada con la metrópoli en la defensa de la integridad del imperio, aunque no podríamos decir lo mismo en relación a la adopción incondicional de los debates y reformas políticas y culturales que provenían fundamentalmente de las Cortes y la prensa liberal gaditana, en particular las concepciones articuladas alrededor del principio de soberanía nacional. ¿Qué impacto tuvo, por ejemplo, en el periódico y en el discurso de su editor, la promulgación de la Constitución de 1812 y su jura en Montevideo en septiembre de ese año? Indagaremos en los debates y polémicas entabladas con los publicistas porteños, preguntándonos también qué uso se le dio a la prensa y a los decretos y proclamas peninsulares en la Gazeta de Montevideo, prestando atención no solo a las reproducciones efectivas, sino también a las dilaciones y las ausencias.

\section{Fray Cirilo de Alameda y su cruzada de pluma y tinta}

La entrada de Cirilo de Alameda y Brea como director no supuso un mero remplazo burocrático si no que le imprimió a la Gazeta de Montevideo un marcado cambio en su línea editorial, acentuándose el tono fidelista y conservador, al punto de poder definirla como ideológicamente reaccionaria. Cuestiones como el respeto a la religión y la autoridad fueron centrales en los artículos bajo su pluma, y dedicó una gran parte de éstos a atacar al gobierno de Buenos Aires y en especial a sus publicistas, acusándolos de "filosofistas", "jacobinos", "ateos", entre otros calificativos de similar factura. Pero, ¿quién era este personaje particular, que se entregó apasionadamente a la dirección del único periódico de la ciudad imprimiéndole un sello ideológico tan definido? Nacido en un pueblo en las cercanías de Madrid, a los doce años entró en la Orden Franciscana y tras alcanzar el sacerdocio prosiguió con su formación teológica. Cuándo aún no contaba con treinta años, tomó contacto con la convulsión americana en 1810 al presidir una comisión de franciscanos al pueblo de Moquegua, en el Virreinato del Perú. Los acontecimientos le impiden llegar a destino, y en junio de aquél año debió permanecer en Montevideo. La estancia en el Río de la Plata se terminó prolongando cuatro largos e intensos años, durante los cuales junto a un cargo como "lector de filosofía" en el convento de San Bernardino, desarrolló, como sabemos, la labor de director de la imprenta y editor de la Gazeta de Montevideo. ${ }^{1062}$ Vinculado

\footnotetext{
1062 Quizás por los valiosos servicios prestados durante ese período, a mediados de 1814 se le encomendó la misión de salvar la correspondencia oficial y otros objetos importantes ante la inminente victoria insurgente. Ya en Río de Janeiro Cirilo se iba a encargar de otra tarea más importante y que sin duda le
} 
políticamente con los sectores más reacios a cualquier tipo de entendimiento con Buenos Aires, se tiene constancia de su oposición junto a los llamados "empecinados" al armisticio en los primeros meses de $1814 .^{1063}$

El ideario contra-revolucionario que iría impregnando el periódico puede percibirse nítidamente en el Criterio de la verdad publicado en septiembre de 1811, a pocas semanas de haber asumido el fraile como editor. Construido en forma de diálogo entre el "fiel y reconquistador Pueblo de Montevideo y un Español", tiene como objetivo explicar cuál había sido el origen de la sociedad y de la soberanía. A contramano de las doctrinas del iusnaturalismo moderno y la roussoniana versión del contrato social -que como ya vimos estaban sirviendo de fundamento para la concepción de soberanía popular que se iba erigiendo en los debates constitucionales en Cádiz como también en las juntas americanas-, el autor del artículo dictamina que el origen del poder de los príncipes se encontraba en la misma naturaleza, y por lo tanto, se derivaba que "la subordinación y el vasallaje eran la más estrecha obligación de los pueblos". ${ }^{1064}$ En su concepción del pacto entre el soberano y los súbditos lo que primaba era el sometimiento de los últimos. Remite sin dudas a la formulación del jesuita Francisco Suarez, uno de los referentes de la tradición escolástica española. En el pacto suareciano, al no poder ejercer el poder, la comunidad debe relegarlo en una autoridad superior, renunciando de esa manera a su "libertad natural". Y a pesar de que existía consentimiento en ese acto, la sesión de soberanía era irrevocable, y por lo tanto, la monarquía absoluta la forma natural de organización del gobierno. ${ }^{1065}$

Volviendo al Criterio, su autor considera que el pueblo podía recurrir a las armas sin el concurso del Rey solo en casos excepcionales: cuando peligraba la Patria y

\footnotetext{
abrió las puertas de su posterior trayectoria. Se trataba, nada menos, que de negociar el enlace de las hijas de Carlota Joaquina, las princesas Isabel María Francisca y María Francisca de Asís, con sus hermanos Fernando VII y Carlos María Isidro. Tras el éxito de su gestión en este negocio matrimonial, regresó a España, donde entró rápidamente en el restringido círculo de la Corte de Fernando VII. Los ascensos en la carrera de fr. Cirilo se sucedieron casi ininterrumpidamente. Fue nombrado por Pío VII Ministro General de la Orden de San Francisco, y poco más tarde Grande de España (19-7-I818). Elegido en 1831 Arzobispo de Santiago de Cuba y más adelante Arzobispo de Burgos en 1849. Su impresionante carrera finalizaría obteniendo el arzobispado primado de España en Toledo en 1857 74. Navarro García, Jesús, "Actitudes políticas de fr. Cirilo Alameda y Brea, arzobispo de Santiago de Cuba, Burgos y Toledo: su etapa cubana", Anales toledanos $\mathrm{N}^{\circ}$. 25, 1988, pp. 222-223. Alameda ha sido involucrado también en la polémica sobre la autoría del "Plan de Operaciones" de la primera junta porteña. Patricio Clucellas sostiene que el franciscano lo habría escrito con el objetivo de desprestigiar a la revolución en el plano diplomático, fundamentalmente en la corte lusitana. Clucellas, P., "El Plan de Operaciones: ¿de Moreno o de fray Ciruelo?"; en Todo es historia. № 383, pp. 70-92

${ }^{1063}$ Ferreira, P., "La guerra de independencia española, los "empecinados" y el Montevideo leal, 18081814". Pasado Abierto. N $^{\circ}$ 4. Julio-Diciembre de 2016, pp. 41-60.

${ }^{1064}$ Gazeta de Montevideo 36, 3/9/11: 317 [de ahora en adelante GM en las citas].

${ }^{1065}$ Halperín Donghi, T., Tradición política ..., pp. 53-67.
} 
actuaba por lo tanto en su natural defensa, pero siempre sin ofender las supremas regalías, porque tanto su causa como la del Rey eran una misma. ${ }^{1066}$ De esa manera justifica el levantamiento y la constitución del gobierno metropolitano tras la invasión francesa a la península desde una perspectiva tradicionalista. Como oportunamente apuntaba François-Xavier Guerra (1992, p.150), el monarca aparece como la clave de bóveda de la Monarquía, unido indisolublemente a la nación: la ofensa al rey es una ofensa a la nación. Un discurso absolutista que se encontraba operando igualmente en un escenario donde estos valores ya coexistían con elementos novedosos. La unanimidad y la intensidad de la reacción patriótica, el rechazo de la población de unas abdicaciones a las cuales no ha dado su consentimiento, la exigencia por los mismos derechos a ambos lados del Atlántico, empezaban a remitir a algo mucho más moderno: a la nación entendida como conjunto de ciudadanos.

Otro ejemplo es el artículo titulado Educación Popular, donde el franciscano despliega todo su repertorio reaccionario atacando sin medias tintas a los que llama filósofos novadores, que confunden sus bajas pasiones por la verdadera ilustración del pueblo, basada en la doctrina práctica moral, o sea en una instrucción de orden religiosa. Pone como ejemplo de las desgracias que ha generado esta "falsa filosofía" al reino de Francia, que "se ha visto asolado de aquella fatalidad desde que Raynal, Voltaire, Rousseau y Montesquieu se hicieron maestros del pueblo". ${ }^{1067}$ Denuncia que los "fastuosos nombres de patria, humanidad e igualdad se han hecho resonar de uno a otro polo sin desentrañar su verdadero significado, [...] haciéndole concebir al pueblo un ansia de poseerlo todo" ${ }^{1068}$. Similares argumentos con los que los grupos denominados serviles en la península atacaban a sus adversarios liberales. Por esos mismos meses en un periódico conservador gaditano se los caricaturiza como "libertinos" imitadores de los sansculottes parisinos, que "se arrogan el impudente título de reformadores y claman a diestro y siniestro libertad, igualdad, gobierno popular, etc.”. Se trata, dice, de estrategas de café que gustan citar a Montesquieu, Rousseau, Diderot; y cuyos verdaderos objetivos no son otros que "descatolizar" y "revolucionar" a los españoles. ${ }^{1069}$

\footnotetext{
${ }^{1066}$ GM 39, 24/9/11: 344-345.

${ }^{1067}$ GM 42, 15/10/11: 366 .

${ }^{1068}$ GM 42, 15/10/11: 367 .

${ }^{1069}$ El Censor General 5, 1811, 67-72; tomado de Fernández Sebastián, Javier, óp. cit., p. 273. Aunque en minoría respecto a la abrumadora presencia de periódicos liberales, no fue para nada despreciable la prensa conservadora española, posibilitadas tanto una como la otra gracias la amplia libertad de prensa que reinaba en Cádiz. Entre los periódicos los detractores del nuevo orden y defensores de la monarquía
} 


\section{La prensa peninsular en las gacetas rioplatenses}

La percepción de que los acontecimientos que sacudían al imperio español formaban parte de un proceso a escala mundial estuvo presente entre los rioplatenses de ambos bandos, tanto fidelistas como insurgentes. Y esto en gran medida se debió a la circulación que tenía la prensa peninsular en la región. Un artículo publicado originalmente en El Conciso de Cádiz en enero de 1811 y transcripto en la Gazeta de Montevideo a comienzos de mayo de 1811 procuraba resaltar las diferencias entre la Revolución Francesa y las insurrecciones americanas, y aunque se lamentaba de la posibilidad de que la revolución fuera un proceso mundial: "se ha dicho que la Revolución dará la vuelta al mundo", el autor confiaba en que los "crímenes y atrocidades de los revolucionarios de Francia, sus absurdos, despropósitos, teorías" fueran "el mejor antídoto para los demás pueblos". ${ }^{1070}$ Consideraba que gran parte de la situación que atravesaban las provincias insurgentes se debía a las miras ambiciosas de algunos particulares y a la desinformación sobre el verdadero estado de la España. Argumentos ambos que se repetían sistemáticamente en las manifestaciones de la dirigencia peninsular en los primeros años del levantamiento americano.

Este mismo artículo de El Conciso sería reproducido una semana después en la Gazeta de Buenos Aires. Como réplica se alegaba que no había ningún tipo de excesos ni ambición si no "un libre uso de los derechos de estos vasallos en la incertidumbre, y dudas que han ocurrido sobre la legitimidad de las autoridades de España". ${ }^{1071} \mathrm{Y}$ adelantándose a cualquier recriminación, se destaca que cuando supieron de la existencia de las Cortes igualmente decidieron mantener el gobierno constituido

[...] porque las hallamos en nuestra opinión tan viciosas, o más que la Regencia, y la Central; porque ellas no representan sino un corto número de pueblos menores, que sin

\footnotetext{
absoluta podemos nombrar: el Diario de la Tarde (24/08/1811-28/1/1815), El Censor General (24/8/1811-12/1/1813, con alguna interrupción), El Procurador General de la Nación y el Rey (1/10/1812-31/12/1813) y el Diario Patriótico de Cádiz (11/8/1813- 24/5/1814) Sánchez Hita, B., "Las empresas periodísticas...".

${ }^{1070} G M$ 19, 7/5/11: 166-167. El Conciso fue un periódico liberal que vio la luz poco semanas antes de la inauguración de las Cortes extraordinarias y cuya vida estuvo muy ligada a ésta, siendo la reproducción de las sesiones uno de sus principales contenidos. Se imprimió entre el 24 de septiembre de 1810 y el 11 de mayo de 1814 y llegó a editar 2.000 ejemplares diarios. Su director fue el vasco Gaspar María de Ogirando, y sus tres principales redactores son conocidos por sus contactos con el grupo de Manuel Quintana: Francisco Sánchez Barbero, Manuel Pérez Gramajo y José Robles. El periódico se preocupaba menos de pedagogía que de afirmación ideológica, haciendo una apología del régimen representativo. Hocquellet, óp. cit., pp. 628-629.

${ }^{1071} G B A$ 49, 16/5/11: 378 .
} 
embargo de no estar ocupados militarmente por los franceses, están en rigor militar sojuzgados con sus capitales, y sin libertad para obrar contra las ideas del tirano [...] porque sus habitantes aunque estuviesen libres son muy pocos con respecto a los que contiene el territorio americano para querer llevar la voz contra el clamor universal de los de estas partes. ${ }^{1072}$

$\mathrm{Y}$ en un tono apenas más componedor se plantea que cuando la situación en España vuelva a la normalidad un congreso general propio determinará qué resolución tomar. El autor confía en que los verdaderos españoles serán cautos y no cerrarán la puerta con el uso de la fuerza a la posibilidad de refugiarse en América si la situación se terminara de complicar en la península. Finalmente les pregunta que si su revolución no era tan atroz como la francesa tal como reconocían en el artículo, por qué entonces estaban empecinados en declararles la guerra.

En la Gazeta de Montevideo del 19/6/11-ya en el contexto de la ciudad sitiada por las tropas orientales bajo el mando de José Artigas- y a lo largo de los cinco números siguientes se inserta un artículo correspondiente al Semanario Patriótico. ${ }^{1073}$ Bajo el título de Discurso histórico político su autor, quién no es otro que Manuel Quintana, reflexiona en profundidad sobre lo sucedido en América y no ahorra en fuertes críticas a los insurgentes. Describe el derrotero de los acontecimientos, centrando su atención en los levantamientos de Caracas, Nueva España y Buenos Aires. Define a esta última como la de mayor moderación y compostura en sus inicios, pero destaca que mientras Montevideo, al llegar la noticia de la instalación del Consejo de Regencia se apresuró a reconocerlo, la Junta de Buenos Aires no actuó de la misma manera, sin atender a las situaciones excepcionales que se vivían. Considera que tras la desastrosa derrota española en Ocaña, los rebeldes americanos "se arrojaron al logro de proyectos con aquella impaciencia impetuosa, propia solo de ánimos ya enconados de antemano, y estudiosamente prevenidos". ${ }^{1074}$ Pero quizás los párrafos más interesantes a destacar del artículo, por las repercusiones que tuvieron a uno y otro lado del Rio de la Plata son aquellos donde el liberal madrileño reproduce lo que, según la insurgencia americana, eran las razones de su levantamiento:

\footnotetext{
${ }^{1072} G B A 49,16 / 5 / 11: 379$.

${ }^{1073}$ En su tercera etapa -de noviembre de 1810 a marzo de 1812- el Semanario Patriótico saldrá a la luz desde Cádiz y estará nuevamente bajo la dirección de Manuel Quintana, quien publica el artículo dividido en tres números en febrero de 1811.

${ }^{1074}$ GM, 19/6/11: 223 .
} 
¿Qué fundamento hay para negar a las provincias de América en un tiempo de desorganización y desorden un derecho que las de España tuvieron al principio de la revolución? Juntas supremas e independientes se erigieron en la península después del fatal 2 de mayo; juntas independientes y supremas se han establecido en las provincias de ultramar después de la invasión de la Andalucía y disolución de la Central. Cómo negar a un reino, una provincia, a un hombre, la acción de mirar por su conservación y su felicidad, cuando las manos de quienes tenia confiado ese cuidado se hacen inhábiles a desempeñarle?

Y más adelante:

¿qué hay que extrañar en los movimientos de los americanos? Al cabo de $\mathbf{3 0 0}$ años de un régimen de hierro, razón es que se acuerden de que son hombres, y que aspiren a elevarse al grado de felicidad que la naturaleza les señala. Los campos feracísimos que los rodean están sin cultivo, las ciudades sin industria, y sin talleres, los puertos sin comercio y sin navíos. La madre patria, que con mano igual debía dispensar sus dones, abre todos los tesoros de la prosperidad al europeo, y los cierra duramente al americano. Para aquel son tas luces, la civilización, los honores, los empleos; para éste el abandono, la ignorancia, la degradación y el olvido. Enviar virreyes que los insulten con su fausto y soberbia; magistrados que los tiranicen con su dureza y sus injusticias [el subrayado es nuestro]. ${ }^{1075}$

Y aunque les recuerda irónicamente que no son descendientes ni de Moctezuma ni Atahualpa como para hacer propias esas quejas, si reconoce que, aunque exageradas, no dejan de ser verdaderas y responden al oprobioso cuadro de opresión y atraso que caracterizaba al sistema colonial. Pero lo entiende como una realidad común a ambos hemisferios, descalificando entonces aquel argumento como motivo de ruptura, más aún cuando considera, desde su liberalismo militante, que una nueva era se había abierto con la revolución española y que ésta dejaría en el pasado toda especie de tiranía. Finalmente aconseja a los insurgentes que, si persisten en compararse con el juntismo peninsular, los imiten en su moderación y trasladen su soberanía al gobierno central.

Lo que resulta paradójico es que aquellos mismos párrafos donde Quintana se hace eco de los reclamos americanos fueran luego reproducidos en la Gazeta extraordinaria de Buenos Aires con el fin de legitimar el desconocimiento a las Cortes gaditanas por parte de los rioplatenses. ${ }^{1076}$ Se insertaron sólo mencionando en una nota

\footnotetext{
${ }^{1075} G M, 19 / 6 / 11: 234-236$.

${ }^{1076} G E B A, 14 / 10 / 11: 806-808$.
} 
al pie que se trata de lo "dicho por un español en Cádiz en un Semanario Patriótico del presente año", sin hacer referencia al número ni la fecha de su publicación, como se acostumbraba. El editor realizó aquí claramente una operación de descontextualización recortando del texto solo lo que consideraba conveniente, sin incluir el conjunto del artículo que como decíamos era fundamentalmente una virulenta crítica a la insurgencia americana. ${ }^{1077}$ Tenemos por lo tanto un mismo artículo, proveniente del alma mater del liberalismo peninsular y una de sus principales plumas, reproducido en los periódicos oficiales de ambas orillas del Plata, con fines totalmente contrapuestos.

Volviendo al artículo de la Gazeta de Montevideo, su autor se propone realizar un paralelo entre las provincias de España y las de América para que así: "algunos publicistas de Cádiz, y Londres, y los de Buenos Aires reformen sus atrevidas y falsas proposiciones". ${ }^{1078}$ Consideramos que el autor no debate únicamente con los revolucionarios porteños o con el "renegado" José María Blanco White. ${ }^{1079}$ Hay una clara intención de polemizar, sin llegar a nombrarlos, con aquellos que desde la metrópoli, como el propio Manuel Quintana, tenían una visión crítica hacia los trescientos años de dominación en el nuevo mundo, tal como pudimos ver en el artículo reproducido tanto en la Gazeta de Montevideo como en su homónima bonaerense. Como si discutiera con el poeta madrileño, el autor se pregunta qué sería del continente americano si no fuera por la colonización europea, quién los habría elevado a la dignidad de hombres y quién les habría enseñado a sus habitantes el uso que debían darle a las riquezas de los suelos a sus habitantes. Salvo el oro y la plata, dice, todo lo destacable de estos países fueron fruto de la fecundidad de la madre patria.

El mismo día en que Cirilo de Alameda publicaba este Discurso, en la otra orilla la Gazeta porteña introduce un artículo titulado Reflexiones sobre la América española publicado originalmente en el periódico gaditano Duende político o la Tertulia

\footnotetext{
${ }^{1077}$ Seguimos a Alejandra Pasino en considerar que el editor para este momento ya era Pazos Silva aunque tradicionalmente la historiografía haya dado por válida su incorporación en esa función el 5/11/11. Pasino, A., "Circulación y apropiación..."

${ }^{1078}$ GM, 19/6/11:350.

${ }^{1079}$ Blanco White fue objeto de ataques de la Gazeta de Montevideo en varias oportunidades. Definido como un escritor imparcial, en la misma línea que aquellos que desde la península lo acusaban de no defender la causa española sino de responder a oscuros intereses producto de su relación con el Foreing Office, Cirilo de Alameda consideraba además que las ideas del sevillano eran muy tomadas en cuenta en Buenos Aires. Para él la razón por la que el gobierno revolucionario aún siguiera declamando fidelidad al monarca español respondía a su consejo, quién en una ocasión le reprochara a los caraqueños lo inoportuna que había sido la declaración de la independencia: "si misterios sirven para fundar repúblicas, ¿tan malo es el misterio de Fernando?” El Español 19, 30/10/11: 46; GM 54, 18/8/12.
} 
resucitada dirigido por el sacerdote y publicista liberal Miguel Cabral de Noroña. En la introducción previa a la reproducción del artículo el editor destaca la importancia de que

[...] todos vean confirmada la verdad de nuestros presupuestos por el intachable testimonio de los españoles sensatos, que lamentan sin fruto aquellos males, en el seno mismo de la Europa, y cuya veracidad, y conocido patriotismo es muy superior al de los autores de todos esos miserables papeles, que circulan con el nombre de Gazetas de esos gobiernos, empeñados en fascinarnos de intento con las más crasas falsedades [el subrayado es nuestro]. ${ }^{1080}$

Desde Buenos Aires se intentaba reivindicar aquellos periódicos que, sin las ataduras de un supuesto control gubernamental, publicaban una realidad que los otros tergiversaban. El artículo consiste en una fuerte crítica no sólo a la conquista sino al conjunto de la dominación española sobre América. Y como si estuviera polemizando con el planteo de Quintana en su Discurso Político Histórico, su autor considera que España también estaba sumida en muchos de esos males pero que en realidad en América el despotismo era aún más extremo. Lo destacable es que Cabral de Noroña va todavía más allá de la condena al pasado colonial, cosa común a muchos liberales, y transpola muchas de esas críticas a los gobiernos surgidos tras la abdicación de Fernando VII:

La Junta Central siguió en esta parte la misma conducta de la antigua corte de nuestros reyes, tan orgullosa y obcecada, como impolítica y funesta [...] en vez de prevenir este acontecimiento elevando desde luego a los americanos a la clase de hombres, y hermanos de los españoles, con la igualdad de todos sus derechos y privilegios, nada hizo, y continúo mandándoles con la misma arrogancia, y aun con mayor imbecilidad y torpeza... [a la cual] añadió la mala elección de sus agentes y empleados. ${ }^{1081}$

Considera que la primera Regencia "cometió injusticias, y absurdos todavía más enormes" y que la segunda tampoco los ha reparado. Entre otras disposiciones a modo de ejemplo critica la designación de Francisco Javier de Elío como Virrey para el Rio de la Plata, teniendo en cuenta la consabida enemistad que existía entre él y los bonaerenses aun antes de Mayo. ${ }^{1082}$ Finalmente le pide a las Cortes, a las que confiere

\footnotetext{
${ }^{1080} G B A 3 / 9 / 11: 706$.

${ }^{1081} G B A$ 3/9/11: 707-708.

1082 Mientras que los tres diputados suplentes por Buenos Aires en las Cortes desconocieron la elección de Elío como virrey, quejándose en sesión secreta de no haber sido parte de esa decisión, el diputado por Montevideo, el presbítero Rafael de Zufriátegui, la defendió a ultranza. Esto le ganó el encono de los bonaerenses y, debido a la positiva consideración que gozaban éstos dentro de la diputación americana,
} 
legitimidad y sabiduría, que sean ellas las que remuevan todos estos estos males, dando en primer lugar "muestras a los americanos de su igualdad con obras y providencias liberales, enérgicas y grandiosas, y no con palabras, y con disposiciones equívocas, o a medias". 1083

No iba a pasar mucho tiempo para que llegase la esperable replica desde Montevideo. Una semana después Fray Cirilo de Alameda respondía con el Discurso sobre la ilustración en la América Española, fruto de la indignación que manifiesta haberle generado la lectura del artículo del periódico gaditano publicado en Buenos Aires, acusando a su autor de necio y mal intencionado. Redobla la apuesta al afirmar que los pocos pueblos que vivían hace tres siglos "en estas vastas regiones en brazos de la ignorancia eran conducidos al sepulcro tan salvajes como nacieron". ${ }^{1084}$ Incapaces naturalmente según él para ilustrarse en las ciencias y las artes, solo era posible instruirlos en los principios de la religión revelada. Pero en cambio, los hijos de europeos nacidos en América habían logrado más adelantos incluso que los peninsulares, víctimas éstos del despotismo y envueltos contantemente en guerras desde el reinado de Fernando V. Resalta que los americanos han aumentado su población, construido populosas ciudades, erigido universidades, colegios y cátedras en mayor número aun que la metrópoli, fundadas por Reyes y Virreyes, y sostenidas por maestros europeos, existiendo según sus cálculos "más doctores en Buenos Aires que en Salamanca". ${ }^{1085}$ Y si no han adelantado más, reconoce, es por estar sujetos a las mismas arbitrariedades y a la rutina que en la península. Descree de las razones esgrimidas por los rebeldes americanos para justificar sus acciones:

Convénzase el, y todos los demás enemigos de la nación española, que ni el hierro, ni la violencia, ni la barbarie han sido la causa de los levantamientos de los Americanos, y si el orgullo de pocos que han hecho presumir a los más, que sin darlos nada podrían ser todo; la ambición y el filosofismo han desterrado de estos países la paz y la tranquilidad [el subrayado es nuestro].

Volvemos a constatar que para el franciscano los "enemigos de la nación española" no eran únicamente las tropas francesas que invadían la madre patria, o los

\footnotetext{
también lo fue aislando del resto de sus pares. Ternavasio, M., "El Río de la Plata divido. La experiencia gaditana en Buenos Aires y Montevideo (1810-1814)", en Breña, R., Cádiz a debate: actualidad, contexto y legado, El Colegio de México, México, 2014, pp. 277-302.

${ }^{1083}$ GBA 3/9/11: 709 .

${ }^{1084}$ GM 37, 10/9/11: 321 .

${ }^{1085}$ GM 37, 10/9/11: 328 .
} 
americanos que osaban no reconocer al gobierno metropolitano y colaborar con él; entre sus filas estaban también aquellos españoles europeos que como Cabral de Noroña o Blanco White, tenían el descaro de alzar la voz criticando la política de la monarquía hacia América, sea ésta del pasado o del angustiante presente.

A diferencia de lo que observábamos anteriormente, cuando el mismo artículo de un periódico peninsular era utilizado tanto por revolucionarios como fidelistas rioplatenses para reforzar sus posiciones, en este caso se da la particularidad de que son los primeros los que echan mano de la prensa liberal gaditana a su favor, obligando a los montevideanos a salir a rebatir esos argumentos, sosteniendo el enfrentamiento discursivo en dos frentes simultáneos. Esto que pareciera curioso o paradójico a simple vista, en realidad no lo es tanto si tenemos en cuenta el sesgo cada vez más reaccionario que fue adquiriendo la Gazeta de Montevideo bajo la dirección de Cirilo de Alameda, sumado a que los espacios que analizamos lejos estaban de ser, y especialmente Cádiz, bloques monolíticos en términos ideológicos.

\section{Usos y sentidos de conceptos políticos en ambas márgenes del Plata y del Atlántico}

Los cambios que atravesaron al mundo hispánico tras la crisis de la monarquía española de 1808 generaron, entre otras cosas, una creciente inestabilidad semántica en la producción conceptual del periodo. Esa polisemia estuvo relacionada además a la “circulación y los procesos de apropiación/selección/traducción” de nuevos lenguajes y modelos de organización política en función de las alternativas que la coyuntura y la acción política marcaban a cada paso en ambas orillas del Río de la Plata. ${ }^{1086}$

En un nuevo artículo, esta vez de tono muy sarcástico y bajo un seudónimo, Cirilo de Alameda vuelve a cargar contra los "filósofos" y el "lenguaje moderno". 1087 Considera que los porteños, guiados por sus "sabios maestros", asocian la voz libertad con la licencia para hacer y mandar lo que se les antoja. Justamente este concepto, tan central en la constelación discursiva tanto de los liberales peninsulares como de los revolucionarios rioplatenses, fue blanco de muchas de las reflexiones del franciscano, seguramente por el lugar destacado que tenía en los escritos de Vicente Pazos Silva y de

\footnotetext{
${ }^{1086}$ Goldman, N., Lenguaje y Revolución..., p. 10-11.

${ }^{1087}$ GM 20, 4/2/12: 241-243.
} 
Bernardo de Monteagudo, editores de la Gazeta de Buenos Aires de los martes y los viernes respectivamente. ${ }^{1088}$

En uno de esos artículo, Pazos Silva define a la libertad como "el derecho más sagrado de la humanidad y el primer germen de la virtud y del bien [...] es la que gobierna la voluntad de los individuos con respecto al interés y voluntad del cuerpo social, conocida y manifestada por las leyes". ${ }^{1089}$ Para que la libertad no degenere en licencia, el publicista entiende que dicha facultad no debe tomarse en sentido absoluto, sino que debe estar sometida a una "infinidad de leyes indispensables al bien general". La libertad debe definirse a partir de su opuesto: el despotismo. Considera entonces que el hombre que vive en sociedad no goza de ninguna especie de libertad absoluta, porque sus más pequeñas acciones están en entera dependencia de las leyes, y de la opinión. No será ésta la única oportunidad que Pazos Silva dedique un espacio de la Gazeta a tratar el tema. El texto titulado "Política" constituye en realidad, como ya vimos en el capítulo anterior, una apropiación del artículo "De los nombres libertad e igualdad" del publicista sevillano José María Blanco White publicado originalmente en el Semanario Patriótico. ${ }^{1090}$

Es en los escritos de Monteagudo donde la voz libertad aparece utilizada más frecuentemente, siempre en mayúsculas, constituyéndose de alguna manera en el concepto articulador de su ideario. En sus famosas observaciones didácticas, el líder de la Sociedad Patriótica escribía: "La LIBERTAD no es sino una propiedad inalienable e imprescriptible que goza todo hombre para discurrir, hablar, y poner en obra lo que no perjudica a los derechos de otro, ni se opone a la justicia que se debe así mismo". ${ }^{1091}$ En Monteagudo, como observamos, el sentido está más asociado a la voluntad y al derecho que a la obligación.

Sentidos similares a los otorgados por el artiguismo, que integró el concepto a un campo léxico amplio, junto a otros como soberanía, patria, revolución, igualdad e independencia. La concepción republicana de libertad se reflejó en las instrucciones dadas a los diputados enviados a Buenos Aires con motivo de la Asamblea

\footnotetext{
${ }^{1088}$ Junto a nación, independencia y constitución, probablemente sea libertad el término más empleado en los textos producidos en la península entre 1808-1814. Portillo Valdés, J., Revolución de Nación..., p. 398. Caracterizando a aquel primer liberalismo español Javier Fernández Sebastián dice que "se distinguió sobre todo por su frontal rechazo al despotismo y a la arbitrariedad, unido a una apasionada afirmación del valor de la libertad en política” Fernández Sebastián, J., óp. cit., 263.

${ }^{1089}$ GBA 70 ,10/10/11: 790-791.

${ }^{1090} G B A 1,5 / 11 / 11$.

${ }^{1091} G B A$ 24, 14/2/12: 126.
} 
constituyente del XIII, que debía postular "la Libertad civil y religiosa". ${ }^{1092}$ Al igual que el sector más radical de los liberales peninsulares, tanto los morenistas como el artiguismo pusieron el acento en el dominio del hombre sobre su voluntad, la capacidad exclusiva de la nación de expresar la del cuerpo de ciudadanos y la centralidad de los derechos.

Para el editor de la Gazeta de Montevideo, por el contrario, la libertad que enarbolaban los insurgentes estaba asociada a otras voces como "libertinaje" e "independencia", y acompañada de adjetivaciones como "filosófica", "inmoderada", "inmoral”, “quimérica” y "enemiga del bien común”. ${ }^{1093}$ No obstante, cuando Montevideo estuviese bajo el paraguas de la Constitución de Cádiz, Cirilo de Alameda la vincularía al respeto por el orden jurídico, acercándose así al sentido otorgado por Pazos Silva y el sector más moderado del liberalismo peninsular: "la libertad no consiste en hacer lo que se quiere, sino en lo que se debe querer; sin ley no hay libertad, y jamás imperan las leyes cuando los pueblos son el juguete de los partidos". ${ }^{1094}$ Como podemos apreciar, la torsión en el sentido de los instrumentos conceptuales para pensar la política fue muy profunda, y no estuvo sólo limitada a los grupos revolucionarios.

Otro de los conceptos al que se le otorgarían diversos usos y sentidos en los periódicos de ambas orillas es el de patriotismo, constituyéndose en un componente clave del lenguaje político rioplatense. Como oportunamente marcara Gabriel Di Meglio, el sentido político de patria se difundió rápidamente en el marco de la crisis revolucionaria que se estaba viviendo. Su sentido ya no se alojaría solo en la tierra donde se había nacido o se vivía, sino también en la causa compartida. ${ }^{1095}$ No remitía sólo a un campo político particular, tanto en Montevideo como en Buenos Aires poseía una connotación positiva, asociándoselo a una virtud en el sentido clásico. Se apelaba usualmente a él con el fin de promover en la población una entrega abnegada a la causa colectiva, y ese sentimiento estuvo detrás y explicó en gran medida la movilización y participación popular en el período. En el campo insurgente, el discurso republicano, fundamentalmente clásico, buscaba politizar e incorporar a la dinámica política a

\footnotetext{
${ }^{1092}$ González Demuro, W., "El concepto de libertad: un acercamiento a su evolución, desde el fin de la época colonial a la primera modernización estatal uruguaya", en Caetano, G., Historia conceptual. Voces y conceptos de la política oriental (1750-1870), Montevideo: Ediciones de la Banda Oriental, 2013, p.178.

${ }^{1093}$ GEM 1, 6/2/12: 9; GM 10, 24/3/12: 122 .

${ }^{1094}$ GEM 64, 5/12/13: 44.

${ }^{1095}$ Di Meglio, Gabriel, "Patria”, en Goldman, N., Lenguaje y revolución...., p. 121.
} 
distintos actores, pero para eso debió también interpretar los intereses de los sectores subalternos y resolver algunas de sus demandas. ${ }^{1096}$

En la Gazeta de Montevideo del 29/10/11 Alameda reflexiona sobre el concepto en un artículo plagado de referencias a la historia clásica. Y en un intento de síntesis concluye que "la verdadera definición del patriotismo es una virtud que autoriza a todos los miembros de la sociedad para sostener su religión, sus leyes, su rey, su gobierno y sus propiedades". ${ }^{1097}$ Nuevamente el sesgo tradicional se hace visible en la articulación conceptual que realiza, presentándose una noción -que algunos autores han denominado "patriotismo colonial"- asociada a la triada base del orden social de la monarquía española: "la religión, el rey, la patria". ${ }^{1098}$ No están contempladas en esa definición otras voces como derechos, libertad, nación, etc. Más adelante, considera que históricamente todas las revoluciones, y en particular la que atravesaba a América, han “degenerado su patriotismo en una fanática ilusión....alterando la paz general y privando a los pueblos del bien común". 1099

En la otra orilla, Bernardo de Monteagudo también dedicó un artículo de la Gazeta de Buenos Aires a intentar darle contenido a la voz patriotismo. ${ }^{1100}$ Para el tucumano es en primer lugar "un hábito producido por la combinación de muchas virtudes, que derivan de la justicia", y considera que "para amar a la Patria basta ser hombre, pero para ser patriota es preciso ser ciudadano". ${ }^{1101}$ Ubica al patriotismo en el extremo opuesto al espíritu egoísta y la ambición individual, y aunque entiende que procede de la inclinación al suelo en el que se nació, lo relaciona al interés en la "causa de la humanidad" que sintetiza en la libertad e independencia de los hombres. En un sentido similar al de los liberales peninsulares, el patriotismo constituía una virtud que se encontraba por encima de la monarquía y la religión. El discurso patriótico tenía un protagonismo central tanto para estos como para los insurgentes en la posibilidad de resolución de la crisis en un sentido constitucional. ${ }^{1102}$

Monteagudo finaliza con lo que entendemos que era en realidad el objetivo principal del artículo: convocar a los "buenos ciudadanos", invocando su patriotismo, a

\footnotetext{
${ }^{1096}$ De Gori, Esteban, La República Patriota ..., p. 286-287.

${ }^{1097}$ Gazeta de Montevideo 29/10/11: 390.

${ }^{1098}$ Caetano, G., óp. cit. p. 215.

${ }^{1099}$ GM 45, 5/11/11: 398 .

${ }^{1100}$ Este artículo aparece, y creemos que no casualmente, la semana inmediatamente anterior al anuncio de la conformación de la Sociedad Patriótica, que él mismo lidera y que reagrupa al morenismo revitalizado.

${ }^{1101}$ GBA 18, 3/1/12: 79 .

${ }^{1102}$ Portillo Valdés, J., Revolución de Nación..., p. 255
} 
colaborar económicamente con la revolución. Y con el Primer Triunvirato como interlocutor, sugiere que ante la premura de las circunstancias, es viable y hasta legítimo recurrir a "donaciones forzosas" de aquellos vecinos potentados y poco afectos a la revolución. A diferencia de la definición de Alameda, no existe referencia alguna a la religión en el texto, y antes que por el respeto al rey, las leyes o al gobierno, el patriotismo para Monteagudo está mejor explicado por el "amor a la humanidad", y la patria es pensada como un "espacio para la libertad". Por otro lado, la propiedad mencionada por el fraile madrileño como uno de los pilares desde donde se sostenía el sistema social y que por lo tanto debía ser preservada por todo patriota que se preciase de tal, era en cambio, para el líder de la facción morenista, factible de ser enajenada en favor de la causa, o sea, de la Patria. Y en ello parecía ubicarse en una posición aún más radical que la de los revolucionarios españoles.

Al debate por el sentido del término se sumó otro actor rioplatense, en este caso reponiendo nuevamente la voz de un protagonista del proceso peninsular. Desde las páginas de El Censor, Vicente Pazos Silva reprodujo bajo el título de Reflexiones sobre el patriotismo un artículo de Manuel Quintana originalmente publicado en el Semanario Patriótico del 15-9-1808. ${ }^{1103}$ Comienza definiendo que acepción tenía la voz patria antiguamente, relacionándola no sólo con la tierra donde se habita sino con la figura de una madre tierna que procura el bienestar de todos sus hijos. Para el poeta es una potestad "tan antigua como las sociedades, fundada sobre la naturaleza y el orden, que somete a sus leyes del mismo modo a los que mandan, que a los que obedecen". ${ }^{1104} \mathrm{El}$ patriotismo es definido como un sentimiento sublime "producido por el instinto más bien que por la reflexión [...] que se alimenta de sacrificios, que prefiere en todos tiempos, y en todas ocasiones, el interés público al individual: fuente eterna del heroísmo, da prodigios políticos, y el resorte, más poderoso para elevar y conservar los estados". ${ }^{1105}$ Realiza un llamamiento, en virtud del patriotismo, a deponer las pequeñas pasiones, odios y discordias internas en pos de interés común y la salvación de la Patria.

\footnotetext{
${ }^{1103}$ Alejandra Pasino señala correctamente que a diferencia de otras ocasiones donde Pazos Silva recurrió abiertamente al plagio de la obra de Quintana - o a Blanco White, como pudimos ver con su artículo Libertad e Igualdad -, en esta ocasión el poeta madrileño es citado como mecanismo de legitimación en el marco de la polémica establecida con Monteagudo, iniciada cuando ambos eran editores de la Gazeta de Buenos Aires. Pasino, A., "Circulación y apropiación...", pp. 17-18. Por la utilización del plural en la introducción al artículo podría estar dialogando también con Cirilo de Alameda: "Mas yo apelo átí, virtuoso Quintana la fuerza irresistible de tu elocuencia encantadora, venga a obrar en las márgenes del Rio de la Plata los prodigios que allá en las opuestas playas del océano. Yo repetiré a mis conciudadanos tus palabras insinuantes, tus reflexiones profundas [el subrayado es nuestro)]".

${ }^{1104}$ El Censor 5, 4/2/12: 17.

1105 Ídem.
} 
A los magistrados les exige prescindir de la ambición individual y los compele a no enfrascarse en inútiles persecuciones y venganzas personales. La elección de este artículo por parte de Pazos Silva no es casual, reforzaba su recurrente predica por mantener un rumbo moderado de la revolución, dejando de lado la medidas más drásticas que desde la Gazeta de Buenos Aires promovía Monteagudo, no sólo en relación a la metrópoli sino contra los sectores desafectos a la causa o demasiado timoratos en el Rio de la Plata. ${ }^{1106}$

Vicente Pazos Silva fue blanco de fuertes críticas por parte de Cirilo de Alameda, recibiendo paradójicamente los mismos calificativos que el mismo utilizaba para desprestigiar a Monteagudo en el fragor del enfrentamiento político que sostenían desde sus periódicos. 1107 "Jacobino", "discípulo de Rousseau”, "filosofista alucinado", son algunas de las expresiones que lanzaba a modo de dardos el madrileño contra quien como decíamos se esmeraba por diferenciarse del ala más radical de la revolución. ${ }^{1108}$ Uno de los artículos que despertó la reacción más virulenta de parte de Cirilo de Alameda fue la editorial de El Censor del 10/3/12 donde Pazos Silva le recrimina tanto al obispo como a los prelados porteños la falta de compromiso con la causa de los americanos. Y lógicamente razona que "si los obispos y sacerdotes suben a sus cátedras tanto en Lima como en Montevideo para atacarnos y justificar que nos subyuguen, por qué no sería justo que los nuestros suban a vindicarnos". 1109

El franciscano reprodujo el artículo de Pazos Silva en la Gazeta de Montevideo acompañado de una introducción y una serie de notas al pie, donde acusa a los revolucionarios porteños de hacer desaparecer la religión pública a la fuerza de bayonetas, de formar un partido anti-cristiano y de querer obligar a los ministros de la Iglesia a reproducir las "perversas máximas de su importunado filosofismo". ${ }^{1110}$ A los sectores conservadores, tanto en España como en América, lo que más les alarmaba era la posibilidad de que se realizara una traducción de la nueva filosofía europea a los términos comprensibles de una renovada moral católica. ${ }^{1111}$ Alameda justifica la posición del Obispo de Buenos Aires de negarse a predicar en favor de la causa de los revolucionarios, y afirma que tanto Jesucristo como la Iglesia condenan a aquellos que se levantan contra las autoridades legítimas. Considera que es deber de los ministros

\footnotetext{
${ }^{1106}$ Goldman, N., "Iluminismo e independencia..."

${ }^{1107}$ El Censor nro. 9 3/3/12: 53-54.

${ }^{1108}$ GEM 1, 6/2/12: 10 .

${ }^{1109}$ El Censor nro. 10 10/3/12: 37.

${ }^{1110}$ GM 10, 24/3/12: 122 .

${ }^{1111}$ Portillo Valdés J., Revolución de Nación...
} 
exponer al pueblo el debido castigo que merecen aquellos insurgente que promueven la sedición y la rebeldía, extremando el discurso de fuerte impronta religiosa hasta emparentarlos con "la imagen del príncipe de las tinieblas".

Cuando Monteagudo en su "paréntesis a las observaciones didácticas", a propósito de la discusión que tenía con el sector moderado sobre si seguir declamando o no fidelidad a Fernando VII, manifestó crudamente su deseo de que no quedase ningún príncipe sobre la faz de la tierra, desde Montevideo se aprovechó para reponer toda la artillería del lenguaje ortodoxo. ${ }^{112}$ Cirilo de Alameda replicó que el pueblo de Buenos Aires prestó en su momento espontáneo y libre reconocimiento a Fernando VII, jurando obedecerle y conservar sus derechos, y por lo tanto defender de sus enemigos al pacto social, la patria y la religión en la que se apoyaba ese juramento. Atacar a la cabeza de ese pacto era atacar a la voluntad general. Considera que de esta manera el tucumano ha dado conocer su verdadero espíritu, "no solo revolucionario, sino anti-religioso, anticristiano y anti-social", para terminar definiéndolo como un "ateísta práctico, o niega que hay dios o le acomoda como Lokio (sic) y Hobbes". ${ }^{113}$ Pero como observamos, más allá de la carga religiosa de su encendida replica, los fundamentos con los que termina defendiendo la lealtad a Fernando VII, y por ende a la monarquía como sistema, reposan más en la idea de voluntad general que en el sometimiento por derecho divino. La cultura política estaba trasmatándose y eso afectaba también a los defensores del status quo.

\section{Las Cortes de Cádiz y la Constitución de 1812 en la Gazeta de Montevideo}

El órgano que dio mayor difusión en el espacio rioplatense al proceso constitucional que se vivía en Cádiz fue naturalmente la Gazeta de Montevideo. Pero como veremos, su enfoque y tratamiento distó mucho de un registro homogéneo y regular, padeciendo los virajes editoriales que ya hemos venido analizando.

En la primera etapa del periódico, durante los meses que van desde diciembre de 1810 a Julio de 1811, bajo la dirección de Mateo de la Portilla y Cuadra, fueron recurrentes las noticias, proclamas y decretos emanados desde las Cortes de Cádiz. Intercalándose con los partes de la situación bélica en la península podemos encontrar regularmente reproducciones del periódico gaditano El Conciso, donde eran reflejadas

\footnotetext{
${ }^{1112}$ GBA 28 13/3/12: 143 .

${ }^{1113}$ GM 12 31/3/12: 147.
} 
con mucho detalle algunas de las sesiones del Congreso español. ${ }^{1114}$ El 1 de enero de 1811 se introduce la declaración del 15 de octubre de las Cortes sobre la igualdad entre los españoles de ambos hemisferios, donde se plantea además como salida al conflicto que, en aquellos lugares donde se manifestaron conmociones, el solo hecho de reconocer al Congreso permitiría dejar "todo en el olvido". ${ }^{115}$ La declaración de las Cortes venía a colación del debate del 26 de septiembre, reproducido en la Gazeta de Montevideo a través de un extracto de El Conciso, con varias intervenciones de los diputados americanos, donde se había planteado terminar con las pesquisas contra los insurgentes, y se pedía una amnistía general porque las motivaciones que originaron los levantamientos no eran de ruptura sino que respondían a la impresión que toda la España había caído. Se exigió también que fuese el mismo el método para la elección de diputados tanto en España como en América, inaugurándose de esa manera el debate sobre la representación americana, que como sabemos no se restringió solo a los recintos del Congreso. ${ }^{1116}$

Varios meses después, se retoma la cuestión introduciendo un artículo editorial del Semanario Patriótico del 17/1/11 donde se plantea como incomprensible la insistencia por parte de los americanos en el tema de la representación, teniendo en cuenta que ya se había resuelto que se discutiría tras la promulgación de la constitución de la monarquía, que se consideraba lo verdaderamente urgente y fundamental. El articulista descree que aquello pudiera resolver las agitaciones en América porque no responden, a su entender, a una cuestión de metafísica política sino a otro tipo de intereses: "La América arde y hay que apagar el incendio si no se quiere perderla para siempre". ${ }^{117}$ Es la primera vez, y por medio de un artículo presumiblemente de Manuel Quintana, que la Gazeta de Montevideo le atribuye esa entidad, esa dimensión, al conflicto. Ya no es considerado sólo una cuestión de cuatro facciosos alborotadores que han logrado engañar al pueblo, sino que constituye un problema que seriamente podría

\footnotetext{
${ }^{1114}$ El 12/12/10 es publicado un artículo de este periódico con la instalación y la primera sesión de las Cortes en la Isla de León el 24/9. GM 11: 92-96. En las extraordinarias de los días 20 y 22/12 los juramentos de los diputados y las primeras disposiciones formales de las Cortes. Cuestiones caras al programa liberal como los proyectos de libertad de imprenta y división de poderes también tendrán su lugar a través de la reproducción de artículos de El Conciso.GM 3, 15/1/11: 20-21, GM 10, 5/3/11: 75 .

${ }^{1115} G M 1,1 / 1 / 11: 2-3$. Este conjunto de definiciones llevó a preguntarse al virrey Elío en marzo de $1811 \mathrm{si}$ tenía sentido mantener la exhibición pública del estandarte real, con su carga de significación, en momentos en que la "investidura política que ha recibido la América de los principios liberales del gobierno supremo" indicaban lo contrario. Vale la pena aclarar que la ciudad-puerto aún no se encontraba sitiada por las fuerzas artiguistas.

${ }^{1116}$ Sobre la diputación americana en las Cortes ver Rieu-Millan, Marie Laure, óp. cit.; Chust Calero, Manuel, La cuestión nacional americana ...

${ }^{1117} G M 25,18 / 6 / 11: 219$.
} 
implicar la desintegración del imperio español. Justamente el día cuando sale a la luz este artículo en la Gazeta, se está cumpliendo un mes de la derrota realista en la batalla de Las Piedras a manos de las fuerzas artiguistas, permitiendo el primer sitio de Montevideo. La situación empieza a percibirse con otros ojos.

Al tomar Fray Cirilo de Alameda las riendas de la Gazeta la labor de las Cortes de Cádiz iban a desaparecer casi completamente del periódico. Y aunque no había críticas directas a ellas ni puntualmente a ninguna de las medidas tomadas allí, su invisibilización iba en sintonía con la profundización reaccionaria de la línea editorial. El Congreso español, donde el sector liberal poseía una destacada iniciativa política, se había constituido en el motor de las trasformaciones que poco a poco buscaban desmontar el andamiaje de Antiguo Régimen en el mundo hispánico. La reticencia de parte del franciscano también la podemos observar en la notoria demora con que eran impresos algunos decretos de cuño liberal que iban con expresa orden de la metrópoli de ser publicados inmediatamente.

Mientras Cádiz se convertía en un hervidero de discusión política, como consecuencia de una proliferación inédita de la prensa, tanto de un signo ideológico como de otro, en Montevideo se elegía sostener la disputa con Buenos Aires desde fundamentos políticos de un claro cuño reaccionario. No creemos que esa estrategia fuese una decisión exclusiva del fraile, ni que éste se manejara de manera completamente autónoma, libre de directrices de parte de las autoridades montevideanas. El virrey Francisco de Elío, quien lo había designado al frente del periódico, compartía seguramente muchas de sus posiciones. Y aunque no tenemos constancias de un vínculo estrecho entre ambos, intuimos esta afinidad por varias razones. En primer lugar el virrey había pedido expresamente al gobierno peninsular que Alameda se mantuviera en Montevideo, retrasando su misión pastoral en el Alto Perú, lo que habla de que estaba seguramente conforme con su labor al frente de la Gazeta. $^{1118}$

Por otro lado las Cortes no eran un escenario donde el Elío gozara de gran aceptación. El diputado montevideano Rafael de Zufriátegui tuvo que sostener desde su misma llegada a Cádiz en julio de 1811 infructuosas tratativas para impedir que el virrey sea removido de su cargo por pedido de los diputados suplentes de Buenos Aires

\footnotetext{
1118 "Real Orden comunicada por el Ministro de la Gobernación de Ultramar, José de Limonta, al Virrey de Buenos Aires disponiendo que el Padre Alameda continúe en la redacción de la Gazeta de Montevideo y en las funciones de Capellán Real del Virreinato hasta que pueda pasar al Colegio de Moquegua". Con resolución del Virrey al final. Por duplicado. Archivo General de Indias, ESTADO, 82, N.114.
} 
-téngase en cuenta que había sido designado por el Consejo de Regencia y no por las Cortes-, cosa que efectivamente sucedió. ${ }^{1119}$ A esto se le suma que el enviado de Elío no sólo no contaba con la simpatía de la representación americana, como ya habíamos mencionado antes, sino que también había generado resquemores en la minoría liberal peninsular por algunas de sus posiciones en las sesiones, fundamentalmente su insistencia en la concreción de una fecha para la disolución de las Cortes extraordinarias tras la promulgación de la nueva Constitución. ${ }^{1120}$

Finalmente, y por sobre todas las cosas, es conocido el carácter contrarrevolucionario del pensamiento de Elío, debelado no sólo a partir de sus manifiestos y correspondencia, donde quedan bien en claro sus posiciones anticonstitucionales, la hostilidad hacia los filósofos y su continúa exaltación de la triada "Dios, Patria y Rey", sino también por sus acciones concretas una vez vuelto a la península. ${ }^{1121}$ Ya en el contexto del retorno de Fernando VII a territorio español, sería aquel el primer General que se pronuncie invitando al monarca a recobrar sus derechos en plenitud, organizando su recibimiento en Valencia y el cortejo hacia Madrid, y ofreciendo el 17 de abril de 1814 sus tropas a disposición ante cualquier amenaza de resistencia de parte de los constitucionalistas. ${ }^{1122}$

Con la llegada y designación de Gaspar de Vigodet por decreto de las Cortes como gobernador y capitán general de las provincias del Río de la Plata en noviembre de 1811, la Gazeta comenzó tímidamente a hacerse eco del proceso constitucional que vivía la monarquía hispánica. El 12 de noviembre de 1811 se anunció que las dos primeras partes del nuevo código habían sido aprobadas por las Cortes y se estaban imprimiendo en Cádiz. A continuación se reproduce una crónica de la sesión del 18 de julio donde se efectuó su lectura con un discurso introductorio dado por el diputado

\footnotetext{
1119 Aunque despreciados por los diputados liberales peninsulares, los sectores absolutistas eran necesariamente sus aliados en América, ya que constituían los pilares fundamentales, en sus respectivas regiones, del orden colonial que ellos también defendían., o que no estaban dispuestos a alterar sustancialmente. Esta contradicción va a ser marcada y explotada tanto por la diputación americana liberal como por los grupos insurgentes. Palti, Elías, óp. cit.

${ }^{1120}$ Propuso su disolución en la sesión secreta del 24/1 y en la sesión pública del 26/2 de 1812. En octubre de ese año se leyó una exposición secreta del ayuntamiento de Montevideo donde a la vez que agradecen la reciente promulgación de la Constitución, manifiestan estar escandalizados por las palabras de su diputado. El ayuntamiento pide entonces a las Cortes poder elegir a otro diputado, lo que ocasionará la intervención del diputado quiteño Mejía, muy lejano ideológicamente del presbítero, rechazando este pedido en defensa de la libertad de expresión de los representantes de la nación. Rieu-Millán, M.L., óp. cit., p. 27.

${ }^{1121}$ García Monerris, Encarna; García Monerris, Carmen, La nación secuestrada. Francisco Javier Elio: correspondencia y manifiesto, Universidad de Valencia, Valencia, 2009, pp. 106-107.

${ }^{1122}$ Durante la restauración absolutista será un protagonista destacado de las persecuciones contra el sector liberal. Tras la Revolución de 1820 es encarcelado y en 1822 será finalmente condenado a muerte y ejecutado, convirtiéndose de esa manera en uno de los primeros mártires de la reacción absolutista.
} 
Agustín de Arguelles, del cual se introduce un extracto donde hace referencia a las fuentes históricas de la Constitución. Entre los elementos que se anuncian se destacan cuál será la forma de gobierno, las facultades y límites del rey y de las cortes. ${ }^{123}$ Pero la publicación de esta importante novedad parece casi a reglamento, no hay comentario de ningún tipo por parte del editor, lo cual es llamativo teniendo cuenta que Fray Cirilo de Alameda no perdía ocasión para compartir sus impresiones ante hechos políticos de semejante envergadura.

En el número siguiente se reproduce una proclama de Vigodet que perfilaba la estrategia discursiva que buscaría desplegar ante Buenos Aires, con la carta gaditana como arma principal: "Las Cortes generales y extraordinarias de la nación ansiosas del engrandecimiento de la Patria, proporcionan a los americanos iguales ventajas que a los europeos: todos somos españoles, una misma familia, tenemos iguales derechos, y disfrutaremos los mismos bienes". 1124

Habría que esperar más de medio año para que la labor de las Cortes volviera a tener lugar en las páginas de la gaceta montevideana, y como resultado nada más ni nada menos que de la jura dela Constitución en Cádiz el 19 de marzo de 1812. Para la ocasión se trascribe una crónica, proveniente de un periódico gaditano al que no se referencia, de la ceremonia del juramento y Te Deum posterior. ${ }^{125}$ Nuevamente, no hay ninguna introducción del editor presentando quizás uno de los acontecimientos más importante de la historia española. Podemos suponer, sin aventurarnos demasiado, que existía una clara intención de devaluar la noticia, cumpliendo sólo formalmente con su publicación.

Pasarían otros dos meses más para que se volviera a mencionar a la Constitución, y sería a partir de la llegada de ejemplares de ésta a la ciudad-puerto a principios de septiembre. ${ }^{1126}$ Un mes que estaría marcado por el recrudecimiento del conflicto con Buenos Aires, en gran medida a causa de la sanción de la Carta Magna gaditana. ${ }^{127}$ Ante una nueva propuesta del gobierno de Buenos Aires para que Montevideo

\footnotetext{
${ }^{1123}$ GM 2: 5-7.

${ }^{1124} G M 3$ 3, 19/11/11: 29. En referencia al primer artículo de la Constitución española: "La Nación española es la reunión de todos los españoles de ambos hemisferios".

${ }^{1125}$ GM 42, 30/6/12: 409 .

${ }^{1126}$ GM 56, 1/9/12: 559 .

1127 "Nos hablan ahora de constitución: pero esa constitución establece al dogma de la soberana nacional, reconoce por única base de su representación a la población dé las provincias, y si ella no ha existido para la América ¿tendrá ésta obligación alguna de obedecerla? Si esta constitución es justa y liberal, solamente la libre sanción de los pueblos puede legitimarla: la fuerza y la opresión jamás han producido derecho". $G B A, 11 / 9 / 1812$.
} 
reconozca su autoridad se respondió desde el periódico montevideano convocando a los porteños a leer la Constitución, calificada como "la más sabia, liberal y digna de todas las naciones". ${ }^{1128}$ Se empieza a percibir un cambio en la posición del editor, que iba en consonancia con la estrategia de Vigodet. ${ }^{1129}$

Pero el reposicionamiento político de Cirilo de Alameda con respecto a las Cortes y la Constitución se produjo al momento de su publicación y jura en Montevideo. Y aunque resulte paradójico, fue justamente el fraile franciscano el encargado de pronunciar allí una oración exhortatoria, gracias a sus reconocidas dotes oratorias. ${ }^{1130}$ Como era de esperarse la oración está plagada de referencias bíblicas, introduciendo en todo momento su concepción cristiana del orden social. Considera que un pueblo sin constitución no puede ser otra cosa que juguete de las pasiones, y recurriendo al historicismo tan característico del constitucionalismo hispánico, afirma que "nuestros progenitores se libraron de un mal tan asolador, las sabias leyes de Castilla, las de Aragón y los fueros que aún conserva Navarra son los monumentos augustos de la dignidad nacional". ${ }^{1131}$ En contraste, juzga severamente los tiempos de Godoy, "cuya memoria debemos borrar para siempre".

Gran parte de la oración está dedicada al análisis y explicación de los preceptos más notables de la Carta Magna, y sobre todo a revelar los fundamentos cristianos del orden constitucional. Concluye con una entusiasta convocatoria a su observancia, sin dejar de acentuar la figura del Rey: "si la constitución ha restituido sus derechos al pueblo español conservando la dignidad e inviolabilidad de su monarca, si ha formado la mejor época de nuestra felicidad, ¡con qué interés, con que religiosidad debemos cumplir la obligación de observarla!". ${ }^{1132}$

\footnotetext{
${ }^{1128}$ GEM 58, 14/9/12: 579-580.

${ }^{1129}$ El 4 de septiembre Vigodet rechaza la propuesta de Buenos Aires para dar una salida negociada al conflicto, y le envía seis ejemplares de la Constitución. "decídase V. E., a jurar la Constitución de la monarquía, y decide así por la libertad e independencia de la América del Sur". Por su parte Buenos Aires toma la promulgación de la Carta magna como la cristalización definitiva de la nula voluntad de la metrópoli de buscar una salida negociada al conflicto y endurecerá como respuesta sus posiciones autonomistas: "Las Cortes han declarado a la faz del mundo que no quieren conciliación con las provincias de América que se hallan en revolución. Desechando la conciliación han declarado implícitamente que es su voluntad, que las armas decidan la cuestión presente, que si los americanos son vencidos se han de someter por derecho de conquista a las leyes que las Cortes le han dado". GBA, 01/01/1813.

${ }_{1130}$ Museo Histórico Nacional de Montevideo, B.6.35: Alameda, Cirilo; Oración exhortatoria...pronunciada el 27 de septiembre de 1812, Montevideo, 1812. Se puso en venta en la imprenta a 4 reales el ejemplar.

${ }^{1131}$ Citado en Roca, C., Vida del Cardenal Arzobispo Cirilo de Alameda y Brea. Montevideo, Biblioteca Nacional, 1974, p. 45.

1132 Ídem.
} 
La ceremonia es relatada en la Gazeta, con una breve introducción donde el editor no ahorra alabanzas al texto gaditano. ${ }^{1133}$ Como hasta el momento no le había dedicado casi ninguna página desde que se hizo cargo como director de la Gazeta de Montevideo, es entendible que haya decidido introducir un artículo del Diario de La Coruña, que dice preferir a otros por su lenguaje llano y sencillo, donde se ensayan definiciones sobre lo que es una constitución liberal -dando cuenta de la polémica que ese adjetivo ha generado- y cuales son y que significan los derechos naturales del hombre. ${ }^{1134}$ Con un lenguaje cifrado en un registro ilustrado, alejado de definiciones propias del liberalismo radical, el artículo está dirigido, como decíamos, al vulgo y no a los literatos, y es además una exhortación a los ciudadanos a esmerarse en conservar y defender la nueva Constitución.

El evidente oportunismo de Cirilo de Alameda le permitirá reacomodarse a la nueva situación, ahora bajo el paraguas constitucional gaditano. ${ }^{1135} \mathrm{~A}$ partir de la jura, las editoriales políticas donde se estilaba atacar a Buenos Aires desde posiciones ideológicamente reaccionarias disminuyeron y el periódico volvió a jugar un rol más centrado en informar sobre la situación militar en España y América. En cambio, las proclamas de las Cortes volverían a aparecer en la Gazeta. En marzo de 1813 se reproduce una de ellas, con una fuerte carga de fundamentos anclados en el constitucionalismo histórico, donde se afirma que: "la religión santa de vuestros mayores, las leyes políticas de sus antiguos reynos, sus venerables usos y costumbres, todo se ha reunido como ley fundamental en la constitución política de la monarquía". ${ }^{1136}$ Más adelante, en un registro discursivo liberal hasta ahora inédito en la Gazeta de Montevideo, se agrega que las Cortes

\section{[...] creyeron necesario desterrar de entre vosotros las reliquias del régimen}

feudal. Abolido para siempre el derecho señorial...os vistes restituidos a la condición de hombres libres $[\ldots]$ hicieron desaparecer de entre muchos de vosotros la prestación de

\footnotetext{
${ }^{1133}$ GM 61, 29/9/12: 609-613.

${ }^{1134}$ El Diario de la Coruña fue el primer periódico de la capital y primer diario gallego y funcionó entre 1808 y 1814 en cuatro etapas. De carácter patriótico y liberal. El artículo creemos que pertenece al editor al momento de la sanción de la Constitución, Ángel Antonio Henry, antiguo funcionario real y devoto absolutista, que con la revolución se había reconvertido en liberal y en 1813 publicará el Catecismo político constitucional para la educación de la juventud española.

${ }^{1135}$ En la GM 20/10/12 se relata la función y fiesta marcial a propósito de la promulgación de la Constitución en Cádiz, tomada de El Conciso del 3 de marzo. Que recién en ese momento se publicase significaba una muestra más del realineamiento de Alameda.

${ }^{1136}$ Proclama de las Cortes de Cádiz del 28/8. GM 11: 140.
} 
unos tributos, que en las vastas regiones de la España de ultramar os humillaba tal vez más que os ofendía [el subrayado es nuestro]. ${ }^{1137}$

A diferencia de los textos que se elegía publicar en la "etapa preconstitucional" de la Gazeta, en ésta la figura del rey prácticamente no es mencionada y cuando se lo hace está subordinada a la Constitución, a la cual se antepone siempre. Así lo dictaminaba su artículo tercero: "la soberanía reside esencialmente en la nación”. Ese principio, central en el programa del liberalismo hispánico, finalmente empezaba a dejar su huella también en la prensa montevideana.

\section{Consideraciones finales}

Tomando en cuenta lo analizado en este capítulo, poniendo en foco la fisonomía del discurso político, podemos dividir la trayectoria de la Gazeta de Montevideo en tres etapas. La entrada de Cirilo de Alameda constituye uno de los puntos de inflexión, mientras el otro responde a un acontecimiento político de mayor envergadura como fue la jura de la Constitución gaditana en Montevideo, que naturalmente impactó en la labor del editor. Entonces podemos afirmar que contamos con una primera etapa: "preAlameda" (10/1810-07/1811), caracterizada fundamentalmente por la reproducción de noticias de la península, tanto de la situación militar como de la labor de las Cortes; una segunda que podemos definir como "Alameda pre-constitucional" (08/1811-09/1812), donde a partir de la llegada del franciscano el foco del periódico se desliza hacia el conflicto local con Buenos Aires y el discurso se vuelve más doctrinario y acentúa su tono reaccionario; y una tercera y última que podríamos denominar "Alameda constitucional" (09/1812-06/1814), donde el editor readecua la línea editorial adaptándola al nuevo marco jurídico, político e ideológico que impone la carta gaditana, retomando la reproducción de proclamas peninsulares y bajándole el tono a sus declamaciones contra los publicistas porteños. ${ }^{1138}$

El contenido de la Gazeta de Montevideo, sobre todo mientras manejó las riendas el franciscano, pareciera abonar la tesis de Guerra de que aun formando parte ambos

\footnotetext{
${ }^{1137}$ GM 11: 141-142. La proclama va en línea con el decreto de las Cortes sobre la abolición de señoríos de agosto de 1811, y del que nunca se había hecho referencia en las páginas de la Gazeta.

${ }^{1138}$ Según los autores del estudio preliminar a la edición facsimilar de la Gazeta de Montevideo, Blanca París y Querandí Cabrera Piñón (1948), existieron dos etapas diferentes en la vida del periódico. Bajo las administraciones de Herrera y Portilla el periódico divulgó preferentemente noticias favorables a la causa monárquica y escritos contra la acción propagandística bonaerense, olvidándose "en un todo del suceder del lugar en que aparecía", mientras que Alameda tuvo más en cuenta la realidad local e intentó administrar la imprenta con mayor austeridad y orden.
} 
espacios de un proceso dialécticamente imbricado sobre la base de una similar cultura política, en los territorios americanos primó un ideario de carácter más tradicional que en la península, que según el hispanista, era producto de un anquilosamiento de las estructuras políticas y sociales mayor. No obstante, debemos entender el discurso que enarbolaba la Gazeta en su contexto de enunciación, que en gran medida era el de la confrontación con la revolucionaria prensa porteña. Se trata, en este caso, de dos ciudades, Montevideo y Buenos Aires, muy cercanas no sólo geográficamente, lo eran también social, cultural y económicamente. Que lenguajes políticos tan dispares operasen sobre un mismo espacio desde la prensa de ambas márgenes del Plata, responde más a las particularidades de la coyuntura y los posicionamientos que los actores políticos ocuparon en el marco de la crisis, que a una estructura social distinta que los estuviera condicionando.

La gravitación de Alameda en el giro del discurso del periódico oficial montevideano, que pasó de un registro conservador a otro abiertamente reaccionario, nos plantea la cuestión de la dimensión contingente en el proceso revolucionario. Y aunque, como aventurásemos anteriormente, existía cierta afinidad doctrinaria entre el editor y el virrey Elío, la comparación de los artículos de la Gazeta con las proclamas, bandos y otros documentos oficiales sugieren que sus posturas ideológicas no parecieran ser del todo representativas, ya no solo del poder metropolitano, sino tampoco de la oficialidad española en Montevideo desde la llegada de Gaspar de Vigodet. Que aun así haya seguido siendo el franciscano el encargado de ese "arma" en la batalla contra Buenos Aires nos estaría hablando no solo de la posesión de innegables destrezas como publicista, y de las necesarias relaciones políticas que lo sostuvieron en esa función hasta el fin de la dominación española en la plaza, sino también del carácter iniciático de este tipo de experiencia periodística en la región, donde evidentemente se estaba descubriendo aún el uso político de la prensa y la necesidad de la disputa -y conformación- de la opinión pública local.

Los argumentos esgrimidos por Cirilo Alameda no distaban mucho, eso sí, de los sus pares de la prensa absolutista peninsular; muy parecidos eran los fundamentos políticos utilizados para interpretar la crisis monárquicas y dar una salida conservadora al proceso. Resulta curioso que, a pesar de ello, el editor no haya recurrido, o por lo menos no tenemos constancia de que lo haya hecho, a la reproducción de artículos de dicha prensa para reforzar sus posiciones, mientras que por el lado de la insurgencia, como pudimos observar, la publicación de escritos de autores liberales peninsulares fue 
una práctica bastante corriente. Lo que efectivamente hemos podido constatar es que en sus "discursos" el fraile no sólo apuntó contra los revolucionarios rioplatenses, sino que en varias ocasiones, hubo de salir al cruce de dictámenes puestos en circulación por los publicistas liberales sobre la "cuestión americana" desde el otro lado del Atlántico.

Que podamos detectar similares usos y sentidos a conceptos como "libertad", "patriotismo", "nación"; y que existieran numerosas coincidencias entre los puntos programáticos elaborados por la dirigencia revolucionaria tanto en la península como en Buenos Aires, también hace referencia a ese amplio escenario de profundas transformaciones interconectadas. La cultura política y la formación intelectual de las elites americanas no se distanciaron mucho de la de sus pares peninsulares. Una vinculación estrechada en gran medida, por un elemento hasta ese momento inédito en el mundo hispánico: el surgimiento y proliferación de una nueva prensa libre y crítica. En palabras de Javier Fernández Sebastián: “en el mundo iberoamericano existía entonces no sólo una cultura compartida, sino también una cierta "comunidad de discurso" o, si se prefiere, unos pocos lenguajes políticos que bebían en parecidas fuentes y circulaban de ciudad en ciudad y de costa a costa, cuyas líneas de fractura pasaban frecuentemente por encima de las fronteras; fronteras porosas que, por lo demás, distaban todavía de haberse estabilizado". ${ }^{1139}$

Se trataba de espacios heterogéneos en cuanto a la diversidad de concepciones y estrategias políticas que circulaban internamente, por lo que sería un grave error entenderlos como ideológicamente monolíticos. Ni Montevideo era un bastión del pensamiento absolutista y reaccionario, ni en Buenos Aires y Cádiz se enseñoreaba sin oposición el republicanismo o el liberalismo. Y en cada uno, dependiendo de las relaciones de fuerza de la coyuntura, alguno de estos sectores políticos lograba transitoriamente hegemonizar el espacio, tensionando a gran parte de los actores involucrados hacia sus posiciones. Todo ello en el marco de un innegable tránsito global del proceso, que iba dejando atrás los valores y estructuras del Antiguo Régimen, pero que se encontraba justamente en plena etapa transicional. Lo que sí estamos en condiciones de afirmar es que durante gran parte de su trayectoria la Gazeta de Montevideo priorizó entablar la disputa con Buenos Aires y su prensa, desde fundamentos políticos de corte reaccionario, disruptivos en relación al discurso y las

\footnotetext{
${ }^{1139}$ Fernández Sebastián, J., "Liberalismos nacientes en el Atlántico iberoamericano: "liberal" como concepto y como identidad política, 1750-1850", Anuario de Historia de América Latina (JbLA) No. 45, Alemania, 2008, pp.164-165.
} 
medidas concretas que emanaban desde las Cortes, y aún más si los comparamos con los que se difundían desde la prensa liberal gaditana.

El enfrentamiento en la Península entre los sectores liberales y absolutistas en torno a la soberanía de la nación y las atribuciones monárquicas, tuvo entonces su variante en el espacio rioplatense en los debates entablados a través de la prensa entre revolucionarios y lealistas, mediados en este caso por otras discusiones que en algunos casos se impusieron y en otros se solaparon: por un lado, la rivalidad y pretensiones de hegemonía de las ciudades-puerto; y por otro, la dicotomía entre la ruptura autonomista/independentista o la continuidad de la subordinación a la metrópoli de las provincias americanas.

El estudio de la Gazeta de Montevideo, y de sus polémicas con la prensa insurgente porteña, nos permitió tomar nuevamente nota de los vínculos entre el liberalismo hispánico y el movimiento revolucionario rioplatense, reafirmando la necesidad de tenerlo en cuenta para entender aspectos sustanciales del proceso. Como pudimos ver, la nueva prensa política se constituyó en la plataforma de un diálogo trasatlántico donde el lenguaje del liberalismo español circulaba con fluidez, siendo esgrimido, apropiado, resignificado, y muchas veces también objetado, pero siempre ocupando un lugar central en los convulsionados años de las revoluciones hispánicas. 


\title{
Conclusiones
}

\author{
¡Cuántas verdades que hoy son comunes, habrían quizá \\ costado la vida al que imprudente las hubiese publicado \\ en los principios de la revolución española! Estas \\ doctrinas que tan escandalosas eran al común de los \\ pueblos, hoy las vemos erigidas en dogma político y \\ publicadas como leyes fundamentales de su gobierno. \\ Ya todos saben que el único origen de toda autoridad \\ pública es la voluntad de los pueblos, bien estén \\ situados en la antigua Europa como en la moderna \\ América [...] He aquí como sensiblemente se han \\ cambiado las ideas del pueblo español. Ya los \\ americanos, y los europeos, reconocen una misma base \\ a su sistema. \\ Nicolás Herrera \\ Gazeta Ministerial (1812), p. 285.
}

La historiografía ha comenzado a dar cuenta del rol determinante que el liberalismo peninsular tuvo en el ideario que acompañó el proceso americano desde 1808, aspecto llamativamente soslayado por las historiografías nacionales latinoamericanas. Construidas sobre las premisas lanzadas desde los flamantes estadosnación, negaron cualquier relación de las independencias con el proceso revolucionario peninsular y sus ideas a fin de construir un relato "nacionalista" que acentuara la idea de ruptura total con el pasado hispánico. Salvo algunas excepciones, recién en las últimas tres décadas podemos apreciar que se empezó a valorar al liberalismo hispánico y a aquellas "doctrinas escandalosas" de las que hablaba el montevideano Herrera, como factores significativos para entender el proceso de emancipación americana.

Igualmente, a lo largo de la tesis creemos haber demostrado que las ideas, conceptos y lenguajes articulados alrededor del reformismo ilustrado español y del liberalismo hispánico, éste último en pleno proceso de gestación, fueron capitales en el proceso revolucionario rioplatense como herramientas no solo para entender la realidad sino fundamentalmente para transformarla. Y que además de un lenguaje común, existió 
también una práctica política y una sociabilidad similar a ambos lados del atlántico; aunque en ocasiones, producto de las dinámicas particulares de cada proceso, adquirieran significaciones y usos divergentes.

Pudimos observar como el reformismo ilustrado español tuvo un papel destacado en la formación intelectual, a través de medios formales e informales, de varios de los que serían dirigentes de primer plano de la revolución en el Rio de la Plata. Cuando todavía no soplaban vientos revolucionarios ni independentistas, tanto en los recintos universitarios como en las tertulias y otros ámbitos de sociabilidad generados alrededor de la vida estudiantil, la crítica al sistema colonial y los planteos de reformas del reino fueron ganando en intensidad y adeptos. En ese sentido destacamos por ejemplo los vínculos establecidos en el medio salamantino entre Manuel Belgrano con letrados reformistas españoles como Ramón de Salas y Muñoz Torrero; compartiendo similares experiencias por esos años con futuros dirigentes liberales peninsulares como Manuel Quintana. O el contacto de Mariano Moreno con uno de los juristas pioneros en el cuestionamiento a las relaciones entre la metrópoli y sus colonias como fue el aragonés Victorián de Villava.

La Ilustración española corría con ventaja entre los americanos, sobre otras variantes europeas, por ofrecer una versión de las reformas más atenta a las condiciones particulares de la monarquía hispana. La presencia de los ilustrados españoles en las bibliotecas de los letrados y en los periódicos rioplatenses era una clara prueba de ello. Los planteos tanto de Jovellanos como de Campomanes, Foronda y otros ilustrados, como pudimos ver, partían de la necesidad de sacar a España y el conjunto del Imperio del atraso en el que se encontraba y recuperar la grandeza perdida. Misma preocupación compartida por las élites americanas. La novel prensa porteña se constituyó entonces como la plataforma donde la incipiente élite letrada rioplatense vehiculizó los debates y problematizaciones sobre la realidad socioeconómica del virreinato, y las posibilidades y opciones para transformarla. Con el contexto cultural hispánico de trasfondo, se produjo la incorporación de ciertos contenidos generales de la ilustración europea, y en particular la peninsular, a través de una receptividad que era a la vez un claro proceso de adaptación reflexiva. En ese sentido, pudimos dar cuenta del proceso selectivo y de adecuación realizado por éstas sobre el pensamiento económico europeo, y particularmente español, de acuerdo a la percepción de las condiciones culturales y socioeconómicas que operan en el plano local. Con una burguesía débil -en algunos casos, prácticamente inexistente- que cumpliera el papel de clase dirigente de la 
modernización capitalista, tanto en la península como en América, se buscó que fuera el Estado borbónico el que se pusiera a la cabeza del proceso de trasformaciones sociales y económicas, en pos de recuperar el tiempo y el terreno perdidos. Los economistas ilustrados rioplatenses fueron convenciéndose que el juego automático de las fuerzas económicas no aseguraba la realización de sus ideales políticos ni éticos; y aunque inicialmente confiaron en que el gobierno virreinal iba a tomar las medidas modernizadoras reclamadas, formando parte muchos de ellos en su calidad de escritores-funcionarios de los aparatos de gobierno o de políticas emanadas de la corona, la realidad es que esto si sucedió fue a cuentagotas, provocando frustración y desencanto en los ilustrados rioplatenses. Como ejemplo paradigmático de aquello, abordamos el infructuoso intento de establecer una Sociedad Económica en el Rio de la Plata. Entendemos que en estos desengaños radica una de las razones, entre otras, que explican que en el marco de la crisis monárquica varios de ellos buscaran replantear los términos de la relación con la metrópoli.

En el contexto de la revolución hispánica, donde la península se constituyó en un primer momento en el epicentro político e ideológico del proceso, pero donde conjunto del mundo hispánico reaccionó inicialmente ante la crisis dinástica y el enemigo exterior como una comunidad extraordinariamente homogénea, pudimos observar la circulación de escritos, procedentes en su mayoría de España, y difundidos vigorosamente en América, contribuyendo a la conformación de una conciencia pública y una movilización de voluntades en la línea de tensión que la etapa marcaba. Sobre la base de una formación jurídica común, al mismo tiempo que llegaban la noticias de los sucesos, el contenido doctrinario de estos papeles -sean proclamas, manifiestos o periódicos- producía un (re) descubrimiento y (re) elaboración de lenguajes e ideas, algunas más novedosas y otras no tanto, pero rescatadas desde una nueva perspectiva que la coyuntura demandaba. Términos como "reforma", "abusos", "constitución" comenzaron su recorrido para volverse no sólo habituales sino centrales en el lenguaje político de la época. De aquí en adelante estas nociones, como vimos, fueron asociándose a otros conceptos y adoptando diversos sentidos de un lado del Atlántico y del otro, expresando de esa manera el distanciamiento que el proceso revolucionario iba tomando en ambas orillas. Este vocabulario reformista, que fue ganando cada vez más lugar en las proclamas peninsulares, tuvo su correlato en el Río de la Plata enarbolado por distintos grupos que en el bienio 1808-1809, detrás del carlotismo o el juntismo localista, también buscaron impulsar una serie de medidas que terminarían con lo que 
ellos consideraban situaciones de "abusos" e "injusticias", de realidades enquistadas en el régimen colonial desde hacía mucho tiempo. Había allí un terreno compartido de lenguajes antidespóticos.

Frente a la naturaleza inédita de la crisis monárquica, en realidad no era posible encontrar una respuesta jurídica única y legítima, una que se revelara más ajustada a la supuesta constitución fundamental del reino. Todo era materia de debate y los argumentos jurídicos se fueron politizando cada vez más. Con respecto al carlotismo, aunque esta variante legitimista se encontraba muy alejada de la idea de soberanía popular que enarbolarían durante los primeros años revolucionarios, era clara la intención de los ilustrados criollos de que la regencia de la Infanta fuera el instrumento desde el cual redefinir los vínculos entre la metrópoli y las colonias para alcanzar de esa manera un mayor grado de autonomía y autogobierno, y poder impulsar las reformas que venían anhelando, discutiendo y publicitando desde hacía ya varios años.

Escritos como la Memoria enviada a Carlota contenían vocablos que se repetían en los impresos y lenguajes que circulaban en el imperio transoceánico desde fines del siglo XVIII, como abusos, opresión, injusticia pero que con la crisis habían sido actualizados y resignificados. El problema de la representación y soberanía nacional comenzaba a tensionar al conjunto de lenguaje político, otorgándole otros sentidos a conceptos antes asociados a fundamentos tradicionales. Uno de los ejemplos que pudimos ver de estas transformaciones es el planteo de una convocatoria a Cortes del reino, realizado también los carlotistas, como mecanismo para la reforma de la monarquía. Que a pesar de los diversos objetivos que perseguían, constituye uno de los puntos en común que podemos establecer entre los reformistas tanto de un margen del Atlántico como del otro.

En relación a los levantamientos juntistas americanos producidos en 1808 y 1809 , en gran parte justificados por sus promotores como respuestas a las supuestas maquinaciones del virrey con franceses, portugueses o independentistas, pudimos detectar la coexistencia de discursos divergentes, aunque no antagónicos, que delatan la presencia de otro tipo de motivaciones y nos hablan de movimientos mucho más complejos como para encasillarlos livianamente. Poniendo el foco en los objetivos de nuestra investigación pudimos ver como algunos letrados montevideanos se apropiaron del discurso "renovador" del proceso abierto con las abdicaciones y legitimaron el paso dado desde argumentos que hacían eje en la igualdad entre europeos y americanos para resolver el vacío de poder y dar una salida a la crisis que tuviera en cuenta la reasunción 
de la soberanía por parte de los pueblos. O en referencia al frustrado levantamiento del 1 de enero de 1809, las representaciones del Cabildo de los meses previos dejaban traslucir un malestar hacia el gobierno virreinal articulado también a través de expresiones como "derecho de los pueblos", "felicidad de la nación”, “déspotas y mandones", abogándose por una absoluta "regeneración" en el gobierno de América. Todos ellos conceptos que como venimos analizando formaban parte del lenguaje político que con gran fuerza había irrumpido en el imperio hispánico a partir de la crisis. Y aunque al igual que la Junta montevideana, la asonada se trató en esencia de una reacción de la élite colonial para mantener sus posiciones y posesiones en medio de la crisis reinante, no significa esto que algunos de sus protagonistas no buscaran a la vez modificar aspectos de la relación con la metrópoli, quizás mayores grados de autonomía. Ambos objetivos no eran necesariamente contradictorios.

En los levantamientos altoperuanos, que también en la mayoría de sus proclamas se justificó como reacción al carlotismo de las principales autoridades virreinales, vemos nuevamente como el lenguaje característico del juntismo hispánico aparece con fuerza en algunos de sus documentos, asociado a la denuncia del estado de "despotismo y tiranía" vivido en América durante los últimos "tres siglos" bajo el "yugo" de un “usurpador injusto". En el manuscrito de Monteagudo o la proclama de la Junta tuitiva de La Paz sorprende la contundencia de las expresiones elegidas para describir la dominación española, de un grado inédito hasta ese momento en los manifiestos americanos. Y es destacable que, aunque no se haga referencia a un fin independentista, los objetivos autonomistas del movimiento quedan muy claros, expresando las expectativas del sector más radicalizado del proceso, por más que no sea extensible al conjunto de los grupos que impulsaron y se vieron comprometidos con el movimiento juntista. La radicalidad de las definiciones a las que nos referíamos y la participación de varios destacados personajes que luego continuarán su trayectoria revolucionaria en las guerras de independencia, nos llevaron a identificar en el juntismo altoperuano, y sobre todo en la junta paceña, elementos precursores del movimiento juntista americano que se desataría en la primera mitad de 1810. Esta interpretación, que da cuenta de la complejidad del proceso que vivió toda la región rioplatense entre 1808 y 1810 , y que ve en la emergencia de las juntas la cristalización y confluencia de tendencias muchas veces antagónicas, se distancia tanto de la interpretación tradicional de ver al juntismo altoperuano como el primer grito independentista americano, como de la interpretación 
historiográfica actualmente dominante de reducirlo solo a disputas y recelos entre esferas de poder locales en búsqueda de mayor autonomía.

Con respecto los decretos del 22 de enero y del 6 de octubre de 1809 de la Junta Central para la convocatoria a diputados americanos al gobierno metropolitano, identificamos la significativa participación de tres rioplatenses en los antecedentes más directos a su elaboración, llegando a la conclusión que lograron dejar una huella en la consideración de los juntistas peninsulares sobre el problema americano. Es probable que el tono moderado de las reformas y la vocación de unidad que destilaba sus informes favorecieran su recepción. En relación a la aplicación de estos decretos en el Rio de la Plata, discutimos la tesis de Guerra sobre la relevancia de su impacto, no sólo porque en ninguna ciudad del virreinato rioplatense se puede verificar un proceso electoral de "alta intensidad", sino que por el contrario lo que se percibe es, en algunos casos, una ejecución lenta y casi desganada, de mero cumplimiento administrativo, y en otros, como en la propia capital virreinal, que ni siquiera se llegaron a implementar.

Otro de los documentos capitales para comprender la coyuntura previa al estallido revolucionario rioplatense y poder observar el proceso de maduración y readecuación que las ideas ilustradas estaban sufriendo en el marco de la crisis monárquica es la Representación de los Hacendados de Moreno. Pudimos tomar nota de cómo el letrado recurrió a los pensadores españoles como Foronda, Villava o Jovellanos, tal como habían hecho sus compatriotas ilustrados en los periódicos fini-coloniales. También a otros menos reconocidos, pero más vinculados al liberalismo peninsular, como Julián Negrete. Importante también es la recepción en el alegato de la llamada "Escuela Napolitana", en particular del jurista y economista Filangieri. Recepción que debe encuadrarse en ese momento bisagra en el que fue escrita la representación, donde el abogado acude a la concepción jurídica iusnaturalista del napolitano y a sus críticas concretas a la legislación comercial entre España y América.

Y a pesar que con este alegato un sector de la historiografía quiso presentar a Moreno como un abanderado del librecambismo más ortodoxo, por otros escritos del autor y por algunas de las disposiciones de la Junta Provisional Gubernativa, consideramos que el futuro secretario no se distanciaba mucho en su pensamiento económico de las posiciones que sus compatriotas ilustrados, como Belgrano y Vieytes, venían sosteniendo en la última década. Ninguno de éstos deseaban para el Río de la Plata un futuro exclusivamente ganadero, ni esperaban que la Corona les asignase únicamente el rol de productor de materias primas. Los economistas criollos seguían 
manteniendo, al igual que muchos de los reformistas peninsulares, la convicción de que era el Estado el principal actor que debía intervenir sobre la realidad social para provocar o permitir las transformaciones necesarias en el camino de racionalización económica y social anhelada.

Hace un tiempo, el historiador Luis Alberto Romero escribía en el diario argentino Clarín: “quienes actuaron en 1810 no querían hacer una 'revolución', sino encontrar una respuesta rápida y práctica a un imprevisto suceso metropolitano: el derrumbe de la monarquía hispana". ${ }^{1140}$ No se trata por cierto de la primera formulación en este sentido, y aunque con matices, este postulado tiene asidero en otros trabajos historiográficos argentinos. Según estas interpretaciones es la crisis metropolitana, y el vacío de legitimidad y poder que deja en cada capital virreinal, la que desata la competencia entre los presuntos herederos del poder vacante, tanto españoles como criollos, sin importar los proyectos políticos y sociales que eran defendidos, ni las voluntades de transformación o preservación del statu-quo. Volviendo a citar a Romero en otro artículo del mismo diario publicado uno años después: "hace tiempo que los historiadores profesionales, los historiadores en serio, vienen criticando esta explicación. Coinciden en que los sucesos de Mayo de 1810 no fueron fruto de un plan previo sino la imprevista consecuencia de un evento lejano: el derrumbe del imperio español luego de la invasión napoleónica. En Buenos Aires, como en cada ciudad importante de Hispanoamérica un grupo de vecinos se hizo cargo del gobierno, de manera provisoria, sin saber para quién ni contra quién (...) Esto pensamos hoy los historiadores". ${ }^{1141}$ Ante la vacancia real, lo que se protagonizó entonces fue una oportunista disputa por ocupar el poder político, sin aspiraciones trascendentes ni ideologías detrás. En esta tesis creemos que estamos, desde los particulares y modestos objetivos de nuestra investigación, demostrando lo contrario.

Los que llevaron adelante la revolución, fundamentalmente su ala más radical, entendían por sobre todas las cosas que ésta debía ser un acto de restauración de la libertad. Se trataba de algo mucho más trascendente que un cambio institucional, la revolución debía transformar a la sociedad haciéndole conocer al pueblo sus verdaderos derechos y así conquistarlos. Ignacio Núñez en sus memorias diría sobre esto: "El verdadero espíritu de la revolución era el de libertarse de la opresión de los antiguos mandones coloniales y ponerse en estado de gozar las ventajas de un gobierno civil, o

\footnotetext{
${ }^{1140}$ Romero, Luis Alberto: "Un origen preciso", en Clarín, 25 de mayo de 1998.

${ }^{1141}$ Romero, Luis Alberto: "Una brecha que debe ser cerrada”, en Clarín, 24 de mayo de 2002.
} 
como decía el doctor Moreno, en suma, el de destruir los tiranos sin dejar en pie la tiranía". El propósito de los revolucionarios era dictar "leyes que protegiesen los derechos de hombres libres en lugar de leyes de Indias que los anatemizasen, tolerancia en lugar de inquisición...",1142

Despojándose de a poco de la carga negativa que el concepto había tenido tradicionalmente, la revolución comenzaba a adoptar un cariz positivo convirtiéndose en una inédita y eficaz fuente de legitimidad política que expresaba la posibilidad de profundos cambios de orden político, social moral y cultural. Fue asociándose a otros conceptos como patria, libertad, independencia y justicia y ligándose a su vez a nociones como redención y regeneración, era concebida por los protagonistas como un proceso providencial casi en términos escatológicos, y necesario en clave secular desde el marco de las leyes del progreso de las filosofías ilustradas. ${ }^{1143}$ La revolución fue a su vez, como señala Carozzi, la conciencia de la inalienabilidad de los derechos, "la conciencia del natural derecho a tener derechos, asumida en clave libertaria". 1144

Que la revolución no fuese evidentemente consecuencia de un "proyecto independentista" compartido por el conjunto del bloque que desplazó a Cisneros, o que no expresara la materialización de una preexistente nacionalidad argentina, o que no alterara las relaciones de producción del virreinato, no significa que debamos despojarle su significación como hecho altamente disruptivo en el plano de lo político; cristalizador y movilizador de manifiestas y potentes voluntades transformadoras. Más allá de cierto grado de espontaneísmo, que toda revolución que se precie posee, ésta había sido preparada y tenía a un heterogéneo conjunto de promotores detrás. La confluencia del grupo civil, que había ganado su prestigio no solo por la participación de varios de ellos como milicianos, sino de su veteranía en tratar de organizar círculos de opinión para enfrentar las alternativas que la crisis imperial y ofrecer soluciones y rumbos a tomar, de fuertes convicciones reformistas y en algunos casos radicales; con los oficiales al mando de cuerpos milicianos urbanos, habían inclinado finalmente la balanza, cuando la coyuntura local e internacional lo permitió, para el desenlace revolucionario. $^{1145}$

\footnotetext{
${ }^{1142}$ Nuñez, I, Noticias Históricas, citado en Lewin, B., "Jacobinos y Moderados en Vísperas de Mayo", Trabajos y Comunicaciones No 9, La Plata, 1960, p. 222.

${ }^{1143}$ Wasserman, F., "Revolución" en Goldman, N., Lenguaje y Revolución, Conceptos políticos clave en el Río de la Plata, 1780-1850, Buenos Aires, Prometeo, 2008, pp. 162-163.

${ }_{1144}$ Carozzi, Silvana, óp. cit., p. 52.

${ }^{1145}$ Halperín Donghi, T., Revolución y guerra ..., pp. 217-218.
} 
La movilización popular inaugurada con las jornadas de mayo es inaudita y en varias ocasiones marcaría ciertos rumbos de la revolución. La crisis metropolitana además de generalizar la vigencia de un principio de legitimidad como es la retroversión de la soberanía, un modo de institucionalizarlo como fue el juntismo, y diferentes vertientes ideológicas y lenguajes políticos como el liberalismo, generalizó también un formato de acción colectiva política que tuvo un papel central en la "eclosión juntera" como fueron las experiencias tumultuarias. Como bien refiere Raúl Fradkin "el proceso revolucionario aparece signado a ambos lados del atlántico por estas nuevas formas de acción colectiva popular, pero que a su vez adquieren necesariamente caracteres locales debido a la heterogeneidad étnica y cultural de los distintos conglomerados populares y al entrelazamiento con tradiciones de movilización preexistente". ${ }^{1146}$ Aun limitada, la politización popular fue un hecho rico en consecuencias, más allá del reparo de la dirigencia revolucionaria en que se les fuera de las manos. El avance del sentimiento igualitarista, fogoneado por un sector de la minoría letrada revolucionaria, junto con el patriotismo, serán las dos fuentes más destacadas de la participación y politización popular. $^{1147}$

Como advertimos, esta tesis no se planteó ofrecer una nueva mirada sobre los fundamentos esgrimidos durante el cabildo abierto del 22 de Mayo. Ni terciar en la vieja polémica si pesó más Rousseau o Suárez en las concepciones de los juntistas. Creemos que es un debate que no tiene sentido y ya ha sido suficientemente superado por la historiografía. Allí están los trabajos de Chiaramonte y Goldman, que complementados, constituyen una adecuada síntesis a la que adherimos. Tanto la persistente noción de consentimiento, como las novedosas de voluntad general y opinión pública tuvieron su trascendencia a la hora de justificar la erección de la Junta. En nuestro caso preferimos poner el acento, de acuerdo a los objetivos de la tesis, en el uso dado por los revolucionarios de mayo a lo sucedido en Cádiz ante la caída de la Junta Central, a pesar de sus diferentes y contradictorias versiones, en particular a la proclama de la junta gaditana de fines de febrero de 1810. Pudimos ver lo importante que fue su uso por parte de los movimientos juntistas en otras capitales americanas. Y a pesar de que el ejemplo de la Junta de Cádiz no fue invocado por Castelli ni figuró en las actas del 25, por ser demasiado inconveniente, ya que en definitiva aquella llamaba a reconocer al

\footnotetext{
${ }^{1146}$ Fradkin, Raúl, "La acción colectiva popular en los siglos XVIII y XIX: modalidades, experiencias, tradiciones", Nuevo Mundo Mundos Nuevos [En línea], Debates, 2010.

${ }^{1147}$ Halperín Donghi, T., Revolución y guerra..., pp. 175-179.
} 
Consejo de Regencia, tras la “intervención selectiva” realizada por Moreno al publicar parte de la proclama en la Gazeta, la Junta y "la regla de Cádiz" pudieron ser utilizadas por los revolucionarios a favor de su propia causa. Finalmente consideramos que el manifiesto de la Junta de Cádiz, tuvo su impacto en América pero no con la intención última que contenía, el llamado a reconocer al Consejo de Regencia, si no que fue la explicación de porqué se pudo formar la Junta gaditana lo que terminó prosperando. Paradójicamente, los revolucionarios americanos terminarían tomando como modelo para la erección de sus propios gobiernos a aquel que expresaría como nadie la intransigencia metropolitana a las reivindicaciones americanas.

Hemos visto como el juntismo americano se inspiró en su homólogo peninsular y que además buscó legitimarse planteándose como parte de un mismo movimiento que daba respuesta a un mismo problema, la "vacatio regis", y que expresaba la reivindicación de los mismos derechos. En esta investigación hemos puesto el foco en el uso que dieron los rioplatenses a las experiencias juntistas peninsulares que tuvieron contradicciones con la autoridad máxima, sea ésta la Junta Central o el Consejo de Regencia. Además de la junta gaditana recién mencionada, el otro ejemplo al que se recurriría en varias ocasiones es el de la Junta Valenciana y sus posturas autonomistas y federalistas.

La herencia peninsular también se puede observar en las pautas elegidas por el primer gobierno criollo para el proceso electoral, que fueron tomadas de las dictadas por la Junta Central y el Consejo de Regencia para elegir diputados americanos a la mencionada Junta y a las Cortes, respectivamente, entre comienzos de 1809 y comienzos de 1810. Además de la homologación de la ciudadanía política con la condición de vecino, la tipología electoral compartida se definía en razón del reconocimiento del derecho de representación a las "provincias" en los máximos órganos políticos, y la atribución a los cabildos de la ejecución y control del acto. El sistema electoral ideado por Castelli para el Alto Perú por ejemplo contemplaba también tres grados y era similar al que la Junta Central había diseñado dos años antes para que los americanos eligieran a sus representantes a las Cortes.

En los artículos de Moreno en la Gazeta podemos percibir como se fue produciendo la radicalización del proceso político a partir de la una serie de deslizamientos de sentido en ciertos enunciados, y de la aparición de otros como efecto de coyunturas determinadas. En la famosa serie de artículos conocida como Sobre las miras de un congreso el secretario realiza un desplazamiento en el plano teórico del 
pacto de sujeción para reemplazarlo por un nuevo contrato de sociedad basado en la soberanía popular. Develando gradualmente una concepción cada vez más radical de lo que entiende por soberanía, la va asociando indefectiblemente a la voluntad general del pueblo. Siendo la soberanía indivisible e inalienable. Similar concepción de la soberanía que la del autor de "Pensamientos de un patriota español", que también entendía que no era otra cosa que "el ejercicio de la voluntad general", que residía siempre en el pueblo, tanto como que es la fuente de donde dimana.

A lo largo del escrito Moreno no deja de destacar el fenómeno inédito que estaba viviendo la península, donde "pululaban escritos llenos de ideas liberales, en los que se sostenían los derechos primitivos de los pueblos". Es recurrente la idea en Moreno de que la revolución viene a recuperar libertades, derechos y saberes perdidos u olvidados, tratando de nunca presentarlos como novedosos sino que habían estado negados por el despotismo reinante de los últimos tiempos. Ese es justamente un rasgo en común sobre todo con los reformistas ilustrados pero también con los liberales peninsulares, formados en el pensamiento del constitucionalismo histórico, o con aquellos que buscaban introducir nuevos conceptos y prácticas pero bajo una pátina de tradicionalismo. Sin embargo, como dijimos, el problema en Moreno es que, al descartar a las Leyes de Indias como un código político válido no tiene, a diferencia de los constitucionalistas peninsulares, desde donde recuperar la tradición para poder aggionarla a los nuevos tiempos. Para el secretario y el proceso rioplatense, la potencia creadora del poder constituyente del congreso a convocarse, estaba en primer plano a la hora de pensar qué constitución y para qué nación.

Consideraba una ventaja para la América que la necesidad haya hecho adoptar en España aquellos principios liberales, "pues al paso que empezaron a familiarizarse entre nosotros, presentaron un contraste, capaz por sí solo de sacar a los americanos del letargo en que yacían tantos años". Contundente afirmación del impacto que el lenguaje de la revolución española había tenido en América. En este pasaje del artículo en particular, Moreno va a hacer referencia a los escritos de "un abogado de Cádiz" -José Manuel de Vadillo- y a "un sabio de Valencia" -José Cangas Argüelles-, justamente aquellas ciudades donde sus juntas provinciales tuvieron grandes contradicciones con el gobierno central.

Moreno, como Monteagudo y San Martín, entendían a la revolución americana dentro de un proceso de carácter universal, que incluía también a la lucha que estaban dando los liberales en la península, un largo combate de la libertad contra la tiranía y el 
despotismo. Pero todos ellos entendían que España ya había agotado sus fuerzas, acechada por enemigos internos y externos, había sucumbido en sus propias contradicciones; tocaba ahora el turno a la América, madura ya para terminar la obra que habían comenzado sus hermanos europeos. Esa fue una de las principales motivaciones que llevó a San Martin a abandonar la península y sumarse a la lucha de los insurgentes americanos, convencido de que en esas trincheras se estaban dando las batallas decisivas por la causa de la Libertad, que ya en España parecían perdidas. Formado en el medio intelectual y cultural peninsular, de convicciones reformistas y moderadas, San Martín, como Vicente Pazos Silva, y tantos otros como seguramente también Belgrano y Funes, consideraban que el monarquismo constitucional representaba la mejor opción para pensar un gobierno para los pueblos americanos. Recordemos que la alternativa carlotista abrazada por muchos dirigentes criollos durante el bienio de 1808-1809 se inscribía en ese modelo de monarquía constitucional.

San Martín pudo ser testigo directo en Cádiz de las contradicciones de un liberalismo español que, a la par que iba avanzando en determinadas transformaciones, no aceptaba modificar realmente la relación con América. Consideramos que el problema americano significó el aspecto de mayor contradicción teórica e ideológica para el naciente liberalismo peninsular. El radicalismo con que éste buscaba transformar la sociedad española no era transferible a América, salvo en el plano de lo simbólico. Los innovadores peninsulares no estaban dispuestos a extender los cambios que en materia de libertades se estaban alcanzando a las posesiones ultramarinas, a riesgo de perder los privilegios históricos gracias a los cuales había hecho usufructo de ellas la metrópoli imperial. Fuertes intereses económicos del grupo social del cual muchos de ellos provenían o al cual estaban ligados por redes familiares o profesionales estaban en juego, sin descartar el marco de mentalidad colonialista -que por ilustrada y filantrópica no lo era menos-, en el que estaba sumergida todavía aquella generación. Estas ambigüedades teóricas resultantes de un liberalismo aún en gestación, interactuando con los condicionantes ejercidos por los intereses económicos de las elites comprometidos en el proceso, son el marco desde donde creemos poder explicar las contradicciones en las que cayó sistemáticamente el primer liberalismo peninsular en relación a la «cuestión americana», y seguramente una de las razones de su fracaso en lograr preservar la integridad de la monarquía hispánica.

Una de las claves desde la cual pudimos percibir los intercambios entre las elites dirigentes de ambos espacios es la cuestión de la libertad de imprenta, central en el 
imaginario del liberalismo hispánico. A los ya conocidos vínculos entre el escrito de Moreno con el texto de Foronda o entre los reglamentos de la Junta Grande y el decreto de las Cortes de Cádiz, nuestra investigación arrojó nuevas evidencias, como por ejemplo que el artículo sobre la libertad de prensa publicado por Belgrano en agosto de 1810 no pertenece a su pluma sino que realidad es una copia textual e íntegra de un artículo que bajo el mismo título fue publicado en el primer número del periódico sevillano El Voto de la Nación española del 13 de diciembre de 1809. Reforzando todavía más el cuadro de la destacada circulación de escritos políticos y doctrinarios de origen hispánico. Pero como pudimos observar con la publicación por parte del sevillano Blanco White en El Español del decreto rioplatense, esa circulación -como la misma palabra lo sugiere- no era unidireccional, desde Europa hacia América, como por mucho tiempo sostuvo la historia de ideas tradicional. Existía un ida y vuelta constante que cruzaba el Atlántico, sin negar por eso las evidentes asimetrías establecidas por el lugar de centro y periferia que ambas orillas ocupaban, en el gran conjunto que constituía el mundo hispánico.

Aun no habiendo reconocido a las Cortes en ningún momento, la relación de la dirigencia rioplatense con respecto a ella tuvo sus bemoles. Con la llegada del Primer Triunvirato se inauguró una etapa más conciliadora que se mantendría sin grandes modificaciones hasta la sanción de la Constitución de Cádiz. Se atenuaron las críticas en la prensa oficial, se estableció un discurso menos combativo y hasta se publicaron con mayor frecuencia fragmentos de las sesiones durante lapso. Al conocerse las noticias de la promulgación de la constitución gaditana, el Triunvirato la rechazó públicamente abandonando su tibia postura ante las Cortes. Con la Logia en el poder, tras el golpe de octubre, este enfrentamiento se agudizaría, buscando avanzar hacia un congreso constituyente propio que, además de dar una constitución a las provincias rioplatenses, declarara finalmente su independencia.

Comparando el proceso de convocatoria a los congresos constituyentes pudimos observar que existió una fuerte pugna entre los sectores moderados y radicales en ambos escenarios. Tanto los liberales peninsulares como la facción revolucionaria porteña debieron enfrentar las resistencias que, los reformistas y conservadores para el caso metropolitano o el moderantismo del Primer Triunvirato, ofrecieron para la instalación de un congreso de carácter constituyente. En la península la disputa se dio hacia el interior mismo de la Junta Central y sus Juntas dependientes, resolviéndose recién a favor de los liberales cuando en el marco de una Cádiz convulsionada por la llegada de 
miles de patriotas refugiados por el avance francés, las ideas más revolucionarias tuvieron el contexto propicio imponerse.

Aun en momentos donde el timón de la revolución rioplatense era tomado por los sectores más radicales y abiertamente favorables a una salida independentista al proceso, el ejemplo peninsular siguió siendo valioso como guía, y no se dudó en "tomar prestada" su rica elaboración discursiva y doctrinaria. Y justamente fueron éstos, convencidos de que ya no era necesario justificar el camino autónomo, los que se sintieron más libres para reconocer en el "enemigo" los avances en términos de libertades. Varios artículos de Monteagudo, como hemos podido ver, dan prueba de aquello. Asimismo, a partir de la comparación de los documentos hemos detectado, en un nuevo aporte inédito de nuestra investigación, que el decreto del Segundo Triunvirato de convocatoria a la Asamblea Constituyente fue en gran parte una adaptación de aquel manifiesto de la Junta Central del 28 de octubre de 1809 que establecía la convocatoria a las Cortes extraordinarias.

En el marco de una misma cultura constitucional hispánica, que se consolidó entre 1808 y 1824, la labor legislativa de las Cortes y fundamentalmente la Constitución doceañista pusieron a disposición de los rioplatenses un nuevo lenguaje constitucional que representó, por un lado, la posibilidad de dotarse de útiles herramientas políticojurídicas para promover los cambios que ambicionaban, pero que a su vez generó fuertes tensiones y contradicciones, en pleno proceso de emancipación de las antiguas colonias americanas. La Constitución de Cádiz sirvió como fuente, como hemos visto, para las legislaciones y proyectos constitucionales que estuvieron en discusión en los primeros años de camino propio de las Provincias Unidas del Rio de la Plata. Puso a su disposición una gramática jurídica que presentaba importantes ventajas para ser asimilada y adaptada por las élites americanas. Pero poco a poco comenzó a ser remplazada por otras fuentes que fueron ganando terreno a medida que la ruptura total con la "Madre Patria" iba confirmándose.

La recepción de los artículos de Blanco White en la prensa rioplatense fue otro de los aspectos más destacados en los intercambios existentes entre Europa y América durante el período y su recorrido estuvo determinado por las características de la coyuntura política general y las variaciones en las relaciones de fuerza entre las facciones que se disputaban el poder en el Rio de la Plata. Si mientras estuvo Moreno al frente el sevillano no tuvo lugar en la Gazeta debido a la insistencia de éste en buscar la conciliación entre España y América, con la llegada del Deán Funes y luego Pedro de 
Agrelo como editores, respondiendo a una estrategia más moderada, los artículos de $E l$ Español se volverían habituales, sirviendo para establecer una crítica a la metrópoli que no terminaba de apuntar a una ruptura. Asimismo se buscaba con sus artículos ganar a los españoles europeos radicados en Buenos Aires y Montevideo a la causa juntista.

Pazos Silva, tanto desde la Gazeta como desde El Censor, fue quién mayor lugar le dio a los escritos del sevillano, en algunos casos citándolo en otros haciéndolos pasar como propios, utilizándolos fundamentalmente en su disputa con el referente de la facción revolucionaria, Monteagudo. Las recurrentes condenas de Blanco White a la deriva independentista y republicana que según él estaba adoptando el proceso americano, sumadas a su concepción cada vez más elitista en términos políticos y sociales, fueron usadas por Pazos Silva en sus polémicas con el líder de la Sociedad Patriótica. La insistencia por parte de Blanco White en la unidad del imperio hispánico, sus críticas cada vez más recurrentes al rumbo que iba tomando la revolución en Caracas y Buenos Aires, llevó finalmente hacia mediados del año XII a un distanciamiento hacia el publicista sevillano de la dirigencia porteña. Ya con la Logia Lautaro en el poder, buscando profundizar nuevamente el rumbo de la revolución, en un primer momento ese distanciamiento se profundizaría, siendo involucrado en el debate local en muy contadas ocasiones y siempre para discutir con sus planteos de “independencia moderada" bajo protección británica. Pero cuando la facción revolucionaria vaya perdiendo sus bríos independentistas y sus aristas más radicales, atravesados ya por el conflicto con la "democracia bárbara" que para ellos expresaba el artiguismo, los herederos del morenismo paradójicamente recurrían a los artículos de $E l$ Español, a ese Blanco White cada vez más conservador, para justificar el rumbo moderado que iba adoptando la Logia bajo la conducción alvearista.

Si el pensamiento revolucionario rioplatense había sido más radical que el peninsular, por lo menos en su variante morenista, con claras tendencias hacia un sistema republicano de gobierno y con un impulso igualitarista mucho más marcado, a partir de 1814, justo cuando en España era restaurado Fernando VII, la deriva conservadora que fue sufriendo lo terminaría acercando a sus pares españoles, en esos momento duramente perseguidos por la reacción absolutista. Claramente el cambio en la coyuntura local y el contexto internacional, marcado por el Congreso de Viena, había incidido mucho más en este viraje que la recepción de autores y libros de corrientes ideológicas contrarrevolucionarias. 
El análisis de la Gazeta de Montevideo, una fuente poco trabajada hasta el momento por la historiografía argentina, nos posibilitó completar el panorama del debate político e ideológico en el Rio de la Plata, rompiendo de esa manera con los acotados marcos que imponen las "historias nacionales" y sus restricciones. Nos permitió observar como determinados discursos tenían posibilidades de echar raíces en los territorios lealistas americanos y cuáles debieron imponerse a fuerza de los cambios políticos y jurídicos emanados desde Cádiz. Los argumentos esgrimidos por Cirilo Alameda, el principal editor del periódico montevideano, no distaban mucho de los sus pares de la prensa absolutista peninsular. Resulta curioso que el editor no haya recurrido a la reproducción de artículos de dicha prensa para reforzar sus posiciones, mientras que por el lado de la insurgencia la publicación de escritos de autores liberales peninsulares fue una práctica bastante corriente. En sus discursos el fraile no sólo apuntó contra los revolucionarios rioplatenses, sino que en varias ocasiones, hubo de salir al cruce de impresiones puestas en circulación por los publicistas liberales sobre la "cuestión americana". Durante gran parte de su trayectoria la Gazeta de Montevideo priorizó entablar la disputa con Buenos Aires y su prensa, desde fundamentos políticos de corte reaccionario, disruptivos en relación al discurso y las medidas concretas que emanaban desde las Cortes, y aún más si los comparamos con los que se difundían desde la prensa liberal gaditana.

Que podamos detectar similares usos y sentidos a conceptos como "libertad", "patriotismo", "nación"; y que existieran numerosas coincidencias entre los puntos programáticos elaborados por la dirigencia revolucionaria tanto en la península como en Buenos Aires, también hace referencia a ese amplio escenario de profundas transformaciones interconectadas. La cultura política y la formación intelectual de las elites americanas no se distanciaron mucho de la de sus pares peninsulares. Una vinculación estrechada en gran medida, por un elemento hasta ese momento inédito en el mundo hispánico: el surgimiento y proliferación de una nueva prensa libre y crítica.

Como hemos querido demostrar, el conflicto abierto con la metrópoli no implicó que ese trasfondo político-cultural común no se expresara a través de similares políticas a ambos lados del Atlántico. En el bienio 1808-1810 la relación había sido fértil en términos doctrinarios entre los promotores del cambio político tanto peninsulares como americanos. Pero esta relación comenzó a resquebrajarse ante la intransigencia de la metrópoli hacia los reclamos y aspiraciones americanas, fundamentalmente en referencia a la igualdad de representación, la descentralización política y la 
liberalización comercial. Las actitudes de los liberales peninsulares hacia los asuntos americanos rara vez se diferenciaban del grupo tradicionalista de las Cortes, alejándose del radicalismo con el que buscaban imprimir los cambios en el contexto peninsular. La dinámica del conflicto entre la península y los territorios insurgentes había llevado a estos últimos a radicalizar sus posiciones hacia planteos que tenían a la independencia total como horizonte cada vez más cercano, pero eso no significó que se dejase de tener en cuenta la rica experiencia peninsular como herramientas para poder seguir pensando la realidad rioplatense y encontrar la mejores soluciones a los problemas que la dinámica revolucionaria iba generando.

A lo largo de nuestra investigación hemos detectado una serie de problemas que por excederse de los objetivos que nos habíamos planteado, o por falta de espacio, o por no haber dado con las fuentes indicadas para poder desarrollarlos en profundidad, no han sido trabajados o sólo han sido insinuados en esta tesis. Consideramos que un problema interesante a profundizar, apenas esbozado por nosotros, es la comparación entre las dinámicas que se establecieron entre las distintas variantes de los poderes legislativo y ejecutivo adoptadas tanto en España como en el Rio de la Plata. Marcela Ternavasio ha dado algunas claves en ese sentido y creemos que es un campo fructífero para poder seguir echando luz sobre el proceso y las relaciones entre ambos espacios. Cómo fueron abordados los problemas de la esclavitud o la inquisición por los revolucionarios de cada orilla del Atlántico también nos parecen temas atractivos para un estudio comparativo. Otro aspecto sugestivo, merecedor de mayor desarrollo, es el desenvolvimiento de la contradicción entre el centralismo y el federalismo en cada uno de los espacios y las vinculaciones que se establecieron entre ellos, teniendo en cuenta la centralidad que esta cuestión fue ganando a medida que avanzaba el proceso revolucionario.

En ese sentido, centrada como estuvo esta tesis en la dinámica política de las elites de Buenos Aires, y en menor medida de Montevideo, en una investigación futura se tiene pensado darle continuidad a algunas líneas de esta investigación indagando en el impacto y difusión del liberalismo hispánico en las provincias del interior del Virreinato -fundamentalmente en la Banda Oriental y el norte de las Provincias Unidas, y su relación con la cultura política y la acción colectiva de los sectores subalternos, buscando pautas para la comprensión del origen de los movimientos sociales federalistas que serán protagonistas del conflicto político en la segunda parte de la década. Ese, esperamos, será nuestro próximo paso en este campo de investigación. 


\section{Fuentes}

\section{Memorias y autobiografías}

Alcalá Galiano, Antonio, "Recuerdos de un anciano", en Obras escogidas de D. Antonio Alcalá Galiano, Biblioteca de Autores Españoles, tomo 83, Madrid: Ediciones Atlas, 1955.

Belgrano, Manuel, “Autobiografía del general Don Manuel Belgrano", en Biblioteca de Mayo, Tomo

II, Buenos Aires, Senado de la Nación, 1960, pp. 957-968.

Beruti, Juan Manuel, Memorias curiosas, Bs. As., Ed. Emecé, 2001.

Guido, Tomás, "25 de Mayo de 1810. Reseña Histórica”, en Biblioteca de Mayo, Tomo V, Buenos Aires, Senado de la Nación, 1960.

Moreno, Manuel, Vida y memorias de Mariano Moreno, Librería Histórica, 2004.

Núñez, Ignacio, "Noticias históricas de la República Argentina" en Biblioteca de Mayo, Tomo I, Buenos Aires, Senado de la Nación, 1960.

Quintana, Manuel, Memoria sobre el proceso y prisión de Don Manuel José Quintana en 1814, Alicante: Biblioteca Virtual Miguel de Cervantes, 1999.

Saguí, Francisco, "Los últimos años de la dominación española, en Biblioteca de Mayo, Tomo I, Buenos Aires, Senado de la Nación, 1960.

\section{Periódicos (ordenamiento cronológico)}

Espiritu de los mejores diarios europeos [1789], Madrid, reproducción digital.

Telégrafo mercantil, rural, político-económico, e historiógrafo del Río de la Plata [1801-1802], Buenos Aires, Imprenta de los Niños Expósitos, reproducción digital.

Semanario de Agricultura, Industria y Comercio [1802-1807], Buenos Aires, Junta de Historia y Numismática Americana, Edición facsimilar, 1928, reproducción digital.

El regañón general o tribunal catoniano: de literatura, educación y costumbres [1804], Madrid, reproducción digital.

Semanario patriótico [1808-1812], Madrid-Sevilla-Cádiz, Biblioteca Nacional Española, reproducción digital.

El voto de la Nación española [1809-1810], Sevilla, Imprenta Real, reproducción digital.

El Espectador sevillano [1809-1810], Sevilla, Imp. de Hidalgo, Biblioteca virtual Miguel de Cervantes, reproducción digital.

El Observador [1810], Cádiz, Biblioteca Nacional Española, reproducción digital.

Correo de Comercio [1810-1811], Buenos Aires, Academia Nacional de Historia, reproducción digital. El Español [1810-1814], Londres, Imprenta de R. Juigné, Biblioteca Nacional Española, reproducción digital. 
El Conciso [1810-1814], Cádiz, Biblioteca Nacional Española, reproducción digital.

Gazeta de Buenos Aires [1810-1814], Buenos Aires, reproducción digital.

Gazeta de Montevideo [1810-1814], Montevideo, reproducción digital.

Duende político o tertulia resucitada [1811], Cádiz, Real Biblioteca, reproducción digital.

El Grito del Sud [1812], Periódicos de la época de la Revolución de Mayo, Buenos Aires, Academia

Nacional de la Historia, 1961, reproducción digital.

Mártir o Libre [1812], Buenos Aires, Museo Mitre, reproducción digital.

\section{Otra documentación primaria impresa}

Biblioteca de Mayo. Colección de obras y documentos para la Historia Argentina, Buenos Aires, Senado de la Nación, 1963.

Mayo Documental, Buenos Aires: Imprenta de la Universidad, 1965.

La Revolución de Mayo a través de los impresos de la época. Primera serie, 1809-1815, Mallié

Augusto E. (comp.), Comisión Nacional del Sesquicentenario de la Revolución de Mayo. Buenos Aires, 1965.

Asambleas Constituyentes Argentinas, Ravignani, Emilio, Buenos Aires: Instituto de Investigaciones Históricas, Universidad de Buenos Aires, 1937-39

Documentos para la historia del general don Manuel Belgrano, Instituto Belgraniano Central, Buenos Aires, 1982.

Documentación relativa a los antecedentes de la Independencia de la República Argentina, F.F. y L., Buenos Aires, 1912.

Documentos del archivo de San Martín. Buenos Aires: Imprenta de Coni, 1990.

Documentos del Archivo de Pueyrredón. Museo Mitre. Buenos Aires: Imprenta de Coni Hermanos, 1912.

Moreno, Mariano, Escritos (prólogo y edición crítica de Ricardo Levene), Clásicos Argentinos, Estrada, Buenos Aires, 1956.

Monteagudo, Bernardo, "Diálogo entre Atawallpa y Fernando VII en los Campos Elíseos [1809]." Castañón Barrientos (ed.). La Paz: Empresa Editora Universo, 1974.

Jovellanos, G. Obras publicadas e inéditas, B.A.E. Madrid, 1859.

Rodríguez de Campomanes, P. Discurso sobre el fomento de la industria popular. Madrid: Imprenta de Antonio Sancha, 1774.

----, Discurso sobre la educación popular de los artesanos y su fomento. Madrid: Imprenta de Antonio Sancha, 1775.

Flórez Estrada, Álvaro, Obras de Álvaro Flórez Estrada, B.A.E., Tomo CXIII, Atlas, Madrid.

Argüelles, Agustín de, Examen Histórico de la Reforma Constitucional de España, Junta General del Principado de Asturias, Oviedo, 1999. 


\section{Bibliografía}

Annino, Antonio, et al, De los imperios a las naciones, Zaragoza, Iberoamérica, 1994.

Arata, Nicolás, La enseñanza de oficios mecánicos durante el Virreinato del Río de la Plata (17761810.Buenos Aires: Libros Libres, 2010, Internet.

Arias de Saavedra Alías, Inmaculada, "Las Sociedades Económicas de Amigos del País: Proyecto y realidad en la España de la Ilustración”, Obradoiro de Historia Moderna, núm. 21, 2012.

Artola, Miguel, Los orígenes de la España contemporánea, Madrid, IEP, 1959.

----, «El camino a la libertad de imprenta, 1808-1810», en Iglesias, Carmen; Moya Carlos; Rodríguez Zúñiga, Luis (comp.), Homenaje a José Antonio Maravall, Madrid: Centro de Investigaciones Sociológicas y otras instituciones, 1985.

Astigarraga, Jesús, "Las Sociedades Económicas en Navarra en la segunda mitad del siglo XVIII", Instituto Gerónimo de Uztarriz, núm. 6/7, 1992, pp. 25-78.

----, «Diálogo económico en la 'otra' Europa. Las traducciones españolas de los economistas de la Ilustración napolitana (A. Genovesi, F. Galiani y G. Filangieri)», Cromohs, 9 (2004).

Blanco Valdés, Roberto, “El 'problema americano’ en las primeras Cortes liberales españolas, 18101814”, Cuadernos Constitucionales México-Centroamérica 16, México, Instituto de Investigaciones Jurídicas, 1995.

Bourdieu, Pierre, "Las condiciones sociales de la circulación de las ideas" en Intelectuales, política y poder, Buenos aires, Eudeba, 1999.

Brading, David, Orbe indiano. De la monarquía católica a la república criolla, 1492-1867, F.C.E., 1993.

Breña, Roberto, «El primer liberalismo español y la emancipación de América: tradición y reforma», Revista de Estudios Politicos (Nueva Época) N 121, Julio-Septiembre 2003, p. 257-289.

----, El primer liberalismo español y los procesos de emancipación de América, 1808-1824. Una revisión historiográfica del liberalismo hispánico, México, El Colegio de México, 2006.

----, José María Blanco White y la Independencia de América: ¿Una postura pro-americana?, Alicante: Biblioteca Virtual Miguel de Cervantes, 2015.

Caetano, Gerardo (coord.), Historia conceptual. Voces y conceptos de la política oriental (17501870), Montevideo: Ediciones de la Banda Oriental, 2013.

Caillet-Bois, Ricardo; González Julio Cesar, “Antecedentes para explicar el proceso de la clausura del Telégrafo Mercantil, el primer periódico impreso bonaerense", Revista de Historia de América, núm.12, 1941.

Calvo, Nancy, "Lo sagrado y lo profano. Tolerancia religiosa y ciudadanía política en los orígenes de la república rioplatense”, Andes. Antropología e Historia, nro.15, Salta, 2004, pp.151-181. 
Camarda, Maximiliano, "De comerciante exitoso a hacendado y revolucionario. La estrategia económica de fines del siglo XVIII en el complejo portuario rioplatense a partir de un actor: José Ramón Milá de la Roca”, Naveg@mérica,n. 12, 2014.

Canter, Juan, Las sociedades secretas, politicas y literarias (1810-1815), Buenos Aires, Imprenta de la Universidad, 1942.

Carozzi, Silvana, Las filosofías de la revolución: Mariano Moreno y los jacobinos rioplatenses en la prensa de Mayo: 1810-1815. Buenos Aires: Prometeo Libros, 2011.

Carzolio, María Inés, «Entre lo privado y lo público: las Cartas sobre la Policía de Valentín de Foronda», XII Jornadas Interescuelas-Departamentos de Historia, Bariloche, 2009. Inédito.

Casals Bergés, Quintí, "Proceso electoral y prosopografía de los diputados de las Cortes extraordinarias de Cádiz (1810-1813)”, Historia Constitucional, n. 13, 2012.

Cassirer, Ernst, La filosofia de la Ilustración, Madrid, FCE, 1993.

Chiaramonte, José Carlos, La ilustración en el Río de la Plata: Cultura eclesiástica y cultura laica durante el Virreinato, Buenos Aires, Puntosur, 1989.

----, "Vieja y nueva representación: Los procesos electorales en Buenos Aires, 1810-1820", Annino Antonio coord., Historia de las elecciones en Iberoamérica, siglo XIX, México DF, Fondo de Cultura Económica, 1995.

----, Ciudades, provincias, Estados: Orígenes de la Nación Argentina (1800-1846), Buenos Aires, Ariel, 1997.

----, "La cuestión de la soberanía en la génesis y la constitución del estado argentino", Historia Constitucional, núm. 2, 2001.

----, “Autonomía e Independencia en el Río de la Plata, 1808-1810”, Historia Mexicana, vol. LVIII, núm. 1, México, 2008, pp. 325-368.

----, "Las dimensiones de las revoluciones por la independencia", Revista Ciencia y Cultura, La Paz, 2009.

----, Fundamentos intelectuales y politicos de las independencias. Notas para una nueva historia intelectual de Iberoamérica, Buenos Aires: Teseo, 2010.

Chust Calero, Manuel, La cuestión nacional americana en las Cortes de Cádiz, Valencia, UNEDUNAM, 1998.

---- (coord.), 1808. La eclosión juntera en el mundo hispano, México, El Colegio de México/Fondo de Cultura Económica, 2007.

---- (ed.), Las independencias iberoamericanas en su laberinto. Controversias, cuestiones, interpretaciones, Valencia, Universitat de Valéncia, 2010.

---- (coord.), España. Crisis imperial e independencia. Tomo 1: 1808-1830, Fundación Mapfre/Taurus. Madrid, 2010.

---- (coord.), 1812, El poder de la palabra, América y la Constitución de 1812, Madrid, AC/E, 2012. 
Clucellas, Patricio, “E1 Plan de Operaciones: ¿de Moreno o de fray Ciruelo?”, Todo es historia. N $^{\circ} 383$ (junio de 1999), pp. 70-92.

----, Un patriota español. El ignoto protagonista de la Revolución de Mayo, Buenos Aires, Ediciones de la Torre de Hércules, 2011.

----, 1810 Revolución de dos mundos. La presencia de España en el Mayo rioplatense, Buenos Aires, Ed. Torre de Hércules, 2012.

Cremonte, Néstor, La Gazeta de Buenos-Ayres de 1810. Luces y sombras de la ilustración revolucionaria, La Plata, Editorial de la Universidad de La Plata, 2010.

Dávilo, Beatriz, "De los derechos a la utilidad del discurso político en el Río de la Plata durante la década revolucionaria", Prismas, Nº 7, 2003, págs. 73-98.

De Gori, Esteban, "La Universidad de Charcas: Teoría y acción política", Revista Historia de la Educación Latinoamericana, vol. 14, 2010, Universidad Pedagógica y Tecnológica de Colombia, Colombia.

----, “Autogobierno y revolución. Lenguaje político de las élites dirigentes de Buenos Aires”. Revista Politeia, UCV, n 43, 2009.

----, La República Patriota: Travesía de los imaginarios y de los lenguajes políticos en el pensamiento de Mariano Moreno, Buenos Aires, Eudeba, 2013.

Dérozier, Albert, Manuel José Quintana y el nacimiento del liberalismo en España, Madrid, Ed Turner, 1978.

Díaz, Cesar, Comunicación y Revolución, 1759-1810, La Plata: EPC, 2012.

Di Meglio, Gabriel, ;Viva el bajo pueblo! La plebe urbana de Buenos Aires y la política, entre la Revolución de Mayo y el rosismo, Buenos Aires, Ed. Prometeo, 2006.

Domínguez Ortiz, Antonio, Carlos IIII y la España de la Ilustración, Alianza, Madrid, 2005.

Durán López, Fernando, "Diputados de papel: la información parlamentaria en la prensa de la etapa constituyente (septiembre de 1810-marzo de 1812)", en Cantos Casenave, M.; Durán López, F.; Romero Ferrer, A. (coord.), Guerra de pluma: Estudios sobre la prensa de Cádiz en la tiempo de las Cortes (1810-1814), Universidad de Cádiz, 2008.

Estrada, Dardo, Historia y bibliografía de la imprenta en Montevideo 1810-1865, Montevideo: Librería Cervantes, 1912.

Fernández Armesto, María Verónica, "Lectores y lecturas económicas en Buenos Aires a fines de la época colonial", Información, cultura y sociedad., No. 13, 2005, pp. 29-56.

Fernández López, Manuel, «Cartas de Foronda: su influencia en el pensamiento económico argentino», en: XLI Reunión Anual de la Asociación Argentina de Economía Política. Salta, 2006.

Fernández Sarasola, Ignacio, «La Constitución española de 1812 y su proyección europea e iberoamericana», Fundamentos, núm. 2, Oviedo, Junta General del Principado de Asturias, 2000. 
----, "El concepto de partido político en la Constitución de 1812", en Miguel Revenga Sánchez / Paloma Biglino Campos, Las huellas de la Constitución de Cádiz, Tirant lo Blanch, Valencia, 2014, págs. 133-172.

Fernández Sebastián, Javier, "Liberalismos nacientes en el Atlántico iberoamericano: "liberal” como concepto y como identidad política, 1750-1850”, Anuario de Historia de América Latina (JbLA) $\mathrm{N}^{\circ} .45$, Alemania, 2008 , págs. 149-195.

---- (coord.), La aurora de la libertad. Los primeros liberalismos en el mundo hispánico, Madrid, Marcial Pons, 2012.

Fernández Segado, Francisco, "La libertad de imprenta en el periodo inmediato anterior a su legalización por las Cortes de Cádiz (1808-1810)”, Pensamiento Constitucional N 17, 2012, pp. 117-176.

Ferreira, Pablo, "La guerra de independencia española, los "empecinados" y el Montevideo leal, 18081814". Pasado Abierto. № 4. Julio-Diciembre de 2016, pp. 41-60.

Ferreiro, Felipe, La disgregación del Reyno de Indias, Montevideo: Barreiro y Ramos. 1981.

Forace, Virginia, "La condición testimonial de un escritor en transición: Memorias curiosas de Juan Manuel Beruti”, Anclajes vol.19 no.1, Sta. Rosa, jun. 2015.

Fradkin, Raúl, "La acción colectiva popular en los siglos XVIII y XIX: modalidades, experiencias, tradiciones", Nuevo Mundo Mundos Nuevos [En línea], Debates, 2010.

Fradkin, Raúl; Gelman, Jorge, Doscientos años pensando la revolución de Mayo, Buenos Aires: Sudamericana, 2012.

Frega, Ana, "Tradición y modernidad en la crisis de 1808. Una aproximación al estudio de la Junta de Montevideo". Sociedad y cultura en el Montevideo colonial. Eds. Luis Behares y Oribe Cures. Montevideo: Fac. de Humanidades y Ciencias de la Educación,1997, pp. 283-294.

----, "Ecos del constitucionalismo gaditano en la banda oriental del Uruguay", Trocadero: Revista de historia moderna y contemporánea, $\mathrm{N}^{\mathrm{0}}$ 24, 2012.

Furlong, Guillermo, Nacimiento y desarrollo de la Filosofía en el Río de la Plata, Buenos Aires, Ed. G. Kraft, 1952.

Gadamer, Hans-Georg, Verdad y método, Salamanca, Ed. Sígueme, 1977.

Galasso, Norberto, Seamos libres y lo demás no importa nada: vida de San Martín, Buenos aires, Ediciones Colihue, 2000.

----, Mariano Moreno, el sabiecito del Sur, Buenos Aires, Colihue, 2004.

----, La Revolución de Mayo: (El pueblo quiere saber de qué se trató), Buenos Aires: Colihue, 2005.

Gallo, Klaus, "Jeremy Bentham y la "Feliz Experiencia". Presencia del utilitarismo en Buenos Aires 1821-1824", Prismas, №. 6, 2002, págs. 79-96.

Gandía, Enrique de, Las ideas politicas de Mariano Moreno. Autenticidad del plan que le es atribuido, Buenos Aires, Peuser, 1946. 
García, Gustavo V., "Incaísmo y legitimación de la "Nación" americana en el diálogo entre Atahualpa y Fernando VII en los Campos Elíseos”, Kañiga, Vol. 41, Núm. 2, 2017.

García Monerris, Encarna; García Monerris, Carmen, La nación secuestrada. Francisco Javier Elío: correspondencia y manifiesto, Universidad de Valencia, Valencia, 2009.

Garriga, Carlos, "Patrias criollas, plazas militares. Sobre la América de Carlos IV", en Eduardo Martiré (coord.), La América de Carlos IV. Cuadernos de Investigaciones y documentos. Buenos Aires, Instituto de Investigaciones de Historia del Derecho, 2006.

Gay Armenteros, Juan C.; Viñes Millet, Cristina, La ilustración andaluza, Sevilla, Editoriales Andaluzas Unidas, 1985.

Gelman, Jorge (dir.), Argentina: Crisis imperial e independencia, Lima, Taurus-Fundación Mapfre, 2010.

Goldman, Noemí, "Iluminismo e independencia: Monteagudo y Pasos Silva (Kanki) en la prensa revolucionaria de 1811-1812, en Eliseo Verón y Leonor Arfuch, El discurso político. Lenguajes y Acontecimientos, Buenos Aires, Hachette, 1987.

----, Historia y lenguaje. Los discursos de la Revolución de Mayo, Buenos Aires, Centro Editor de América Latina, 1992.

----, "Libertad de imprenta, opinión pública y debate constitucional en el Rio de la Plata (1810-1827)", Prismas. Revista de historia intelectual, n 4, 2000, pp. 9-20.

----, Lenguaje y Revolución, Conceptos políticos clave en el Río de la Plata, 1780-1850, Buenos Aires, Prometeo, 2008.

----, «La ciudad letrada (1776-1820)». En Fradkin, Raúl (coord.), Colección Historia de la Provincia de Buenos Aires, Buenos Aires: Universidad Pedagógica Provincial, 2012, 297-319.

-----, Mariano Moreno. De reformista a insurgente. Buenos Aires. Edhasa, 2016.

Goldman, Noemí; Ternavasio, Marcela, "Construir la república: semántica y dilemas de la soberanía popular en Argentina durante el siglo XIX", Rev. Sociol. Polit., Curitiba, v. 20, n. 42, jun. 2012, pp. 11-19.

González, Ariosto, Las primeras fórmulas constitucionales en los países del Plata: 1810-1813, Montevideo, Ed. Claudio García y Cía, 1941.

González, Julio V., Filiación histórica del gobierno representativo argentino, Buenos Aires, La vanguardia, 1937.

González Bernaldo de Quirós, Pilar, "La Revolución Francesa y la emergencia de nuevas prácticas de la política: la irrupción de la sociabilidad política en el Río de la Plata revolucionario (18101815)" Boletín del Instituto de Historia Argentina y Americana "Dr. E. Ravignani" Tercera Serie, núm. 3, Buenos Aires, 1991.

González Demuro, Wilson, La prensa de Montevideo, 1814-1825 Imprentas, periódicos y debates públicos en tiempos de revolución. Tesis de Maestría, Inédito.

Guerra, François-Xavier, Modernidad e independencias, Madrid, Mapfre, 1992. 
----, "Voces del pueblo. Redes de comunicación y orígenes de la opinión en el mundo hispánico, 18081814", Revista de Indias nro. 225, 2002, 357-384.

Halperín Donghi, Tulio, Tradición política española e ideología revolucionaria de mayo, Buenos Aires, Eudeba, 1961.

----, Revolución y guerra. Formación de una elite dirigente en la Argentina criolla, Buenos Aires, Siglo XXI, 1972.

Hernández González, Manuel, "Entre Europa y América. El periodismo de Cabral de Noroña. Del Duende Político gaditano al Observador Español en Londres", Cuadernos de ilustración y romanticismo. 16 (2010), Cádiz, pp. 1-24.

Herr, Richard, España y la revolución del siglo XVIII, Madrid, Aguilar, 1962.

Herrero, Fabián, “'Localistas' radicalizados. Pasquines infamatorios distribuidos luego de la asonada de los orilleros en abril de 1811”, en Bragoni, B. y Mata de López, S., Entre la colonia y la república. Insurgencias, rebeliones y cultura política en América del Sur, Buenos Aires, Prometeo Libros, 2009.

----, "Fragmentos para armar. Indicios sobre la presencia artiguista en Buenos Aires", Revista de Indias, vol. LXX, núm. 250, 2010, pp. 623-665.

Hocquellet, Richard, «La publicidad de la Junta Central española (1808-1810)», en Guerra, FrançoisXavier; Lemperiere, Annick et al. Los espacios públicos en Iberoamérica, Ambigüedades y problemas. Siglos XVIII-XIX, FCE, México, 1998, pp.140-167.

----, «La aparición de la opinión pública en España: una práctica fundamental para la construcción del primer liberalismo (1808-1810)», Historia Contemporánea. 2003 (II), nº 27, pp. 615-629.

Irazusta, Julio, Tomás de Anchorena, o la emancipación americana a la luz de la circunstancia histórica, Buenos Aires, Huemul, 1962.

La Parra López, Emilio, La libertad de prensa en las Cortes de Cádiz, Alicante: Biblioteca Virtual Miguel de Cervantes, 2005.

Levaggi, Abelardo, "La Constitución española de 1812 e Hispanoamérica”, Iushistoria, Buenos Aires, 2009, pp. 7-30.

Levene, Ricardo, Vida y escritos de Victorián de Villava, Buenos Aires, Peuser, 1946.

----, Ricardo, Las ideas políticas y sociales de Mariano Moreno, Buenos Aires, Emecé, 1948.

----, Ensayo histórico sobre la revolución de Mayo y Mariano Moreno: contribución al estudio de los aspectos político, jurídico y económico de la Revolución de 1810, Buenos Aires, El Ateneo, 1949.

----, El mundo de las ideas y la revolución hispanoamericana de 1810, Santiago de Chile: Editorial Jurídica de Chile, 1956.

Lewin, Boleslao, "Jacobinos y Moderados en Vísperas de Mayo", Trabajos y Comunicaciones № 9, La Plata, 1960, pp. 221-230.

Loaiza Cano, Gilberto, «La libertad de imprenta en la América española (ensayo de historia comparada sobre la opinión pública moderna)», Historia y memoria, n 13 (2016): 47- 84. 
López, Vicente Fidel, Historia de la República Argentina, su origen, su revolución y su desarrollo político hasta 1852, Buenos Aires, Imp. de G. Kraft, 1913.

Llombart, Vicent, «Ni teoría sin aplicación, ni aplicación sin teoría: Economía política y realismo en Jovellanos», Revista asturiana de economía núm. 45 (2012): 7-31.

Maggio Ramírez, Matías. "Un puro vegetar. Representaciones de la lectura en el Semanario de Agricultura, Industria y Comercio (1802-1807)". En Paulina Brunetti (et. al.). Ensayos sobre la prensa. Primer Concurso de Investigación en Periódicos Argentinos en Homenaje al Prof. Jorge B. Riviera. Buenos Aires: Ediciones Biblioteca Nacional, 2008.

---- "Civilización imaginada. Lecturas sobre civilidad e identidad en el Buenos Aires colonial a través de su prensa periódica”. La Biblioteca 8, 2009, pp. 254-262.

Martínez Gramuglia, Pablo, «El pensamiento agrario ilustrado en el Río de la Plata: un estudio del Semanario de Agricultura, Industria y Comercio (1802-1807)». Mundo agrario [online] vol.9 núm. 18, 2009.

---- "Autores y publicistas entre la colonia y la Revolución de Mayo". En Alabart, M.; Fernández, M.A.; Pérez, M. (ed.). Buenos Aires, una sociedad que se transforma. Buenos Aires: Prometeo, 2012.

----, "Nuevos textos, nuevos (y viejos) lectores: la representación del público en los periódicos desde 1801 hasta 1810. En Graciela Batticuore y Sandra Gayol (eds.). Lecturas de la cultura argentina 1810-1910-2010. Buenos Aires: Prometeo, pp. 24-41.

Martínez Quinteiro, María Esther, Los grupos liberales antes de las Cortes de Cádiz, Madrid, Narcea, 1977.

Martini, Mónica, Francisco Antonio Cabello y Mesa, un publicista ilustrado de dos mundos (17861824), Buenos Aires: Universidad del Salvador, 1998.

Marx, Karl; Engels, Friedrich, Revolución en España, Barcelona, Ed. Ariel, 1960.

Mitre, Bartolomé: Historia de Belgrano y de la Independencia Argentina. Buenos Aires, 1950.

Molina, Eugenia, "Las modernas prácticas asociativas como ámbitos de definición de lazos y objetivos políticos durante el proceso revolucionario (1810-1820)", Universum $\mathrm{N}^{\circ} 16$, Chile, Universidad de Talca, 2002, pp. 407-437.

----, El poder de la opinión pública. Trayectos y avatares de una nueva cultura política en el Río de la Plata, 1800-1852, Santa Fe, Ediciones de la Universidad del Litoral, 2009.

----, “Sociabilidad y redes político-intelectuales: Algunos casos entre 1800 y 1852", CILHA, a. 12 n. 14, Mendoza, 2011.

Molinari, Diego, La Representación de los hacendados de Mariano Moreno: su ninguna influencia en la vida económica del país y en los sucesos de mayo de 1810, Imp. y Casa Editora de Coni Hnos., 1914.

Moliner Prada, Antonio, "De las Juntas a la Regencia. La difícil articulación del poder en la España de 1808”, Historia Mexicana, vol. LVIII, núm. 1, 2008, pp. 135-177. 
Moreno Alonso, Manuel, La generación española de 1808, Madrid, Alianza Editorial, Alianza Universidad, 1989.

----, Divina libertad: la aventura liberal de Don J. M. Blanco White 1808-1824, Sevilla, Alfar, 2002.

Morelli, Federica, «Tras las huellas perdidas de Filangieri: nuevas perspectivas sobre la cultura política constitucional en el Atlántico hispánico», Historia contemporánea núm. 33, 2006: 431462.

----, «Filangieri y la "Otra América": historia de una recepción». Revista Facultad de Derecho y Ciencias Políticas vol. 37 núm. 107, 2007: 485-508.

Narancio, Edmundo M., «Las ideas políticas en el Río de la Plata a comienzos del siglo XIX. Contribución al estudio de su filiación y desarrollo iniciales», Rev. de la Fac. de Hum. y Ciencias (Montevideo), núm. 14, 1955.

Navallo, Tatiana, "Articulaciones históricas y culturales en zonas de frontera, difundidas en la prensa del Río de la Plata (XIX)”. Estudios Históricos 3, 2009.

----, “Ideas ilustradas en el Río de la Plata: de los manuscritos al 'Proiecto Geográfico' del Telégrafo Mercantil (1801-1802)", TINKUY No 14, 2010, pp. 159-197.

Navarro Floria, Pedro. «llustración y radicalización ideológica en el Consulado de Buenos Aires (1755-1810)». Revista de Indias vol. XLIX núm. 186, 1989.

Navarro García, Jesús, "Actitudes políticas de fr. Cirilo Alameda y Brea, arzobispo de Santiago de Cuba, Burgos y Toledo: su etapa cubana" Anales toledanos No. 25, 1988, pp. 221-243.

Navarro García, Luis, "Convocatoria de vocales americanos para la Junta Central, 1809", Naveg@mérica,n. 10, 2013.

Nogueira de Azevedo, Francisca, Carlota Joaquina na corte do Brasil, Río de Janeiro, Civilizacao Brasileira, 2002.

Olivero Orecchia, José M., "La junta de Montevideo en 1808, una situación interna con repercusiones internacionales: algunos aspectos de los intereses y acciones portuguesas, estudios históricos", CDHRP No 3, Diciembre 2009.

O’Phelan Godoy, Scarlett, "Los diputados peruanos en las Cortes de Cádiz y el debate sobre el tributo, la mita y la ciudadanía indígena”, Revista de Historia Iberoamericana nro. 5 (1), 2012, pp. 94 110.

Palti, Elías J., El tiempo de la politica. El siglo XIX reconsiderado, Buenos Aires: Siglo XXI, 2007.

Parada, Alejandro, Cuando los lectores nos susurran: Libros, lecturas, bibliotecas, sociedad y prácticas editoriales en la Argentina, Buenos Aires: UBA, 2007.

----, De la biblioteca particular a la biblioteca pública: libros, lectores y pensamiento bibliotecario en los orígenes de la Biblioteca Pública de Buenos Aires, 1779-1812. Buenos Aires: Errejotapé, 2002. 
Pasino, Alejandra, “El Español de José María Blanco-White en la prensa porteña durante los primeros años revolucionarios", en Herrero, F. (comp.), Revolución. Política e ideas en el Río de la Plata, Buenos Aires, Ediciones Cooperativas, 2004.

----, "Los escritos de Manuel J. Quintana y José M. Blanco White en el Semanario Patriótico (18081810): sus aportes a la construcción del lenguaje político del primer liberalismo español", Anuario del Centro de Estudios Históricos "Prof. Carlos S. A. Segreti", n 10, 2010, pp. 343363.

----, “Independencia y República: La polémica José María Blanco White - Servando teresa de Mier y su recepción en el Río de la Plata revolucionario”, en Francisco Ortega y Yobenj A. Chicangana Bayona (Eds.) 200 años de independencia. Las culturas políticas y sus legados, Universidad Nacional de Colombia, 2011.

----, "Las impugnaciones a las Cortes de Cádiz en el Río de la Plata revolucionario a través de la recepción de El Español de José María Blanco White. (1810-1812), en Gullón Abao, A.; Gutierrez Escudero, A., La Constitución gaditana de 1812 y sus repercusiones en América. Universidad de Cádiz, 2012.

----, "Circulación y apropiación de escritos políticos en la prensa porteña revolucionaria: la labor de Vicente Pazos Silva (Pazos Kanki) como editor de La Gazeta de Buenos Aires y El Censor (18111812)", I Congreso Internacional de Historia Intelectual de América Latina, Universidad de Antioquia, Medellín, 2012.

----, “Buenos Aires - Cádiz - Londres: circulación y recepción de la legislación sobre libertad de imprenta. (1810-1812)”, PolHis, núm. 12, 2013, pp. 83-94.

Pastore, Rodolfo, «El pensamiento económico rioplatense y sus vínculos con el debate económico en la España ilustrada», en Actas del Encuentro «El libro en el protopaís» (2002). Disponibles en: http://www.bibnal.edu.ar/protopais/mat/h10.htm

Pastore, Rodolfo y Calvo, Nancy, «Cultura colonial, ideas económicas y formación superior 'ilustrada' en el Río de la Plata. El caso de Manuel Belgrano», Prohistoria núm. 4 (2000), pp. 27-57.

----, "Ilustración y economía en el primer periódico impreso del Virreinato del Río de la Plata: el Telégrafo Mercantil (1801-1802)”, Bulletin Hispanique, núm. 107-2, 2005, pp. 433-462.

Peña Díaz, Manuel, José Isidoro Morales y la libertad de imprenta (1808-1810), Huelva: Universidad de Huelva, 2008.

Pérez-Prendes Muñoz Arraco, José Manuel, “Álvaro Flórez Estrada y la emancipación de américa”, en Varela Suanzes-Carpegna, Joaquín, Álvaro Flórez Estrada (1766-1853): política, economía, sociedad, Oviedo, Junta General del Principado de Asturias, 2004.

Piñero, Norberto, Escritos políticos y económicos de Mariano Moreno, Talleres Rosso, Bs. As., 1937.

Pons, André, Blanco White y España, Oviedo, Instituto Feijoo de Estudios del Siglo XVIII de la Universidad de Oviedo, 2002. 
----, Blanco White y América, Oviedo, Instituto Feijoo de Estudios del Siglo XVIII de la Universidad de Oviedo, 2006.

Portillo Valdés, José María, Revolución de Nación. Orígenes de la cultura constitucional en España, 1780-1812, Madrid, Centro de estudios Políticos y Constitucionales, 2000.

----, “La constitución en el atlántico hispano, 1808-1824” Fundamentos, n. 6, Oviedo, Junta General del Principado de Asturias, 2010, pp. 123-178.

Quintela, Guido, "Conceptos Políticos en la Gazeta de Montevideo hacia el final del segundo sitio (Enero-Junio de 1814). El caso de la Lealtad”, Revista Historia Para Todos nro. 3, 2016, pp. 4453.

Raffo de la Reta, Julio Cesar, Historia de Juan Martín de Pueyrredón, Espasa - Calpe, Academia Nacional de la Historia, 1948.

Ramos, Demetrio, "Formación de las ideas políticas que operan en el movimiento de mayo de Buenos Aires en 1810", Revista de estudios políticos, Vol. 134, Madrid: Inst. de Studios Políticos, 1964, pp. 139-218.

Ramos, Jorge Abelardo, Revolución y Contrarrevolución en la Argentina, Buenos Aires, Editorial Distal, 1999.

Ramos Santana, Alberto, "El manifiesto de la Junta Cádiz a la América española”, Funes, Leonardo (coord.), Hispanismos del mundo, Buenos Aires, Ed. Miño y Dávila, 2015.

Rieu-Millán, Marie-Laurie, Los diputados americanos en las Cortes de Cádiz: Igualdad o independencia, Madrid, CSIC, 1990.

Ripodas Ardanaz, Daisy, Refracción de ideas en la Hispanoamérica colonial, Buenos Aires, Ediciones Culturales Argentinas, 1983.

Robledo, Ricardo, «Tradición e Ilustración en la Universidad de Salamanca: sobre los orígenes intelectuales de los primeros liberales», en Robledo, Ricardo et al. (eds.): Orígenes del liberalismo. Universidad, política, economía, Salamanca, Ed. Universidad de Salamanca, 2003.

Roca, C. Alberto, Vida del Cardenal Arzobispo Cirilo de Alameda y Brea. Montevideo, Biblioteca Nacional, 1974.

Rojas, Ricardo Manuel, El pensamiento económico de Juan Hipólito Vieytes, Fundación San Antonio, 2010.

Rosanvallon, Pierre, Para una historia conceptual de lo político, México, FCE, 2003.

Rosetti, Mariana, "La práctica de la libertad civil: La polémica de Servando Teresa de Mier y José Blanco White en la fragmentación de la monarquía española”, Dieciocho-Hispanic Enlightenment, vol. 37, nro. 2, pp. 295-320.

Ruiz y González de Linares, Ernesto, Las Sociedades Económicas de Amigos del País, Burgos, Instituto Fernán González, 1972.

Sánchez Gómez, Julio, "Un rey para El Plata: monárquicos y monarquía en el oriente del Río de la Plata”, en Álvarez Cuartero, Izaskun, Sánchez Gómez, Julio (eds.) Visiones y revisiones de la 
independencia americana: Realismo/Pensamiento conservador: ¿una identificación equivocada?, Salamanca: Ediciones Universidad de Salamanca, 2014.

Sánchez Hita, Beatriz, "María del Carmen Silva, la Robespierre Española: una Heroína y Periodista en la Guerra de la Independencia”, Irene Castells Oliván, M. Gloria Espigado Tocino, María Cruz Romeo Mateo (coord.), Heroínas y patriotas: mujeres de 1808, Madrid: Ediciones Cátedra, 2009.

----, "Las empresas periodísticas del marqués de Villapanés: Literatura y prensa absolutista en las Cortes de Cádiz”, El Argonauta español №. 9, 2012.

Sarrailh, Jean, La España ilustrada de la segunda mitad del siglo XVIII, México: Fondo de Cultura Económica, 1979.

Serulnikov, Sergio, Conflictos sociales e insurrección en el mundo colonial andino. El norte de Potosí en el siglo XVIII, Buenos Aires, Fondo de Cultura Económica, 2006.

Soux, María Luisa, "El tema de la soberanía en el discurso de los movimientos juntistas de La Plata y La Paz en 1809”, Rev. Ciencia y Cultura n.22-23, La Paz, 2009.

Stern, Steve J. (comp.) Resistencia, rebelión y conciencia campesina en Los Andes. Siglo XVIII al XX, Instituto de Estudios Peruanos, 1990.

Stoetzer, O. Carlos, Las raices escolásticas de la emancipación de la América española, Madrid, Centro de Estudios Constitucionales, 1982.

Ternavasio, Marcela, Gobernar la revolución: poderes en disputa en el Río de la Plata, 1810-1816, Buenos Aires, Siglo XXI Editores Argentina, 2007.

----, Historia de la Argentina, 1806-1852, Siglo XXI, Buenos Aires; 2009.

----, "Una princesa para América: la alternativa carlotista frente a la crisis monárquica de 1808", en Landavazo, Marco; Guzmán Pérez, Moisés (coord.), Guerra, política y cultura en las independencias hispanoamericanas, Editorial Porrúa, Morelia, 2013.

----, "El Río de la Plata divido. La experiencia gaditana en Buenos Aires y Montevideo (1810-1814)", en Breña, R., Cádiz a debate: actualidad, contexto y legado, El Colegio de México, México, 2014, pp. 277-302.

----, Candidata a la corona: la infanta Carlota Joaquina en el laberinto de las revoluciones hispanoamericanas. Buenos Aires: Siglo Veintiuno editores, 2015.

Thibaud, Clement, La Academia Carolina y la independencia de América. Los abogados de Chuquisaca (1776 - 1809), Sucre, Editorial Charcas, 2010.

Tío Vallejo, Gabriela, Antiguo Régimen y liberalismo: Tucumán, 1770-1830, (Cuadernos de Humanitas, number 62), San Miguel de Tucumán, Argentina: Facultad de Filosofía y Letras, Universidad Nacional de Tucumán, 2001.

----, "Rupturas precoces $y$ legalidades provisorias. El fin del poder español en el Rio de la Plata", Ayer 74, 2009.

Torre Revello, José. El libro, la imprenta y el periodismo en América durante la dominación española. Buenos Aires: FFyL, Instituto de Investigaciones Históricas, 1940. 
Varela Suanzes-Carpegna, Joaquín, «La Constitución de Cádiz y el Liberalismo español del siglo XIX», $R C G \mathrm{n}^{\circ} 10$, Madrid, 1987.

----, Álvaro Flórez Estrada (1766-1853). Política, economía y sociedad, Oviedo, Junta General del Principado de Asturias, 2004.

----, «La Constitución de Cádiz en su contexto español y europeo», ponencia presentada en el X Congreso Asociación de Constitucionalistas de España, UCA, 2012.

Walker, Charles, The Tupac Amaru Rebellion, Harvard University Press, 2014.

Wasserman, Fabio, «La historia como concepto y como práctica: conocimiento histórico en el Río de la Plata (1780-1840)», História da historiografía núm. 4 (2010): 15-36.

----, Comentarios al texto de Marcela Ternavasio "Política y cultura política ante la crisis del orden colonial", Bol. Inst. Hist. Argent. Am. Dr. Emilio Ravignani [online], 2011, n.33.

----, Juan José Castelli. De súbdito de la corona a líder revolucionario, Buenos Aires, Edhasa, 2011.

Weinberg, Félix, Estudio preliminar. Vieytes, J. H. Antecedentes económicos de la Revolución de Mayo. Buenos Aires: Raigal, 1956.

Williams Álzaga, Enrique, Dos revoluciones: $1^{\circ}$ de enero de 1809 - 25 de mayo de 1810, Buenos Aires, Emecé Editores, 1963. 